\title{
OECD Internet Economy Outlook 2012
}

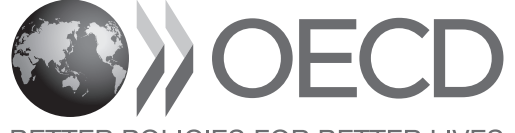


This work is published on the responsibility of the Secretary-General of the OECD. The opinions expressed and arguments employed herein do not necessarily reflect the official views of the Organisation or of the governments of its member countries.

This document and any map included herein are without prejudice to the status of or sovereignty over any territory, to the delimitation of international frontiers and boundaries and to the name of any territory, city or area.

\section{Please cite this publication as:}

OECD (2012), OECD Internet Economy Outlook 2012, OECD Publishing.

http://dx.doi.org/10.1787/9789264086463-en

ISBN 978-92-64-08645-6 (print)

ISBN 978-92-64-08646-3 (PDF)

The statistical data for Israel are supplied by and under the responsibility of the relevant Israeli authorities. The use of such data by the OECD is without prejudice to the status of the Golan Heights, East Jerusalem and Israeli settlements in the West Bank under the terms of international law.

Photo credits: Cover @ Shutterstock/violetkaipa.

Corrigenda to OECD publications may be found on line at: www.oecd.org/publishing/corrigenda.

(c) OECD 2012

You can copy, download or print OECD content for your own use, and you can include excerpts from OECD publications, databases and multimedia products in your own documents, presentations, blogs, websites and teaching materials, provided that suitable acknowledgement of OECD as source and copyright owner is given. All requests for public or commercial use and translation rights should be submitted to rights@oecd.org. Requests for permission to photocopy portions of this material for public or commercial use shall be addressed directly to the Copyright Clearance Center (CCC) at info@copyright.com or the Centre français d'exploitation du droit de copie (CFC) at contact@cfcopies.com. 


\section{Foreword}

$T_{h}$ he OECD Internet Economy Outlook 2012 has been prepared by the OECD under the guidance of the OECD Committee for Information, Computer and Communications Policy (ICCP), and in particular the Working Party on the Information Economy. This edition is the first in a series designed to provide a broad overview of trends, policy developments and data on the expanding impact of the Internet on the economy and society, replacing and building upon the long-running OECD Information Technology Outlook. This publication also updates the key data series from the OECD Information Technology Outlook 2010.

The Internet Economy Outlook is a resource to help inform policy making and support research related to the Internet economy. It explores the economic and social importance of the Internet, the different waves of Internet development, and presents new research, approaches and methodologies for measuring the Internet economy.

The Outlook provides data on the top 250 firms in the broader ICT sector to help put the growth of the Internet economy into context and perspective. Building on this data, the Outlook provides a forward-looking perspective on recent trends in ICT technologies, applications and services, and offers predictions for development over the next few years, highlighting particular trends that could have a substantial impact on future policy.

Policy makers aim to base their policy making on empirical data and the Outlook provides extensive data on Internet use by businesses and households to cover selected issues related to key aspects of individuals' and firms' engagements in the information economy. These data help identify and clarify both shorter- and longer-term trends and benchmark countries against each other. The Internet economy is evolving rapidly and in different ways in OECD countries and the Internet Economy Outlook leverages data from across the OECD members to highlight emerging trends and important developments. In particular, it analyses intangible digital content that is increasingly downloaded, streamed or hosted in the "cloud". It discusses key trends that have characterised the growth of digital content markets and factors that have enabled this development. It also devotes a chapter to examining recent trends in information and communication technologies for health and ageing, covering issues such as electronic health records, telehealth, mobile applications and social networking for health and wellness.

The growth and ultimate success of the Internet economy will depend on whether individuals and businesses feel they can rely on it and use it safely. The Outlook presents trends in research and development $(R \& D)$ investments in the area of security and privacy. It also discusses business models and the role of employment and skills as enabling factors for innovation in security and privacy. Finally, the Outlook concludes with data submitted by OECD countries on government priorities for different ICT policy areas and maps them against the wider economic, social and political context. 
The Internet Economy Outlook was drafted under the direction of Taylor Reynolds, with Cristina Serra Vallejo, Piotr Stryszowski, Christian Reimsbach-Kounatze, Deborah Alcocer Delano, Elettra Ronchi, and Karine Perset of the OECD's Information, Communications and Consumer Policy Division and Pierre Montagnier of the OECD's Economic Analysis and Statistics Division within the Directorate for Science, Technology and Industry. Chapter two was drafted by Christoph Meinel, Mario Tobias, Maxim Schnjakin, and Christian Willems from the Hasso-Plattner-Institut and Institute for Advanced Sustainability Studies.

It benefited from valuable contributions from Julia Acas, Brigitte Acoca, Nadim Ahmad, Frederic Bourassa, Chris Bruegge, Anne Carblanc, Michael Donohue, Agustin Díaz Pinés, Kayoko Ido, Andrew Kessinger, Joseph Loux, Arthur Mickoleit, Andrea de Panizza, Rudolf Van der Berg, Colin Webb, Verena Weber, Andrew Wyckoff and Dimitri Ypsilanti of the OECD secretariat. The publication also benefitted greatly from the work of the OECD Publishing team, in particular Janine Treves, Patrick Love and Toby Green. In addition, it benefited from review and valuable input from delegates to the ICCP Committee's Working Party on the Information Economy, chaired by Daniela Battisti (Italy), particularly regarding national IT policy developments and up-to-date national statistics on the use of ICTs and the Internet. 


\section{Table of contents}

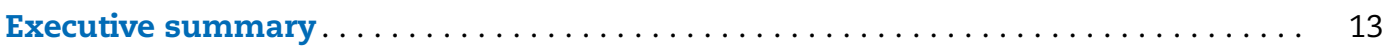

Expanding connectivity and measuring the Internet economy ............ 19

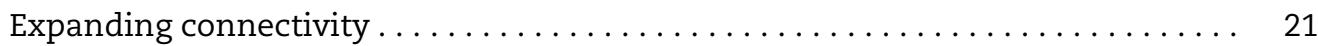

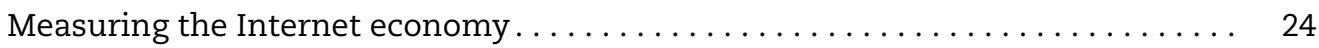

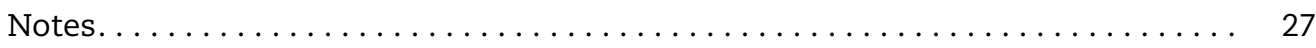

References ......................................... 28

Chapter 1. ICTs, the Internet and the crisis: Macro trends . . . . . . . . . . . 31

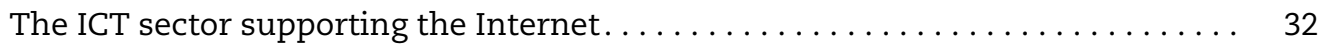

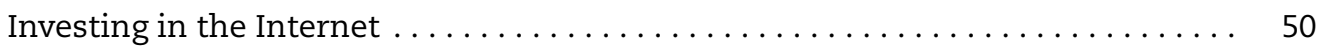

Conclusion ........................................ 58

Notes.......................................... 59

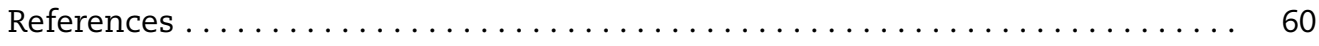

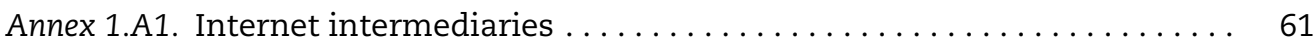

Chapter 2. Internet trends and development $\ldots \ldots \ldots \ldots \ldots \ldots \ldots \ldots \ldots \ldots \ldots$

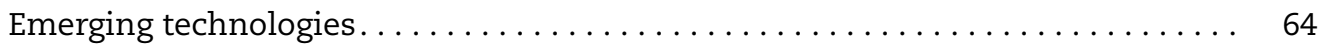

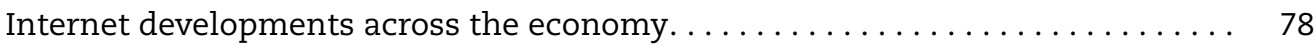

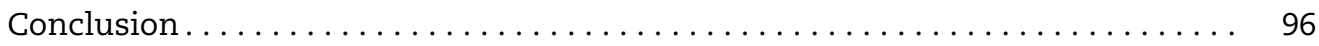

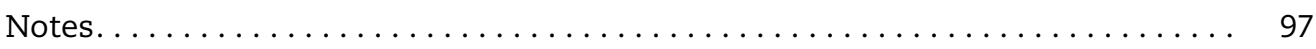

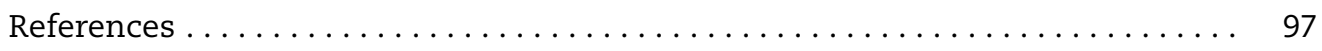

Chapter 3. Internet adoption and use: Households and individuals . . . . . . . . . 101

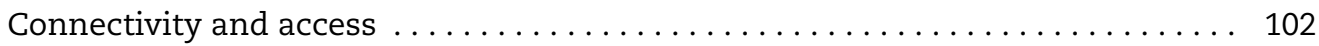

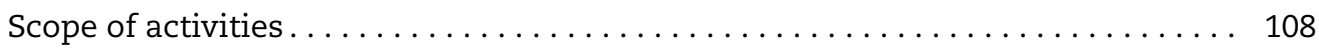

Challenges ahead: digital divides and barriers to access . . . . . . . . . . 121

Conclusion ...................................... 127

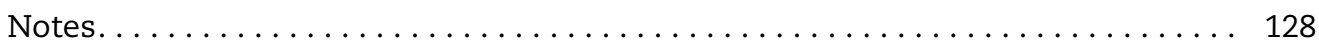

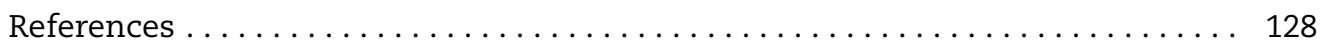

Chapter 4. Internet adoption and use: Businesses. . . . . . . . . . . . . 131

Pervasiveness of Internet use . . . . . . . . . . . . . . . . . . . . . 134

Broadband in firms..................................... 135

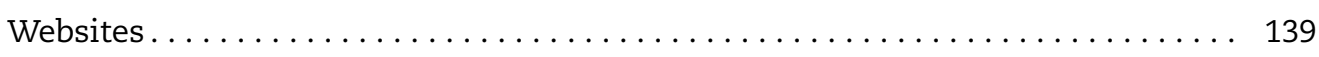

The Internet improving business processes . . . . . . . . . . . . . . 140

ICT impacts on businesses: Perceived benefits and real impacts . . . . . . . 150

Beyond perceived benefits: The impact of the Internet (ICT) on business

performance and innovation . . . . . . . . . . . . . . . . . . . . . . . . 151

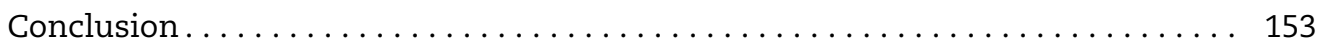

Notes. . . . . . . . . . . . . . . . . . . . . . . . . . . . . . . . 153

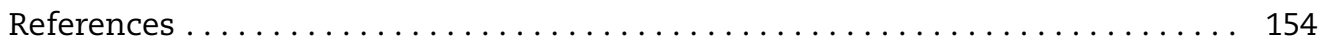


Chapter 5. Developments in digital content . . . . . . . . . . . . . . . . 157

Enabling factors. . . . . . . . . . . . . . . . . . . . . . . . . . . . 159

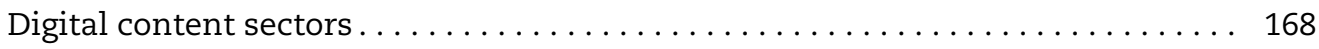

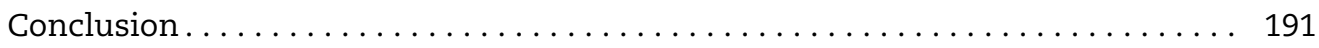

Notes. . . . . . . . . . . . . . . . . . . . . . . . . . . . . . . . . . . . . . 192

References ................................. 193

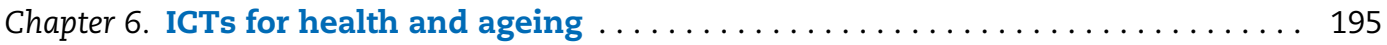

A broad range of health ICT initiatives . . . . . . . . . . . . . . . . . . 196

Growing public investment in health ICTs . . . . . . . . . . . . . . . . . . . 199

Building broadband capacity for health ICTs . . . . . . . . . . . . . . . . . . . . 201

Telehealth. . . . . . . . . . . . . . . . . . . . . . . . . . . . . . . . . . 203

Electronic medical claims processing . . . . . . . . . . . . . . . . . . 205

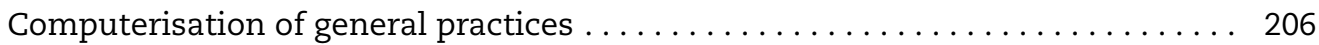

Electronic prescriptions . . . . . . . . . . . . . . . . . . . . . . . . . 209

Health information exchange . . . . . . . . . . . . . . . . . . . . . . 210

Health ICTs deliver greater convenience and closer connections with health

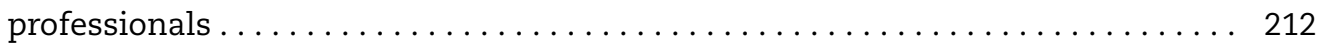

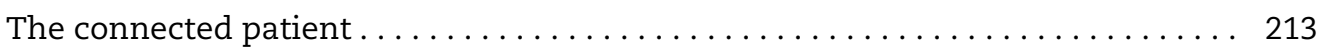

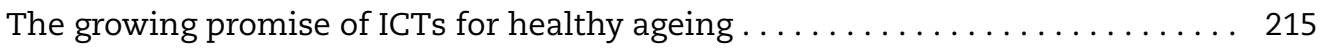

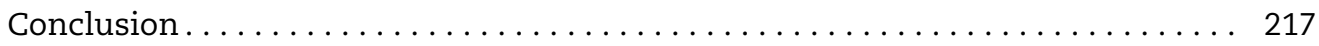

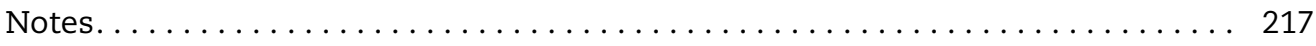

References .................................... 217

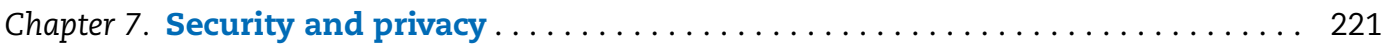

Research and development in security and privacy . . . . . . . . . . . . 224

Innovative products and business models . . . . . . . . . . . . . . . . . . 229

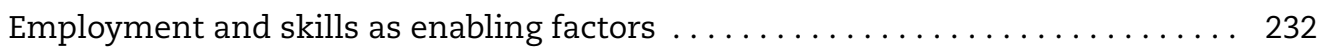

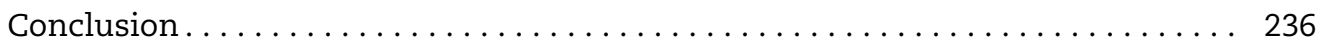

Notes. . . . . . . . . . . . . . . . . . . . . . . . . . . . . . . . . 237

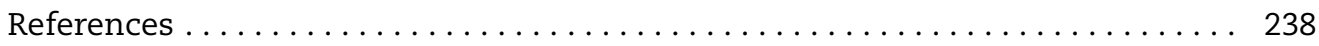

Annex 7.A1. Basic Principles of National Application

(OECD Privacy Guidelines, Part 2) . . . . . . . . . . . . . . 241

Chapter 8. Government priorities and policy developments . . . . . . . . . . . 243

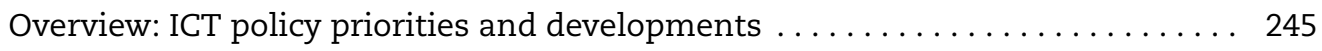

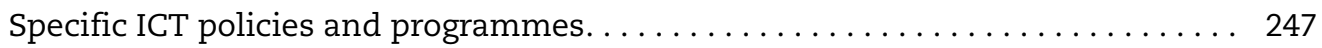

Conclusion ................................... 259

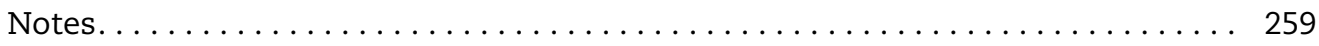

References .................................. 260

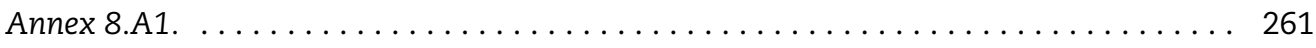

Annex A. Methodological considerations. ..................... 263

Tables

1.1. Economies represented in the top 250 ICT firms by economy of registration,

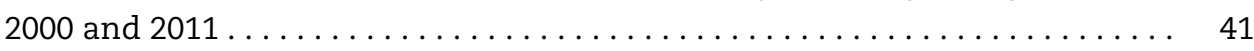

1.2. Top 250 ICT firms by sector, 2000 and $2011 \ldots \ldots \ldots \ldots \ldots \ldots$ 
1.3. Top 50 public Internet firms . . . . . . . . . . . . . . . . . . . . . . 44

2.1. Application categories in Apple's App Store and Google's Android Market. . . . 73

3.1. Merchandise/services purchased or traded online in Japan, 2002-10 . . . . . . 114

5.1. Geographical access to digital content . . . . . . . . . . . . . . . . 165

5.2. Evolving sector-specific online business models . . . . . . . . . . . . . 170

5.3. Platforms for user-created content . . . . . . . . . . . . . . . . . . . . . . 170

5.4. Facebook usage and web-traffic rankings in OECD countries . . . . . . . . . . 173

5.5. Online full-feature film providers, selected examples from the United States,

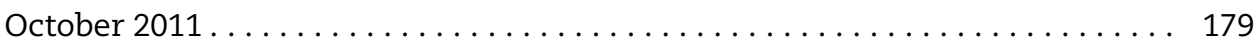

5.6. Music industry-ISP partnerships . . . . . . . . . . . . . . . . . . . . . . . 182

5.7. Summary of measures of local content . . . . . . . . . . . . . . . . . . 189

6.1. Current budget for ICT initiatives in three OECD countries . . . . . . . . . 200

6.2. Total budget allocated by national government in two OECD countries . . . . 201

8.1. Examples of digital strategies per country . . . . . . . . . . . . . . . . . 244

A1. Internet-related value added in various economies; results from existing

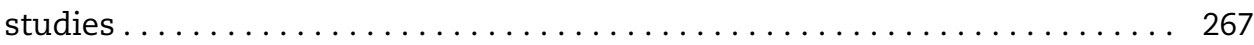

A2. Value added (VA) in the United States (NAICS 2002) . . . . . . . . . . . . . . 270

A3. The information sector in the United States (NAICS 51), estimated revenue for employer firms, $2006-10 \ldots \ldots \ldots \ldots \ldots \ldots \ldots \ldots \ldots \ldots$

A4. E-commerce in the United States in selected industries (NAICS 2002) . . . . . 273

A5. The impact of the Internet on the US economy under four scenarios. . . . . . 282

Figures

1. Wireless Internet access overtaking fixed broadband subscriptions . . . . . 22

2. Peak period aggregate traffic composition, North America . . . . . . . . . . . 23

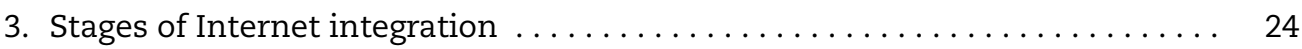

1.1. ICT sector value added as a proportion of business sector value added in the OECD area, 1995-2009. . . . . . . . . . . . . . . . . . . . . 33

1.2. Growth of ICT sector and business sector value added (VA) in the OECD area,

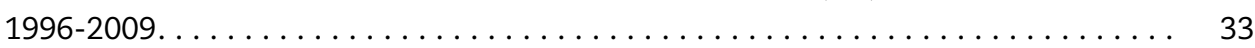

1.3. Growth in monthly output in ICT goods, December 2007-April 2012. . . . . . . 34

1.4. Growth in monthly output in computer and related services,

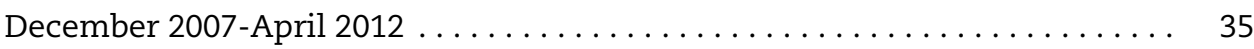

1.5. Growth in monthly output in telecommunications services, December 2007-April 2012 . . . . . . . . . . . . . . . . . . . . . . . . . . .

1.6. Share of ICT sector employment in business sector employment, 1995 and 2009

1.7. Growth in quarterly employment in ICT manufacturing,

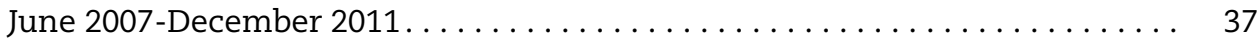

1.8. Growth in quarterly employment in ICT services, June 2007-December 2011 . . 38

1.9. Performance trends of top 250 ICT firms, $2000-11 \ldots \ldots \ldots \ldots$. . . . . . . . 40

1.10. Share in revenue, net income, net debt and employment of top 250 ICT firms

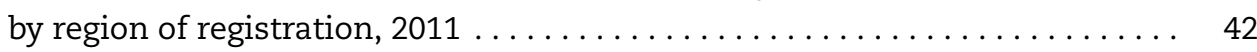

1.11. Revenue growth of top 250 ICT firms by economy of registration, $2000-11 \ldots 43$

1.12. Revenue trends of top 250 ICT firms by sector, $2000-11 \ldots \ldots \ldots \ldots$

1.13. Employment trends in the top 250 ICT firms by sector, $2000-11 \ldots \ldots . \ldots 46$ 
1.14. Average annual revenue per employee of the top 250 ICT firms

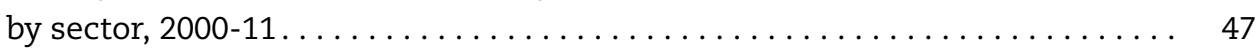

1.15. Profitability of top 250 ICT firms by sector, $2008-11 \ldots \ldots \ldots \ldots \ldots \ldots \ldots$. 47

1.16. R\&D expenditure shares of top 250 ICT firms by sector, $2011 \ldots \ldots \ldots \ldots \ldots 48$

1.17. R\&D intensity of top 250 ICT firms by sector, 2008 and $2011 \ldots \ldots \ldots \ldots \ldots 48$

1.18. Worldwide semiconductor market by region, May 2007-May 2012 . . . . . . 49

1.19. Growth in monthly semiconductor worldwide market billings,

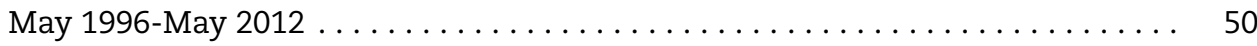

1.20. ICT investment by asset in OECD countries, $2010 \ldots \ldots \ldots \ldots \ldots \ldots \ldots \ldots$

1.21. Quarterly venture capital investments in the ICT sector in the United States,

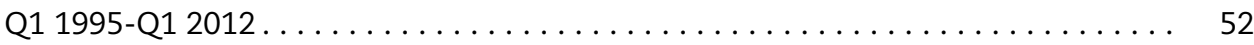

1.22. Quarterly venture capital investments in the Internet sector

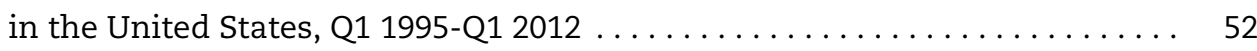

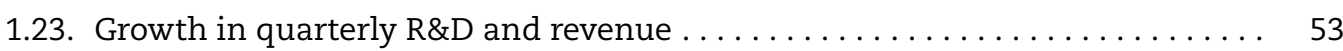

1.24. ICT BERD specialisation, 2010 or latest year available .............. 54

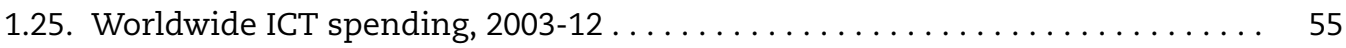

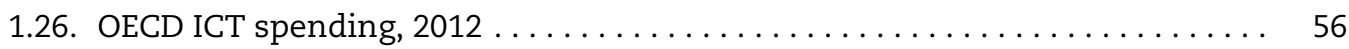

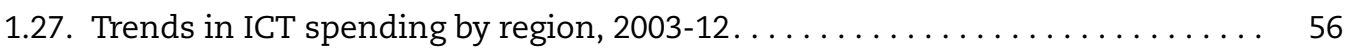

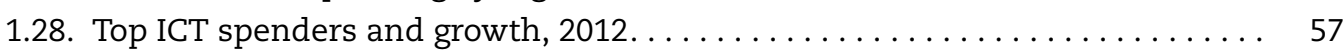

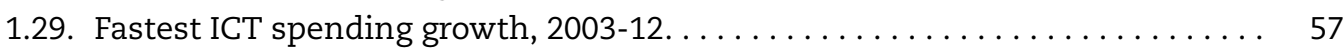

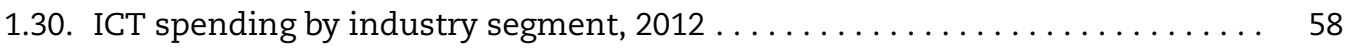

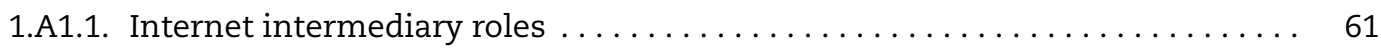

2.1. Fibre broadband penetration, December $2011 \ldots \ldots \ldots \ldots \ldots \ldots \ldots 65$

2.2. OECD wireless broadband subscriptions per 100 inhabitants, December 2011. . 66

2.3. Total fixed line, mobile and broadband access paths.............. 69

2.4. US smartphone penetration, Q2 2007-Q4 $2011 \ldots \ldots \ldots \ldots \ldots \ldots \ldots \ldots \ldots$

2.5. Platform shares for installed base of US smartphones .............. 71

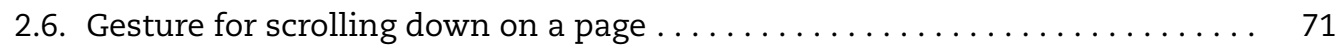

2.7. Android apps available on the Android Market, June 2012 . . . . . . . . . . . . 73

2.8. MyTaxi passenger app (left) and Driver App (right) ............... 75

2.9. Layar AR browser displaying estimated apartment prices $\ldots \ldots \ldots \ldots \ldots 76$

2.10. Future of social networking with augmented reality .............. 76

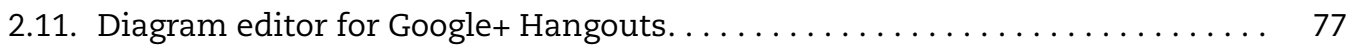

2.12. Leading IPTV countries, Q4 2010-Q4 $2011 \ldots \ldots \ldots \ldots \ldots \ldots \ldots \ldots \ldots \ldots$

2.13. The Multitoe project: touch-sensitive floors $\ldots \ldots \ldots \ldots \ldots \ldots \ldots \ldots \ldots$. . . 87

2.14. Remote collaboration with Tele-Board . . . . . . . . . . . . . . . . 89

2.15. Evolution of US retail e-commerce sales, Q1 2000-Q1 2012 . . . . . . . . . 93

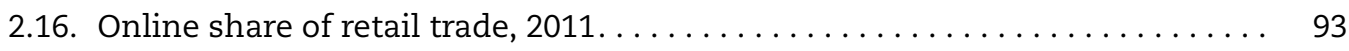

2.17. Revenue per unique user for tech companies, $2011 \ldots \ldots \ldots \ldots \ldots \ldots . \ldots 4$

3.1. Internet access and broadband connections in OECD households, 2011 or latest available year. . . . . . . . . . . . 103

3.2. Non-OECD households/individuals using the Internet, 2010 . . . . . . . . . 104

3.3. Breakdown of wired broadband subscriptions in OECD countries......... 105

3.4. OECD wireless broadband subscriptions per 100 inhabitants, December 2011105

3.5. Breakdown of wireless broadband subscriptions in OECD countries. . . . . . 106

3.6. Individuals using portable devices to access the Internet, $2010 \ldots \ldots \ldots \ldots$. . . 107

3.7. Non-computer devices traffic in selected countries. . . . . . . . . . . . . 107 
3.8. Internet access by place, EU $27 \ldots \ldots \ldots \ldots \ldots \ldots \ldots \ldots \ldots \ldots \ldots \ldots \ldots \ldots$

3.9. Individuals who used Internet for communicating, 2010 or latest available

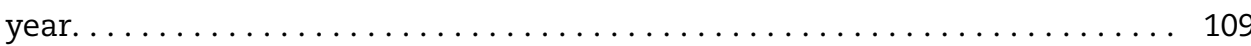

3.10. Internet users who created a web page, 2011 or latest available year . . . . . . 110

3.11. Demographics of social networking activity in the EU27 area, 2010 . . . . . . 111

3.12. Internet users engaging in social networking, $2011 \ldots \ldots \ldots \ldots \ldots \ldots \ldots$

3.13. Individuals who ordered or purchased goods or services on the Internet, 2011 or latest available year . . . . . . . . . . . . . . . . . . . . 112

3.14. Reasons for shopping online in Japan, 2006 and 2010 . . . . . . . . . . . 113

3.15. Goods and services ordered in the last 12 months for EU27, $2011 \ldots \ldots \ldots \ldots 114$

3.16. Individuals using the Internet for banking services, 2011 or latest available

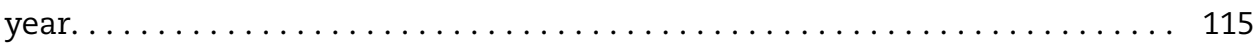

3.17. Internet use for learning, 2010 or latest available year . . . . . . . . . 116

3.18. Schools with Internet connection and usage, $2009 \ldots \ldots \ldots \ldots \ldots \ldots \ldots \ldots \ldots$

3.19. Individuals using the Internet for job searches, 2011 or latest available year . . 118

3.20. Individuals using the Internet to obtain information from the public authorities' websites, 2011 or latest available year. . . . . . . . . . . . 119

3.21. Number of online tax declarations . . . . . . . . . . . . . . . . . . . . . . . . 120

3.22. Individuals using the Internet to play/download games, music or films, 2010 or latest available year . . . . . . . . . . . . . . . . . . . . . 120

3.23. Internet users using P2P file sharing to exchange content, 2011 or latest available year. . . . . . . . . . . . . . . . . . . 121

3.24. Individuals using the Internet from any location by educational level, 2011 or latest available year . . . . . . . . . . . . . . . . 122

3.25. Households with broadband access, by region, $2010 \ldots \ldots \ldots \ldots \ldots \ldots \ldots . . \ldots \ldots$

3.26. Trends in Internet use by age in the EU27 area . . . . . . . . . . . . . . 124

3.27. Individuals using the Internet from any location, by age group, 2011

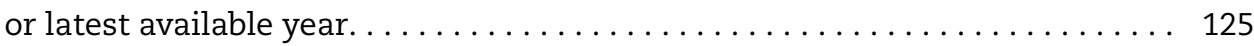

3.28. Gender gap in using the Internet, 2011 or latest available year . . . . . . . . . 126

3.29. Trends in Internet use by gender in the EU27 area . . . . . . . . . . . 126

3.30. Household Internet access by income, 2011 or latest available year . . . . . . . 127

4.1. Historical diffusion of ICT within firms in selected OECD countries . . . . . . . 133

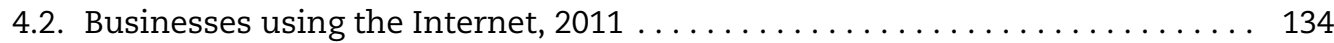

4.3. Share of enterprises with Internet access by size in Australia and Norway . . 135

4.4. Diffusion of broadband access in firms, selected OECD countries, 2001-10 . . . . 136

4.5. Share of enterprises with fixed broadband and fixed broadband

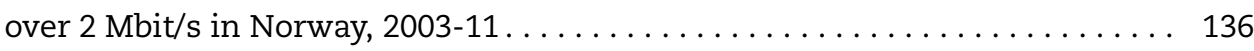

4.6. Businesses with a broadband connection, 2011 or latest available year . . . . 137

4.7. OECD businesses broadband penetration by size class, 2011 or latest available year. . . . . . . . . . . . . . . . . . . . . . . 137

4.8. Share of employed persons at work using an Internet-connected computer, selected OECD countries, 2005 and $2011 \ldots \ldots \ldots \ldots \ldots \ldots \ldots \ldots \ldots \ldots \ldots$

4.9. Businesses with a website, selected OECD countries, 2011 or latest available

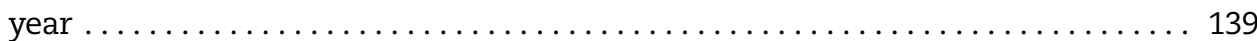

4.10. Intranet and extranet use in selected OECD countries, 2010 . . . . . . . . 140

4.11. Wireless access use within internal computer networks in the EU15, 2003-10 . . 141 
4.12. Various phases of e-business development by company size, selected OECD countries, 2010.

4.13. Companies sharing information electronically (internally and externally) suitable for automatic processing, by country (selected OECD countries), 2010 . . 144

4.14. Companies sharing information electronically (internally and externally) suitable for automatic processing, by sector (EU25), $2010 \ldots \ldots \ldots \ldots \ldots \ldots$

4.15. Companies using automatic data exchange to receive or send e-invoices, selected OECD countries, by country, 2010 . . . . . . . . . . . . . . . 145

4.16. Companies using Automatic Data Exchange to receive or send e-invoices

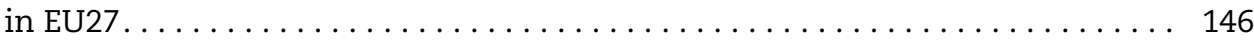

4.17. Business use of supply chain management via a website,

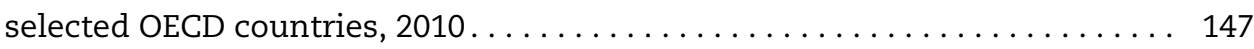

4.18. Total turnover of companies from e-commerce, 2011 or latest available year .. 148

4.19. Businesses selling/purchasing over the Internet, 2011 or latest available year . . . 149

4.20. Businesses using the Internet to return completed forms to public

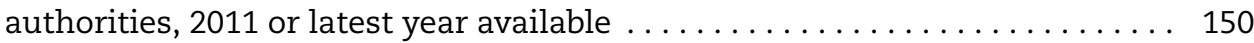

4.21. Perceived benefits of conducting business over the Internet . . . . . . . 151

4.22. Internet use intensity and innovation frequency, selected OECD countries. . 152

5.1. Digital content enabling factors. . . . . . . . . . . . . . . . . . . . . . 159

5.2. OECD broadband price and speed changes, similar offers $\ldots \ldots \ldots \ldots \ldots \ldots 161$

5.3. Global price differentials for communication services .............. 161

5.4. Changes in the proportion of OECD household's expenditure by category ..... 162

5.5. Growth of telephony as a communication tool .................. 162

5.6. Smartphone penetration and share in the United States, February 2012 . . . . 163

5.7. Digital content product characteristics and broadband functionalities ..... 166

5.8. Global consumer Internet traffic, $2010-15 \ldots \ldots \ldots \ldots \ldots \ldots \ldots \ldots \ldots \ldots . \ldots \ldots$

5.9. Digital broadband content business models . . . . . . . . . . . . . . . . . . . . . 169

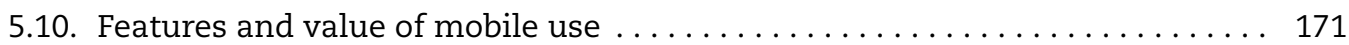

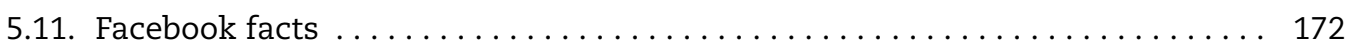

5.12. Proportion of Wikipedia articles by language (top 5 languages) . . . . . . . 174

5.13. Number of blogs indexed by Google . . . . . . . . . . . . . . . . 174

5.14. Digital and physical recorded music forecast, 2006-15 . . . . . . . . . . 179

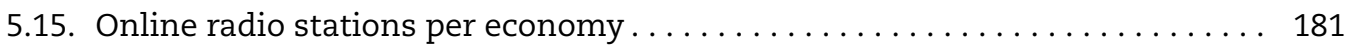

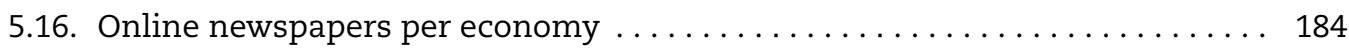

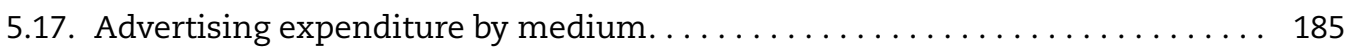

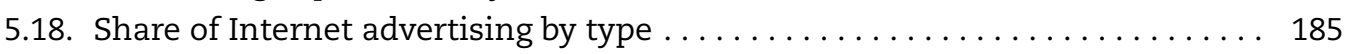

5.19. Global computer and video games sector revenue ................ 188

5.20. Geotagged Flickr photos per economy . .................... 190

5.21. YouTube: national and international viewing of domestically uploaded content. . . . . . . . . . . . . . . . . . . . . . . . . . . 191

6.1. Type of Internet connection in hospitals . . . . . . . . . . . . . 202

6.2. Total number of telehealth sessions performed in Canada, 2010 . . . . . . . 204

6.3. Percentage of claims processed electronically by HIRA, Korea, 2003-09 . . . . 206

6.4. Computerisation of GP practices in the United Kingdom . . . . . . . . . . . 207

6.5. Use of electronic medical records by physicians in seven OECD countries,

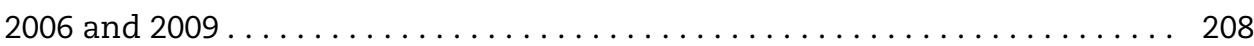

6.6. E-prescription as a \% of total prescriptions in Sweden, by region, 2000-07 . . . . 209 
6.7. Use of EHRs and electronic discharge and referrals by primary care centres in Finland and Norwegian Health Trusts, 2007 . . . . . . . . . . . . . . . . . . . 210

6.8. Electronic booking of medical appointments in EU hospitals . . . . . . . . 212

6.9. Percentage of broadband and narrowband users who report seeking health

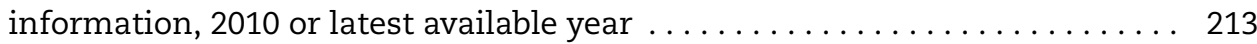

6.10. Internet users with a social networking activity, $2010 \ldots \ldots \ldots \ldots$. . . . . . . 214

6.11. Senior people using the Internet from any location by age group, 2011

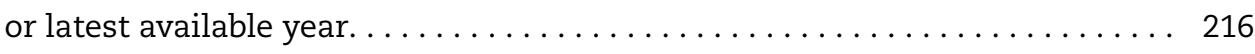

7.1. Stuxnet infection rates by country, September 2010 . . . . . . . . . . . . . 225

7.2. ICT business expenditure in R\&D, 2010 or latest available year . . . . . . . . . 227

7.3. R\&D intensity of selected IT security firms, 2010 . . . . . . . . . . . . . . . 228

7.4. Relative number of patent applications in information security and privacy filled under PCT, 1990-2010. . . . . . . . . . . . . . . . . . . . . . 229

7.5. Relative number of trademark applications in information security

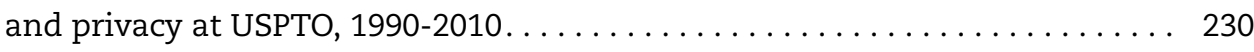

7.6. Relative number of trademark applications in information security

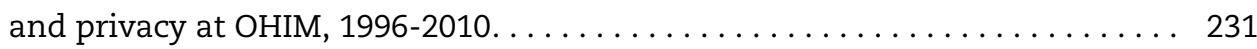

7.7. Share of ICT specialist users in the total economy, 1995 and 2010 . . . . . . 233

7.8. Number of (ISC) $)^{2}$ certified individuals worldwide, $2003-10$. . . . . . . . . . . 234

7.9. Approaches used to inform staff of their ICT security obligations,

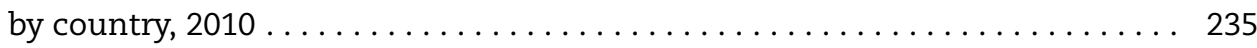

7.10. Total number of IAPP members, $2000-12 \ldots \ldots \ldots \ldots \ldots \ldots \ldots \ldots \ldots$

8.1. Recently increased priority ICT policy areas . . . . . . . . . . . . . . . . . . . . . 245

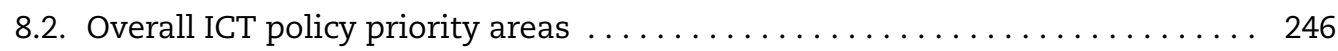

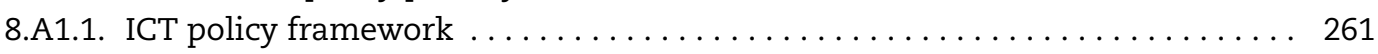

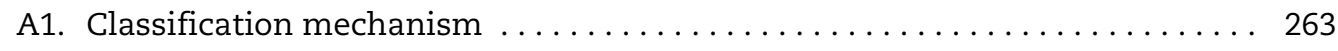

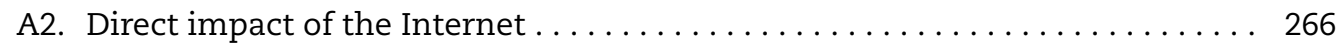

A3. Estimation of the direct impact of the Internet. . . . . . . . . . . . . . 272

A4. Sizes of various sectors in the United States economy . . . . . . . . . . . . . 275

A5. Dynamic impact of the Internet $\ldots \ldots \ldots \ldots \ldots \ldots \ldots \ldots \ldots \ldots \ldots$

A6. The impact of the Internet on the US economy under four scenarios. . . . . . 282

A7. Dynamic impact of the Internet on the US economy . . . . . . . . . . . . . 282

A8. The Internet economy in the US (measured by Approaches 1 and 2). . . . . . 283

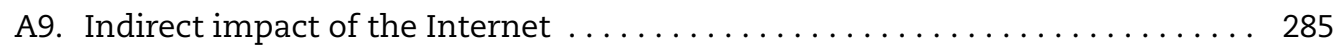

A10. The Internet and consumer surplus: channels of transmission . . . . . . . . . 289

\section{This book has...}

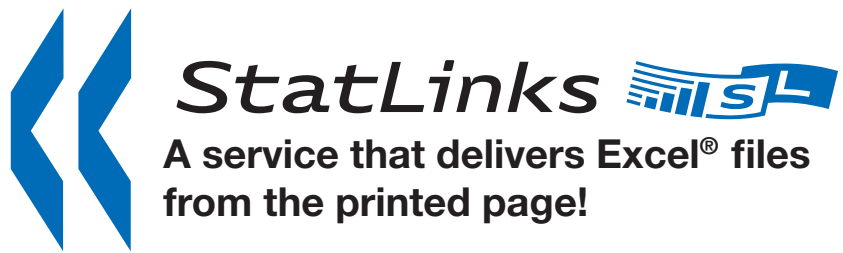

Look for the StatLinks at the bottom right-hand corner of the tables or graphs in this book. To download the matching Excel ${ }^{\circledR}$ spreadsheet, just type the link into your Internet browser, starting with the $h t t p: / / d x . d o i . o r g$ prefix.

If you're reading the PDF e-book edition, and your PC is connected to the Internet, simply click on the link. You'll find StatLinks appearing in more OECD books. 

OECD Internet Economy Outlook

(c) OECD 2012

\title{
Executive summary
}

\begin{abstract}
$\mathrm{T}_{\mathrm{h}}$ he Internet began as a way of linking different computers over the phone network, but it now connects billions of users worldwide from wherever they happen to be via portable or fixed devices. People with no access to water, electricity or other services may have access to the Internet from their mobile phone. The Internet is a multi-billion dollar industry in its own right, but it is also a vital infrastructure for much of the world's economy. The OECD Internet Economy Outlook provides data on the evolving Internet economy, emphasises trends across the OECD area, and highlights emerging policy issues.
\end{abstract}

Rapidly expanding broadband

The combination of widespread network coverage, sufficient data transfer capacity, affordable devices and connectivity options in most OECD markets has encouraged growth in services and ways in which people use the Internet.

Wireless connections are the key source of recent Internet expansion, overtaking fixed broadband subscriptions in 2009. As of December 2011, the estimated number of wireless broadband connections in the OECD (667 million) was more than double that of fixed broadband subscriptions (315 million) and the growth rate for wireless subscriptions continues to increase. Broadband speed has improved while prices have fallen. Advertised speeds of DSL and cable broadband increased annually by $32 \%$ and $31 \%$ respectively in OECD countries over 2008-11, while prices declined by $3 \%$ and $4 \%$ respectively.

The number of mobile phone subscriptions worldwide has more than doubled since 2005 and tripled in non-OECD countries. Tablet PCs and smartphones are making computers ubiquitous while cloud services and mobile Internet are enabling "everything/everywhere" data access, thus paving the way for new services and applications. The two technologies that will shape the near future of connectivity are very-high-speed fibre connections being deployed closer to population areas and new high-speed wireless connections.

The ICT sector and the crisis

The expansion of mobile Internet connectivity has helped buoy the ICT sector during the crisis, with $6 \%$ growth a year in revenue between 2000 and 2011 for the top firms. ICT services is doing better than ICT manufacturing, reaching output growth of $5 \%-10 \%$ in 2012. Employment in the sector has benefited too, with the top firms hiring more than 14 million people worldwide in 2011, a 6\% increase from 2010. Among the top ICT firms, Internet firms performed the best in terms of revenue and employment growth. 
E-commerce represents an increasing share of total business revenue. Although this share is still small in many countries, it is growing generally, as is the share of businesses selling and purchasing over the Internet.

The ICT sector continues to attract venture capitalists, accounting for more than $50 \%$ of all venture capital in the United States, the world's largest market, in 2011. Venture capital investment is at its highest level ever, with the exception of an anomalous peak in 2000 during the dot-com bubble. ICT business R\&D also continues with both Korea and Finland reaching over $1.5 \%$ of GDP.

Business adoption and use

The Internet is affecting nearly all sectors of the economy, from making hard-to-find data available online to transforming entire markets, as is occurring with music, video, software, books and news.

Businesses were among the earliest adopters of the Internet and helped lead the upgrade to higher speeds. In 2003, less than four out of ten companies had broadband access in the EU15; by 2009, this proportion had increased to nine firms out of ten. At the end of 2011, nearly all companies in OECD countries were connected to the Internet. In two thirds of OECD countries, more than $95 \%$ of the companies use the Internet, with only a small proportion of the smallest businesses not yet connected; in 2010, only $5.7 \%$ of small firms (10-49 employees) in the EU25 were not accessing the Internet.

At the company level, the restructuring of business models in association with Internet use has led to improved efficiency and the rapid growth of new online businesses. There is scope for improvement, however, as significantly fewer firms sell goods online compared to those ordering online. In 2010, on average, $35 \%$ of all businesses with ten or more persons employed used the Internet for purchasing, and only $18 \%$ for selling goods and services.

Household adoption and use

The Internet is reshaping the way individuals live, bringing a larger variety of digital goods and services, lower prices, improved information gathering, more distribution channels and so forth. Approximately $70 \%$ of OECD households have access to broadband Internet, at increasingly higher speeds and lower costs. The shift to mobile Internet connectivity is also changing the way in which people interact and consume content, via social networking.

The Internet has also become a vital tool to help match available workers with jobs: in 2010, an average of 17\% of Internet users reported using the Internet in a job search.

Despite recent advances in connectivity, however, certain segments of the population are much more likely to use the Internet (16-24 years old) than others (people over 65). Additional demographic characteristics, such as lower income or educational levels, are also correlated with lower levels of Internet access. 


\section{Digital content}

Digital content is arguably the most important driver of consumer Internet adoption, with related revenues growing rapidly across all sectors. Advertising represents the biggest online market in absolute terms, followed by computer and video games, online music and film and video. In 2010, games led global consumer demand, accounting for an estimated $39 \%$ of digital revenues. According to the International Federation of the Phonographic Industry (IFPI), digital music worldwide accounted for $29 \%$ of recording companies' revenues - more than four times that of the combined online revenues from the book, film and newspaper industries, despite these other industries being much larger overall.

The last two years have seen significant growth in devices capable of accessing online digital content. Sources of content are also expanding, with social networking and new video and audio services helping to drive ICT industry growth and create new business models. Indeed, the switch to digital technologies has forced businesses in a growing list of sectors to rethink their business models and adapt to survive.

Bandwidth usage continues to increase each year, with video and entertainment services demanding an increasing share on both fixed and mobile platforms. Sandvine reports that real-time entertainment applications have overtaken peer-to-peer (P2P) as primary drivers of network capacity in North America, accounting for $58 \%$ of peak traffic and almost $65 \%$ of peak downstream traffic in 2012. The streaming video service Netflix alone reached a peak of $32.9 \%$ of all US downstream traffic in the same year.

Devices such as set-top boxes and gaming consoles are also helping to drive this shift to online entertainment. Cisco predicts that IP traffic will grow fourfold between 2010 and 2015 at an annual growth rate of $32 \%$. Sandvine also reports that the majority of real-time entertainment traffic (54.3\%) is going to streaming video and audio and that $15.6 \%$ of this traffic is viewed on mobile devices and tablets being used from home via Wi-Fi.

\section{ICT for health}

The Internet is affecting all sectors of the economy but ICTs in health offer particular promise. The use of ICTs in the health sector can provide increased quality of care and efficiency, reduced operating costs and entirely new modes of care. OECD governments have recognised this potential and are taking on an increasingly larger share of implementation costs to ensure that the potential benefits are realised.

One example is electronic health records (EHRs) which enable timely access and better transmission of medical information across the healthcare continuum, thereby making patient care more responsive and efficient. Telehealth is also increasingly seen as an important tool for enhancing healthcare delivery, particularly in rural and remote areas where healthcare resources and expertise are often scarce or even non-existent.

However, many health ICT systems still cannot communicate with other systems and health information exchange remains a serious problem, even in countries where EHRs have proven particularly successful. Continued commitments to broadband, open standards and interoperability will be essential for successful change. 
Security and privacy

The future of the Internet economy depends on whether users, businesses and governments feel safe using the network and trust it for critical applications and services. Malware, denial of service (DoS) attacks and other incidents compromising the confidentiality, integrity or availability of information systems and networks are increasing. Where personal data are collected, stored or processed, these incidents also heavily affect privacy. As a result, governments are paying increasing attention to cybersecurity and data privacy threats.

Data on the role of innovation in privacy are incomplete, either because R\&D figures are hard to find or because privacy-enhancing technologies are less frequently patented. Statistics on trademarks seem to capture innovation in privacy much better; however, the number of trademark applications related to privacy is six times lower than those related to information security. This may indicate a lower level of ongoing technological and product innovation in the field of privacy compared to information security.

The increasing relevance of information security and privacy at the organisational, national and international level suggests that demand for security and privacy professionals will increase, making skills a potential bottleneck for enhancing innovation in information security and privacy.

The Internet of things

Internet development is on the cusp of a potentially large expansion to objects typically not associated with communication capabilities. Electricity plugs, automobiles and even light bulbs for instance are increasingly connected to the Internet as a way to introduce new functionality. This forthcoming third wave of Internet connectivity is expected to connect anywhere from ten to a hundred devices per family, and thousands or potentially millions of devices per company.

Two enabling factors are driving this Internet of things: the ubiquity of networks and ever lower prices for the communications modules used to connect devices. Ericsson estimates that there will be 50 billion mobile wireless devices connected to the Internet by 2020, and this could eventually reach 500 billion. For example, incorporating a communication device into each automobile, and assuming a lifespan of ten years, would result in around 700 million "machine-to-machine enabled" cars by 2020. Connecting every power socket in North America to a network as part of a smart grid rollout would easily result in 10 billion connections.

As economies and societies become increasingly intermeshed with devices that continuously communicate with each other and provide information to users, data will be processed and delivered as a myriad of signals across multiple devices and networks. It will increasingly inform people about their surroundings, but also provide information about people to third parties. The privacy considerations are therefore significant. 
Governments increasingly fund broadband rollouts, either through direct public investment or via the modification of universal service programmes, yet there is still no widely accepted methodology or single measure to capture the whole Internet economy. But the existing OECD research presented here in the Internet Economy Outlook illustrates the importance of establishing an international definition and the need to develop related policies. The data shows that at least $3 \%$ and up to $13 \%$ of business sector value added in the United States in 2010 could be attributed to Internet-related activities depending on the scope of the definition.

Two important requirements for further analysis are high-quality data as inputs and a robust model to interpret them. In addition, cross-country comparisons require harmonisation of data collections across countries, which will likely take years. As such, the full impact of the Internet on our economies remains far from clear, even as the available means of communicating and connecting to information continue to expand rapidly. What is clear is that the Internet is becoming a key economic infrastructure, revolutionising businesses and serving as a platform for innovation.

\section{Government priorities}

Policy makers across governments are increasingly focused on policies related to the Internet and ICTs as our reliance on them grows. In 2011, OECD governments indicated their policy priority areas and the results are provided in the table below. Overall, broadband remains a key priority but there is a new emphasis on ICT skills and employment as many countries continue to face economic challenges. Governments are also looking for ways to move more government services online.

\section{Table 0.1. Overall ICT policy priority areas}

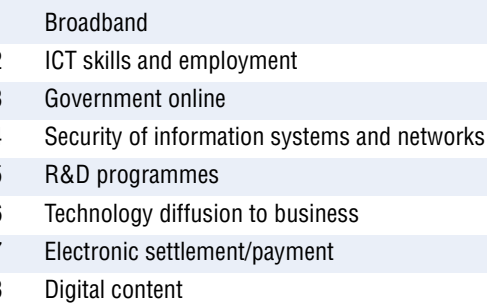

The data and research in this OECD Internet Economy Outlook highlight the spread of the Internet's influence throughout the economy and help support empirically-based policy making. In the coming years, the Internet will continue to expand while businesses, individuals, and governments will find new, innovative ways to leverage the potential of networks. 



\section{Expanding connectivity and measuring the Internet economy}

This opening chapter examines the key driving factors behind the recent growth in mobile connectivity tied to smartphones and tablets, anticipating the third wave of smart connected objects (the Internet of things) and the ways in which markets, businesses, governments and the daily lives of citizens are being reshaped in the process. It also discusses the importance of and challenges to measuring the Internet economy, and presents new research, approaches and methodologies in this field. 
$\mathrm{T}_{\mathrm{h}}$ he Internet began as an important tool for improving communication, but has transformed into a ubiquitous technology supporting all sectors across the economy. Most policy makers in OECD countries now consider the Internet a fundamental infrastructure, in much of the same way as electricity, water and transportation networks. In recent years, the term Internet economy has become a widely used expression, evoking the key economic role the Internet now plays in our daily lives. ${ }^{1}$

The universal, transformational character of the Internet means that its economic impact is observable in many different areas, at various levels. The Internet affects the everyday activities of individuals, companies and governments in numerous ways, but also tends to produce broad, economy-wide effects.

The Internet is reshaping the way individuals live, bringing the benefits of higher consumer welfare through a larger variety of digital goods and services, lower prices, improved information gathering, more distribution channels and so forth. In addition, individuals benefit from a more efficient labour market ${ }^{2}$ and, at a broader level, from positive impacts to the environment (OECD, 2009, 2010; Prasad, 2010) and in education. For example, the Internet has become a vital tool for helping match available workers with jobs requiring a certain set of skills.

At the company level, the restructuring of business models in association with Internet use has led to improved efficiencies (Bertschek, Cerquera and Klein, 2011; Brynjolfsson, 2003; Forman and van Zeebroeck, 2010; Grimes and Ren, 2009; Majumdar, Carare and Chang, 2009; OECD, 2008, Spezia, 2011). Its impact is also visible in the rapid growth of new online businesses. The Internet's enhanced communication capabilities are affecting nearly all sectors of the economy in ways both subtle and profound, from making available online previously hard-to-find data to transforming entire markets, as is occurring with music, video, software, books and news.

For governments, Internet development enables better communication with citizens, industry and other organisations and also promotes more efficient governance through improved information sharing, increased transparency and the automation of various resource-intensive services.

The full impact of the Internet on our economies remains far from clear, even as the available means of communicating and connecting to information continue to expand rapidly. What is clear is that the Internet is becoming a key economic infrastructure, revolutionising businesses and serving as a platform for innovation.

This Internet Economy Outlook serves as a tool for policy makers and researchers by providing data on the evolving Internet economy, emphasising Internet trends across the OECD, and highlighting emerging policy issues. It grew out of a request made in 2008 by 40 ministers at the OECD Ministerial Meeting on the Future of the Internet Economy to 
analyse the future development of the Internet economy, develop policy principles, and improve statistical systems to measure the changing access and use of the Internet. ${ }^{3}$

The chapters in the Outlook examine the role of the Internet and the ICT sector in the economy, particularly during the recent economic recession. They explore evolving Internet trends, including innovative Internet uses, and study Internet adoption by both households and businesses. They look at the transformations resulting from improved access in specific sectors of the economy, such as digital content and health, wellness and ageing, and examine the implications for security and privacy as the Internet becomes an economic platform and a repository of personal information. Finally, the Outlook concludes with a chapter focusing on the policy priorities of OECD governments related to the Internet and the ICT sector in general.

\section{Expanding connectivity}

The Internet is firmly in its second stage of development, evolving from a data network connecting PCs with wires to a much broader network reaching a wide range of new portable devices such as mobile phones and tablet computers. The recent expansion of Internet connectivity is tied to the explosive growth of new smartphones and portable devices such as handheld computers and tablets.

Many of the technologies supporting this growth have been available for more than a decade. Wireless Internet connectivity via 3G networks was first deployed in 2000 (ITU, 2011) and handheld computing devices such as the Apple Newton (1993), ${ }^{4}$ the PalmPilot (1996), ${ }^{5}$ and PocketPCs (2000) ${ }^{6}$ were available in the preceding years. Tablet computers were launched with much fanfare in $2002^{7}$ as the predecessors of modern tablets. But what was missing, until recently, was the important conflux of widespread Internet coverage, sufficient data capacity, affordable devices and connectivity options, as well as appealing services.

These elements are now largely in place in most OECD markets and parallel a significant shift in available services and ways in which people use the Internet. Internet applications such as social networking, location-based services, user-created content and blogging continue to evolve as more users access the Internet via mobile networks. Increasingly connected homes are even leading to changes in the ways that household members interact with one other (Box 1).

\section{Box 1. Use of portable devices for communication within the home}

ICTs are changing the ways in which people communicate, not just with business and social acquaintances, but also with members of the same household. A recent UK study found that people use the Internet as a domestic intercom with $20 \%$ of parents reporting that they increasingly use ICTs to communicate with their own children while inside in the home, via mobile phones, laptops, PCs and tablets.

Respondents to the study indicated that the most common message relayed internally at home was "dinner is ready", sent by $13 \%$ of those surveyed. Other common messages included "clean your room" and "do your homework".

Sources: Kim, R. (2011), "1 in 5 parents use gadgets as in-home intercom with kids", Gigaom, 12 December 2011; YourASDA (2011), The Internet is the New Intercom, Study Finds, 9 December 2011. 
Wireless Internet connections are the key source of recent Internet growth, increasing rapidly since 2001 and overtaking fixed broadband subscriptions in 2009. The growth rate for wireless Internet subscriptions has continued to increase, and as of December 2011 the estimated number of wireless broadband connections (667 million) in the OECD was more than double that of fixed broadband subscriptions (315 million) (Figure 1).

\section{Figure 1. Wireless Internet access overtaking fixed broadband subscriptions}

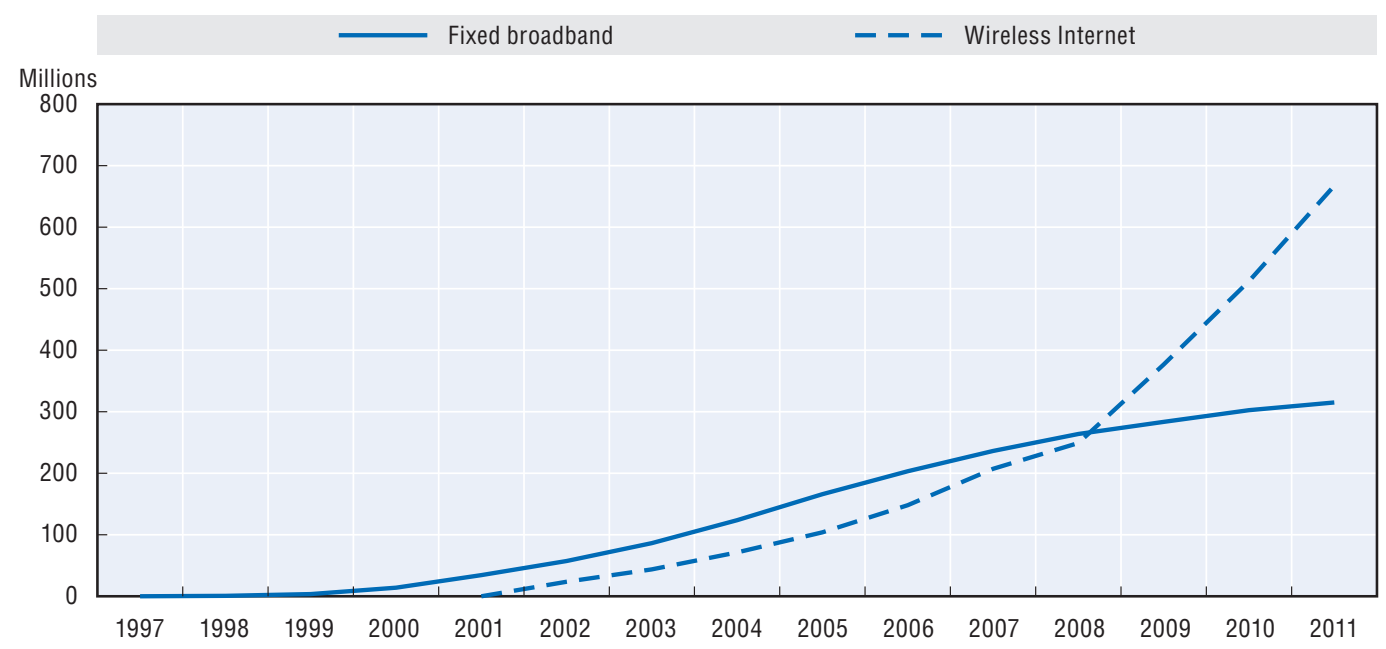

Note: Data for 2011 include estimates for some countries.

Source: OECD Broadband Portal, July 2012.

Bandwidth usage continues to increase each year with significant changes to composition of total traffic. Video and entertainment services are demanding an increasing share of bandwidth on both fixed and mobile platforms. For example, Sandvine reports that real-time entertainment applications have overtaken peer-to-peer (P2P) as primary drivers of network capacity in North America, accounting for $58 \%$ of peak traffic and almost 65\% of peak downstream traffic in 2012 (Figure 2). The streaming video service Netflix in the United States reached $32.9 \%$ of all US downstream traffic in the same year (Sandvine, 2012).

The adoption of devices such as set-top boxes and gaming consoles are driving, in part, the significant shift to online entertainment as a percentage of aggregate traffic. These new consumer devices can display high-definition video content and are driving demand for bandwidth, particularly on wired networks. As an example, the networking company Cisco predicts that IP traffic, much of it from video services, will grow fourfold between 2010 and 2015 at an annual growth rate of 32\% (Cisco, 2012). Sandvine also reports that the majority of real-time entertainment traffic (54.3\%) is going to streaming video and audio and that $15.6 \%$ of this traffic is viewed on mobile devices and tablets being used in the home via Wi-Fi.

The figure below illustrates the shifting nature of traffic on the Internet, but does not take into account the increasing capacity of Internet connections, both on wired and wireless networks. For example, web browsing shows a decline between 2010 and 2011, but the capacity of networks and individual broadband subscriptions generally increases on a yearly basis. 
Figure 2. Peak period aggregate traffic composition, North America

Fixed access networks

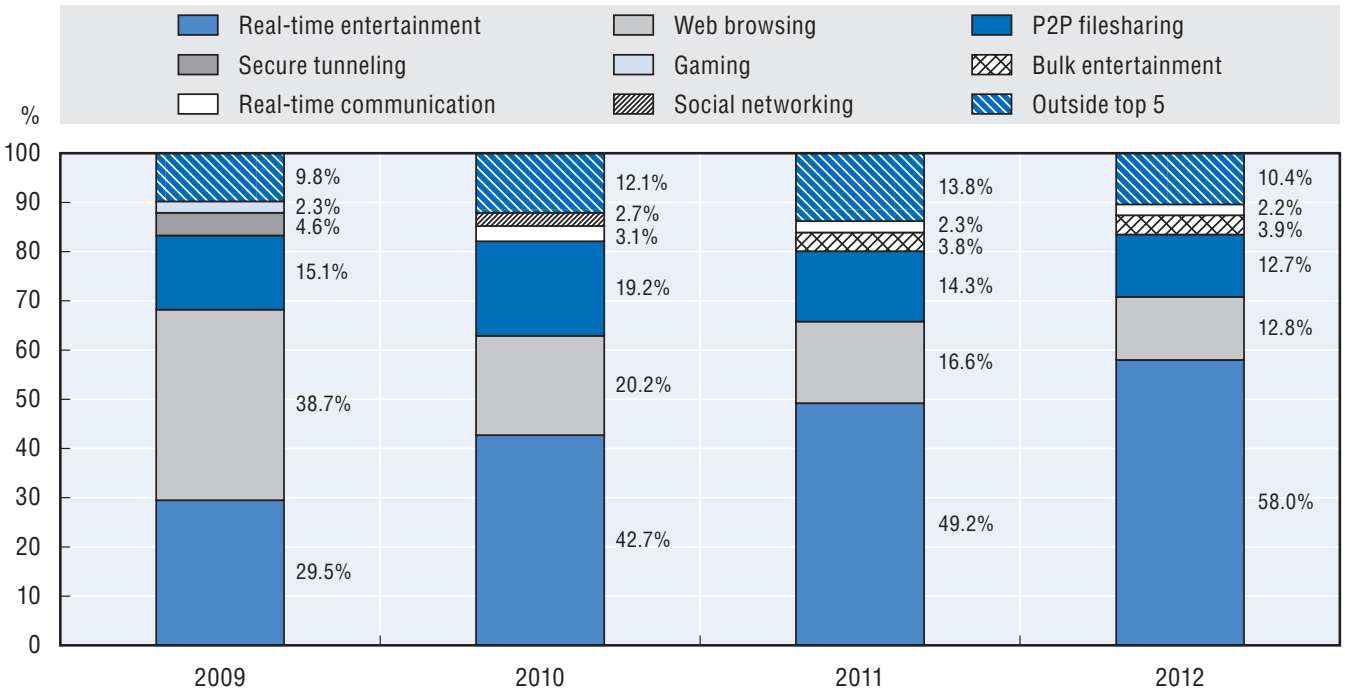

Source: Global Internet Phenomena Report, 1H 2012, Sandvine, Ontario, Canada.

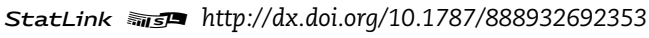

Internet development has clearly hit something of a stride with the expansion of connectivity to mobile devices; however, it is on the cusp of a potentially much larger expansion to objects typically not associated with communication capabilities (Figure 3). Television sets, electricity plugs, GPS devices, automobiles and even light bulbs and water levees are increasingly connected to the Internet as a way to introduce new functionality. This forthcoming third wave of Internet connectivity is expected to connect a much larger number of objects to the Internet, ranging from ten to a hundred connected devices for each family to thousands or potentially millions of devices managed by individual companies.

The ICT firm Ericsson estimates that there will be 50 billion mobile wireless devices connected to the Internet across the globe by 2020 , and predicts that the total number of devices connected to the Internet could reach 500 billion (OECD, 2012). Projections of the number of devices connected to the Internet vary, but all highlight the commonly held idea that the "Internet of things" will have significantly more connections than users.

Although these figures may seem high, they are easy to illustrate. For example, incorporating a communication device into each automobile, and assuming a lifespan of 10 years, would result in around 700 million "machine-to-machine enabled" cars by 2020. Connecting every power socket in North America to a network as part of a smart grid rollout would easily result in 10 billion connections (OECD, 2012). Google recently demonstrated an Android-powered light bulb, ${ }^{8}$ start-ups are working on power plugs that communicate over home electricity networks; and car companies are collecting sensor data from traction control systems to warn other drivers of slippery roads. Effectively every component of a system can become an addressable part of the "Internet of things".

Two enabling factors drive the Internet of things: the ubiquity of networks and increasingly lower prices for communications modules. These allow increasing numbers of devices to be equipped with Internet capabilities. In many cases, communication 


\section{Figure 3. Stages of Internet integration}

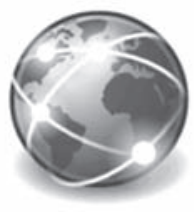

Internet (Wave 1)

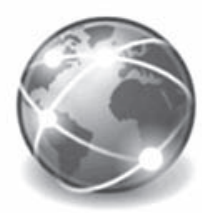

Internet

(Wave 2)

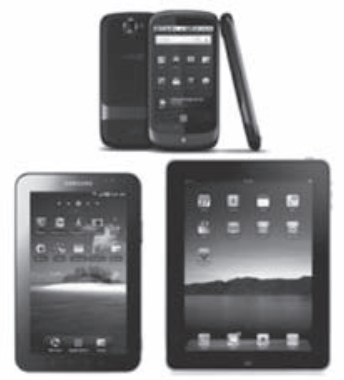

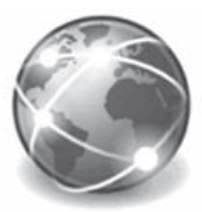

Internet

(Wave 3)
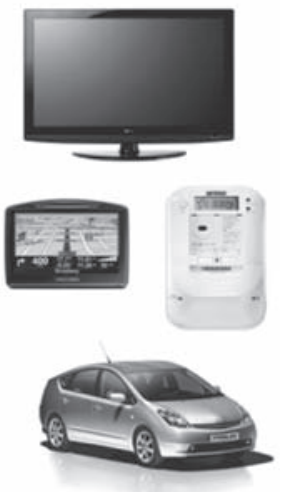

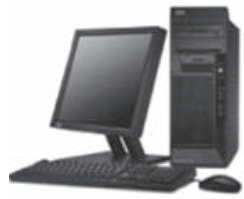

capabilities are difficult to avoid because communication modules are now integrated into the basic chipsets that make up a device.

This raises many important issues for stakeholders. Economies and societies are becoming increasingly intermeshed with devices that continuously communicate with each other and provide information to users. That data will be processed and delivered as a myriad of signals across multiple devices and networks. It will increasingly inform people about their surroundings, but also provide information about them to third parties. The privacy considerations are therefore significant.

\section{Measuring the Internet economy}

Policy makers are keenly aware of the Internet's increasing economic importance, yet, there is still no widely accepted methodology for assigning an economic value to the Internet. Policy makers look to broadband and mobile data networks as platforms for innovation and development, while governments increasingly fund broadband rollouts, either through direct public investment or via the modification of universal service programmes, to extend access and achieve these goals.

The size of the Internet economy is particularly relevant given the growing importance of the Internet as a policy tool. There is a high level of interest in measuring the Internet economy 
as a way to understand the effects of various investment strategies, regulatory rulings and policy decisions. Various studies have attempted to address this issue, but the proposed methodologies are not always consistent with statistical standards and economic concepts.

An illustrative example is the case of Egypt where Internet access was disrupted for several days on 28 January 2011. The direct economic impact of shutting off the Internet was significant as telecommunication revenues alone amount to approximately $3 \%$ of Egyptian GDP. But the indirect social and economic effects of the Internet shutdown were likely much larger, particularly as the loss of connectivity threatened existing and future foreign direct investment, despite the fact that Egypt had worked tirelessly over the past decade to establish itself as a hub for outsourcing. For example, the repercussions of shutting down Egyptian Internet access were felt in countries as far away as New Zealand, where Vodafone New Zealand was unable to route calls to its customer support call centre in Cairo.

This event lead to questions about the economic consequences of such a service disruption and consequently about the economic dimension of the Internet and the size of the Internet economy. The Egyptian experience and the increasing reliance of firms, governments and society on the Internet led for calls to measure the size of the Internet economy and the potential negative effects of a loss of access.

In early 2011, the OECD initiated a new line of research to construct a set of methodologies to measure the Internet economy. It builds upon existing research, including the statistical definitions set by the OECD Guide to Measuring the Information Society, and OECD estimates of ICT value added in countries for the last 10 years. The project brought together experts from academia, governments and the private sector to develop core methodologies capable of making comparisons over time and across countries.

There are two main challenges related to quantification of the Internet economy:

- First, it needs to be clearly stated whether a given study or exercise is attempting to measure the Internet or the Internet economy. Although both concepts might sound similar, they refer to different economic notions. The "Internet" can be defined here as the physical networks and the provision of data connectivity. The "Internet economy" is a much broader concept that can encompass all uses and benefits resulting from the connectivity that the Internet provides.

- Second, given the general, transformational character of the Internet and the large area of its economic impact, the scope of any exercise that attempts to measure the Internet economy must be precisely defined.

Concerning the first challenge, any measures of the Internet (i.e. as a global network of interconnected computer networks using a standard Internet Protocol) cannot be used interchangeably with measures of the Internet economy, which refer to various types of economic impact (direct and indirect, static and dynamic) of the Internet. However, both measures are conceptually related, as any robust quantitative analysis of the impact of the Internet first requires a reliable, aggregated proxy of Internet development (Lehr, 2012). This implies that measures of the Internet economy (e.g. measures of the economic impact of the Internet) need not be identical to proxies of the Internet. Even though the term "Internet economy" lacks a precise definition, there are several measures that describe the Internet only and cannot be used to measure the Internet economy and vice versa.

Possible measures of the Internet that do not measure the Internet economy include: adoption rates (e.g. penetration rates) and measures of access prices that do not attempt to quantify the economic impact of the Internet, but instead focus on measurement of one of 
its other dimensions (e.g. technical). Examples of measures that refer to the Internet economy only, and do not address measurement of the Internet, mostly describe the economic effects of the Internet, including: measures of the effects the Internet might have on company profits or on the growth of GDP. Measures that address both the Internet and the Internet economy focus on the size of the Internet expressed in monetary terms (e.g. investment in Internet infrastructure).

The second challenge to the consistency of quantification of the Internet stems from its general, transformational and dynamic character (Lehr, 2012). Indeed, the economic impact area of the Internet is such that if Internet connectivity failed on a large scale over an extended period of time, the whole economy would probably suffer a major shock in the short run, similar to the effects of oil shortages during the oil crisis or extended electricity blackouts. There are myriad areas where researchers can observe and measure the economic dimension of the Internet or its economic impact. It is therefore important to define the scope of measurement (e.g. a given country or industry) and selection of methodology (e.g. the time horizon of the assessed economic impacts).

The large spectrum of possible impact areas could result in a trade off between precision and scope of measurement. As Lehr (2012) notes, significant changes underway in the Internet - to enable mobility, cloud computing resources, social-networking, and sensor networks - imply that tomorrow's critical Internet components are not well-measured by today's Internet metrics. Line counts, fibre miles, megabytes of traffic, or IP addresses are not good proxies for assessing the intensity of the trends identified.

To reiterate, it is extremely difficult to provide a single measure to capture the whole Internet economy. The continuously evolving Internet has changed from a service used by some to an essential, basic economic infrastructure that will soon be used by nearly everyone in nearly all places. It affects almost all economic activities and its impact is found in numerous short and long-term economic processes.

\section{A proof of concept}

One result emerging out of this new research area in the OECD is a method for categorising different approaches to measuring the Internet economy. There are three approaches that are detailed in the Annex A but summarized here. Approach 1 is the most conservative and reliable method of the three because it relies mainly on official data. It groups studies that measure the size of the Internet economy expressed as a part of GDP or business sector ${ }^{9}$ value added. Approach 2 looks at the dynamic impact that the Internet might have on all industries, and hence on rates of productivity growth and eventually GDP growth. Studies here build upon a set of robust, economic literature, but represent new efforts to capture and integrate the effects of the Internet. Approach 3 takes into account the indirect impact of the Internet. Studies within this broader approach examine the effects of the Internet on economic phenomena such as consumer surplus, or explore how the Internet contributes to social welfare gains. These studies look at additional impacts of the Internet on economic welfare not measured by official statistics. They represent a new frontier of analysis that is still relatively undeveloped.

The next step is to develop methodologies to measure the impact of the Internet once broad, baseline approaches have been established. Two of the most important elements for a successful data analysis are high-quality data as inputs and a robust model to interpret them. But measuring the Internet economy is a relatively new target for policy makers, and analyses typically lack sufficiently detailed data. In addition, cross-country comparisons 
require harmonisation of data collections across countries, which take a significant amount of time.

However, some data are available in certain countries. The development of harmonised measures, where data are available, across countries for each of the approaches will likely take years. However, this Internet Economy Outlook takes advantage of sufficiently detailed data available for the United States to produce estimates using methodologies that fall into Approaches 1 and 2 (see Annex A). This "proof of concept" will hopefully lead to future data development and methodological refinement.

The methodology used on official data from the United States in Approach 1 relies on two key assumptions (see Annex A) ${ }^{10}$ to transpose Internet-related activities and e-commerce data into weights for value added in each sector of the economy. The US data used cover the business sector of the economy, and imply that the Internet plays a very significant role in the overall US economy. At least $3 \%$ and up to $13 \%$ of business sector value added in the United States in 2010 could be attributed to Internet-related activities depending on the scope of the definition.

This area of measurement is still in its relatively early stages and the estimates only represent orders of magnitude. However, the research seems to confirm what policy makers have been stating in OECD governments for quite some time: that the Internet is becoming a core economic infrastructure for the entire economy.

Future work will need to focus on refining the methodologies and developing a harmonised approach using comparable data across countries. This will not be an easy task and will take time. However, the growth of the Internet and its impact on the economy will remain one of the most important questions for policy makers over the next few years, as they work to leverage the Internet as a tool to stimulate innovation, create new jobs and make operations more efficient.

\section{Notes}

1. The "Internet economy" is one of several terms used to define the transformation that the Internet, and information and communication technologies (ICTs) in general, are supporting throughout the economy. In the past, the term "information economy" was commonly used, particularly as a reference to the broader effects of ICTs. But the phenomenal growth of the Internet and the shift of traditional communication technologies such as fixed and mobile voice to Internet-protocol based technologies have helped support the shift from "information economy" to "Internet economy". The OECD's decision to retire the Information Technology Outlook series and begin a new Internet Economy Outlook reflects this transformation. In some areas, the term digital economy is more commonly used, but it often refers to digital technologies such as DVD and CD distribution that are not necessarily Internet based.

2. The adoption of Internet-based IT solutions might raise demand for highly skilled workers (Bresnahan, Brynjolfsson, and Hitt, 2002), which might also temporarily reduce demand for lower skilled tasks (Spiezia and Vivarelli, 2002).

3. The Ministerial Declaration can be found at: www.oecd.org/dataoecd/49/28/40839436.pdf.

4. Hormby, T. (2010), “The Story Behind Apple's Newton”, Gizmodo, 19 January 2010, http://gizmodo.com/ 5452193/the-story-behind-apples-newton.

5. Niccolai, J. and N. Gohring (2010), "A Brief History of Palm”, PCWorld, 29 April 2010, www.pcworld.com/ article/195199/a_brief_history_of_palm.html.

6. Microsoft (2000), "Steve Ballmer Speech Transcript - Pocket PC Launch", 19 April 2000, Microsoft News Center, www.microsoft.com/en-us/news/exec/steve/04-19pocketpc.aspx.

7. Microsoft (2002), "With Launch of Tablet PCs, Pen-Based Computing Is a Reality", 7 November 2002, Microsoft News Center, www.microsoft.com/en-us/news/features/2002/nov02/11-07tabletlaunch.aspx. 
8. The demonstration can be viewed at: www.youtube.com/watch?feature=player_embedded\&v=zD3Q4kJhD5w Android@Home a presentation at the Google I/O conference 2011.

9. In order to get a comparable aggregate across countries, the business sector is defined as per ISIC Rev.4, activities 05-66, 69-82. It does not take into account agricultural activities, real estate, nor community, social and personal services.

10. Assumption 1: It is assumed that the share of revenue from Internet-related activities in total revenue for the information sector is proportional to the share of value added from these activities in total value added for that sector. Assumption 2: It is assumed that the share of revenue from e-commerce in total revenue for each industry sector is proportional to the share of value added from e-commerce in total value added for that same industry sector.

\section{References}

Bertschek, I., D. Cerquera and G. Klein (2011), "More Bits - More Bucks? Measuring the Impact of Broadband Internet on Firm Performance", Discussion Paper No. 11 032, ZEW (Centre for European Economic Research), Mannheim, Germany, ftp://ftp.zew.de/pub/zew-docs/dp/dp11032.pdf.

Bresnahan, T., E. Brynjolfsson, and L.M. Hitt (2002), "Information Technology, Workplace Organization, and the Demand for Skilled Labor: Firm-Level Evidence", Quarterly Journal of Economics, Vol. 117, No. 1, pp. 339-376.

Brynjolfsson, E. (2003), “Computing Productivity: Firm-Level Evidence”, Review of Economics and Statistics, Vol. 85, No. 4, pp. 793-808.

Cisco (2012), Visual Networking Index, Cisco, 19 January 2012, www.cisco.com/en/US/netsol/ns827/ networking_solutions_sub_solution.html\# forecast.

Forman, C. and N. van Zeebroeck (2010), From Wires to Partners: How the Internet has Fostered R\&D Collaborations within Firms, http://papers.ssrn.com/sol3/papers.cfm?abstract_id=1725780.

Grimes, A. and C. Ren (2009), "The Need for Speed: Impacts of Internet Connectivity on Firm Productivity", MOTU Working Paper 09-15, MOTU, Wellington.

ITU (International Telecommunication Union) (2011), “About Mobile Technology and IMT-2000”, ITU, www.itu.int/osg/spu/imt-2000/technology.html.

Kim, R. (2011), "1 in 5 parents use gadgets as in-home intercom with kids", Gigaom, 12 December 2011, http://gigaom.com/2011/12/12/one-in-five-parents-use-gadgets-as-in-home-intercom-with-kids/.

Lehr, W. (2012), "Measuring the Internet: The Data Challenge”, OECD Digital Economy Papers, No. 194, OECD Publishing. doi: http://dx.doi.org/10.1787/5k9bhk5fzuzx-en.

Majumdar, S. K., O. Carare, and H. Chang (2009), "Broadband Adoption and Firm Productivity: Evaluating the Benefits of General Purpose Technology", Industrial and Corporate Change, Vol. 19, No. 3, pp. 641-674.

OECD (2008), "Broadband and the Economy", OECD Digital Economy Papers, No. 146, OECD Publishing. doi: http://dx.doi.org/10.1787/230450810820.

OECD (2009), "Smart Sensor Networks: Technologies and Applications for Green Growth”, OECD Digital Economy Papers, No. 167, OECD Publishing. doi: http://dx.doi.org/10.1787/5kml6x0m5vkh-en.

OECD (2010), "Greener and Smarter: ICTs, the Environment and Climate Change", in OECD, OECD Information Technology Outlook 2010, OECD Publishing. doi: http://dx.doi.org/10.1787/it_outlook-2010-7-en.

OECD (2012), "Machine-to-Machine Communications: Connecting Billions of Devices", OECD Digital Economy Papers, No. 192, OECD Publishing. doi: http://dx.doi.org/10.1787/5k9gsh2gp043-en.

Prasad, R., S. Ohmori and D. Simunic (eds.) (2010), Towards Green ICT, River Publishers, Gistrup, Denmark.

Sandvine (2012), Global Internet Phenomena Report, 1H 2012, Sandvine, Ontario, Canada, www.sandvine.com/news/global_broadband_trends.asp.

Spiezia, V., and M. Vivarelli (2002), "What Do We Know About The Effects Of Information And Communication Technologies On Employment Levels?”, in J. Mairesse and N. Greenan (eds.), ITC, Productivity and Employment, MIT Press, Cambridge, United States. 
Spiezia, V. (2011), “Are ICT Users More Innovative?: an Analysis of ICT-Enabled Innovation in OECD Firms", OECD Journal: Economic Studies, Vol. 2011/1. doi: http://dx.doi.org/10.1787/eco_studies-2011-5kg2d2hkn6ug.

YourASDA (2011), The Internet is the New Intercom, Study Finds, 9 December 2011, http://your.asda.com/ press-centre/the-internet-is-the-new-intercom-study-finds. 



\section{Chapter 1}

\section{ICTs, the Internet and the crisis: Macro trends}

This chapter examines the Internet within the broader view of the ICT sector as a whole. It explores the impact of the recent fiscal and economic crisis on the sector in terms of both ICT goods and services. It examines the top 250 ICT firms by country and sector, and looks at the current status of Internet intermediary and semiconductor firms. The chapter also looks at the various aspects of Internet investment, including venture capital, investment in R\&D, as well as ICT markets, spending and investment. Finally, it offers its conclusions on the current health and growth of the ICT sector. 
$\mathrm{T}_{\mathrm{h}}$ he Internet is an integral part of the larger ICT sector and its influence overall within the sector is increasing as more standard ICT devices are Internet enabled. The larger ICT sector also provides insight into trends and technologies supporting the Internet. This new Internet Economy Outlook begins with an overview of trends in the global ICT sector supported by time-series data. These trends provide a foundation for the remainder of the analysis, which focuses on the subset of the Internet economy.

\section{The ICT sector supporting the Internet}

The first half of 2012 has seen the continuation of the global financial and economic crisis in many OECD countries. Although the prospects for the global economy may appear to be improving slightly compared with the beginning of 2012, the global economic recovery is weak and considerable downside risks remain. Concerns about the sustainability of sovereign debt in the European monetary union continue and unemployment remains a significant concern in many countries (OECD, 2012b).

While challenges remain, the ICT sector has proven to be resilient during the recent economic crisis. The broader sector of ICTs has been affected, but growth in the Internet portion has helped the entire sector escape much of the turmoil seen in other key sectors of the economy.

\section{ICT output and value added}

Study of the value added (VA) generated by the ICT sector helps to illuminate the overall state of the sector. Value added is a key indicator that represents the incremental contribution added along the value chain by firms. This is calculated by subtracting from revenues the cost of inputs purchased from other firms to create the product or service. Country-level data from the OECD show ICT value added as a proportion of total business value added, as well as market trends.

The share of ICT value added as a proportion of total value added in the business sector ${ }^{1}$ has remained relatively stable over time, exhibiting a slight upward compound annual growth rate (CAGR) of $0.7 \%$ over the last 14 years. In 2009, the share of value added attributed to the ICT sector was 8.6\%, up from $7.8 \%$ in 1995 (Figure 1.1). This upward trend indicates that output in the ICT sector is growing relative to the rest of the economy, highlighting the importance of the ICT sector overall.

Recent economic downturns have buffeted ICT value added, but it has managed to grow year on year with the exception of brief episodes corresponding to the most difficult economic periods: total ICT value added dipped briefly into negative growth in 2009 (Figure 1.2). The ICT sector follows general trends in business sector value added, however, some ICT sector components are stable while others exhibit significant volatility. ICT manufacturing is more sensitive to business cycles while ICT services are more resilient to outside shocks, holding relatively stable throughout recent crises. Indeed, ICT services maintained year-to-year growth in terms of value added throughout the decade and only dipped into negative growth in 2009. This means that the economic crisis is affecting firms differently even within the ICT sector depending on whether they produce ICT goods or ICT services. 
Figure 1.1. ICT sector value added as a proportion of business sector value added in the OECD area, 1995-2009

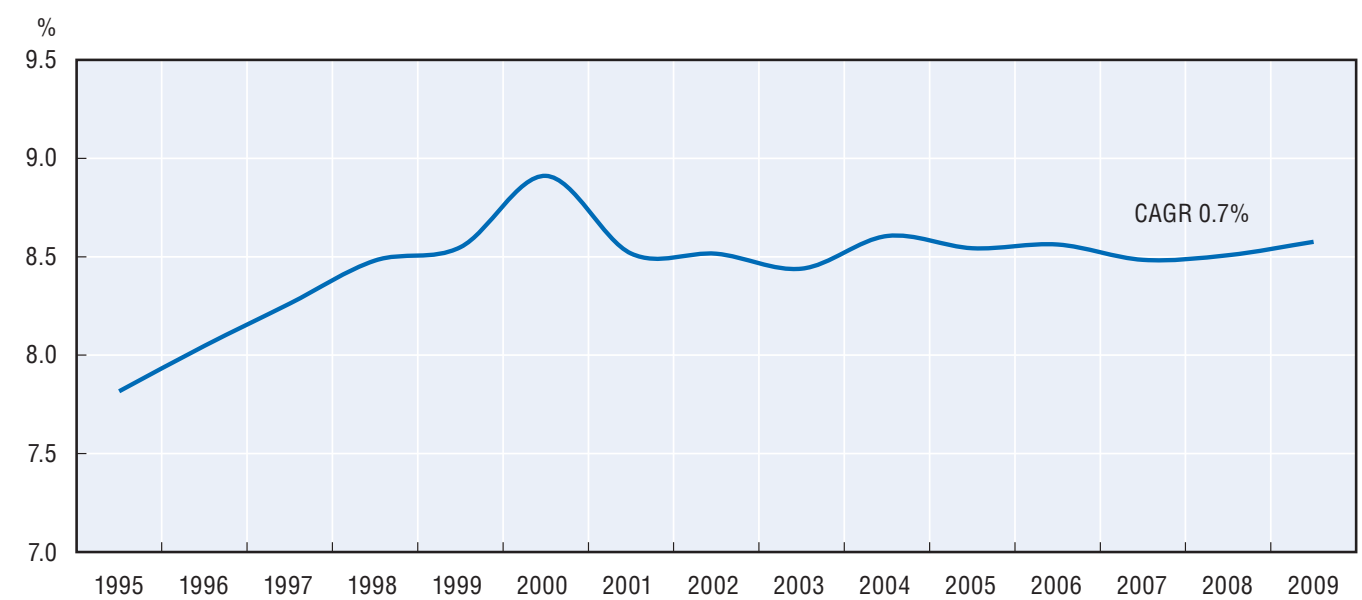

Note: Data for Australia, Canada, Chile, Ireland, Israel, Poland, Portugal, Switzerland, Turkey and the United Kingdom were not available as of this date. The ICT sector is defined according to the 2002 OECD ICT sector definition (see endnote 2), based on ISIC Rev. 3.1.

Source: OECD estimates based on national sources; STAN and National Accounts Databases, October 2011.

StatLink तils http://dx.doi.org/10.1787/888932692372

Figure 1.2. Growth of ICT sector and business sector value added (VA) in the OECD area, 1996-2009

Year-on-year percentage change

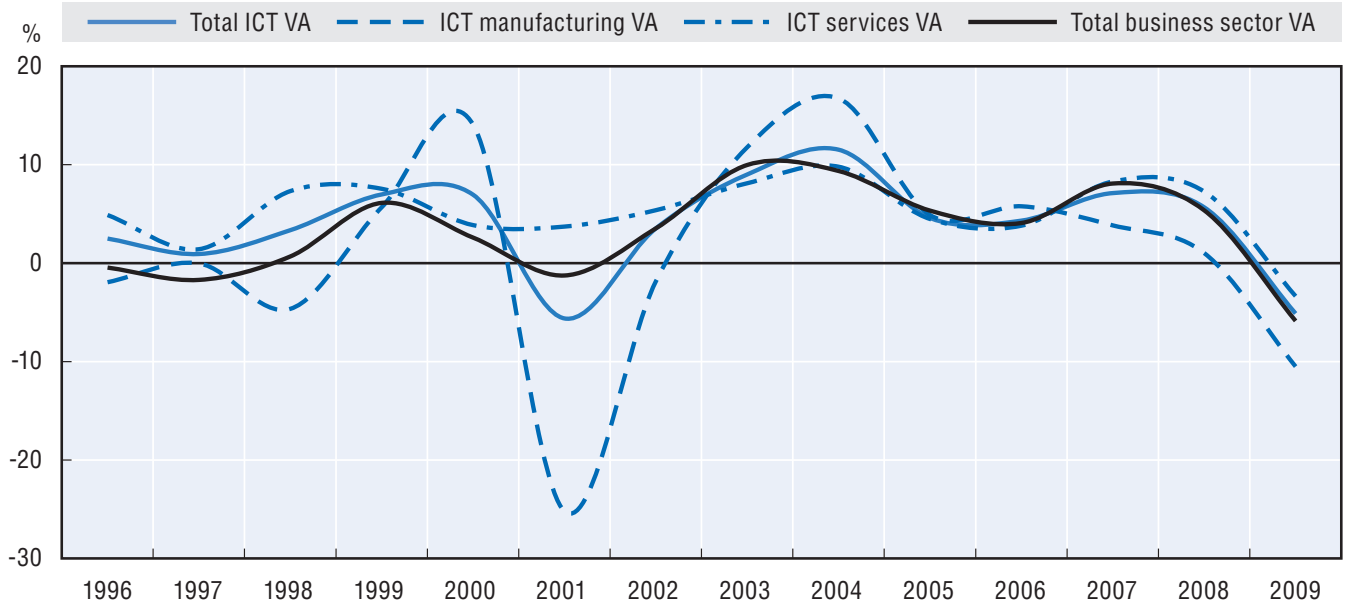

Note: Data for Australia, Canada, Chile, Ireland, Israel, Poland, Portugal, Switzerland, Turkey and the United Kingdom were not available as of this date. The ICT sector is defined according to the 2002 OECD ICT sector definition based on ISIC Rev. 3.1.

Source: OECD estimates based on national sources; STAN and National Accounts Databases, October 2011.

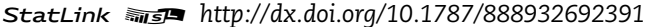

In 2009, ICT services and goods together dipped into negative growth for the first time since 2001. There was a significant decline in the ICT goods sector of up to $40 \%$ in the first half of 2009 in some OECD countries (Figure 1.3). By early 2010, the ICT goods sector ${ }^{3}$ had begun to grow once more in most countries, with some of the largest gains in economies such as Japan, Korea and Chinese Taipei. However, the ICT goods sector did not keep growing in all countries. Among the countries for which short-term data on ICT good output are available, only Germany, Korea, United States, and China had significant growth 
Figure 1.3. Growth in monthly output in ICT goods, December 2007-April 2012

Year-on-year percentage change, three-month moving average

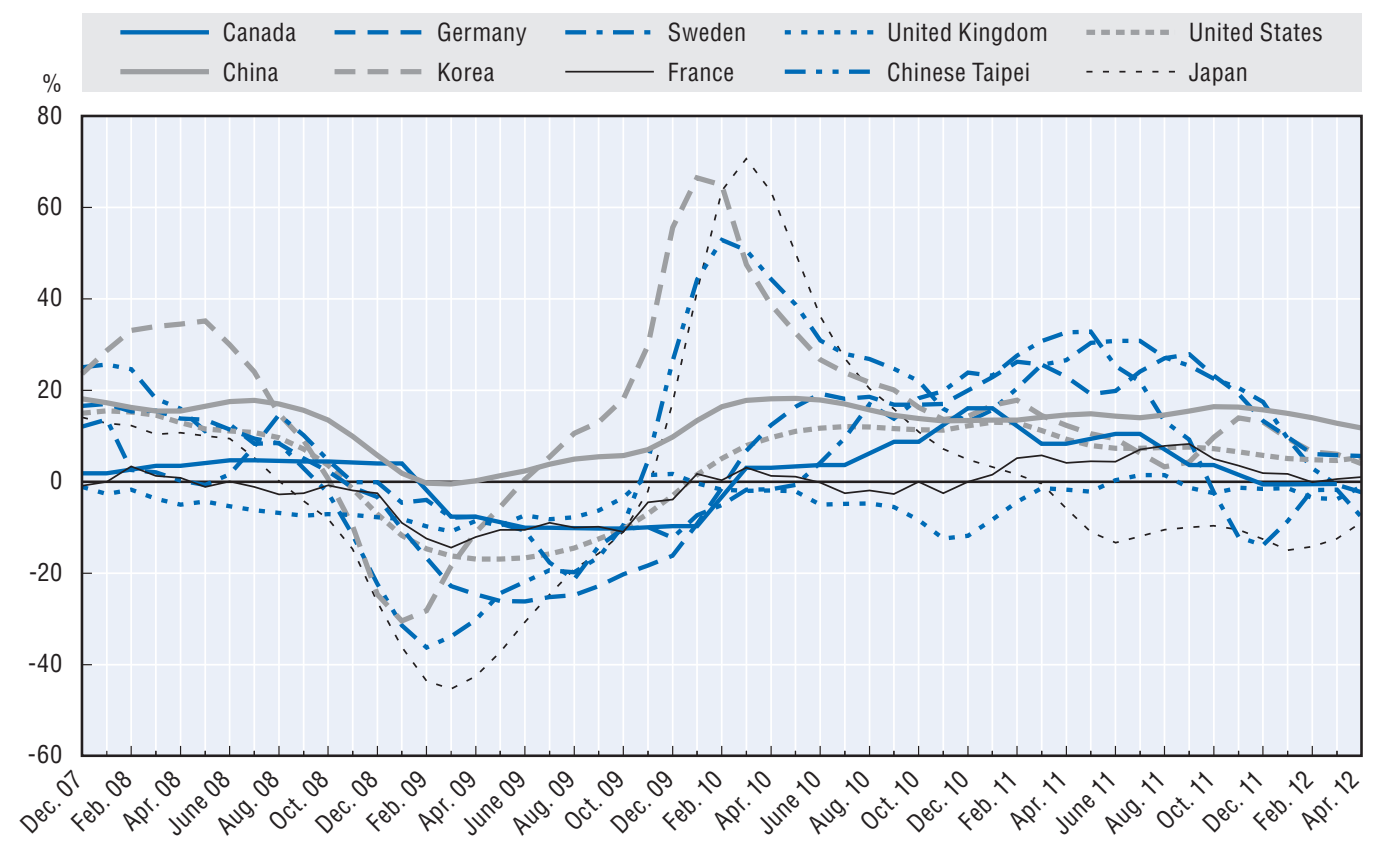

Source: OECD calculations based on data from national statistical offices, short-term indicators.

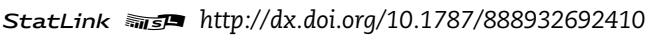

rates (at around 10\%). In Japan, output in ICT goods started to drop in March 2011, with the occurrence of the 2011 Tohoku earthquake and tsunami. Sweden and the United Kingdom are also facing negative growth as well as Chinese Taipei where ICT goods output decreased slightly by approximately $1 \%$.

The ICT service industry weathered the economic crisis much better than ICT manufacturing. This is likely due to increasing specialisation in ICT services across OECD countries, while ICT manufacturing has shifted to lower-cost production areas. The ICT service sector experienced slight declines at the peak of the crisis but quickly rebounded into positive growth by early 2010. Data on monthly service output in computer and related activities show that some countries, such as Korea, experienced positive growth for almost the entire period (early 2008-12), despite the crisis (Figure 1.4). The magnitude of growth rate fluctuations has also been significant. Korea reached nearly $20 \%$ for ICT services in 2011, while the United Kingdom reached a peak growth rate of $15 \%$ in 2010, but dropped to negative growth by the end of the year 2011. By the beginning of 2012, ICT services output began growing again, including in the United Kingdom.

The strength of the ICT service sector, even during the economic crisis, is partially the result of the increasing role ICTs play in supporting business efficiency gains. Firms may look to ICTs as a way to improve efficiency and cut costs during economic downturns. This leads to continued demand for ICT services even as budgets in other areas are cut.

One of the key ICT sector areas to maintain steady growth throughout the crisis was the telecommunication sector, which supplies Internet connectivity. The end of 2008 saw growth decline, just briefly, before returning to pre-crisis annual output growth of $5 \%$ to $10 \%$ (Figure 1.5). Some of the strongest growth in telecommunication output came from outside the OECD with China maintaining growth rates above 10\% from 2007 to early 2012. 
Figure 1.4. Growth in monthly output in computer and related services, December 2007-April 2012

Year-on-year percentage change, three-month moving average

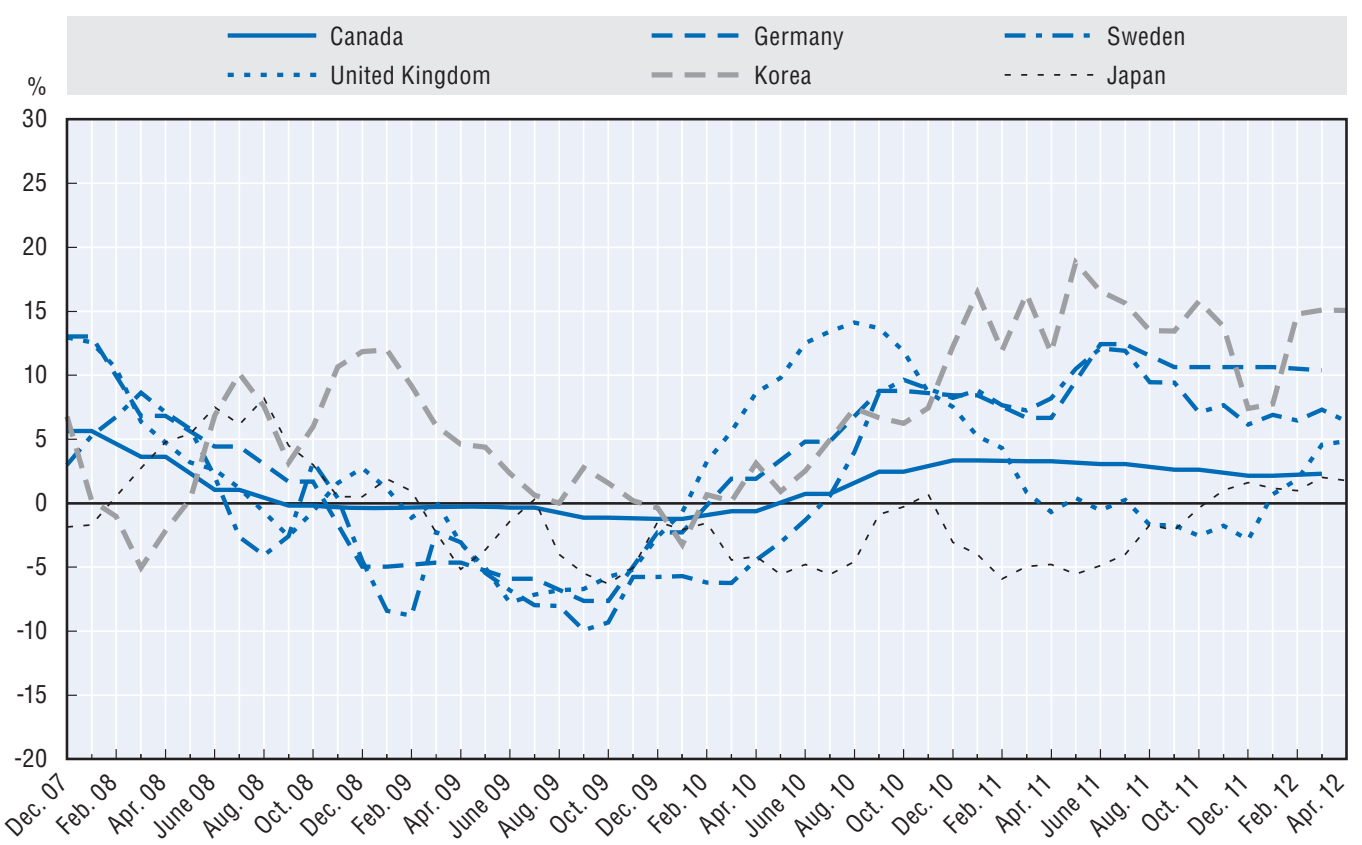

Note: Data for Canada correspond to a combination of Computer Systems Design and Related Services, Data proccesing services and Software publishers.

Source: OECD calculations based on data from national statistical offices, short-term indicators.

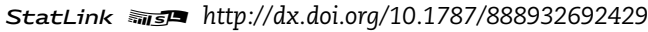

\section{Figure 1.5. Growth in monthly output in telecommunications services,} December 2007-April 2012

Year-on-year percentage change, three-month moving average

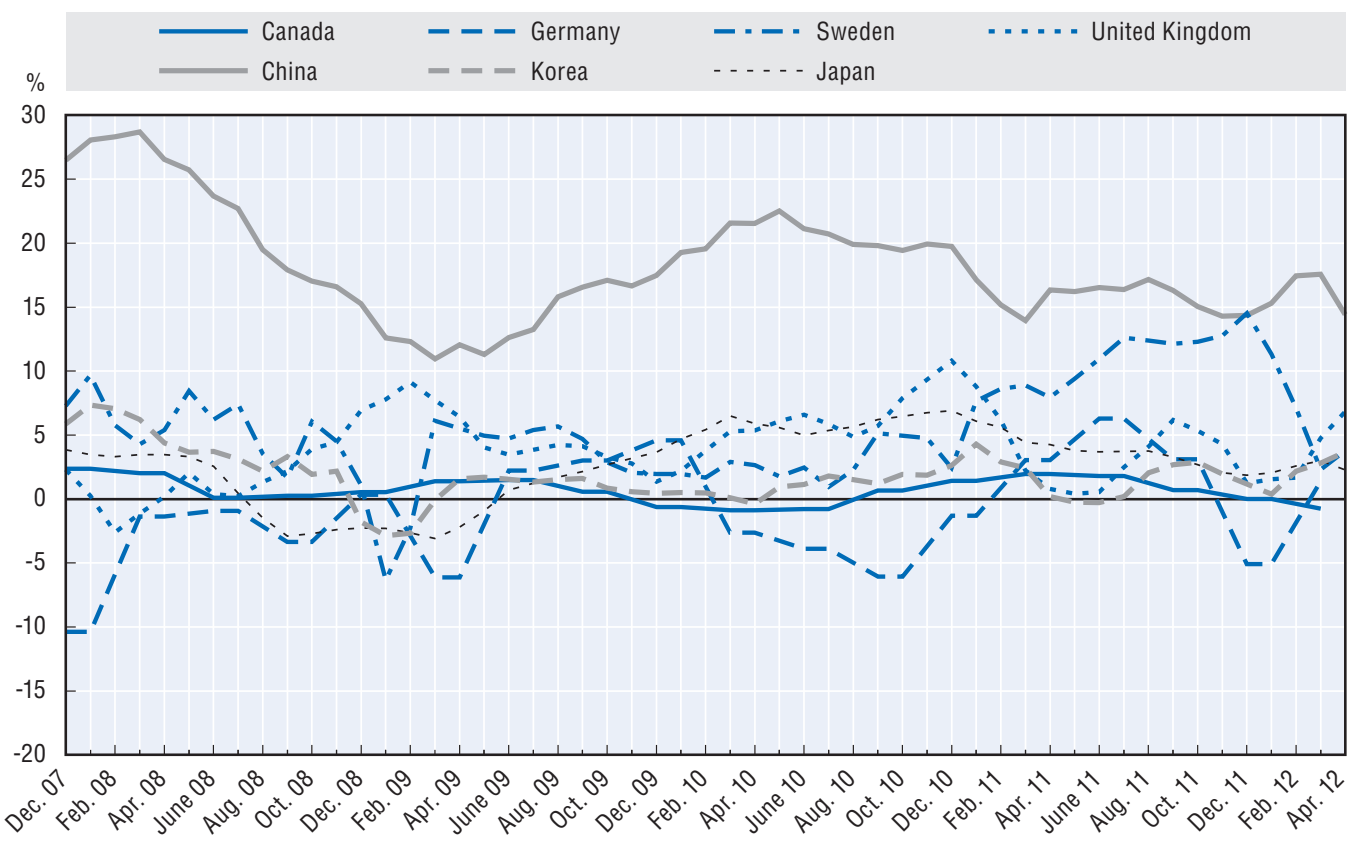

Source: OECD calculations based on data from national statistical offices, short-term indicators.

StatLink तiाs $h$ ttp://dx.doi.org/10.1787/888932692448 
Data on monthly output in the telecommunication sector demonstrate relatively stable growth for several countries throughout the crisis. In general, it appears that the crisis did not shift growth rates significantly. Mobile phones and Internet access are now considered a necessity for households and individuals maintain services even during difficult times. Demand for certain communication services can even increase during a crisis as a larger proportion of unemployed or under-employed make use of the Internet and mobile phones to locate new work opportunities.

\section{ICT employment}

The recent financial crisis has put pressure on the ICT labour market, but recovery in ICT services employment and ICT-skilled employment has been much faster than across the economy as a whole, leading to employment gains in the last quarter of 2010 (OECD, 2012a).

The ICT sector contributes to a significant share of total employment, accounting for almost 15 million people in OECD countries in 2009, or almost $6 \%$ of total OECD business sector employment (Figure 1.6). Long-term growth across the sector was $0.8 \%$ a year from 1995 to 2009, higher than total business employment growth. Finland and Sweden represented the largest shares of ICT employment in total business employment at over $8 \%$, shares that have increased markedly over time. The same is true for (in decreasing order) Luxembourg, Hungary, the Czech Republic, Switzerland and Norway. ICT sector employment in the United States accounted for more than 30\% of total OECD ICT sector employment in 2009. This was by far the largest share, followed by Japan (16\%) and Germany (9\%) (OECD, 2010). The share of employment in the ICT sector declined in countries such as Austria,

\section{Figure 1.6. Share of ICT sector employment in business sector employment,} 1995 and 2009

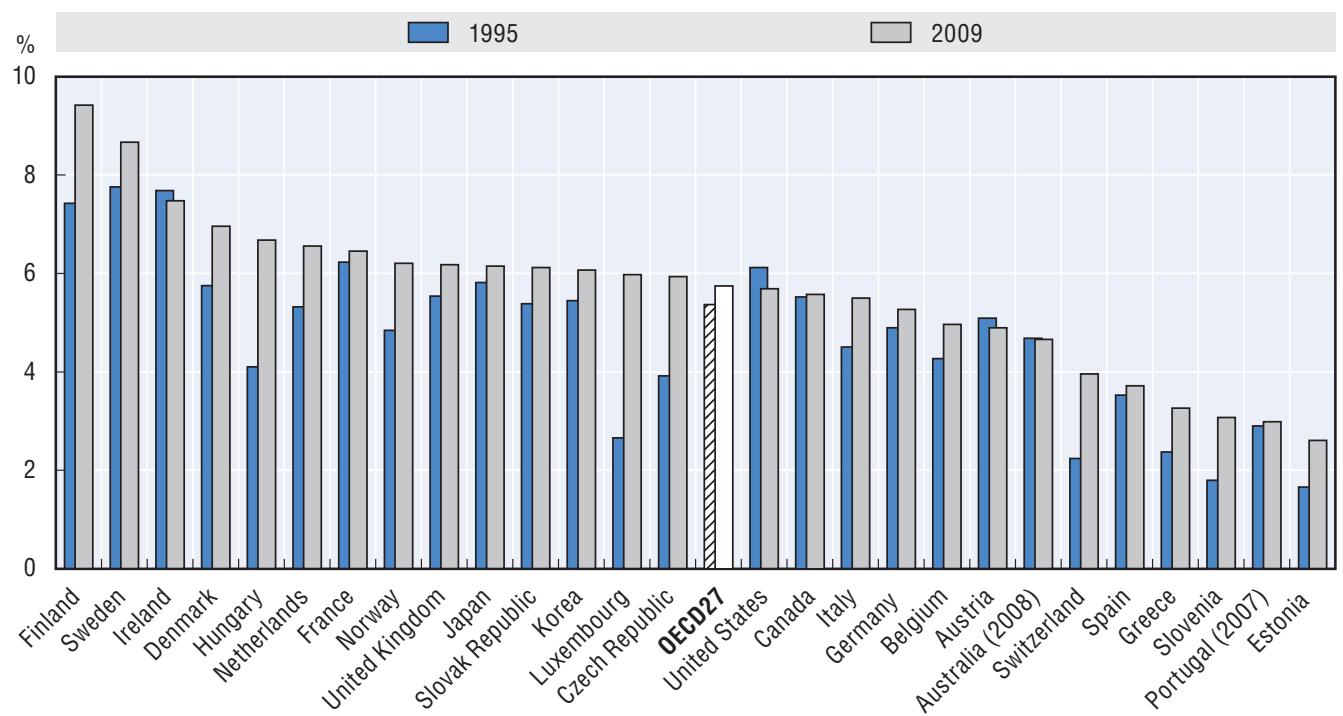

Note: The data for Estonia are from 2001 instead of 1995. Data are not available for Chile, Iceland, Israel, Mexico, New Zealand, Poland and Turkey. The ICT sector is defined according to the 2002 OECD ICT sector definition based on ISIC Rev. 3.1 (see endnote 2). In order to obtain ICT aggregates compatible with national accounts totals, data have been partly estimated based on data from other official sources. In some cases, such estimates were not possible, resulting in an underestimated ICT sector. This is the case for Estonia, Slovenia and Switzerland where data on software publishers (ISIC 72) in Estonia and on telecommunications (ISIC 642) in Slovenia and Switzerland were not available. For industries such as renting of office machinery and equipment (ISIC 7123) estimates were only available for seven countries. Sources: OECD estimates, based on national sources; OECD STAN and National Accounts Databases, March 2012. 
Ireland and the United States, an indication of the increase in sourcing of manufacturing and services trade from non-OECD economies. In the United States, for example, the number of workers affected by mass layoffs in the ICT sector increased from the second half of 2008. In the second half of 2009, the number of affected workers reached a peak, with three times more ICT employees laid off than in June 2000. Nevertheless, employment in the ICT sector suffered less than during the dot.com collapse in 2001-03, when almost seven times more people were laid off than in June 2000. As was the case in the 2001-03 crisis, job cuts in 2009 were deeper in ICT manufacturing than in ICT services (see OECD, 2012a).

In 2009, the ICT services sector accounted for the largest proportion of ICT sector employment in OECD countries, employing more than 10.5 million people ( $4 \%$ of total business sector employment), compared to almost 4.5 million in ICT manufacturing (less than $2 \%$ of total business sector employment). From 1995 to 2009, employment in ICT services grew more rapidly than business services as a whole (including ICT services), increasing by more than $2 \%$ a year and $1.3 \%$ a year, respectively. Over the same period, ICT manufacturing employment declined more rapidly than manufacturing employment overall, decreasing by $1.9 \%$ a year and $1.5 \%$ a year, respectively. In most OECD countries, increases in ICT services employment outweighed declines in ICT manufacturing employment, so that the ICT sector continued to increase its share of total business sector employment (see OECD, 2012a).

The fluctuating demand for ICT goods during the crisis led to changes in ICT employment in the manufacturing sector: employment fell by up to $15 \%$ in countries such as the United Kingdom, but rebounded by December 2010 (Figure 1.7). In the last quarter of 2009, employment in ICT manufacturing in all reporting economies had dropped by between 5\% and 15\% year on year (Figure 1.5). Canada, Germany, the United Kingdom and the United States fared the worst with ICT manufacturing employment falling by more

Figure 1.7. Growth in quarterly employment in ICT manufacturing, June 2007-December 2011

Year-on-year percentage change

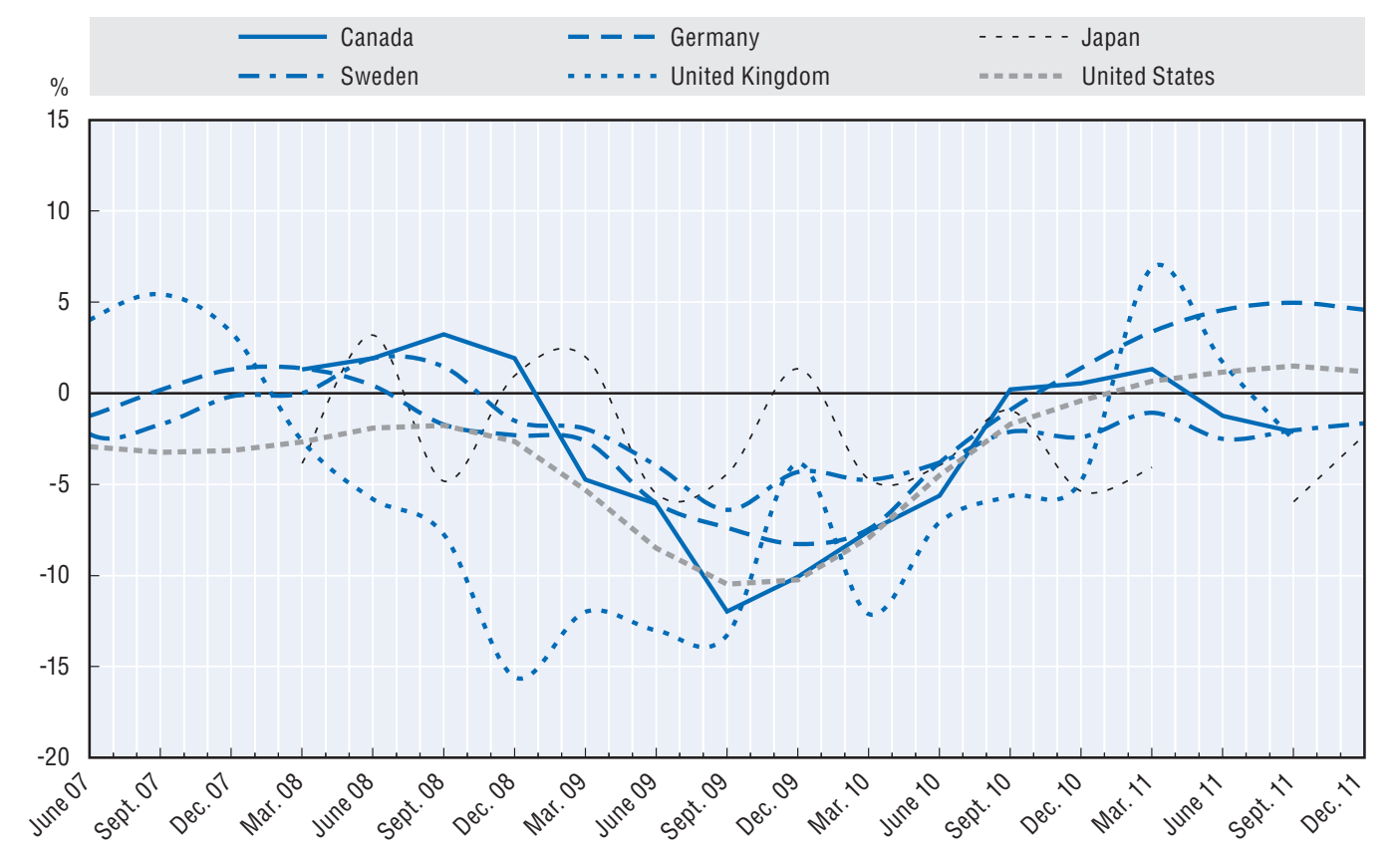

Source: OECD calculations based on data from national statistical offices, short-term indicators, March 2012. 
than $10 \%$ at the end of 2009. Nevertheless, by the end of 2011, employment in ICT goods was holding up better with employment in Germany and the United States, in particular, stabilising or even growing again. Compared to the downturn of 2002-03, ICT manufacturing employment performed better in 2008-11.

Available data show that ICT services employment growth in 2009 tended to remain flat during the crisis for most European countries or decrease slightly, never dropping by more than $5 \%$ in a given year. In the United Kingdom and in most Asian countries, ICT services employment increased by between $2 \%$ and $7 \%$ (Figure 1.8). In 2011, ICT services employment regained momentum in most countries.

Figure 1.8. Growth in quarterly employment in ICT services, June 2007-December 2011

Year-on-year percentage change

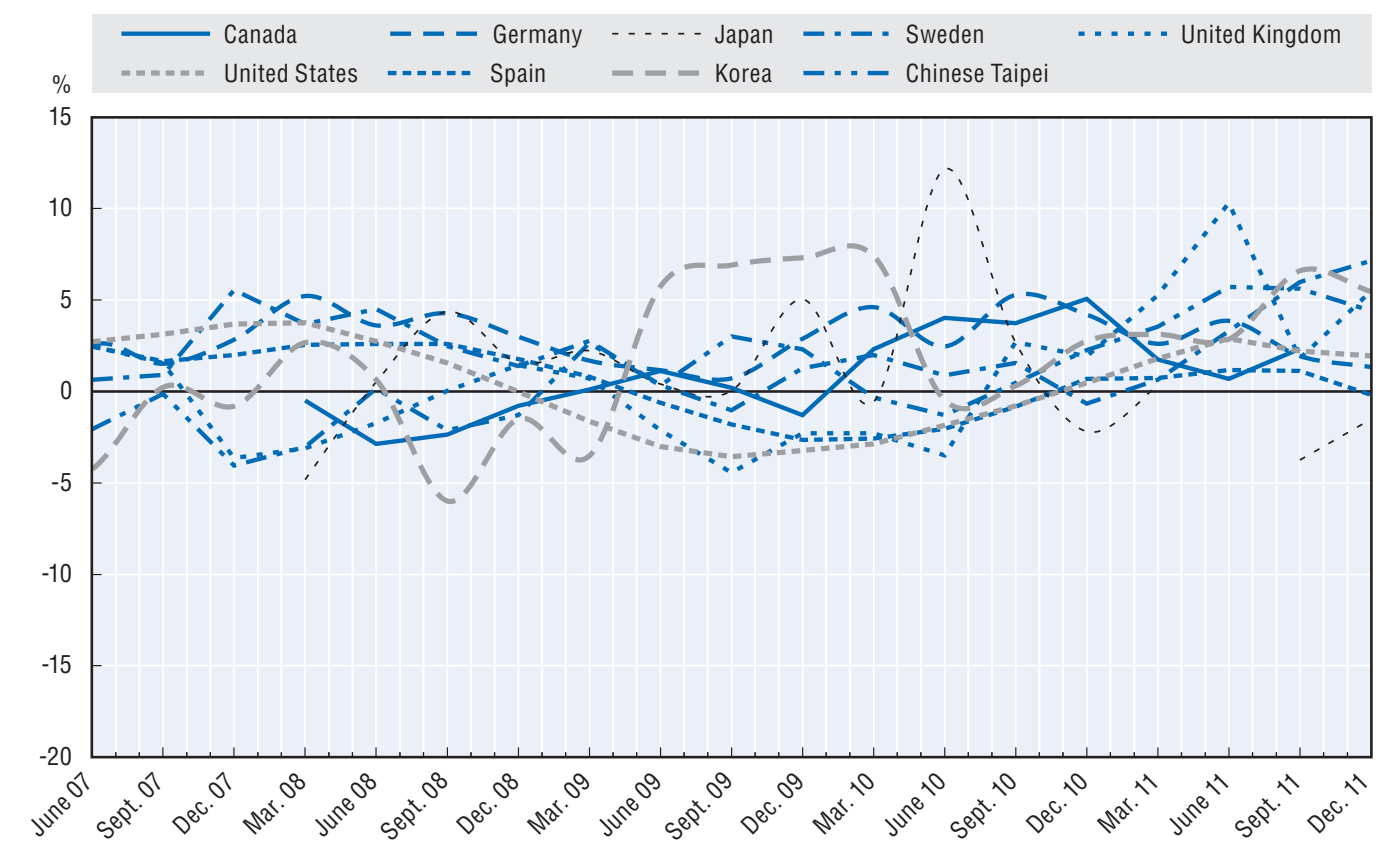

Source: OECD calculations based on data from national statistical offices, short-term indicators, March 2012.

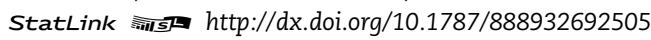

\section{Top 250 ICT firms}

Another way to track developments relating to the Internet and the larger ICT sector, as a whole, is to examine the growth of ICT firms using a number of key indicators. This section analyses the performance of the top 250 ICT firms, looking in particular at annual revenues, net income, R\&D expenditure, net cash and employment for 2000-11. The data presented show the state of the ICT sector following the most difficult periods of the 2008-09 economic crisis. Furthermore, the analysis places particular emphasis on Internet firms. The methodology used to compile the 2011 top 250 ICT firms is described below (Box 1.1).

The top 250 ICT firms are ranked by 2010 total revenues, the most recent financial year for which reporting was complete at the time of the data collection. Historical data are drawn from company annual reports. In each case, company name, country, industry, revenue, employment, $R \& D$ expenditure, and net income are recorded. The current list of the ICT top 250 continues to include firms' net cash/debt, defined as cash and short-term 


\section{Box 1.1. Methodology used to compile the 2010 top 250 ICT firms}

The 2011 list of the ICT top 250 builds on a list of firms identified in previous editions of the Information Technology Outlook. Sources used to identify these firms include Business Week's Information Technology 100, Software Magazine's Top 50, Forbes 2000, the Washington Post 200, Forbes Largest Private Firms, Top 100 Outsourcing, and the World Top 25 Semiconductor firms. Annually reported data from various Internet investor sources were also used to compile the list, including: Google Finance, Reuters and Yahoo! Finance. Details for private firms were taken from the Forbes listing of the largest private firms, Business Week's Private Company Information and from company websites.

Each of the top 250 firms is classified by ICT industry sector: i) communication equipment and systems, ii) electronics, iii) specialist semiconductors, iv) IT equipment and systems, v) IT services, vi) software, vii) Internet and viii) telecommunication services. Broadcast and cable media and content are excluded. Each firm's main ICT-related activity is derived on the basis of revenue generated through each activity and used to classify by sector. In cases of ambiguity, firms were classified according to the official industry classification (primarily SIC), if possible. There have been recent changes for firms such as IBM and Fujitsu, which now derive a majority of their revenues from services (and software) and are now classified under "IT services".

investments minus short and long-term debt. Net cash indicates the short-term liquidity and acquisition power of firms and provides a forward indicator of their likely survival and their potential to self-finance R\&D and innovation. All time series data reflect current reporting and restatements of historical data relating to continuing operations.

\section{Performance trends}

In the aftermath of the crisis in 2009, total revenues of the top 250 ICT firms decreased by more than 3\% in current USD (compared to 2008) to around USD 4000 billion. In 2011, the top 250 ICT firms had total revenues of more than USD 4600 billion, an increase of almost USD 240 billion or $+5 \%$ compared to 2010 (tracking the same panel of top 250 ICT firms over time). The average annual growth rate in revenue between 2000 and 2011 was $6 \%$ per year, owing to the sharp drop in 2009. The top 250 ICT firms worldwide employed more than 14 million people in 2011. This is $6 \%$ more than in 2010. Employment among the top ICT firms thus continues to increase, with an average growth rate (CAGR) of almost $2 \%$ a year between 2000 and 2011. The crisis in 2009 had a considerable impact on employment growth in the top 250 firms: in 2009 employment growth in the top 250 firms slowed to $1 \%$ (CAGR), but regained momentum in 2010 and 2011, when average employment grew by 4\% and 6\% year-on-year respectively (Figure 1.9).

The ICT sector remains one of the most innovative sectors and the top 250 ICT firms continue to significantly increase investment in research and development (R\&D). In 2011, the top ICT firms spent almost USD 1.2 billion on R\&D on average. This is almost a $6 \%$ increase compared to previous year and an average $R \& D$ expenditure growth of approximately 3\% a year between 2000 and 2011 (compared to 2\% between 2000 and 2009). During the crisis in 2009, the top 250 ICT firms only slightly increased R\&D spending (by $0.5 \%$ ) compared to the previous year. However, even in 2009, the ICT sector remained one of the top R\&D spenders with R\&D intensity (i.e. R\&D spending as a percentage of revenue) remaining at $6 \%$ in 2011 (OECD 2009; WIPO, 2011). 
Figure 1.9. Performance trends of top 250 ICT firms, 2000-11

Average number of employees and current USD (index $2000=100$ on averages for those firms reporting)

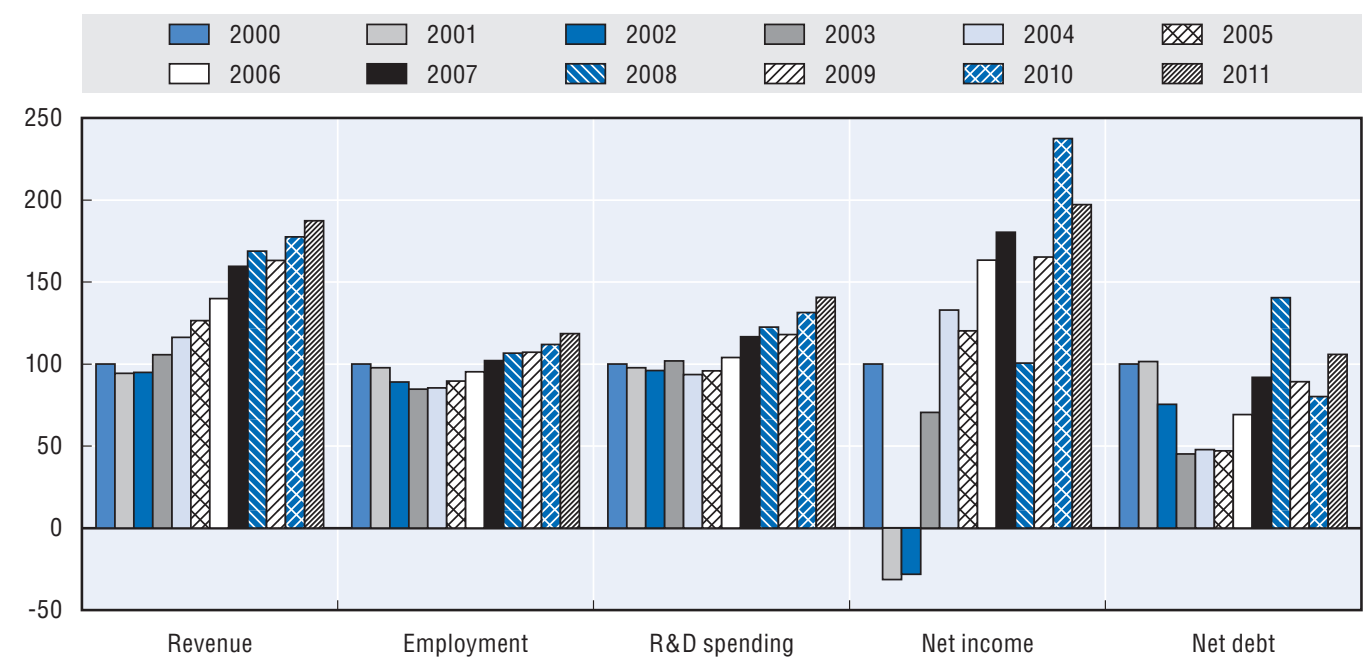

Note: This figure is based on averages for those firms reporting in 2000-11.

Values for 2011 are estimates based on interim reports where annual reports were not available for 2011.

Source: OECD Information Technology Database; compiled from annual reports, SEC filings and market financials, July 2012.

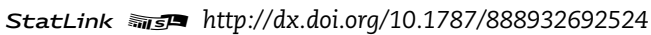

Net income fell dramatically in 2008 (by 44\% compared to 2007) as an early result of the crisis, but recovery has been strong, in particular in 2010, when the average top 250 ICT firm had a net income of USD 1.6 billion, 44\% more than in 2009 and more than double the net income of 2008. In 2011, however, net income decreased by $17 \%$ (year-on-year). Overall, average net income increased by 6\% per annum between 2000 and 2011. As a consequence of the $44 \%$ drop in average net income in 2008, average net debt in 2008 rose by more than 53\% (compared to 2007) to USD 3.1 billion per firm. In 2009 and 2010, average net debt decreased by $37 \%$ and 10\% to USD 2 billion and USD 1.8 billion respectively. However, average net debt in 2011 increased again to more than USD 2.3 billion per firm $(+32 \%$ compared to 2010), a level previously reached in 2007.

These performance indicators prove that the ICT sector was more resistant to the 2008-09 crisis than during the 2001-02 crisis, where employment and R\&D spending remained low for a period of more than five years after the crisis began and average net income even turned negative. Most top 250 ICT firms quickly regained their pre-crisis growth trajectory in 2011. One possible explanation is the high net cash of many top ICT firms, in particular, (non-telecommunications) IT firms. ${ }^{4}$ The top 250 (non-telecommunications) IT firms had on average USD 1 billion net cash on their balance sheets for 2011.

\section{Top 250 ICT firms by economy}

In 2011, Japan and the United States accounted for the largest portion of top 250 ICT firms: 82 (33\%) were based in the United States, 49 (20\%) were based in Japan and 18 in Chinese Taipei (7\%). France, Germany, the Netherlands and the United Kingdom are the European countries most likely to host top 250 ICT firms (see Table 1.1).

Regionally, the 98 firms based in the Americas and the 89 firms in the Asia-Pacific region ${ }^{5}$ accounted for around 40\% and 36\% of total revenue (around USD 1800 billion and 1600 billion respectively) in 2011. However, the Americas accounted for the highest 
Table 1.1. Economies represented in the top 250 ICT firms by economy of registration, 2000 and 2011

In employment numbers and USD millions (in current prices)

\begin{tabular}{|c|c|c|c|c|c|c|c|}
\hline & $\begin{array}{l}\text { Number } \\
\text { of Firms }\end{array}$ & $\begin{array}{l}\text { Revenue } \\
2000\end{array}$ & $\begin{array}{c}\text { Revenue } \\
2011\end{array}$ & $\begin{array}{c}\text { Employment } \\
2000\end{array}$ & $\begin{array}{c}\text { Employment } \\
2011\end{array}$ & $\begin{array}{l}\text { Net income } \\
2000\end{array}$ & $\begin{array}{c}\text { Net income } \\
2011\end{array}$ \\
\hline Argentina & 1 & .. & 4869 & .. & 16237 & .. & 659 \\
\hline Australia & 1 & 10969 & 19557 & . & 39464 & 2350 & 3089 \\
\hline Austria & 1 & 2594 & 6118 & 18301 & 16573 & -263 & -346 \\
\hline Belgium & 2 & 9782 & 12950 & 22200 & 27442 & 597 & 939 \\
\hline Bermuda & 1 & 144 & 3393 & 207 & 5893 & -235 & 615 \\
\hline Brazil & 7 & 20286 & 68477 & 28448 & 80488 & 2830 & 7973 \\
\hline Canada & 6 & 28698 & 65832 & 125496 & 193500 & 3866 & 6159 \\
\hline China & 3 & 9720 & 49942 & 102647 & 417785 & 2372 & 1622 \\
\hline Denmark & 1 & 5676 & 4826 & 18363 & 7400 & 1142 & 555 \\
\hline Egypt & 1 & 553 & 3636 & & 16522 & 37 & 628 \\
\hline Finland & 1 & 27994 & 53094 & 60289 & 135949 & 3629 & -1599 \\
\hline France & 10 & 126019 & 195291 & 609158 & 621402 & 7851 & 14398 \\
\hline Germany & 6 & 115455 & 214292 & 590073 & 693880 & 13578 & 15810 \\
\hline Greece & 1 & 3314 & 6920 & 19604 & 28675 & 579 & 164 \\
\hline Hong Kong, China & 4 & 38892 & 148511 & 68318 & 446523 & 2715 & 19635 \\
\hline Hungary & 1 & 1580 & 3132 & 14380 & 10324 & 236 & 378 \\
\hline India & 4 & 1285 & 39398 & . & 498140 & 249 & 5868 \\
\hline Indonesia & 1 & 1587 & 6658 & . & 26852 & 419 & 1086 \\
\hline Ireland & 3 & 29037 & 42811 & 71300 & 311191 & 3871 & 3444 \\
\hline Italy & 2 & 27338 & 52030 & 120973 & 107340 & -866 & -6677 \\
\hline Japan & 49 & 683416 & 855404 & 1072428 & 2910346 & 18501 & 7219 \\
\hline Korea & 5 & 83868 & 215276 & 305444 & 308202 & 5119 & 14334 \\
\hline Mexico & 1 & 3365 & 48889 & 13450 & 52879 & 101 & 6088 \\
\hline Morocco & 1 & 1201 & 3987 & & 13281 & 163 & 1050 \\
\hline The Netherlands & 6 & 53191 & 88062 & 266762 & 255039 & 11131 & 2921 \\
\hline New Zealand & 1 & 2562 & 3068 & . & 8297 & 292 & 100 \\
\hline Norway & 1 & 4153 & 15376 & 24950 & 33000 & 122 & 1118 \\
\hline Philippines & 1 & 1209 & 3386 & & 29035 & -662 & 685 \\
\hline Poland & 1 & 3654 & 5208 & 71443 & 28955 & 350 & 403 \\
\hline Portugal & 1 & 4743 & 5140 & 18539 & 3 & 498 & .. \\
\hline Qatar & 1 & 364 & 8730 & 1755 & 1832 & 199 & 716 \\
\hline Russian Federation & 1 & 1212 & 9194 & . & 22372 & -87 & 1436 \\
\hline Saudi Arabia & 1 & 4514 & 11944 & .. & $\ldots$ & 1054 & 2943 \\
\hline Singapore & 1 & 2864 & 13539 & $\ldots$ & 819 & 1166 & 2869 \\
\hline South Africa & 3 & 7350 & 21849 & 12835 & 48437 & 167 & 2369 \\
\hline Spain & 3 & 29620 & 100961 & 170645 & 301359 & 2422 & 8023 \\
\hline Sweden & 3 & 37124 & 47928 & 149432 & 137031 & 3373 & 4556 \\
\hline Switzerland & 2 & 16217 & 20168 & 61109 & 73129 & 3322 & 1271 \\
\hline Chinese Taipei & 18 & 43121 & 315478 & 90991 & 1789186 & 7114 & 7947 \\
\hline Turkey & 3 & 4202 & 17750 & 2523 & 54627 & 326 & 2057 \\
\hline United Kingdom & 8 & 69466 & 152008 & 75247 & 373806 & -21005 & 16836 \\
\hline United States & 82 & 691482 & 1637517 & 2451885 & 4084060 & 78138 & 175764 \\
\hline Total & 250 & 2209822 & 4602598 & 6659195 & 14227275 & 156763 & 335106 \\
\hline OECD & 201 & 2075519 & 3889607 & 6353994 & 10813873 & 139261 & 277004 \\
\hline Key Partners & 18 & 40228 & 186324 & 143930 & 1071702 & 6036 & 18917 \\
\hline
\end{tabular}

Note: Cohort data are necessarily incomplete where firms did not exist and/or report in 2000. As a result, these data marginally exaggerate revenue growth for Argentina, China, France, Germany, India, Italy, Japan, Chinese Taipei, Turkey, the United Kingdom and the United States.

Source: OECD Information Technology Database; compiled from annual reports, SEC filings and market financials, July 2012. 
share in overall net profit in 2011 (more than 50\% of total net income), while the Asia-Pacific region accounted for the highest share in employment (more than $45 \%$ of total employment). Europe, in contrast, has the highest share in total net debt with European firms (mainly in telecommunications) accounting for more than $60 \%$ of the overall net debt on their balance sheets (see Figure 1.10).

Figure 1.10. Share in revenue, net income, net debt and employment of top 250 ICT firms by region of registration, 2011

Revenue, net income and net debt in USD billions; employment in thousands

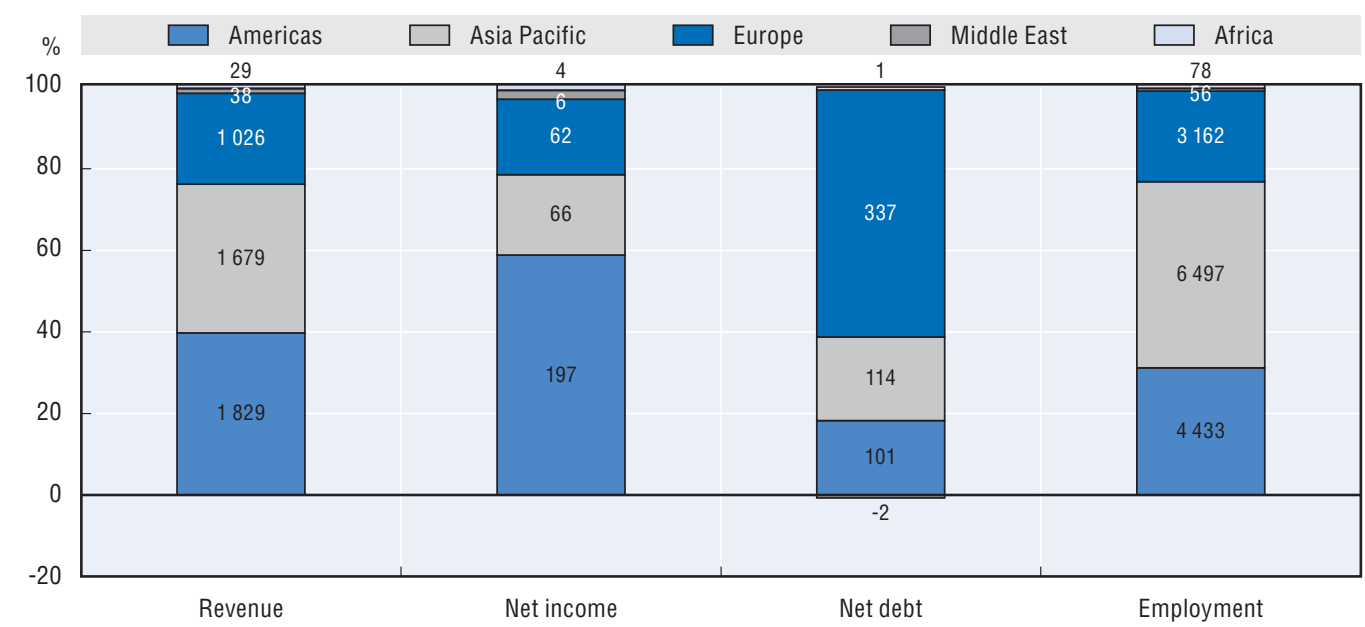

Sources: OECD Information Technology Database; compiled from annual reports, SEC filings and market financials, July 2012. StatLink त्ञाज $h$ ttp://dx.doi.org/10.1787/888932692543

Company performance across economies has been mixed. Regionally, revenues have grown faster over the last 11 years in the Middle East (15\% a year) and Africa (12\% a year), although from a low base, than in the Americas ( $9 \%$ a year), the Asia-Pacific region ( $7 \%$ a year) and Europe (6\% a year). Top 250 ICT firm revenues rose by more than $20 \%$ a year in India (40\%), Qatar (37\%), Bermuda (37\%), Mexico (31\%), the Russian Federation (22\%), Chinese Taipei (22\%), and Egypt (21\%) (Figure 1.11). This reflects a number of factors, including: GDP growth and ICT market growth, whether or not the firms are in high-growth sectors, and changing roles in global production systems. It reflects, in particular, the emergence of developing economies both as new growth markets and as locations for ICT production by indigenous as well as multinational firms (e.g. the IT services sector in India and Egypt). ${ }^{6}$

\section{Top 250 ICT firms by sector}

By sector, 76 (30\%) of the total 250 firms in 2011 were telecommunication services providers, 64 (26\%) were electronics manufacturers, 32 (13\%) were IT equipment and systems producers, 29 were IT services providers, 20 were semiconductor firms, 12 were communication equipment and systems producers, 10 were software publishers and 7 were Internet firms. Telecommunication services firms and electronics firms together accounted for the largest shares of top 250 revenues in 2011, at around 60\% (USD 1617 billion and USD 1145 billion respectively). IT equipment firms accounted for 17\% (USD 780 billion), IT services firms for $8 \%$ (USD 365 billion), communications equipment firms for $5 \%$ (USD 235 billion), semiconductor firms for 4\% (USD 188 billion), software firms for 3\% (USD 156 billion), and Internet firms for 2\% (USD 113 billion) (Table 1.2). 
Figure 1.11. Revenue growth of top 250 ICT firms by economy of registration, 2000-11

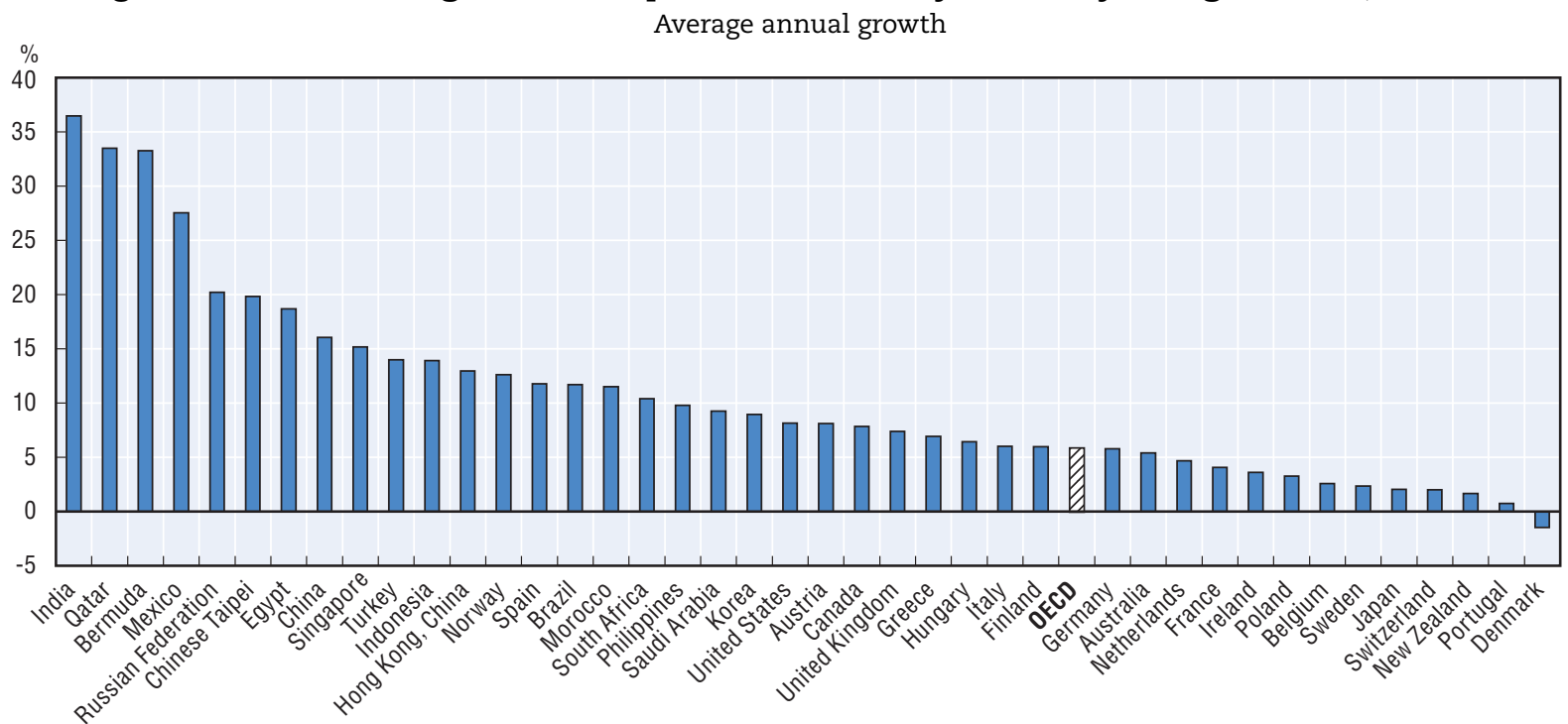

Note: Cohort data are necessarily incomplete where firms did not exist and/or report in 2000. As a result these data marginally exaggerate revenue growth for Argentina, China, France, Germany, India, Italy, Japan, Chinese Taipei, Turkey, the United Kingdom and the United States. Sources: OECD Information Technology Database; compiled from annual reports, SEC filings and market financials, July 2012.

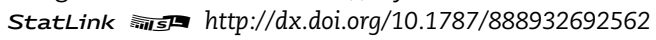

Table 1.2. Top 250 ICT firms by sector, 2000 and 2011

USD millions in current prices and number of employees

\begin{tabular}{|c|c|c|c|c|c|c|c|c|}
\hline Industry & $\begin{array}{c}\text { Revenue } \\
2000\end{array}$ & $\begin{array}{c}\text { Revenue } \\
2011\end{array}$ & $\begin{array}{c}\text { Employment } \\
2000\end{array}$ & $\begin{array}{c}\text { Employment } \\
2011\end{array}$ & $R \& D 2000$ & R\&D 2011 & $\begin{array}{c}\text { Income } \\
2000\end{array}$ & $\begin{array}{c}\text { Income } \\
2011\end{array}$ \\
\hline Communications equipment & 152261 & 235085 & 499243 & 645909 & 16346 & 28080 & 12045 & 16553 \\
\hline Electronics \& components & 737852 & 1144637 & 2618862 & 4204283 & 29445 & 45984 & 41007 & 34835 \\
\hline Internet & 5911 & 113623 & 15186 & 122901 & 521 & 10692 & -1672 & 17240 \\
\hline IT equipment & 299489 & 780423 & 393142 & 2750281 & 10550 & 21664 & 12146 & 47751 \\
\hline IT services & 189763 & 366521 & 706587 & 2080974 & 5972 & 7073 & 16974 & 29074 \\
\hline Semiconductors & 104885 & 188614 & 293631 & 481033 & 10919 & 25684 & 20162 & 26696 \\
\hline Software & 51817 & 156313 & 147797 & 341650 & 8090 & 21523 & 10536 & 42155 \\
\hline Telecommunications & 667844 & 1617381 & 1984747 & 3600244 & 4777 & 636 & 45567 & 120801 \\
\hline Total & 2209822 & 4602598 & 6659195 & 14227275 & 86621 & 161336 & 156763 & 335106 \\
\hline
\end{tabular}

Note: Cohort data are necessarily incomplete for firms that did not exist and/or report in 2000.

Sources: OECD Information Technology Database; compiled from annual reports, SEC filings and market financials, July 2012.

\section{Box 1.2. Identifying the top Internet firms}

There is no clear definition of an "Internet firm"; however, there are a number of examples of firms earning their revenues from Internet-based activities, some of which are enjoying spectacular growth. The OECD Information Technology Outlook has identified a large number of these firms as "Internet" firms (OECD, 2008; 2010). They include firms such as Google (USD 29 billion in revenues in 2010, 24\% revenue growth compared to 2009) and United Internet (USD 2.6 billion, $+15 \%$ ), which provide fundamental services needed to operate or use the Internet. Other firms, however, are earning their revenues through activities related to other ICT industries, which are increasingly being shifted online. These include software firms such as IT security company Symantec (USD 6.1 billion, $+3 \%$ ) and online game provider Activision Blizzard (USD 4.4 billion, $+4 \%$ ). These companies provide software that increasingly relies on the Internet for most of its functionalities. 


\section{Box 1.2. Identifying the top Internet firms (cont.)}

Another type of Internet firm is that of "Internet intermediaries". They provide the Internet's basic infrastructure and platforms by enabling communication and transactions between third parties. Intermediaries can be commercial or non-commercial in nature, and include Internet service providers (ISPs), hosting providers, search engines, e-commerce intermediaries, payment intermediaries and participative, networked platforms. Their main functions are: i) to provide infrastructure; ii) to collect, organise and evaluate dispersed information; iii) to facilitate social communication and information exchange; iv) to aggregate supply and demand; v) to facilitate market processes; vi) to provide trust; and vii) to take account of the needs of both buyers/users and sellers/advertisers (see Annex 1.A1 for more detail).

The most significant share of Internet firms, however, comprises those providing traditional offline services that are increasingly migrating online. These include online stores and other e-commerce platform firms, such as Amazon.com (USD 34 billion, $+40 \%$ ) and ASOS.com (USD 525 million, +52\%); e-finance providers such as E*Trade Financial (USD 2.4 billion, -15\%), and online travel agencies such as Expedia (USD 3.3 billion, +13\%).

The 2010 ICT top 250 list included only seven Internet firms, given that the revenues of many such firms were still far lower than those of most top ICT firms. However, the number is increasing: the 2008 ICT top 300 included eight Internet firms, and if ranked by 2011 revenues, the 2011 ICT top 300 would include 10 Internet firms. The top 50 public Internet firms as identified through various Internet investor sources (Google Finance, Reuters and Yahoo! Finance) are listed here with their current rank (by 2010 revenues) and their country of registration (Table 1.3).

Table 1.3. Top 50 public Internet firms

\begin{tabular}{|c|c|c|c|c|c|}
\hline Rank & Firm name & Country & Rank & Firm name & Country \\
\hline 35 & Amazon.Com Inc & US & 720 & Rue Du Commerce S.A. & FR \\
\hline 43 & Google Inc & US & 724 & WebMD Health Corp & US \\
\hline 109 & eBay Inc & US & 736 & Stream Co Ltd & JP \\
\hline 146 & Yahoo! Inc & US & 753 & Digital River Inc & US \\
\hline 230 & Expedia Inc & US & 812 & Blue Nile Inc & US \\
\hline 239 & Yahoo Japan Corp & $J P$ & 846 & Shutterfly Inc & US \\
\hline 240 & Priceline.com Inc & US & 870 & Ariba Inc & US \\
\hline 264 & United Internet AG & $\mathrm{DE}$ & 885 & Liquidity Services Inc & US \\
\hline 269 & TD Ameritrade Holding Corp & US & 900 & US Auto Parts Network Inc & US \\
\hline 277 & $E^{\star}$ Trade Financial Corp & US & 902 & Internap Network Services Corp & US \\
\hline 301 & Netflix Inc & US & 915 & Start Today Co Ltd & $J P$ \\
\hline 364 & IAC/InterActivecorp & US & 921 & J2 Global Inc & US \\
\hline 433 & Salesforce.com Inc & US & 933 & Taleo Corp & US \\
\hline 502 & United Online Inc & US & 971 & Move Inc & US \\
\hline 544 & Findel PLC & GB & 995 & NetSuite Inc & US \\
\hline 574 & Shanda Interactive Entertainment Ltd & $\mathrm{CN}$ & 997 & Ultimate Software Group Inc & US \\
\hline 592 & Internet Initiative Japan Inc & $J P$ & 1011 & RightNow Technologies Inc & US \\
\hline 609 & Manutan International S.A. & $\mathrm{FR}$ & 1024 & Start Today Co Ltd & $J P$ \\
\hline 619 & Baidu Inc & $\mathrm{CN}$ & 1045 & Global Sources Ltd & BM \\
\hline 638 & Verisign Inc & US & 1047 & iPass Inc & US \\
\hline 665 & NetEase.com Inc & $\mathrm{CN}$ & 1057 & NetSuite Inc & US \\
\hline 675 & ASOS PLC & UK & 1074 & Gigamedia Ltd & TW \\
\hline 681 & Sohu.com Inc & $\mathrm{CN}$ & 1086 & Online Resources Corp & US \\
\hline 696 & GMO Internet Inc & JP & 1148 & Buch.De Internetstores Ag & $\mathrm{DE}$ \\
\hline 719 & ValueClick Inc & US & 1169 & Dmail Group Spa & IT \\
\hline
\end{tabular}

Note: The rankings in the table correspond to the ranking by revenues of the firm within the larger ICT sector.

Sources: OECD Information Technology Database; compiled from annual reports, SEC filings and market financials, July 2012. 
Average revenue in 2011 was highest among IT equipment firms and telecommunications firms, at USD 24 billion and USD 21 billion, respectively. Communications equipment firms and electronic firms had average revenues of USD 20 billion and USD 18 billion, respectively, followed by Internet firms (with USD 16 billion), software firms (USD 16 billion), and IT services firms (USD 13 billion). Semiconductors firms had the smallest average revenue in 2011 (USD 9 billion).

Revenue growth of Internet firms has not slowed significantly since 2000, even during the crisis. Between 2000 and 2011, the top Internet firms saw a 31\% yearly increase in their average revenues. In contrast, average revenue growth in software, IT equipment and telecommunications services firms was approximately 10\% per annum between 2000 and 2011. As a result, the average revenue of Internet firms surpassed that of software firms, for the first time in 2011, after surpassing that of IT services firms for the first time in 2010. If revenue growth rates remain the same for all sectors, the average revenue of Internet firms will surpass that of electronic firms in 2013-14. Revenues of IT services firms increased by approximately $5 \%$ per annum, while electronics, semiconductors and communications equipment firms have seen revenues increase by $3 \%$ per annum. The low average growth rates of these industries is due to the significant decrease in revenues during the crisis in 2009, which had a considerable impact on hardware manufacturing firms (see Figure 1.12).

Between 2000 and 2011, employment in the top Internet firms grew fastest (by 15\% a year), followed by IT equipment firms (11\% a year) and software firms (7\% a year) (Figure 1.13). In 2009, despite the downturn, Internet, IT equipment, telecommunications, and communications equipment were the only firms to increase employment (on average by $6 \%, 3 \%, 1 \%$ and $1 \%$, respectively). Average employment decreased the most in semiconductor firms (by 9\%). In 2011, average employment significantly increased in Internet firms (+29),

Figure 1.12. Revenue trends of top 250 ICT firms by sector, 2000-11 USD current prices (index $2000=100$ )

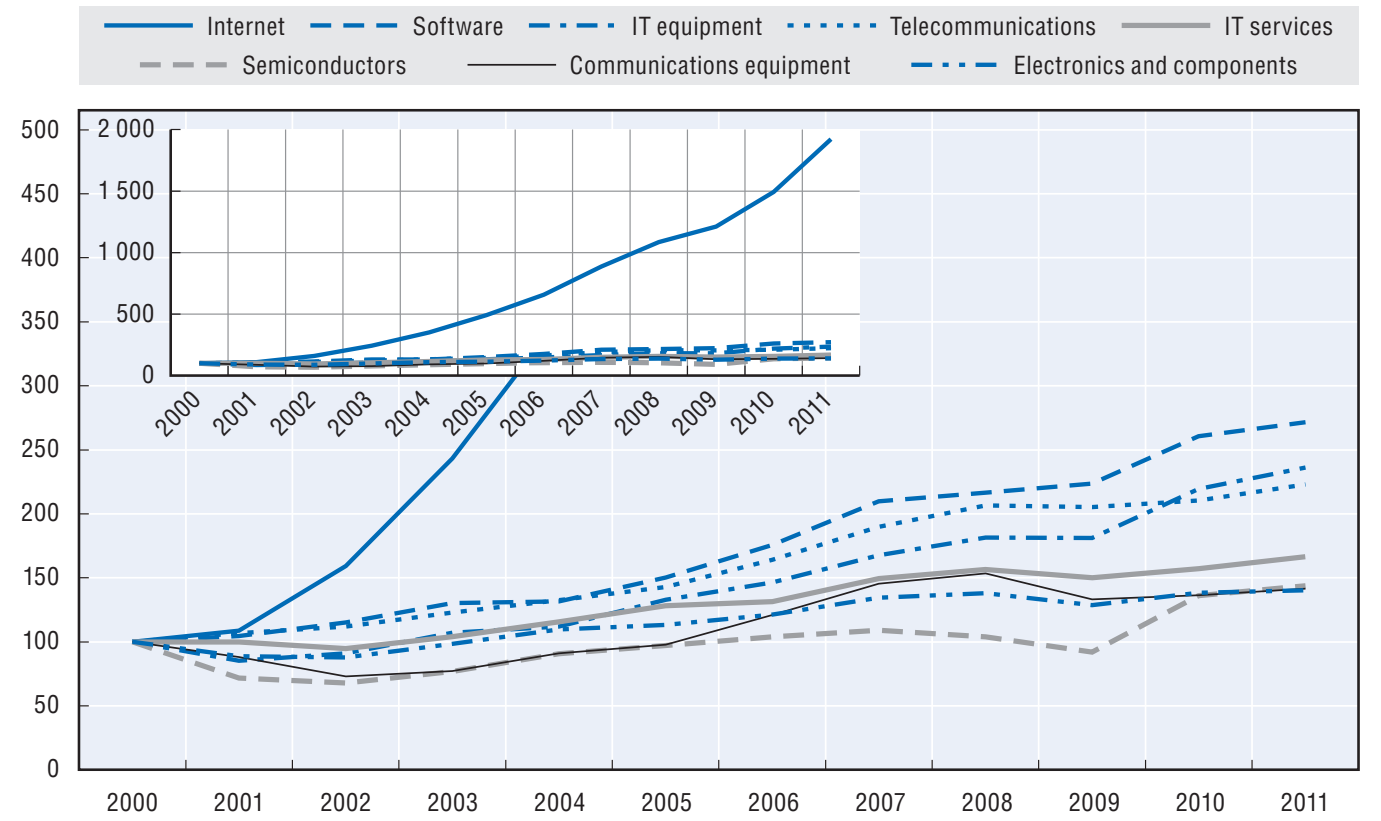

Note: The figure is based on averages for those firms reporting in 2000-11.

Sources: OECD Information Technology Database, compiled from annual reports, SEC filings and market financials, July 2012. StatLink त्तारी http://dx.doi.org/10.1787/888932692581 
Figure 1.13. Employment trends in the top 250 ICT firms by sector, 2000-11

Average number of employees (index $2000=100$ )

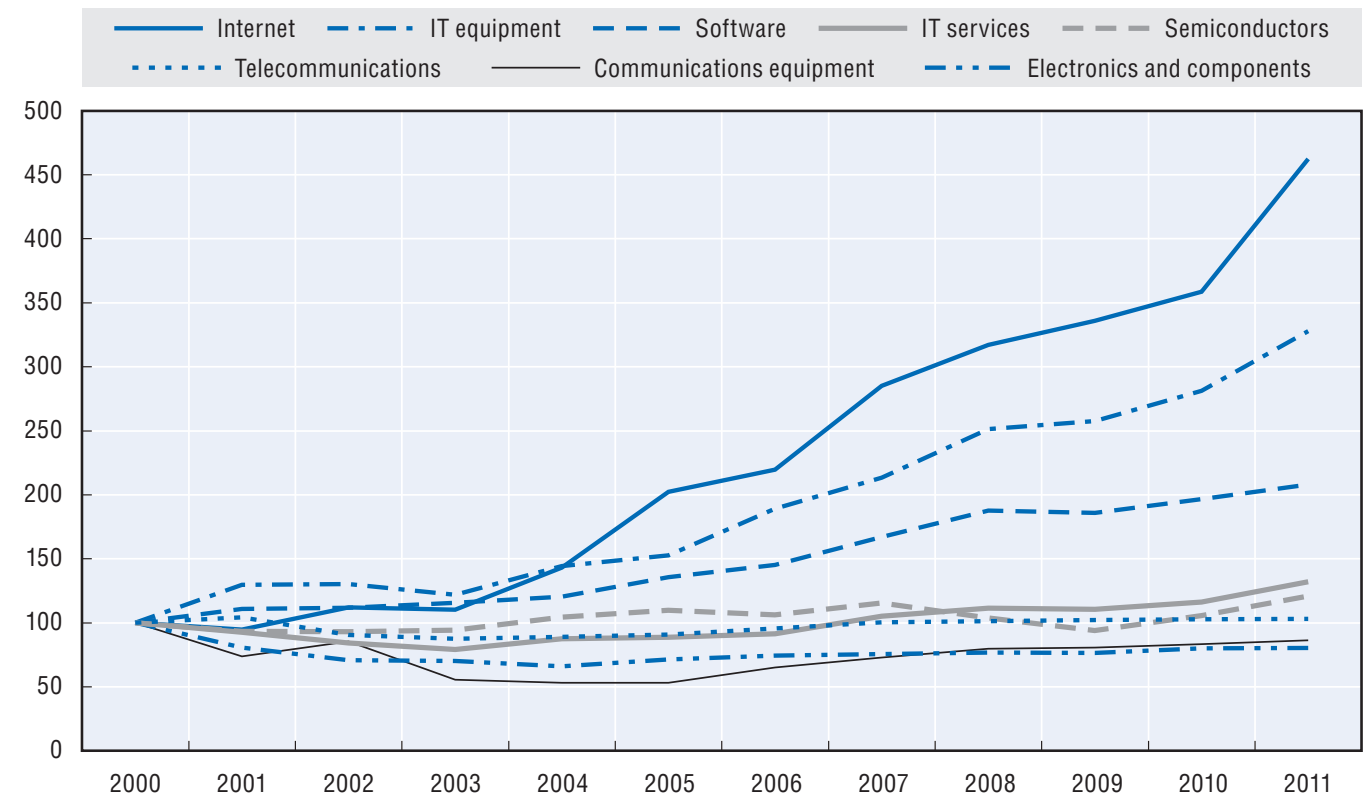

Note: The presentation is based on averages for those firms reporting in 2000-11.

Sources: OECD Information Technology Database, compiled from annual reports, SEC filings and market financials, July 2012.

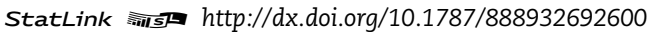

largely as a result of a 50\% increase in employees at Amazon.com and Google between 2010 and 2011. Average employment has increased in IT equipment, IT services and semiconductor firms by double digits $(17 \%, 14 \%$ and $14 \%$, respectively). In communications equipment and software, average employment increased by $6 \%$ and $4 \%$ respectively, while in electronics and components average employment stayed at the same level as in 2010.

Analysis of firm data confirms that the ICT sector is becoming less employment-intensive. Average revenue per employee in the top 250 ICT firms has increased steadily since 2000; revenue per employee started to fall slightly only in 2009, mainly due to declining revenues. In 2011, the top 250 ICT firms generated average revenues of more than USD 320000 per employee, slightly less than in 2010 (with USD 332 000), but still 4\% more than in 2009. A breakdown by sector shows that top Internet firms had the highest average revenue per employee (Figure 1.14). For every person employed in the Internet sector in 2011, Internet firms generated USD 925000 on average. All other ICT sectors generated revenues per employee of between USD 460000 (software) and USD 176000 (IT services).

All sectors except IT services were more profitable in 2011 than in 2008, before the crisis, with the strongest income growth found in semiconductors, IT equipment and the Internet sector. In 2008, semiconductors suffered substantial income losses, and all other segments except IT services showed lower income than in 2007. The large reduction in net income in the communications equipment sector was partly due to large goodwill impairment charges. The average profit margin of the top 250 ICT firms was $7 \%$ in 2011, compared to $9 \%$ in 2010 , 7\% in 2009 and 4\% in 2008 (i.e. average net income over average revenue, to account for missing data). Average margins in 2011 were highest among software, and Internet, and semiconductors firms at $25 \%, 15 \%$ and $15 \%$, respectively (Figure 1.15 ). 
Figure 1.14. Average annual revenue per employee of the top 250 ICT firms by sector, 2000-11

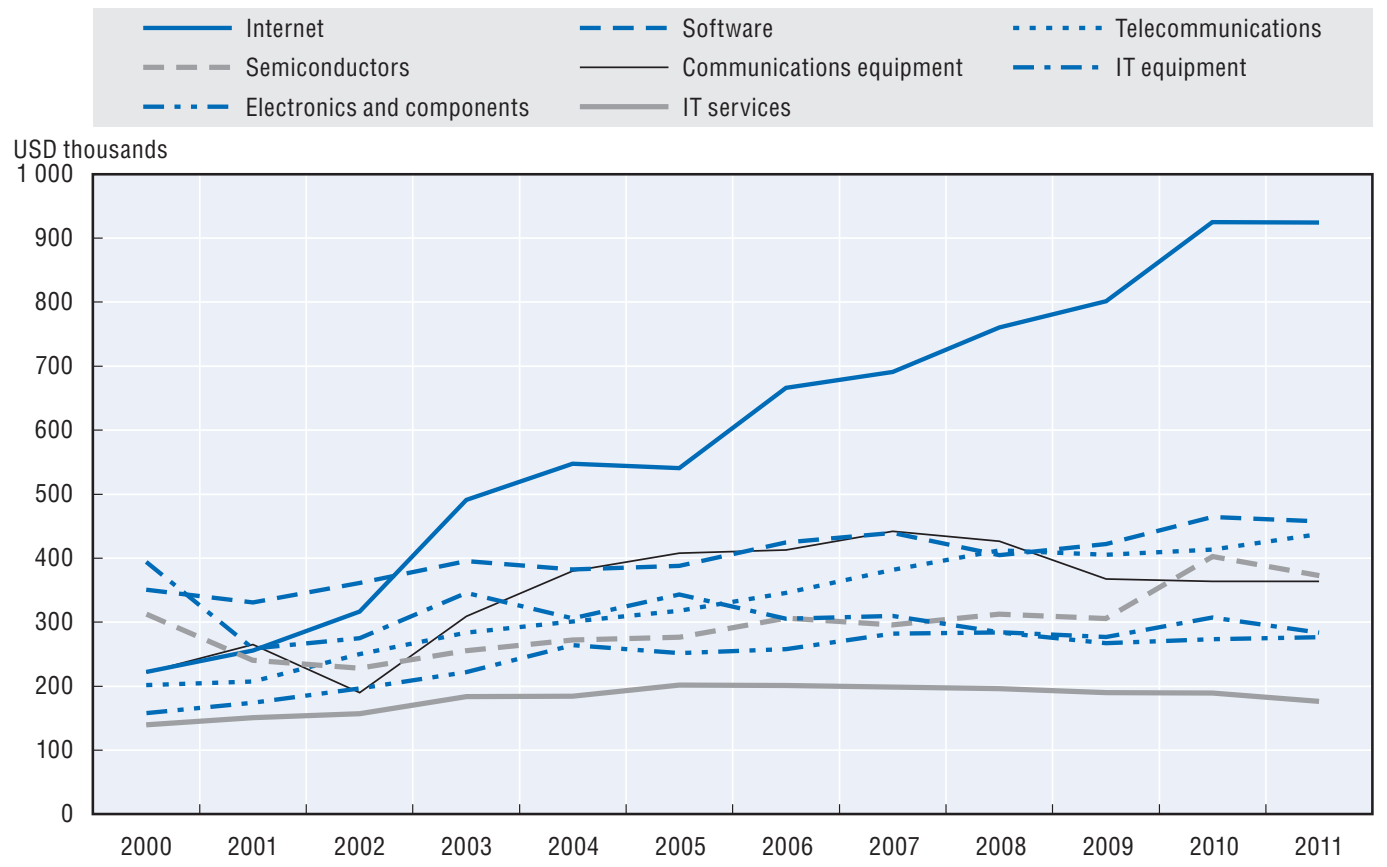

Note: The presentation is based on averages for those firms reporting in 2000-11.

Sources: OECD Information Technology Database; compiled from annual reports, SEC filings and market financials, July 2012.

StatLink त्ञाज्ञा http://dx.doi.org/10.1787/888932692619

Figure 1.15. Profitability of top 250 ICT firms by sector, 2008-11

Average net income as a share of average revenue

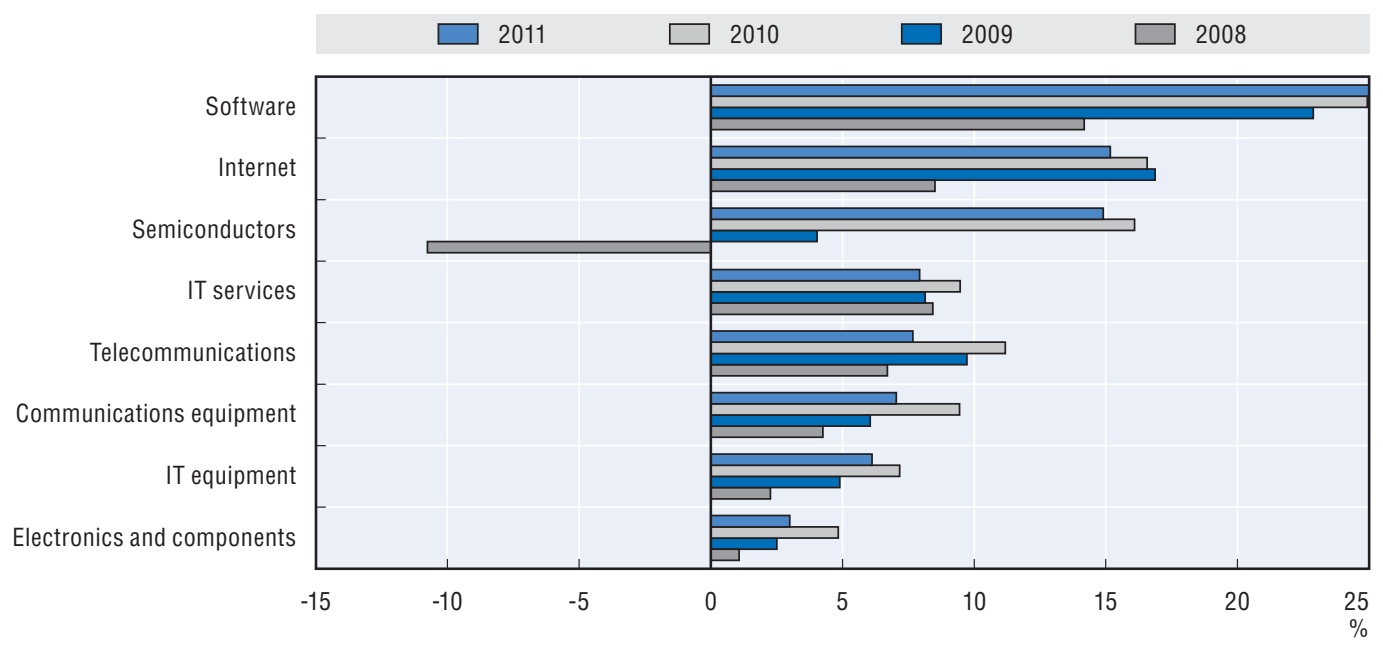

Source: OECD Information Technology Database; compiled from annual reports, SEC filings and market financials, July 2012. 
Available data show that electronics firms and communications equipment firms together accounted for the largest shares of R\&D, with almost 50\% (USD 46 billion and USD 28 billion, respectively) of total R\&D expenditure out of the top 250 ICT firms in 2011. Semiconductors accounted for $16 \%$ (USD 26 billion), followed by software and IT equipment firms with an average each of around 13\% (USD 22 billion). Telecommunication services, Internet and IT services had the smallest shares (Figure 1.16). R\&D data are incomplete as not all firms report R\&D expenditure.

Figure 1.16. R\&D expenditure shares of top 250 ICT firms by sector, 2011

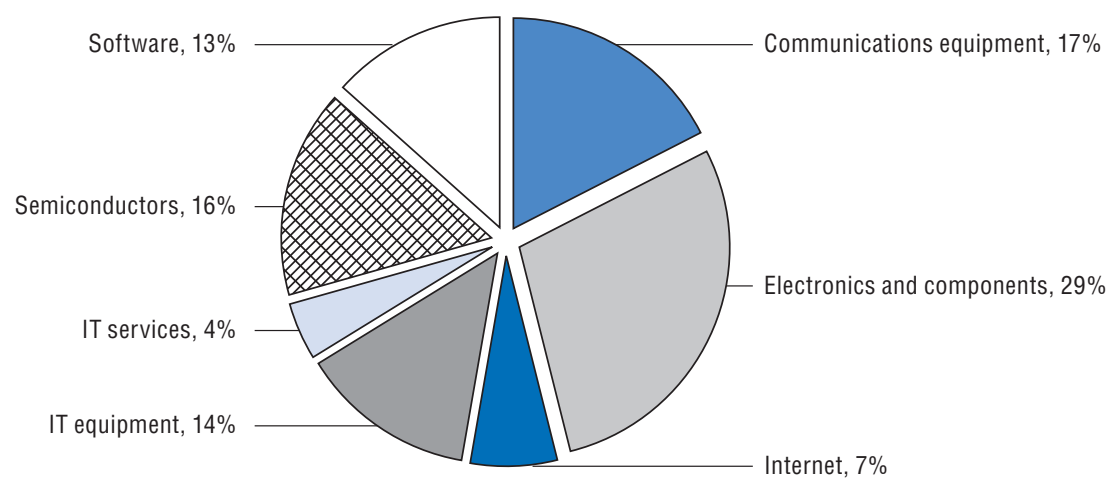

Note: R\&D expenditure data are incomplete and the presentation is based on those firms reporting R\&D compared with the whole database. There are fewer firms making R\&D data available in service sectors than in manufacturing and systems sectors. Reporting and accounting practices also vary.

Source: OECD Information Technology Database, compiled from annual reports, SEC filings and market financials, July 2012.

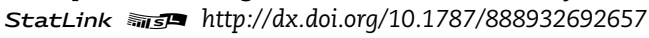

Communications equipment, software, semiconductor, and Internet firms were, on average, the most R\&D-intensive in 2011 (Figure 1.17). Internet firms were the only top 250 ICT firms to significantly increase R\&D expenditure in 2009 (up by $6 \%$ compared to 2008). ${ }^{7}$ All other industries reduced 2009 R\&D spending by $6 \%$ to $8 \%$ on average, with the exception

Figure 1.17. R\&D intensity of top 250 ICT firms by sector, 2008 and 2011 Average R\&D spending as a share of average revenue (percentages)

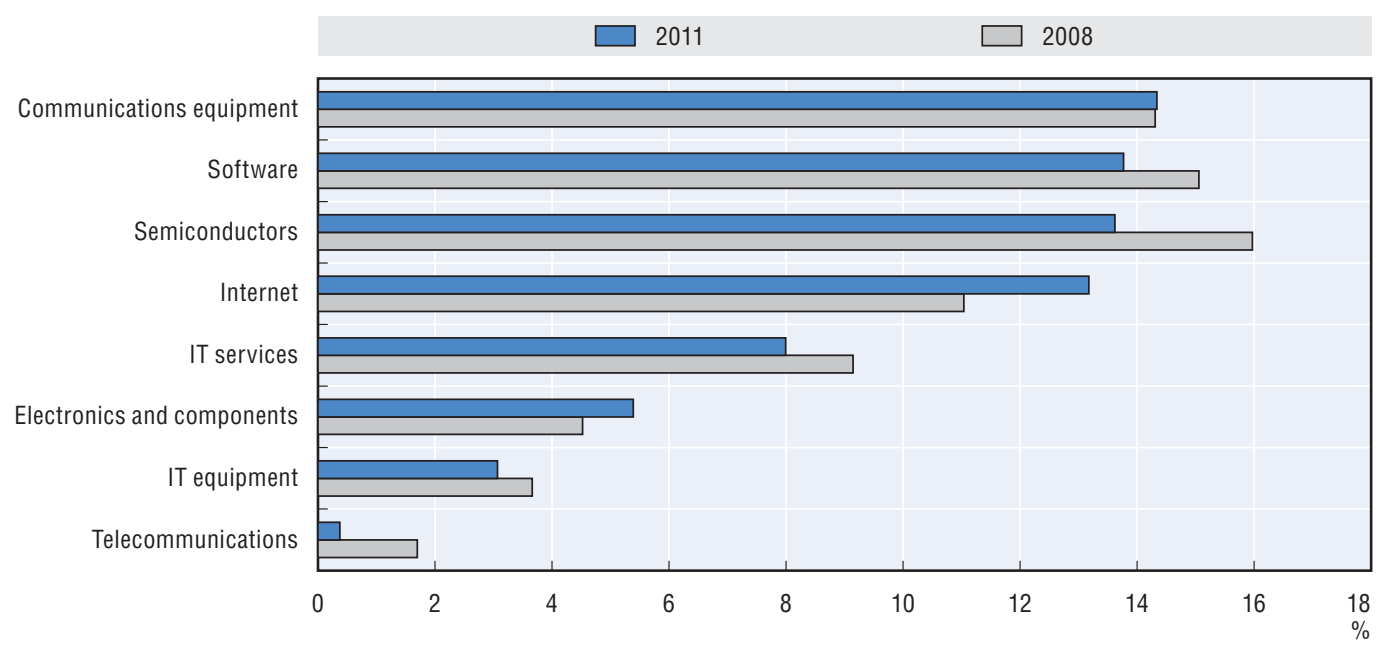

Note: R\&D expenditure data are incomplete and the presentation is based on those firms reporting R\&D.

Source: OECD Information Technology Database; compiled from annual reports, SEC filings and market financials, July 2012.

StatLink iाts $h$ ttp://dx.doi.org/10.1787/888932692676 
of electronics, software, and telecommunications firms, where R\&D spending decreased by approximately $1 \%$. In 2011, however, all sectors except telecommunications increased R\&D expenditure by $5 \%$ to $10 \%$ on average. Internet firms are again notable, increasing R\&D expenditure by $37 \%$ in 2011.

\section{Semiconductors}

Semiconductor production remains a leading indicator for the ICT sector due to its importance in ICT products. The semiconductor sector is typically sensitive to changes in economic conditions and provides an early indication of future developments in the ICT sector in general. The industry is one of the first to enter into recession, but is also one of the earliest to recover.

The semiconductor market experienced a significant decline of approximately one third at the end of 2008 and early 2009, but the market quickly recovered to its pre-crisis level in just one year. From September 2009 onwards, the semiconductor market continued its ascent before levelling out in October 2010 and thereafter remaining relatively stable.

The Asia-Pacific region maintains a lead in semiconductor production, but also experiences the largest fluctuations in demand compared to other countries or regions.

After suffering during this economic downturn, the semiconductor market has grown as a result of the explosion in smartphone and tablet computer sales (Figure 1.18). Users are upgrading their existing standard feature phones to new smartphones, and tablet computers such as the iPad have proven extremely popular with consumers and businesses. The global semiconductor market is also benefitting from the introduction of ICTs into new devices.

Figure 1.18. Worldwide semiconductor market by region, May 2007-May 2012 USD billions (three-month moving average)

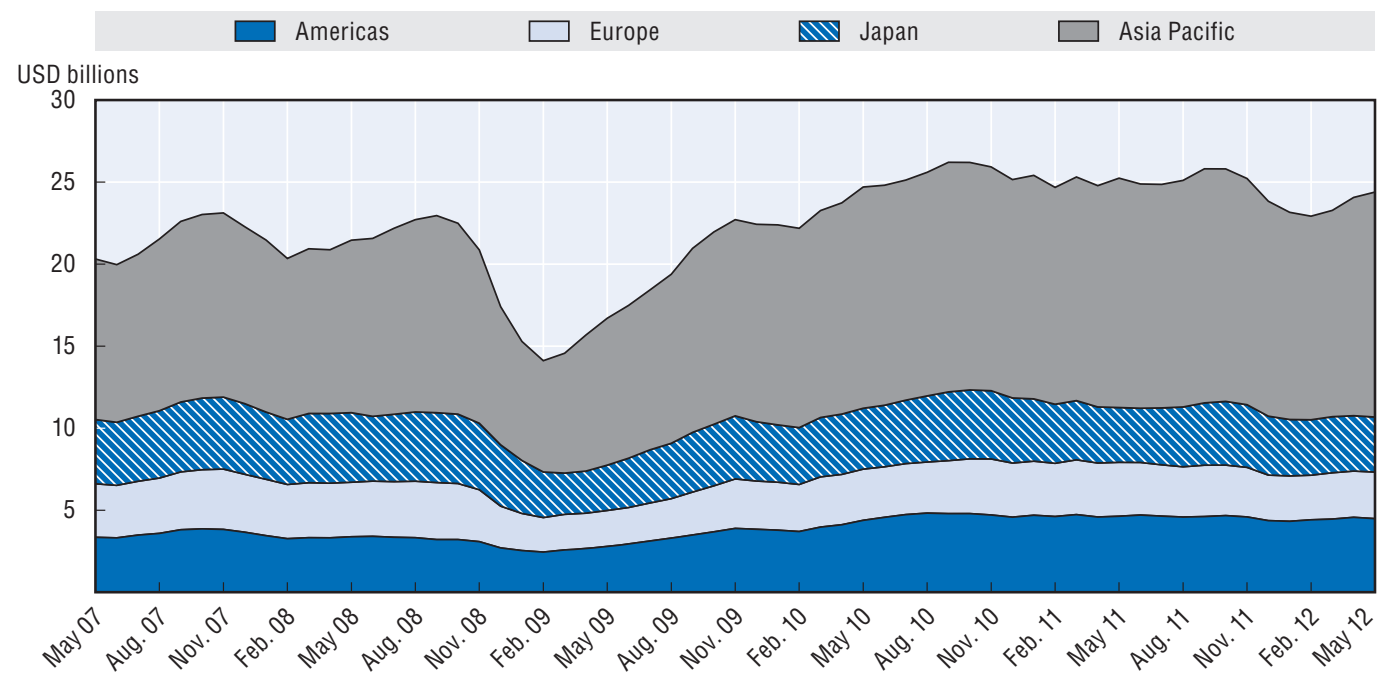

Note: Monthly sales numbers represent a three-month moving average. Source: Based on World Semiconductor Trade Statistics (WSTS), July 2012.

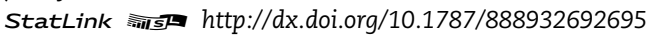

An analysis of semiconductor billing (deliveries) shows a steep decline in 2008 and again in 2011 (Figure 1.19). While the semiconductor industry seemed to avoid as drastic a 
drop in the recent crisis as previously occurred in 2000, emerging trends point to a slight slowdown in the sector as the number of billings decreased in the beginning of 2012 . Despite this, the semiconductor market is forecasted to reach USD 300 billion in revenues at the end of 2012, representing growth of $0.4 \%$ over 2011. The year 2013 is projected to see the market grow at a much faster pace of $7.2 \%$ over the previous year (WSTS, 2012).

Figure 1.19. Growth in monthly semiconductor worldwide market billings, May 1996-May 2012 Year-on-year percentage, three-month moving average

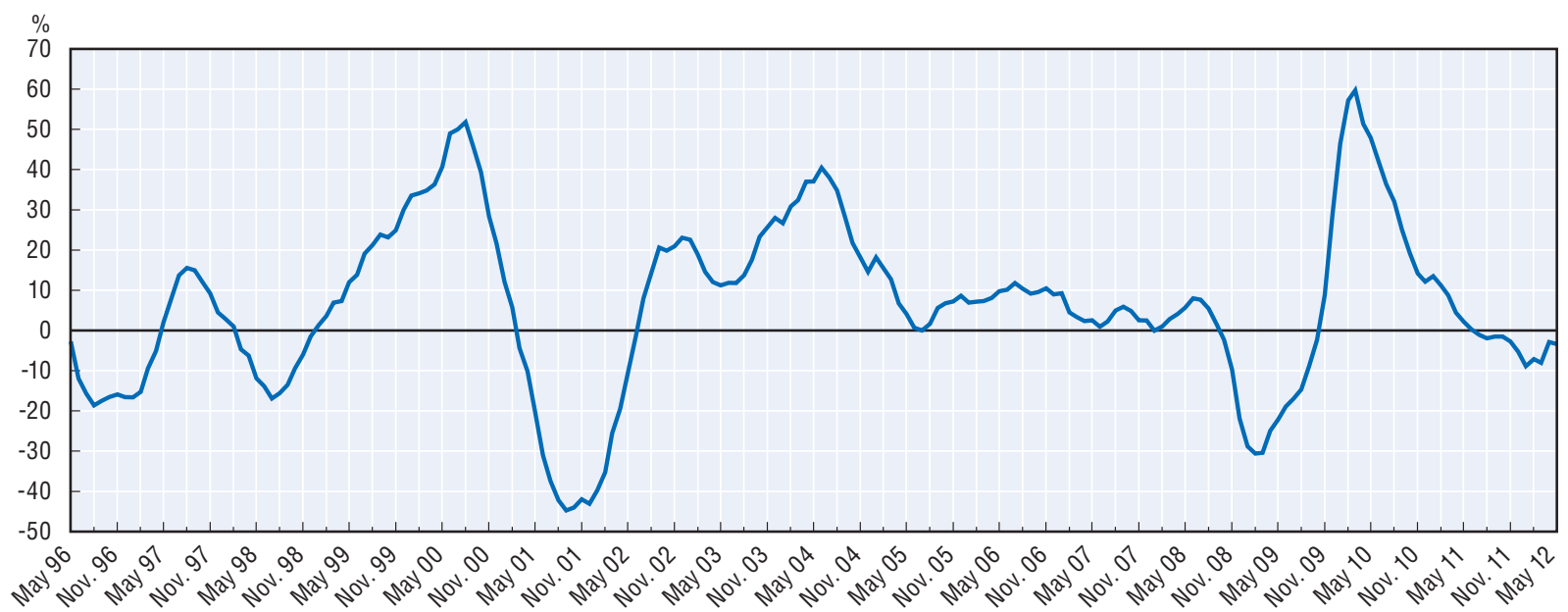

Source: Based on World Semiconductor Trade Statistics (WSTS), July 2012.

\section{Investing in the Internet}

Internet connectivity in a country depends on investment in ICT for communication equipment, software and IT equipment. Firms and governments invest in fixed capital for their operations and a certain percentage of these investments are allocated for ICTs.

The ICT sector receives a significant share of all gross fixed capital formation in the economy (Figure 1.20). This ICT investment is broken down into three separate categories: software, communication equipment and IT equipment (OECD, 2011a).

Within selected OECD countries, the United States has the highest percentage of ICT investment relative to total capital formation (32\%) followed by Sweden and Denmark $(25 \%)$ and the majority of their investments are in software. In Belgium and Denmark, the majority of ICT investment targets IT equipment, while in Portugal the focus is communications equipment.

\section{Venture capital}

Venture capital (VC) is money provided by investors to start-ups and small firms in exchange for equity in the company. Venture capital plays an important role in the economy because it provides financing to new firms that may not otherwise have access to capital markets due to their size or stage of development. Within the business ecosystem, VC firms are an important source of funding for innovation, and many countries look for ways to improve the supply of venture capital. 
Figure 1.20. ICT investment by asset in OECD countries, 2010

Percentage of non-residential gross fixed capital formation, total economy

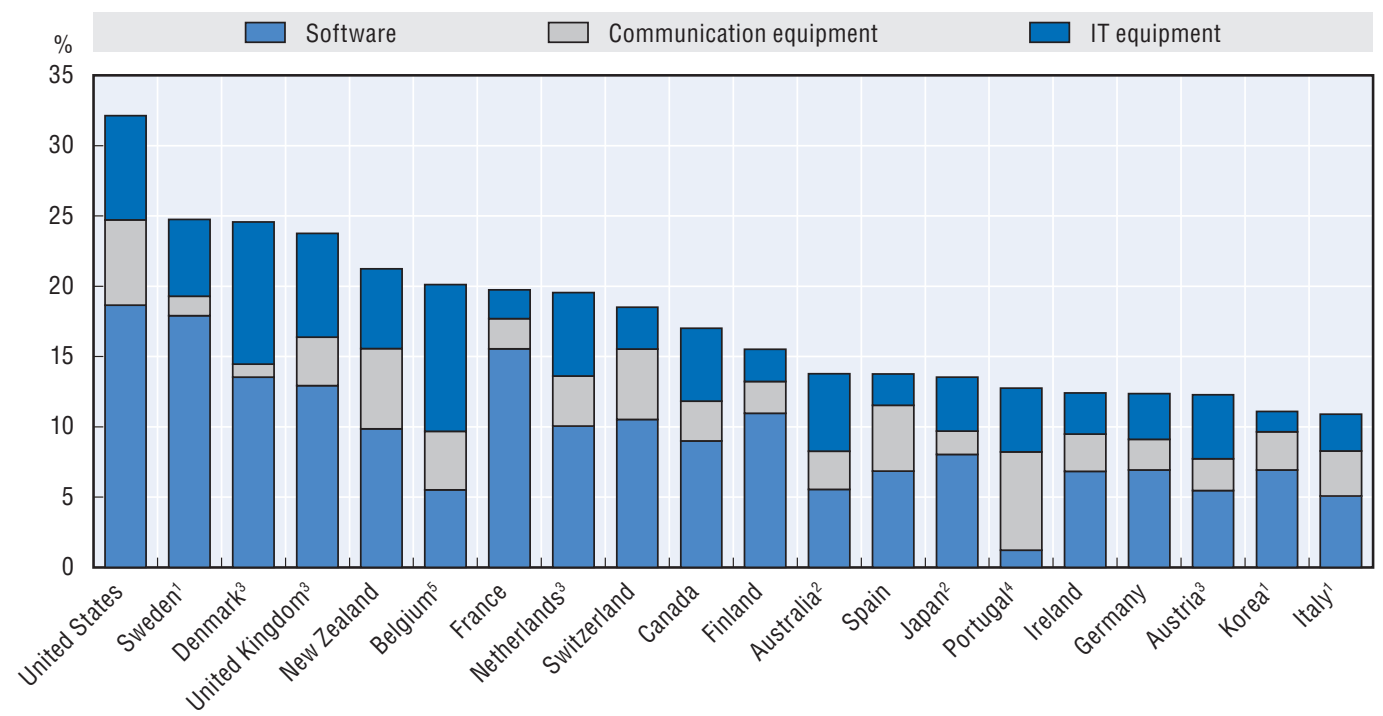

Note: ICT equipment is defined here as computer and office equipment and communication equipment; software includes both purchased and own account software. Software investment in Japan is likely to be underestimated, owing to methodological differences.

1) 2009; 2) 2008; 3) 2007; 4) 2005; 5) 2004.

Source: OECD Productivity Database, May 2012.

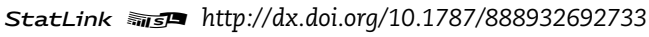

The ICT sector remains a key area of focus for venture capital investment and accounted for more than $50 \%$ of all VC investment in the United States, the largest market, in early 2012. The VC market in the United States reached its peak in 2000 at the height of the dot-com bubble. The amount of ICT venture capital investment, at the time over USD 20 billion and nearly $80 \%$ of total VC financing, was approximately seven times that at the beginning of 2012. The dot-com era, however, was an anomaly and the VC market has shown considerable stability over the last 10 years.

Venture capital financing returned to steady growth after the collapse in 2001 and this growth continued for the next seven years at a moderate rate (Figure 1.21). Investment began to fall again during 2008, but began to recover again in early 2009 , returning quickly to the longer-run growth path.

ICTs still account for over $50 \%$ of total VC investments, highlighting the perception of future value in the ICT sector. These persistent high percentages of investment are particularly impressive given that venture capitalists are increasingly investing in other areas such as green technologies and biotechnology.

Internet firms remain the key recipients of venture capital investments within the ICT sector. The amount of venture capital investment in Internet firms has yet to come close to the record of USD 13.5 billion reached in 2000, but has moved back to a more sustainable growth path (Figure 1.22). 


\section{Figure 1.21. Quarterly venture capital investments in the ICT sector in the United States, Q1 1995-Q1 2012}

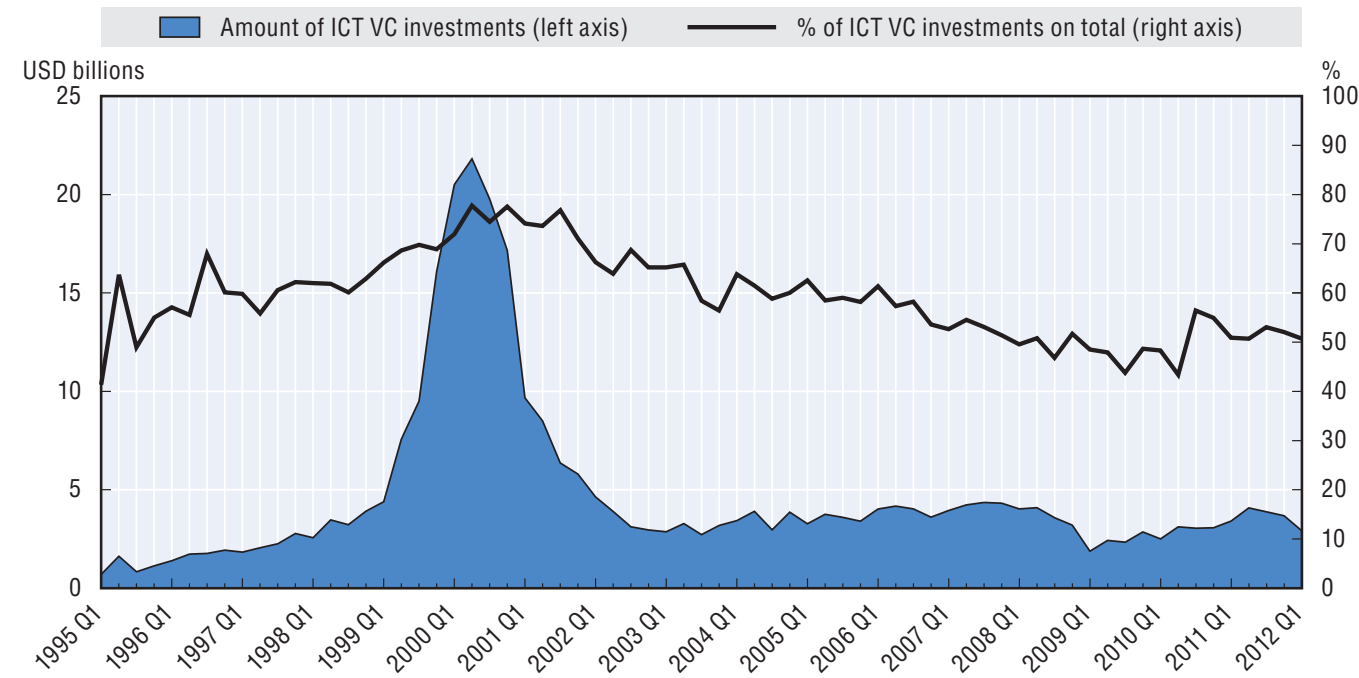

Source: Based on MoneyTree survey Report, PricewaterhouseCoopers (2012), April.

Figure 1.22. Quarterly venture capital investments in the Internet sector in the United States, Q1 1995-Q1 2012

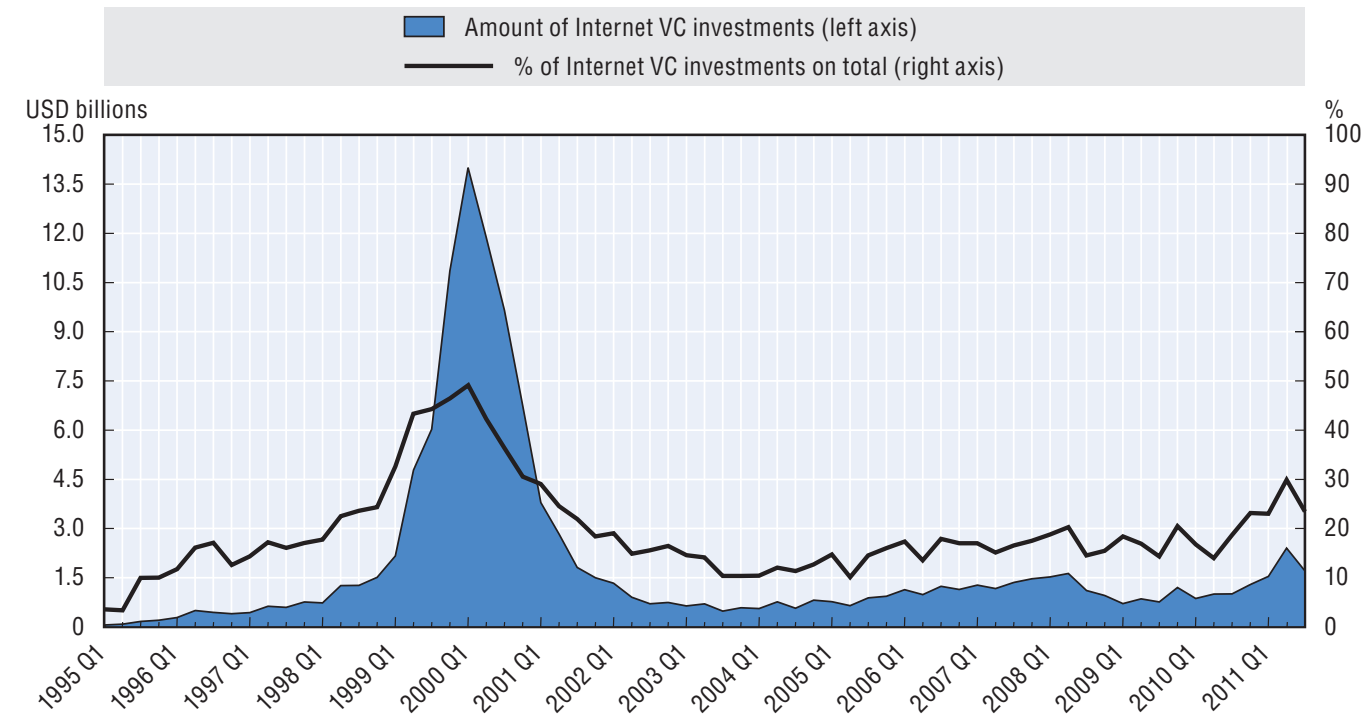

Note: The Internet sector comprises companies whose business models are fundamentally dependent on the Internet, regardless of the company's primary industry category.

Source: Based on MoneyTree survey Report, PricewaterhouseCoopers (2012), April.

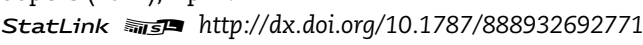

Venture capital investments in Internet firms dropped in mid-2008, but then began growing in 2009. The amount of VC entering the Internet sector reached its highest point ever in 2011, with the exception of the year 2000. This highlights the strength of the Internet sector relative to the rest of the economy, and implies that venture capitalists still see room for significant growth in the sector and among firms operating on the Internet. 


\section{ICT research and development}

Research and development ( $R \& D$ ) is a fundamental aspect of an economy's innovative capacity. Business enterprise expenditure on R\&D (BERD) is considered important for innovation and economic growth. In the OECD area, business R\&D reached approximately $1.6 \%$ of OECD GDP (OECD, 2011a).

Innovation in the ICT sector is supported by large investments in $R \& D$, as highlighted by the desire of policy makers to maintain high levels of R\&D activity even during economic downturns. Indeed, some governments have focused on policy to support R\&D during economic downturns as a way to promote innovation and growth.

Data show that investment in R\&D for ICTs is closely tied to the overall revenue of ICT firms (OECD, 2010) (Figure 1.23). During times of economic difficulty, $R \& D$ investment falls, but recovers when revenues rebound. R\&D investment retracted in 2002 and again in 2009 and 2010.

Figure 1.23. Growth in quarterly R\&D and revenue

Top 200 ICT firms reporting R\&D spending, Q1 2001-Q1 2010 (four-quarter moving average)

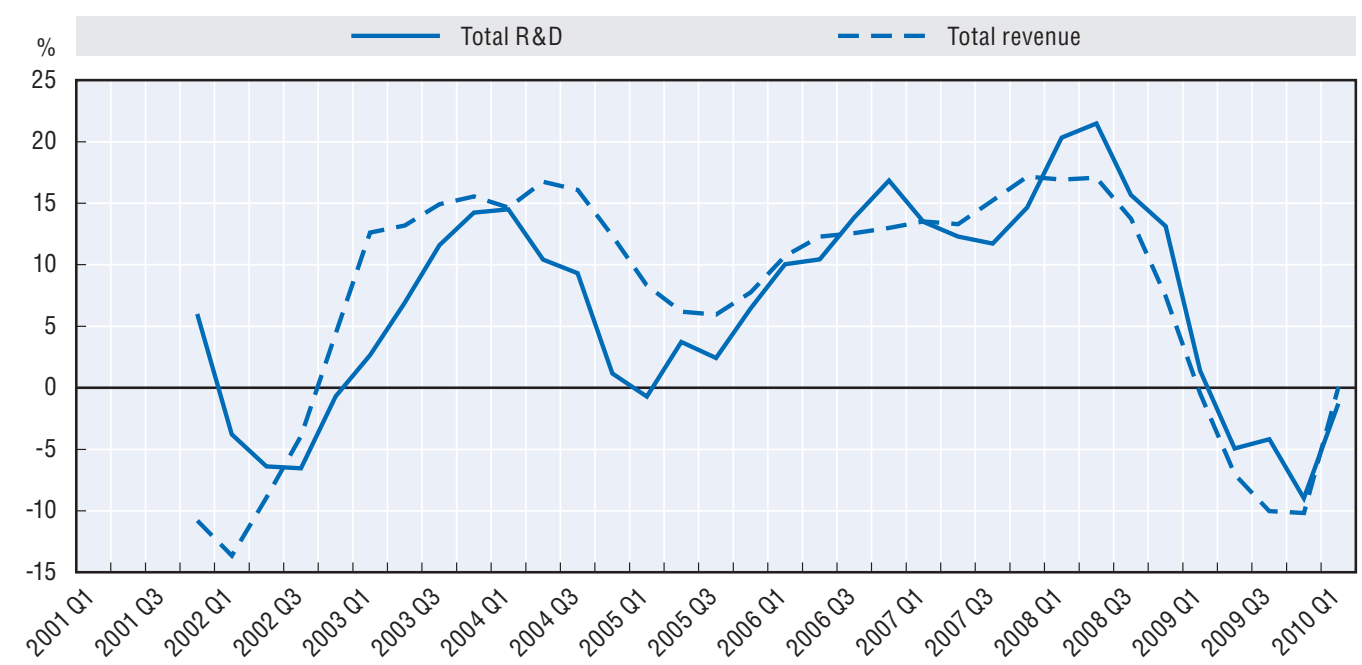

Source: OECD (2010), OECD Information Technology Outlook 2010.

Standard trade theory suggests that countries will specialise in certain types of production where they have a comparative advantage, and trade with countries with complementary specialisations. An examination of R\&D data from ICT firms in OECD countries highlights examples of specialisation within the sector.

ICT BERD varies significantly across economies (Figure 1.24). In 2010, Chinese Taipei, Finland and Korea ICT BERD reached around 1.5\% of GDP. On the other hand, in two thirds of OECD countries, ICT BERD was less than $0.25 \%$ of GDP. Finland, Israel and Korea stand out with the highest ICT BERD intensity, ${ }^{8}$ highlighting a specialisation in the overall ICT sector. Japan, Sweden and the United States follow with relatively high investment rates. Among non-OECD economies, the highest ICT BERD intensity was recorded in Chinese Taipei, followed by Singapore.

Research and development in ICTs can be split into two categories: manufacturing and services. Chinese Taipei, Finland, Japan, Korea, Singapore and Sweden specialise more in ICT manufacturing, while Denmark, Iceland, Ireland, Israel and the United Kingdom specialise more in ICT services R\&D. Other countries have a more balanced mixture of the two. 
Figure 1.24. ICT BERD specialisation, 2010 or latest year available

Percentage of GDP and as share of total BERD

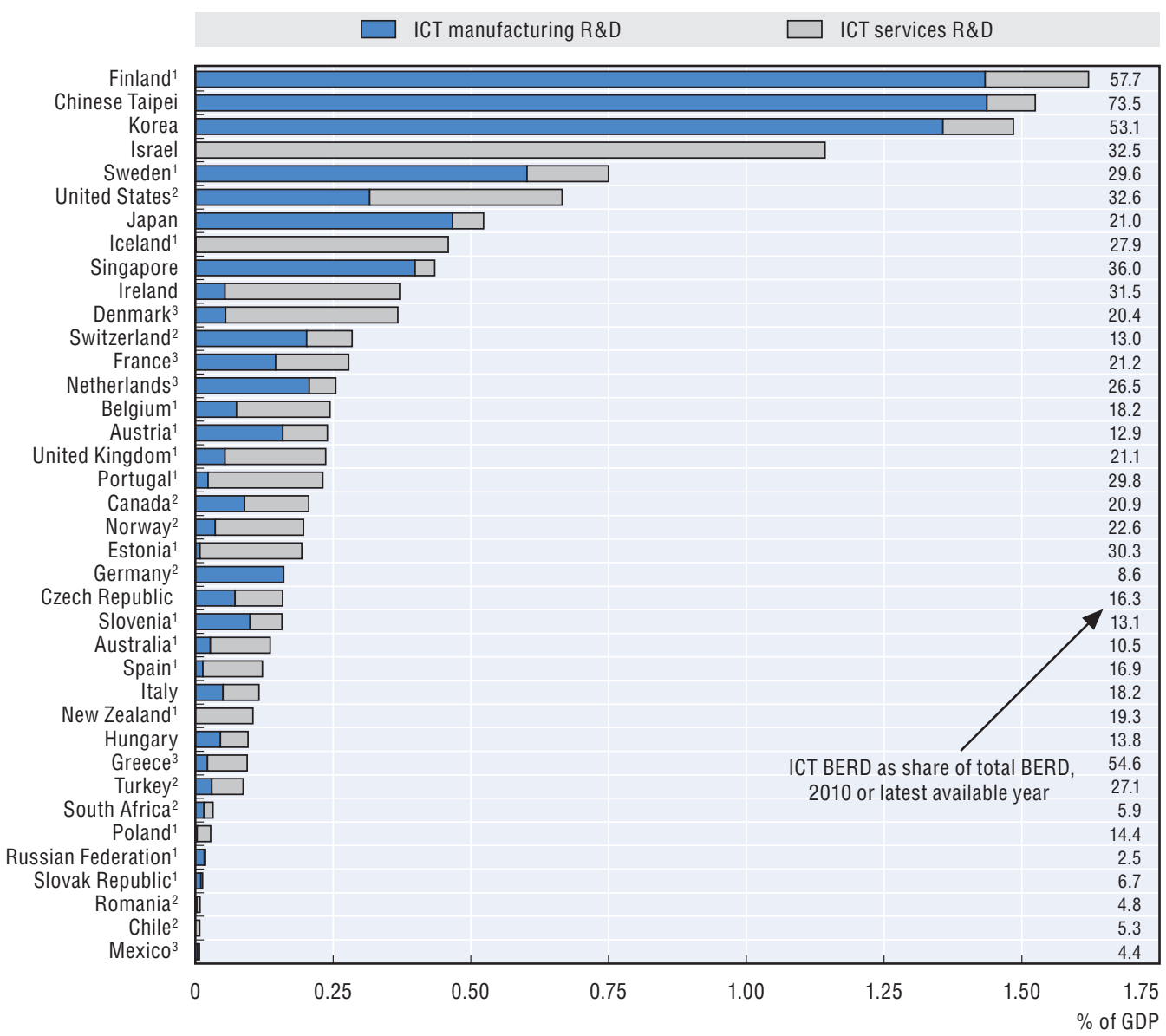

Note: ICT sector is defined here as the sum of the following categories in ISIC 3 Rev. 1: 30, 32, 642 and 72. Data on ICT manufacturing is not available in Chile, Israel and New Zealand. Data on ICT services is not available in Germany. See also endnote 9. For Belgium, France, Russian Federation and South Africa, data are distributed according to the product field of the R\&D. For the Czech Republic, data are distributed according to the main activity of the enterprise carrying out the R\&D. Since 2004, the R\&D of enterprises in the research and development industry (ISIC, R-3: 73) has been redistributed to the industries for which the R\&D was carried out. For United Kingdom, data are distributed according to the product field of the R\&D for large firms, while for small firms the R\&D is allocated to their main activity. R\&D firms are redistributed to the industry served. Telecommunications (ISIC, R-3: 642) includes postal services (ISIC, R-3: 641). For all the other countries in the chart, data are distributed according to the main activity of the enterprise carrying out the R\&D.

Information on data for Israel: http://dx.doi.org/10.1787/888932315602.

1) 2009; 2) 2008; 3) 2007.

Source: OECD ANBERD and RDS Databases, June 2012; Statistics Sweden, June 2011.

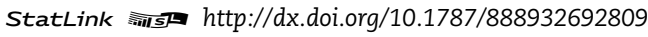

Another way to examine the importance of ICT investment in the economy is to look at the percentage of ICT Business R\&D expenditure as a percentage of total BERD in the economy. On average, $20 \%$ of total BERD investment is focused on the ICT sector. But the data show very large differences across countries. In 2010, ICT BERD accounted for more than a half of total business R\&D expenditure in Chinese Taipei, Greece, Finland and Korea. It accounted for more than $30 \%$ in Estonia (30\%), Ireland (32\%), Singapore $(36 \%)$ and the United States (33\%). 


\section{ICT markets and spending}

Total worldwide ICT spending is estimated to reach USD 4406 billion in 2012, of which 58\% (USD 2572 billion) is on communications services and equipment, 21\% (USD 910 billion) on computer services, 12\% (USD 539 billion) on computer hardware and 9\% (USD 385 billion) on software (Figure 1.25).

Figure 1.25. Worldwide ICT spending, 2003-12

USD billions, current prices

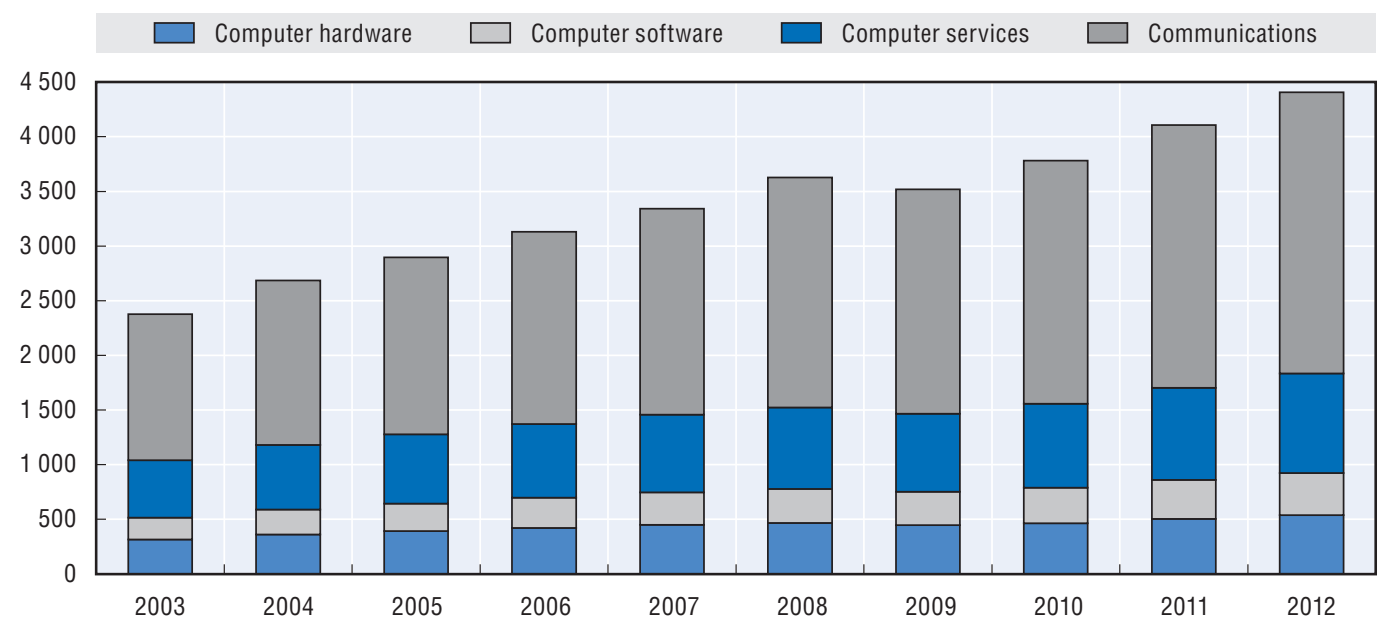

Source: Based on data published by World Information Technology and Services Alliance (WITSA), based on research conducted by Global Insight, Inc. December 2010.

The contraction of the ICT sector by $3 \%$ in 2009 mainly affected computer hardware and communications equipment. But ICT spending returned to growth during 2010 after which moderate long-term growth is expected through to 2013 (WITSA, 2010). Estimates suggest that in 2012, software spending will increase more rapidly (by $7.6 \%$ a year) than computer hardware (6.1\% a year), as hardware prices continue to fall. Spending on communications, both services and equipment, will also increase rapidly (by 7.6\%), reflecting the uptake of more advanced services and the rapid spread of mobile services in developing countries.

The North American market (Canada, Mexico and the United States,) remains the largest for ICT spending, accounting for 31\% of global spending in 2012. This is followed closely by the Asia-Pacific region and Europe, both accounting for $30 \%$. With the emergence of new high-growth, non-OECD markets (e.g. Brazil, China, India and the Russian Federation) for ICT products and services, worldwide ICT spending is expected to increase by $7.1 \%$ a year from 2003 through 2012 while OECD spending has increased by an annual $5.1 \%$. OECD countries account for 72\% of the estimated global ICT spending (USD 3154 billion) in 2012, down from 85\% in 2003 (Figure 1.26).

Communication services and equipment in OECD countries account for half of total OECD ICT spending, followed by spending on computer services, which accounts for $26 \%$. A somewhat larger share of total spending on computer services suggests a structural shift to outsourcing these business-related services, with a higher share of these services in more economically developed OECD countries (Denmark, France, Sweden, the United Kingdom and the United States). Greece, Mexico and the Slovak Republic have the highest share in communication services and equipment spending (at around 80\%) (Figure 1.27). However, 


\section{Figure 1.26. OECD ICT spending, 2012}

USD millions, current prices
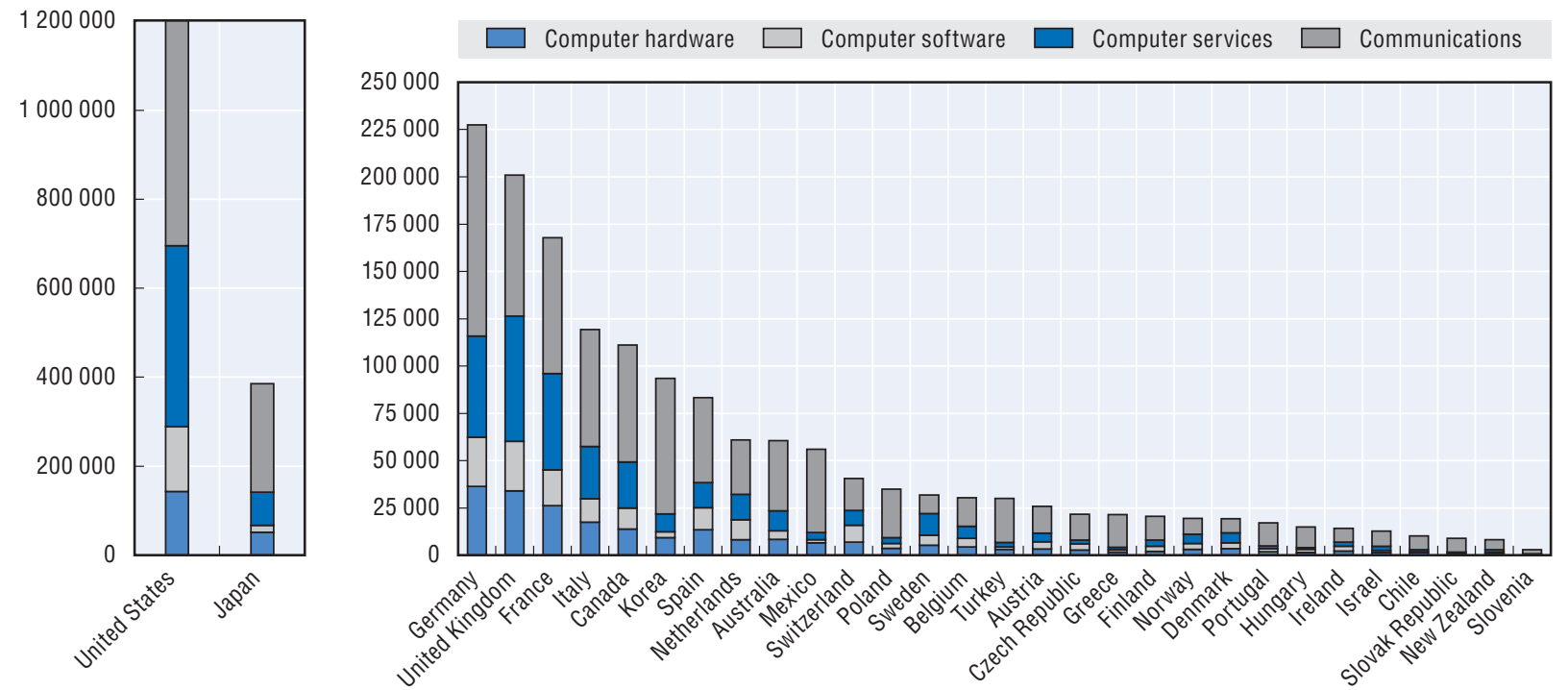

Source: Based on data published by World Information Technology and Services Alliance (WITSA), based on research conducted by Global Insight, Inc. December 2010.

StatLink त्राजी http://dx.doi.org/10.1787/888932692847

Figure 1.27. Trends in ICT spending by region, 2003-12

Index $2003=100$

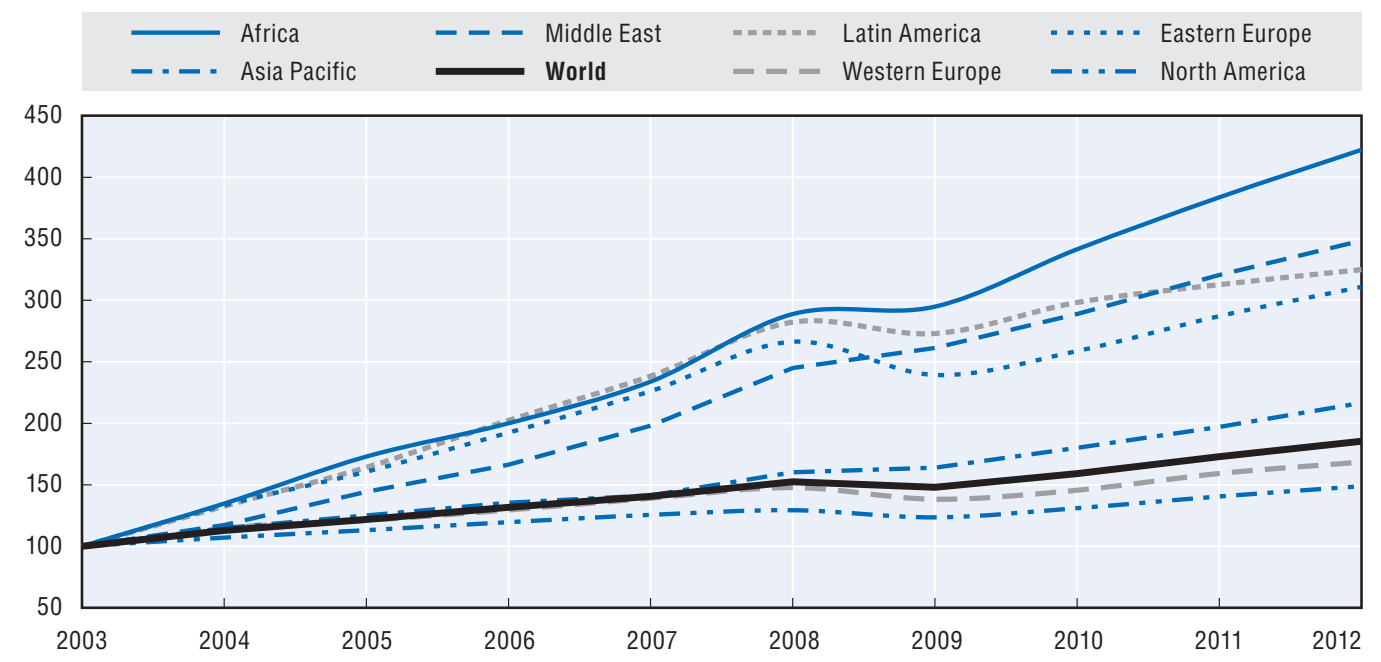

Source: Based on data published by World Information Technology and Services Alliance (WITSA), based on research conducted by Global Insight, Inc. December 2010.

StatLink :

the share of IT hardware and service spending is well below average in Greece, Korea, Mexico, Poland, Portugal, the Slovak Republic and Turkey, because of lower business use of ICTs and the rapid growth of mobile and other consumer communication services.

Following the noticeable recession in 2009, ICT spending is increasing most rapidly in Africa, the Middle East, and Latin America, followed by Eastern Europe (Figure 1.27). In the Asia-Pacific region, Western Europe and North America, growth in spending is more subdued. In current prices, Japan and the United States are the OECD countries with the slowest growth. 
In 2012, the United States still dominates the list of top 15 ICT spenders, followed by China and Japan (Figure 1.28). However, in terms of growth, India ranks first at $22 \%$ per year from 2003 through 2012, followed by China and the Russian Federation at 15\%, and Brazil at $14 \%$. Australia, despite its position at the bottom of the top 15 list, is fifth in terms of growth. ICT spending is increasing rapidly in most emerging non-OECD economies. Worldwide, India is forecast to rank fifth, Indonesia ninth, the Russian Federation twenty-second and China twenty-fourth. In seventeenth place, the Slovak Republic remains the only OECD country in the top 25 in terms of market growth (Figure 1.29).

Figure 1.28. Top ICT spenders and growth, 2012

USD billions (annual average growth rate)

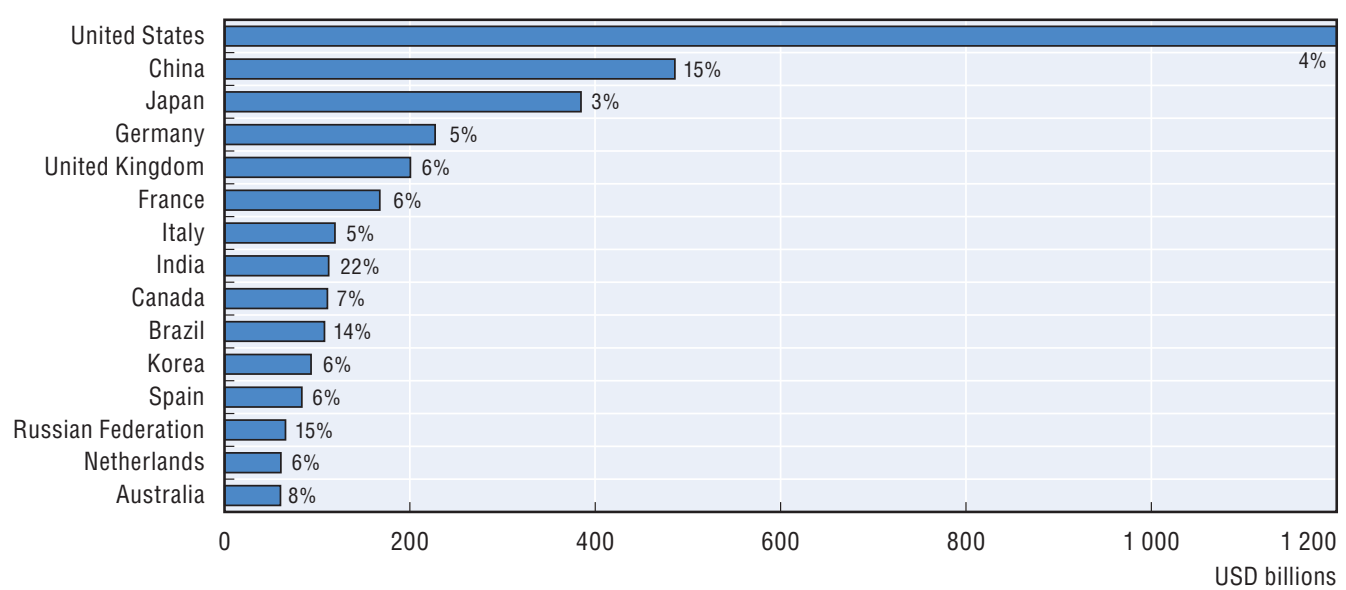

Source: Based on data published by World Information Technology and Services Alliance (WITSA), based on research conducted by Global Insight, Inc. December 2010.

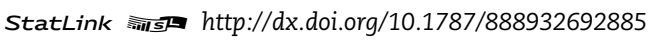

Figure 1.29. Fastest ICT spending growth, 2003-12

Average annual growth rate

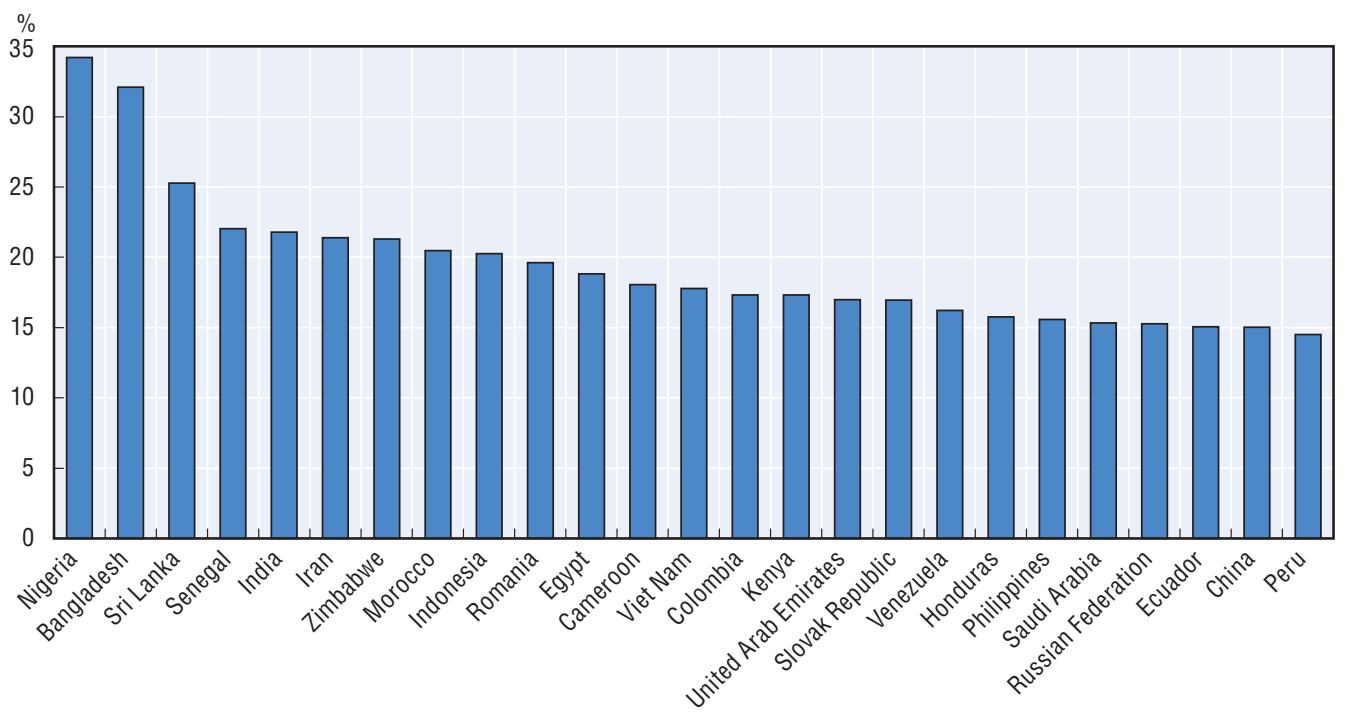

Source: Based on data published by World Information Technology and Services Alliance (WITSA), based on research conducted by Global Insight, Inc. December 2010. 
Finally, the structure of ICT spending by segment is slowly shifting. The most notable change is the increasing share of consumer spending, which now constitutes one third of the total ICT market (Figure 1.30). This is mainly driven by the increasing demand for mobile devices (smartphones, netbooks, tablets). ICT spending is also growing faster in the natural resources sector, followed by the construction and the energy and utilities sector, possibly owing to the commodities boom and the shift to "smart" infrastructures (see OECD, 2010, Chapters 5 and 6). The educational services sector is also growing rapidly. Spending by transport, retail trade and wholesale and distribution has grown somewhat more slowly, and in some cases their shares have even declined. Relatively slow growth by financial services is attributable in part to the collapse in expenditures during the crisis.

\section{Figure 1.30. ICT spending by industry segment, 2012}

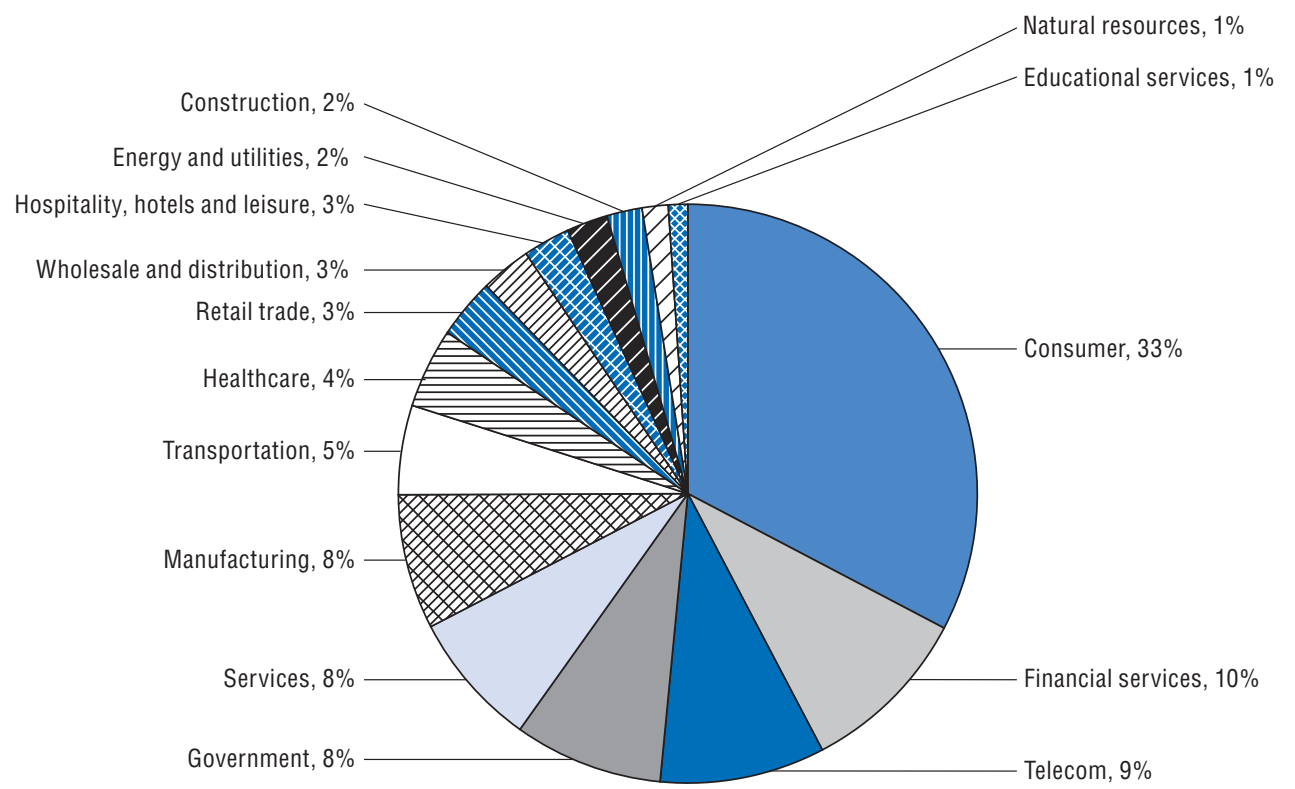

Source: Based on data published by World Information Technology and Services Alliance (WITSA), based on research conducted by Global Insight, Inc. December 2010.

StatLink त्राजा http://dx.doi.org/10.1787/888932692923

\section{Conclusion}

The expansion of mobile Internet connectivity has helped buoy the ICT sector, and in many ways the economy as a whole, during a period of sustained economic malaise. The ICT goods sector declined for the first time since the dot-com era in 2001-02, but is quickly recovering in some OECD countries. ICT services, in contrast, fared much better than ICT manufacturing, as maintained strong growth in several countries throughout the recent crisis.

Top ICT firms have fared well throughout the crisis. Telecommunication service providers made up the largest component of the top 250 ICT firms, followed by equipment manufacturers. Internet firms accounted for only 7 of the top 250 ICT firms by revenues.

ICT sector growth has not gone un-noticed by investors, as the sector remains a key area of focus for venture capitalists. In 2011, ICTs accounted for more than 50\% of all venture capital in the United States, the world's largest market. Venture capital investment is at its highest level, with the exception of anomalous peak in 2000 during the dot-com 
bubble. ICT business R\&D also continues with both Korea and Finland reaching over 1.5\% of GDP.

In terms of policy, national ICT strategies in OECD countries generally consider ICT R\&D programmes a key priority for economic recovery because they are essential to industrial capacity and to underpin innovation. In the 2012 OECD ICT policy questionnaire, 16 out of 22 countries indicated a high or medium priority for R\&D programmes. ICT R\&D programmes also feature among the top 3 priorities for a sustainable economic recovery. Chapter 8 on government priorities and policy developments provides more information and specific examples of R\&D strategies from countries.

This chapter has examined the Internet within the broader view of the ICT sector as a whole. The remainder of the Internet Economy Outlook focuses on the Internet and the economy, with chapters on Internet trends and developments, ICT and Internet use, emerging technologies, e-health, broadband content, security and privacy, and concluding with a chapter on policy issues and developments.

\section{Notes}

1. The business sector is usually an aggregate used for international comparisons, which is activity based rather than institution based. Here it is defined as per the ISIC Rev. 3.1 activities 10 to 74, excluding 70.I.e. excluding Agricultural activities, Real Estate and Community and personal services.

2. The Information, Communication Technology sector (ICT) is here defined by the OECD in terms of the following ISIC Rev. 3.1 classes:

Manufacturing

3000 - Office, accounting and computing machinery

3130 - Insulated wire and cable 3210 - Electronic valves and tubes and other electronic components

3220 - Television and radio transmitters and apparatus for line telephony and line telegraphy

3230 - Television and radio receivers, sound or video recording or reproducing apparatus, and associated goods

3312 - Instruments and appliances for measuring, checking, testing, navigating and other purposes, except industrial process equipment

3313 - Industrial process equipment

Services

5151 - Wholesale of computers, computer peripheral equipment and software

5152 - Wholesale of electronic and telecommunications parts and equipment

6420 - Telecommunications

7123 - Renting of office machinery and equipment (including computers)

72 - Computer and related activities.

This definition was originally approved in 1998. It was amended slightly in 2002 to reflect ISIC Rev. 3.1 changes to wholesale.

3. Note that definitions of ICT goods and services groupings vary across countries depending on the industry classification and available level of detail.

4. The high share of net debt among the top 250 ICT firms is largely due to telecommunication services firms, for which the net debt tends to increase with firm size. The correlation between 2009 annual revenue and net debt is only significant for telecommunication companies. The R2 is 0.85 excluding China Mobile, the richest firm in the top 250 ICT firms, and the relationship between annual revenue and net debt is a linear function: net debt [USD million] $=0.5 \times$ annual revenue [USD million] + 1395 [USD million]. See OECD (2010).

5. The Asia Pacific region includes Australia, China, Hong Kong (China), India, Indonesia, Japan, Korea, New Zealand, Philippines, Russian Federation, Singapore, and Chinese Taipei.

6. Where there are few firms, performance is firm-specific rather than industry-based or country-based. 
7. R\&D spending reflects past firm performance and potential future performance. Past performance provides funding for current R\&D spending and current R\&D a platform for future growth and profits. It may also be seen as an element of cost affecting operating margins, although in the revised System of National Accounts, output of R\&D will be classified as assets and expenditure as investments, OECD (2010).

8. Research and development (R\&D) intensity for a country is defined as the R\&D expenditure as a percentage of gross domestic product (GDP). For an enterprise, R\&D intensity is the ratio of a firm's $R \& D$ investment to its revenue (the percentage of revenue that is reinvested in $R \& D$ ). $R \& D$ is an important driver of innovation, and R\&D expenditure and intensity are two of the key indicators used to monitor resources devoted to science and technology worldwide.

9. For Canada, Finland, Greece, Ireland, Iceland, Singapore, Slovak Republic, South Africa and Switzerland, data on ISIC 30 were not available. For Canada, Chile, Denmark, Estonia, Finland, Hungary, Ireland, Israel, Japan, Netherlands, New Zealand and Slovak Republic data on ISIC 642 were not available and for South Africa and Switzerland data on ISIC 72 were not available either.

\section{References}

OECD (2008), OECD Information Technology Outlook 2008, OECD Publishing. doi: http://dx.doi.org/10.1787/it_outlook-2008-en.

OECD (2009), "The Impact of the Crisis on ICTs and their Role in the Recovery", OECD Digital Economy Papers, No. 163, OECD Publishing. doi: http://dx.doi.org/10.1787/221641027714.

OECD (2010), OECD Information Technology Outlook 2010, OECD Publishing. doi: http://dx.doi.org/10.1787/it_outlook-2010-en.

OECD (2011a), OECD Science, Technology and Industry Scoreboard 2011, OECD Publishing. doi: $h t t p: / / d x . d o i . o r g / 10.1787 /$ sti_scoreboard-2011-en.

OECD (2011b), The Role of Internet Intermediaries in Advancing Public Policy Objectives, OECD Publishing. doi: http://dx.doi.org/10.1787/9789264115644-en.

OECD (2012a), OECD Economic Outlook, Vol. 2012/1, OECD Publishing. doi: $h$ ttp://dx.doi.org/10.1787/eco_outlook-v2012-1-en.

OECD (2012b), "ICT Skills and Employment: New Competences and Jobs for a Greener and Smarter Economy", OECD Digital Economy Papers, No. 198, OECD Publishing. doi: http://dx.doi.org/10.1787/5k994f3prlr5-en.

PricewaterhouseCoopers (2011), MoneyTree Survey Report, October. London, PwC.

WIPO (World Intellectual Property Organization) (2011), World Intellectual Property Report 2011: The Changing Face of Innovation. Geneva, WIPO, www.wipo.int/econ_stat/en/economics/wipr/.

WITSA (World Information Technology and Services Alliance) (2010), Digital Planet 2010, WITSA, based on research conducted by Global Insight, Inc.

WSTS (World Semiconductor Trade Statistics) (2012), WSTS Semiconductor Market Forecast Spring 2012, June 2012, www.wsts.org/PRESS/Recent-News-Release.

ZenithOptiMedia (2011), "Quadrennial events to help ad market grow in 2012 despite economic troubles", www.zenithoptimedia.com/about-us/press-releases/zenithoptimedia-adspend-forecast-updatedec-2011/. 


\section{ANNEX 1.A1}

\section{Internet intermediaries}

Another type of Internet firm is that of "Internet intermediaries". They provide the Internet's basic infrastructure and platforms by enabling communication and transactions between third parties. Intermediaries can be commercial or non-commercial in nature, and include Internet service providers (ISPs), hosting providers, search engines, e-commerce intermediaries, payment intermediaries and participative, networked platforms. Their main functions are: i) to provide infrastructure; ii) to collect, organise and evaluate dispersed information; iii) to facilitate social communication and information exchange; iv) to aggregate supply and demand; $v$ ) to facilitate market processes; vi) to provide trust and vii) to take account of the needs of both buyers/users and sellers/advertisers. Related public policy issues concern notably their roles, legal responsibilities and liability for the actions of users of their platforms (Figure 1.A1.1).

Because Internet intermediaries' services create network externalities, they need a critical mass of users. They also often operate in two-sided markets as an intermediary between different groups, such as users and advertisers or buyers and sellers, adopting

\section{Figure 1.A1.1. Internet intermediary roles}

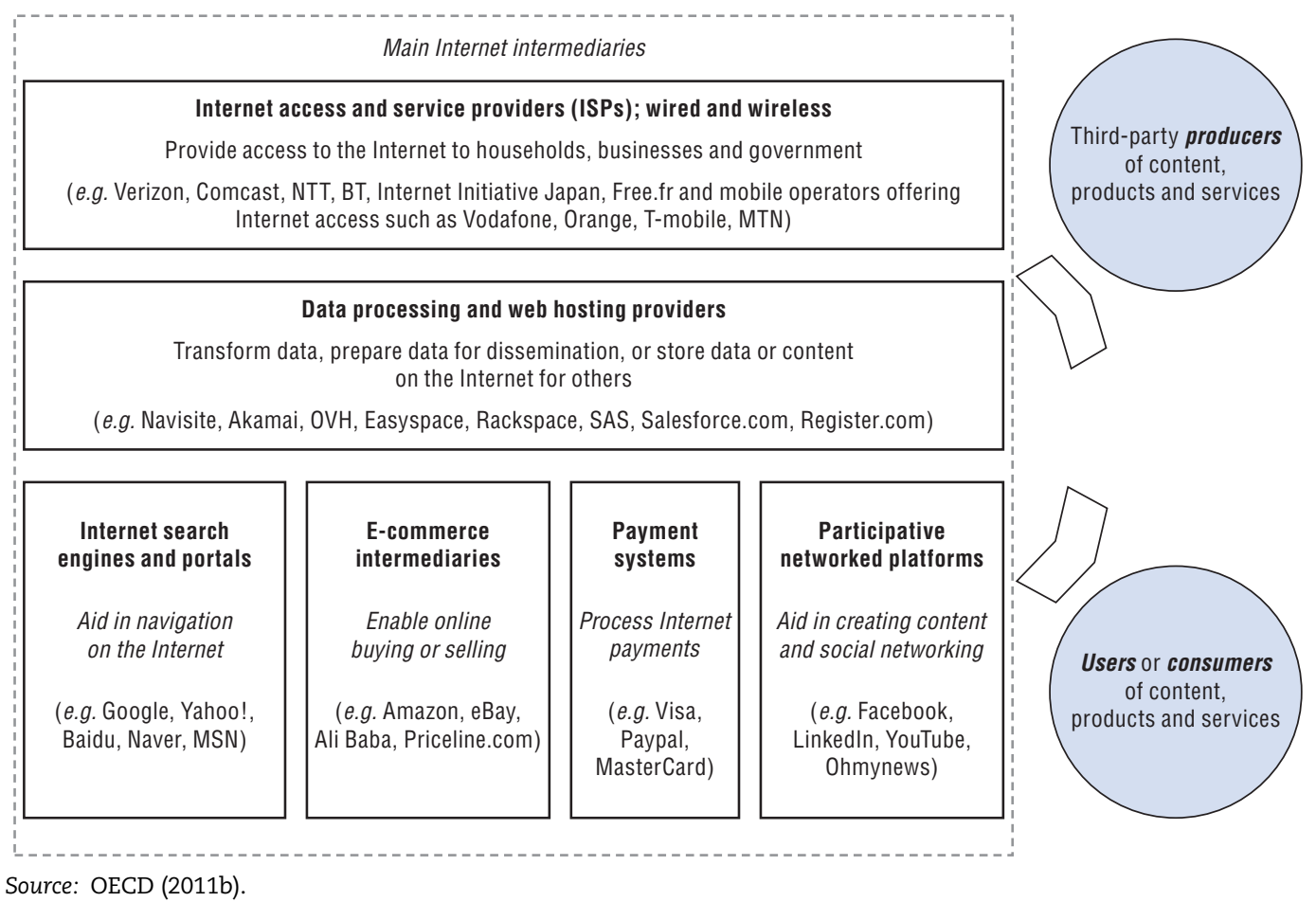


pricing and investment strategies designed to attract both sides and balance their interests. For example, online advertisers (which accounted for nearly $16 \%$ of global advertising revenue in 2011), allow intermediary platforms to provide increasingly sophisticated content and services at no monetary cost to users (ZenithOptiMedia, 2011). Other revenue models include subscription and paid "on-demand" service models, brokerage fees, donations and community development models for content or software.

The available data indicate that intermediary markets are a significant source of growth and innovation. For example, US census data show that identified Internet intermediaries represented at least $1.7 \%$ of business sector value added in 2009: ISPs, data processing and web-hosting providers, and Internet search engines accounted for $0.85 \%$; retail e-commerce intermediary platforms for $0.22 \%$; and wholesale e-commerce intermediary platforms for $0.7 \%$. In comparison, the broadcasting and telecommunications sector accounted for $2.52 \%$ of GDP value added, the publishing industries for $1 \%$, and the motion picture and sound recording industries for $0.4 \%$.

Intermediary platforms provide essential tools that enable the Internet to drive economic, social and political development, for example, by facilitating access to knowledge, demand aggregation, new models of collaboration, citizen journalism and civic participation. But intermediary platforms can also be misused for harmful or illegal purposes, such as the dissemination of security threats, fraud, infringement of intellectual property rights, or the distribution of illegal content. Most OECD countries have adopted specific liability regimes for Internet intermediaries for the activities of third-party users of their platforms, based on two broad concepts. First, intermediaries are not generally liable for the unlawful actions of third-party users of their services or platforms, in particular, where such intermediaries act only as hosts or mere conduits for such unlawful material. Second, they do, nonetheless, have specific obligations, such as removing hosted content upon receiving a valid notice (known as "notice and take-down") or upon becoming aware of specific instances of illegal or infringing content; identifying their users under certain circumstances; or designing policies and procedures to prevent the use of their platforms for illegal purposes.

As the Internet permeates all aspects of the economy and society, there is increasing national and international pressure from governments, intellectual property right-holders, child protection groups, some consumer groups and others to recognise the important role that Internet intermediaries may play to help, for example, control intellectual property infringement, protect children, reduce fraud or improve cyber security. Factors driving this evolution include the maturing of the Internet economy, the development of Internet intermediary business models that use third-party content, and technological evolutions and cost reductions that may allow the automation of certain types of proactive controls.

In 2012, policy questions were being raised throughout OECD member countries on the degree to which Internet intermediaries should be responsible for content originated by third parties using their network or services, or how far responsibility should remain solely with the original author, provider or party distributing unauthorised content. In different policy areas such as the global free flow of information, cyber security, child sexual abuse material, copyright, counterfeit, illegal Internet gambling or consumer protection, the practices and legal responsibilities of Internet intermediaries differ, with policy and legal implications in terms of effectiveness, technical feasibility, costs of compliance, appropriateness and reasonableness, privacy, speech and due process. 


\section{Chapter 2}

\section{Internet trends and development}

This chapter provides a forward-looking perspective on recent trends in ICT technologies, applications and services, and offers predictions for development over the next few years, highlighting particular trends that could have a substantial impact on future policy. It examines these trends in terms of networks, devices and services. It concludes with an analysis of Internet developments in various sectors of the economy. The chapter also highlights three key overarching trends: the growth of broadband, the importance of mobility, and the shift to cloud computing. 


\section{Emerging technologies}

The pace of technological change on the Internet and in the ICT sector in general is extremely rapid, compared to other sectors of the economy. In just a period of two years or less, the entire sector can shift as a result of new technologies, applications and services. New companies can rapidly gain market share while former market leaders quickly falter.

Markets move so quickly that policy makers and other market participants constantly need to keep an eye on developments and evolving market trends as a way to respond quickly to new policy challenges. This chapter focuses on some of the most promising and important Internet trends that are emerging and will continue to evolve over the next two years, providing an early glimpse of potential policy implications. The chapter begins by examining emerging technologies related to networks, devices and services. It continues with broader trends of how the Internet is transforming different sectors across the economy.

\section{Networks}

Networks are the underlying physical infrastructure of the Internet, which support evolving applications and services. High-speed networks are increasingly viewed as fundamental for economic and social development. They serve as a communication and transaction platform for the entire economy and can be used to improve productivity across all sectors.

Broadband has thus become a key focus of government policy makers. Many governments seeking to increase private sector investment in high-speed broadband networks have reviewed existing legal and regulatory frameworks so as to ensure the levels of investment necessary to achieve policy goals. Most governments have set targets as part of their plans, such as requiring certain levels of geographic coverage and minimum or average transmission speeds (e.g. $100 \mathrm{Mbps}$ ). Short-term targets include detailed explanations of the necessary requirements for their achievement, while longer-term targets are less specific to allow further refinement and development (OECD, 2011d).

Two key trends are emerging that will shape the near future of connectivity: very-high-speed fibre connections are being deployed closer to population areas and new high-speed wireless connections are spreading connectivity to an increasingly mobile population.

The upgrading of broadband subscriptions to fibre, so as to support much higher speeds, has begun in OECD countries (Figure 2.1). However, a recent assessment suggests that, with some notable exceptions, fibre-to-the-home/broadband (FTTH/B) deployment remains tentative or at an early stage. The exceptions are Korea and Japan, both of which have prioritised fibre deployment. Estonia, Japan, Korea, the Slovak Republic and Sweden lead the OECD in number of fibre subscriptions as a percentage of total wired broadband subscriptions (over 25\%). Meanwhile, the Global FTTH Council reports that no more than 26 economies worldwide have at least $1 \%$ of their households connected to FTTH or fibre-to-the-building (FTTB), and of these only eight are G20 members (Global FTTH Council, 2011). 
Figure 2.1. Fibre broadband penetration, December 2011

Percentage of fibre connections in total broadband subscriptions

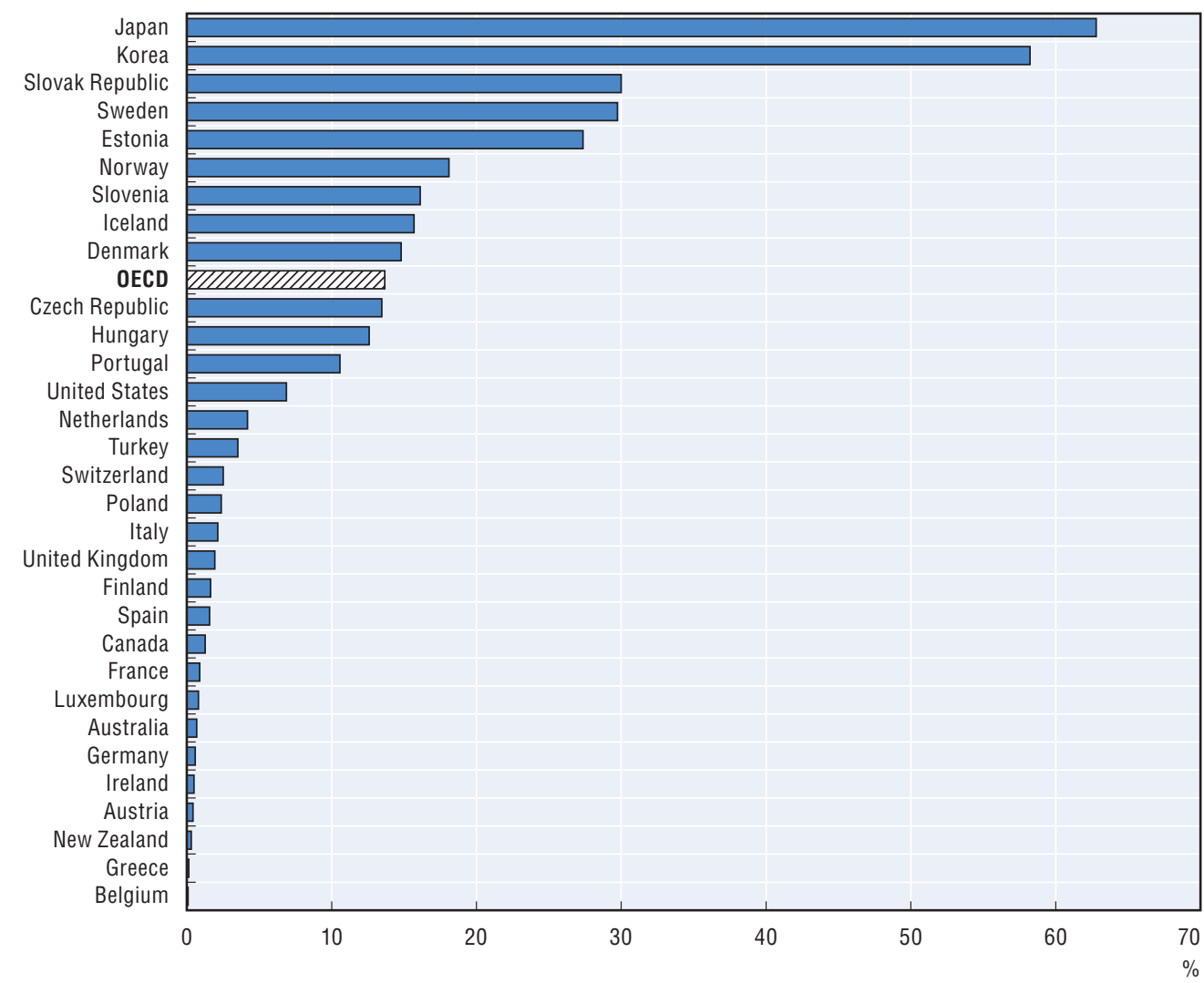

Note: Includes fibre-to-the-home (FTTH) and fibre-to-the-building (FTTB or apartment LAN) connections. Some countries may have fibre, but have not reported figures so they are not included in the chart. See the OECD broadband portal for information on data sources and notes.

Source: OECD Broadband Portal, July 2012.

StatLink त्राIs http://dx.doi.org/10.1787/888932692942

Fibre-based broadband connections offer the fastest data transfers, but it is the mobile segment of the Internet access market that has seen the most impressive growth over the last two years. Wireless broadband has quickly become the dominant broadband access channel in OECD countries. In December 2011, there were 315 million wired and 667 million wireless broadband subscriptions throughout the OECD. Standard mobile subscriptions with wireless broadband access outnumbered DSL subscriptions by two-to-one across the OECD. Finland, Japan, Korea and Sweden lead the OECD in terms of wireless broadband subscriptions per 100 inhabitants (Figure 2.2).

High-speed networks have become increasingly important for new services and applications. Indeed, the fusion of cloud computing, mobile devices and broadband are changing the way companies deal with computing resources and the way people perceive and use computer technology. Tablet PCs and smartphones are making computers ubiquitous, while cloud services and mobile Internet enable "everything/everywhere" data access.

The demand for high-speed bandwidth continues to climb and the breakdown of traffic is evolving. Traditional media broadcasting is transitioning to on-demand programmes, such as Internet TV and mobile audio and video streaming. According to Cisco, in 2010 global Internet video traffic surpassed global peer-to-peer (P2P) traffic, which has dominated networks over the past ten years. Cisco's Visual Networking Index (Cisco, 


\section{Figure 2.2. OECD wireless broadband subscriptions per 100 inhabitants, December 2011}

By technology

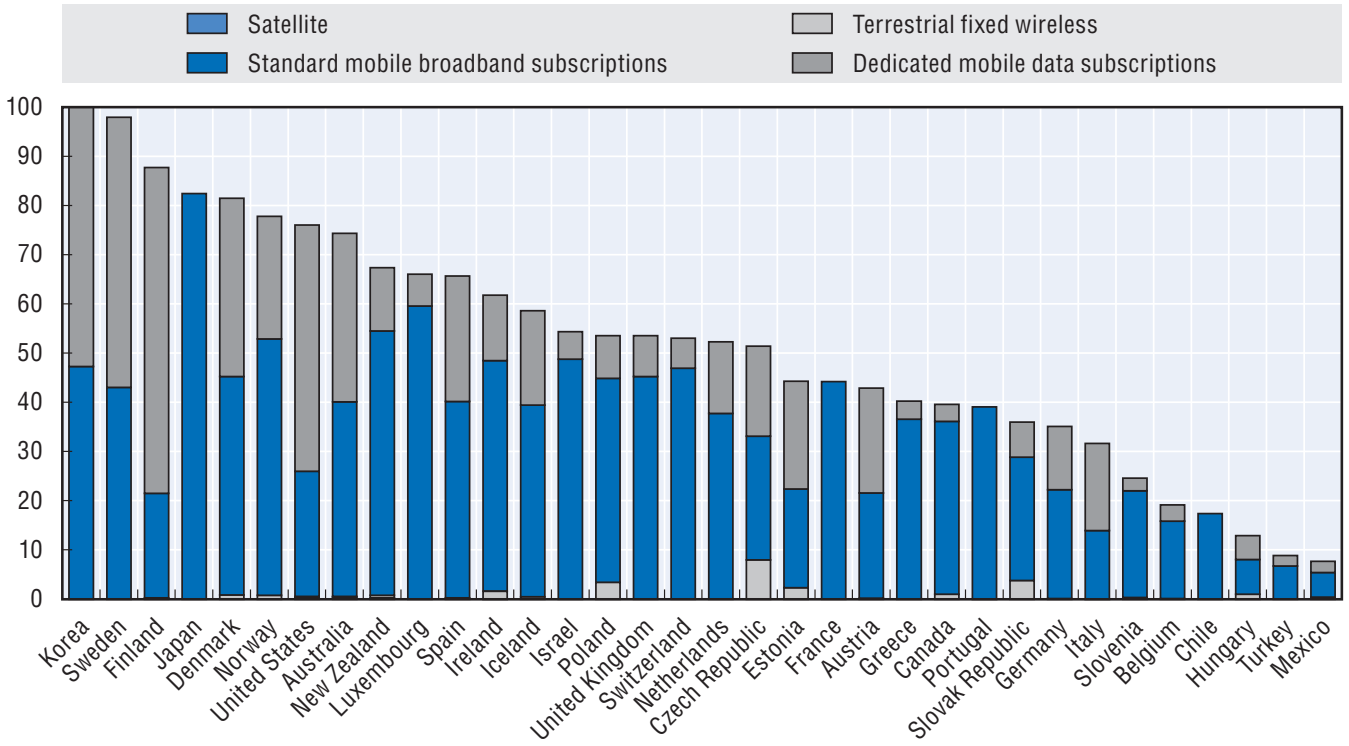

Note: Standard mobile broadband subscriptions may include dedicated mobile data subscriptions when breakdowns are not available. See the OECD broadband portal for information on specific country notes.

Information on data for Israel: $h t t p: / / d x . d o i . o r g / 10.1787 / 888932315602$.

Source: OECD Broadband Portal, July 2012.

StatLink त्ञाज http://dx.doi.org/10.1787/888932692961

2011) also predicts that by 2012 Internet video will account for over $50 \%$ of consumer Internet traffic. In 2010, video traffic accounted for $40 \%$ of total traffic and Cisco predicts that this will rise to $50 \%$ by the end of 2012 and $62 \%$ by 2015 .

Wireless networks are also seeing large growth in traffic volumes. The use of unlimited data tariff plans, popular with many users, has stimulated traffic growth and raised questions over pricing structures on some mobile networks. In the United States, AT\&T (and its affiliates), which had an exclusive handset arrangement with Apple for the iPhone, announced that it would move to tiered pricing for new customers, and would no longer offer a plan for unlimited data use. In response, some competitors stepped up their advertising for unlimited plans with rival smartphones. They also offered customers various choices to tether smartphones and portable devices, such as tablet computers, to their mobile handsets, with unlimited tariff plans.

Unlimited data plans undoubtedly encourage increased data usage and most likely the development of applications for smartphones. At the same time, increased use may challenge network capacity, requiring higher investment by operators to avoid network congestion. The extent to which data caps will curtail usage and network enhancements will match increasing data usage remains to be seen.

Next-generation mobile networks are currently being upgraded to support these new data demands. In the first quarter of 2011, the 3rd Generation Partnership Project (3GPP) announced the first implemented technology to meet the requirements of full-featured $4 \mathrm{G}$ technology: Long Term Evolution (LTE) Advanced (Parkvall et al., 2008). Agilent demonstrated LTE at the Mobile World Congress 2011 (Agilent, 2011). The above requirements are known as International Mobile Telecommunications (IMT)-Advanced criteria and include: peak data rates of $100 \mathrm{Mbit} / \mathrm{s}$ for high mobility (train or car), up to $1 \mathrm{Gbit} / \mathrm{s}$ for low mobility (pedestrians 
and fixed-access points), and an all-IP packet switched network. LTE Advanced is competing with WiMAX-Advanced, currently under development at the Institute of Electrical and Electronics Engineers (IEEE, 2008).

Even though such systems are far from ready for large-scale market deployment, mobile telecommunication providers are selling many existing products under the $4 \mathrm{G}$ label that claim to offer high-speed Internet connectivity.

Another key trend affecting the Internet is the transition from IPv4 to IPv6. The ability of the Internet to scale to connect billions of people and devices relies upon the Internet Protocol (IP) system. This addressing protocol specifies how communications take place between one device and another. Each device must have an IP address in order to communicate. However, the current version, IPv4, is expected to run out of previously unallocated addresses in 2012.

Once this has happened, operators and service providers will need to migrate to the newer version of the Internet Protocol, IPv6, in order to add additional customers or devices to their networks. The only alternative is to employ complex and expensive layers of network address translation (NAT) to share scarce IPv4 addresses among multiple users and devices. For this reason, the timely deployment of IPv6 by network operators and content/application providers is an increasing priority for all Internet stakeholders. In terms of public policy, IPv6 plays an important role in enabling Internet growth to support further innovation. In addition, the depletion of IPv4 implies security, interoperability and competition issues (Perset, 2010).

The supply of available unallocated IPv4 addresses began to run out in February 2011, when the Internet Assigned Numbers Authority (IANA) allocated its remaining address blocks to regional registries. This has made the need to migrate to IPv6 more pressing.

There are numerous metrics for measuring IPv6 deployment, although meaningful data are hard to identify. All sources point to rising numbers of hosts and networks with native IPv6 support, but report the monitored IPv6 traffic share at less than 1\%. This indicates that most ISPs and mobile operators do not yet offer IPv6 service to their customers.

\section{Devices and operating systems}

Interaction with the Internet is based on a combination of hardware and software. Devices such as PCs, tablets and mobile phones provide the hardware for users to connect to the Internet, and serve as a platform for the software interface that guides interaction with information and content. This section examines some key developments in both hardware devices and the software platforms and operating systems that support the Internet economy.

\section{Device trends}

Several seemingly contrary trends for emerging and upcoming computing devices in fact support a single paradigm shift. Hardware advancements are producing very powerful super-computers with extraordinary computing power. At the same, there is a current trend to transfer some computational requirements of mobile devices back into the cloud to reduce cost and improve battery performance (see the section on cloud computing later in the chapter for more details).

In the first case, manufacturers, such as Hewlett Packard or Fujitsu, are developing very high-performance servers for massive parallel computation, for example, computers featuring 8 central processing units (CPUs) with 10 cores each ( 80 cores) and main memory of up to 4 terabytes (128 banks for 32GB memory). Some current products on the market make use of terabyte-scale main memory capacities, and many more applications are under development to take advantages of gains in computing power. 
One of the most important developments in improving computational speed is the focus on in-memory database technology. This eliminates time-consuming access to disk access by storing and manipulating data in memory. This is a key component for the implementation of next-generation business analytics operating on real-time data. Analysts at Gartner expect $30 \%$ of analytic applications to use in-memory functions for add scale and computational speed by 2014 . Gartner also estimate that by $2014,30 \%$ of analytic applications will use proactive, predictive and forecasting capabilities based on real-time computation.

Examples of the second case include personal computing devices such as mobile phones and tablets, as well as a number of highly specialised embedded computers for applications, such as smart grids, and even smaller devices that enable sensor networks for various monitoring applications, for example, in environmental sensing, perimeter surveillance or agricultural monitoring.

Together these two trends describe a shift in computational capabilities from the desktop to central instances (on-premise servers or the cloud), while personal devices transform presentation tools and human-computer interfaces.

A state-of-the-art example of this paradigm shift and the influence of changes in device technology on application design is the triumvirate of Amazon's Kindle Fire tablet, Amazon Cloud Services and the Amazon Silk browser (Amazon, 2011b) (Box 2.1).

\section{Box 2.1. Amazon's Kindle Fire browser: Using cloud computing to display web pages faster}

Traditional browser software employs HTTP communication to obtain resources (HTML code, images, CSS layout styles and JavaScript) to render a website as presented to users. New technologies for website layout mean that rendering has become a computing-intensive task. The increasing dissemination of HTML 5 and CSS 3 will place even higher demands on browser rendering engines, in particular, the use of substantial visual effects and animation on webpages, which are then rendered natively in the browsers. Amazon's Silk browser project for the Android operating system presents a solution for higher computing demands to mobile devices: the Silk browser need not perform all the rendering tasks locally on the mobile device, but can make use of the Amazon cloud to execute expensive computation tasks. In this case, the browser is used just for the presentation of the output results rendered in the cloud.

Another key trend is the increasing use of mobile devices connected to the Internet. Initially, mobile Internet connections were largely linked to mobile phones, and later, to dongles for personal computers. However, the rapid growth of tablet computers has changed the landscape.

Mobiles phones still constitute the most prevalent communication path, both in OECD countries and worldwide (Figure 2.3). As such, the mobile phone remains the communication path with the largest potential to extend Internet connectivity, as users upgrade previous "feature phones" to new smartphones with applications that rely on Internet connectivity.

The upgrade of mobile phones to smartphones has been brisk with analysts projecting that smartphones will cross the $50 \%$ penetration line in the United States for the first time in late 2012 (Kellogg, 2011; Waterfall Mobile, 2011). Figure 2.4 shows that the uptake of smartphone users started to be more significant by the end of 2009 with a smartphone 
Figure 2.3. Total fixed line, mobile and broadband access paths Subscriber access (millions)

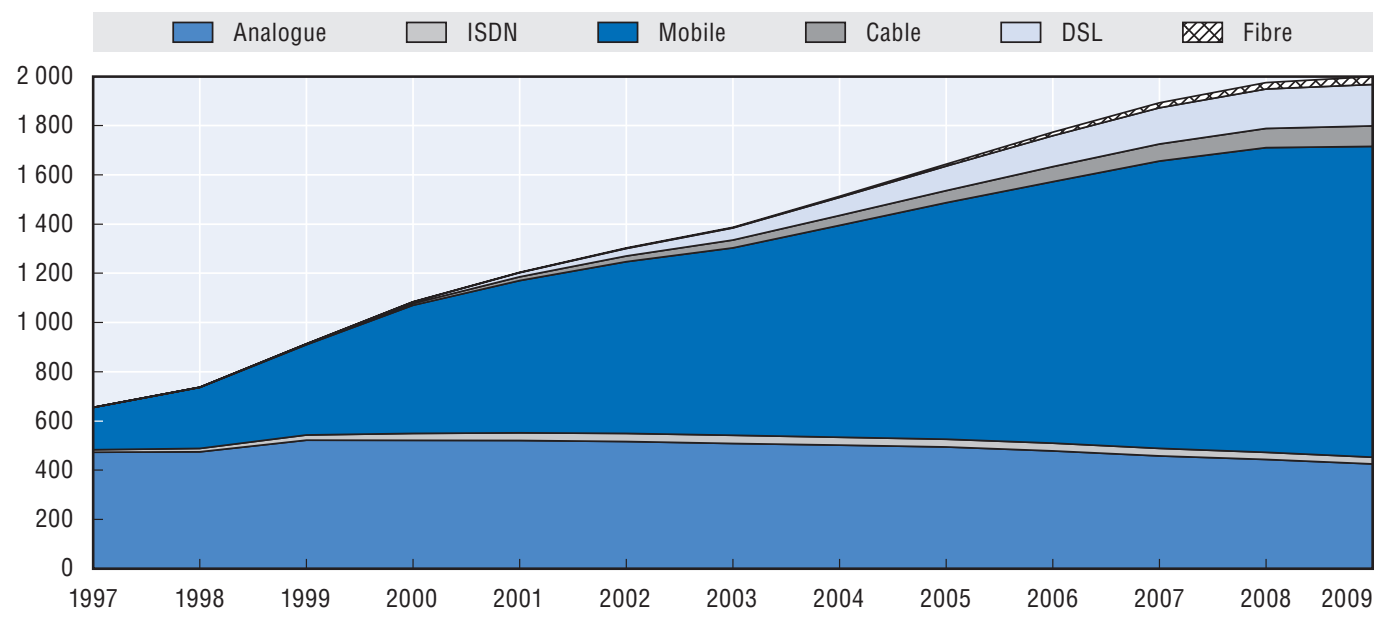

Source: OECD Communications Outlook 2011, OECD, Paris

Figure 2.4. US smartphone penetration, Q2 2007-Q4 2011

Percentage of total mobile phones

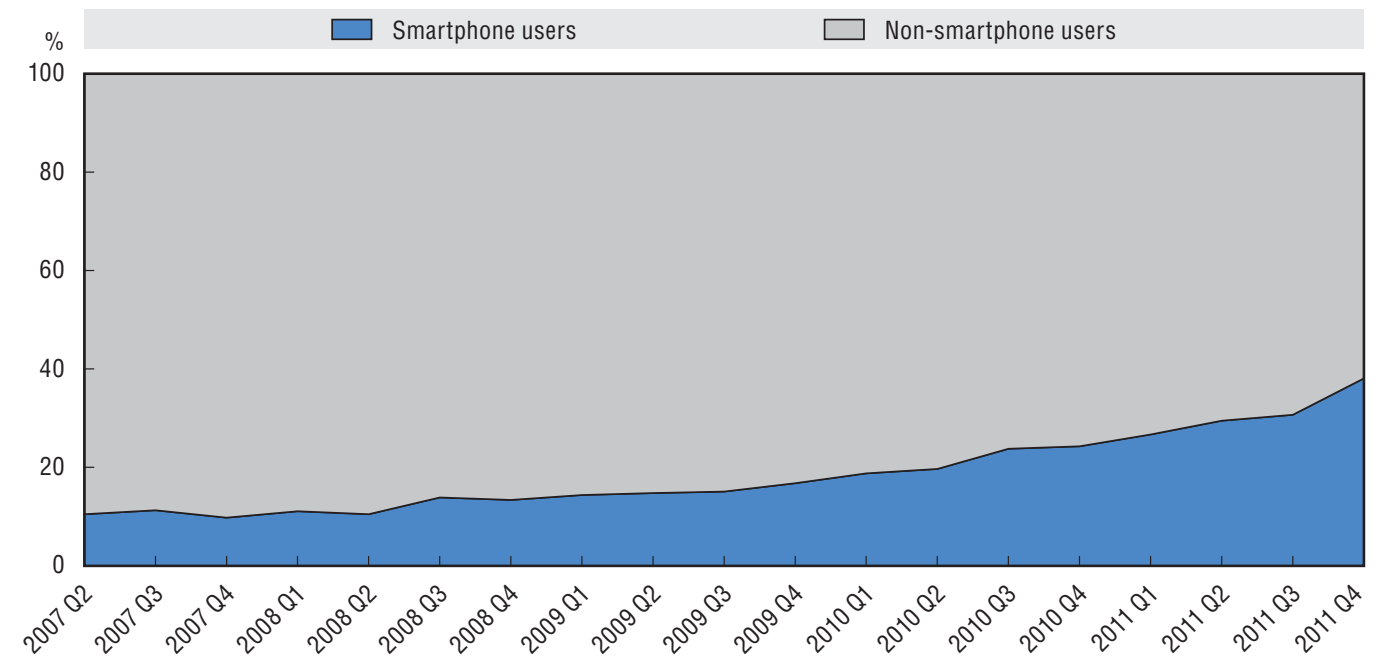

Source: Based on Dediu, H. (2012), “The US Smartphone Landscape”, Asymco, June 2012.

penetration of 17\%. By the end of 2011, this rate had doubled, reaching 38\% (Dediu, 2012). Smartphone penetration has also been faster in certain segments of the population. For example, smartphone penetration is as high as $62 \%$ among users in the United States between the ages of 25 to 34 (Waterfall Mobile, 2011).

The rapid adoption of smartphones throughout OECD countries will continue as their prices decline. Inexpensive Android-based smartphones from providers such as Huawei are available in some markets for as low as USD 75 (SIM unlocked and without a contract). Even popular smartphones such as Apple's iPhone 3GS are now available for free (with a handset subsidy) from various operators with a two-year contract. The same applies for a number of 2010 and 2011 Android-driven smartphones. 
While smartphones will remain the dominant access path for mobile connectivity for some time, the growth of tablets has been rapid and new devices are increasing market competition, which will likely usher in lower prices for consumers and increased penetration. Tablets do not seem to be displacing mobile phones, but rather laptop computers. For example, Gartner predicts that "by 2015, media tablet shipments will account for roughly 50\% of laptop shipments" (Cooney, 2011). Already in 2011, analysts noted a significant drop in PC (laptop + desktop) sales. Gartner has found a global PC shipment drop rate of 1.1\% in Q1 of 2011, compared to the same period in 2010, while IDC calculates a $3.2 \%$ decline. Laptops comprise a major share of the decrease in sales, while desktop PC shipments remains relatively stable. Both analysts identify tablets as the cause of weak sales figures: "With the launch of the iPad2 in February, more consumers switched to buying an alternative device, or simply held back from buying PCs" (Gartner, 2011a; IDC, 2011a).

Consumers are increasingly carrying one or more devices that offer Internet connectivity, and it is becoming more common for these to be used both in the home and work environments. In the past, people typically used different devices in different settings. But devices today tend to be more personalised and tied to important services that people use throughout the day. This is one reason behind the growth of the "bring your own device" (BYOD) culture in businesses and schools.

Companies are currently evaluating the benefits of BYOD environments (higher productivity, employer satisfaction, lower training costs) against the downsides, which include a more heterogeneous IT infrastructure posing new challenges for IT departments. The introduction of private laptops in the workplace also raises security concerns, but the use of virtual machines is helping to support the use of different devices in various settings. A virtual machine is a piece of software that emulates a physical computing environment. The benefit is that multiple virtual machines can run simultaneously on the same hardware.

One key technological enhancement for laptops in this regard is the integration of bare-metal (type 1) client hypervisors. These act as the "go-between" for virtual machines and the hardware platforms that support them. These hypervisors allow companies to deliver a workplace desktop as a virtual machine image that can be run directly on a user's personal laptop or tablet computer. Malware infecting operating systems used for private use, which are kept on the same device, cannot harm the centrally maintained company desktop. Software solutions already exist from Citrix (XenDesktop and XenClient).

\section{Platforms/operating systems}

There have also been significant shifts in operating systems for Internet-connected devices, in particular, in the mobile sector. The last two years have witnessed a significant transformation in mobile platforms. Android, an open-source software stack for mobile devices from Google, has emerged as the new dominant platform, quickly capturing $50 \%$ of the overall smartphone market share. Apple's iOS operating system has grown its market share, while other operating systems, such as Blackberry, Symbian and Windows Mobile have seen significant declines in market share since the last quarter of 2009 (Figure 2.5).

Desktop platforms are also evolving and there will likely be convergence between desktop and mobile platforms in the future. One example of this trend is Apple's release of Mac OS X 10.7 (Lion) for desktop computers. The changes since the previous release (Snow Leopard) imply that Apple may be moving towards a converged product with an operating system based around the ways users interact with hardware. Apple has now aligned gestures in both Mac OS X and iOS (see Box 2.2). It also introduced an App store for desktop computers following the successful App store for mobile devices that run iOS. 
Figure 2.5. Platform shares for installed base of US smartphones

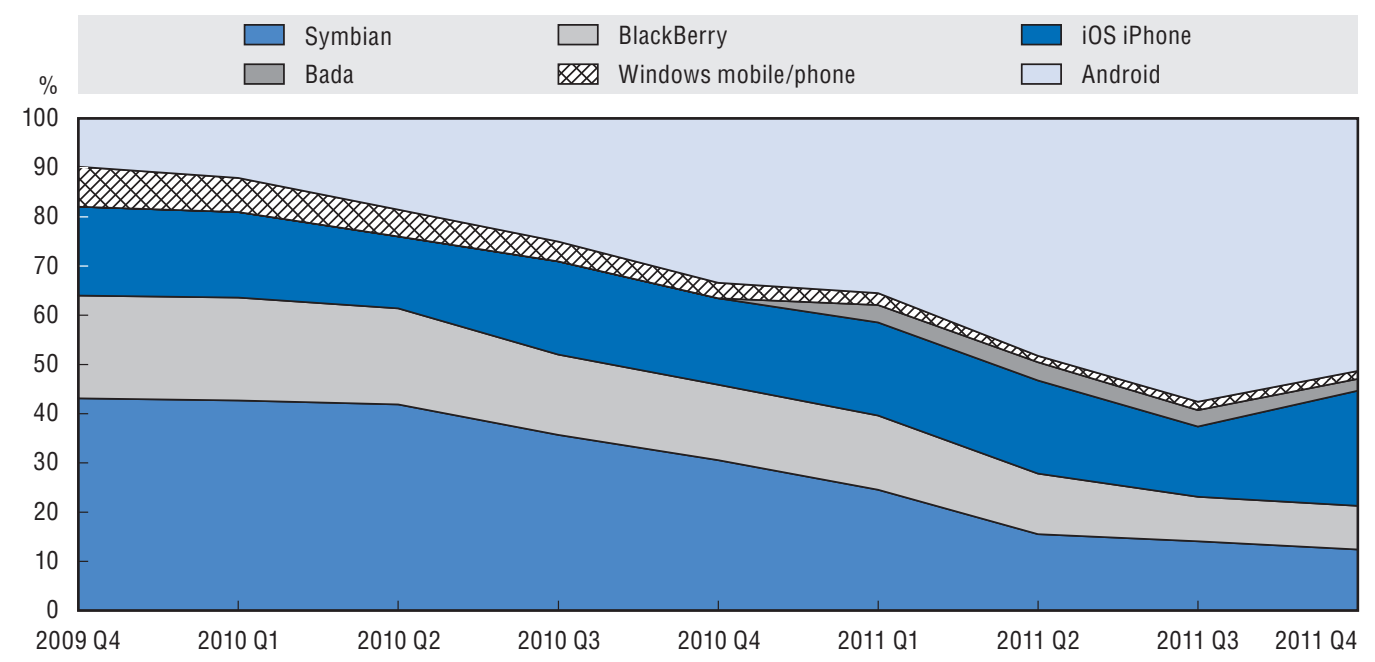

Source: Based on Dediu, H. (2012), “The US Smartphone Landscape”, Asymco, June 2012.

\section{Box 2.2. Mouse gestures: the effect of tablet use on personal computers}

Apple recently changed the touchpad mouse gestures of its Mac OS X operating system. Previously, pulling two fingers toward the user would scroll down a page. However, Apple's iOS platform for mobiles employed a different gesture: users would push up with two fingers to move down in a document.

The introduction of Mac OS X Lion finally aligned the gestures in the two operating systems by choosing the gesture familiar to iOS users. The change highlights the convergence between desktop and mobile devices, which is likely to continue over the next few years.

\section{Figure 2.6. Gesture for scrolling down on a page}

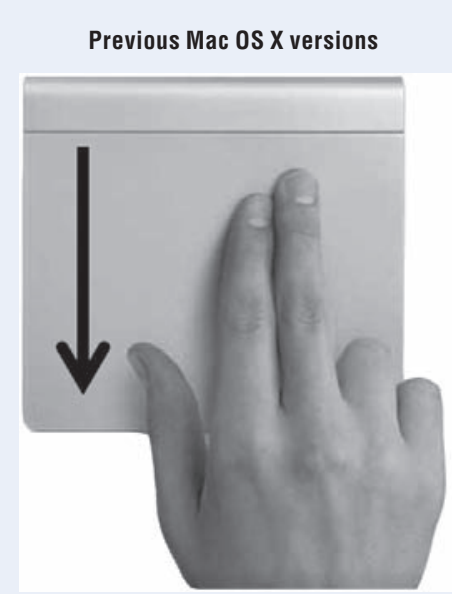

iOS: iPad, iPod, iPhone Mac OS X Lion

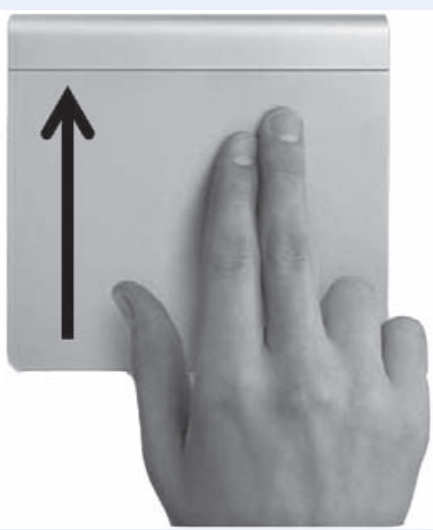

Source: Modified by OECD. Original graphic from Apple.com. 
Microsoft's roadmap for Windows also follows this trend. Windows 8, due for release in 2012, will include a default user interface that constitutes a progression of the current Windows Phone desktop. It is being designed not only for traditional desktops and notebook PCs, but also for tablets. Some analysts are predicting that Windows Phone apps will directly run on Windows 8 (Schonfeld, 2011).

Google is also focusing heavily on convergence, its CEO stating that: "convergence lies in the heart of Google's mobile OS road map" (Lomas, 2011). Chrome OS and Android will eventually merge into a single operating system.

One of the key supporting elements of this convergence is the emergence of application distribution platforms, or "app stores". The launch of Apple's iOS and Google's Android introduced large numbers of users to these markets. Popular app markets now include the App Store for iOS, the Android Market, Amazon's Appstore for Android, the Blackberry App World and Windows Phone Marketplace. Google's Android Market reached 10 billion downloads in December 2011 and adds approximately an additional billion downloads each month (TechCrunch, 2011).

App stores have proved very popular with mobile phone users and the experience is now moving to desktop computing. Apple's App Store for Mac (personal computers) reached 100 million downloads in less than a year of operation, making it the "largest and fastest growing PC software store in the world" according to Apple (Apple, 2011b). Google offers the Chrome Web Store with applications for Chrome OS and the Chrome Browser platform, while Microsoft announced the upcoming Windows 8 App Store (NIST, 2010). One way to gauge the growth of this phenomenon is to consider terminology: in a few years the phrase used to describe application software has changed from "program" or "application" to "app".

The new shape of distribution platforms changes the way in which software is bought and sold. Software delivered on a data carrier with license keys printed on paper is now an exception to the rule. App stores actually bring a number of benefits for consumer: app licenses are stored in the respective app store account and are easy to locate; and apps themselves can be installed, removed and reinstalled on demand and on any device. In many cases, app store customers are less concerned about malware or spyware, because the apps provided in the online stores are reviewed by the company operating the platform before being offered.

The app store paradigm also provides an important market opportunity for small software vendors without their own distribution channel. The image editing application Pixelmator originated in Lithuania and grossed USD 1 million on the App Store for Mac within just 20 days. A potential downside of software distribution via these digital platforms is the control that the operating companies retain over acceptance or rejection of apps submitted for distribution in their store. Some vendors report that their products are rejected for elusive reasons.

\section{Services}

The emergence of fast Internet networks, paired with new platforms and operating systems, has helped form a dynamic ecosystem for new and innovative services. In June 2012, the Android Market reached more than 450000 apps available for download, from which $27 \%$ were classified as low-quality apps (Figure 2.7 ). This has spurred the development of service applications. 
Figure 2.7. Android apps available on the Android Market, June 2012

Total number of apps

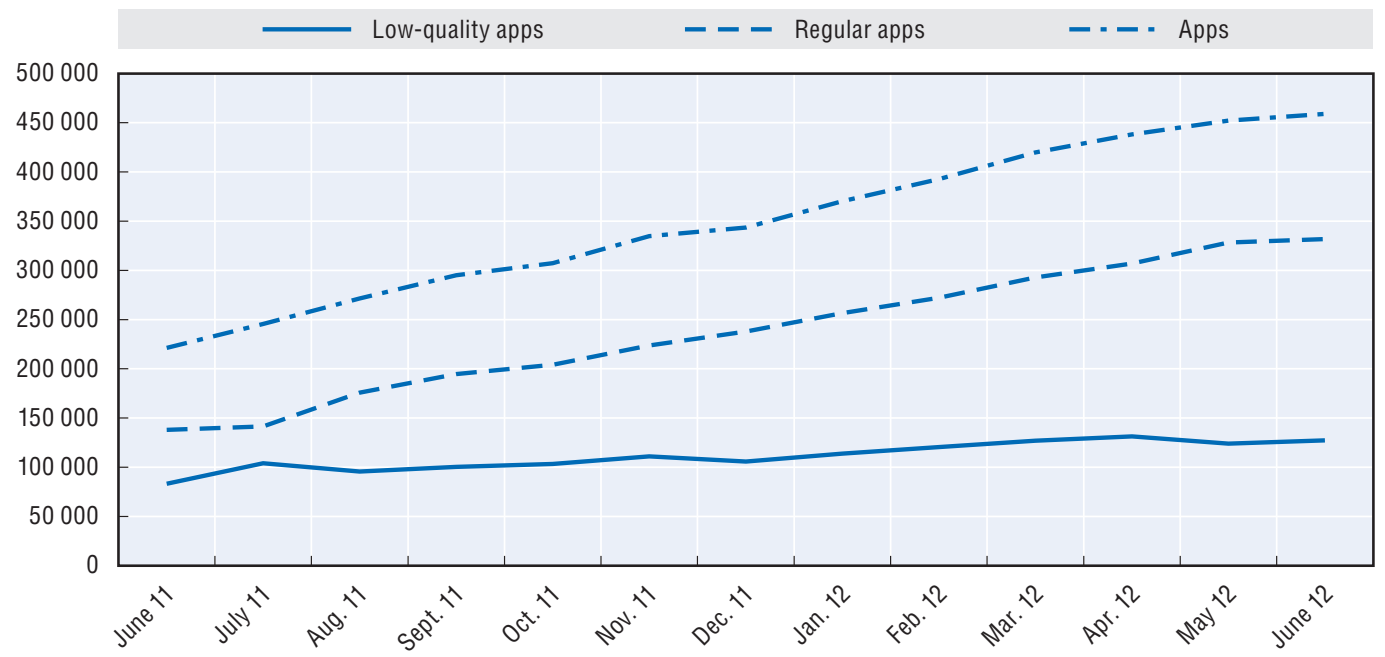

Note: Google occasionally removes apps from the Android Market, which causes the total number of available apps to sometimes decrease. AppBrain subdivides apps into regular and low-quality ones.

Source: Based on AppBrain (2012) "Number of available Android applications", March 2012.

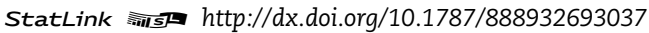

These new services are available in a large number of different areas. Moreover, new and specialised apps are constantly appearing. The Apple App Store lists 21 categories of apps on its iOS platform, while Google's Android Market has 25 categories with a separate breakdown within the games segment (Table 2.1).

Table 2.1. Application categories in Apple's App Store and Google's Android Market

\begin{tabular}{|c|c|c|}
\hline Apple App Store & Android Market Applications & Android Market Games \\
\hline Books & Books \& Reference & Arcade \& Action \\
\hline Business & Business & Brain \& Puzzle \\
\hline Education & Comics & Cards \& Casino \\
\hline Entertainment & Communication & Casual \\
\hline Finance & Education & Live Wallpaper \\
\hline Games & Entertainment & Racing \\
\hline Health \& Fitness & Finance & Sports Games \\
\hline Lifestyle & Health \& Fitness & Widgets \\
\hline Medical & Libraries \& Demo & \\
\hline Music & Lifestyle & \\
\hline Navigation & Live Wallpaper & \\
\hline News & Media \& Video & \\
\hline Newsstand & Medical & \\
\hline Photo \& Video & Music \& Audio & \\
\hline Productivity & News \& Magazines & \\
\hline Reference & Personalisation & \\
\hline Social Networking & Photography & \\
\hline Sports & Productivity & \\
\hline Travel & Shopping & \\
\hline Utilities & Social & \\
\hline \multirow[t]{5}{*}{ Weather } & Sports Games & \\
\hline & Tools & \\
\hline & Transportation & \\
\hline & Travel \& Local & \\
\hline & Weather & \\
\hline
\end{tabular}


The breadth of applications, as seen by the sheer number of categories in each of the app stores, highlights the difficulty in selecting specific service trends within the sector. This section focuses on three key types of services that are evolving, and which have the potential to significantly change user-device interaction and influence the economy at large. They include: new location-based services, augmented reality and relationship management tools.

\section{Location-based services}

Location-based services rely on technologies such as GPS, Wi-Fi databases or mobile cell tower details to determine the location of users and tailor services accordingly. The development of location-based services is strongly connected to the rapid growth of smartphones and tablets, as GPS chips and technology have become a common feature in mobile devices. The latest Pew Research Center survey (Zickuhr and Smith, 2011) shows that $23 \%$ of American adults (55\% of smartphone users) use mobile and social location-based services. Nearly all of them use services to obtain location-based directions and recommendations, while $12 \%$ of smartphone owners also use geosocial services (e.g. Foursquare, Facebook Places) and location-based tagging (e.g. for Twitter).

At present, mature location-based services such as traffic navigation (driving direction and public transport) or location-based recommendations (Yelp, Qype, etc.) are the most used. In some cases, location-based services have the potential to significantly alter existing markets, making them more efficient by combining location information with specific communication services (Box 2.3).

Location information is finding its way into many applications beyond transportation or navigation. One example is location-based reminders, such as those introduced by Apple with the release of iOS 5 (Weigert, 2011). iPhone owners can now define reminders that are triggered by leaving or reaching a specified location. For example, the application can initiate a reminder to stop and buy bread when the person leaves work. Several location-aware reminder apps are available on the Android Market, including RemindThat, Location Alert and ByTheWay GPS Reminders.

Location-based services will likely grow in importance and new applications will emerge to better tailor a wide range of services to individuals and businesses. Telecommunication operators are particularly interested in the potential of location-based services as a way to leverage their relationships with subscribers and develop new, higher-level revenue streams.

\section{Augmented reality (AR)}

Another emerging technology related to location-based services and enabled through the rising computational power of modern smartphones is mobile augmented reality (AR) applications. While the first mobile AR applications in the field of gaming and product marketing were primarily technology showcases, modern applications clearly show useful functionality, especially in the area of travel guidance and direction. Examples include mobile applications that allow users to find the nearest public transport stops (e.g. Next Subway or Fahrinfo-Berlin for the iPhone), or apps where users can store and memorise the position of their parked car.

Another very promising use case is the Layar AR browser. Like most mobile AR applications, the browser uses the mobile phone's sensor data (e.g. the camera, GPS and digital compass) to identify the user's location and field of view. By using the geographical position, various layers of data are inserted over the camera view. The data used to augment the browser view is third-party content, provided via a public Application 


\section{Box 2.3. Revolution of the taxi business}

Taxi passenger applications, such as MyTaxi (available for iOS and Android), are an example of successful businesses enabled by mobile Internet in combination with location-based services (Treiss, 2011). The mobile application allows passengers to locate their position (via GPS), select options for a taxi (e.g. credit card payment, taxi-van, minimum rating or specific driver/taxi company), and order the closest matching taxi. The user can track the taxi's progress and receive information on the driver, arrival time and remaining distance. Users can also rate taxis and drivers after a trip (or an unfulfilled request).

Figure 2.8. MyTaxi passenger app (left) and Driver App (right)
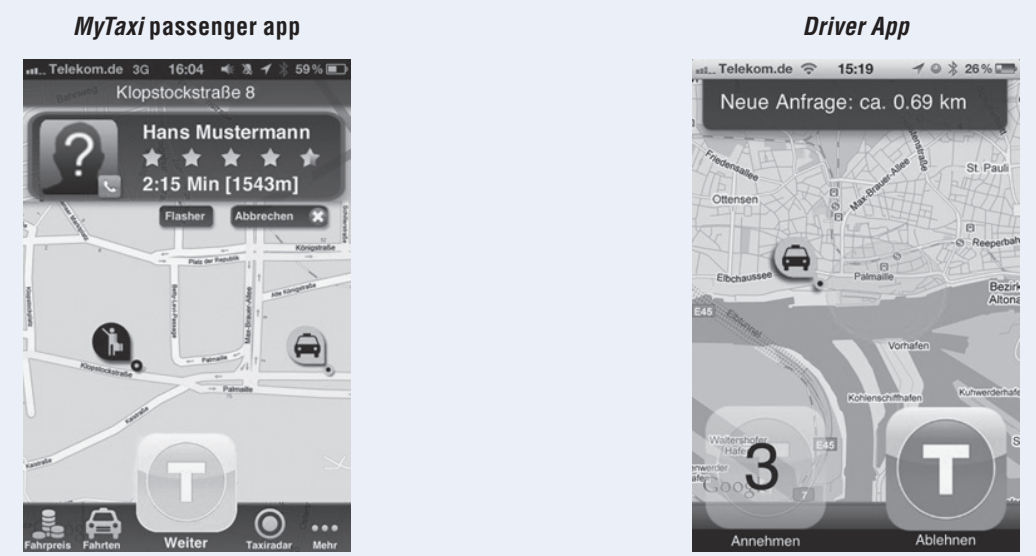

Source: http://myTaxi.net.

The taxi drivers use a smartphone to run the driver's variant of the application, which informs them of trip requests within their current radius of service. The driver has 3 seconds to read the request and an additional 3 seconds to accept the request. If confirmation is not given within this period, the request is passed to the next driver in range. Taxi drivers pay a fee of approximately EUR 0.80 to Intelligent Apps for each trip.

This method of booking taxis dispenses with the need for traditional taxi offices. Passengers and taxi drivers deal directly with one other via an intelligent platform. There are clear benefits for both parties: passengers can profit from and provide feedback on their trip, and drivers can significantly reduce the monthly fee payable to taxi offices for radio dispatch, in addition to the fee for each tour. These services are already forcing changes in the taxi dispatch market and have put pressure on drivers to offer a higher level of service (DiePresse, 2011; Weigert, 2011). Both reactions are strong indicators of the impact that ICTs are having in just one specific market.

MyTaxi shows how an emerging service enabled by mature technology with large-scale dissemination (mobile Internet on smartphones) can massively influence a very traditional business.

Programming Interface (API). As of September 2011, Layar had roughly 3000 layers, which shows a growth of $200 \%$ in one year. Layers can be created for many different purposes, including: tourist information at points of interest, augmented camera views of buildings with price estimations for apartments for rent or sale (Figure 2.9), or enhancing data artefacts with geotags from social media applications such as photos from Flickr or Panoramio, tweets and social recommendations. In 2010, the World Economic Forum named the Dutch company Layar a 2011 Technology Pioneer (Grose, 2011). 
Figure 2.9. Layar AR browser displaying estimated apartment prices

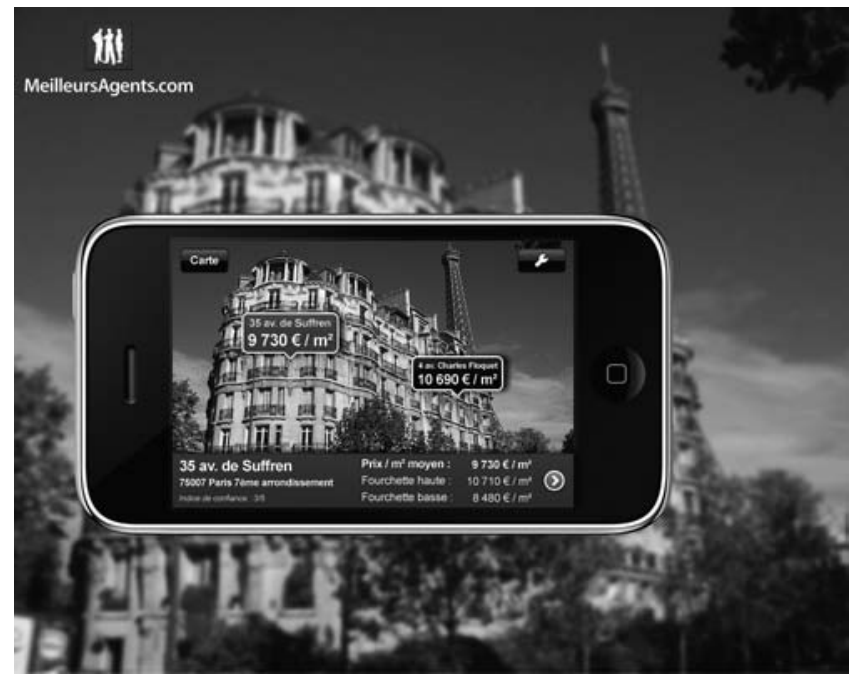

Source: www.meilleursagents.com.

The enhancement of mobile AR with social media data highlights an important trend for the future development of social networks. Augmented reality applications such as the TAT app Augmented ID combine facial recognition capabilities with links to relevant information from social networking and other data-sharing sites. Users are able to choose which of their social networking profiles are displayed when anyone else uses the software to identify them using their phone's camera (Figure 2.10). For example, a user may select different profiles to be shown during working hours and another on weekends. In academia, these new developments have been called "the context of reality" (Buckland and Langley, 2011).

\section{Figure 2.10. Future of social networking with augmented reality}

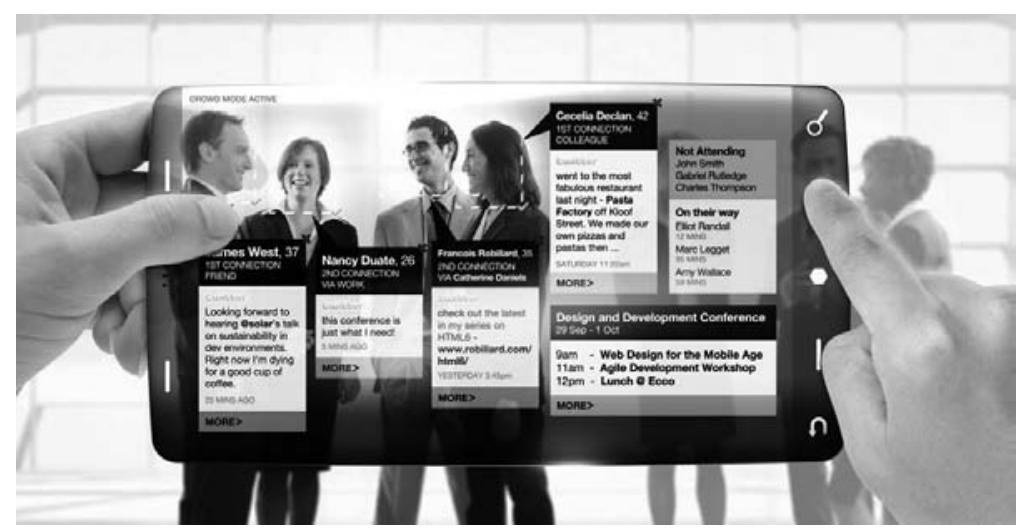

\section{Relationship management tools}

The growth of social media has been one of the most important Internet developments over the past two years. Online social networking and media services will continue to evolve over time, but one emerging trend is the advancement of social media monitoring as a way to develop better relationships with customers. 
Social customer relationship management (CRM) is the use of social media services, techniques and technology by organisations to actively engage with customers. The variety of CRM applications cover marketing, customer services and sales, including peer-to-peer customer service, market research and brand reputation management.

The growth of social CRM is recent and relatively few data points are available to analyse its growth to date. Analysts at Gartner predict that the market for social CRM will surpass USD 1 billion in revenue by the end of 2012 (Gartner, 2011b). What is clear is that traditional CRM products will increasingly merge with social media as a way to improve client relationships. Dedicated analysis for monitored social network activity (such as return-on-investment analysis) will also be a future focus of social CRM.

Another important change in the social networking sector is the launch of new social network platforms, such as Google+ in 2011. Until recently, social networks focused on the individual, however, one of the key new trends is the use of social networking by groups, companies and organisations. Major platforms such as Google+ and Facebook include features that allow users to target updates to specific groups as a way to tailor information delivery. In the early days of online social networks, status updates were only shared with predefined friends. Now, social networks are making it much easier to share information with the public.

Social networks such as Google+ can play a useful role in project workflows. Collaborative features that use Google+ APIs can enhance productivity tools, as demonstrated by the Diagram Editor for Google Plus Hangouts (Goderbauer, 2011). Hangouts are multi-user video chats in Google+ (Figure 2.11).

\section{Figure 2.11. Diagram editor for Google+ Hangouts}

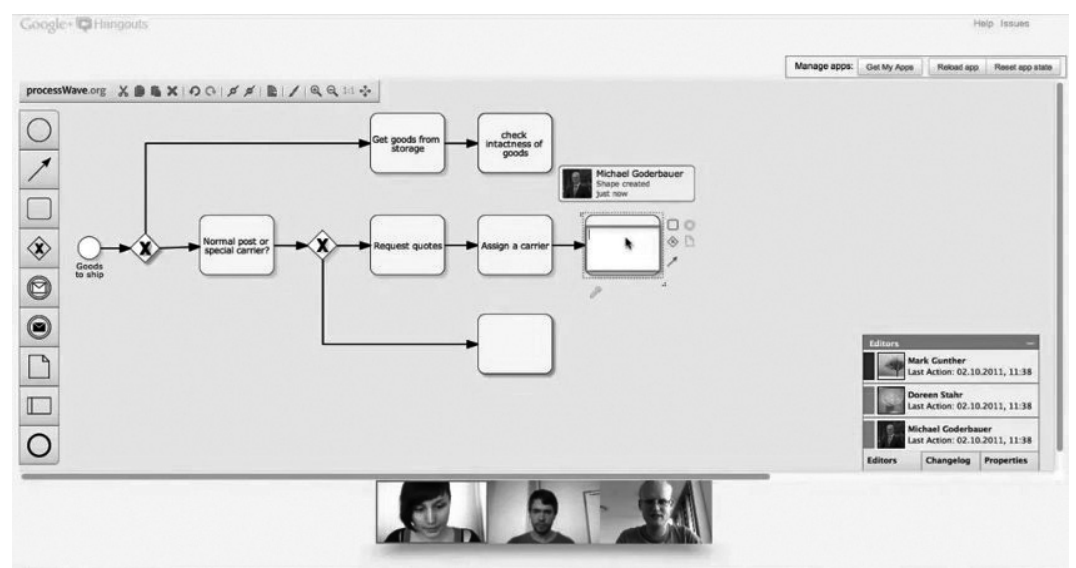

Source: Diagram Editor for Google+ Hangouts, http://code.google.com/p/diagram-editor-for-google-plus/.

The editor enables Google+ users to collaboratively create diagrams with their contacts while they videochat with them in a Google+ Hangout. Everyone can contribute to the diagram and all updates are displayed in real time. This is essentially a digital adaption of a classic collaborative working mode with local presence in a conference room where users edit the diagram on a whiteboard. The editor includes a number of diagram types. The editor tool example clearly shows that social networking can be used in application scenarios beyond marketing and customer relations, but also for company workflows. 
Customer relationship management has always been a key element of business operations and intelligence. A promising trend cited by many analysts for the near future is mobile business apps on tablets and smartphones for CRM or business resource planning.

Executives from SAP (Systems, Applications and Products in Data Processing) stated at the 2011 Sapphire exhibition that: "the enterprise terminal of the future is a tablet or smartphone". SAP co-CEO Bill McDermott even noted that he could "run the company from an iPad" (Dignan, 2011). SAP's Sybase Mobile Sales for SAP CRM product for the iPad and Blackberry was released in 2010. Competitors such as Oracle (Oracle Mobile Sales Assistant, iPhone only) or salesforce.com (Salesforce Mobile CRM, iOS and Blackberry) also offer mobile CRM solutions.

\section{Internet developments across the economy}

The following section looks at how networks, devices and services are being used in various sectors of the economy and society, including E-energy, the smart home, the future of work and learning environments, e-government, e-commerce and digital payment services.

\section{Cloud computing}

The last two years have seen cloud computing emerge as one of the most important platforms for innovative new services. It is changing the way computing is done. Users no longer have to make significant, up-front investments in IT infrastructure and software, but can now pay for computing resources via a pay-as-you go model. Cloud computing providers have much lower operating costs than companies that run their own IT infrastructure. This is because of the global scale of cloud computing providers and the possibility to aggregate the demands of multiple users, especially in public clouds. Providers are able to provision computing resources in a rapid and elastic way allowing adaptation to changing requirements (OECD, forthcoming).

Currently, multiple definitions of cloud computing exist. For the purpose of OECD's work on cloud computing, cloud computing is defined as "as a service model for computing services based on a set of computing resources that can be accessed in a flexible, elastic, on-demand way with low management effort" (OECD, forthcoming). Cloud computing covers a whole range of services that can be further structured into three service models, and four deployment models (private, community, public and hybrid cloud) (Mell and Grance, 2011).

The service model defines the different layers of the traditional IT resource stack: infrastructure, platform and software. Infrastructure as a Service (IaaS) replaces the purchase of hardware like servers or storage. Platform as a Service (PaaS) provides a standardised middleware stack. Software-as-a-Service (SaaS) offerings in the cloud replace the traditional purchase and installation of software packages with subscription access to a managed environment.

The deployment model defines with whom IT resources are shared. Levels of sharing start with a single user via a private cloud service, then proceed to a limited number of defined and trusted users, and finally move to up-to-unlimited and general use. A hybrid cloud is a composition of several clouds (e.g. public or community). The latter approach benefits from multiple deployment models.

Cloud computing has grown in importance over the last few years (Box 2.4) and is not confined to storage or web-based services; computing-intensive desktop applications are also moving to the cloud. The shape of personal computing devices is changing from desktop 
workstations with extensive computational power to thin, mobile devices such as netbooks, tablets and slates, and of course mobile phones (Baudisch, 2010). One of the most advanced implementations of this paradigm is Google's Chromebook (Google, 2011). These Chrome OS-driven netbooks only run applications on the web (Software as a Service), which therefore results in very limited capabilities when offline. Smartphones and slate devices such as the iPad will behave similarly, as the newly introduced iCloud services imply (Apple, 2011a).

\section{Box 2.4. DropBox: Relying on the cloud for a business model}

Dropbox is an example of a business model that relies on cloud computing to provide a data/storage intensive service without the need for its own data centre. Dropbox is a digital storage service provided by only 70 employees, but which serves an estimated 50 million users, with another user joining every second. The number of users has increased threefold from one year ago. The service has successfully employed a "freemium" business model (where basic services are provided for free and users can choose to pay for additional or expanded services) and is projected to reach USD 240 million in revenue in 2011, despite the fact that $96 \%$ of users have free accounts (Barret, 2011).

Dropbox was devised by an MIT student looking for a way to enable anywhere-access for files without a USB drive. Users have access to 2GB of free storage, while paying customers can obtain as much as 100 GB of space.

Dropbox has been able to accommodate its own rapid growth by relying on Amazon's Simple Storage Service (S3) in addition to the user's own computer. Amazon operates multiple data centres across the United States, and Dropbox's resources are spread out among them (NetHosting, 2011).

By relying on cloud computing infrastructure, Dropbox has created a backup, file-sharing and syncing service without needing to build its own data centre.

However, Dropbox also exemplifies the security challenges facing cloud computing. In June 2011, a problem in the service's authentication software made passwords optional for about four hours. This meant that anyone could access a user's account by simply entering the user name.

An additional driver of growth in cloud computing is the ever-increasing amount of data, which is predicted to outpace growth in storage capacity. Currently, it is very difficult to estimate future volume of data, but different estimates are being published. According to IDC Iview, the amount of digital information created and replicated is estimated to surpass 1.8 zettabytes $^{1}$ by the end of 2011 , and this amount is supposed to more than double over the next two years. In addition, IDC estimate that nine times more information is available today than five years ago (IDC, 2011b).

The number of containers representing information (files) is growing faster than the information itself. According to the same study, the number of files will grow by a factor of eight over the next five years. In the next decade, the number of files will grow by a factor of 75 , while the amount of information will grow by a factor of 50 . At the same time, the number of servers needed to manage all the information will grow by a factor of 10 worldwide. This behaviour will result in a need for effective management of IT resources, and flexible and scalable IT infrastructure. Cloud technology may provide an opportunity for new tools for search and discovery, information classification and management, information security and even information disposal. 
From an economic perspective, cloud computing significantly lowers the entry barriers for new firms entering the market in various sectors. It has the potential to become a veritable platform for innovation spurring the development of new products and services. In the context of innovation, cloud computing also facilitates online collaboration on a global basis. In addition, it is particularly interesting for SMEs, which are an important source of growth and innovation in many OECD member countries. Cloud computing enables them to save on investment costs, while benefiting from access to cutting-edge technology and services, including software updates. Large companies, institutions and governments are examining cloud computing as an important cost-saving option that reduces expenditure on IT infrastructure and services and ongoing maintenance costs (OECD, forthcoming).

There are a number of challenges and open issues concerning cloud computing that need to be addressed, however. Among these is privacy, including cross-border issues related to privacy protection (see below). Security is another key concern. It is essential that firms undertake a thorough and holistic risk management exercise, since cloud computing is the acme of networked computing. This is feasible for multinationals, but not necessarily for SMEs or consumers. Furthermore, the current terms and conditions of standard cloud computing contracts raise liability issues. An additional major open issue is the current lack of standards, especially in the area of platform as a service. Finally, cloud computing may also have structural implications for the IT sector, and it is likely that business models will have to change or risk becoming obsolete.

\section{The role of governments and government policy}

In addition to businesses, governments also see cloud computing as an opportunity to save costs. The twin pressures of reduced budgets and the need for greater efficiency have led the US federal government to strongly promote cloud computing as a solution whenever possible. The US Office of Management and Budget in December 2010 declared that the government now operates under a cloud-first policy, meaning that agencies must first try to incorporate some type of cloud computing into projects. If they choose not to use a cloud scenario, they must justify their decision. Various vendors provide private clouds to the US government, including IBM, Hewlett-Packard, Lockheed Martin and Oracle. Examples of cloud computing use by government-related agencies include the following:

- NATO's Allied Command Transformation, in concert with IBM, is developing a private, on-premise cloud for testing and developing network solutions for command, control, intelligence, surveillance and reconnaissance projects.

- Last year, the US Customs and Border Patrol agency started moving its collaboration software and e-mail services to a private cloud inside of one of the Homeland Security Department's data centres.

- The US Los Alamos National Laboratory has implemented a private cloud with HP technology that allows researchers to use servers on demand.

- The US Department of Energy (DOE) is exploring the cloud concept with its federal partners to identify opportunities to provide better service at lower cost through cloud services.

Other examples of cloud computing deployment by governments and non-profit organisations in Europe include OPTIMIS, launched by the European Commission, EuroCloud and the trusted cloud initiative in Germany.

In 2010, the European Commission launched the OPTIMIS project to enable an open and dependable Cloud Service Ecosystem that delivers IT services that are adaptable, reliable, auditable and sustainable (ecological and economical) (OPTIMIS, 2011). The 
funding of the initiative amounted to EUR 10.4 million (USD 13.83 million). The key goal is to allow organisations to automatically and seamlessly externalise services and applications to trustworthy and auditable cloud providers.

EuroCloud is another European initiative. This independent non-profit organisation comprises a two-tier setup whereby European countries may participate as long as they respect the EuroCloud statutes. In less than two years, 27 countries have acquired a EuroCloud presence and 17 European countries have a formally established local EuroCloud (EuroCloud, 2012). The initiative aims to create transparency for the various cloud service offerings and support for providers and users with regard to the numerous questions relating to security, law and compliance.

\section{Box 2.5. Germany's TrustedCloud programme}

One example of the future relevance of cloud computing to individual governments is Germany's "TrustedCloud" programme. The German Federal Ministry of Economics and Technology (BMWi) uses the programme to promote 14 technology projects, each addressing IT security and data protection issues at different levels of the IT resource stack. Over the next 3.5 years around EUR 100 million (USD 133 million) will be available to support the development and testing of innovative, secure and legal cloud solutions. BMWi will contribute approximately EUR 50 million (USD 66.5 million) and project partners will contributed the remainder. One of the projects is the "Sealed Cloud", which aims to provide a "sealed" or extremely secure infrastructure for cloud solutions to eliminate the risk of unauthorised access to hosted resources. The system design prevents even the cloud provider from accessing customer data.

Source: www.bmwi.de/BMWi/Navigation/Service/Projekte-und-Wettbewerbe/Archiv/trusted-cloud.html.

Given the positive impacts of cloud computing, but also the inherent challenges, policy makers have an important role to play in a multitude of areas (OECD 2012):

- Spurring the use of cloud computing. Governments have a key role to play in this regard, by acting as lead users, fostering skills and education, supporting R\&D projects, and establishing public-private partnerships.

- Standardisation. A major challenge is the lack of standards and the fear of vendor lock-in. Governments could encourage the development of cloud computing interoperation standards as well as open source clouds.

- Measurement of cloud computing. At present, there is a lack of data on the field of cloud computing. Policy makers could help develop a framework for the measurement of cloud computing.

- Cloud computing for development. Cloud computing constitutes an important tool for organisations and consumers in developing countries. However, certain challenges must be addressed, such as the availability of network infrastructure. Policy makers have a role to play in spurring the development of cloud computing and the adaptation of cloud services in developing countries.

- Broadband infrastructure. With the growth of cloud computing, demand for bandwidth is expected to increase significantly. Policy makers should promote flexible network technologies and topologies, and spur competition to develop future solutions that promote increased bandwidth. 
- Trade and competition implications. It is probably too early to evaluate the trade and competition implications of cloud computing. However, policy makers should keep potential trade and competition issues in the area of cloud computing in mind, such as the possible implications of a future cloud computing market dominated by few companies.

- Tax implications. Policy makers have a direct role to play in dealing with the tax implications of cloud computing, mainly seen as related to record-keeping requirements and possible tax evasion.

- Contractual issues. Certain challenges remain regarding standard cloud computing contracts. For example, policy makers could urge cloud-computing providers to do more in the area of privacy and security. In addition, service-level agreements should address service outages and propose concrete remedies.

- Security and risk management. The starting point for cloud-computing security assessments is that cloud computing is not a completely new technology. Consequently, a new security approach is not necessarily required. The OECD Guidelines for the Security of Information Systems and Networks towards a Culture of Security (2002) provide a valuable approach to dealing with cloud computing security challenges. They highlight four fundamental principles: i) risk assessment; ii) risk management; iii) security design and implementation; and iv) risk reassessment.

- Privacy. A global approach to privacy that is harmonised among governments would facilitate the deployment of cloud computing. In particular, policy makers should address questions of which legal authorities have access to data in the cloud, whose laws apply to the data stored in the cloud, and under which circumstances data processing in the cloud amounts to a cross-border transfer, implicating data protection laws in some countries. In addition, individuals that conduct substantial online activities through cloud-based services will face identity management challenges.

\section{Smart energy}

Global energy challenges are immense. Over the past three decades, global energy production and consumption have accelerated to unprecedented levels. Between 1973 and 2008, total energy production has basically doubled (OECD calculations based on IEA World Energy Statistics and OECD, 2012a). This is problematic because close to $70 \%$ of global energy demand is satisfied using energy generated from sources that emit relatively large amounts of greenhouse gases (e.g. carbon dioxide). The energy supply sector, which is responsible for one quarter of global greenhouse gas (GHG) emissions, has therefore become a major target of climate change mitigation action (IPCC, 2007).

Electricity is a pivotal element in understanding global energy challenges. Electricity by itself and its consumption does not emit greenhouse gas emissions. It is an energy carrier, an intermediary between the supply of primary energy sources (e.g. coal) and the demand for energy-using services (e.g. transport, heating and lighting). In fact, electricity is one of the main energy carriers used around the world for residential, commercial and industrial processes.

The smart grid has great potential to drive innovation in the ways electricity is produced, managed and consumed, as it relies on communication channels largely provided over Internet data networks (OECD, 2012a). The application of ICTs and opportunities provided by the Internet can help sustain electricity supply while limiting environmental impacts. ICTs are seen as promoting a wider integration of renewable energy sources, promoting low-carbon transport options including electric vehicles, and inducting structural shifts in electricity 
consumption.

Political interest and media coverage regarding the smart grid is increasing, comparable to cloud computing. However, both topics are difficult to define and the potential impact on future markets and society is not yet fully recognised.

Smart grids are typically described as electricity systems complemented by communications networks, monitoring and control systems, "smart" devices and end-user interfaces (OECD, 2009, 2010, 2012a). The International Energy Agency (IEA) proposes a definition that blends both functions and components:

A smart grid is an electricity network that uses digital and other advanced technologies to monitor and manage the transport of electricity from all generation sources to meet the varying electricity demands of end-users. Smart grids co-ordinate the needs and capabilities of all generators, grid operators, end-users and electricity market stakeholders to operate all parts of the system as efficiently as possible, minimising costs and environmental impacts while maximising system reliability, resilience and stability (IEA, 2011).

The United States' National Institute of Standards and Technology (NIST) defines the smart grid as a modernised, better protected, optimised and self-healing infrastructure with bidirectional communication between all components involved in the system. In the smart grid, existing electrical networks and communications technologies are linked to a distributed infrastructure to form a new intelligent system, in which a large number of producers, consumers and storage facilities act on the extremely complex energy market. NIST also call the smart grid "the world's largest and most complex machine" (NIST, 2010).

The smart grid is expected to significantly lower electricity-related greenhouse gas emissions in the future. Direct reductions are typically attributed to more efficient processes in electricity generation, transmission and distribution, as well as to energy conservation at customer sites. Indirect reductions are expected in the sense that the smart grid will facilitate wider diffusion of renewable energy sources as well as their integration with the wider uptake of electric vehicles.

However, national roadmaps that concern the smart grid make clear that this technology will not be fully developed by the end of the decade. It will take time to address the many challenges (and opportunities) related to international standardisation, regulation and implementation, to enable the world's largest machine to work. Experts expect the first national smart grids to be established in the 2020s (e.g. in Germany (Niemand, 2011)). While the IEA general roadmap for interconnected smart grids on the global energy market is projected through to 2050 (IEA, 2011).

Furthermore, many of the discussions surrounding smart grid deployment in 2011 concerned Advanced Metering Infrastructures (AMI). These projects mainly cover the installation of smart metering devices in test region households, and gather metre data using the prototypical metre data management systems of energy providers, who run the test deployments. Efforts in smart metre deployment can be observed in many OECD countries. Sweden is one of the leading countries in the OECD, achieving a $100 \%$ smart metre rollout in July 2010.

Yet smart metre deployment is just one component of a smart grid. Smart metre deployment provides the information leverage needed to support advanced smart grid applications. One of the first applications to reach mature development will be energy information display (EID) technology for home energy management. EIDs are designed to raise awareness of energy use among customers. Companies such as General Electric 
provide comprehensive software, while the Google PowerMeter and Microsoft Hohm have been discontinued due to slow market adoption. Nevertheless, the Google and Microsoft experiences highlight the importance of visualising energy information for customers. Studies show that informed customers were able to reduce energy use by up to $15 \%$ (Darby, 2006). Sophisticated solutions for home energy management visualisation will be an important part of the future smart home.

Other trends for smart grid applications focus on energy providers and cover distribution automation, data analytics, demand response and carbon management (Wheelock et al., 2011). Distribution automation concerns technologies that sense, monitor, report, control and automate the operation of the energy distribution network, and thereby integrate advanced metering infrastructure into the electricity grid. The driving forces for such projects include expected reliability improvements due to the ability to remotely control field devices, and the possibility to optimise electricity distribution.

Smart grids will also create substantial real-time data that will need analysing to allow informed decisions on realising potential efficiency gains. Technologies such as in-memory technology and massive parallel computation will likely provide support for smart grids in this regard.

Large data collections directly from the smart grid will form a key part of business data intelligence for energy firms. Currently, each subsystem of the utility system, such as metre data management (MDM) systems and distribution management systems (DMS), has its own analytics technologies. This will likely change over time as IT firms with analytics expertise enter the market and provide comprehensive analytics tools for the whole set of smart grid data. Analysed data can help operators gain insight into infrastructure operation, as well as forecast load, improve reliability, and determine business risks for energy providers and make available advanced energy advice for consumers.

In terms of a timetable, currently available smart grid applications such as ICT solutions can help provide information on household electricity use and the digital energy marketplace. Other fields of research and development that rely on electrical and mechanical engineering to support efficient smart grids are still in the early stages, and are not expected to reach maturity in the near future.

Furthermore, the growing cost of fuel and the negative effects on the environment caused by conventional energy production are convincing more people to produce electricity at home. The desire to save money and provide environmentally sustainable energy is resulting in increasing number of private households becoming producers of renewable energy.

A significant technical and financial outlay is required to store and/or transport such generated energy over greater distances. From an economic perspective it is more beneficial to utilise this energy both locally and promptly. However, this requires a system that can cope with excess production at short notice. While no widespread solution to this problem is currently available, this is an area of significant research and could see developments in the next few years.

In Germany, for example, an ongoing technology project called the "Peer Energy Cloud" aims to provide a virtual market place for local power trading. The project also aims to develop new recordings and forecast methods within a so-called "micro grid". The integration of local sensors and actuators at end-user locations, via fiber-optic cable, would enable new services to access usage data in real-time, which can then be used, for example, to generate forecasts. 
The use of household-related context information can result in additional added value. Examples include adjusting refuse collection dates and frequency in line with actual requirements, or providing dynamic price models that support energy utilisation geared towards the actual situation. A specific case is currently under review relating to a micro grid in the city of Saarlouis. The grid consists of approximately 500 housing units and numerous photovoltaic facilities. The German Federal Ministry of Economics and Technology (BMWi) is promoting the initiative in the context of the Trustedcloud programme (Der neue Personalausweis, 2010).

\section{Smart home}

The smart homes of the (near) future will integrate a large variety of home automation technology. Since electric device control uses the same communication bus systems or wireless technologies as smart metres both the smart grid and advanced metering technologies will play a role. In addition, home displays for energy monitoring will likely converge with multi-purpose home control devices and become apps for mobile devices (CEDIA, 2011). General Electric is one of the leading providers in home energy management systems and already offers a smartphone app for energy monitoring and thermostat controls based on their Nucleus system.

In addition to monitoring electricity consumption, another important element of smart homes will be home entertainment. Television and video delivery are largely moving onto the Internet and this creates significant opportunities for converged displays for the entire home via a mobile phone, laptop, tablet or television. This convergence is already taking place. The French market leads the OECD area with nearly 12 million IPTV subscribers who receive traditional television signals over a broadband line, allowing for a much richer and interactive viewing experience (Figure 2.12). France's strong performance relative to other European countries is largely down to the energy of new entrant

Figure 2.12. Leading IPTV countries, Q4 2010-Q4 2011 Million subscribers

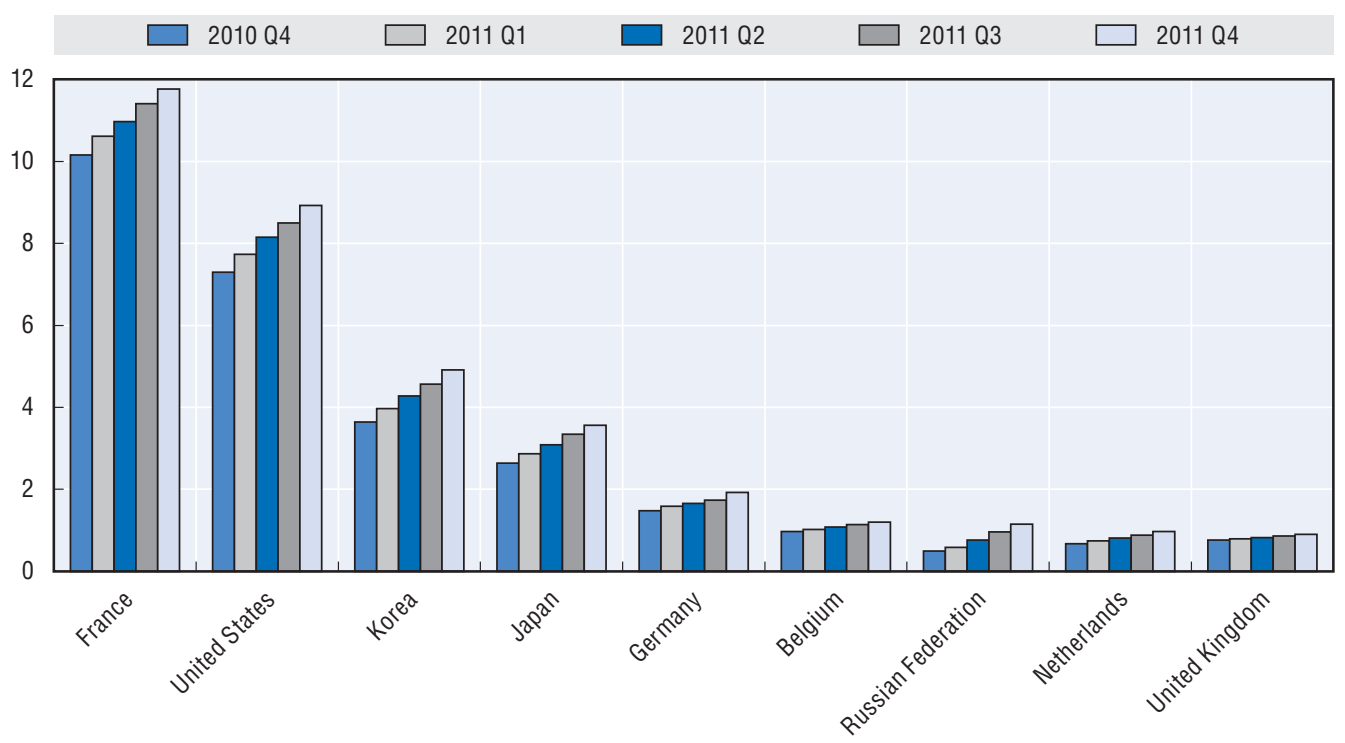

Source: Based on Point Topic Ltd. (2012), IPTV: Short Report - Q4 2011. April 2012, Point Topic, London. 
broadband operators that included IPTV in all inexpensive broadband bundles. However, China managed to overtake France for the first time in Q1 2011 and continued to grow ever since, reaching 13 million subscribers by the end of 2011 (Point Topic, 2012).

While the current economic crisis may dampen adoption rates of some new technologies, the shift from classic radio and TV devices to network-bound variants will likely continue for the next few years, led by IPTV dissemination. A new generation of devices will be integrated into home automation networks via the Internet-connected household. This applies to stationary devices as well as mobile ones.

Mobile devices and cloud computing will be two of the pillars supporting home automation. Industry experts predict a number of important future trends for the next few years, including the development of "integrated audio" or the ability to control the audio of individual rooms through a mobile device, often accessing content via the cloud (CEDIA, 2011). Consumers will be able to use wireless control via a mobile or tablet to manipulate home devices, such as the audio produced by installed speakers and amplifiers. Options in this category will grow significantly in the years ahead, while installation costs are expected to simultaneously decrease thanks to improvements in wireless technologies and cloud-based content. These developments in audio flexibility will also apply to video.

The year 2011 witnessed the introduction of a number of commercial audio services that use the cloud. Apple introduced a cloud-based service for music delivery that integrated iTunes and the iCloud through iTunes Match (Apple, 2011c). The application matches a local music library with Apple's iTunes Store and allows streaming playback of all matching titles from the cloud services to any device connected to the same iTunes user account. Amazon (with the Cloud Drive), mSpot and Google Music also offer cloud-based services for music streaming. All these services follow a similar approach: users upload their media files to a cloud storage service and then use a proprietary player application on their computers or mobile devices. In most cases, these services also allow users to stream video files in the same fashion.

These cloud-based services in combination with integrated audio hardware enable access to a centralised music library throughout the home (or anywhere with an Internet connection). Some existing products allow users with a portable device to play music played through other compatible devices in the home such as televisions and computers and stereo equipment. Examples include Sonos (Sonos, 2011) and Apple's AirPlay (in cooperation with major consumer audio companies like Denon, Marantz and JBL). These products use wireless networks to stream music to receivers (integrated speaker docks with streaming clients or stand-alone clients connected to existing hi-fi equipment). Consumers can configure and control the whole interconnected audio system from a central location. Users can playback different songs in different rooms, change the volume for each streaming client or synchronise music playback in every room by means of their personal mobile device. Manufacturers are also introducing their own apps for home audio control, for example, iTunes for Airplay-based installations and a legacy app for Sonos hardware. These integrate access to local music libraries, such as iTunes, and a number of streaming services (e.g. some Internet radio stations, social music services such as last.fm, and commercial streaming services such as Pandora, Spotify and Napster/Rhapsody).

Ten years ago, predictions for the entertainment system of the future envisioned a central home server that would host all content and share it among devices throughout the home. Some devices using this model have emerged, but the growth of cloud computing infrastructure has called into question the future dominance of the home-based server 
model. As broadband connections become more widespread, it is likely that digital content will shift largely to the cloud to be accessed via a streaming model. Legacy systems for home control may also be superseded by apps for mobile devices. Home owners will not only control their entertainment system, but also any other aspect of home automation, such as thermostats, security systems or energy management, from their smartphones or tablets.

An additional driving force for $R \& D$ in home automation is healthcare applications and services for older people and those with disabilities (see Chapter 6). Home automation is becoming a viable option for those who would prefer to stay in the comfort of their homes rather than move to a healthcare facility. This field uses much of the same technology and equipment as home automation for security, entertainment and energy conservation, but tailors it for this new market. Home automation for healthcare systems includes lighting and motion sensors, environmental controls, video cameras, automated timers, emergency assistance systems and alerts.

The next generation of technology in the home will be built to support health and wellness, not just assist in times of crisis. These systems can track long-term issues such as glucose levels and weight, monitor stress levels, and help individuals to identify which habits or daily practices to change to help lead a healthier lifestyle. Tools of this nature that are currently or will soon be available include automated pill dispensers that provide scheduled alerts for medication, wireless motion sensors that detect when one is up and moving, or networked diagnostic devices, such as heart rate and blood pressure sensors.

Novel human-computer interfaces such as touch-sensitive floors enable new approaches for healthcare applications in the smart home. These interfaces have capacitive proximity sensors and can detect shapes on or above the ground. For example, a ground sensor can detect if a person is standing or lying on the floor, and track movement (Figure 2.13). Other applications include fall detection alerts, activating orientation lights, and dispatching care workers if an unattended, unstable patient leaves the bed (Future Shape, 2005).

\section{Figure 2.13. The Multitoe project: touch-sensitive floors}

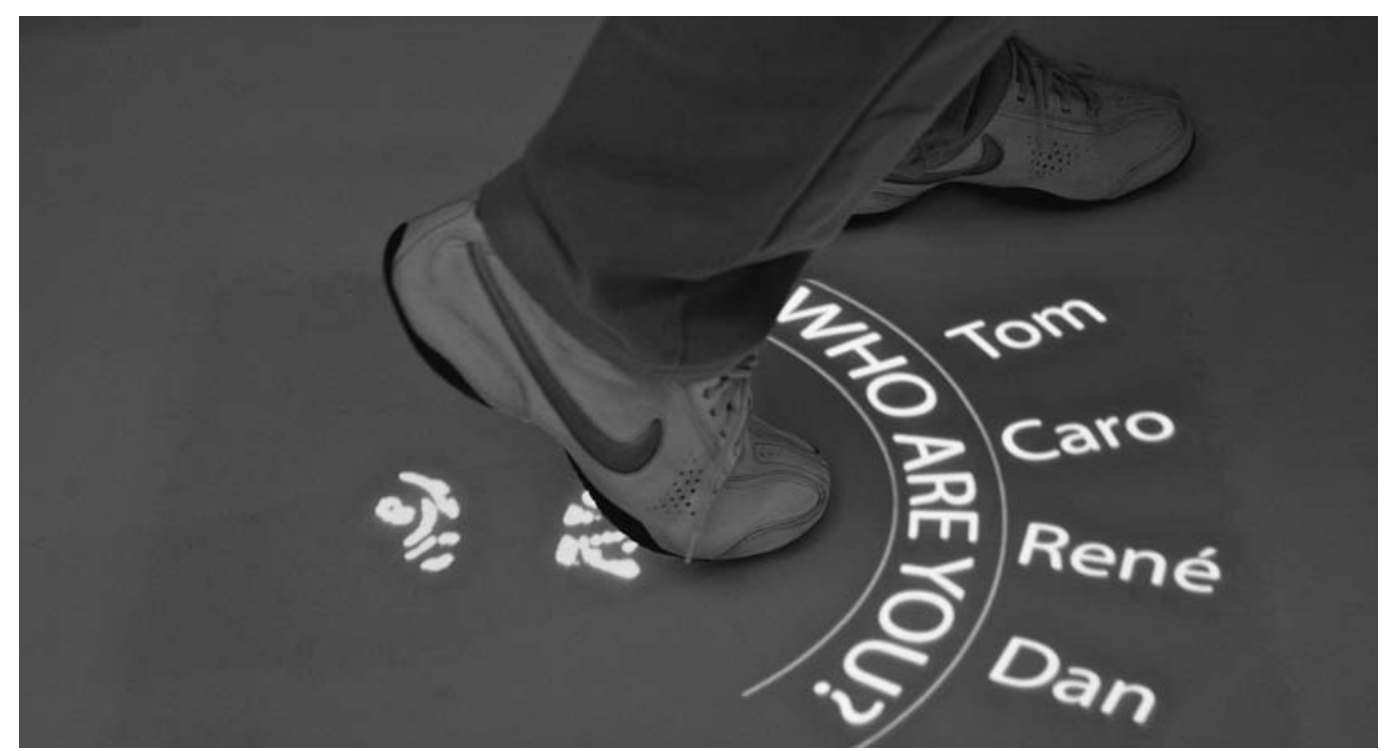

Source: T. Augsten et al., Multitoe: high-precision interaction with back-projected floors based on high-resolution multi-touch input, Proceedings of the 23nd annual ACM symposium on User interface software and technology, ACM Press, New York, 2010. 
Touch-sensitive floors can also acts as sensors for a wide range of commercial applications, such as security (counting passers-by, access control, door control), and the design of interactive rooms. Research projects demonstrate the ability of high-resolution sensor technology to even detect and distinguish different users once a shoe or foot profile has been assigned to an identity (Augsten, 2010). Home automation can use this technique for a wide range of personalised ambient applications.

\section{E-Work and e-Learning}

Advances in technology are influencing the way we work, communicate and learn. The main drivers are digital mobility (i.e. sophisticated mobile personal devices, high-bandwidth connections everywhere and social networks) and limitations to traditional mobility (travelling or being on-site).

Companies have focused on travel as an area to potentially reduce costs. In particular, the eruption of Iceland's Eyjafjallajokull volcano in 2010 caused the cancellation of thousands of business meetings due to cancelled flights and highlighted the need for e-work solutions. E-work has the potential to reduce travel expenses, and time costs caused by employees in transit and administrative overheads. Reducing unnecessary travel is also a way for companies to promote green thinking and limit their carbon footprint. There have been sustained calls for new ways of collaborating over long distances and for improvements in the work-life balance of employees, especially valuable, highly qualified personnel.

New forms of working practice include flexible work (working from home or from the nearest local office, client site or co-working facility) and home-based telework, as well as modern tools for computer supported collaborative work (CSCW).

One of the most important aspects of CSCW remains video conferencing. Existing solutions that demonstrate business value have a consistent balance of quality, repeatability and ease-of-use. Although each of these attributes is difficult to perfect, improving video quality has been the primary focus of videoconferencing vendors. Telepresence (Polycom/Cisco) has been the upper-end of high-quality video conferencing and does not mark the end of improvements in video resolution. What high-end systems such as Telepresence show is that video quality is now sufficient for most use cases because they provide an experience that can effectively mimic a live interaction. Vendors have now shifted to multiple (and larger) displays and better bandwidth efficiency. Current developments aim to reduce bandwidth for high-definition conferencing with new codecs (i.e. H.264 based), to allow HD video below a data rate of $1.5 \mathrm{Mbit} / \mathrm{s}$, approximately the maximum upload speed of current ADSL broadband offers.

Other traditional means of collaborative software in remote environments include classic asynchronous communication tools (email, bulletin boards, groupware or version control). One interesting toolkit for the support of creative teams is the Tele-Board research project of the German Hasso-Plattner-Institute. Tele-Board software allows remote teams to use the novel creative working mode of "Design Thinking", a process and set of methods for problem-solving and methodic innovation. ${ }^{2}$

The Tele-Board platform allows users to collaborate in globally dispersed teams by means of digital whiteboards. The software suite permits synchronous work with sticky notes and writing and painting on the board surface, while an integrated video conferencing client transmits the audio and gestures of the remote team members. The system also integrates tablets and smartphones (iOS and Android based) as personal sticky note pads (Figure 2.14). 
Figure 2.14. Remote collaboration with Tele-Board

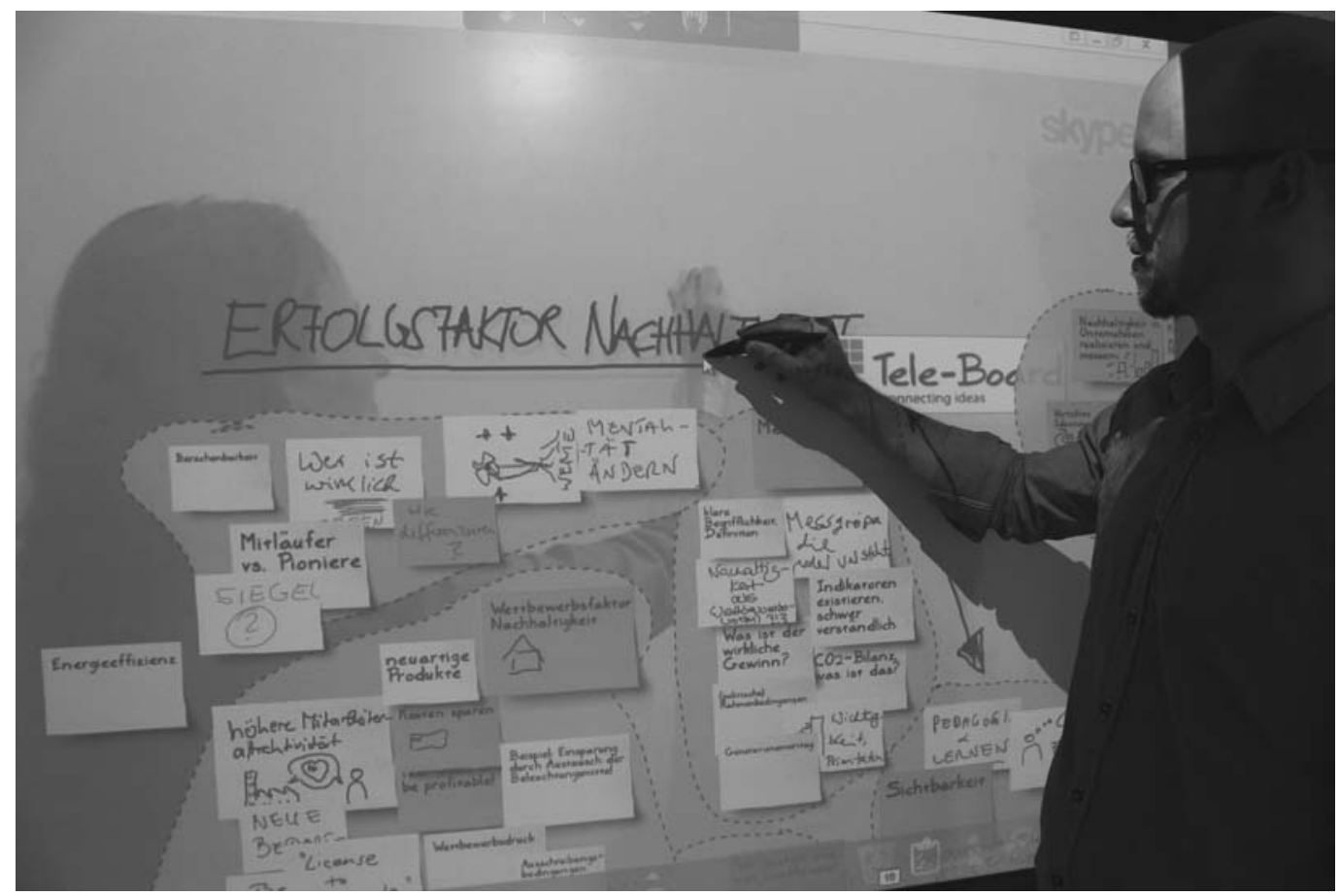

Source: www.tele-board.de.

Business intelligence services that help firms to visualise historical, current operations and future trends are also moving to mobile devices. A number of manufacturers have mature products on the market, such as CliqView, MicroStrategy and Roambi/SAP. One of the key benefits cited by managers is the "always on" behaviour of tablets, compared to traditional PC environments.

In addition to emerging company-specific solutions (business intelligence, business resource planning and CRM) are a number of other commonly used tablet/smartphone apps for business productivity: office suites for mobile devices (Google Docs, Apple's iWork), mind-mapping tools (Mind Manager) or diagramming/charting software (OmniGraffle for iOS or Smart Diagram for Android). Exchange integration for iOS and Android indicate the growing importance of modern smartphones for company communication and as groupware clients.

At the intersection of today's working practice and education is the requirement for life-long learning programmes. Technology changes rapidly and employees must dedicate a significant share of their time to further education to remain conversant with technological and methodological changes. Self and distance-learning courses are becoming more important and widely accepted, and are supported by technology advances in e-learning such as virtual and remote laboratories or mobile learning concepts. This trend is also supported by the growing dissemination of Learning Management Systems (i.e. Moodle) in business environments.

Social applications also drive recent innovations in e-learning. Innovative applications have emerged in particular in the sector of community language learning (CLL). A mature example is the web application busuu.com. The website provides learning units for several different languages (e.g. English, French, German or Spanish). Learners can set up a profile, 
add one or more of these languages to their learning portfolio, work through the units at their own pace, and keep track of their progress. For each unit, users benefit from several types of material, such as vocabulary and key phrases, dialogues, audio, podcasts and PDFs. Throughout their study users can test their progress through interactive reviews. The community aspect of the site enables each user to be simultaneously a foreign language "student" and a "tutor" of his or her own mother tongue. Tutors review assessment results of other users.

A more general example of a community-supported learning platform is AnkiSRS. Anki is an open-source flash-card learning system accompanied by desktop applications and a web interface. Users can create decks of flash cards (e.g. for language learning, studying medical or legal facts, etc.) and share those with other users.

Research is also focusing on domain-independent, autonomous learning systems that implement natural language and multimedia processing as well as deeper reasoning techniques to allow the emulation of natural student-teacher interaction.

\section{E-government}

Governments face the double challenge of reducing expenditures while meeting expectations to improve public services and to increase citizen engagement (OECD, 2012b). Government bodies make wide use of ICTs; however, effective e-government also requires rethinking organisations and processes, and changing behaviour to ensure that public services are delivered more easily to the people who need them. E-government services could enable all citizens, companies and organisations to carry out their business with the government more easily, more quickly and at lower cost (EC, 2007). Moreover, effective e-government could also improve governance and enable citizens to become more involved in the activities of their governments.

As in other fields, a key driving force is the large potential cost savings. In Denmark, for example, electronic invoicing saves taxpayers EUR 150 million and businesses EUR 50 million a year. Projected annual savings for European OECD countries could exceed EUR 50 billion (EC, 2011a). In Italy alone, e-procurement systems cut over EUR 3 billion in costs. This represents a tremendous impetus to move forward with higher quality, cost-effective government services and a better relationship between citizens and government (Fang, 2002). E-government represents a big opportunity, however, certain challenging issues require consideration.

In a global, interconnected world, more citizens and businesses deal with public bodies outside their home regions or countries. This places emphasis on the need for interoperability with existing software and hardware platforms.

Digital identity is also becoming an increasingly important foundation for e-government, as many government services require a high level of assurance of a user's identity. New digital identity practices generally rely on an electronic proof of identity, which enables online identity confirmation. This allows authentication processes such as login and confirmation of age or place of residence to be more efficient and more secure. A comparative analysis of national strategies and policies for digital identity management in OECD countries highlighted e-government as the main driver for such strategies in most countries (OECD, 2011a, 2011b). However, countries are adopting various approaches regarding the management of digital identities online for transactions that carry a high level of risk, such as registering a company or buying a house. Governments tend to transpose 
existing identity management practices in the physical world to the digital world. For example, countries like Germany, Portugal and Spain, which have a pre-existing, paper-based national identity card, are replacing it with an electronic identity card (eID) that enables more secure online transactions. But countries such as Australia, Canada, the United Kingdom and the United States which lack such a tradition follow approaches that are more distributed and less centralised, where authentication credentials issued by some actors are recognised by others, enabling multiple credentials to coexist.

The European Union and its member states consider eIDs a key enabler to achieving the digital single market. The large-scale pilot STORK ${ }^{3}$ aims to achieve interoperability among national eID systems to enable citizens to access online public services in another country regardless of his or her place of residence. In mid-2012, the European Community will propose a legislative framework that aims, among other items, to ensure mutual recognition of eID and eAuthentication systems across the European Union.

\section{Box 2.6. Electronic IDs in Germany}

Germany introduced electronic identity cards on 1 November 2010. The cards are called nPAs. The German system to identify individuals electronically was established with particular emphasis on compliance with data protection regulations: only authorised service providers are allowed to request the data on the identity card. Identity cardholders retain full control over which of their personal data are transferred to the service provider. The security concept of the new card is designed as an aid in the fight against Internet crime and to increase confidence in electronic transactions. It is also designed to increase protection against identity theft and provide new options for ensuring the protection of minors at places such as vending machines that sell cigarettes.

Service providers offer an online identity function to increase the convenience and security of user registration procedures. These providers include banks, insurance companies, online shops, e-mail providers and social networks. Public authorities may also use online identity cards for e-government services, such as vehicle registration or child allowance applications. Identity confirmation can also be integrated into ticket machines, car and bicycle rental services and hotel checking-in procedures. In Germany, more than 25 applications currently support the electronic identity card (Der neue Personalausweis, 2010). As in other countries, it is not yet possible to measure the success of these services as there is no comparative data available on their use in specific areas.

The number of issued cards does not necessarily correlate with their level of use for e-government, as many citizens receiving a new electronic identity card on the expiration of their old paper-based identity card are unfamiliar with its digital features and do not actively use them (Kubicek and Torsten, 2009). Clear communication of e-government services is crucial for wide acceptance, as the perceived added value of the new services may not outweigh the potential reservations of users (Grote et al., 2010).

E-participation is another promising area facilitated by digital identity management. Public resistance to disputed government initiatives within the OECD states (e.g. the Stuttgart 21 project in Germany, the Digital Economy Act in the United Kingdom, and healthcare reform in the United States) is clear evidence of the willingness of many citizens to participate in democratic processes. The e-identity functionality provides a basis to develop participation and provide interested citizens with relevant information on 
projects in their area. These tools can be used to build a bridge between citizens and government, and thereby increase the confidence of the population in decisions relevant to them and in politics in general.

E-Participation was a priority in the previous EU eGovernment Action Plan, and also features prominently in the current one. The aim is to demonstrate tools for effective public debate and participation in democratic decision-making. In recent years, the European Union and its member states have mounted a concerted effort to find workable mechanisms and solutions to boost e-participation. An existing range of great and small initiatives aims to enhance this intention (EC, 2007). The European Commission supported 21 eParticipation projects between 2006 and 2009. The launch of the European Citizens Initiative in April 2012 is a major project, which promotes citizen engagement in EU-level decision-making processes (EC, 2011b).

One example of innovative e-participation services is the project bePart in Germany. This project provides citizens in Berlin and the surrounding area with the option of requesting, viewing and evaluating targeted information. This can create a basis for discussions at an early stage, thereby avoiding unnecessary costs and misunderstandings, and facilitate the reaching of consensus between the population and the government. bePart also provides the government with an ongoing barometer of sentiment, giving it access to current, anonymous opinions of citizens. It also provides citizens with the option to present proposals for improvement on their own initiative, to enable them to actively shape urban development (bePart, n.d.).

At present, regions provide information on infrastructure projects in different forms. Potsdam, for example, provides an option for participation with the "citizens' budget", but only provides information on infrastructure and urban development plans indirectly in its official journal. Berlin, in contrast, provides urban development plans online, but does not provide information on infrastructure projects in centralised form. Thus, citizens do not have a simple way of accessing information on projects planned for their area. bePart aggregates data on infrastructure projects from planning approval procedures, building plans and land development plans. The government has to aggregate the data from existing e-government sources and enter any missing data.

The projects are marked online with a zone of influence. Citizens can locate projects that affect their current location either on a map or as an "augmented reality" view. They can then select a detailed view for information on the costs and schedule of the project. A timeline gives citizens information on project steps that have already taken place or are planned (such as meetings, minutes, hearings, etc.). The project can be re-evaluated by citizens at any point. Citizens can also subscribe to projects via a "favourites view". bePart also goes one step further and provides a "map view", as well as an option to propose new projects. The aim is to encourage both participation and initiative in infrastructure policy. Projects may address road damage caused by adverse weather conditions, inadequate waste disposal facilities or insufficient municipal facilities.

\section{E-commerce and payment services}

The path of online shopping has not been entirely smooth since its debut more than a decade ago. But after a stuttering start, e-commerce levels are experiencing robust growth worldwide. The increased uptake of broadband, a more technologically aware population, and improved e-commerce infrastructure has made this growth possible. Various research studies demonstrate the impressive rise of global e-commerce services. 
For example, in 2010 the industry analyst Marketer estimated that global e-commerce would reach USD 711 billion in sales by the end of the year with an annual growth rate (CAGR) of $19 \%$. The US Department of Commerce reported that e-commerce in the United States reached over USD 53 billion for the first quarter of 2012, accounting for almost $5 \%$ of total commerce (Figure 2.15) (US Department of Commerce, 2012). According to CRR research, e-commerce is one of the fastest growing markets in Europe (see Figure 2.16). Forrester Research also estimated that 32 million UK consumers shopped online in 2011. The research firm IDC predicts that USD 134 billion will be spent online in China in 2012.

\section{Figure 2.15. Evolution of US retail e-commerce sales, Q1 2000-Q1 2012}

As a percentage of total retail sales

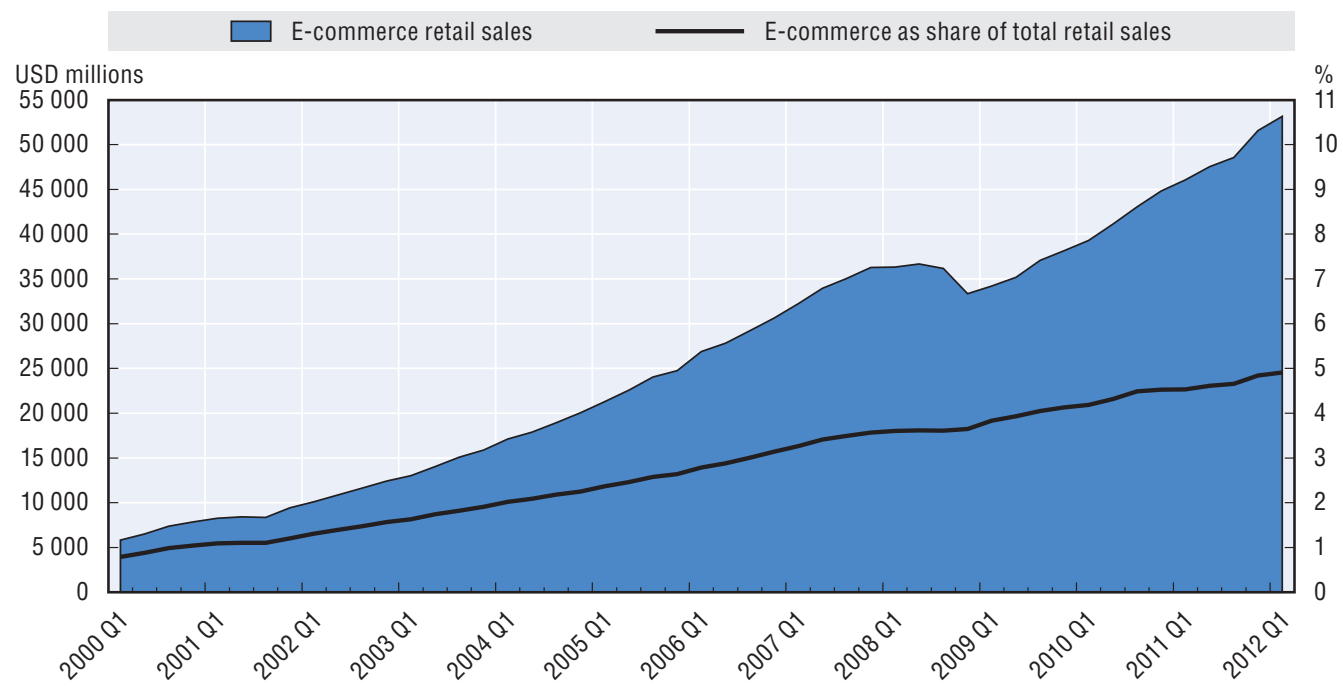

Note: E-commerce sales are sales of goods and services where an order is placed by the buyer or price and terms of sale are negotiated over an Internet, extranet, Electronic Data Interchange (EDI) network, electronic mail, or other online system. Payment may or may not be made online. Estimates are adjusted for seasonal variation, but not for price changes. Total sales estimates are also adjusted for trading-day differences and moving holidays.

Source: Based on US Census Bureau, Quarterly Retail E-Commerce Sales, 1st quarter 2012, May 2012. StatLink त्त्ताs http://dx.doi.org/10.1787/888932693075

Figure 2.16. Online share of retail trade, 2011

Percentage of total retail sales

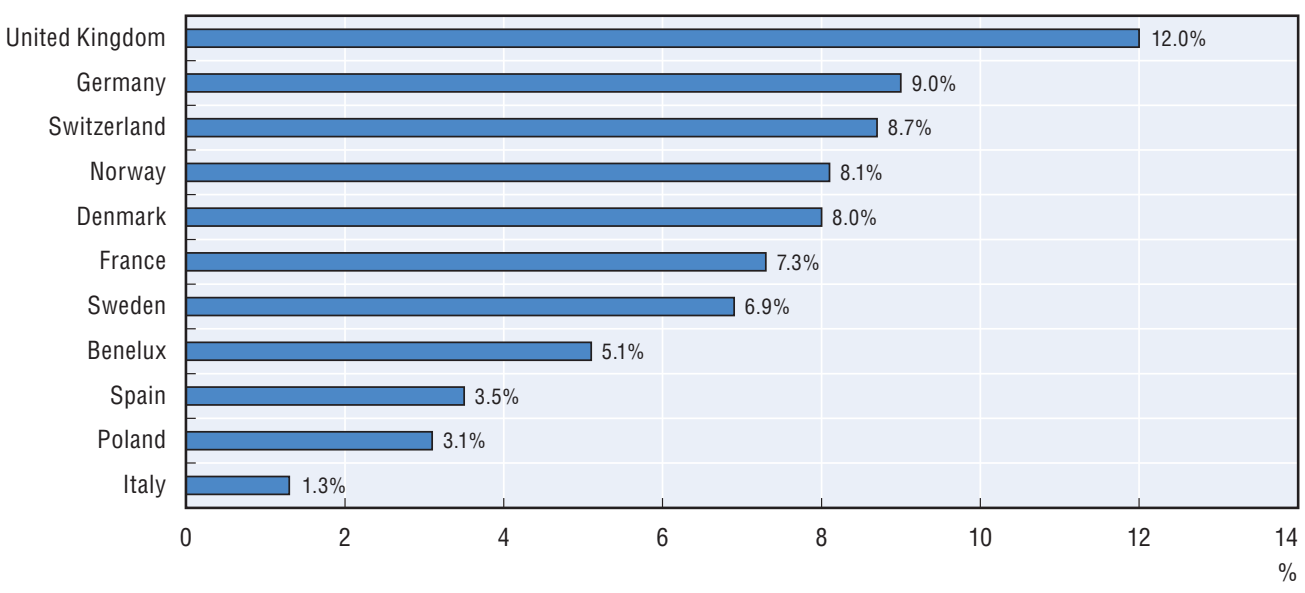

Source: Based on Centre for Retail Research (CRR), Online Retailing: Britain and Europe, May 2012.

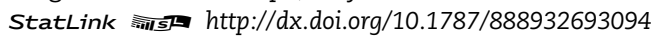


Nevertheless, the market remains highly polarised geographically, with a "digital divide" clearly evident. For example, nearly half of the Swedish adult population made an online purchase in 2010, compared to just one in ten Italians, (OECD, 2011c). A lack of infrastructure may play a role in this divide, but so do cultural factors, such as trust levels in businesses and attitudes towards distance shopping.

According to nVision, personal country-of-origin proves to be the most accurate indicator of e-commerce uptake. Other variables, such as age and gender, are seeing their influence lessen as the online population diversifies, with online shopping set to grow fastest amongst older age groups over the next few years (nVision, 2008). This can be explained by the group's increased level of online experience, a factor that has an essential influence on every group's propensity to shop online. As stated above, broadband access is a major driver of e-commerce participation.

In surveys across countries, consumers say that saving time and money and convenient search options are among the top reasons for shopping online. Amazon is one of the leading online retailers worldwide, and was able to sustain high growth levels in 2011 despite challenging economic conditions. Net sales increased $40 \%$ to USD 34.20 billion, compared with USD 24.51 billion in 2009 (Amazon, 2011a). The world's largest online retailer performs exceptionally efficiently measured against revenue per visitor, which is one of the key measures for any commercial website, regardless of whether it is a media site, search engine, social network, a transactional retailer or offers travel or financial services. Globally, Amazon generates almost 3.3 times more revenue per user than eBay, Facebook, Google and Mail.ru combined (Figure 2.17).

While factors such as the wider selection of goods, convenience and the ability to simultaneously compare prices have been crucial in driving online shopping, a number of issues still limit the market's development. Despite significant strides forward in the

\section{Figure 2.17. Revenue per unique user for tech companies, 2011}

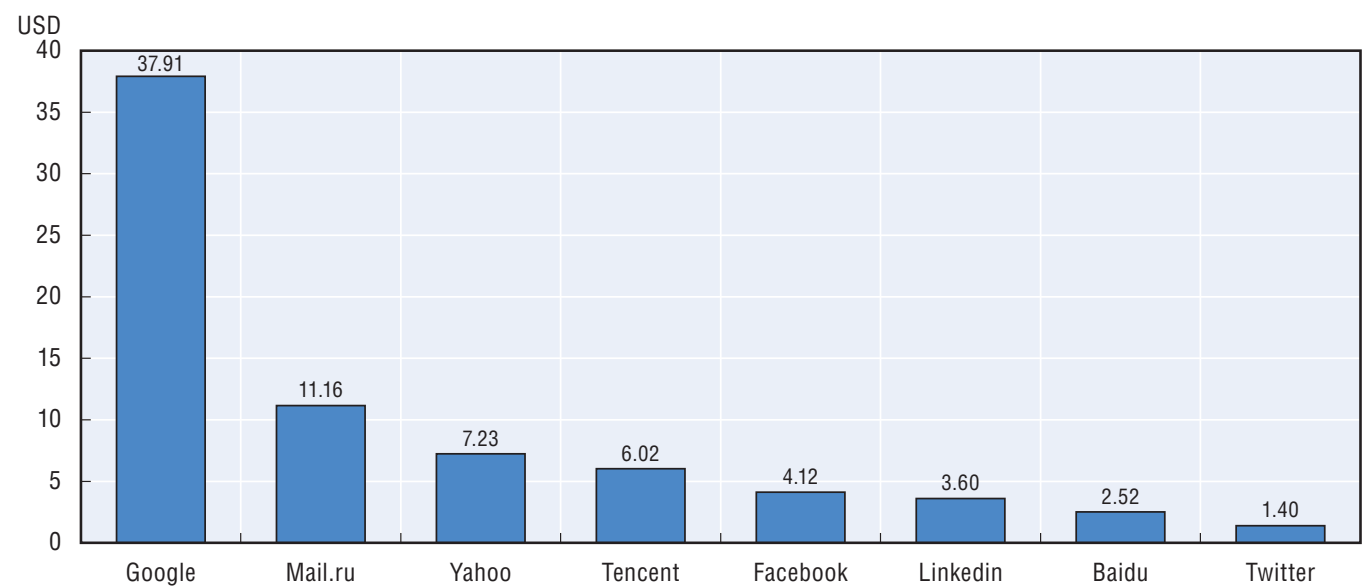

Notes: For Tencent \& Baidu, revenues were converted from RMB to USD. US dollars in this annual report is based on the noon buying rate in New York City for cable transfers in RMB as certified for customs purposes by the Federal Reserve Board. Unless otherwise noted, all translations from RMB to U.S. dollars and from U.S. dollars to RMB in this annual report were made at a rate of RMB 6.2939 to USD 1.00, the noon buying rate in effect as of 30 December 2011. For public companies data was retrieved to company's annual reports to stakeholders for the closing year 2011. Data for number of users was retrieved both from company's annual reports, and comScore's ARPU (Average revenue per user) reports. Data for number of users is considered for ending December 2011, with the exception of Facebook (March 2012), Google \& Yahoo (May 2011) and Baidu (June 2009).

Source: OECD based on comScore, Bloomberg, Companies financial annual statements, June 2012 
domain of security, a significant number of consumers have fears about releasing personal details online (HPI, 2011). Low credit card ownership is also proving to be a barrier in some of Europe's largest economies, with a lack of alternative payment mechanisms hindering development (nVision, 2008).

One of the most important trends is the ability to make payments via a mobile phone. The payment service provider Ogone currently offers an iPhone app for mobile payment transactions. Retailers and service providers can use their Apple smartphone as a virtual mobile card reader to accept credit and debit card payments (direct debit). Taxi drivers and pizza and furniture deliverers can process PCI-secured payments via their iPhone without the need for a traditional terminal. One promising advance is near-field communications (NFC), a short-range wireless technology that uses interacting electromagnetic radio fields instead of radio transmissions to exchange information. Typically, NFC devices must be held next to each other to exchange information, such as a mobile phone held next to a reader to make payments for public transport.

Visa has begun NFC payments via an iPhone accessory. In Turkey, iPhone users can also make non-touch payments. In cooperation with Visa Europe, the bank Yapi Kredi and the Turkish mobile phone operator Turkcell offer their customers the "iCarte" accessory. This plug-on module produced by Wireless Dynamics adds the NFC wireless technology and Radio Frequency IDentification (RFID) support to the iPhone, and contains an integrated smart chip that makes the data from the Visa card available for payment transactions.

In September 2011, Google and the wireless carrier Sprint in the United States launched an NFC payment option using the Google Nexus S mobile phone. Apple is also implementing an NFC-based payment system: the new iPad3 supports NFC wireless technology and will thus enable mobile payment transactions, and it seems likely that the next version of the iPhone5 will follow suit.

In many OECD countries, payment options such as bank transfers and direct withdrawals continue to dominate, but there has been a marked increase in the use of alternative payment options. The most popular of these is the online payment system PayPal, which has grown rapidly in recent years. In 2011, the eBay subsidiary reported a $32 \%$ increase in turnover to USD 1.1 billion. The value of its transactions increased by $31 \%$ to USD 29.3 billion, and the number of active account holders increased by $14 \%$ to 103 million. The company is currently developing an identification service that will allow customers to authenticate themselves and buy in various online stores after entering their e-mail address and password only once. In addition, a new platform is due to be introduced in some markets, which will allow face-to-face retailers to accept mobile payments without having to invest in new hardware. The new PayPal payment platform can be used via mobile phones and smartphones, as well as via special PayPal cards. In-store terminals, where users type in their telephone number and a PIN code, will also be available. To complete payments, users just scan the bar or quick response (QR) code with their mobile phone, or use an NFC chip if one is installed.

Mobile payment services are commonly viewed as an important market for growth. Service providers are focusing primarily on user-friendliness, convenience, reliability and a sense of security. For example, customers feel more secure when they do not have to give unknown retailers their confidential data, such as account or credit card numbers. 


\section{Internet in business: Supply chain management}

Today, e-commerce and ICTs are fundamentally changing the nature of supply chains. They are redefining how consumers learn about, select, purchase and use products and services. The result has been the emergence of new business-to-business supply chains that are consumer focused rather than product focused.

Increasingly rigorous competition in global markets, short time-to-market, short product lifecycles and high customer expectations are forcing companies to become more cost effective. The necessary cost reductions can be made by optimising corporate processes (Simchi-Levi, Kaminsky and Simchi-Levi, 2008). Specifically, improving the predictability of material flows between source suppliers and consumers helps balance out customer-side fluctuations in demand and supply-side difficulties. The speed and quality of information exchange is becoming an increasingly decisive factor for competitive advantage.

However, many companies are still a long way off from end-to-end solutions, and only use individual automated purchasing and sales processes involving computer-aided exchange of data either internally or with business partners (B2B). Most e-business applications are still used as standalone solutions.

Standards play a crucial role in integrating e-business solutions, as these require homogeneous information to be available at the right place at the right time along the whole value chain. The main task of standards is to define data flows between the systems involved. The benefit of applying standards is accelerated business processes, improved data quality and lower IT complexity, which in turn cut costs and increase investment security.

However, the cost involved in applying standards will be high, particularly with regard to implementation, maintenance of ongoing operations, and above all, the wide range of available standards. The number of standards also increases the time and expense needed for coordination. This explains why many companies find it difficult to accurately assess the expenses and investment costs needed to apply them. In fact, the unclear cost-benefit ratio is the reason why many businesses are against the application of standards.

To enable the widespread application of standards, it is important to provide companies with tools that can deliver realistic cost-benefit and return-on-investment analyses. E-business standardisation therefore harbours great market potential for IT service providers and technology providers, and support of these standards opens up new segments and business areas for them.

Furthermore, the standardisation of e-business will also drive growth in the software-as-a-service and cloud models, currently the subject of widespread debate. The support of standards simplifies and speeds up internationalisation and thereby opens up markets abroad. IT service providers and technology providers should tap this potential and consistently support their customers in introducing and implementing standards-based e-business solutions.

\section{Conclusion}

Some of the Internet developments across the economy highlighted in this chapter are also areas that OECD governments have assigned a high priority in the 2012 OECD ICT policy questionnaire. Rolling out broadband infrastructure remains the highest priority over with 21 out of 23 countries assigning it a high priority. In addition, 19 countries that responded to the questionnaire stated that e-government continues to be a high strategic priority. Green growth and public-sector information are also important priorities 
emerging from the questionnaire responses. A discussion of these priorities and specific examples from OECD countries can be found in Chapter 8 focusing on policy.

\section{Notes}

1. 1 zettabyte is equivalent to 1 billion terabytes or roughly the capacity of 213 million DVDs.

2. Methodic innovation is a suite of methods that allows teams to improve their work and innovate by giving participants the ability to define their job or role in a way that best suits their talents.

3. For further information on STORK, see: www.eid-stork.eu.

\section{References}

Agilent (2011), “Agilent Technologies Introduces Industry's First LTE-Advanced Signal Generation, Analysis Solutions", www.agilent.com/about/newsroom/presrel/2011/02feb-em11015.html, accessed 1 November 2011.

Amazon (2011a), Annual Report Summary for 2011, Amazon.com Inc., Seattle, United States.

Amazon (2011b), Amazon Silk: The Official Blog of the Silk Team, http://amazonsilk.wordpress.com, accessed 14 November 2011.

AppBrain, (2012), "Number of available Android applications", www.appbrain.com/stats/number-ofandroid-apps, accessed 4 June 2012.

Apple (2011a), “iCloud - Keep the Same Documents Up-to-date Everywhere”, www.apple.com/icloud/ features/documents.html, accessed 25 October 2011.

Apple (2011b), “Apple's Mac App Store Downloads Top 100 Million”, press release, www.apple.com/pr/ library/2011/12/12Apples-Mac-App-Store-Downloads-Top-100-Million.html, accessed 22 March 2012.

Apple (2011c), "iTunes in the Cloud”, www.apple.com/icloud/features, accessed 22 March 2012.

Augsten, T., K. Kaefer, R. Meusel, C. Fetzer, D. Kanitz, T. Stoff, T. Becker, C. Holz and P. Baudisch. (2010), "Multitoe: High-precision Interaction with Back-projected Floors Based on High-resolution Multi-touch Input", Proceedings of the 23nd Annual ACM Symposium on User Interface Software and Technology, ACM Press, New York.

Barret, V. (2011), “Dropbox: The Inside Story of Tech's Hottest Start-Up”, Forbes, 18 October 2011, www.forbes.com/sites/victoriabarret/2011/10/18/dropbox-the-inside-story-of-techs-hottest-startup/, accessed 25 October 2011.

Baudisch, P. (2010), "My New PC is a Mobile Phone: Techniques and Technology for the New Smallness", opening keynote at MobileHCI 2010, Lisbon, 7-10 September, 2010, www.patrickbaudisch.com/ publications/talks.html, accessed 22 March 2012.

bePart (n.d.), "bePart - Mobile eParticipation for Urban Development", be-part.info, accessed 22 March 2012.

Buckland, M. and P. Langley (2010), "The Future of Social Networking - A Concept Investigation with Augmented Reality”, matthewbuckland.com/?p=1041, accessed 22 August 2010.

CEDIA (Custom Electronic Design \& Installation Association) (2011), "Industry Experts Forecast 2012 Home Electronic Trends", www.pitchengine.com/cedia/industry-experts-forecast-2012-home-electronictrends, accessed 10 November 2011.

Cisco (2011), "Visual Networking Index: Forecast and Methodology, 2010-2015", www.cisco.com/en/US/ solutions/collateral/ns341/ns525/ns537/ns705/ns827/white_paper_c11-481360_ns827_Networking_Solutions_ White_Paper.html, accessed 22 March 2012.

Cooney, M. (2011), "Gartner: The Top 10 Strategic Technology Trends for 2012", Network World, www.networkworld.com/news/2011/101811-gartner-technology-trends-252100.html, accessed 14 November 2011.

CRR (Centre for Retail Research) (2011), Official website, CRR, Nottingham, United Kingdom, http:// retailresearch.org.

Darby, S. (2006), The Effectiveness of Feedback on Energy Consumption, Environmental Change Institute, University of Oxford, Oxford, United Kingdom. 
Dediu, H. (2012), “The US Smartphone Landscape”, Asymco, www.asymco.com/2011/11/06/the-ussmartphone-landscape, accessed in June 2012.

Der neue Personalausweis (2010), Official website, www.personalausweisportal.de/DE/Home/ home_node.html, accessed 22 March 2012.

DiePresse (2011), "Handy-App "mytaxi": Funkzentralen drohen Taxlern", diepresse.com/home/panorama/ wien/704219/HandyApp-mytaxi_Funkzentralen-drohen-Taxlern (in German), accessed 30 November 2011.

Dignan, L. (2011), “The Mobile Enterprise App Tipping Point is Here: Can Business Tech Learn UI?", ZDnet, www.zdnet.com/blog/btl/the-mobile-enterprise-app-tipping-point-is-here-can-business-tech-learnui/49059, accessed 20 May 2011.

EC (European Commission) (2007), “Information Society Activities at a Glance”, ec.europa.eu/ information_society/activities, accessed 22 March 2012.

EC (2011a), eGovernment on the Fast Track, http://ec.europa.eu/information_society/activities/egovernment/ policy/index_en.htm, accessed 4 April 2012.

EC (2011b), The European Citizens Initiative, ec.europa.eu/dgs/secretariat_general/citizens_initiative, accessed 22 March 2012.

EuroCloud (2012), Official website, www.eurocloud.org/about-eurocloud, accessed 22 March 2012.

Fang, Z. (2002), “E-Government in Digital Era: Concept, Practice and Development”, International Journal of the Computer, Vol. 10, No. 2, pp. 1-22.

Future Shape (2005), "SensFloor", www.future-shape.com/en/technologies/23/sensfloor, accessed 22 March 2012.

Gartner Research (2011a), "Gartner Says Worldwide PC Shipments in First Quarter of 2011 Suffer First Year-Over-Year Decline in Six Quarters”, press release, www.gartner.com/it/page.jsp?id=1632414, accessed 14 November 2011.

Gartner Research (2011b), “Gartner Says the Market for Social CRM Is on Pace to Surpass \$1 Billion in Revenue by Year-End 2012", press release, www.gartner.com/it/page.jsp?id=1777938, accessed 30 November 2011.

Global FTTH Council (2011), “Global FTTH Councils' Latest Country Ranking Shows Further Momentum on All-Fiber Deployments", www.fthcouncil.org/en/newsroom/2011/02/10/global-ftthcouncils-latest-country-ranking-shows-further-momentum-on-all-fiber-, accessed 20 October 2011.

Goderbauer, M. (2011), “Diagram Editor for Google+ Hangouts”, http://code.google.com/p/diagram-editorfor-google-plus, accessed 30 November 2011.

Google (2011), Chromebook, official website, www.google.com/chromebook, accessed 25 October 2011.

Grose, T.K. (2011), “10 Start-Ups That Will Change Your Life”, Time, www.time.com/time/specials/ packages/article/0.28804.2017050_2017049_2017043.00.html, accessed 30 October 2011.

Grote, J.H. et al. (2010), HPI Studie. "Vom Client zur App: Ideenkatalog zur Gestaltung der Software zum Einsatz des neuen Personalausweises", www.bmi.bund.de/SharedDocs/Downloads/DE/Themen/ Sicherheit/PaesseAusweise/studie3_npa.html?nn=294838 (in German), accessed 22 March 2012.

IDC (International Data Corporation) (2011a), “Global PC Market Contracts in the First Quarter, But Swaths of Growth Remain, According to IDC”, press release, www.idc.com/getdoc.jsp?containerId=prUS22790811, accessed 14 November 2011.

IDC (2011b), “Extracting Value from Chaos”, idcdocserv.com/1142, accessed 22 March 2012.

International Energy Agency (IEA) (2011), Technology Roadmap. Smart Grids, Paris, IEA.

IEEE (Institute of Electrical and Electronics Engineers) (2008), The Draft IEEE 802.16m System Description Document, www.ieee802.org/16/tgm/docs/80216m-08_003r1.pdf, accessed 1 November 2011.

IPCC (Intergovernmental Panel on Climate Change) (2007), Contribution of Working Group III to the Fourth Assessment Report of the Intergovernmental Panel on Climate Change, (edited by B. Metz, O.R. Davidson, P.R. Bosch, R. Dave and L.A. Meyer), Cambridge University Press, Cambridge, UK.

Kellogg, D. (2011), “40 Percent of U.S. Mobile Users Own Smartphones; 40 Percent are Android”, Wire, blog.nielsen.com/nielsenwire/online_mobile/40-percent-of-u-s-mobile-users-own-smartphones-40-percentare-android, accessed 15 November 2011. 
Kubicek, H. and T. Noack (2009), "Elektronische Identität im Scheckkartenformat - was Deutschland von anderen Ländern lernen kann” (in German), Vitako Aktuell, Vol. 1/2009, pp. 8-9.

Lomas, N. (2011), “Android, Chrome OS to Converge, Says Google's Eric Schmidt”, silicon.com, www.silicon.com/technology/software/2011/02/16/android-chrome-os-to-converge-says-googles-eric-schmidt39746988, accessed 14 November 2011.

Mell, P. and T. Grance (2011), The NIST Definition of Cloud Computing, csrc.nist.gov/publications/nistpubs/ 800-145/SP800-145.pdf, accessed 22 March 2012.

NetHosting (2011), "DropBox Case Study", www.nethosting.com/buzz/case-studies/dropbox-case-study, accessed 22 March 2012.

Niemand, T. (2011), Smart Grids - Hype oder heute schon Realität?, RWE Deutschland AG, Deutsche Kommission Elektrotechnik Elektronik Informationstechnik (DKE), Frankfurt, Germany, www.dke.de/de/Wirueberuns/MitteilungenderDKEGeschaeftstelle/2011/Documents/Niemand.pdf (in German), accessed 22 March 2012.

NIST (National Institute for Standards and Technology) (2010), "NIST \& the Smart Grid”, www.nist.gov/ smartgrid/nistandsmartgrid.cfm, accessed 16 November 2011.

nVision (2008), E-commerce across Europe: Progress and prospects, www.eaca.be/_upload/documents/ publications/E-commerce\%20across\%20Europe.pdf, accessed 22 March 2012.

OECD (2009), “Smart Sensor Networks: Technologies and Applications for Green Growth”, OECD Digital Economy Papers, No. 167, OECD Publishing. doi: http://dx.doi.org/10.1787/5kml6x0m5vkh-en.

OECD (2010), Greener and Smarter. ICTs, the Environment and Climate Change, OECD, Paris, www.oecd.org/ dataoecd/27/12/45983022.pdf, accessed 22 March 2012.

OECD (2011a), "National Strategies and Policies for Digital Identity Management in OECD Countries”, OECD Digital Economy Papers, No. 177, OECD Publishing. doi: http://dx.doi.org/10.1787/5kgdzun5rfs2-en.

OECD (2011b), “Digital Identity Management for Natural Persons: Enabling Innovation and Trust in the Internet Economy - Guidance for Government Policy Makers", OECD Digital Economy Papers, No. 186, OECD Publishing. doi: http://dx.doi.org/10.1787/5kg1zqsm3pns-en.

OECD (2011c), “The Future of the Internet Economy: A Statistical Profile”, June 2011 Update, OECD, Paris. www.oecd.org/dataoecd/24/5/48255770.pdf.

OECD (2011d), "National Broadband Plans", OECD Digital Economy Papers, No. 181, OECD Publishing. doi: http://dx.doi.org/10.1787/5kg9sr5fmqwd-en.

OECD (2012a), "ICT Applications for the Smart Grid: Opportunities and Policy Implications", OECD Digital Economy Papers, OECD, Paris.

OECD (2012b), "New ICT Solutions for Public Sector Agility", summary report of OECD E-leaders meeting, Mexico City, 26-27 March, www.oecd.org/governance/eleaders.

OECD (forthcoming), "Cloud Computing: The Concept, Impacts and the Role of Government Policy", OECD Digital Economy Papers, OECD, Paris.

OPTIMIS (2011), Official website, www.optimis-project.eu, accessed 22 March 2012.

Parkvall, S., et al. (2008), "LTE Advanced - Evolving LTE towards IMT-Advanced", Vehicular Technology Conference, 2008. VTC 2008-Fall. IEEE 68th, Stockholm, Ericsson Research.

Perset, K. (2010), “Internet Addressing: Measuring Deployment of IPV6: Measuring Deployment of IPV6", OECD Digital Economy Papers, No. 172, OECD Publishing.

doi: $h$ ttp://dx.doi.org/10.1787/5kmh79zp2t8w-en.

Point Topic Ltd. (2012), IPTV: Short Report - Q4 2011. April 2012, Point Topic, London.

Schonfeld, E. (2011), "Will Windows 8 Merge The Desktop With The Smartphone?" Seeking Alpha, seekingalpha.com/article/291769-will-windows-8-merge-the-desktop-with-the-smartphone, accessed 14 November 2011.

Simchi-Levi, D., P. Kaminsky and E. Simchi-Levi (2008), Design and Managing the Supply Chain: Concepts, Strategies and Case Studies, McGraw-Hill/Irwin, Boston.

Sonos Inc. (2011), Sonos - The Wireless HiFi System, official website, www.sonos.com, accessed 22 March 2012. 
TechCrunch (2011), "Android Market: 10 Billion Apps Served So Far, And Another 1 Billion Each Month”, TechCrunch, techcrunch.com/2011/12/06/android-market-10-billion-apps-served-so-far-and-another1-billion-each-month, accessed 22 March 2012.

Treiss, F. (2011), "Mobilbranche hält HTML5, Location-based Services und Mobile Payments für die wichtigsten Zukunftstrends", Mobilbranche, mobilbranche.de/2011/10/mobilbranche-halt-html5location-based-services-und-mobile-payments-fur-die-wichtigsten-zukunftstrends/7790 (in German), accessed 30 November 2011.

US Department of Commerce (2012), Quarterly Retail E-Commerce Sales, 1st quarter 2012, US Government, Washington, DC, www.census.gov/retail/mrts/www/data/pdf/ec_current.pdf, accessed 17 May 2012.

Waterfall Mobile (2011), "Smartphone Penetration Stats: Comparing Then And Now", blog.msgme.com/ 2011/09/01/smartphone-penetration-stats-comparing-then-and-now, accessed 14 November 2011.

Weigert, M. (2011), “Callcenter Adé: Wie die Taxi-Branche auf myTaxi reagiert”, Netzwertig.com, netzwertig.com/2011/10/31/callcenter-ade-wie-die-taxi-branche-auf-mytaxi-reagiert (in German), accessed 30 November 2011.

Wheelock, C. et al. (2011), Smart Grid Apps: Six Trends That Will Shape Grid Evolution, Pike Research, Boulder, USA.

Zickuhr, K. and A. Smith. (2011), PewInternet and American Life Project: 28\% of American adults use mobile and social location-based services, Technical Report, PewResearchCenter, Washington, DC. 


\section{Chapter 3}

\section{Internet adoption and use: Households and individuals}

This chapter examines Internet adoption by households and individuals. It looks at connectivity trends with a particular focus on the widespread uptake of smartphones as Internet-enabled devices. It then describes currents forms of Internet usage and details the services provided via this powerful communication platform. It explores the growth of e-commerce and e-banking to the use of the Internet in education for learning and training. Finally, data in this chapter highlight digital divides in key segments of the population, cutting across different groupings by education, geography, age, gender and income level. 
$\mathrm{T}_{\mathrm{h}}$ he Internet, as a data network, is only valuable to society if it can produce economic and social benefits. Governments place significant focus on encouraging the rollout of high-speed broadband networks but these networks are only valuable if they are used.

While businesses are often the earliest adopters of any new technology, it is households and individuals who comprise the largest market segment and ultimately drive the direction of the market. Policy makers, therefore, need a good understanding of how the Internet is being used by individuals, not just domestically but also internationally. Benchmarking Internet use and service adoption across countries can help policy makers target domestic areas that may need improvement. This chapter provides an extensive range of indicators of Internet use and take-up by households and individuals across countries.

The data highlight that access to the Internet is nearing ubiquity with the growing diffusion of a wide array of devices across economies with connectivity embedded in their hardware (PCs, mobile phones, tablets etc.). The Internet is becoming the key communication platform in OECD countries, with voice and written communication increasingly shifting online. The Internet is also becoming the largest platform in the world for storing photographs, videos and other multimedia content, particularly on new social media sites.

The Internet is transforming sectors across the economy. This chapter looks at key trends from the growth of e-commerce and e-banking to the use of the Internet in education for learning and training. Governments are now using the Internet to improve interaction with citizens, making it easier to obtain information, fill out necessary forms and file taxes. The Internet is also supporting huge growth in terms of digital content use, and the survey data used in this chapter highlight the ways in which the Internet is being used for entertainment.

There is still scope for progress in terms of connecting households and individuals to the Internet. The data in this chapter highlight digital divides in key segments of the population, cutting across different groupings by education, geography, age, gender and income level.

\section{Connectivity and access}

Internet adoption is growing worldwide, but at different rates. Internet access in households exceeds $30 \%$ worldwide, but there are clear divides by regions. The penetration rate is highest in developed countries (over $70 \%$ ), but remains low but growing in developing countries (around 20\%) (ITU, 2011a).

\section{Most households have a connection}

The growth of Internet adoption across the OECD has been rapid over the past 20 years. In 1992, only a few consumers had access to the Internet via dial-up connections; 20 years later, Internet adoption is nearly universal in many OECD countries and has reached 
at least $50 \%$ of households in all but three countries (Figure 3.1). Internet connectivity for consumers began as dial-up connections over telephone lines at speeds ranging from $9.6 \mathrm{kbit} / \mathrm{s}$ to $64 \mathrm{kbit} / \mathrm{s}$. These dial-up connections have effectively disappeared in most OECD countries and have been replaced with much faster broadband connections offering 5 to 15000 times the capacity of a $64 \mathrm{kbit} / \mathrm{s}$ line. Today, the vast majority of Internet connections in OECD countries are broadband (high-speed) connections offering speeds of at least $256 \mathrm{kbit} / \mathrm{s}$ (Figure 3.1).

OECD countries, as a whole, are typically in the top-tier in global league tables on Internet adoption with an average of almost $67 \%$ of households reporting a broadband subscription. Broadband is available in at least $60 \%$ of households in four fifths of OECD countries (Figure 3.1).

\section{Figure 3.1. Internet access and broadband connections in OECD households, 2011 or latest available year}

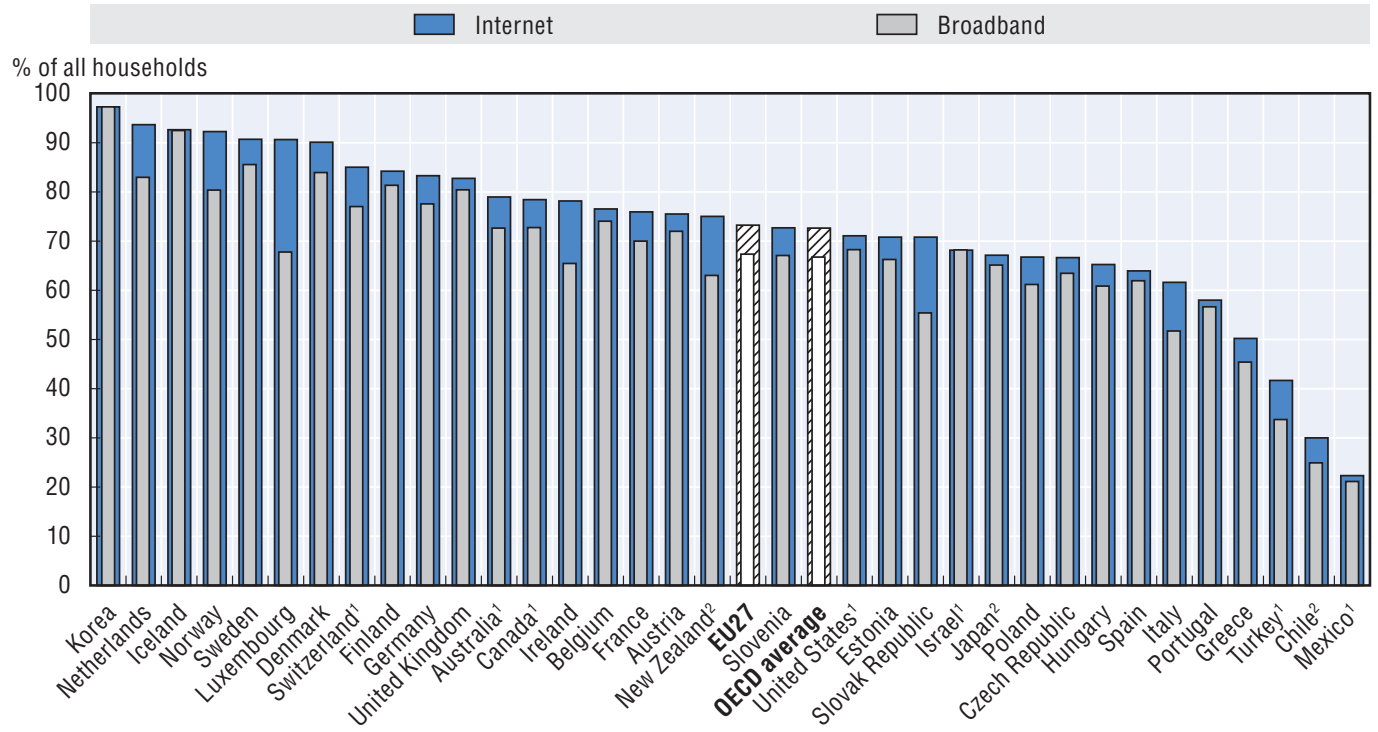

Notes: Internet access at home is via any device (desktop computer, PC, TV, mobile phone etc.) with the exception of Japan, which covers only access to PCs. Broadband connection stands for the use of technologies such as DSL, fixed wire (cable, fibre, Ethernet, etc), Fixed wireless (satellite, public Wi-Fi, WiMax) and mobile connection (3G/ UMTS, etc).

Household refers to domiciles with at least one person aged 16-74.

For Australia: only includes private dwelling households. Households in remote and sparsely settled parts of Australia are excluded from the survey. For Canada: Statistics for 2001, and every 2nd year thereafter, include the territories. For other years, statistics include the 10 provinces only. For Israel: The household expenditure survey does not distinguish between broadband and other bandwidth Internet channels. For Japan: Internet access through mobile phones, TV and game consoles are also included. Households with Internet broadband access via FTTx, ADSL, cable and fixed wireless broadband. For Korea: Internet access through mobile phone, TV and game consoles are also included. For Mexico: Households with Internet access via cable, ADSL or fixed wireless. For New Zealand: Geographic selection of households. This refers to the civilian usually resident, non-institutionalised population aged $15+$.

Information on data for Israel: $h t t p: / / d x . d o i . o r g / 10.1787 / 888932315602$.

1) 2010; 2) 2009.

Source: OECD ICT Database and Eurostat Community Survey on ICT usage in households and by individuals, May 2012. 
Some economies outside the OECD report higher penetration rates than the OECD average. For example, Bahrain; Bermuda; Hong Kong, China; Macao, China; and Singapore all report Internet penetration rates in households above the OECD average of almost $72 \%$ in 2010 (Figure 3.2).

Figure 3.2. Non-OECD households/individuals using the Internet, 2010

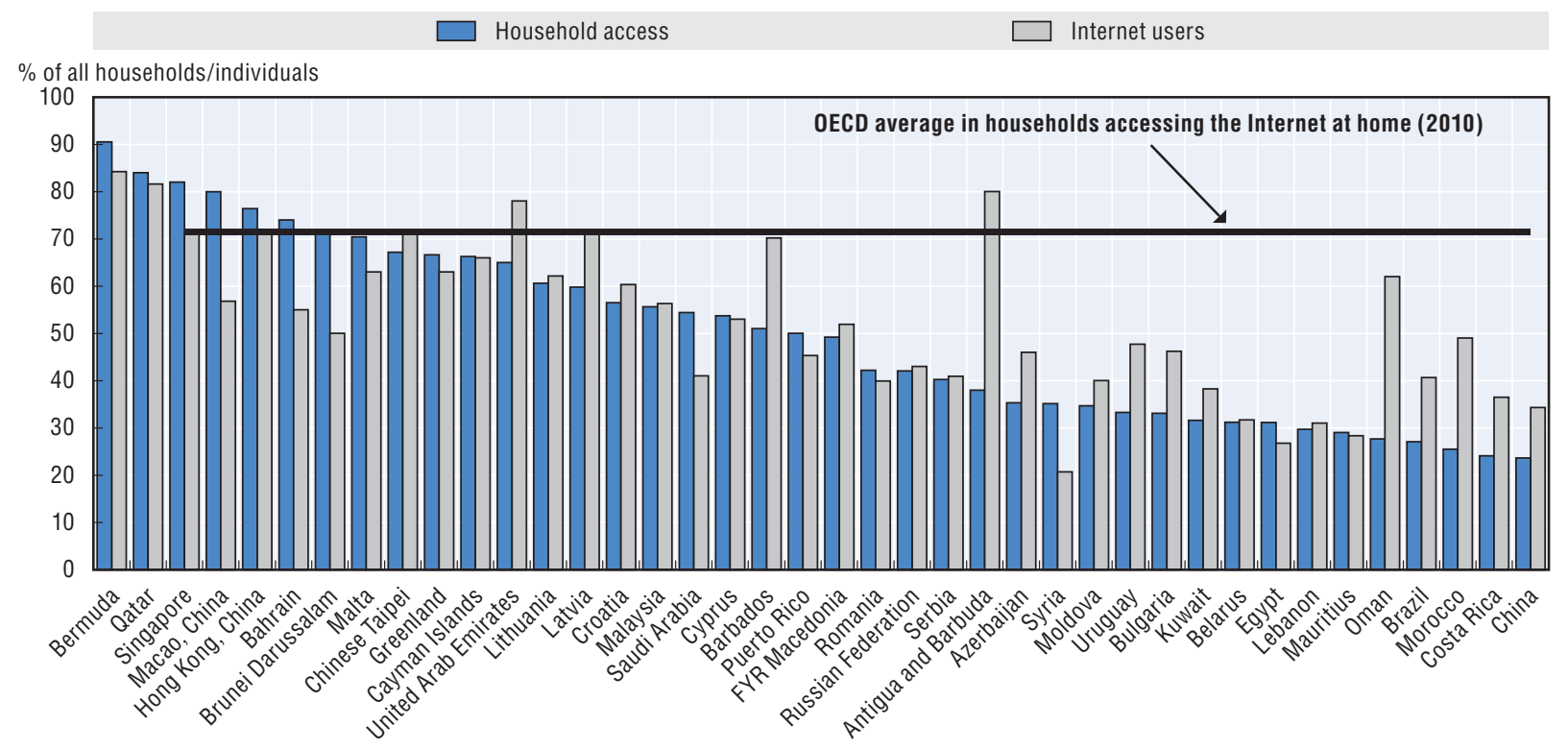

Notes: For a large number of countries, data for 2010 are ITU estimates. Access to the Internet and use is not assumed to be only via a computer. Households with at least one person aged under 15. Individuals aged 15-74 years, except for Eurostat countries (16-74). Data generally refer to Internet use in the last 12 months; for EU countries data refer to Internet use in the last three months.

For Costa Rica: Data refer to dwellings not households. For Lebanon: Individuals aged 25-69 years.

Source: Based on ITU, ICT Indicators Database, 2011.

StatLink त्नाज्ञा $h t t p: / / d x . d o i . o r g / 10.1787 / 888932693151$

Biannual data collected directly from telecommunication firms and national regulators on the total number of broadband subscriptions can supplement survey data on Internet use. Direct comparison of these data should be done with caution because they come from different sources and measure different things. For example, subscription data are a very good measure of physical lines in a country, but do not provide information on how lines are used. Such data also combines household and business lines.

DSL subscriptions over telephone lines remain the most popular type of wired connection in the OECD area, accounting for $56 \%$ of all wired connections (Figure 3.3). Cable networks account for $30 \%$ of wired broadband subscriptions, but the coverage of cable networks is not as extensive as DSL in most countries. Finally, the highest-speed connections based on fibre or LAN technologies account for around $14 \%$ of subscriptions.

\section{Mobile is booming and important for access}

Wired broadband connections still constitute the basis of high-speed data transport, but growth in mobile broadband has helped usher in a new era of connectivity to a wide range of devices. Since 2005, the number of mobile phone subscriptions worldwide (voice and/or data) has doubled, with particularly strong growth in non-OECD countries where the number has tripled. 
Figure 3.3. Breakdown of wired broadband subscriptions in OECD countries By technology, December 2011

Source: OECD Broadband statistics, July 2012.

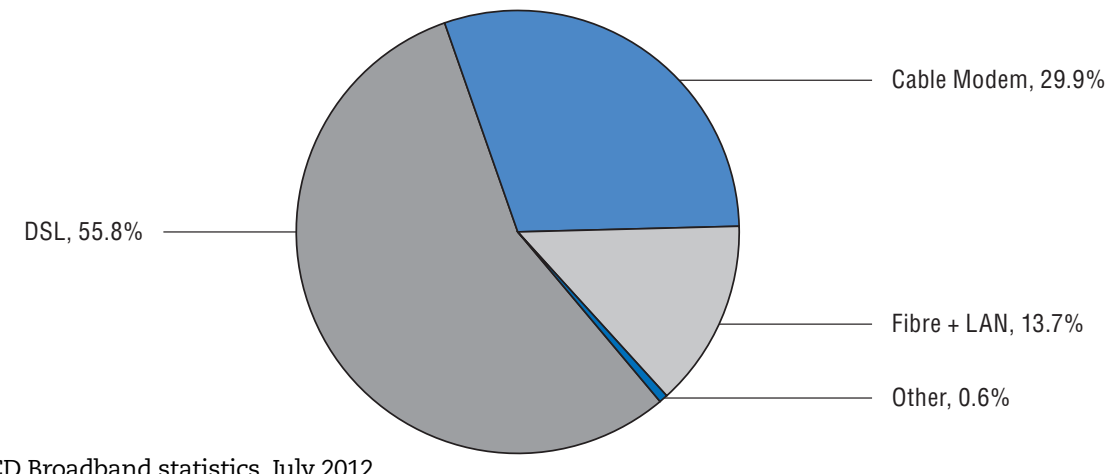

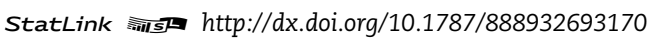

Data connectivity over a mobile network is not new. Indeed, the commercial introductions of WAP (Wireless Application Protocol) in 1997 and GPRS (General Packet Radio Service) in 2000 gave mobile users the ability to visit specifically designed web pages (in the case of WAP) or the general Internet (for GPRS), but at data prices that kept them out of reach of everyday use. It is the introduction of higher-speed mobile data networks and attractive data plans over the last two years that has led to the widespread adoption of mobile broadband seen in OECD countries today.

Many mobile data subscriptions today qualify as broadband under the OECD's mobile broadband definition. ${ }^{1}$ Penetration rates have grown quickly with Korea leading the OECD with 101 wireless broadband subscriptions per 100 inhabitants, followed by Sweden (98), Finland (88) and Japan (82) (Figure 3.4).

\section{Figure 3.4. OECD wireless broadband subscriptions per 100 inhabitants,} December 2011

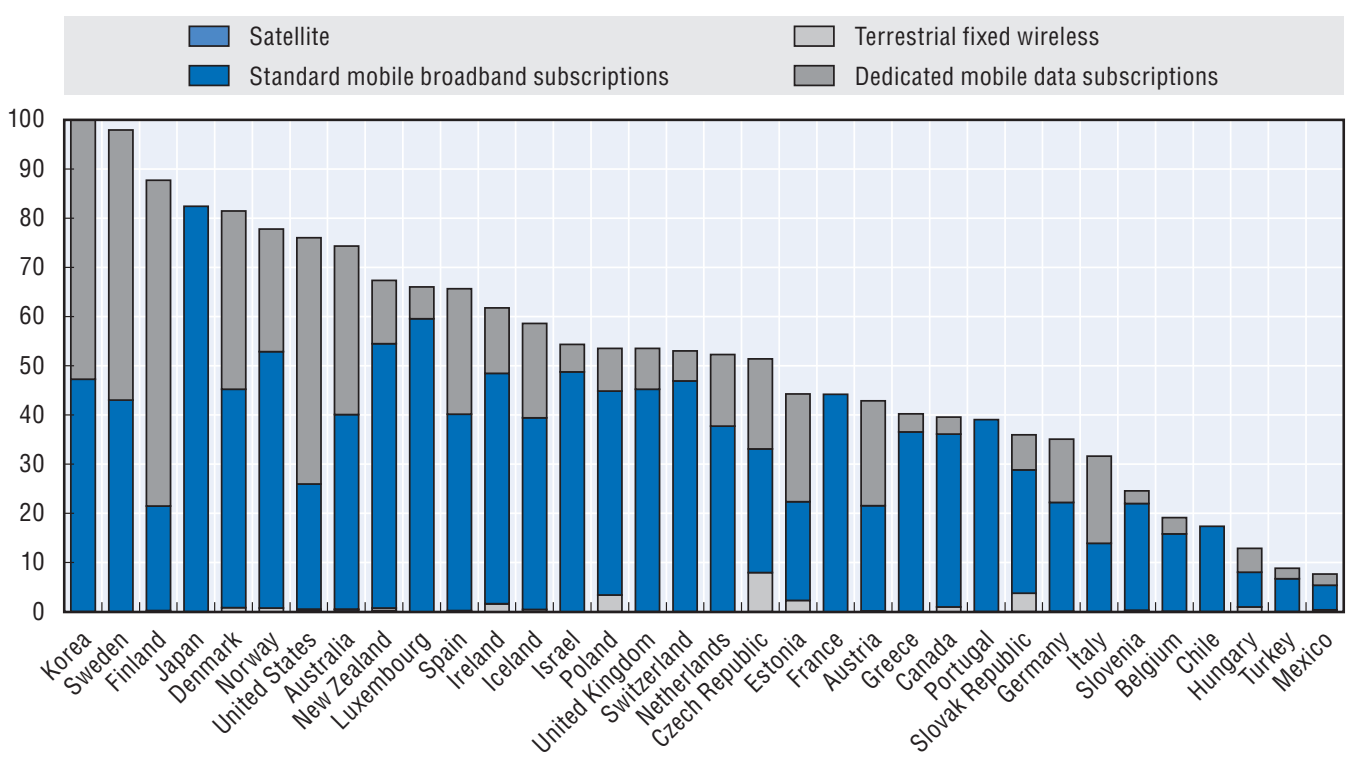

Note: Standard mobile broadband subscriptions may include dedicated mobile data subscriptions when breakdowns are not available.

Information on data for Israel: http://dx.doi.org/10.1787/888932315602.

Source: OECD Broadband statistics, July 2012.

StatLink त्तारी http://dx.doi.org/10.1787/888932693189 
The majority of wireless broadband subscriptions are via stand-alone mobile subscriptions that have a data component. Dedicated data subscriptions, where the consumer pays for data separately, account for almost 39\% of all wireless broadband subscriptions. Satellite and fixed-terrestrial connections account for a very small minority of all wireless broadband connections (Figure 3.5).

Wireless broadband has quickly become the dominant broadband access channel in OECD countries. In December 2011, there were 315 million wired and 667 million wireless broadband subscriptions throughout the OECD. Standard mobile subscriptions with wireless broadband access outnumbered DSL subscriptions by more than two-to-one in the OECD in December 2011.

\section{Figure 3.5. Breakdown of wireless broadband subscriptions in OECD countries}

By technology, December 2011

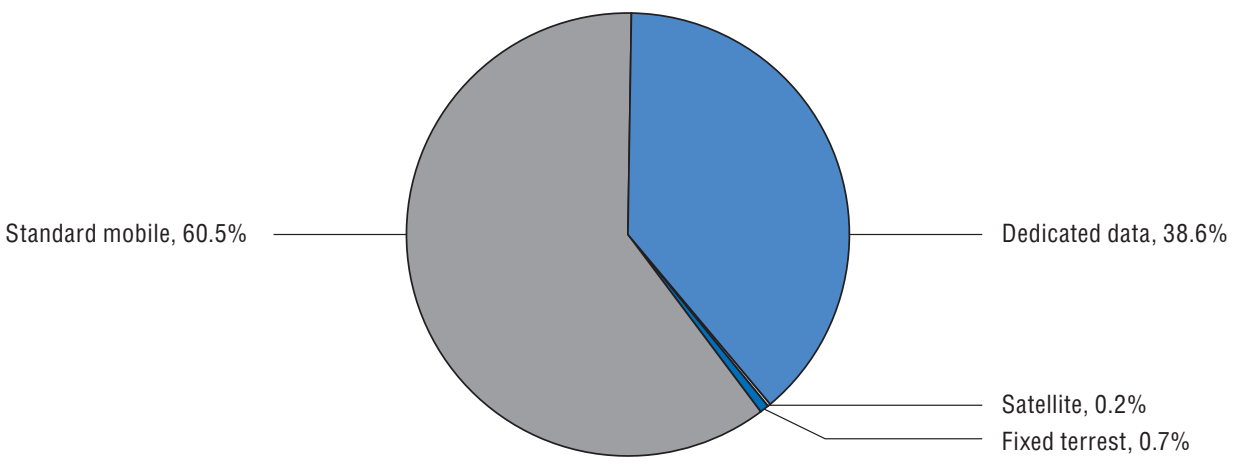

Source: OECD Broadband statistics, July 2012.

Survey data asking individuals if they use a mobile phone (or smartphone) to access the Internet via a broadband connection can be used to complement information on wireless broadband subscriptions. The number of people who use portable devices to access the Internet and in particular those who say they use a mobile phone are shown in Figure 3.6. In 2010, more than one out of five Internet users in Iceland, Luxembourg, Norway, Spain and Sweden reported using a mobile phone with an Internet connection, while in Korea it is one out of three Internet users.

The shift to accessing the Internet via a mobile device is a key trend since 2010, and the evolution of smartphones has changed the surfing behaviour of individuals. One way to examine this shift is to look at the types of devices that are visiting websites. In an analysis of Internet traffic, measured as browser-based page views from ten selected global markets in August 2011, Singapore had the highest share coming from non-computer sources (i.e. connected devices and mobile phones) at 7.2\% (comScore, 2011). The United Kingdom and United States followed closely, each with $6.8 \%$ of total Internet traffic coming from mobile and connected devices (Figure 3.7). This trend is expected to continue as smartphones increasingly replace older mobile phones and mobile data plans become the norm. 
Figure 3.6. Individuals using portable devices to access the Internet, 2010

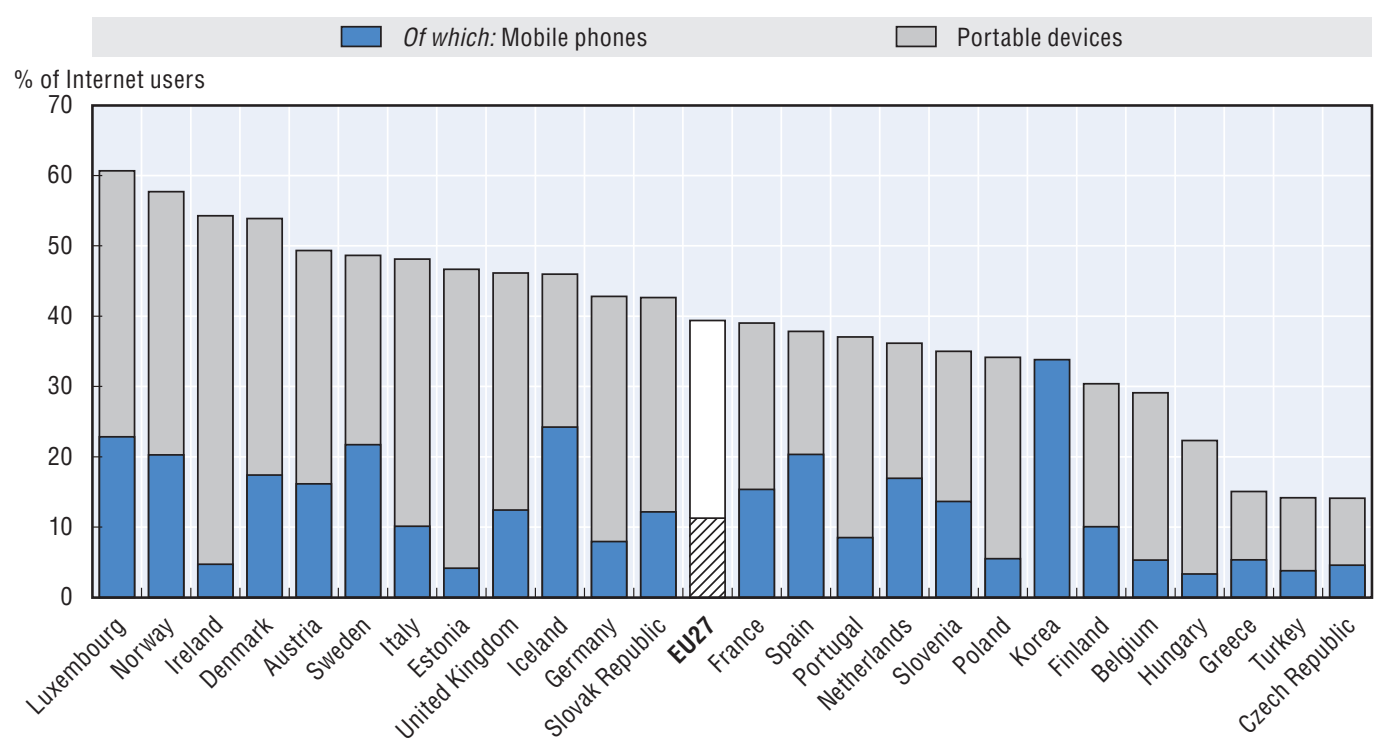

Notes: Portable devices refer here to mobile phones or smartphones, handheld computers, PCs or any other mobile devices used to access the Internet. Data from the EU Community Survey covers EU countries plus Iceland, Norway and Turkey. Internet users are individuals aged 16-74 who used the Internet in the last three months for countries covered by Eurostat and 12 months for other OECD countries. For Finland: Data on the use of a mobile phone is only available for 2009. Korea only reports data on the use of mobile phones.

Source: OECD ICT Database and Eurostat Community Survey on ICT usage in households and by individuals, May 2012.

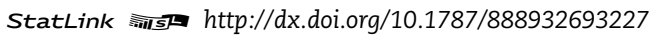

Figure 3.7. Non-computer devices traffic in selected countries As percentage of total Internet traffic

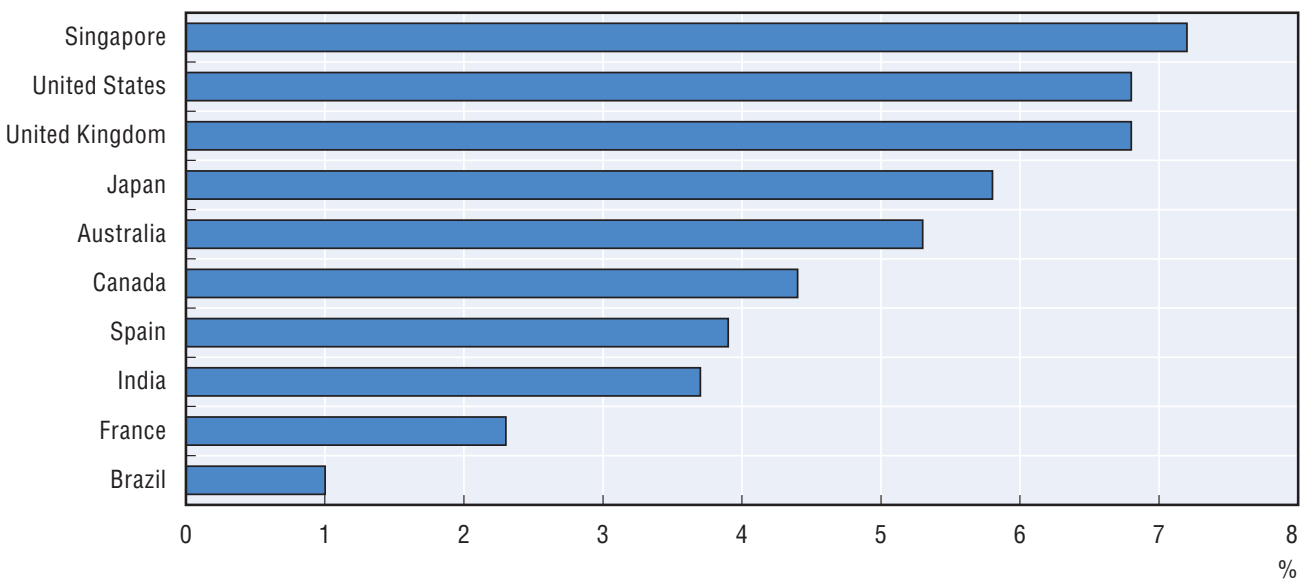

Note: Internet traffic is measured as browser-based page views. Source: Based on comScore Device Essentials, August 2011. 


\section{Internet access largely takes place in the home}

Smartphones are leading to a surge in mobile broadband usage, but Internet access still largely takes place in the home. Data from Europe show that the percentage of individuals accessing the Internet from home has increased considerably between 2005 and 2011 , from almost $40 \%$ to over $66 \%$. Over the same time period, the percentage of individuals accessing the Internet at work has moderately increased and those accessing at school has remained stable (Figure 3.8 left). In 2011, almost $90 \%$ of young people reported accessing the Internet from home and around $45 \%$ from an educational institution (Figure 3.8 right). In other non-European OECD countries, the levels of access from home are higher than European Union member countries. For example, data from surveys show that four out of five individuals in Canada and Switzerland use the Internet from home. The United States and Australia report more than 70\%. Also, Korea reports that $80 \%$ of the Internet users are using the Internet from home.

Figure 3.8. Internet access by place, EU27

Percentage of total individuals

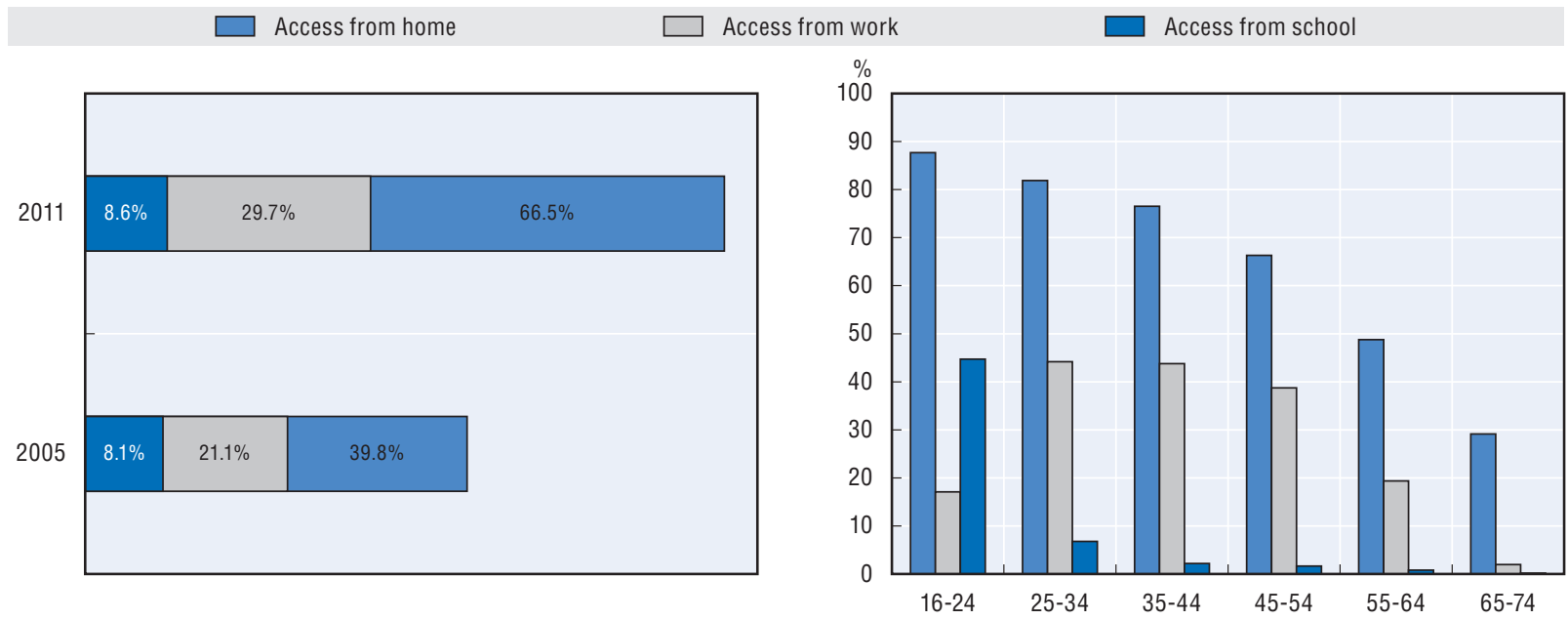

Source: Based on Eurostat, Community Survey on ICT usage in households and by individuals, May 2012.

\section{Scope of activities}

As the Internet becomes a pervasive part of daily lives, the ways in which people use connectivity will continue to evolve. The Internet was initially a medium to exchange text-based e-mail and basic information, which could be displayed on a website. By 2011, the Internet had become a repository for digital elements of daily lives. The Internet is increasingly relied upon for communicating, shopping, learning and work.

\section{How is the Internet being used?}

\section{Communicating}

The Internet is, first and foremost, a tool for communication. On average, more than $65 \%$ of adults in OECD countries report using the Internet to send e-mails or make voice calls, and in some countries this figure rises to nearly $90 \%$ of adults (Figure 3.9). The gains between 2007 and 2010 are significant, and it is clear that at these growth rates the Internet will be used by nearly all adults in the economy for some type of communication within a few years. 
Figure 3.9. Individuals who used Internet for communicating, 2010 or latest available year

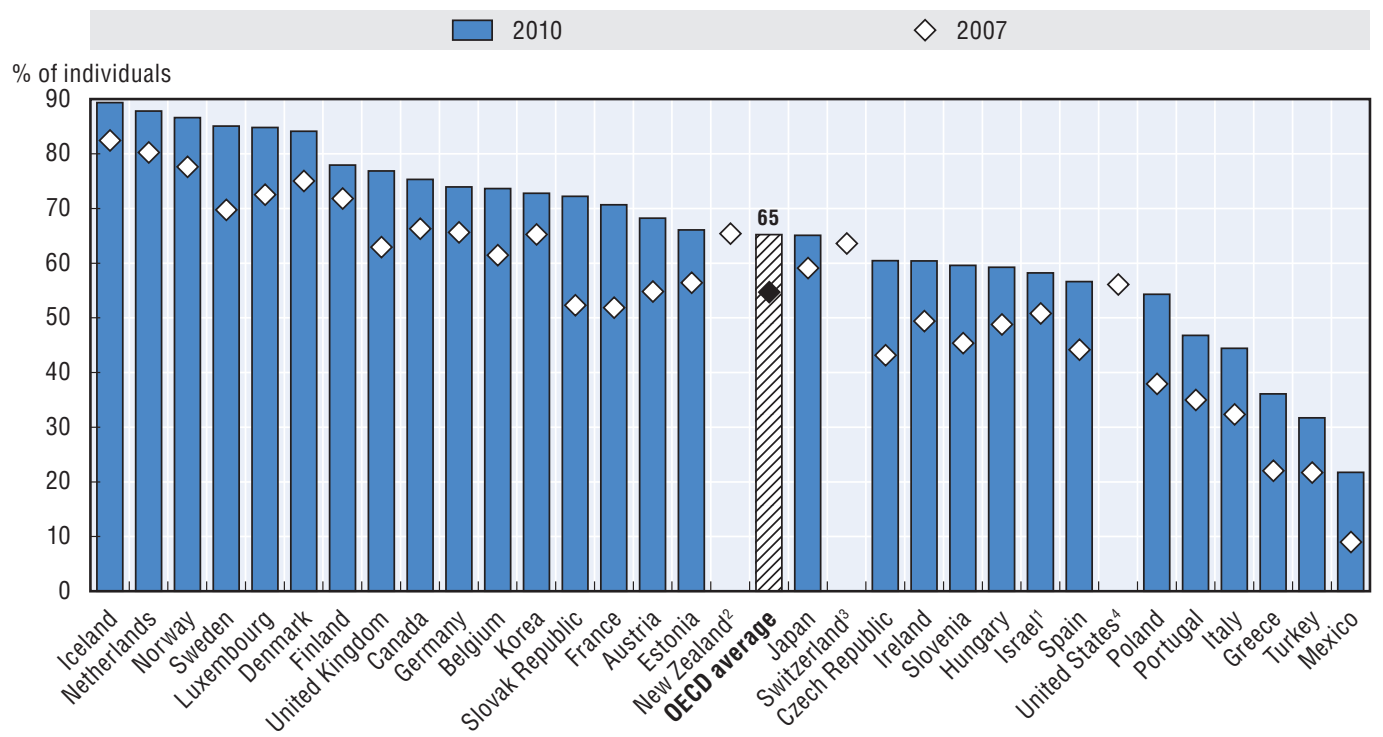

Note: Individuals aged 16-74 years, except for Canada (16+), Israel (20-74), Japan (6+), Switzerland (14+). For countries covered by Eurostat, individuals were asked about activities they had carried out on the Internet in the last three months. For the other OECD countries, it generally refers to the last 12 months. Data generally refer to communicating for Eurostat countries. For Israel, Japan, Mexico, New Zealand and Switzerland data refer to sending and/or receiving e-mails only. For Korea, data refer to sending/receiving e-mails and making voice calls (VoIP). For the United States data refer to e-mail or instant messaging.

Information on data for Israel: $h t t p: / / d x . d o i . o r g / 10.1787 / 888932315602$.

1) 2009 ; 2) 2006; 3) 2005; 4) 2003.

Country notes: For Israel: Data refer to the use of Internet in the last 3 months. For Japan: Internet Users accessing from personal computers and mobile phone. For Switzerland: Data refer to Internet users who used the Internet at least once within the last six months.

Source: OECD ICT Database and Eurostat, Community Survey on ICT usage in households and by individuals, May 2012. Canadian Internet Use Survey, 2010 from Statistics Canada.

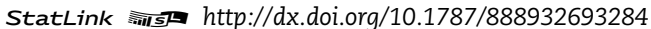

The Internet has increasingly become a platform for distributing user-created content. Initially, consumers and businesses created web pages to share information and relied upon user visits for dissemination. But the rise of social media platforms such as Facebook, Twitter and YouTube has greatly facilitated content upload to the Internet, side-stepping the need for stand-alone websites. A significant number of users still reported creating a web page in 2011 and the leading six countries saw gains between 2007 and 2011. In the majority of countries however, the number of users reporting they had created a web page decreased (Figure 3.10). This fall in website creation activity is linked to the rise in use of weblogs (or "blogs") and social media such as Twitter for personal communication. At the end of 2011, the number of blogs hosted by two of the major blog service providers (Tumblr and WordPress) reached 110 million and Twitter reported 100 million active users (Pingdom, 2012).

The widespread usage of social media sites such as Facebook is one of the most important trends to appear over the past two years. The interactive nature of social media has helped make social media sites the most visited sites on the Internet in many countries. Recent data show that more than 8 out of 10 Internet users visit a social networking destination (comScore, 2011). 
Figure 3.10. Internet users who created a web page, 2011 or latest available year

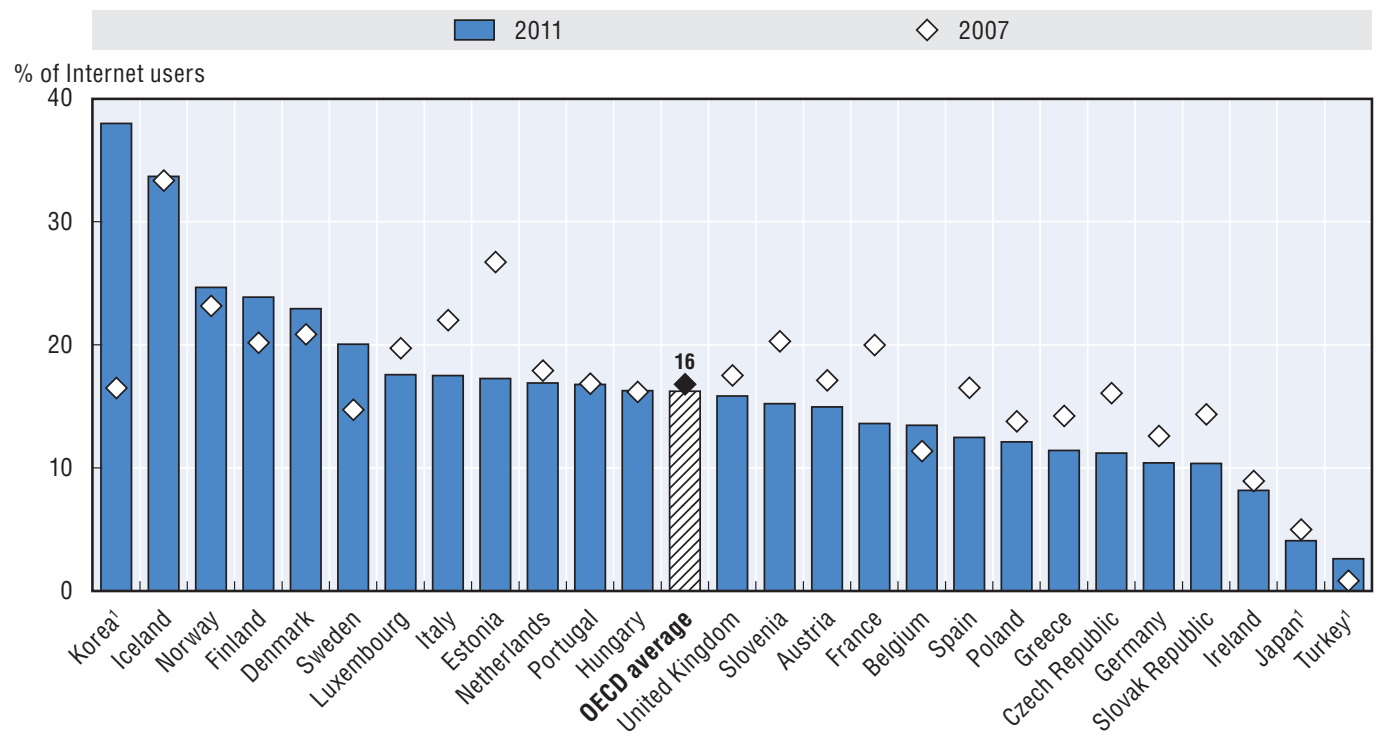

Note: Data from the EU Community Survey covers EU countries plus Iceland, Norway and Turkey. Internet users are considered for this figure as individuals who have ever used the Internet for countries covered by Eurostat. For countries covered by the OECD ICT questionnaire, data are presented as a percentage of individuals with the exception of Japan and Korea. Individuals aged 16-74 years, except for Japan (6+). Country notes: For Japan: Internet users accessing from personal computers and mobile phone. For Korea: Minihomepages ("minihompys") and web pages.

1. 2010.

Source: OECD ICT Database and Eurostat Community Survey on ICT usage in households and by individuals, May 2012.

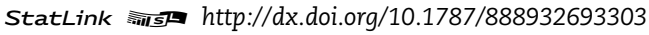

Nearly 50\% of OECD Internet users are active social network users. In 2010, at least $60 \%$ of Internet users in Poland, Portugal, Turkey and the United States engaged in social networking on the web (OECD, 2011). In the EU27 area, also in 2010, 32\% of Internet users uploaded self-created content to websites to be shared. Statistics show that these activities are particularly notable among European youth; over $80 \%$ used the Internet for posting messages to social media sites or sending instant messages and over $50 \%$ used the Internet to upload self-created content to share (Figure 3.11). Facebook has become the largest social networking site on the Internet and had 800 million users at the end of 2011. In some countries, the level of participation is very high; three out of four Internet users in Hungary and Iceland participated in social networks in 2011 (Figure 3.12). Specialised social networks in some areas complement individuals' activities on Facebook (e.g. LinkedIn, DeviantArt). In some regions of the world, other social networking sites are more prominent than Facebook (e.g. Badoo, Orkut, VK).

\section{E-commerce/e-banking}

The Internet is an important platform for commerce. People increasingly buy online or use the Internet to locate information about goods and prices before they buy products (either online or off). This is often referred to as "window shopping". The Internet can significantly reduce the search costs of locating information about products and comparing prices, which leads to a more efficient market for goods and services. 


\section{Figure 3.11. Demographics of social networking activity in the EU27 area, 2010}

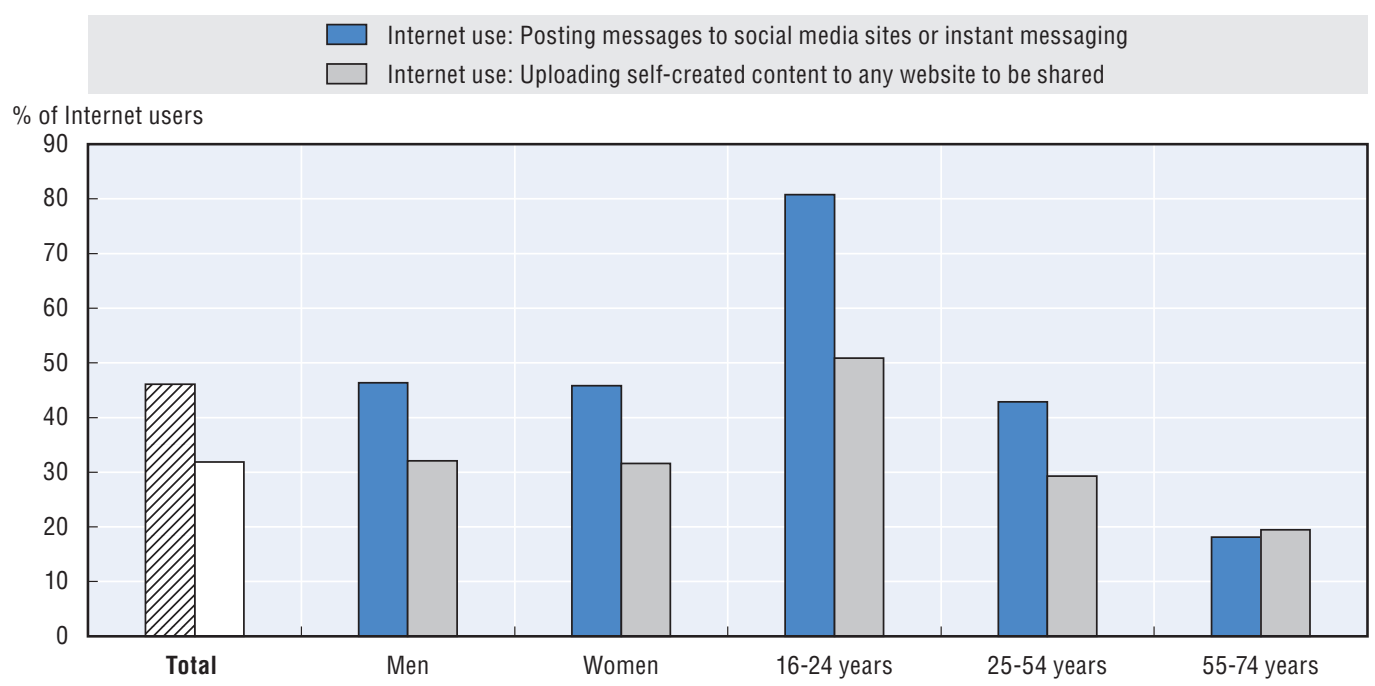

Source: Based on Eurostat Community Survey on ICT usage in households and by individuals, May 2012.

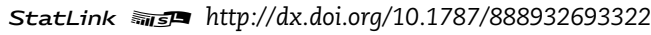

Figure 3.12. Internet users engaging in social networking, 2011

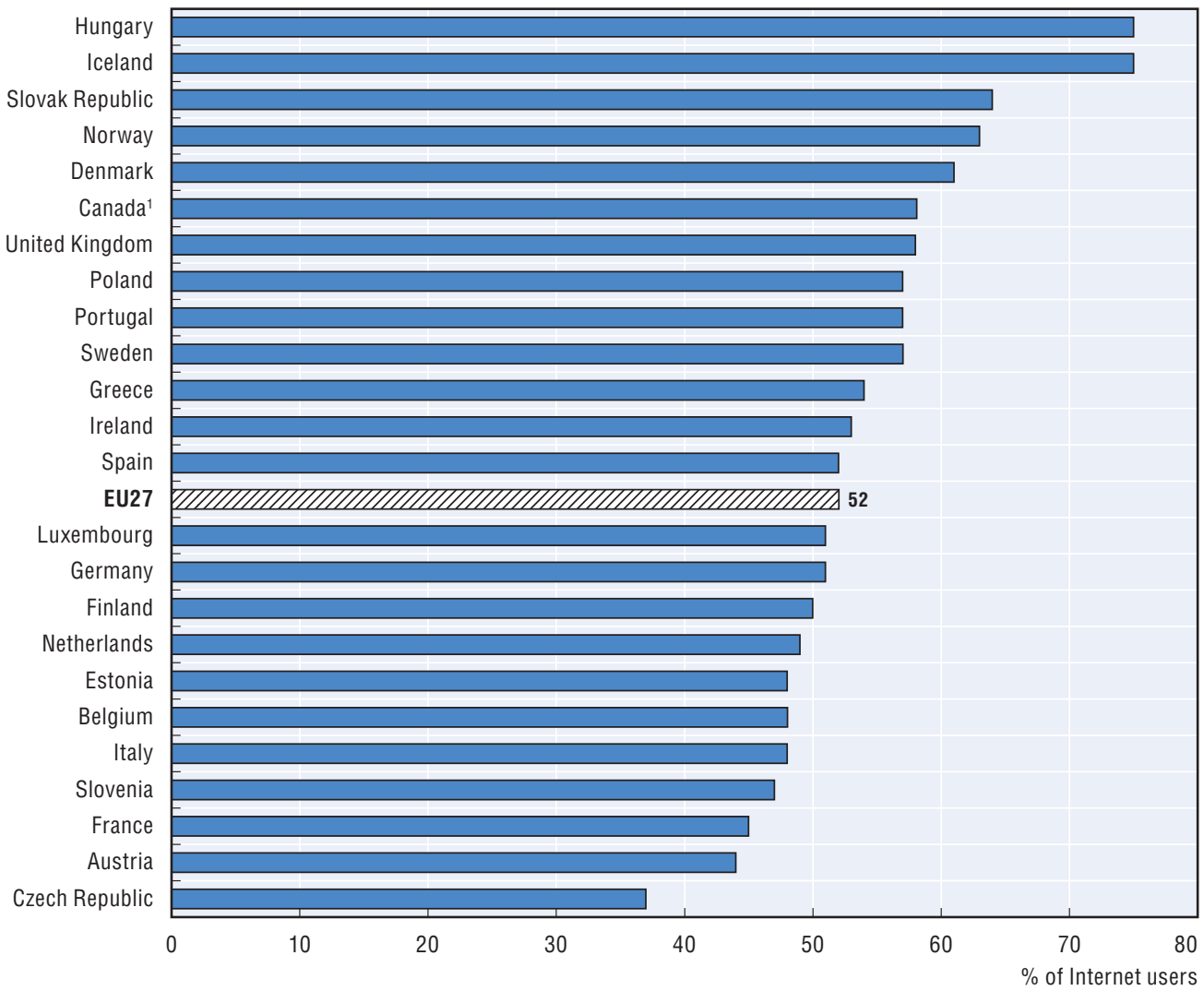

Note: Engaging in social networking is considered as creating a user profile and posting messages or other contributions to Facebook, Twitter, etc. Internet users are considered for this figure as individuals who have used the Internet in the last three months for European countries. Individuals aged 16-74 years, except Canada (16+). 1. 2010.

Sources: Based on Eurostat Community Survey on ICT usage in households and by individuals, May 2012. Canadian Internet Use Survey, 2010 from Statistics Canada.

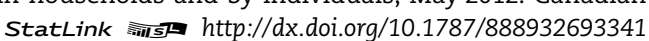


Firms, both large and small, use the Internet to sell goods and services. In a way, the Internet has become an important equaliser for many small firms wishing to sell products on a national or global scale. A small firm offering goods on the Internet, in many ways, can now compete more effectively with much larger firms because of the Internet. This is important because the target audience is growing. More than $30 \%$ of people in the OECD buy goods or services over the Internet (Figure 3.13). In the United Kingdom, almost $64 \%$ of individuals engage in e-commerce, followed by Australia, Denmark, Germany, Korea, Luxembourg, the Netherlands, Norway and Sweden with more than 50\%.

\section{Figure 3.13. Individuals who ordered or purchased goods or services on the Internet, 2011 or latest available year}

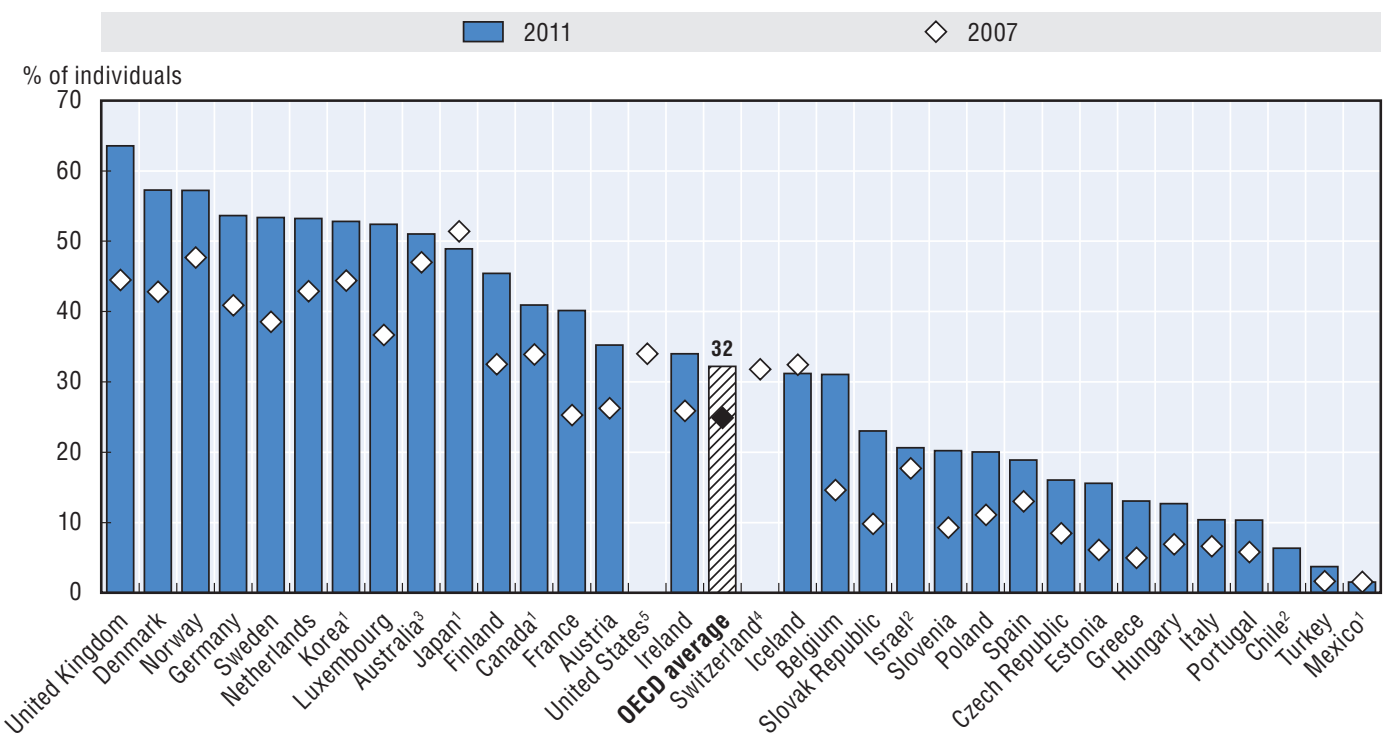

Note: Data from the EU Community Survey covers EU countries plus Iceland, Norway and Turkey. It refers to individuals aged 16-74 years, except for Canada (16+), Israel (20-74), Japan (6+), Switzerland (14+). Data refer to individuals who have bought or ordered goods or services over the Internet, for non-work use, in the last three months (for countries covered by Eurostat). For the rest of the OECD countries it refers to individuals placing orders over the Internet in the last 12 months.

Information on data for Israel: http://dx.doi.org/10.1787/888932315602.

1) 2010; 2) 2009; 3) 2008; 4) 2005; 5) 2003.

Sources: OECD ICT Database and Eurostat Community Survey on ICT usage in households and by individuals, May 2012. Canadian Internet Use Survey, 2010 from Statistics Canada.

StatLink त्ताइ http://dx.doi.org/10.1787/888932693360

There are many reasons that people choose to shop online (Box 3.1), but for many the Internet is more convenient for many types of goods and services. Standard goods such as books, videos and packaged products are often identical across sellers, and consumers are able to compare prices easily on the Internet. In other cases, users have access to significantly more information online about products than they would if they were shopping in a retail store. 


\section{Box 3.1. Time matters in Japan}

In 2010, the main reason cited by Japanese people for choosing to shop online was flexibility regarding business hours. At least one out of two people stated that they buy online because they can purchase or trade things regardless of shop hours. The second-most important consideration was saving money by not physically going to the store. The third was the ability to comparison shop.

Figure 3.14. Reasons for shopping online in Japan, 2006 and 2010

Percentage of individuals

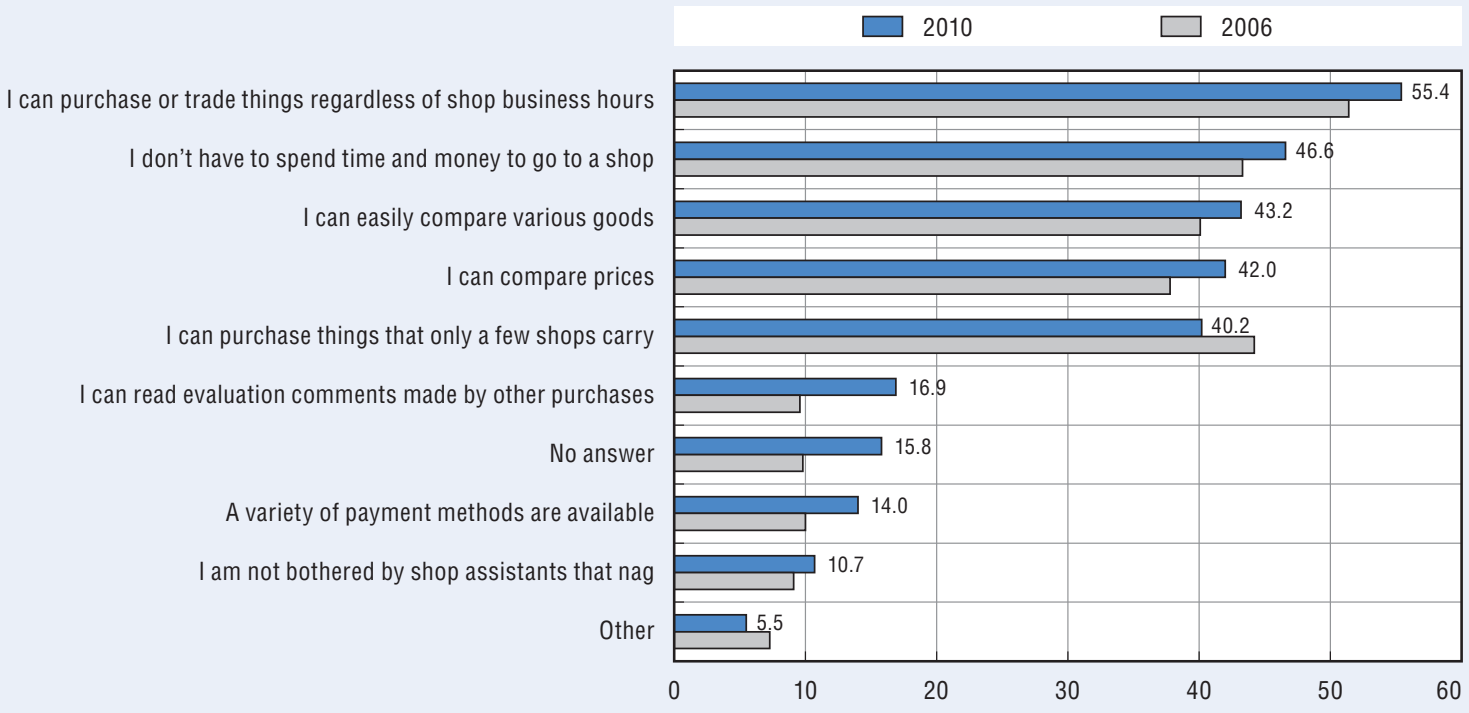

Source: Based on Communications Usage Trend Survey in 2010, Ministry of Internal Affairs and Communications of Japan (MIC).

StatLink ज्ञात http://dx.doi.org/10.1787/888932693379

An important Internet trend is the growth of sites that provide customer reviews of products as a way to guide the purchases of others. This volume of supplemental information was largely unavailable in traditional retail sectors and consumers typically had to rely on word of mouth from people they knew before buying "experience goods" for the first time. Product reviews on the Internet have greatly expanded the "word of mouth" network, and the Internet has reduced the transaction costs of obtaining information about experience goods before purchase.

In the EU27 area, the most commonly purchased goods and services on the Internet in 2011 among those who purchased online for private use are travel and holiday accommodation and clothes and sporting goods (both at 52\%), followed by books/ magazines/e-learning material and household goods (both at $38 \%$ ), tickets for events (37\%) and films/music (29\%) (Figure 3.15). Purchasing digital content is also increasing in Europe. In the EU27 area, one out of four people ordering online bought digital content in 2011. Denmark and Norway were the biggest digital content consumers with almost $30 \%$ of the population aged 16-74 years buying and downloading content in 2010.

Many of these goods are identical across retailers or possess characteristics easily evaluated across providers. These types of goods are often referred to as "search goods". For example, customers purchasing films online can expect the content to be the same regardless of the supplier they choose to buy from. Consumers can find the same product 
Figure 3.15. Goods and services ordered in the last 12 months for EU27, 2011 Percentage of individuals who ordered goods or services, over the Internet, for private use, in the last year

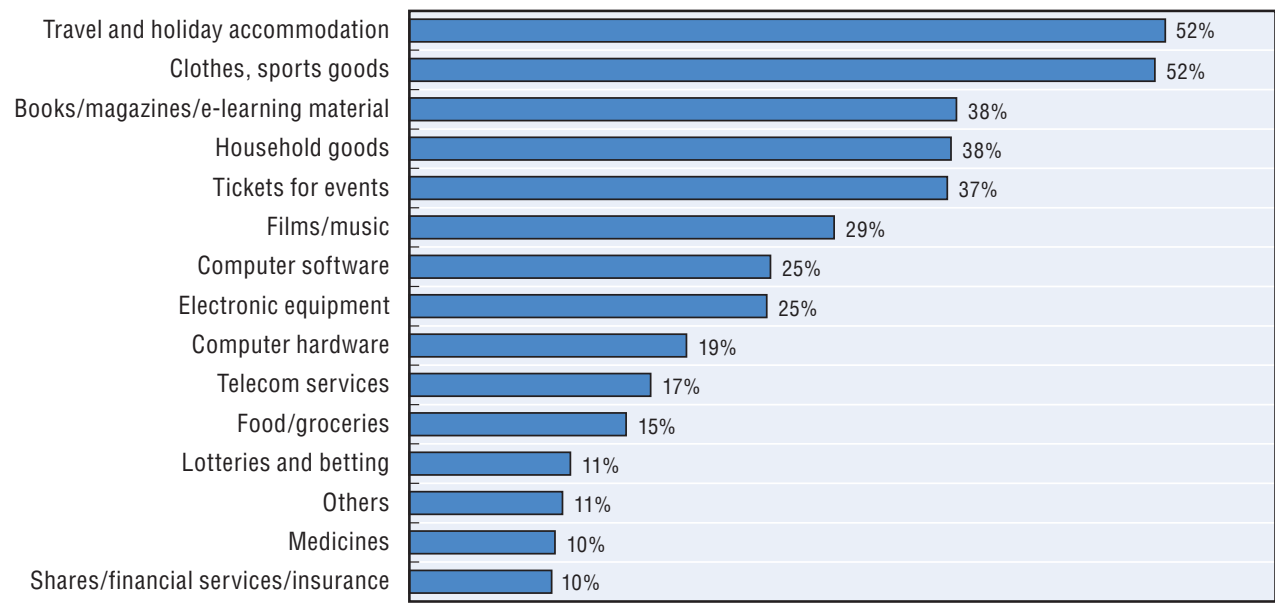

Note: Telecom services refer to, for example, TV, broadband or subscription, uploading money on prepaid phone cards. Source: Based on Eurostat Community Survey on ICT usage in households and by individuals, May 2012.

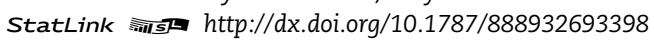

online from multiple retailers and simply choose the supplier with the lowest price. The Internet brings together a much larger variety of suppliers than would have been possible otherwise, so price competition becomes more intense.

The following table provides a breakdown of the types of goods and services purchased or traded on the Internet in Japan over time. The leading category is digital content, followed by clothing and accessories, books/CDs/DVDs and hobby supplies (Table 3.1).

Table 3.1. Merchandise/services purchased or traded online in Japan, 2002-10

Percentage of Internet users

\begin{tabular}{|c|c|c|c|c|c|c|c|c|c|c|}
\hline & $\begin{array}{l}\text { Digital } \\
\text { content }\end{array}$ & $\begin{array}{l}\text { Clothing and } \\
\text { accessories }\end{array}$ & $\begin{array}{l}\text { Books CDs } \\
\text { and DVDs }\end{array}$ & $\begin{array}{c}\text { Hobby } \\
\text { supplies and } \\
\text { general items }\end{array}$ & $\begin{array}{l}\text { Tickets } \\
\text { coupons and } \\
\text { vouchers }\end{array}$ & $\begin{array}{c}\text { Financial } \\
\text { trading }\end{array}$ & Foodstuffs & Travel & $\begin{array}{c}\text { PCs and } \\
\text { accessories }\end{array}$ & Other \\
\hline 2010 & 40.7 & 36.0 & 34.8 & 33.0 & 24.0 & 22.2 & 22.1 & 20.5 & 17.1 & 22.2 \\
\hline 2009 & 47.4 & 32.7 & 33.6 & 30.0 & 22.6 & 23.1 & 20.5 & 19.2 & 16.6 & 19.6 \\
\hline 2008 & 49.0 & 31.8 & 32.4 & 31.0 & 21.9 & 22.7 & 19.9 & 18.3 & 17.0 & 11.3 \\
\hline 2007 & n.a & 35.1 & 39.7 & 35.2 & 25.7 & 15.5 & 24.1 & 20.8 & 22.3 & 11.0 \\
\hline 2006 & n.a & 36.1 & 40.1 & 37.0 & 25.6 & 16.6 & 21.9 & 20.4 & 23.2 & 10.8 \\
\hline 2005 & n.a & 34.8 & 38.9 & 37.8 & 26.1 & 14.3 & 21.6 & 20.4 & 23.6 & n.a \\
\hline 2004 & n.a & 23.8 & 38.7 & 26.4 & 27.1 & 8.2 & 16.1 & 15.1 & 22.5 & n.a \\
\hline 2003 & n.a & 26.9 & 39.7 & 27.7 & 27.0 & 4.8 & 18.1 & 12.1 & 24.3 & n.a \\
\hline 2002 & n.a & 16.9 & 23.8 & 19.8 & 19.1 & 3.8 & 10.8 & 9.7 & 19.7 & n.a \\
\hline
\end{tabular}

Note: Internet users aged 15 years or more and who purchased online.

Source: Communications Usage Trend Survey in 2010, Ministry of Internal Affairs and Communications of Japan (MIC).

The banking sector is also seeing significant shifts as a result of the Internet. Online banking has become a key component of nearly all bank offers, as a way to reduce costs for banks and increase customer convenience. Banks are increasingly imposing service charges on customers for bank statements mailed by post or interactions with the bank via a clerk. As an example, Westpac bank in New Zealand waives its monthly account 
maintenance fees if users stop delivery of posted statements and instead access the information online. Westpac also imposes a USD 2.40 (NZD 3) fee on manual transactions within the bank with the aid of a clerk, such as deposits, withdrawals and cheques. ${ }^{2}$ Similar fees and waivers are increasingly common in banks across the OECD area.

Data show that take-up of these services is high in OECD countries. On average, over $40 \%$ of people in OECD countries report using banking services on the Internet. The leading countries for e-banking penetration are the Nordic countries and the Netherlands, where more than $75 \%$ of individuals report using the Internet for banking purposes. Online banking use was high in many countries by 2007, but growth continued through 2011 (Figure 3.16).

\section{Figure 3.16. Individuals using the Internet for banking services, 2011 or latest available year}

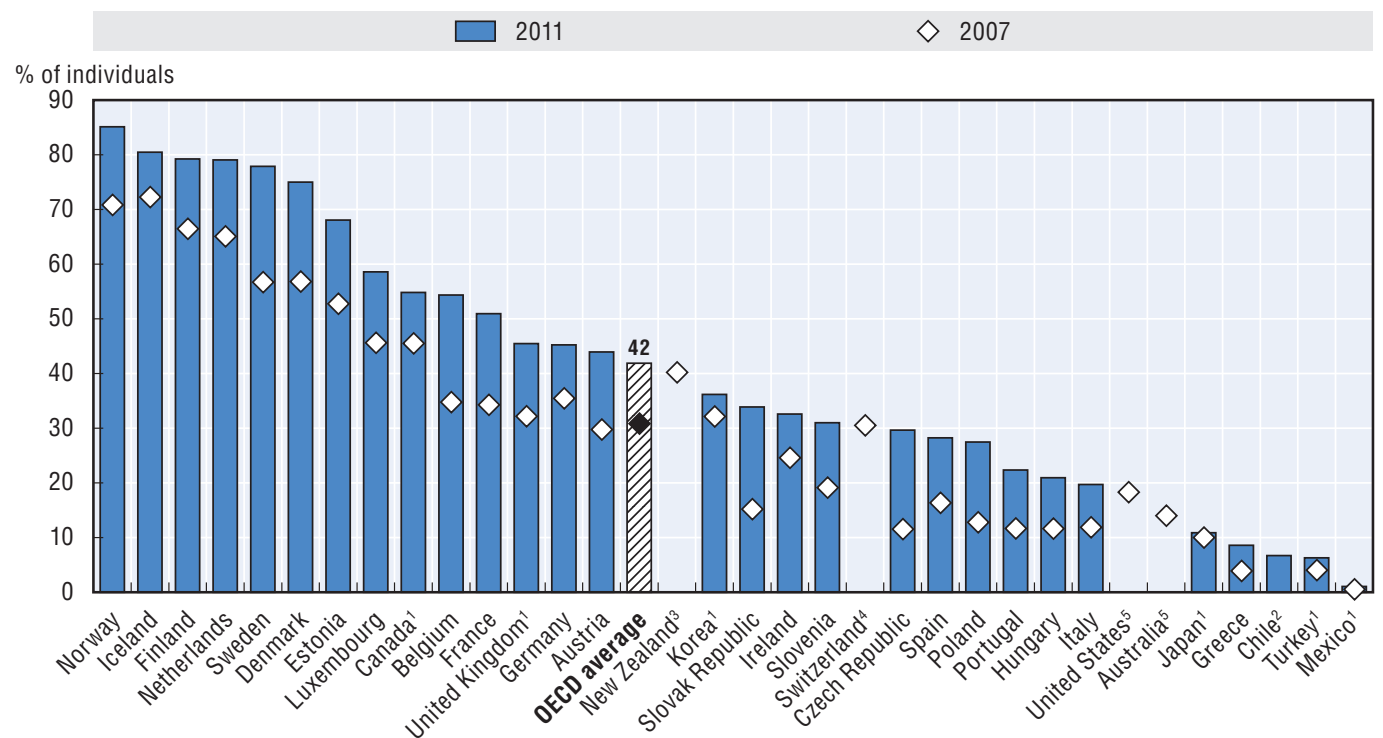

Note: Data from the EU Community Survey covers EU countries plus Iceland, Norway and Turkey. Individuals aged 16-74 years, except for Canada (16+), Japan (6+) and Switzerland (14+). For countries covered by Eurostat, individuals were asked about activities they had carried out on the Internet in the last three months. For the other OECD countries, it generally refers to the last 12 months. Country notes: For Switzerland: Data refer to Internet users who used the Internet at least once within the last six months.

1) 2010; 2) 2009; 3) 2006; 4) 2005; 5) 2003.

Source: OECD ICT Database and Eurostat Community Survey on ICT usage in households and by individuals, May 2012. Canadian Internet Use Survey, 2010 from Statistics Canada.

StatLink 게에 $h t t p: / / d x . d o i . o r g / 10.1787 / 888932693417$

The type of device used to access online banking has changed significantly over the last three years with the mobile phone becoming a key entry point in addition to traditional access via a PC. Most banking websites offer a dedicated version of their website that presents content in a way easily readable on mobile phones. In the United States, Bank of America reported 6 million mobile banking subscribers in May 2011 (Bank of America, 2011). In addition, some banks have standalone applications for e-banking available on Apple's iOS and Google's Android platform for mobile phones and tablets. These applications provide secure connections and easy access to key account functions. 


\section{Education}

The Internet is becoming an increasingly important platform for learning, both in formal and informal settings. In the United States, MIT and Stanford University make some classes available online to the general public for free. In December 2011, MIT announced the creation of MITx, an online interactive learning platform available on the Internet free of cost for people and schools to use (MIT, 2011). Stanford also has an online option whereby videos of classes and copies of slides shown are posted online on a dedicated webpage for a few days after each class meeting. ${ }^{3}$ Sanford has developed its programme in cooperation with Apple. In terms of economic benefits for individuals, the content provided by universities online constitutes a great opportunity to acquire state-of-the-art knowledge. For the universities, it is a novel way of demonstrating teaching quality and the richness of the curriculum.

Learning resources on the Internet need not be tied to formal academic institutions. The Kahn Academy is a site offering thousands of educational training videos on subjects ranging from mathematics to art history and finance. ${ }^{4}$ The project started as a way for Salman Khan to tutor his niece remotely over the Internet. In December 2011, the site reported over 90 million distributed lessons worldwide.

Statistics on the use of the Internet for learning show that almost half of all Internet users say they use the Internet for formalised educational activities (Figure 3.17). There is a large variation across OECD countries: more than $70 \%$ of users in Finland, Iceland, Luxembourg and Portugal report using the Internet for formal learning, while in four countries the number of users is lower than $30 \%$.

Figure 3.17. Internet use for learning, $\mathbf{2 0 1 0}$ or latest available year

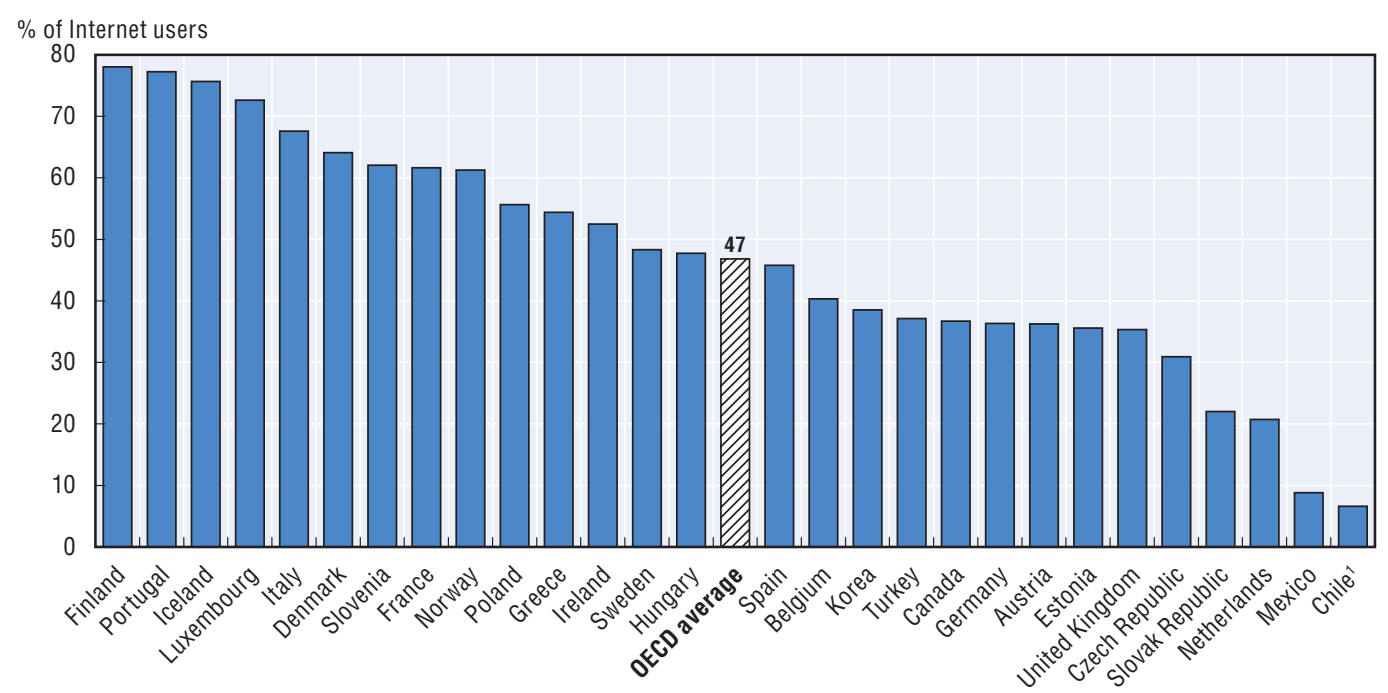

Note: Data from the EU Community Survey covers EU countries plus Iceland, Norway and Turkey. For countries covered by Eurostat, individuals were asked about activities they had carried out on the Internet in the last 3 months. For the other OECD countries, it generally refers to the last 12 months. Internet users are considered for this figure as individuals who have used the Internet in the last 3 months for countries covered by Eurostat. For Chile, data is presented as a percentage of individuals.

1. 2009.

Source: OECD (2011), The Future of the Internet Economy: A Statistical Profile, June 2011 Update. Canadian Internet Use Survey, 2010 from Statistics Canada. 
In 2011, more than $70 \%$ of OECD households reported having access to Internet at home. Yet, formalised education still takes place largely in classrooms in schools. Connecting schools to the Internet has been a key ICT policy goal in OECD countries for the last 10 years and data show that, for the most part, these goals have been accomplished.

Figure 3.18. Schools with Internet connection and usage, 2009

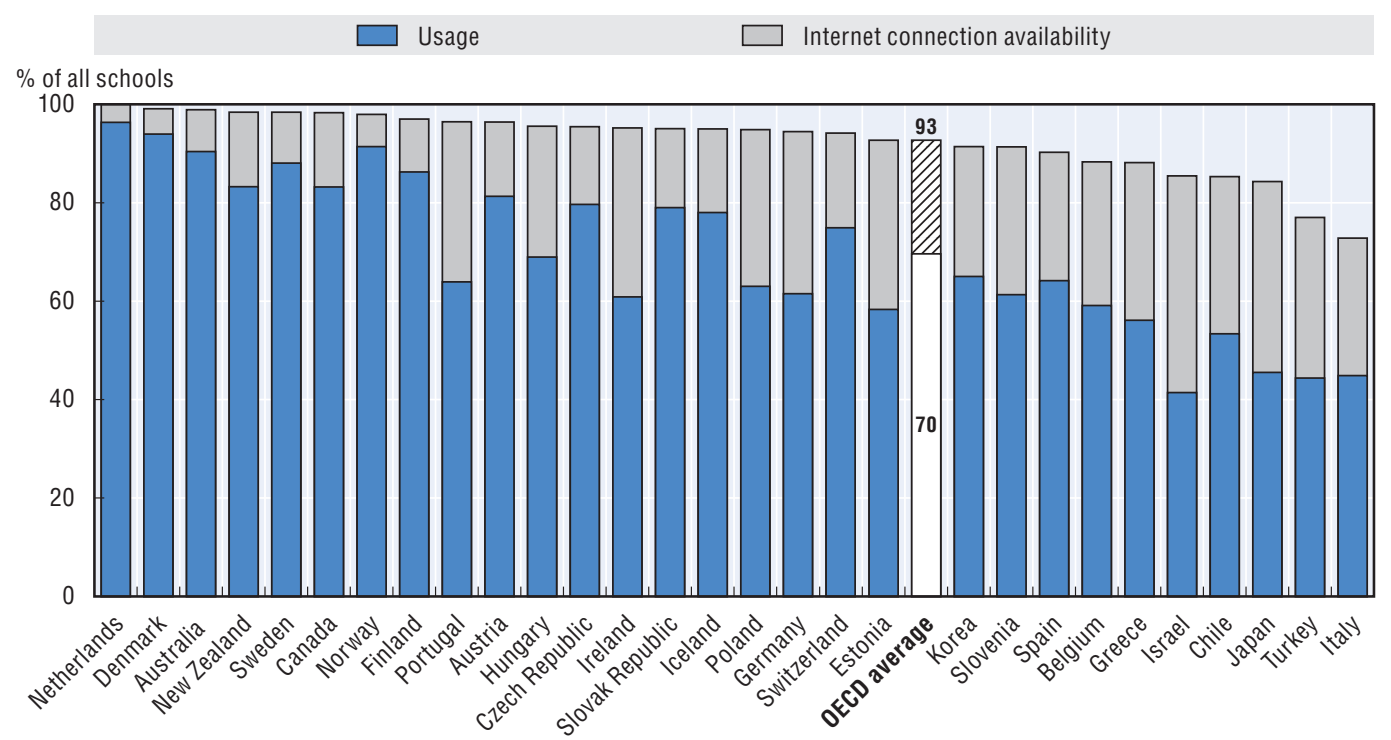

Note: Information on data for Israel: $h t t p: / / d x . d o i . o r g / 10.1787 / 888932315602$.

Source: OECD Programme for International Students Assessment, PISA 2009 ICT questionnaire. Based on students' self-reports as to whether an Internet connection is available for the student to use at school and whether the student reports that Internet is available and that he/she uses it.

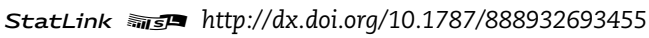

While the goal of connecting schools has largely been achieved, the data show that there is still work to be done in improving Internet use at schools. Only $70 \%$ of students reported using the Internet at school, even though over $90 \%$ of schools provide students with an Internet connection (Figure 3.18). Access to the Internet for education has steadily improved in OECD countries, although usage among students could still increase.

\section{Finding employment}

The economic crisis, which began in 2008 , continues in relation to employment. Policy makers are looking to boost employment in an era of lower economic performance. The Internet helps labour markets function more efficiently by helping to match job seekers with employers seeking specific skills or qualifications.

In $2011,18 \%$ of adults in the OECD area reported using the Internet to search for a job (Figure 3.19). That number was considerably higher in countries such as Canada, Denmark, Finland, Iceland, Korea, Norway and the United Kingdom, where more than $25 \%$ of adults used the Internet to look for a job. These numbers point to a more general trend where traditional government employment agencies have lost ground to online job marketplaces such as Monster over the past decade. In France, for example, candidates channelled via the public employment service provider fill less than one in five job vacancies (OECD, 2012). Individuals in other OECD countries are also increasingly using the employment mediation services of commercial Internet companies. 


\section{Figure 3.19. Individuals using the Internet for job searches, 2011 or latest available year}

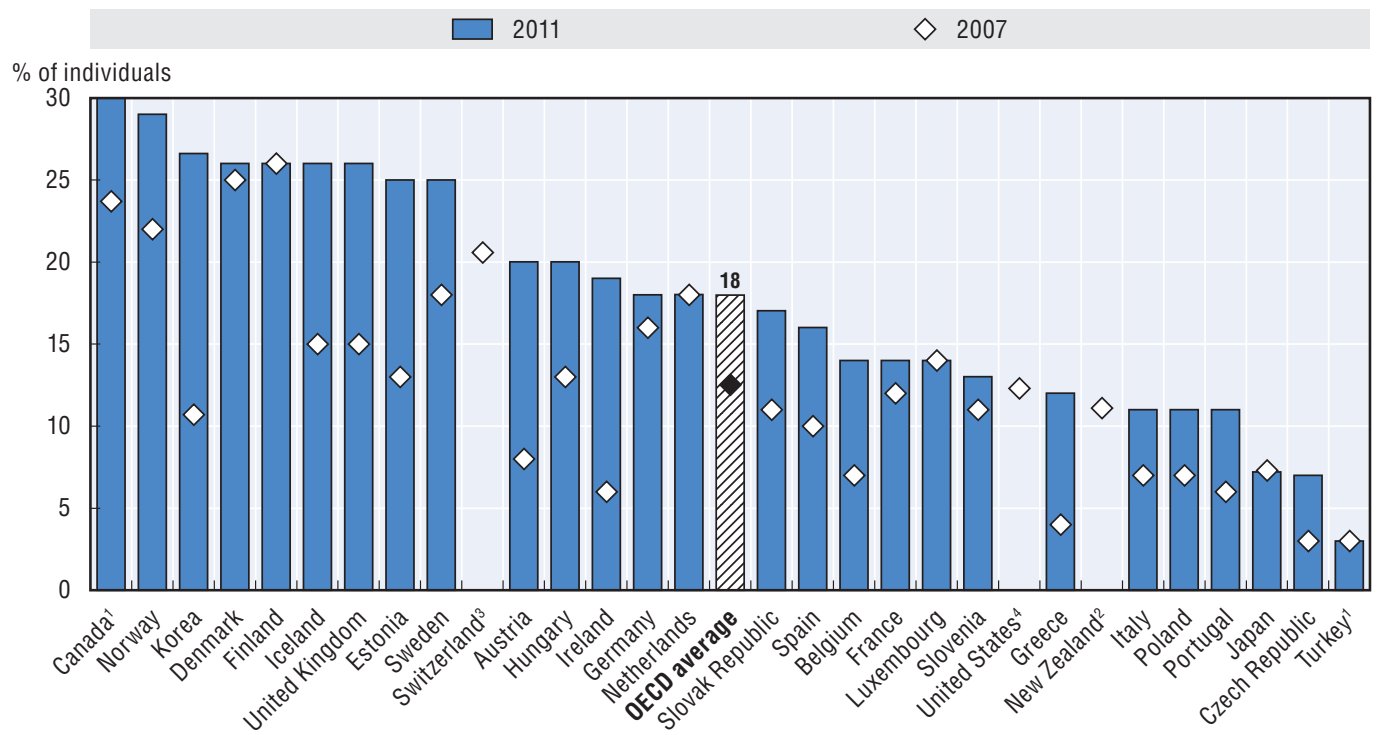

Note: Data from the EU Community Survey covers EU countries plus Iceland, Norway and Turkey. Individuals aged 16-74 years, except for Canada (16+), Japan (6+), Switzerland (14+). For countries covered by Eurostat, individuals were asked about activities they had carried out on the Internet in the last three months. For the other OECD countries, it generally refers to the last 12 months. Data refer for Eurostat countries to individuals who used the Internet in the last three months for job research or for sending job applications. Country notes: For Switzerland: Data refer to Internet users who used the Internet at least once within the last six months.

1) 2010; 2) 2006; 3) 2005; 4) 2003.

Source: OECD ICT Database and Eurostat Community Survey on ICT usage in households and by individuals, May 2012. Canadian Internet Use Survey, 2010 from Statistics Canada.

StatLink त्नाIst http://dx.doi.org/10.1787/888932693474

\section{Government interaction}

As connectivity becomes commonplace among firms and households, governments invest more resources to deliver services and information via the Internet. This connectivity is expected to bring improvements to government efficiency, internal and external information sharing, and collaboration with citizens and stakeholders.

People use the Internet to interact with government in many ways. These range from simply obtaining information from websites to more complex two-way interactions such as vehicle registration, e-voting and the joint use of public sector information (PSI) or "open data". In the past, governments typically chose methods of interaction that provided access to the largest percentage of the population. Whereas the number of Internet connections was previously limited, developments over the last five years have seen connectivity reach $70 \%$ of households, and the high penetration of mobile phones as Internet-enable devices has dramatically increased the potential reach of online government services.

Across the OECD, 39\% of citizens use the Internet to obtain information from the public authorities' websites in 2011. These numbers are significantly higher in the Nordic countries, reaching more than two thirds of the adult population in Denmark, Iceland, Norway and Sweden (Figure 3.20). 
Figure 3.20. Individuals using the Internet to obtain information from the public authorities' websites, 2011 or latest available year

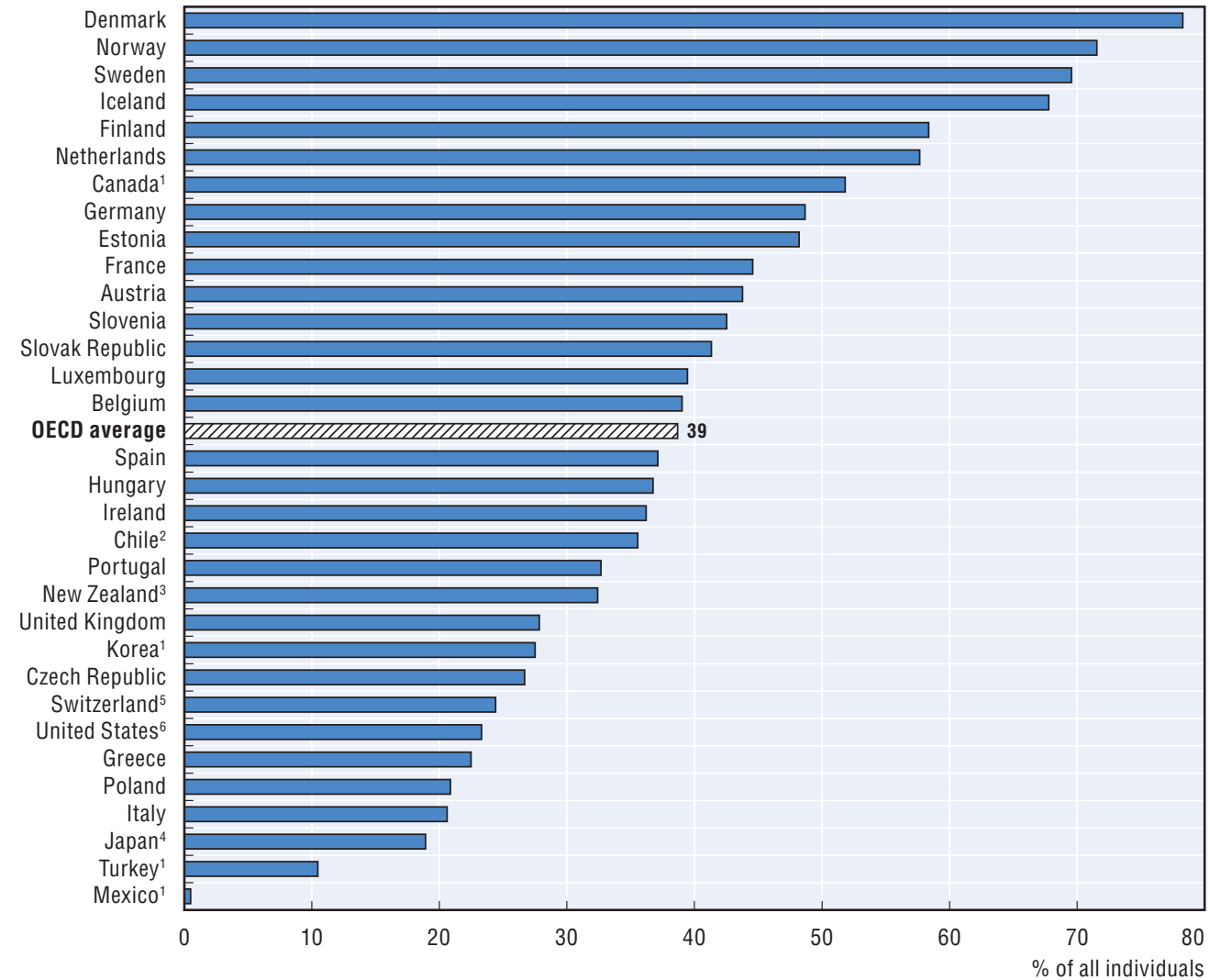

Note: Data from the EU Community Survey covers EU countries plus Iceland, Norway and Turkey. Data in this chart refer to Internet use in the last 12 months for all countries. Individuals aged 16-74 years, except for Canada (16+), Japan (6+) and Switzerland (14+). For Canada, the figure responds to the question "to visit or interact with government websites". 1) 2010; 2) 2009; 3) 2006; 4) 2005; 5) 2004; 6) 2003.

Sources: OECD ICT Database and Eurostat Community Survey on ICT usage in households and by individuals, May 2012. Canadian Internet Use Survey, 2010 from Statistics Canada.

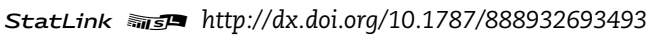

One area where the Internet has had a significant and visible impact is the collection of taxes. The number of online tax declarations has grown significantly since the year 1999 (Figure 3.21). Governments are keen for more taxes to be filed online as it improves and accelerates collection, produces cost savings, and can help to raise awareness and confidence among citizens regarding the use of other online government services.

\section{Entertainment}

The Internet is often discussed in terms of its potential to boost productivity, but it is also transforming entertainment. One of the leading sectors in terms of digital content distribution is the game industry (OECD, 2010b). Gaming is not a niche market; nearly $30 \%$ of all individuals in the OECD used the Internet for playing or downloading games in 2010 (Figure 3.22). Playing and downloading games and music is most popular in Korea (52\%), the Netherlands (51\%), Finland (47\%) and Norway (41\%). 
Figure 3.21. Number of online tax declarations

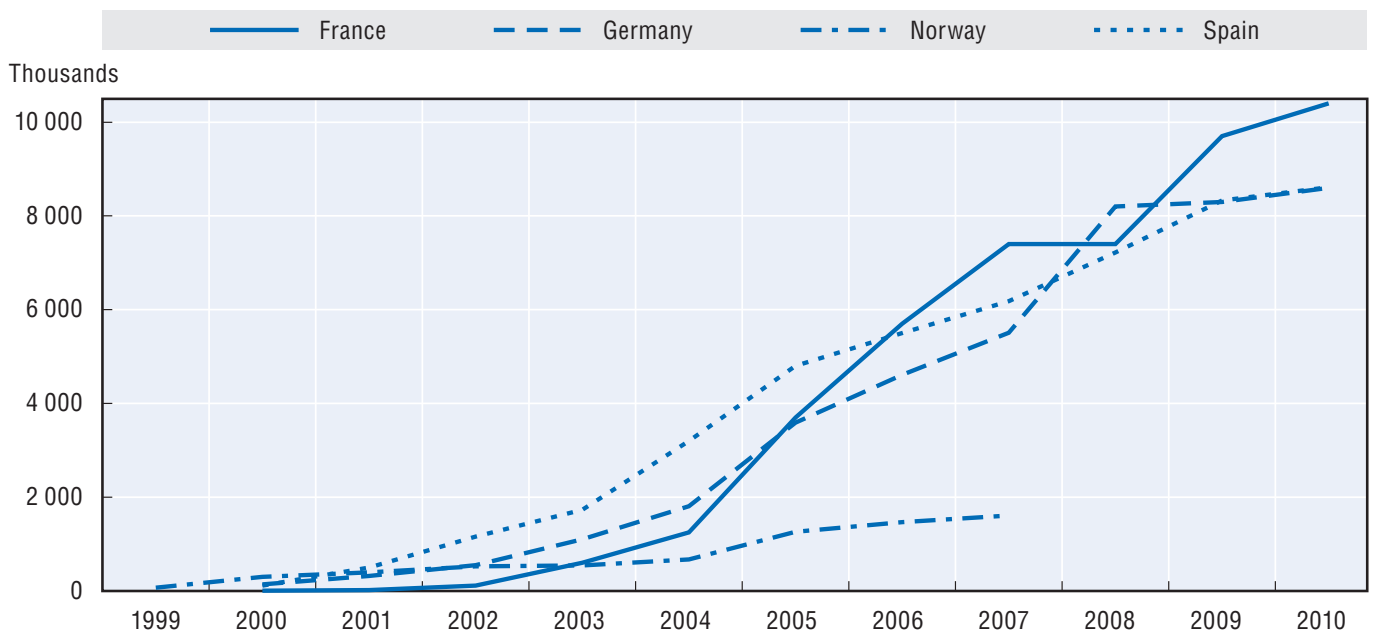

Source: OECD (2011), The Future of the Internet Economy: A Statistical Profile, June 2011 Update.

StatLink त्ताs http://dx.doi.org/10.1787/888932693512

\section{Figure 3.22. Individuals using the Internet to play/download games, music or films, 2010 or latest available year}

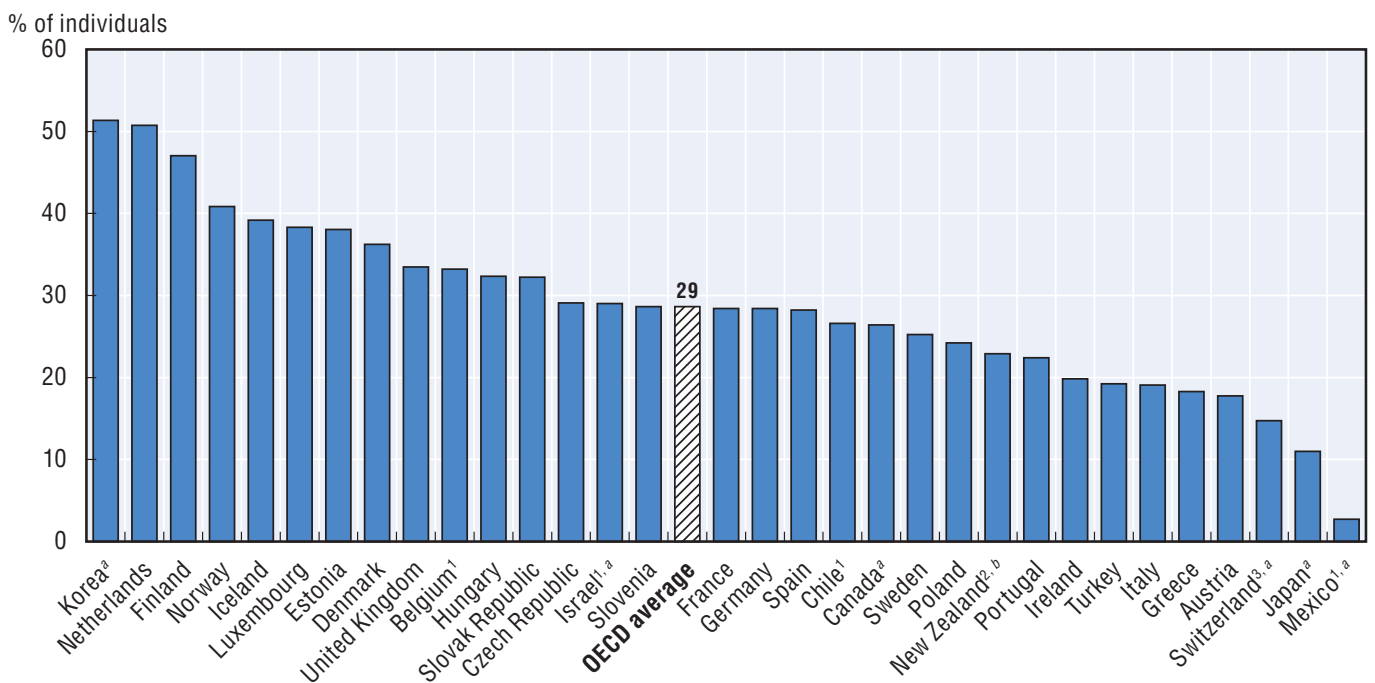

Note: Data from the EU Community Survey covers EU countries plus Iceland, Norway and Turkey. Individuals aged 16-74 years, except for Canada (16+), Israel (20-74), Japan (6+) and Switzerland (14+). For countries covered by Eurostat, individuals were asked about activities they had carried out on the Internet in the last 3 months. For the other OECD countries, it generally refers to the last 12 months.

Country notes: For Israel: Data refer to the use of Internet in the last 3 months. For Switzerland: Data refer to Internet users who used the Internet at least once within the last six months.

Information on data for Israel: http://dx.doi.org/10.1787/888932315602.

1) 2009 ; 2) 2006; 3) 2005.

a) Playing/downloading games only.

b) Playing/downloading music only (excluding web radio and peer-to-peer).

Source: OECD (2011), The Future of the Internet Economy: A Statistical Profile, June 2011 Update. Canadian Internet Use Survey, 2010 from Statistics Canada. 


\section{Peer-to-peer file sharing}

The Internet is an important network for distributing content. Peer-to-peer file sharing is one of the key technologies for sharing files with other users. Over 20\% of OECD Internet users said they use peer-to-peer (P2P) file sharing in 2011 (Figure 3.23). Slovenia has the highest percentage at 37\%, followed by Hungary, Iceland, Spain, Norway and Estonia (all over 30\%).

\section{Figure 3.23. Internet users using P2P file sharing to exchange content, 2011 or latest available year}

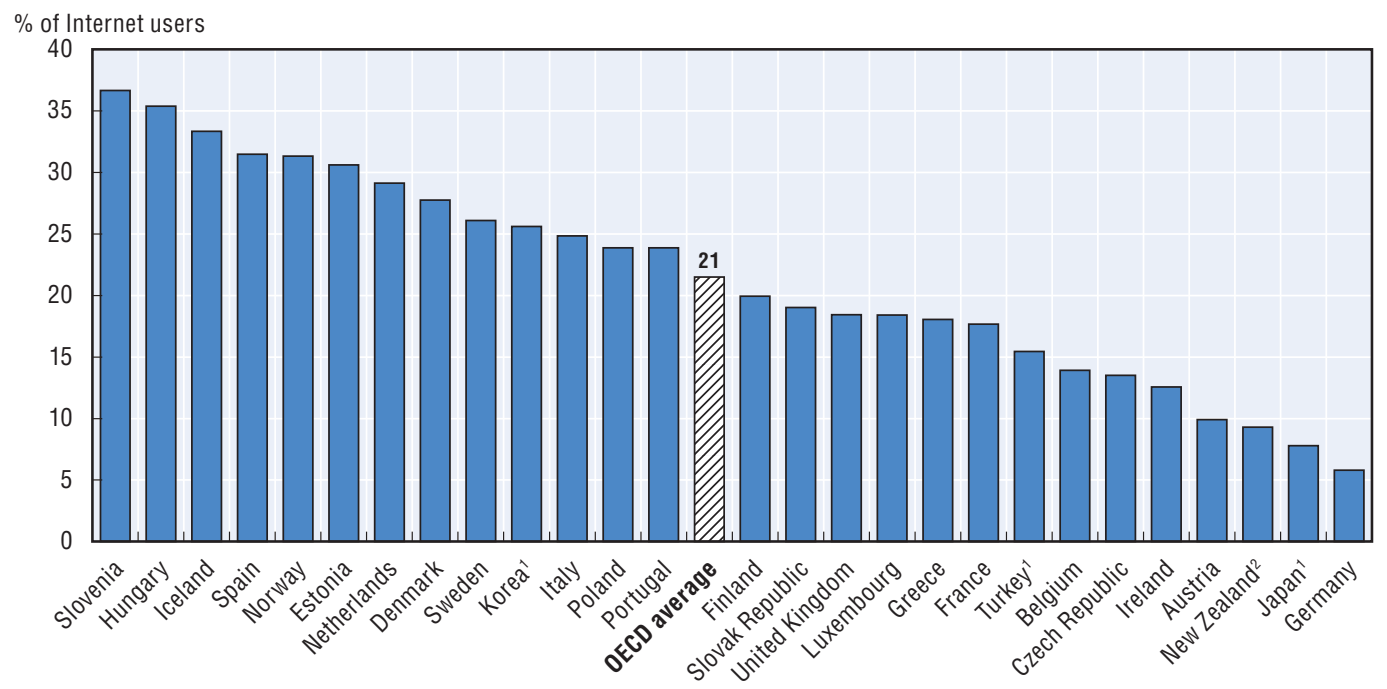

Note: Content Data from the EU Community Survey covers EU countries plus Iceland, Norway and Turkey. Internet users are considered for this figure as individuals who have ever used the Internet for countries covered by Eurostat. Individuals aged 16-74 years, except for Japan (6+). Country note: For Japan: Internet users accessing from personal computers and mobile phone. For New Zealand: data are presented as a percentage of individuals.

1) 2010; 2) 2006.

Source: OECD ICT Database and Eurostat Community Survey on ICT usage in households and by individuals, May 2012. Canadian Internet Use Survey, 2010 from Statistics Canada.

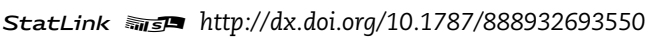

\section{Challenges ahead: digital divides and barriers to access}

Data on Internet use by individuals and households show significant gains over the last few years; however, challenges remain. Connectivity continues to grow, but significant divides persist between those who use the Internet and those who do not. These need to be addressed.

One way to examine this divide is to look at Internet access broken down by the various social and economic characteristics of its users. This approach enables policy makers to target efforts to increase penetration precisely to those groups under-represented among Internet users.

\section{Education}

Data on Internet use by level of education show that Internet usage is lower for less-educated individuals among both men and women. Figure 3.24 shows Internet usage rates according to educational attainments of "low", "medium" or "high" (based on ISCED) 5 and those with the highest level of education are more likely to use the Internet than those with less education. A higher educational level generally also implies higher income and greater computer literacy, both of which are important factors that drive Internet use (ITU, 
2011b). In Iceland and the Nordic countries, for example, the gap between people with a high level of education and lower levels is relatively small. In other countries the Internet access gap between those with the lowest and highest levels of education is much larger. The gap is particularly pronounced in countries such as Greece, Slovenia and Turkey.

Figure 3.24. Individuals using the Internet from any location by educational level, 2011 or latest available year

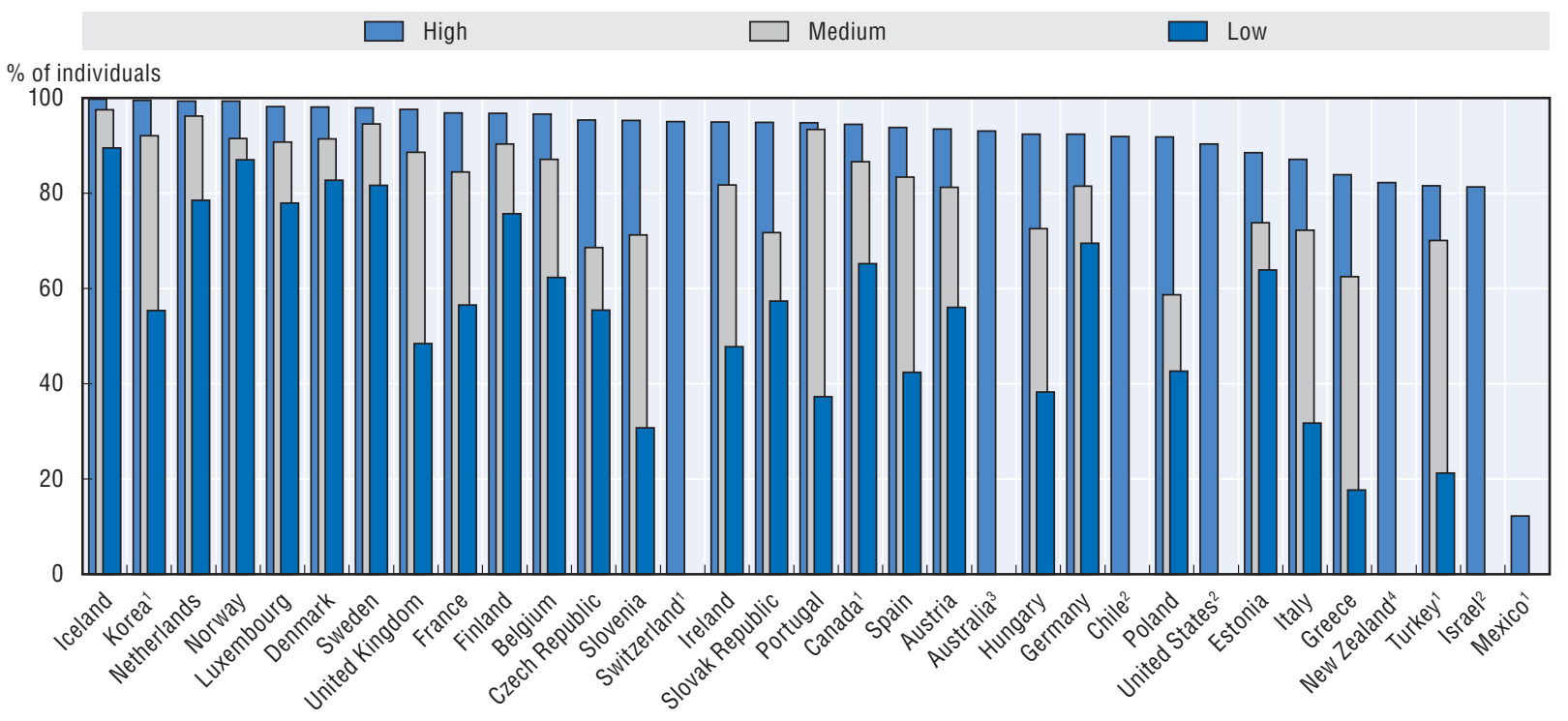

Note: Low refers to ISCED 0 to 2; medium to ISCED 3 to 4; high to ISCED 5 to 6. Data from the EU Community Survey covers EU countries plus Iceland, Norway and Turkey. Data generally refer to Internet use in the last 12 months for non-Eurostat countries and last 3 months for countries covered by Eurostat. Individuals aged 16-74 years with the exception of Canada (16+) and Israel aged 20-74 years. Country notes: For Australia: Underestimated as tertiary level certificate courses are not included. For Israel: Data refer to the use of the Internet in the last 3 months. For Mexico: The tertiary level of education includes studies of degree and postdegree. For Switzerland: Data refer to Internet users who used the Internet at least once within the last six months. For the United States: Tertiary is at least a bachelor's degree.

Information on data for Israel: http://dx.doi.org/10.1787/888932315602.

1) 2010; 2) 2009; 3) 2008; 4) 2006.

Source: OECD ICT Database and Eurostat Community Survey on ICT usage in households and by individuals, May 2012. Canadian Internet Use Survey, 2010 from Statistics Canada.

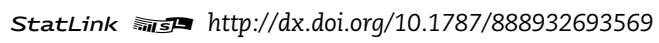

\section{Geography}

Data on regional broadband access show that differences in penetration can be significant (Figure 3.25). Geography seems to be an important factor as small countries such as Denmark, Finland and the Netherlands have the lowest regional differences in broadband access (less than 10 percentage points between the highest and lowest regions), partially due to geographical similarities across areas.

The data can also highlight similar gaps across countries that may have very different geographical profiles. For example, the access gap between Canada and Slovak Republic is identical (14 percentage points between the highest and lowest regions), but the geographic size of the Canada is almost 80 times that of Slovak Republic. Australia and Portugal have almost the same range of regional differences in broadband access (18 and 17 percentage points respectively), but very different sizes and geographical characteristics. 
Regional data can also help to highlight countries where even the regions with the lowest penetration rates are more advanced than the most advanced areas in other countries. Denmark, the Netherlands, Norway and Sweden all have very high penetration levels both for the best-performing regions and the least-performing regions within the countries.

Figure 3.25. Households with broadband access, by region, 2010

Percentages, sorted by size of gap between regions with highest and lowest penetration

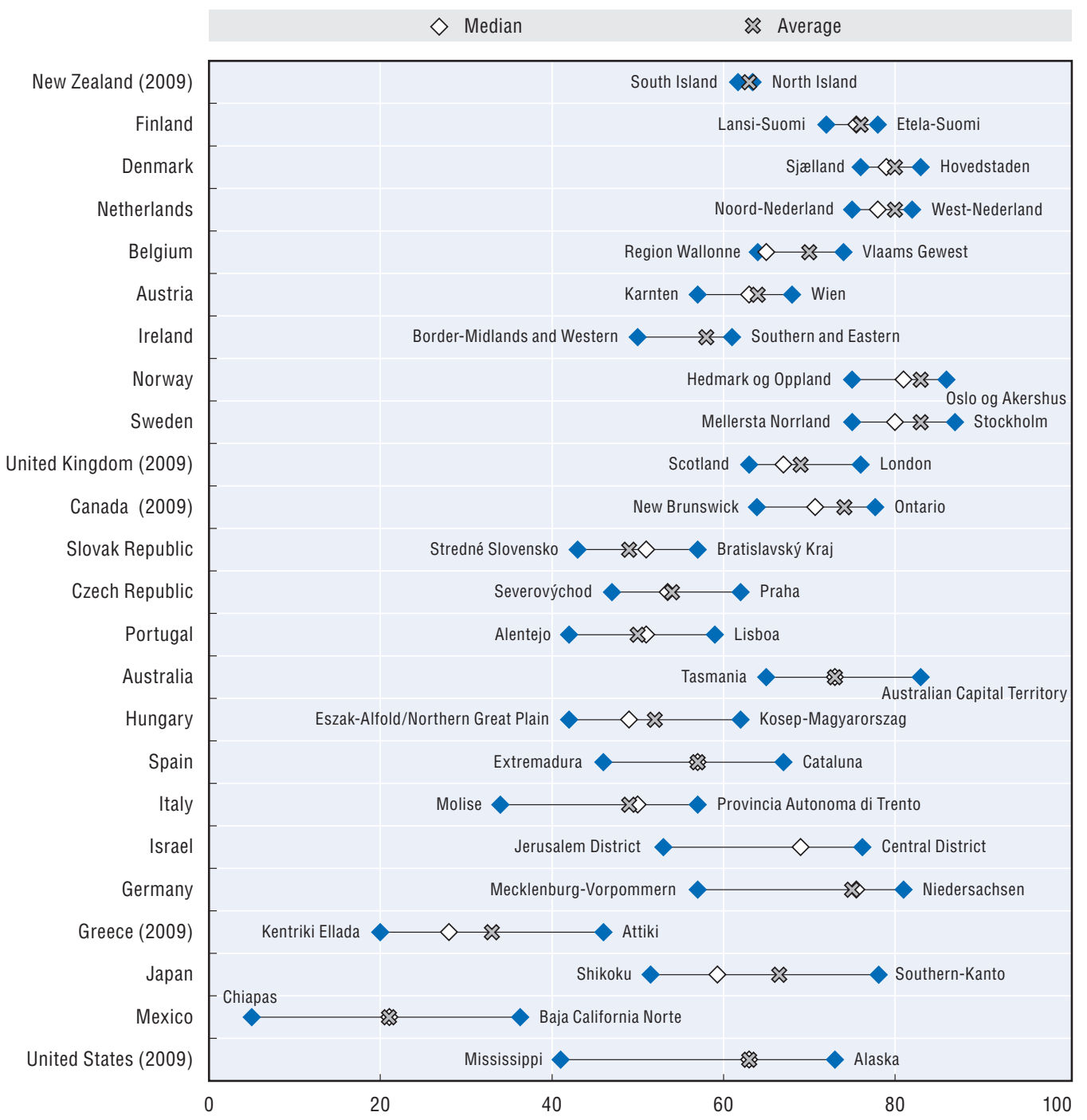

Notes: Geographic coverage: All regions within OECD member countries at the TL2 level (See "Territorial Grids of OECD Member Countries" available at: www.oecd.org/dataoecd/24/41/42740381.pdf). Data for the region of Aland in Finland, for the regions of Bremen in Germany, and for Northern Ireland in the United Kingdom are not available. Ireland has only two regions, the median is therefore not calculated. Estonian, New Zealand and Luxembourg data are not presented since these countries have only one TL2 region. No data for Chile, France, Korea, Poland, Slovenia, Switzerland and Turkey. Iceland data only for 2008 have not been included.

Information on data for Israel: http://dx.doi.org/10.1787/888932315602.

Source: OECD, Regional Database, June 2012. 


\section{Age}

Another significant factor for differences in Internet usage is age. People aged 16-24 are the most likely to use the Internet in all OECD countries (Figure 3.27). In 2011, the older the age group, the less likely the person was to respond that they used the Internet. This in itself illuminates a future trend. As the youngest generations become older, they will take with them skills and experience gained on the Internet that can, in turn, be used to access digital goods and services. In the meantime, policies targeting older populations will be important for continuing to bridge the digital gap in societies.

The growing number of channels and devices via which Internet services can be accessed might prove an important factor in increasing access for older age brackets. Whereas PCs and smartphones can be perceived as too complex by older Internet users, devices such as tablets, digital television sets and specific service terminals can possibly lower access barriers.

Data on Internet use among the older segments of the population are very promising, but more work is needed. The oldest age category (65-74) in the EU27 area has tripled its Internet use since 2004, growing from $10 \%$ to $30 \%$ in seven years (Figure 3.26 ) but no country has reached a penetration rate of $70 \%$ for this age group. In some cases, the penetration for the oldest population segment is less than $10 \%$, highlighting a core policy area related to providing services to the "silver economy" (Chapter 6). The gaps between the youngest and the elderly are most significant in Greece, Poland, Portugal, Slovak Republic and Slovenia with more than 80 percentage points of difference (Figure 3.27).

Figure 3.26. Trends in Internet use by age in the EU27 area

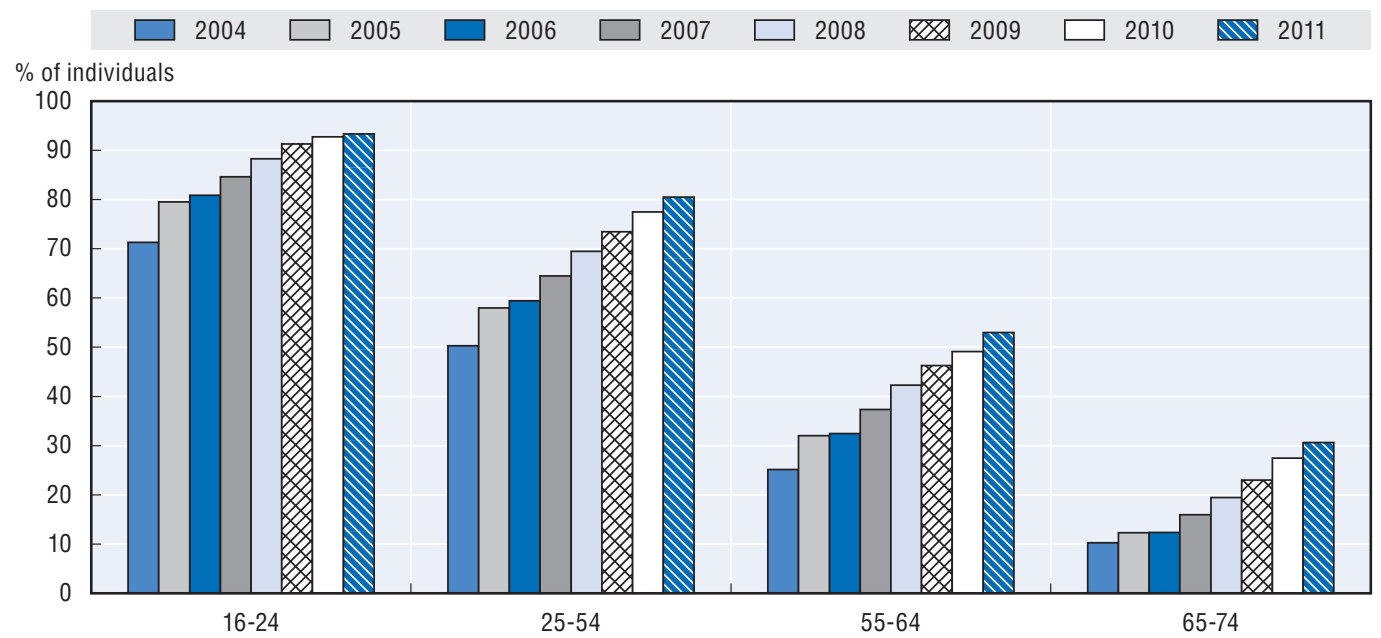

Note: Data refer to the use of the Internet in the last 3 months. Individuals aged 16-74.

Source: Based on Eurostat Community Survey on ICT usage in households and by individuals, May 2012.

StatLink 角西 http://dx.doi.org/10.1787/888932693607

\section{Gender}

Men are more likely than women to use the Internet in most OECD countries. There are some notable exceptions, though, such as Estonia, Ireland, New Zealand and the United States where in 2011, slightly more women used the Internet than men. But the gap still remains large (over 9 percentage points) in Austria, Italy, Switzerland and Turkey 


\section{Figure 3.27. Individuals using the Internet from any location, by age group, 2011 or latest available year}

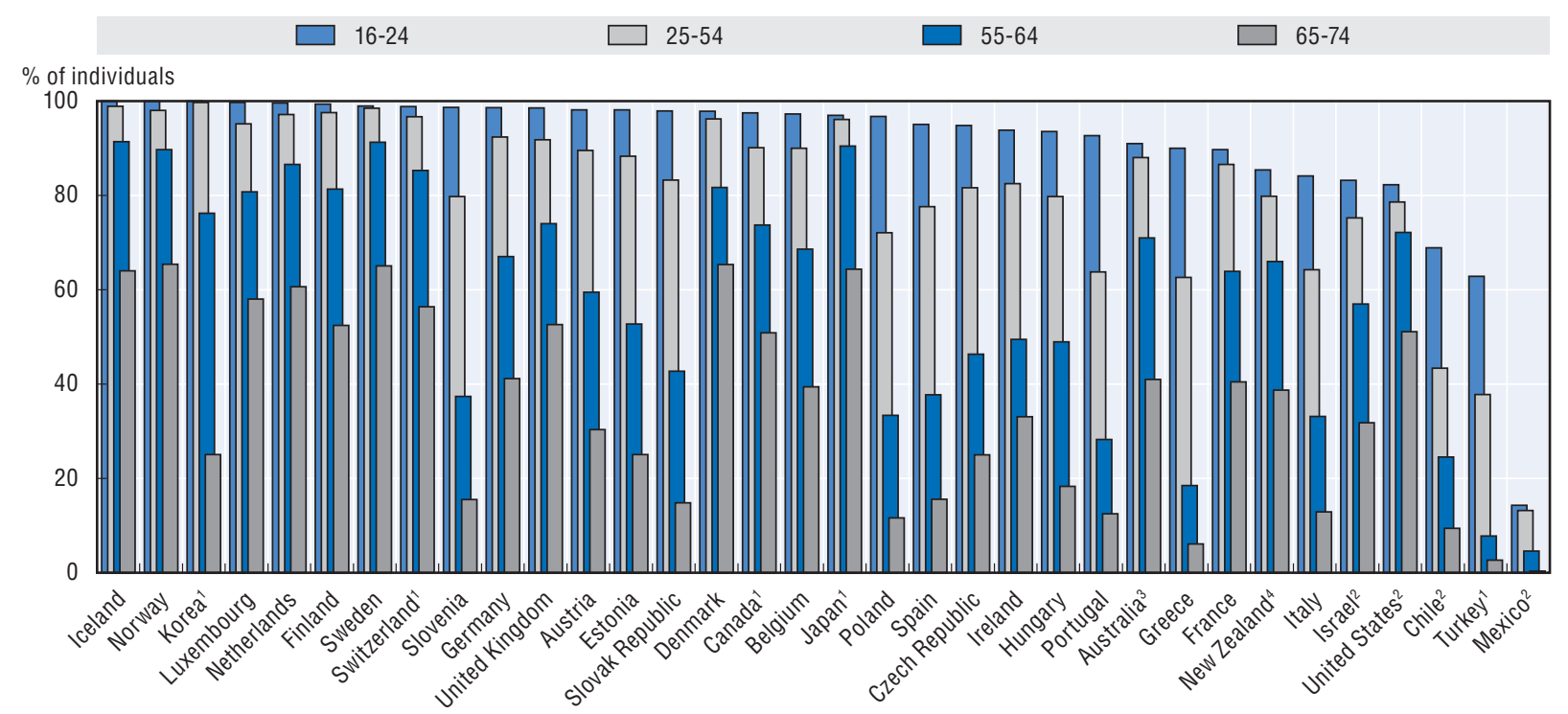

Note: Data from the EU Community Survey covers EU countries plus Iceland, Norway and Turkey.

Data generally refer to Internet use in the last 12 months for non-Eurostat countries and last 3 months for countries covered by Eurostat. Individuals aged 16-74 years, except for Israel (20-74) and Japan (6+). Age group breakdown for Eurostat countries and Canada: 16-24; 25-54; 55-64 and 65-74. For non-Eurostat countries: 25-44 and 45-64 instead of 25-54 and 54-64. Country notes: For Israel: Data refer to the use of the Internet in the last 3 months. For Japan: Age group breakdown: 15-19, 20-39, 40-59 and 60-69. For Switzerland: Data refer to Internet users who used the Internet at least once within the last six months.

Information on data for Israel: http://dx.doi.org/10.1787/888932315602.

1) 2010; 2) 2009; 3) 2008; 4) 2006.

Sources: OECD ICT Database and Eurostat Community Survey on ICT usage in households and by individuals, May 2012. Canadian Internet Use Survey, 2010 from Statistics Canada.

StatLink न्नाडs http://dx.doi.org/10.1787/888932693626

(Figure 3.28). Between 2004 and 2011 in the EU27 area, the percentage of women using the Internet increased by almost $70 \%$, nevertheless there is still a gap of almost 5 percentage points in 2011 (Figure 3.29).

\section{Income}

The Internet needs to be affordable if it is to become a ubiquitous platform for social and economic communication. The gap between Internet penetration rates among high-income and low-income households is narrowing in some OECD countries, but remains wide in others (Figure 3.30). For example, the gap in Denmark is negligible, while the difference in penetration rates among high and low-income households in Czech Republic, Hungary, Poland and Portugal remains very large (over 50 percentage points).

While differences between high and low-income households tend to decrease over time, the divides between elderly and young people, and between higher and less educated individuals are more persistent.

A recent OECD study, including data from 18 European countries, Canada and Korea, addresses the issue of digital divide among households and individuals by using micro-data analysis of ICT usage patterns and socio-economic variables. The study addresses the divide at two levels (access and use on the one hand, and online activities on the other), and measures the influence of one variable, while controlling for other variables. In particular, the study uses factors including age, gender, educational attainment, 
Figure 3.28. Gender gap in using the Internet, 2011 or latest available year

Difference between male and female individuals using the Internet

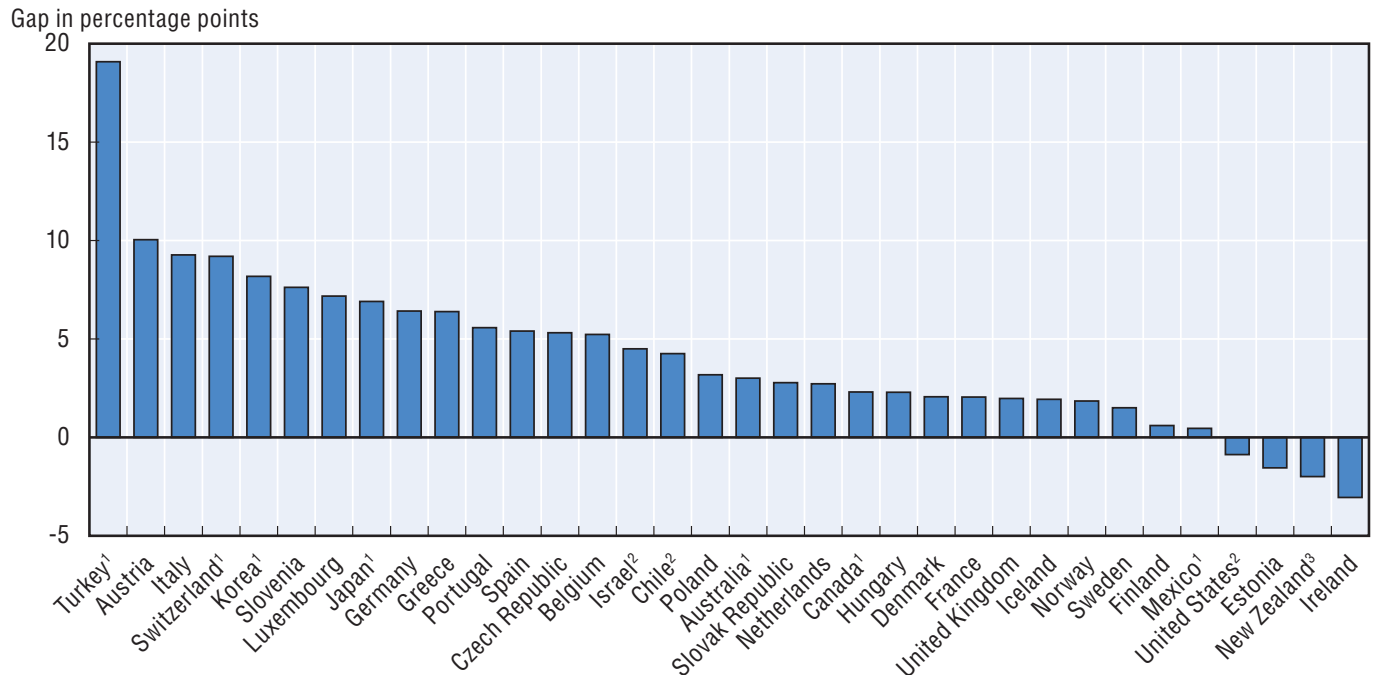

Note: Data from the EU Community Survey covers EU countries plus Iceland, Norway and Turkey.

Data generally refer to Internet use in the last 12 months for non-Eurostat countries and last 3 months for countries covered by Eurostat. Individuals aged 16-74 years, except for Canada (16+), Israel (20-74) and Japan (6+). Country notes: For Israel: Data refer to the use of the Internet in the last 3 months. For Switzerland: Data refer to Internet users who used the Internet at least once within the last six months.

Information on data for Israel: http://dx.doi.org/10.1787/888932315602.

1) 2010; 2) 2009; 3) 2006.

Sources: OECD ICT Database and Eurostat Community Survey on ICT usage in households and by individuals, May 2012. Canadian Internet Use Survey, 2010 from Statistics Canada.

StatLink त्ताइ http://dx.doi.org/10.1787/888932693645

Figure 3.29. Trends in Internet use by gender in the EU27 area

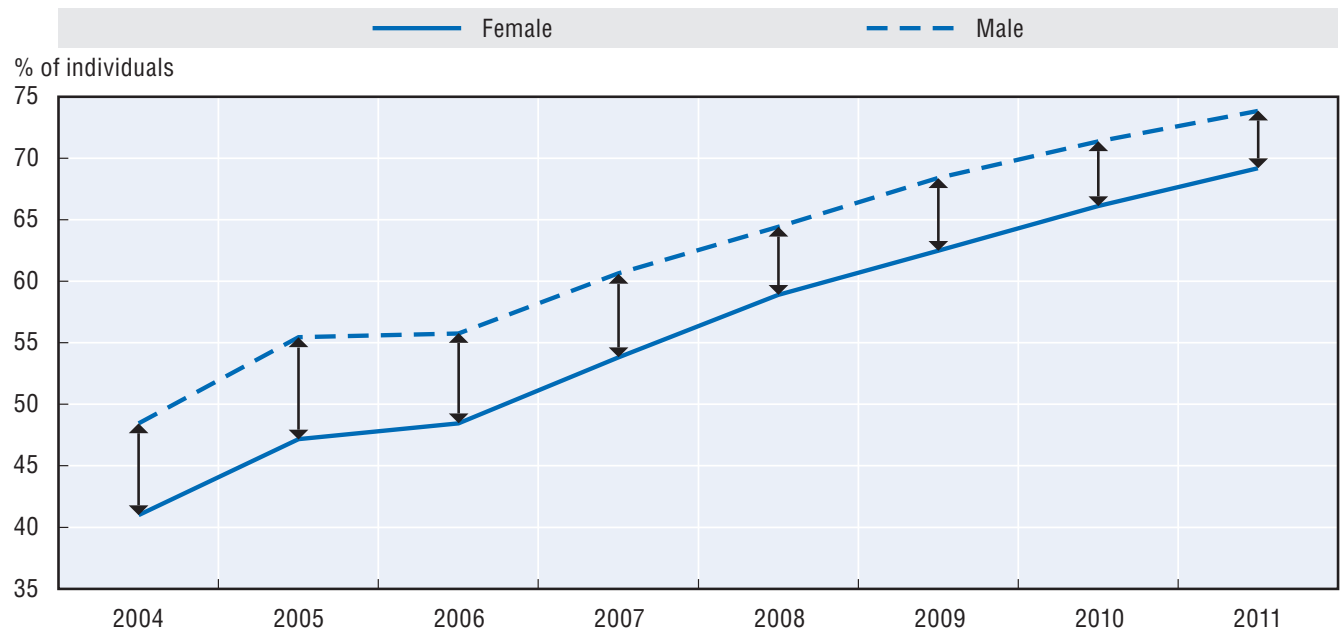

Note: Data refer to the use of the Internet in the last 3 months. Individuals aged 16-74.

Source: Based on Eurostat Community Survey on ICT usage in households and by individuals, May 2012.

StatLink त्ञाज http://dx.doi.org/10.1787/888932693664 
Figure 3.30. Household Internet access by income, 2011 or latest available year

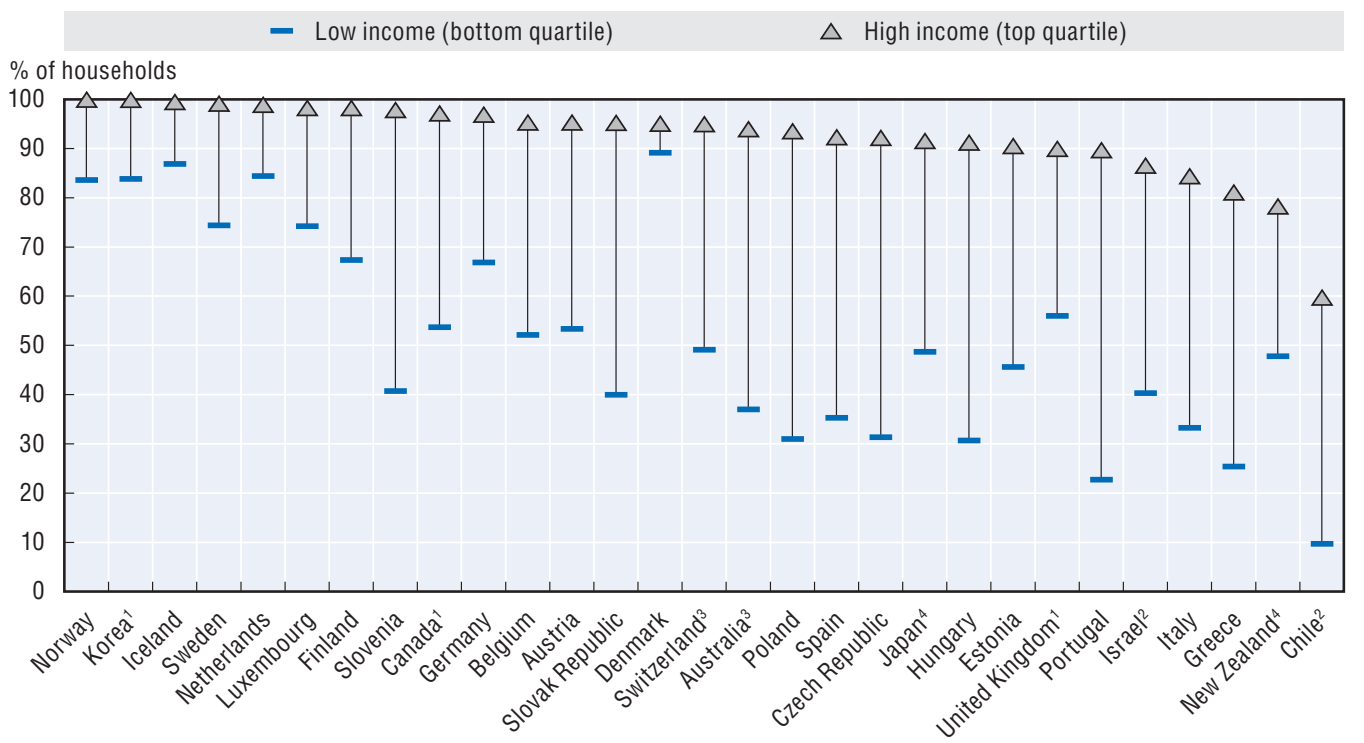

Note: Country notes: For Korea: The survey is not organized by quartile. Top income quartile corresponds to income of more than 300 million won, and bottom income quartile corresponds to income of less than 100 million won. Information on data for Israel: $h t t p: / / d x . d o i . o r g / 10.1787 / 888932315602$.

1) 2010; 2) 2009; 3) 2008; 4) 2006.

Sources: OECD ICT Database and Eurostat Community Survey on ICT usage in households and by individuals, May 2012. Data for Canada in 2010 provided by Canadian Internet Use Survey (CIUS) and data for United Kingdom provided by Ofcom. StatLink inist http://dx.doi.org/10.1787/888932693683

employment situation, geographical location, household income and composition to explain the observed differences in computer and Internet access and use (first level of the divide), and Internet frequency of use, selected Internet activities and Internet scope of use (second level of the divide) (Montagnier and Wirthmann, 2011).

The study shows that, controlling for other variables: i) low income is the single most important factor for non-access to a computer and the Internet; ii) the presence of children is the second most important factor for access to a computer and the Internet; iii) living in a town in Europe increases the likelihood of having access to a computer and the Internet by over $30 \%$ as compared to living in the countryside; iv) older age and economic inactivity are by far the most important factors for having never used a computer or the Internet; $v$ ) entering unemployment is the most important factor for stopping using the Internet; vi) education is the most important determinant of intensity of Internet use; vii) being a student is the second most important determinant of intensity of Internet use; and viii) young age and higher education are the main determinants for scope of Internet use in Canada, Europe and Korea.

\section{Conclusion}

Internet connectivity is flourishing. Wired connectivity is available to most households in the OECD and approximately $70 \%$ of households subscribe. The growth of household access underscores the importance of the Internet in the economy and society as a whole. Internet connections to households offer higher speeds now than two years ago and high-speed connections are slowly but steadily replacing traditional DSL lines.

The real growth, however, has been in the adoption of wireless broadband, now the dominant access method in the OECD with almost double the number of subscriptions of fixed broadband. This shift to mobile Internet connectivity is also changing the way in 
which people interact and consume content on the Internet, one example being the rapid adoption of social media. At present, nearly half of all Internet users in the OECD area visit social networking sites.

The growth of Internet connections is also changing other institutions in key sectors of the economy. Nearly all schools in the OECD area are connected to the Internet and the web has become a key educational tool. Nearly half of all Internet users report having used the Internet for learning.

Beyond school, the Internet is also helping job-seekers to locate employment during the current economic crisis. In 2010, an average of $17 \%$ of Internet users reported using the Internet in a job search. Governments are also leveraging Internet connectivity to communicate better with their constituents.

Despite recent advances in connectivity, challenges remain. Certain segments of the population are much more likely to use the Internet than others. The age group leading in access are between 16-24 years old while people over 65 have much lower rates of connectivity. Other demographic characteristics such as income or educational level are correlated with different levels of Internet access.

With unemployment rates still high in most OECD economies, fostering ICT skills and employment has remained a key priority for governments in the short and long-term according to the 2012 OECD ICT policy questionnaire. Governments have proposed a wide range of policies to support ICT-related employment and skills, emphasising measures to tackle unemployment, some of which relate to green ICTs. Overall, most OECD governments have established policies and programmes to: i) further IT education and training, ii) improve labour market information, and iii) promote international sourcing of ICT skills. A more detailed view of these policies is available in Chapter 8.

\section{Notes}

1. See definition in OECD (2010a).

2. For more details, see: www.westpac.co.nz/olcontent/olcontent.nsf/Content/Everyday+accounts.

3. For more details, see: http://itunes.stanford.edu.

4. For more details, see: www.khanacademy.org.

5. The International Standard Classification of Education (ISCED) was designed by UNESCO in the early 1970's to serve "as an instrument suitable for assembling, compiling and presenting statistics of education both within individual countries and internationally".

\section{References}

Bank of America (2011), "Putting Bank of America in Customers' Hands", web online article, http:// ahead.bankofamerica.com/assisting-customers/putting-bank-of-america-in-customers-hands/.

comScore (2011), "Digital Omnivores: How Tablets, Smartphones and Connected Devices are Changing U.S. Digital Media Consumption Habits”, www.comscore.com/Press_Events/Presentations_Whitepapers/ 2011/Digital_Omnivores.

Eurostat (2011), Information Society statistics website, database on ICT diffusion and use among households and individuals, http://epp.eurostat.ec.europa.eu/portal/page/portal/information_society/ data/comprehensive_databases.

ITU (International Telecommunication Union) (2011a), ICT Indicators Database, www.itu.int/ITU-D/ict/ publications/world/world.html. 
ITU (International Telecommunication Union) (2011b), Measuring the Information Society, ITU, Geneva. www.itu.int/net/pressoffice/backgrounders/general/pdf/5.pdf.

MIT (Massachusetts Institute of Technology) (2011), “MIT launches online learning initiative”, MIT News, 19 December 2011, http://web.mit.edu/newsoffice/2011/mitx-education-initiative-1219.html.

Montagnier, P. and A. Wirthmann (2011), "Digital Divide: From Computer Access to Online Activities A Micro Data Analysis", OECD Digital Economy Papers, No. 189, OECD Publishing. doi: http://dx.doi.org/10.1787/5kg0lk60rr30-en.

OECD (2010a), “Wireless Broadband Indicator Methodology”, OECD Digital Economy Papers, No. 169, OECD Publishing. doi: http://dx.doi.org/10.1787/5kmh7b6sw2d4-en.

OECD (2010b), OECD Information Technology Outlook 2010, OECD Publishing. doi: $h t t p: / / d x$.doi.org/10.1787/it_outlook-2010-en.

OECD (2011), “The Future of the Internet Economy: A Statistical Profile”, June 2011 Update, www.oecd.org/dataoecd/24/5/48255770.pdf.

OECD (2012), OECD Public Governance Reviews: France. An International Perspective on the General Review of Public Policies, OECD Public Governance Reviews, OECD Publishing. doi: http://dx.doi.org/10.1787/9789264167605-en.

Pingdom (2012), Internet 2011 in Numbers, online article, http://royal.pingdom.com/2012/01/17/internet2011-in-numbers/. 



\section{Chapter 4}

\section{Internet adoption and use: Businesses}

This chapter provides an overview of ICT diffusion and use within businesses in OECD countries, focusing mainly on the Internet. Using the most up-to-date datasets and building on a series of indicators, it attempts to cover selected issues related to key aspects of firms' engagements in the information economy. It examines the extent of computer and Internet access and use among firms, and analyses the growth in broadband access and quality of connections. The chapter also looks at the various phases of e-business development and levels of complexity of external and internal communications, going from simple information sharing to more integrated issues such as supply chain management. The chapter then looks at the development of electronic commerce and its perceived benefits, and concludes with some considerations on real impacts of ICTs on business performance. 
$\mathrm{B}$ usinesses are the cornerstone of market economies and anything that improves their efficiency is clearly of interest to policy makers. Researchers now have a significant repertoire of studies linking ICT and Internet adoption to increased firm productivity. It is therefore vital to follow the adoption of ICTs and the Internet by businesses. This chapter provides extensive data on ICT diffusion and use in businesses as a way for policy makers to track and benchmark the progress of their own countries with others in the OECD.

The Internet is at the heart of the transformations in the digital landscape. It encompasses all economic actors: households and individuals, organisations and private businesses. The last decade has witnessed huge growth in connectivity with the Internet becoming an integral part of companies and business processes. Practically all large firms and most of the smallest are now connected to the Internet.

The way in which businesses are accessing the Internet has also changed. Previously, fixed-line access was the norm. Now businesses are using smartphones and tablets to access the Internet, mirroring the significant growth in mobile use among individuals.

The Internet has become a key asset for firms, functioning not just as a network, but also as an important tool for the production and organisation of enterprises in relation to employees, customers, suppliers and business partners. This manifests both in terms of internal processes and external communication with clients, providers and business partners. In short, the Internet as a generic purpose technology is now a tool used by firms to optimise their production process.

The current chapter provides an overview of ICT diffusion and use within businesses in OECD countries, focusing principally on the Internet. Indeed, the Internet is the foundation of communication for many companies as they invest in internal and external network connectivity. This chapter uses up-to-date datasets and builds on a series of indicators to explore key aspects of business engagement in the information economy. It evaluates the extent of computer and Internet access and use among firms, and takes a particular look at rates of broadband access and the quality of connections.

This chapter also examines the various phases of e-business development and the levels of complexity of external and internal communications, going from simple information sharing to more integrated issues such as supply chain management. The chapter concludes with a look at the development of electronic commerce and its perceived benefits, and presents some considerations on the real impacts of ICTs on business performance.

As a starting point, it is helpful to examine adoption trends for a variety of technologies in a given economy. The diffusion of Internet access within firms has varied across selected OECD countries, stimulated by the generalised presence of the PC (Figure 4.1). Interestingly, the adoption of high-speed broadband lines in firms has been 
much faster than the original adoption of basic Internet access. Data on the establishment of a web presence among firms show slower uptake but significant progress.

The data also highlight the growth of e-commerce, in particular, with regard to purchasing and placing orders over the Internet. In policy circles, the ability of firms to sell goods globally to consumers receives significant attention. However, the data show that firms use the Internet more often for purchasing than selling or taking orders.

Figure 4.1. Historical diffusion of ICT within firms in selected OECD countries Businesses with 10 or more persons employed

$$
\begin{aligned}
& -\cdot-- \text { Broadband } \\
& -\cdot-- \text { E-sales }
\end{aligned}
$$

Australia $^{1}$

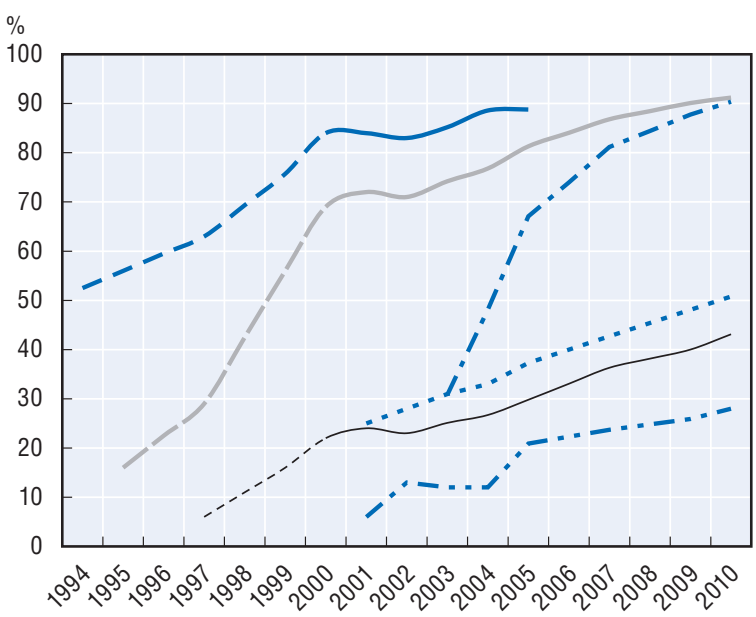

Korea

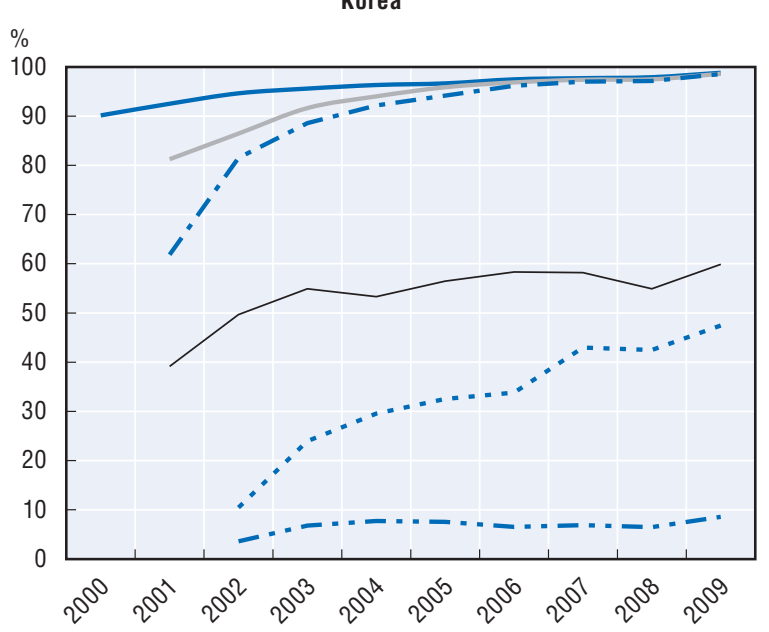

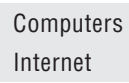

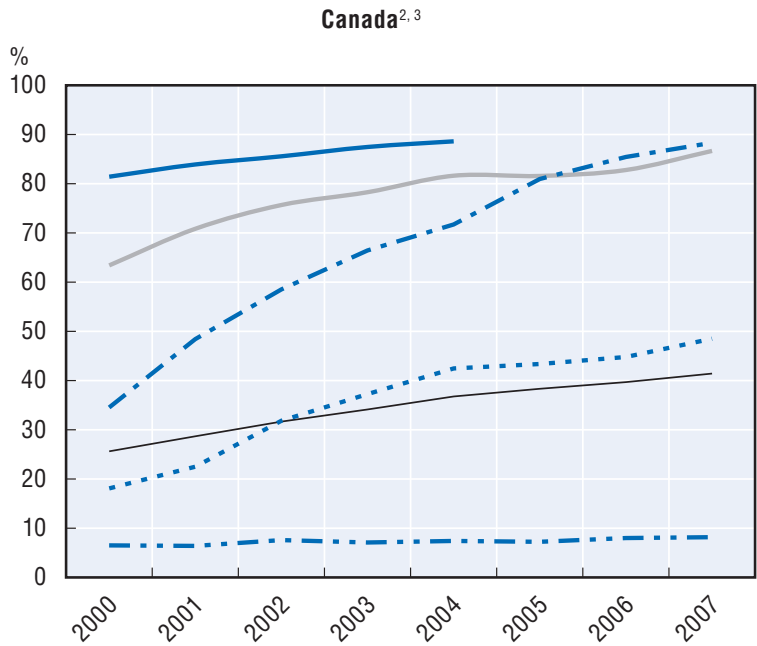

Norway ${ }^{4}$

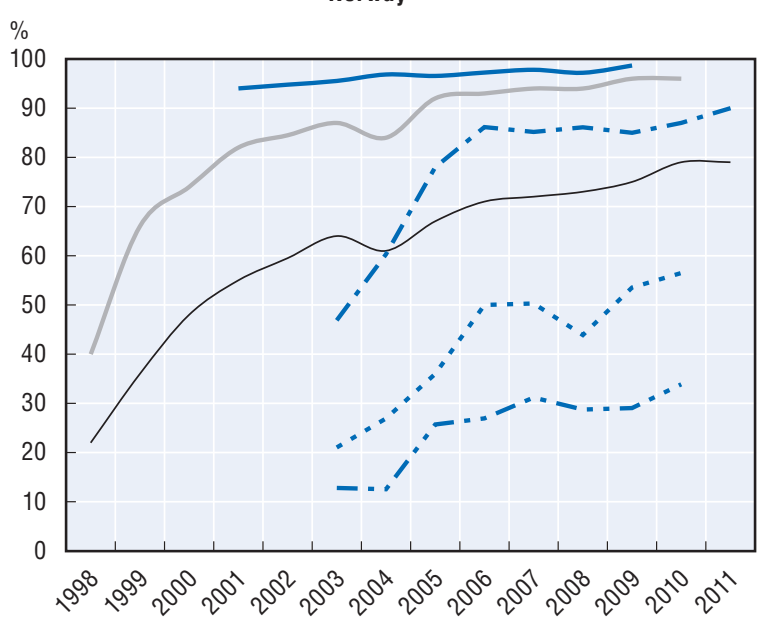

1. Data for calendar year $\mathrm{N}$ correspond to data issued from Australian Bureau of Statistics " $\mathrm{N} / \mathrm{N}+1$ " released survey.

2. Broadband includes cable, ISDN/xDSL line, T1 line or greater.

3. E-purchases with or without online payment.

4. E-commerce includes Internet, EDI or other networks.

Source: OECD, based on ICT Database and data from the Australian Bureau of Statistics, Statistics Canada, Statistics Norway and Eurostat. 


\section{Pervasiveness of Internet use}

At the end of 2011, nearly all companies in OECD countries were connected to the Internet. In two thirds of OECD countries, more than $95 \%$ of the companies are using the Internet (Figure 4.2).

All large firms (250 employees or more) are now using the Internet, and small and medium firms are catching up with virtually all now using the Internet. Only a small proportion of the smallest businesses are not yet connected. In 2010, only 5.7\% of small firms (10-49 employees) in the EU25 were not accessing the Internet, and in Australia, this was the case for only $10.5 \%$ of very small firms (0-19 employees).

Figure 4.2. Businesses using the Internet, 2011

Percentage of businesses with 10 or more persons employed

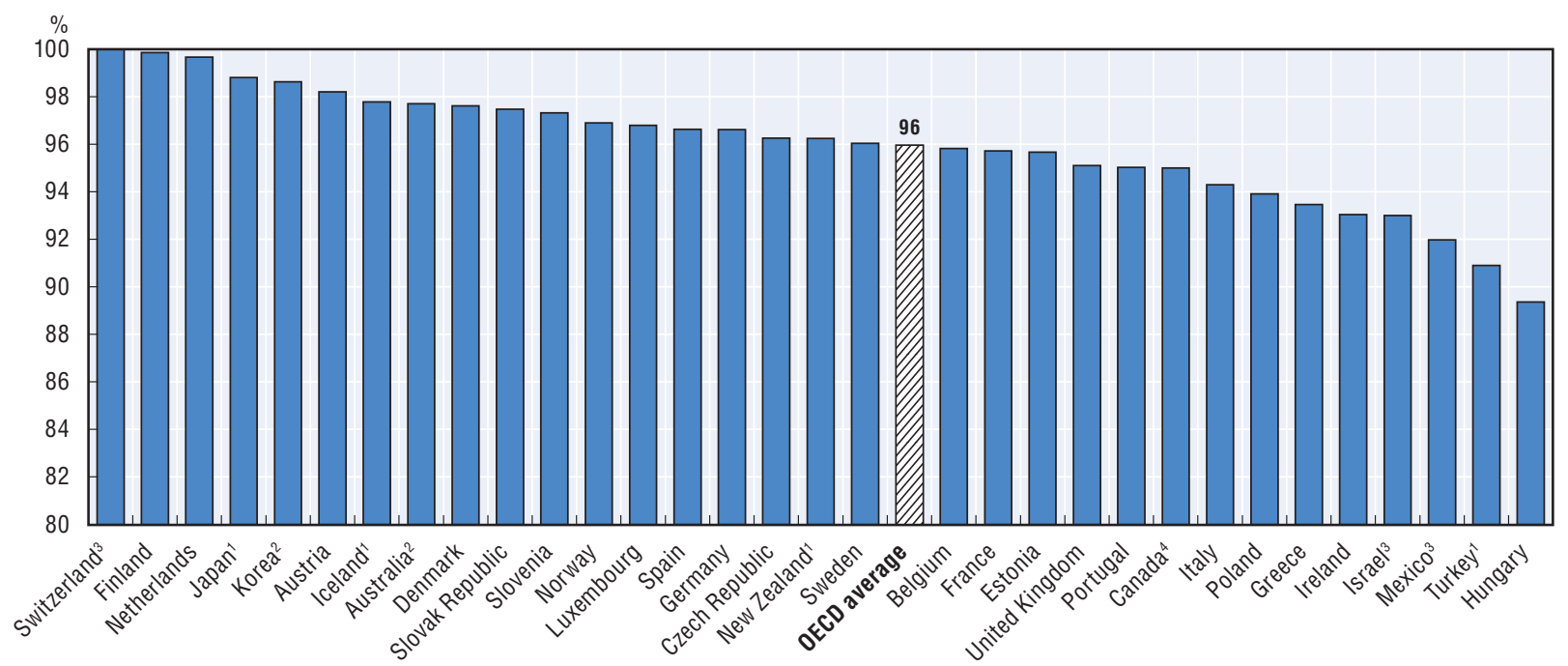

Notes: See also endnote 1: For Japan: Businesses with more than 100 regular employees. For Mexico: Businesses with 50 or more employees for 2003 and with 20 or more personnel for 2008 data. For Switzerland: Businesses with five or more employees and connections equal to or faster than 144 Kilobits per second (mobile and fix).

Information on data for Israel: $h t t p: / / d x . d o i . o r g / 10.1787 / 888932315602$.

1) 2010; 2) 2009; 3) 2008; 4) 2007.

Source: OECD ICT Database and Eurostat Community survey on ICT usage and e-Commerce in enterprises, June 2012.

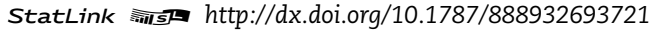

The diffusion of Internet access and its subsequent use among businesses has been extremely rapid. Although smaller firms are still lagging slightly behind, the examples of Australia and Norway suggest that only a tiny minority will remain unconnected in the coming years (Figure 4.3). 
Figure 4.3. Share of enterprises with Internet access by size in Australia and Norway
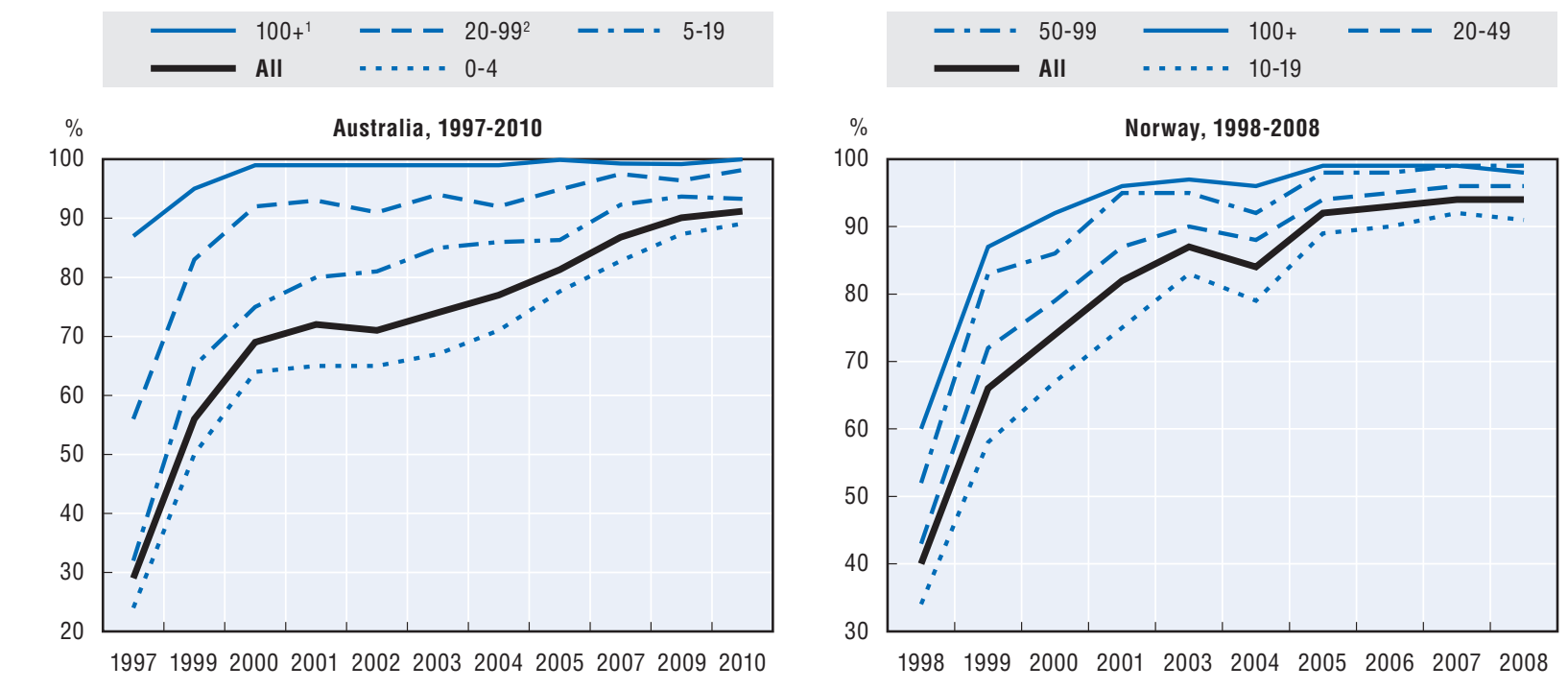

Notes: For Australia, data calendar year N correspond to data issued from Australian Bureau of Statistics "N/N+1" released survey.

1. From 2008 onwards, this changed to 200 or more persons.

2. From 2008 onwards, this changed to $20-199$ persons.

Source: Based on Australian Bureau of Statistics (ABS) and Statistics Norway.

StatLink त्नाड़ी http://dx.doi.org/10.1787/888932693740

\section{Broadband in firms}

Businesses were among the earliest adopters of Internet connectivity and were among the leaders in upgrading early Internet connections to higher speeds. So while firms were the first to adopt Internet connectivity, they have also quickly switched to broadband when it became available. In less than a decade, a majority of firms have been connected to the Internet via broadband. In 2003, less than four out of ten companies had broadband access in the EU15; by 2009, this proportion had increased to nine firms out of ten (Figure 4.4).

Shifting from basic Internet connectivity to broadband implies upgrading the Internet connection to support higher speeds. The broadband speeds that consumers enjoy today are beyond the Internet capacity of many businesses earlier in the decade. For example, in 2003 in Norway, only 50\% of firms had Internet connections at speeds over $2 \mathrm{Mbit} / \mathrm{s}$. Today, Norwegian broadband providers advertise speeds of up to $100 \mathrm{Mbit} / \mathrm{s}$ with consequent benefits to consumers. In $2011,80 \%$ of firms connected to fixed broadband had more than $2 \mathrm{Mbit} / \mathrm{s}$ of fixed capacity (Figure 4.5).

In $2010,88 \%$ of OECD firms had a broadband connection and in 2011, this was the case of more than $94 \%$ of the firms in 12 countries (Figure 4.6). The data help paint a picture for SMEs. If virtually all larger firms have broadband then SME penetration is likely to be significantly lower if the overall average is $88 \%$. This implies a need for further work to help smaller firms benefit from high-speed Internet connectivity.

Small firms (10-49 employees) have the lowest broadband penetration rate among all firms, but are still generally well connected. Indeed, in 2011 only four countries have a broadband penetration rate below $80 \%$ among small firms. However, further work is required to bring the rest online as only five countries have reached the threshold of $95 \%$ of small firms connected.

Medium-sized firms (50-249 employees) are more likely to have broadband connectivity than their smaller counterparts. The percentage of medium-sized firms with broadband has reached the $95 \%$ threshold in 17 countries. In some cases, the differences between penetration 
Figure 4.4. Diffusion of broadband access in firms, selected OECD countries, 2001-10 Percentage of firms with 10 or more persons employed

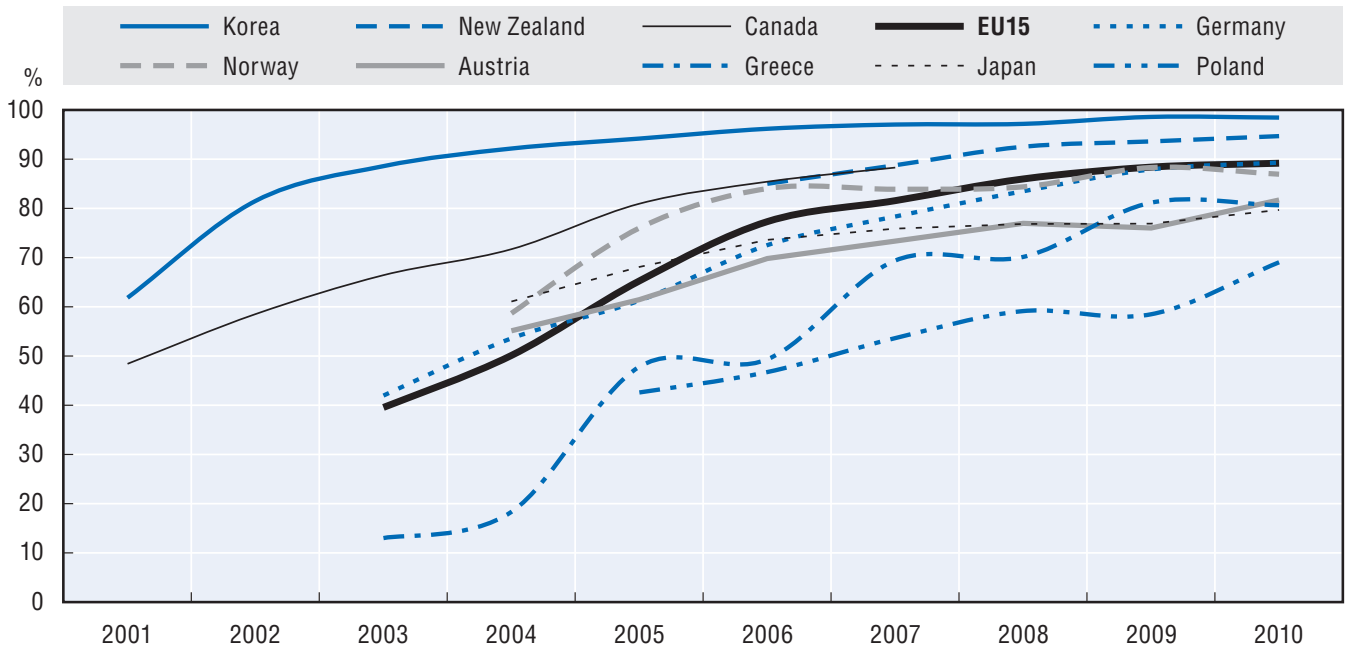

Notes: There is a break in series in 2010 for the European countries (Austria, Germany, Greece, Norway, Poland, and EU15): 2003-09 data based on NACE Rev. 1.1 and includes only fixed broadband, and 2010 based on NACE Rev. 2 and includes fixed or mobile broadband. Non-EU data based on fixed or wireless broadband. For Canada, broadband is defined as "high speed" (cable, ISDN/xDSL line, T1 line or greater). For Japan, data refer to firms with 100 and more employees. For New Zealand, OECD estimates are provided for the years 2007 and 2009. Businesses with 6 or more employees and with a turnover greater than NZD 30000.

Source: OECD ICT Database and Eurostat.

StatLink ails http://dx.doi.org/10.1787/888932693759

\section{Figure 4.5. Share of enterprises with fixed broadband and fixed broadband over $2 \mathrm{Mbit} / \mathrm{s}$ in Norway, 2003-11}

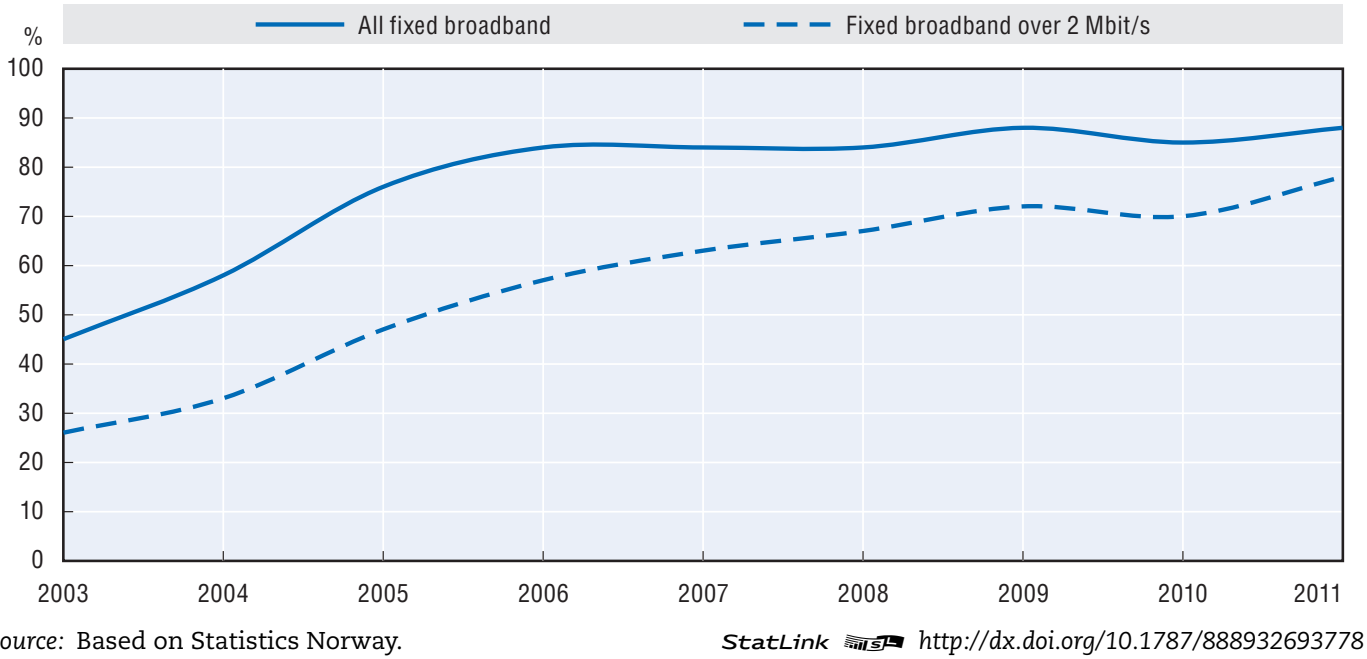

rates in large and small firms can be significant: in Greece and Poland, for example, differences in penetration rates between large and small firms exceed 20 percentage points. In contrast, in Korea and Switzerland almost all firms with 10 or more employees have broadband (98\%), while in Australia, Finland, New Zealand and Spain the gap between large and small firms is less than 5 percentage points (Figure 4.7).

Bringing connectivity to a company is only one step in creating a connected workplace. The connection then must be shared with employees across the company. A growing 
Figure 4.6. Businesses with a broadband connection, 2011 or latest available year

Percentage of businesses with 10 or more persons employed

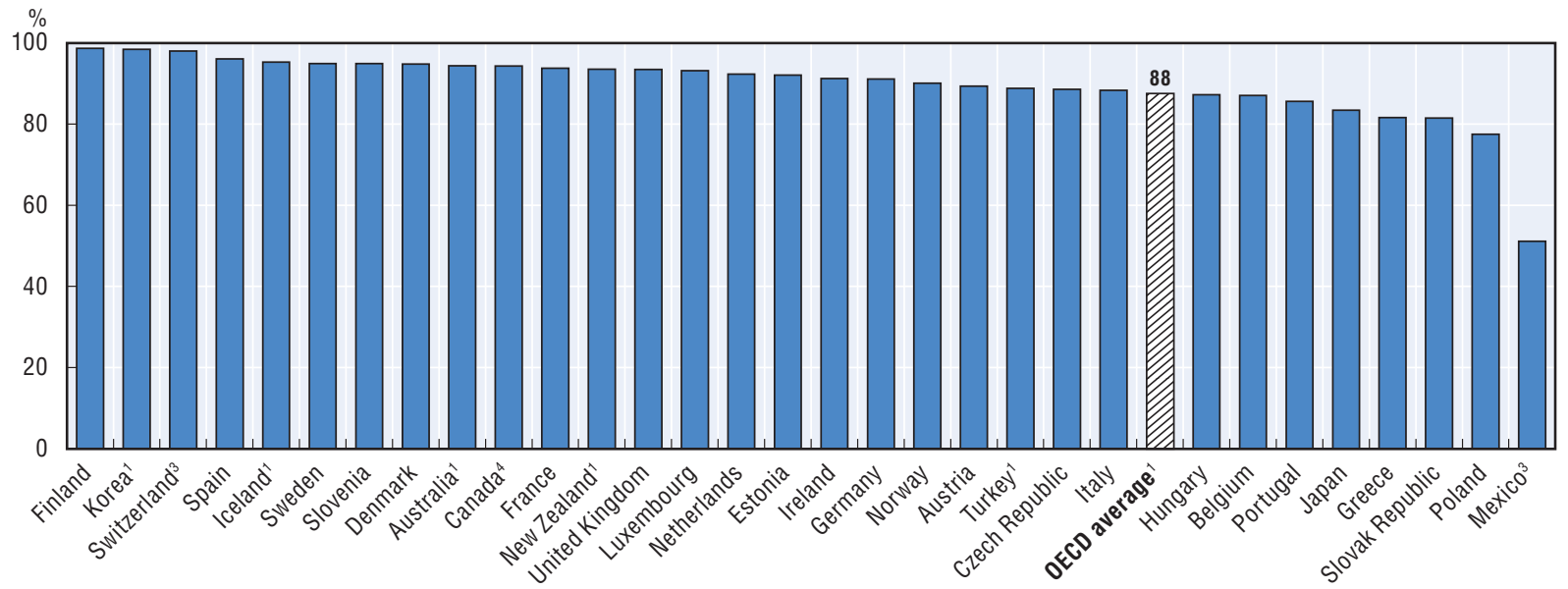

Notes: Most countries define broadband in terms of technology (e.g. ADSL, cable, etc.), rather than speed. See also endnote 1. Data from the EU Community Survey covers EU countries plus Iceland, Norway and Turkey, and includes enterprises with fixed or mobile broadband access. For Australia, from 2010 businesses within ANZSIC06 Division A Agriculture, forestry and fishing industry were included for the first time. For Japan, businesses with 100 or more employees. For Mexico, businesses with 20 or more employees. For New Zealand, businesses with 6 or more employees and with a turnover greater than NZD 30 000. For Switzerland, businesses with five or more employees and connections equal to or faster than 144 Kilobits per second (mobile and fix).

1) 2010; 2) 2009; 3) 2008; 4) 2007.

Source: OECD ICT Database and Eurostat Community survey on ICT usage and e-Commerce in enterprises, June 2012.

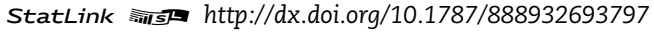

Figure 4.7. OECD businesses broadband penetration by size class, 2011 or latest available year Percentage of businesses with 10 or more persons employed

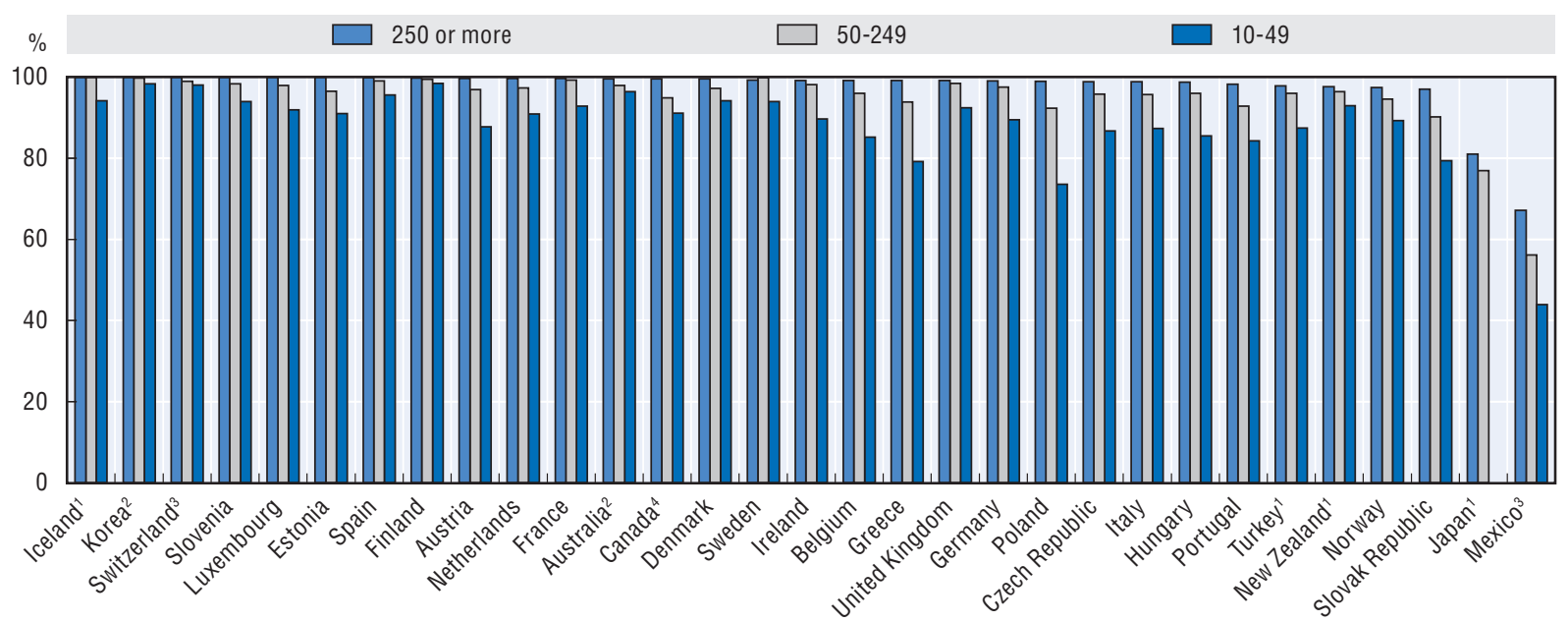

Notes: In general, enterprises are broken down by size: small (10-49), medium (50-249) and large enterprises (250 and more persons employed). For Canada: 50-299 employees instead of 50-249, and 300 or more instead of 250 or more. For Japan: 100-299 instead of 50-249, and 300 or more instead of 250 or more. For Mexico: 20 or more employees. For Switzerland: 5-49 instead of 10-49 employees. See also endnote 1.

1) 2010; 2) 2009; 3) 2008; 4) 2007.

Source: OECD ICT Database and Eurostat Community survey on ICT usage and e-Commerce in enterprises, June 2012.

StatLink त्राज्ञा http://dx.doi.org/10.1787/888932693816 
number of employees are using computers connected to the Internet, mirroring the fact that within companies, the web is increasingly seen as an important source of information, help and efficiency for people carrying out daily activities. For example, companies are actively turning to social networking tools as a way to promote their business and interact with customers. This interaction requires extensive connectivity within the company.

In the EU15 in 2011, excluding the financial sector, more than $46 \%$ of employees used a computer connected to the Internet at work. Iceland is leading the trend within the OECD: in 2005 nearly half of all employees in companies were connected to the Internet, and by 2011 nearly all employees had an Internet connection at work. The use of Internet-connected computers at work is particularly high in the Nordic countries (Figure 4.8). Similarly, in Korea in 2009 three out of five employees used the Internet for work (NIA, 2010). In Canada, 52\% of private sector employees already had access to the Internet in 2002 (Statistics Canada, 2003).

\section{Figure 4.8. Share of employed persons at work using an Internet-connected computer, selected OECD countries, 2005 and 2011}

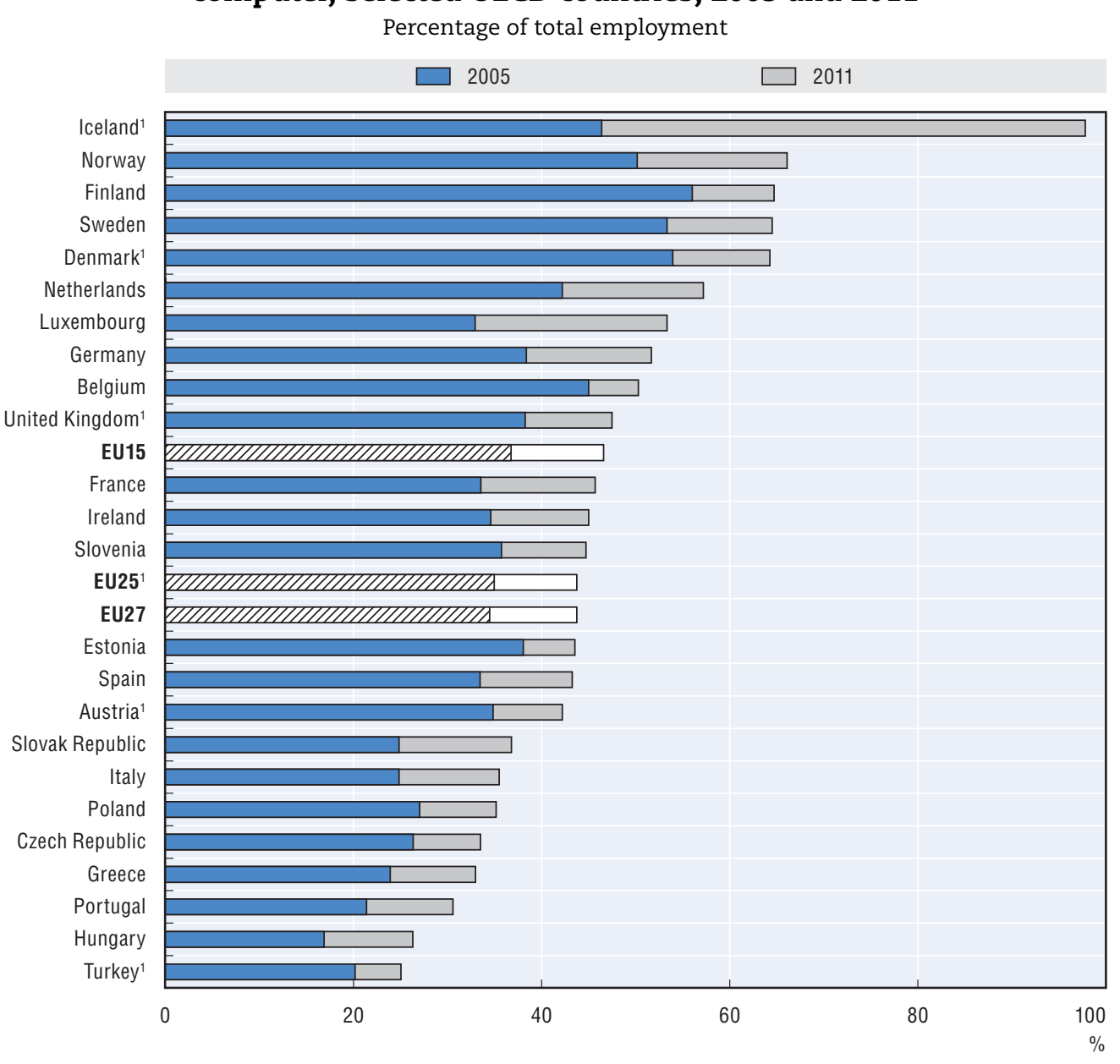

Notes: Excluding the financial sector. See endnote 1.

1. 2010.

Source: Based on data from the Eurostat Community survey on ICT usage and e-Commerce in enterprises, June 2012.

StatLink त्ञात http://dx.doi.org/10.1787/888932693835 


\section{Websites}

Businesses used information networks long before the invention of the World Wide Web. These networks supported core business functions, many of which have now transferred to the Internet. But it was the development and commercialisation of the Internet that led to a historic shift in business processes, taking advantage of the extraordinary flexibility and adaptability of the Internet, largely due to e-mail and web-based communication. The Internet has produced changes across the entire value chain for many companies, from purchasing fundamental production inputs to selling final goods directly to consumers. The transformation is both an internal one, increasing communication within companies, and an external one, influencing relationships and processes outside the firm.

One area where this transformation is visible is companies with a website. In 2011, $70 \%$ of businesses had a website in two thirds of OECD countries (for which data were available). In the other third, more than half of firms had a web presence. This is an important change compared with the early 2000s, where a minority of businesses had a website in most OECD countries. For example, in 2003, only $34 \%$ of businesses had a website in Canada, $46 \%$ in Australia and 53\% in average in the EU15 area (Figure 4.9).

\section{Figure 4.9. Businesses with a website, selected OECD countries, 2011 or latest available year \\ Percentage of businesses with 10 or more persons employed}

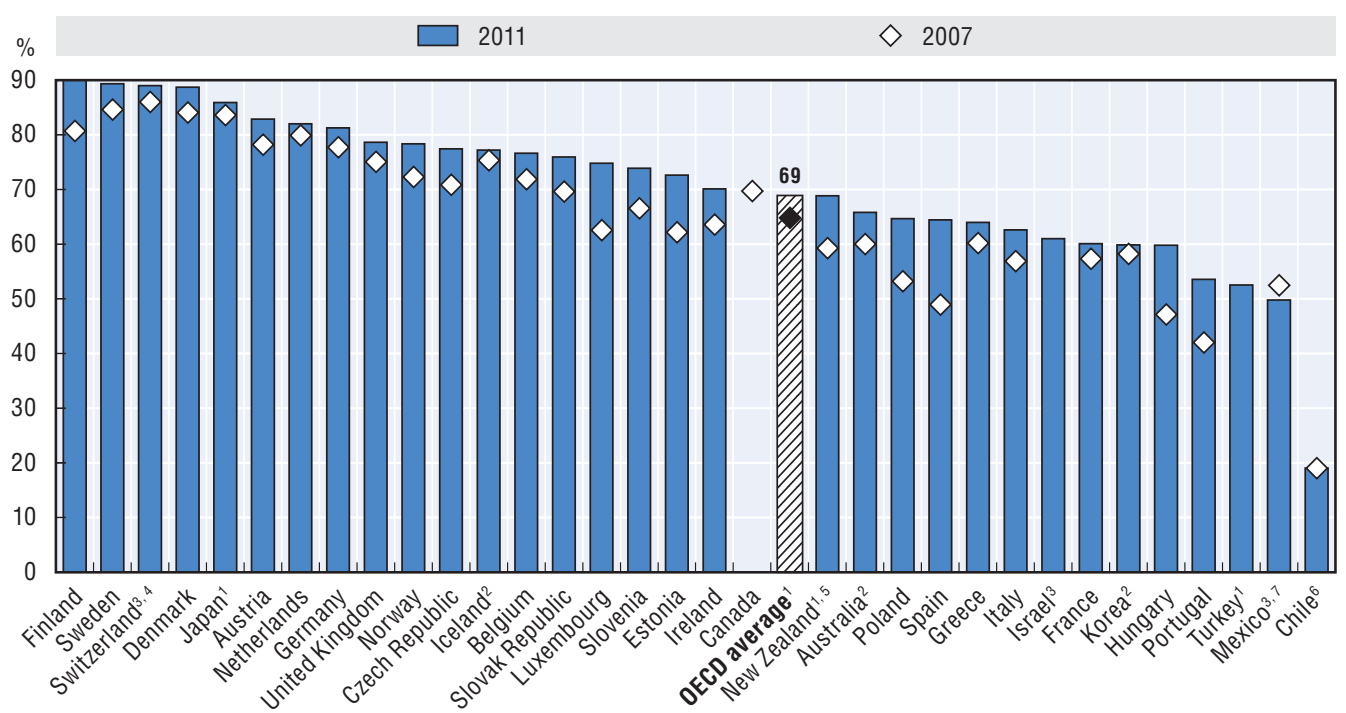

Notes: For Australia: Website includes a presence on another entity's website. See endnote 1.

Information on data for Israel: $h t t p: / / d x . d o i . o r g / 10.1787 / 888932315602$.

1) 2010; 2) 2009; 3) 2008; 4) 2007; 5) 2006; 6) 2004; 7) 2003.

Source: OECD ICT Database and Eurostat Community survey on ICT usage and e-Commerce in enterprises, June 2012. StatLink Ailsta $h t t p: / / d x . d o i . o r g / 10.1787 / 888932693854$ 


\section{The Internet improving business processes}

Companies use the Internet, and broadband in particular, as a way to improve efficiency. These gains are traceable to a number of key areas in the work of the company. This section examines the adoption of Internet technologies that support internal and external communication.

\section{Internal and external networks}

Internet technologies and tools are commonly used within company internal computer networks (intranet). These internal networks use Internet protocols to share information, but are secured against outside access to resources. Intranets are more common among larger firms because they require technical skills to build and maintain. This can make them uneconomical for smaller firms.

Companies are also increasingly using the Internet to communicate and share information with customers and suppliers. Companies use extranets to open their own networks to others outside the organisation. Within the EU27, the share of companies with an extranet jumped from $12 \%$ in 2004 to $21 \%$ in 2010. In four countries, more than one third of companies had an extranet (Belgium, Finland, France and Luxembourg). Generally, extranet deployment among companies is significantly lower than intranet deployment, except in Belgium, Luxembourg and Portugal. Among the latter, the share of companies with extranet is even higher than those with an intranet (Figure 4.10).

Extranets and intranets are more common in certain sectors of the economy, such as the information, communication, financial and insurance sectors. More than half of firms in these four sectors had an intranet in 2010. Approximately 33\% of companies in the professional, scientific and technical sectors had an intranet compared with only $25 \%$ in the wholesale and retail sectors (Eurostat, 2011).

Figure 4.10. Intranet and extranet use in selected OECD countries, 2010

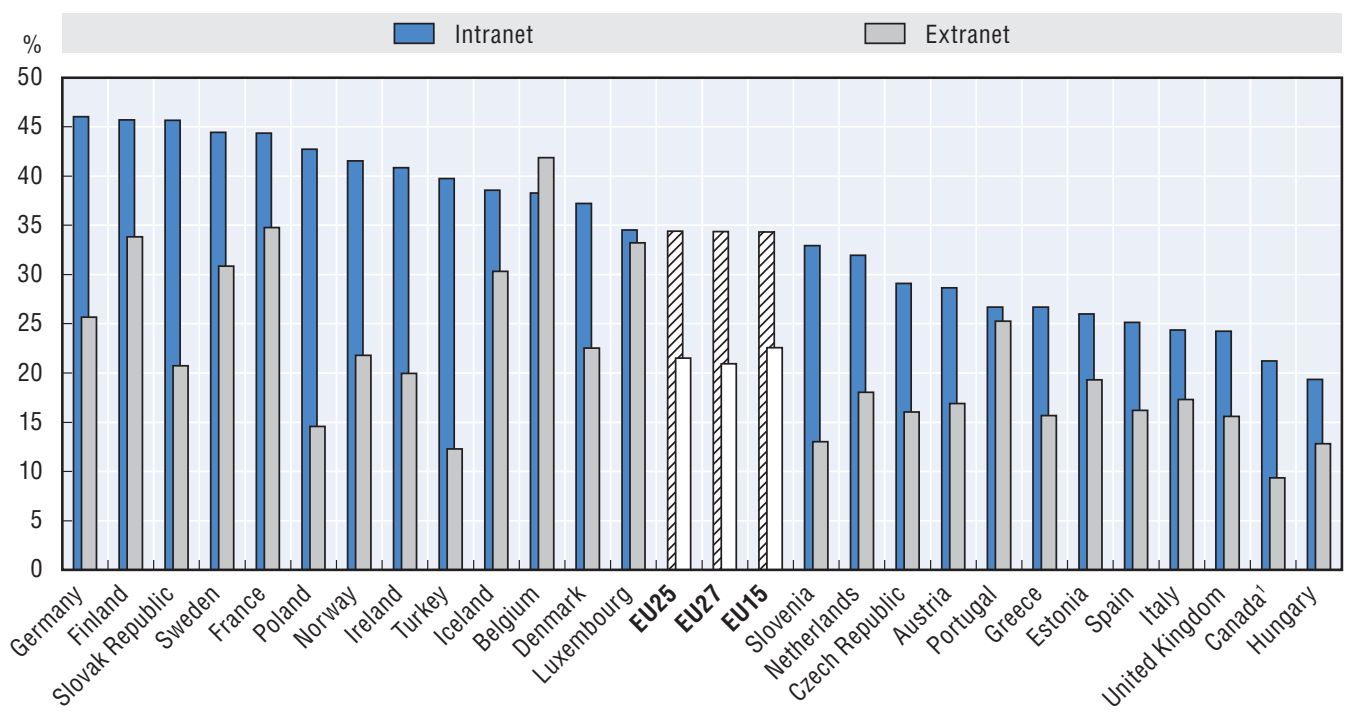

1. 2007.

Source: Based on data from the Eurostat Community survey on ICT usage and e-Commerce in enterprises, March 2012; and Statistics Canada. 


\section{Internal data communication}

ICTs are widely used for internal communication, and the Internet provides both a high level of flexibility and a broad potential for many business functions (i.e. inventory management/accounting). Wireless applications now play an important role in internal ICT deployment, providing both flexibility and mobility to employees. In the European Union, approximately one third of companies had deployed internal wireless connectivity by 2010 (Figure 4.11). Similarly, the use of wireless communication by Canadian companies jumped from 58\% in 2002 to $77 \%$ in 2007 (Statistics Canada, 2010).

Figure 4.11. Wireless access use within internal computer networks in the EU15, 2003-10

Percentage of companies by size

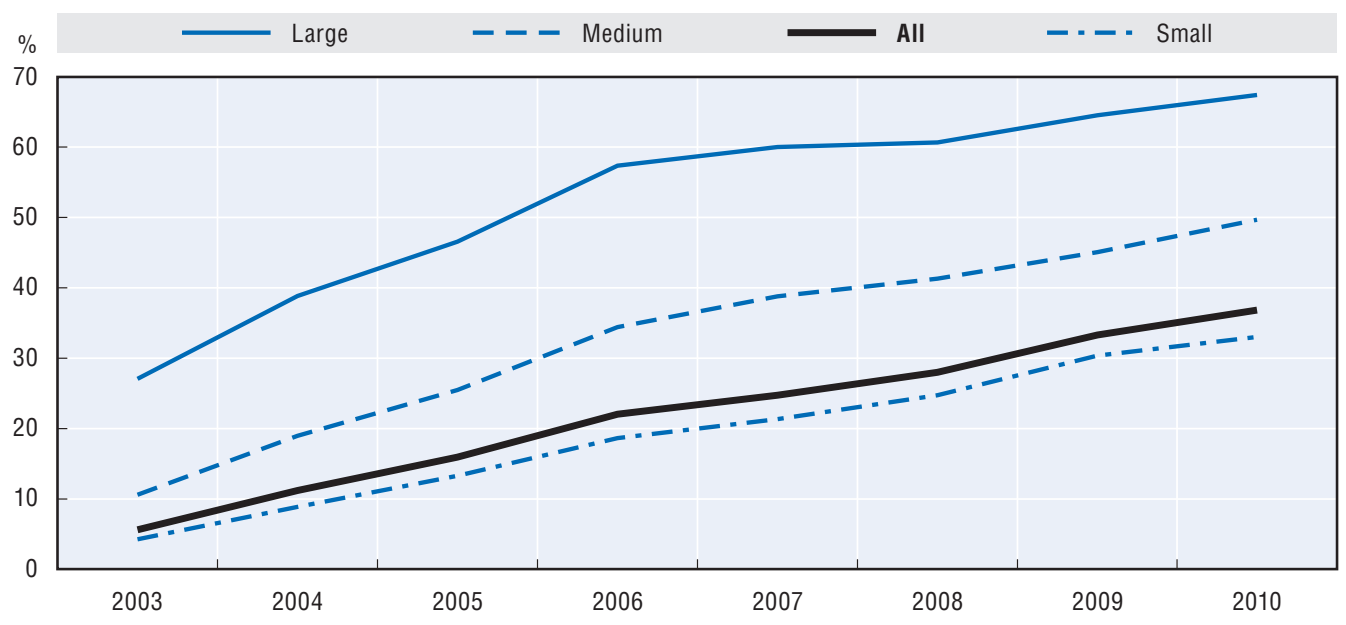

Note: Large: 250 employees and more; medium: 50 to 249 employees; small: 10 to 49 employees.

Source: Based on data from the Eurostat Community survey on ICT usage and e-Commerce in enterprises, March 2012.

StatLink Ailsts $h$ ttp://dx.doi.org/10.1787/888932693892

Data show that a majority of large firms operate their own intranet. In Europe (EU15) in 2010 , more than $80 \%$ of large firms operated an intranet, but numbers fall dramatically for smaller firms. During the same time period, only $25 \%$ of small firms reported operating an intranet.

Current trends show more companies building and operating their own intranets. In Canada, the share of firms using an intranet doubled between 2000 and 2007 to reach 21\%, and firms from the information and cultural industries were the most intensive intranet users at $50 \%$ in 2007 . This trend is also seen among European firms.

\section{External data communication and e-business development}

One of the most important economic developments related to the Internet is the growth of business-to-business (B2B) communications, often through the linking of communication networks. B2B communication has undergone a transformation over the last decade. Companies have progressively increased interaction via the Internet with other firms, for example, for electronic purchases, electronic sales and communication with public authorities. This has led to the development of e-business processes. 
The impetus for this transformation was the potential for better coordination and improved efficiency of client-supplier relations. For example, firms have been able to link their invoicing and payments systems. These technological advances have taken place within an overall shift in the business environment. Since the beginning of the 2000s, in France and also at the European level for example, there has been an increase in cooperation between firms that reaches beyond conventional client-supplier relations (SESSI, 2004). These new methods of cooperation cut across all functions (procurement, production, marketing, R\&D) and take various forms (e.g. pooling of resources, exclusive agreements, management of a common structure, etc.), depending on the nature of the business and the size of the firm. Increasingly, firms have developed cooperative partnerships covering one or more business functions.

The following chart provides an illustration of the situation in 2010 for various phases of e-business development in selected OECD countries (Figure 4.12). The phases are ordered from simple basic connectivity to the most complex level of relative integration of the process, linking orders received from customers with internal functions. The highest and lowest countries within the EU27 area, as well as the EU27 average for all firms, are selected for each phase of e-business activity. A distinction is also made between large, medium and small firms. The chart shows that the more sophisticated the activity, the lower the adoption rate.

\section{Figure 4.12. Various phases of e-business development by company size,} selected OECD countries, 2010

Percentage of businesses
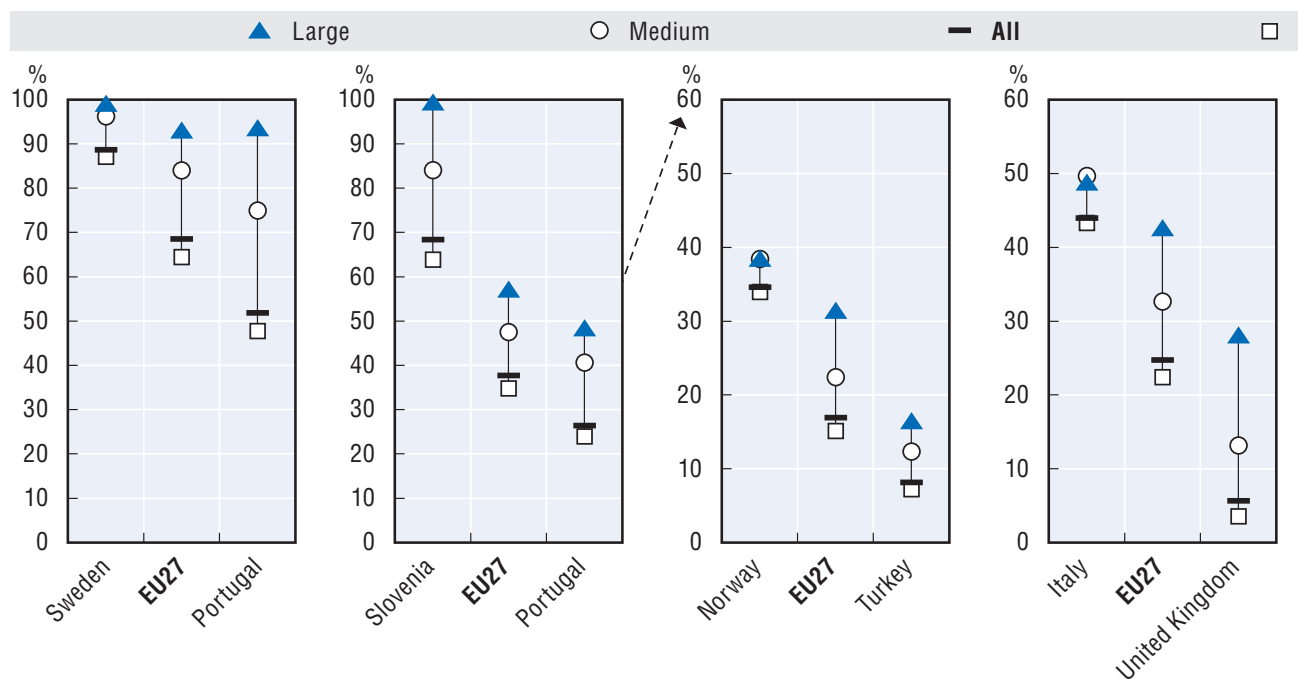

Small

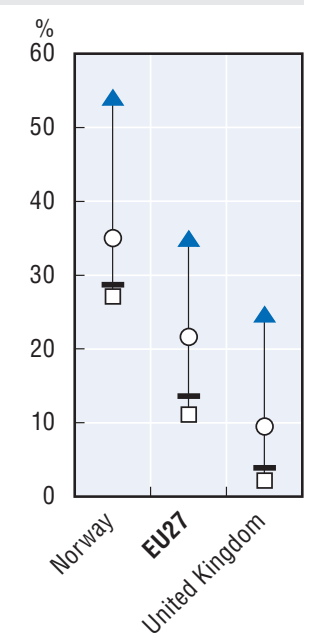

Phases of e-business development/level of complexity

Have a website or a homepage.
Website or home page has product catalogues or price lists.
Website or home page has online ordering, reservation or booking, e.g. shopping cart.
Electronic transmission of data suitable

for automatic processing used for receiving orders

from customers.
Use electronic transmission of data suitable for automatic processing for receiving orders from customers and also share information on sales with the software used for any internal function. 
The chart examines different phases of e-business development from the beginning stage of setting up a web page to more complex issues such as the electronic transmission of data suitable for automatic processing.

The initial phase starts with the implementation of a website or home page. More than $90 \%$ of firms in Sweden have a website or home page compared with $70 \%$ in the EU27 and only $50 \%$ in Portugal. The second phase looks at whether the website (or home page) has product catalogues or price lists. In the EU27, only $40 \%$ of companies have a website offering a product catalogue or available price lists.

The third phase of e-business development examines whether the company has a website that enables direct orders from clients. The percentage of firms with such capacity is significantly lower than firms with a web page or an available product catalogue in the EU27 area. The two last phases include the electronic transmission of data for automatic processing of orders received from customers, but only the final phase includes the ability to integrate data into internal functions of the firm using software tools. The gap between large and small firms in the final phase is large because of the technical skills required to implement and maintain these systems.

These results in Europe mimic findings in North America. In Canada, early findings on business adoption in 2002 already showed that e-commerce adoption is largely tied to business size (Statistics Canada, 2002). Large firms typically have more developed e-business processes, although the gap should continue to close as more cloud-based applications appear and open up possibilities to smaller firms.

\section{External integration of company business processes: from information sharing to supply chain management (SCM)}

In addition to enabling new flows of information, the Internet has provided new ways of organising and managing those flows around business activities. Many of these steps can be measured using existing statistical tools and indicators, and illustrate the emergence of more integrated links within and between businesses as a result of the Internet and ICTs in general.

The optimal use of electronic information sharing has been one of the driving forces of e-business development. Information sharing occurs within firms, but also with external business partners. Electronic information-sharing systems can create links between different functions of a company, but also between external business partners via automatic information exchange, allowing for automated processing. These systems are seen as one of the key productivity drivers within firms.

Productivity is closely linked to levels of automation for business processes and information exchange. A key tool in enabling automatic processing is data formatting. Data exchanges between company divisions or with external partners rely on standard formats to send, accept and integrate data into business processes. One way to measure the progress of companies that are connected to the Internet and integrating their business processes is to examine whether they have implemented systems for electronic data interchange (EDI), internally and externally. Aral, Bynolfsson and Wu (2008) have highlighted a virtuous cycle where IT spending leads to higher productivity, which then leads to more IT spending.

Internet development has also led to a progressive increase in the external integration of business processes (i.e. linking with customers and/or suppliers, but also with financial institutions and public authorities). External integration implies a continuum of possible 
actions and many steps. Such indicators range from: i) simply sharing information under a format suitable for automatic processing; to ii) receiving or sending e-invoices; and iii) ultimately to the complete management of the supply chain.

In 2010, firms first and foremost shared information electronically within the company. Approximately $70 \%$ of firms in Austria, Belgium and Norway had systems in place to share information electronically internally. Systems for sharing information externally and automatically with partners were less common across all countries and typically lagged by $20 \%$ to $30 \%$ (Figures 4.13 and 4.14 ).

\section{Figure 4.13. Companies sharing information electronically (internally and externally) suitable for automatic processing, by country (selected OECD countries), 2010}

Businesses with 10 or more persons employed

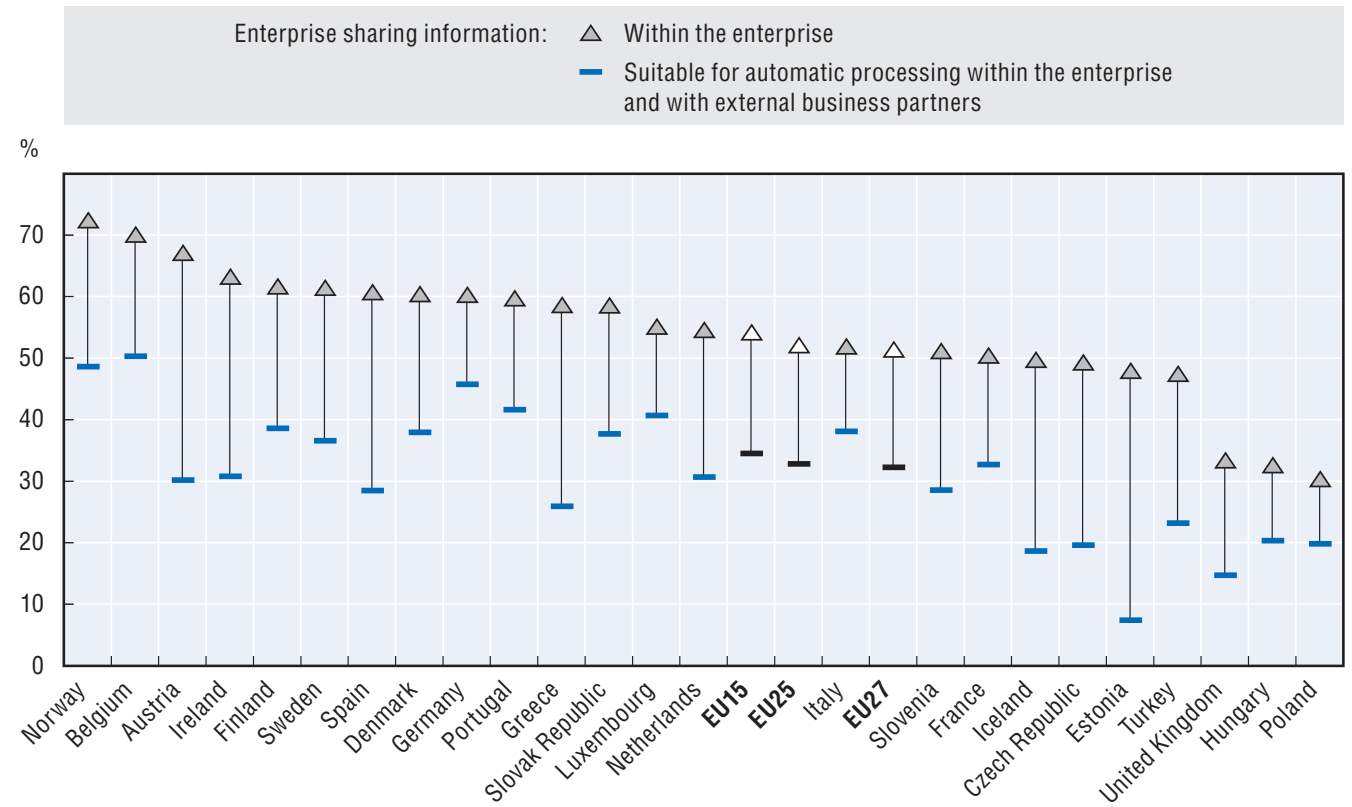

Note: Electronic transmission of data suitable for automatic processing or automatic data exchange corresponds to the concept of EDI, enlarged from data interchange on closed proprietary computer networks to electronic transmission of data on any network.

Source: Based on data from the Eurostat Community survey on ICT usage and e-Commerce in enterprises, March 2012.

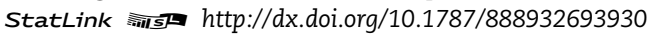

Certain sectors lead in terms of information sharing, both within and outside of firms. Financial and insurance firms are the most likely to have systems in place for information sharing. The information and communication sector, and wholesale and retail trade sectors also have a high level of information sharing across firms and with external partners. This is not surprising given these are also the sectors that are the most likely to have intranets and extranets in place. The sector with the smallest amount of information sharing is accommodation and food service activities (Figure 4.14).

\section{Receiving and sending e-invoices}

One area where the Internet has significantly transformed business is in supporting automation and e-invoices via an automated data exchange (ADE). In terms of implementation, fewer firms use an automated data exchange to send out e-invoices than have the infrastructure to receive an e-invoice, with the exception of Denmark (Figure 4.15). 
Figure 4.14. Companies sharing information electronically (internally and externally) suitable for automatic processing, by sector (EU25), 2010

Businesses with 10 or more persons employed

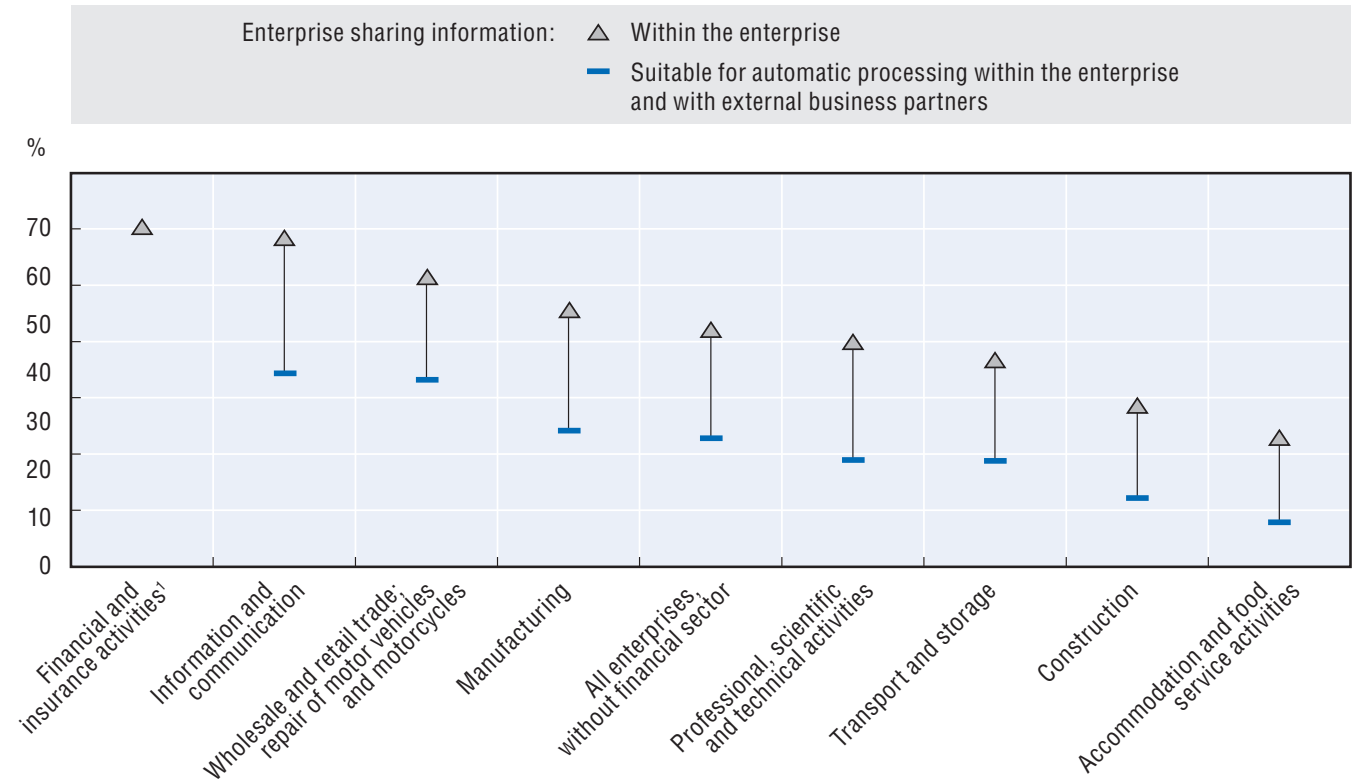

Notes: Electronic transmission of data suitable for automatic processing or automatic data exchange corresponds to the concept of EDI, enlarged from data interchange on closed proprietary computer networks to electronic transmission of data on any network.

1. Firms sharing electronically information suitable for automatic processing within the enterprise and with external business partners not available for this sector.

Source: Based on data from the Eurostat Community survey on ICT usage and e-Commerce in enterprises, March 2012.

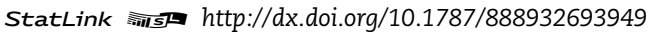

\section{Figure 4.15. Companies using automatic data exchange to receive or send e-invoices, selected OECD countries, by country, 2010}

Businesses with 10 or more persons employed

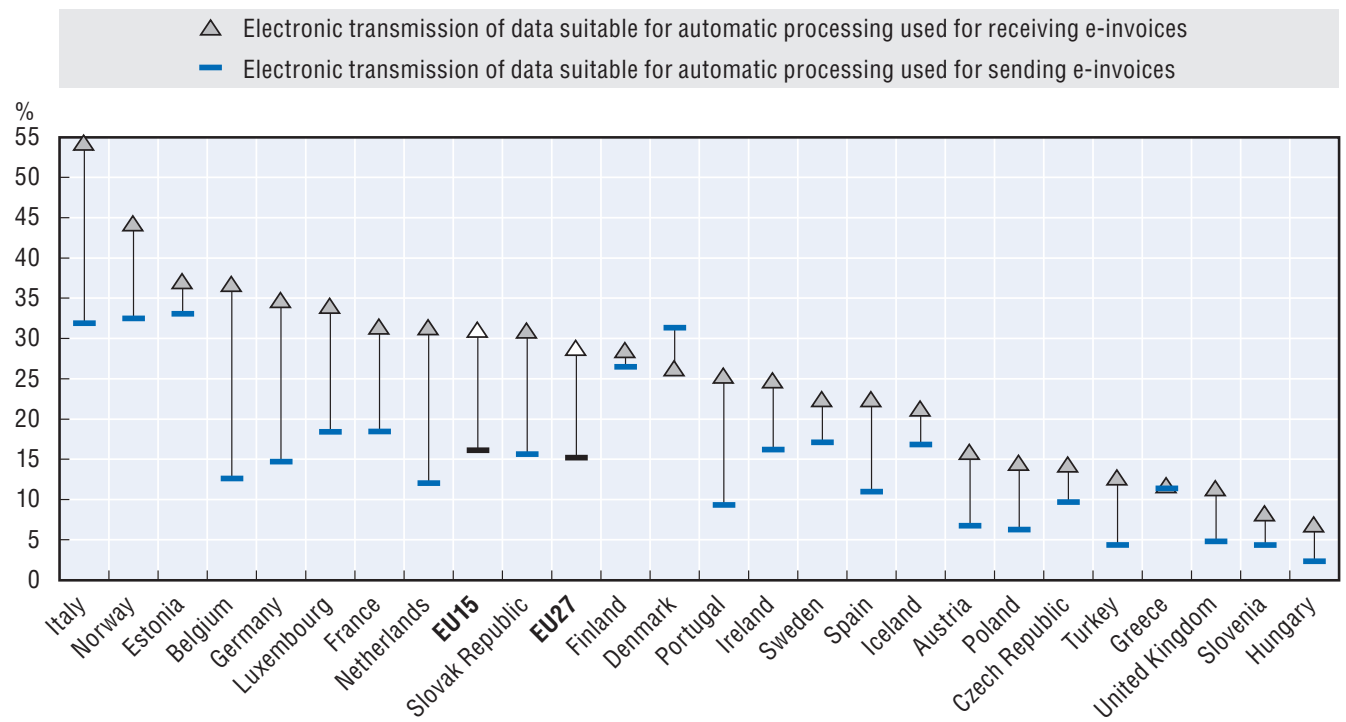

Note: Electronic transmission of data suitable for automatic processing or automatic data exchange corresponds to the concept of EDI, enlarged from data interchange on closed proprietary computer networks to electronic transmission of data on any network.

Source: Based on data from the Eurostat Community survey on ICT usage and e-Commerce in enterprises, March 2012.

StatLink न्ता sta http://dx.doi.org/10.1787/888932693968 
The information and communication sector, the financial sector and the trade sector are the most intensive users of e-invoices with suppliers or customers (Figure 4.16). The gap between the percentage of firms able to send an e-invoice and the percentage able to receive an e-invoice highlights the need for further improvement.

\section{Figure 4.16. Companies using Automatic Data Exchange to receive or send e-invoices in EU27}

By sector and size, 2010, businesses with 10 or more persons employed

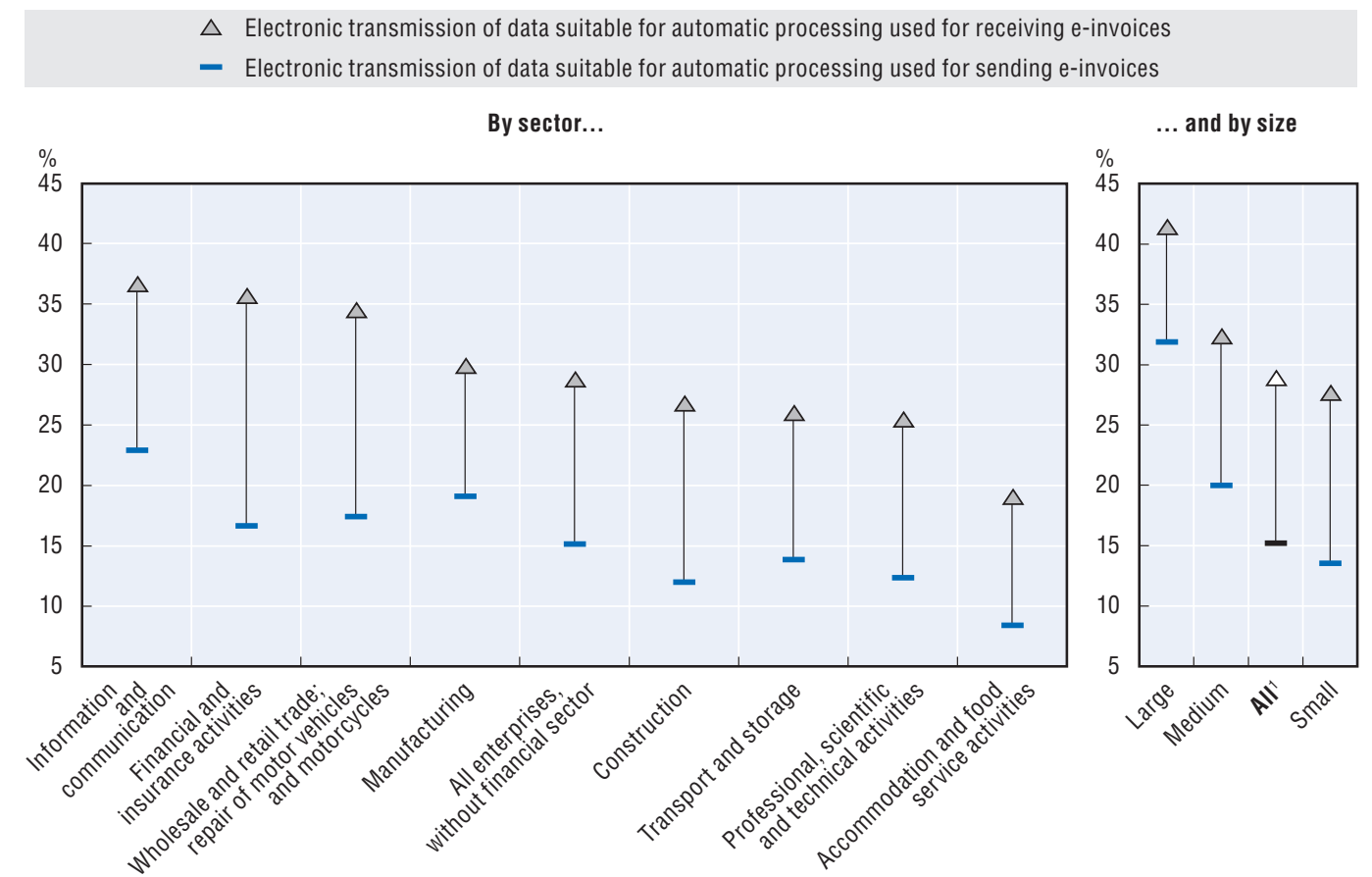

Notes: Electronic transmission of data suitable for automatic processing or automatic data exchange corresponds to the concept of EDI, enlarged from data interchange on closed proprietary computer networks to electronic transmission of data on any network.

1. Without the financial sector.

Source: Based on data from the Eurostat Community survey on ICT usage and e-Commerce in enterprises, March 2012.

StatLink Aन्ता $h$ ttp://dx.doi.org/10.1787/888932693987

\section{Supply chain management}

From the raw material to the final product, the production chain is made up of links between companies that, put together, form a supply chain of entities purchasing, processing, distributing and selling inputs and products. The output of one link in the production chain forms the input for the next link.

Supply chain management (SCM) coordinates the various activities involved in the supply chain. It aims to improve the results of each individual company and the supply chain as a whole. Efficiency gains as a result of SCM can include better integration between business partners through improved articulation of various processes. SCM can also improve efficiency by reducing communication costs and improving the overall quality of communication.

Integrated systems enable better automation of inventory management, reducing errors and associated costs. On the sales side, SCM lowers costs by offering more efficient invoicing (the financial information of supplier and buyer is collected, exchanged and stored electronically). Companies also employ SCM to secure future orders, which can translate into favourable prices for customers. 
ICT systems are at the heart of SCM, supporting the various management channels and business processes through communication and data tools. Improving the integration of the business processes of the partners makes both parties more efficient (Statistics Netherlands, 2010).

ICTs are an important support for domestic as well as global value chains. At the global level, rapid technological advances in ICTs over the last decades have significantly decreased the costs of transacting, organising and coordinating complex activities over (long) distances.

At the end of 2010, 18.8\% of companies in Europe were using some form of supply chain management, an additional 3.3\% compared to 2008. Portugal and Belgium are leaders in SCM with over $30 \%$ of firms indicating they use SCM regularly to share information electronically with customers or suppliers. Over $25 \%$ of firms use SCM in Germany, Luxembourg, Norway, Slovak Republic and Sweden. In all the countries, SCM is accessed mainly through company websites. These websites and the Internet are critical assets for the day-to-day running of the business process for more than one business out of five in the Slovak Republic and Sweden, and for nearly one out of three in Portugal (Figure 4.17).

\section{Figure 4.17. Business use of supply chain management via a website, selected OECD countries, 2010 \\ Businesses with 10 or more persons employed}

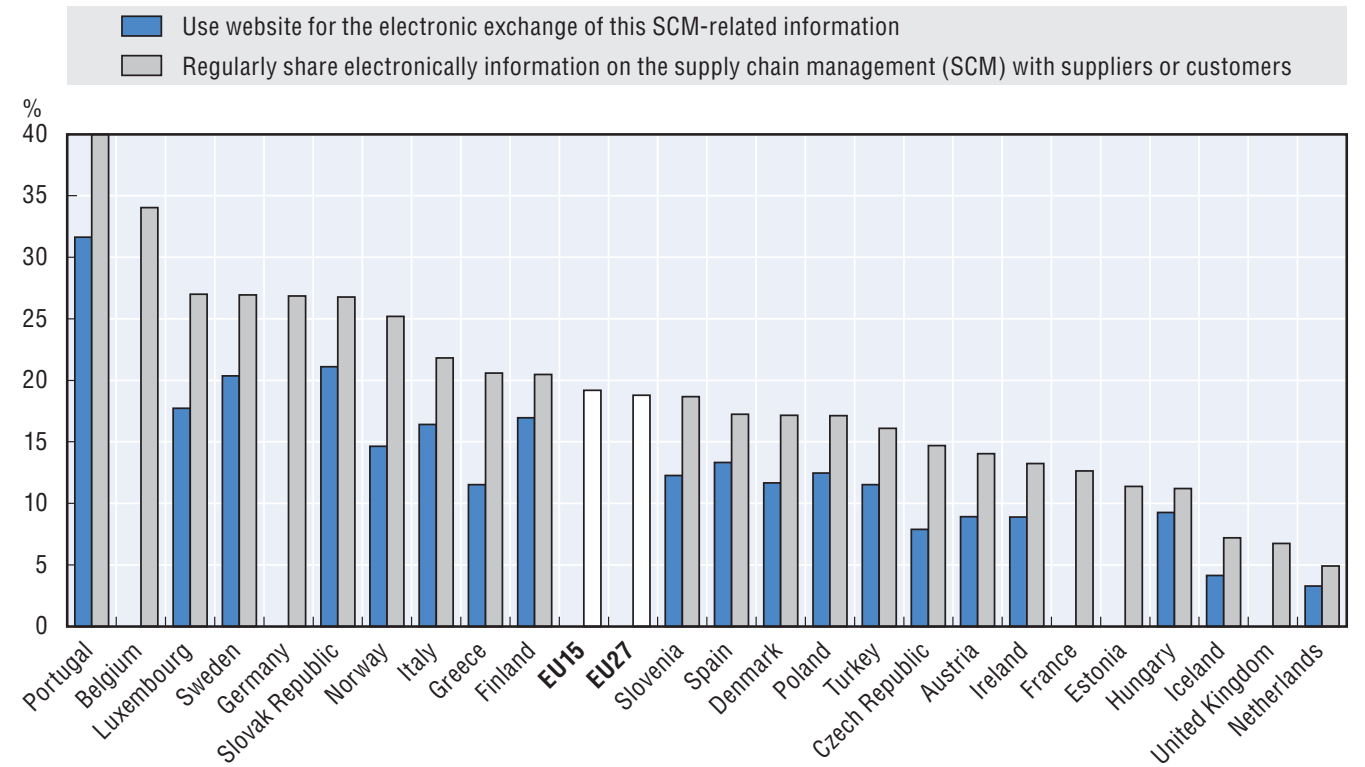

Source: Based on data from the Eurostat Community survey on ICT usage and e-Commerce in enterprises, March 2012.

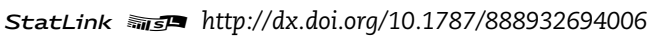

Data on SCM reveal that large firms are much more inclined towards using SCM than small firms, mirroring, among other factors, differences in the degree of sophistication of ICT systems. Differences of use also vary according to economic activity. Wholesale and retail trade and manufacturing are more inclined to use SCM compared to services activities. A noticeable exception is the information and communication sector which also makes extensive use of SCM. 


\section{Electronic commerce}

The number of firms carrying out business transactions (placing or receiving orders) over the Internet has increased dramatically over the last decade. The Internet facilitates transactions such as ordering goods and services, many of which would have taken place offline in its absence. The Internet has effectively made transactions that would have otherwise taken place more efficient and less expensive. At the same time, the Internet facilitates new transactions that could not have occurred without its existence (e.g. the use of the Internet by SMEs to sell goods globally).

Electronic commerce has shown a significant increase in many OECD countries during the last decade (OECD, 2011). For example, in the Netherlands, e-commerce as a share of total revenue of companies increased from 3.4\% in 1999 to $14.1 \%$ in 2009. Moreover, between 2004 and 2011 this share increased from 2.7\% to 18.5\% in Norway and from $2.8 \%$ to $11 \%$ in Poland. Based on comparable data, e-commerce is nearing $20 \%$ of total turnover in Finland, Hungary and Sweden and 25\% in Czech Republic (Figure 4.18). Nevertheless, in 2011 it still represented a relatively modest share of total sales in most OECD countries.

\section{Figure 4.18. Total turnover of companies from e-commerce, 2011 or latest available year}

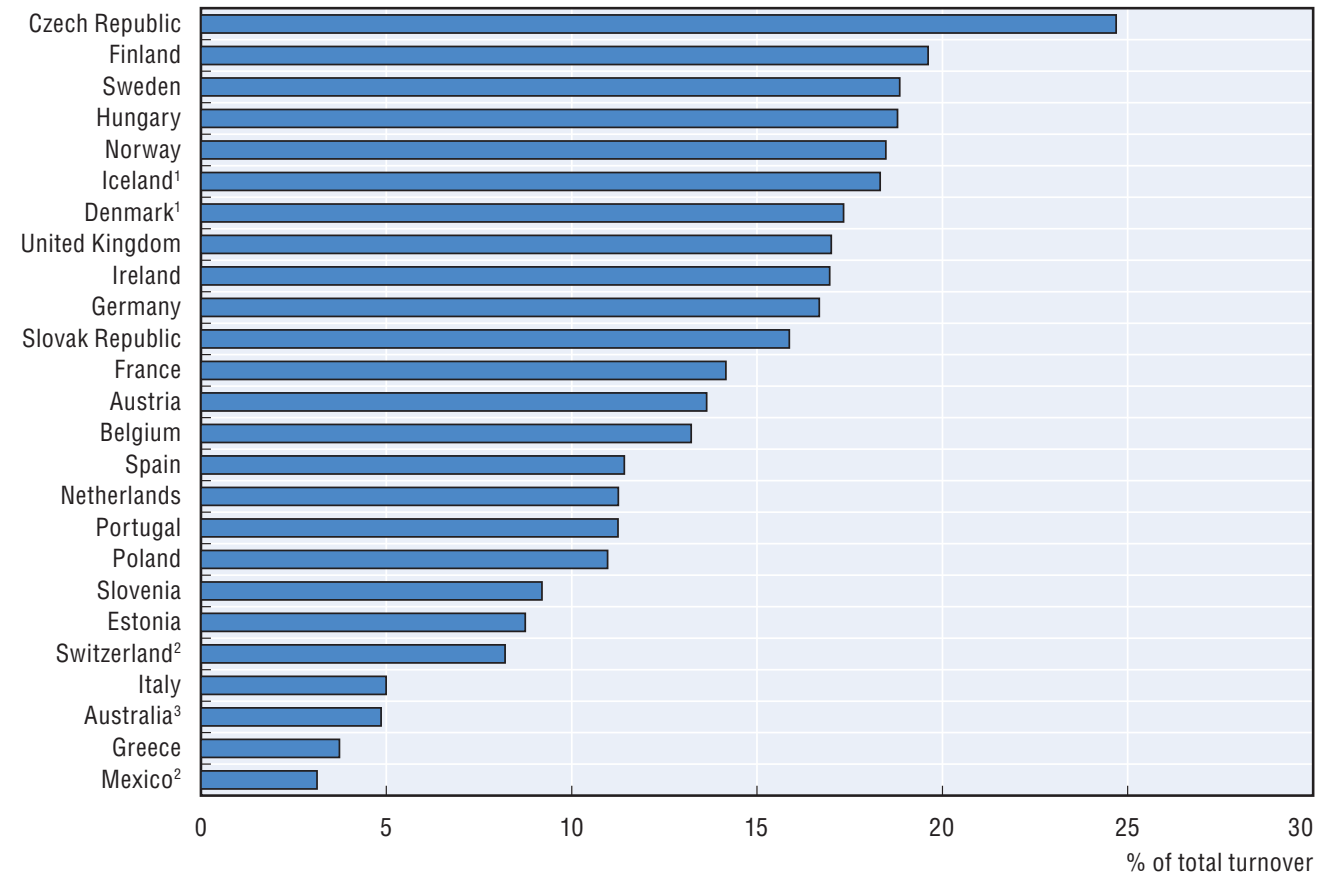

Notes: The figure shows total sales via the Internet or other networks during the reference year, excludingVAT. Businesses with at least 10 persons employed. Country notes: See endnote 1. For Australia and Switzerland, economic activities data correspond to the classification ISIC Rev. 4. Include the following industries: Manufacturing (ISIC C); Construction (ISIC F) Wholesale trade, except of motor vehicles and motorcycles (ISIC G: Division 46); Retail trade, except of motor vehicles and motorcycles (ISIC G. Division 47); Accommodation and food service activities (ISIC I); Transportation and storage (ISIC H); Information and communication (ISIC J); Real estate activities (ISIC L) Professional, scientific and technical activities (ISIC M); Administrative and support service activities (ISIC N). Finance and Insurance (ISIC J) are excuded. For Mexico, economic activities data correspond to the classification ISIC Rev. 3. Include the following industries: Manufacturing (ISIC D); Construction (ISIC F); Wholesale trade (ISIC 51); Retail trade (ISIC 52); Hotels and restaurants (ISIC H); Transport, storage and communications (ISIC I); Real estate, renting and business services (ISIC K).

1) 2010; 2) 2008; 3) 2009.

Source: OECD ICT Database and Eurostat Community survey on ICT usage and e-Commerce in enterprises, June 2012. StatLink ints http://dx.doi.org/10.1787/888932694025 
Companies generated more than $4 \%$ of their turnover through sales via a website in approximately one third of OECD countries in 2011. In Czech Republic and Slovak Republic, the increase in turnover from e-commerce was particularly strong between 2010 and 2011, with a growth of more than 5 percentage points for companies in the countries (Eurostat, 2011).

At the beginning of the 2000s, the Internet was used much more frequently to purchase/order goods and services than to receive orders, and significantly fewer firms sold goods online compared to those ordering online (OECD, 2004). A decade later, in 2011, this is still the case (Figure 4.19). In 2010, on average, 35\% of all businesses with 10 or more persons employed used the Internet for purchasing, and $18 \%$ for selling goods and services (OECD, 2011).

\section{Figure 4.19. Businesses selling/purchasing over the Internet, 2011 or latest available year}

Businesses with 10 or more persons employed

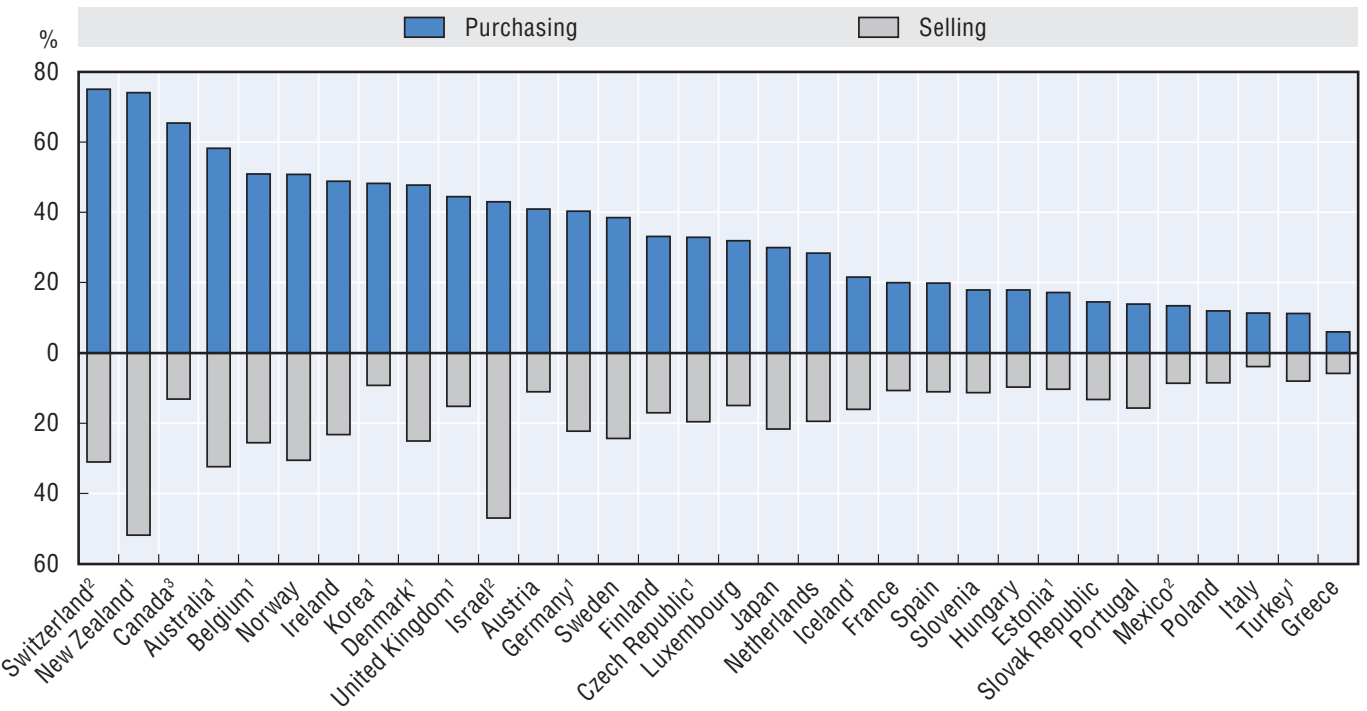

Notes: The definition of Internet selling and purchasing varies between countries, with some explicitly including orders placed by conventional e-mail (e.g. Australia and Canada) and others explicitly excluding such orders (e.g. Ireland, the United Kingdom and some other European countries). Most countries explicitly use the OECD concept of Internet commerce, that is, goods or services are ordered over the Internet but payment and/or delivery may occur offline. For countries covered by Eurostat, see endnote 1. Selling/purchasing data refer to "over any networks" excluding manually typed e-mails (except United Kingdom where for 2007 manually typed mails were included). See endnote 2.

1) 2010 ; 2) 2008; 3) 2007

Source: OECD ICT Database and Eurostat Community survey on ICT usage and e-Commerce in enterprises, June 2012.

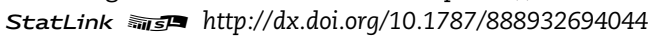

Companies also use the Internet as a way to communicate more efficiently with governments. This has led to improved communication channels and lower costs for both governments and firms (OECD, 2009). The range of interactions is relatively broad. A majority of companies now use the Internet to interact directly with public authorities, both to receive and transmit information (e.g. declarations of social contributions, corporate taxes, VAT and customs, etc.). 
In 2011,10 countries reported that over $80 \%$ of firms used the Internet to return completed forms to public authorities. In two thirds of OECD countries, $70 \%$ of firms supply forms electronically (Figure 4.20). The ultimate goal of public authorities is to move to a fully electronic process to take advantage of efficiency gains and improve the process for companies.

For example, in the EU27 on average, the share of firms using the Internet for administrative procedures increased from 15\% in 2004 to almost 50\% in 2010 (Eurostat, 2011). Large firms are more engaged in this process (62\%) than medium and small firms (respectively 59\% and 45\%).

\section{Figure 4.20. Businesses using the Internet to return completed forms to public authorities, 2011 or latest year available}

Businesses with 10 or more persons employed

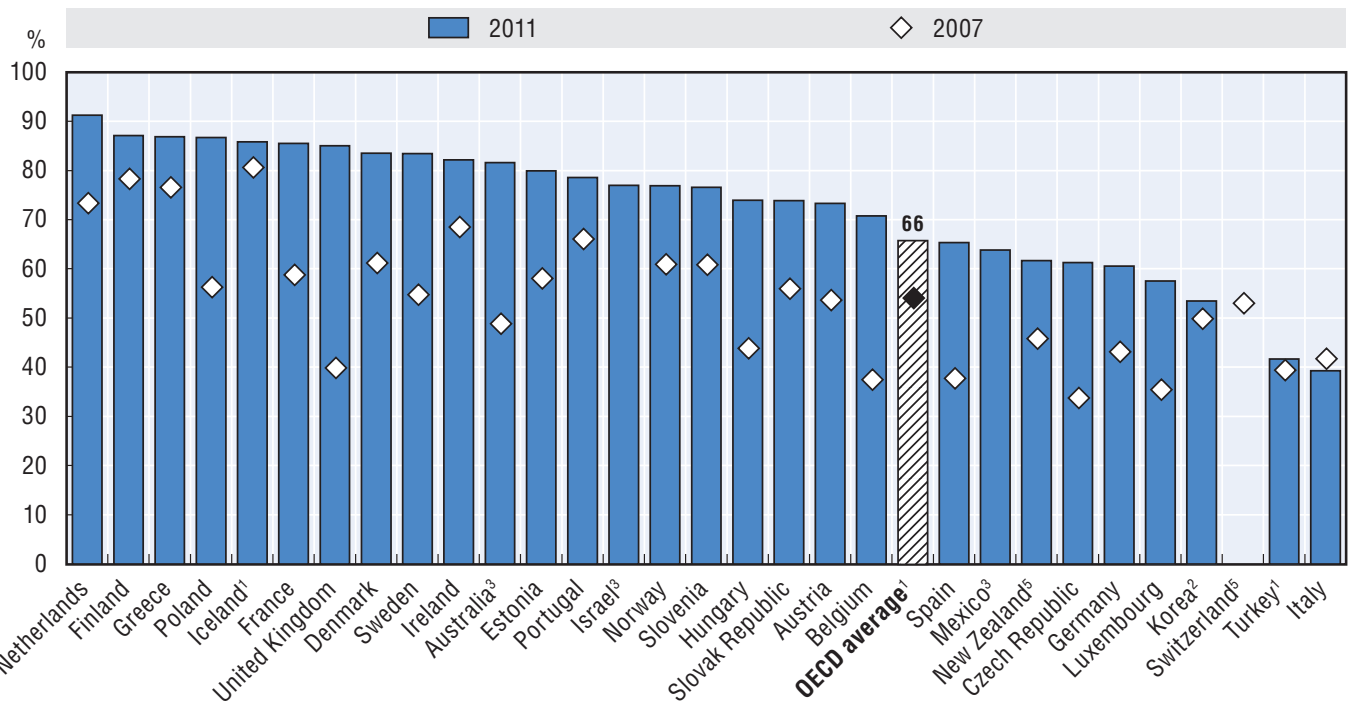

Notes: Data from the EU Community Survey covers EU countries plus Iceland, Norway and Turkey. For countries covered by Eurostat, the reference period corresponds to January of the survey year. For countries covered by the OECD ICT questionnaire, the reference period is that of the year surveyed. For Israel and Switzerland: data refer to dealing with public authorities in general. For Mexico, data refer to businesses using the Internet for government procedures. For Mexico: Businesses with 20 or more personnel for 2008 data. For Switzerland: Businesses with five or more employees. See endonte 1.

Information on data for Israel: http://dx.doi.org/10.1787/888932315602.

1) 2010; 2) 2009; 3) 2008; 4) 2007; 5) 2006.

Source: OECD ICT Database and Eurostat Community survey on ICT usage and e-Commerce in enterprises, June 2012.

StatLink तiाlsta http://dx.doi.org/10.1787/888932694063

\section{ICT impacts on businesses: Perceived benefits and real impacts}

The growth of Internet penetration among both households and businesses has helped usher in an era of productivity gains for companies conducting business online. Internet connectivity increases information fluidity and allows markets to remain open around the clock and around the globe. The Internet also reduces transaction costs by increasing integration of various business processes within and between companies.

These efficiency gains come into better focus as time goes by so it is informative to look at how firms alter their perception of the benefits over time. During the early days of e-commerce a key cited benefit of the Internet was the ability to reach new customers. However, it is the Internet's capacity to transform internal and external processes that has 
led to much of the efficiency gains within companies. It is also clear that efficiency gains result not just from the adoption of ICT and e-commerce, but also from associated modifications of business processes and structure related to the Internet.

Canada provides an informative example. In 2001, 30\% of Canadian firms did not have access to the Internet. However, between 2001 and 2007 there was a significant shift in the perceived benefits of the Internet. In 2007, "better coordination with suppliers, customers or partners" overtook "reaching new customers" as the biggest benefit of Internet access (Figure 4.21).

The findings in Korea are similar. Between 2006 and 2009, Korean firms assigned more benefit to reducing business and transactions costs than to reaching new customers with the Internet.

\section{Figure 4.21. Perceived benefits of conducting business over the Internet}

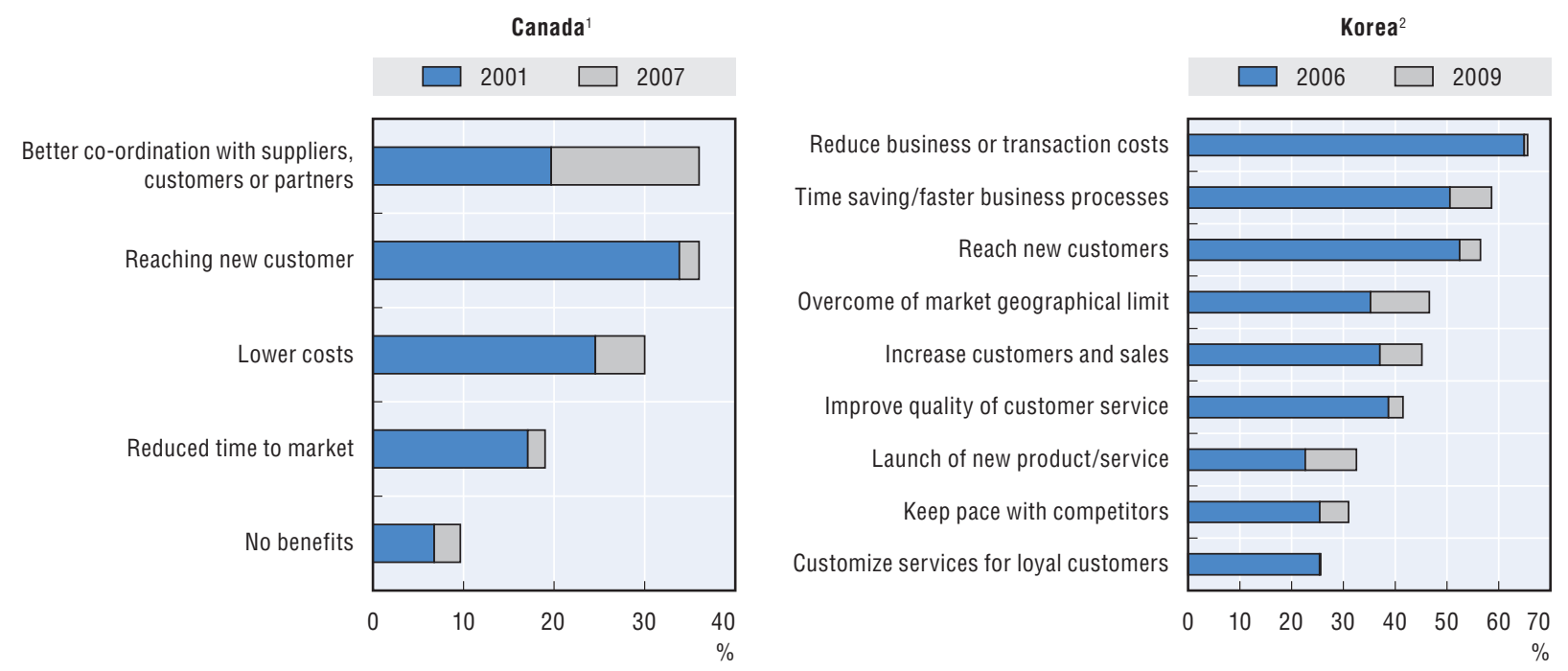

1. Percentage of businesses reporting perceived benefits of conducting business over the Internet.

2. Percentage of businesses with 10 or more employees that have enacted sales over the Internet or the web during the reference period. Source: Based on data from Statistics Canada and the Korean National Information Society Agency (NIA).

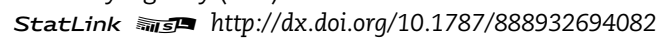

Similarly, in most European countries in 2009, large and medium-sized enterprises ranked reduction of transaction costs as the most favourable effect of the Internet (electronic sales). This was typically followed closely by increasing sales potential due to access to new markets. Small firms, however, ranked increasing access to new markets as the most important benefit (Eurostat, 2011).

\section{Beyond perceived benefits: The impact of the Internet (ICT) on business performance and innovation}

Although companies report benefits from using the Internet, it has been difficult historically to capture these impacts in economic models, particularly at the macroeconomic level. Many efforts have been made during the last decade to go beyond the Solow paradox, ${ }^{3}$ using macroeconomic or microeconomic approaches to better understand the role of ICTs in the economy. 
The increasing availability of large micro-data sets and the possibility of linking them together have enabled numerous econometric analyses, highlighting the role of ICT as a general-purpose technology tied to productivity, growth and innovation. Recent research provides evidence of the strength of these links and relevant examples, based on micro-data from surveys. The Eurostat ICT impact project (Eurostat, 2008), for example, reveals that ICT usage is positively related to firm performance.

A recent analysis of inter and intra-firm diffusion of electronic commerce (both B2B and $\mathrm{B} 2 \mathrm{C}$ ) also reveals key ways in which e-commerce impacts are manifest. In particular: large firms are more likely to adopt e-commerce than small firms, but do not necessarily use it more intensively; human capital plays an important role for the diffusion of e-commerce; innovative activities (products and process) of the company matter for both inter and intra-firm diffusion; and companies use e-commerce as a strategic tool to compete in their markets (Vicente and Lopez, 2009). Another recent work uses micro-data from both ICT business use and innovation surveys and applies the same model and assumptions to nine OECD countries. The study controlled for other determinants of innovation (e.g. R\&D, firm size and skills) as well as for endogeneity, and found that ICT, and more specifically Internet use, may be acting as an enabler of innovation (Spiezia, 2011).

ICT intensity, measured by number of web facilities, ${ }^{4}$ increases the probability of innovation both in manufacturing and services industries, and more significantly in the former than in the latter (Figure 4.22). In Spain and Italy, companies in the manufacturing sectors with three web facilities are $81 \%$ and $66 \%$ respectively more likely to innovate than companies with no web facilities.

Figure 4.22. Internet use intensity and innovation frequency, selected OECD countries Increase in the probability to innovate as compared to firms with no web facilities
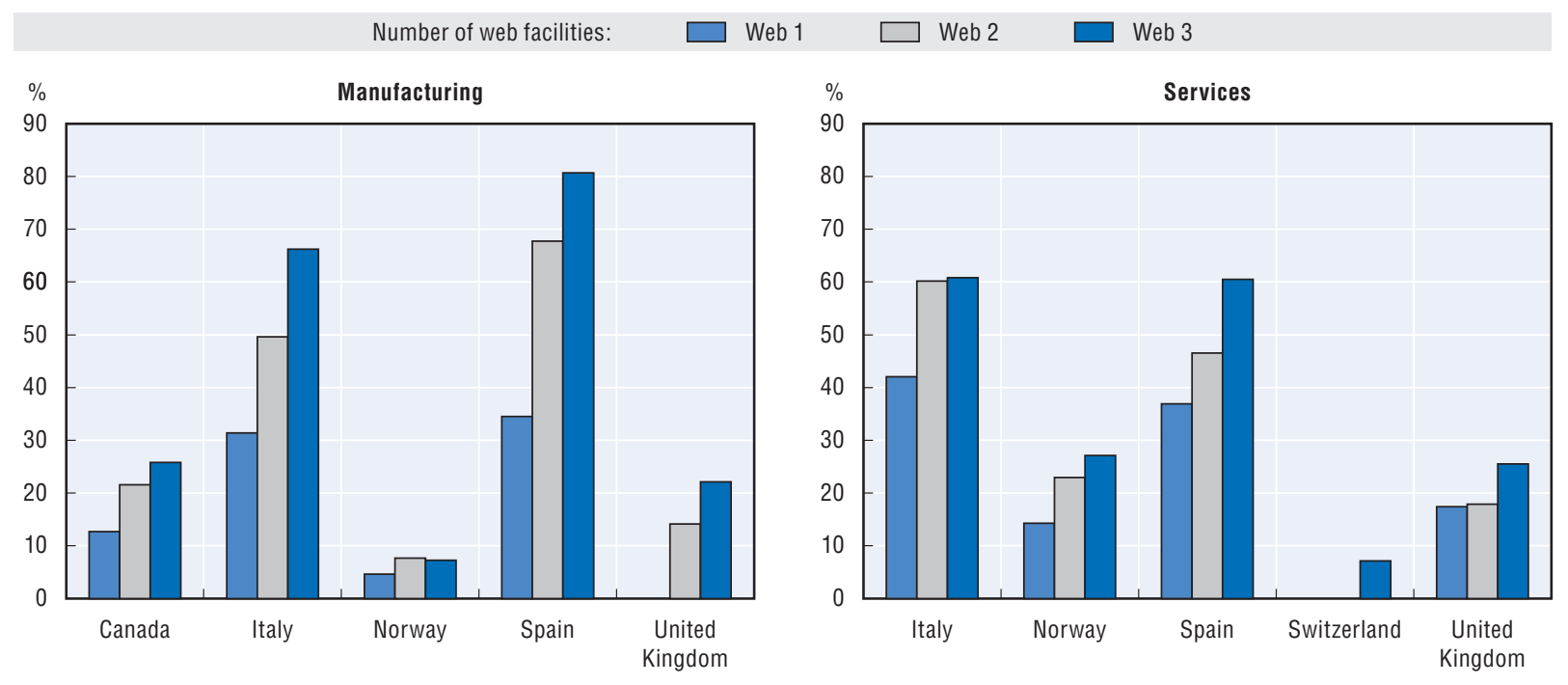

Notes: ICT intensity is measured as the number of web facilities used by a company. The indicator varies between 0 (the firm uses no web facilities) and 3 (the firm uses all web facilities). The number of web facilities is computed from (Yes/No) answers to the following question Did the website of your enterprise provide the following facilities during January 2006? (your enterprise as provider of Internet services): a) Marketing the enterprise's products; b) Facilitating access to produce catalogues and price lists; c) Providing after-sales support. (Eurostat model for a Community Survey on ICT usage and e-commerce in Enterprises 2006).

Source: Spiezia (2011). 


\section{Conclusion}

Information and communication technologies have developed and spread at a rapid pace during the last 15 years, and the digital landscape has evolved. Economic actors and businesses, in particular, have taken advantage of the opportunities provided by the Internet to change the ways they interact with each other and to improve efficiency. Many businesses have also entered into a restructuring process by which they modify internal and external business processes around the Internet, and where innovation is one of the key components.

This chapter has highlighted the widespread use of ICTs and Internet access among companies in OECD countries. Broadband access has dramatically increased with large companies now almost universally connected and small companies not far behind. In Europe, nearly half of all employed persons are connected to the Internet at work.

Companies are at different levels of e-business development. Many companies use the Internet for basic communication, but relatively fewer have integrated it into a full supply chain management system. One core reason is that large companies have the technology and skills to maintain complex systems, but smaller companies may not. For all the various steps previously mentioned, generally the more integrated the business process and information sharing, the lower the share of companies involved as compared to large companies.

Companies also increasingly interact electronically with public authorities. In 2010 , on average, two companies out of three used the Internet to return completed forms to public authorities in the OECD area. Many governments are working to make as many administrative procedures as possible available on the Internet. In 2010, firms in the OECD area undertook nearly half of these procedures electronically.

E-commerce continues to grow and represents an increasing share of total business revenue. Although this share is still small in many countries, it is growing generally, as does the share of businesses selling and purchasing over the Internet.

As government policy makers work to improve business adoption of Internet technologies and services, they have put an emphasis on policies that expand network connectivity, improve skills and foster security. Chapter 8 focuses on policy priorities emerging from the 2012 OECD ICT policy questionnaire and provides specific information on policies related to each of these areas.

\section{Notes}

1. Data from the EU Community Survey covers EU countries plus Iceland, Norway and Turkey. For countries covered by Eurostat, the reference period corresponds to January of the survey year. For countries covered by the OECD ICT questionnaire, the reference period is that of the year surveyed. For countries covered by Eurostat: Economic activities for 2011 and 2010 data correspond to the classification NACE Revision 2. The sectors covered are: manufacturing, electricity, gas and steam, water supply, construction, wholesale and retail trades, repair of motor vehicles and motorcycles, transportation and storage, accommodation and food service activities, information and communication, real estate, professional, scientific and technical activities, administrative and support activities, and repair of computers and communication equipment. Financial intermediation and insurance are excluded for the figures referring to the total economic activities.

For countries covered by the OECD ICT questionnaire: The reference period is that of the year surveyed. Economic activities for 2010 data correspond to the classification ISIC revision 3.1 with the exception of New Zealand, which used ISIC Rev. 4. All sectors are covered, including agriculture and forestry, fishing, mining and quarrying, and finance and Insurance. 
For countries covered by Eurostat: Enterprises with 10 or more persons employed.

For countries covered by the OECD ICT questionnaire: Enterprises with 10 or more employees.

2. Data on e-commerce refer to the calendar year prior to the survey year. For Australia: Data are based on ANSZIC06. The following are excluded: general government, rest of the world, agriculture, forestry and fishing, public administration and safety, education and training, financial asset investing and superannuation funds, religious services and civic, professional and other interest group services, private households employing staff. For Canada: Data are based on NAICS 2007. The following are excluded: agriculture, fishing, hunting and trapping, and public administration and defence, compulsory social security, education, health and social work, other community, repair and personal service activities. For Israel: The following are excluded: agriculture, fishing, hunting and trapping, and public administration and defence, compulsory social security, education, health and social work, other community, repair and personal service activities. The statistical data for Israel are supplied by and under the responsibility of the relevant Israeli authorities. The use of such data by the OECD is without prejudice to the status of the Golan Heights, East Jerusalem and Israeli settlements in the West Bank under the terms of international law. For Japan: The following are excluded: public administration and defence, compulsory social security, education, health and social work, other community, repair and personal service activities. Businesses with 100 and more employees. For Switzerland: Agriculture, fishing, hunting and trapping is excluded.

3. The Solow paradox refers to the difficulty of measuring the productivity gains from computerisation in the 1980s. It was a time when the introduction of personal computers was helping drive business transformation but economists struggled empirically to link computers to productivity gains. Robert Solow famously stated that "You can see the computer age everywhere but in the productivity statistics".

4. Web facilities are facilities provided by the website of the company (as provider of Internet services). They include: i) marketing the company's products; ii) facilitating access to produce catalogues and price lists; and iii) providing after-sales support.

\section{References}

Aral S., E. Brynjolfsson E. and D.J. Wu (2007), Which Came First, IT or Productivity? A Virtuous Cycle of Investment and Use in Enterprise Systems, Working Paper, www.nber.org/public_html/confer/2007/ si2007/PRB/brynjolfsson.pdf.

Eurostat (2008), Information Society: ICT Impact Assessment by Linking Data from Different Sources Final Report of the Project http://epp.eurostat.ec.europa.eu/portal/page/portal/information_society/ documents/Tab/ICT_IMPACTS_FINAL_REPORT_V2.pdf.

Eurostat (2011), Information Society statistics website, database on ICT diffusion and use among businesses, http://epp.eurostat.ec.europa.eu/portal/page/portal/information_society/data/ comprehensive_databases.

NIA (National Information Society Agency) (2010), 2010 Yearbook of Information Society Statistics, NIA, Seoul, http://eng.nia.or.kr/open_content/board/fileDownload.jsp?tn=JS_0000093\&id=56951\&seq=1\&fl=7.

OECD (2004), OECD Information Technology Outlook 2004, OECD Publishing. doi: http://dx.doi.org/10.1787/it_outlook-2004-en.

OECD (2009), Rethinking e-Government Services: User-Centred Approaches, OECD Publishing. doi: http://dx.doi.org/10.1787/9789264059412-en.

OECD (2011), The Future of the Internet Economy: A Statistical Profile, June 2011 Update, OECD, Paris, www.oecd.org/dataoecd/24/5/48255770.pdf.

SESSI (2004), “Inter-business Relations, Numerous and Primarily within France”, Les 4 Pages des statistiques industrielles, No. 195, November, www.industrie.gouv. fr/sessi/4pages/pdf/4p195A.pdf.

Spiezia V. (2011), "Are ICT Users More Innovative? An Analysis of ICT-enabled Innovations in OECD firms", OECD Journal of Economic Studies, Vol. 2011.

Statistics Canada (2002), Embracing e-Business: Does Size Matters?, Connectedness Series, Statistics Canada, Ottawa, www.statcan.gc.ca/pub/56f0004m/56f0004m2002006-eng.pdf.

Statistics Canada (2003), "Electronic Commerce and Technology", The Daily, 2 April 2003, Statistics Canada, Ottawa, www.statcan.gc.ca/daily-quotidien/030402/dq030402a-eng.htm. 
Statistics Canada (2010), Canada Yearbook 2010, Canada, Ottawa, www.statcan.gc.ca/pub/11-402-x/ 2010000/chap/information/tbl/tblo6-eng.htm.

Statistics Netherlands (2010), The Digital Economy 2009, Statistics Netherlands, The Hague, www.cbs.nl/ NR/rdonlyres/E4311D6B-6BE6-4996-A4AB-804FC0A07A4C/0/2009p38pub.pdf.

Statistics Norway (2003), Use of ICT in Enterprises, web publication, Statistics Norway, Oslo, www.ssb.no/ iktbrukn_en/arkiv/art-2003-12-01-01-en.html.

Vicente, Maria Rosalia, and Lopez J. (2009), "To what extent firms are using e-commerce? Some evidence for the EU-27”, University of Oviedo, ftp://ftp.zew.de/pub/zew-docs/veranstaltungen/ICT2009/ papers/Vicente.pdf. 



\section{Chapter 5}

\section{Developments in digital content}

This chapter analyses intangible digital content products: goods and services that are downloaded, streamed or hosted over the Internet. It discusses key trends that have characterised the growth of digital content markets and factors that have enabled this development, focusing in particular on Internet infrastructure, the increasing availability of digital content products, and the skills required to create and access them. It analyses the growth of Web 2.0, social media networks, local content and adaptive approaches in the film, music, news, gaming and related industries leading to new business models, including the evolution of online advertising. 
$\mathrm{D}$ igital content is arguably the most important driver of consumer Internet adoption. The switch to digital technologies has forced businesses in a growing list of sectors to rethink business models and adapt in order to survive. As digital content permeates across all sectors of the economy, policy makers will need to follow trends and watch for potential opportunities to harness its benefits across different sectors of the economy. At the same time, the transition to digital also introduces new challenges, some of which will need to be addressed at the policy level.

This chapter provides an overview of emerging trends in digital content. While not an exhaustive list of digital trends, the chapter does follow developments in the three key areas supporting digital content, namely infrastructure, availability and skills. It also pulls together available data on the growth of digital content in several key sectors of the economy. Over the past five years, the digital content marketplace has developed rapidly, spurred by increased convergence of delivery channels and platforms online, thus resulting in a shift from physical media to delivery over the Internet. Projections for the European Union area assume that digital content and applications will be almost entirely delivered online by 2020 (EC, 2010). ${ }^{2}$ Digital content revenues are growing rapidly across all sectors, but growth rates and shares in overall revenues vary. Advertising represents the biggest online market in absolute terms, followed by computer and video games, online music and film and video.

Global consumer demand for buying and using digital content products across multiple channels and platforms is increasing. In 2010, games led global consumer demand, accounting for an estimated $39 \%$ of digital revenues. ${ }^{3}$ According to the International Federation of the Phonographic Industry (IFPI), digital music worldwide accounted for about $29 \%$ of recording companies' revenues, with the United States constituting the largest marketplace. Digital music revenue amounted to more than four times that of the combined online revenues generated by the book, film and newspaper industries (IFPI, 2011), although these other industries are much larger overall.

According to the Pew Internet \& American Life Project, music, software and applications were the most popular digital content purchases in the United States in late 2010, although games, e-books and news articles also featured among the intangible digital products purchased by consumers. Figures for newspaper, magazine and/or journal articles or reports were much lower: just $18 \%$ of consumers stated that they had paid to access or download these types of digital content. ${ }^{4}$ The majority of users preferred paying for subscription services (23\%) as opposed to downloading individual files (16\%) or streaming content (8\%) (Jansen, 2010). 


\section{Enabling factors}

Specific factors have enabled the development and growth of digital content, and these affect both supply and demand-side behaviour. The dynamic nature of the Internet has transformed the ways in which companies provide new products, services and applications to consumers. As new distribution channels are created, firms need to innovate and modify their traditional business models in order to participate in this new and ever-changing economic environment. Innovation brings new products and services to consumers who now have a wide range of content to choose from, often at lower cost. Increases in content availability drive consumers to demand better accessibility. This is driven by growth in available infrastructure, the requirement for faster broadband, and increasing demand for upstream bandwidth, as well as technology development to enable wider coverage for wireless access. The demand for better accessibility may mean that consumers have developed greater Internet skills, show greater willingness to pay for Internet content, and have greater confidence in Internet applications. This section outlines the components that have enabled the development of digital content: infrastructure, skills and availability of content (Figure 5.1).

\section{Figure 5.1. Digital content enabling factors}

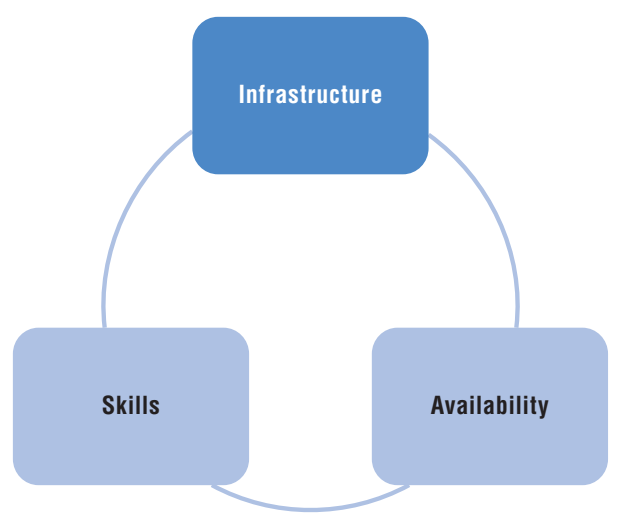

A vibrant digital content ecosystem requires all of these pieces to be in place. Infrastructure provides the physical platform to create, preserve, disseminate and use digital content. Availability refers to the production of digital content and its availability on the market. Finally, accessing and using digital content requires a certain set of skills and knowledge to operate equipment and understand elements such as digital rights management (DRM) restrictions.

\section{Infrastructure}

Infrastructure has been one of the primary enablers of digital content expansion over the past two years. As more and better content becomes available on the web, end users require better infrastructure to access it. This section analyses the infrastructure required to deploy digital content. It is divided into two parts: how consumers access the Internet (through data networks) and the means by which consumers use the Internet (devices). 


\section{Data networks}

Digital content available over the Internet is increasingly delivered over two different types of networks: wired broadband and wireless mobile networks. High-speed Internet connections on both platforms are becoming the foundation for innovation in the digital content sector. These connections create new distribution channels driving companies to modify their traditional business models. Robust networks and powerful access devices are creating a user base that is attractive to content providers. In turn, as content grows, so does the demand for high-speed networks.

This growth in content has led to a growing appetite for Internet bandwidth. Private sector operators and governments have both stepped forward to help fund upgrades to high-speed broadband networks (both wired and wireless) and the extension of connectivity to rural and remote areas. These upgrades are in part a response to the bandwidth demands of various digital content products.

There is a dichotomy developing in OECD countries with regard to infrastructure and digital content. Very fast, next-generation broadband connections delivered over wired networks are supporting very high-bandwidth, visual content such as high-definition video-on-demand services. Simultaneously, mobile broadband is witnessing phenomenal growth and content creators are focusing on ways to provide content on devices with smaller screens and lower bandwidth than a wired connection can provide.

The digital content landscape is changing in most OECD countries: the number of individual mobile broadband subscriptions has overtaken that for fixed broadband; and the growing popularity of smartphones and tablet computers is driving growth in mobile broadband services. The two networks are considered to be competitive and complimentary. Many consumers are giving up traditional telephony services over fixed networks, but rely on new fixed broadband connections to do the "heavy lifting". In the United Kingdom in 2011, for example, the average $3 \mathrm{G}$ subscription had throughput of 0.24 gigabytes of data per month, compared to 17 gigabytes for a fixed broadband connection.

However, where wired and wireless networks are available, the prices of Internet access and the devices used to connect remain beyond the reach of some consumers. High prices for Internet service can therefore constitute a barrier to take-up and also to the development of local content and the local ICT industry. The digital content ecosystem benefits from two key trends: increasing speeds and decreasing prices for Internet connections. Over the period 2008-11, the advertised speeds of DSL and cable broadband increased annually by $32 \%$ and $31 \%$ respectively in OECD countries. At the same time, prices declined by $3 \%$ and $4 \%$ (see Figure 5.2 ).

One way to analyse this is to compare price differences for services based on purchasing power parities (PPP). These PPP adjusted prices take into account the prices of other goods and services in the country. Significantly, the prices of fixed and mobile cellular services in developed and developing countries are relatively similar in terms of PPPs. This means that the prices of fixed and mobile telephony are roughly comparable across most countries relative to the prices of other goods and services. However, this changes with fixed Internet access. In 2010, the International Telecommunications Union (ITU) reported that the average monthly price for broadband services was USD 28 per month in developed countries, but much higher at USD 144 per month in developing countries (see Figure 5.3). Penetration rates also tend to be negatively correlated with local access prices (OECD, ISOC, UNESCO; 2012). 
Figure 5.2. OECD broadband price and speed changes, similar offers September 2008-11

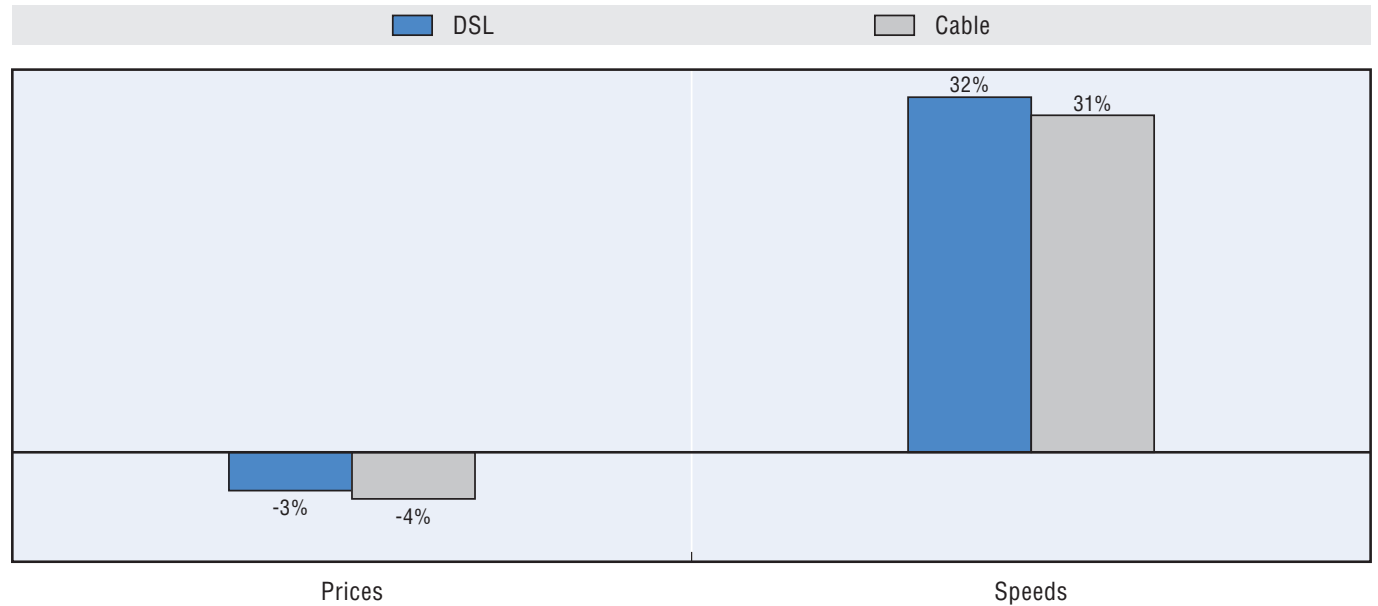

Source: OECD and Teligen

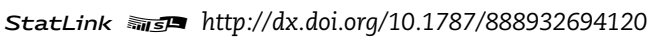

Figure 5.3. Global price differentials for communication services

Average prices for a monthly subscription, by technology, in USD PPP, 2010

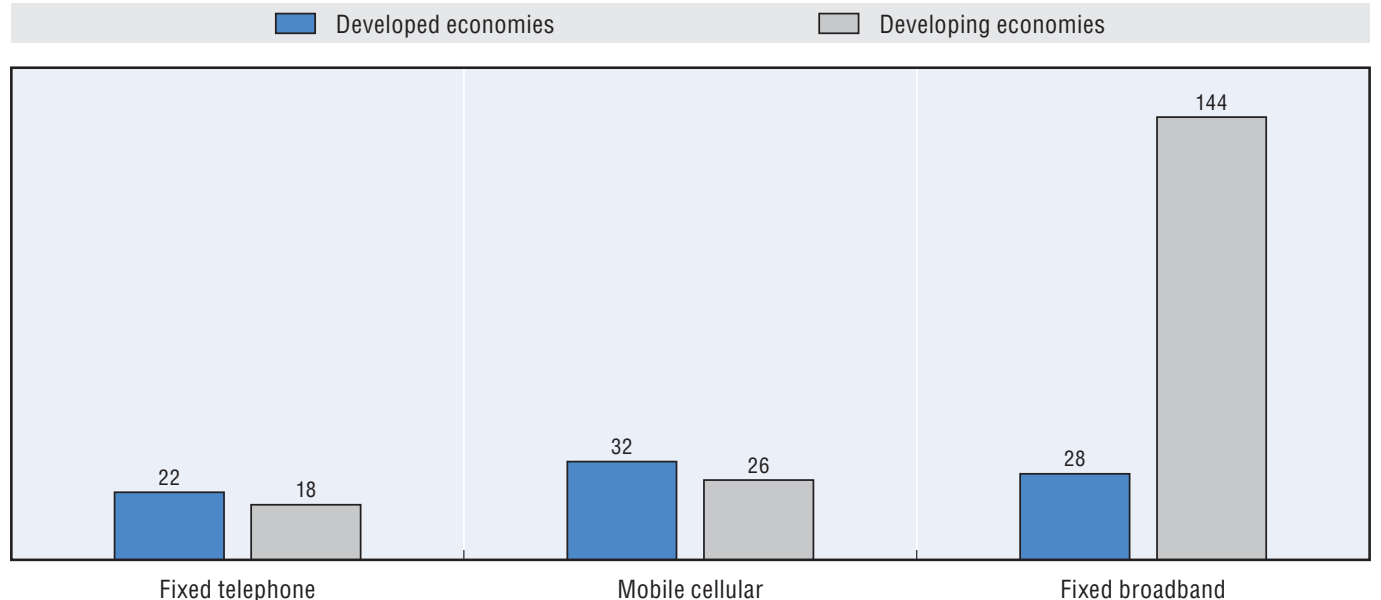

Source: OECD, ISOC, UNESCO (2012), The Relationship Between Local Content, Internet Development and Access Prices, OECD, Paris.

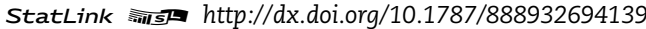

The combination of better Internet connectivity, improved content availability and lower prices has triggered demand for fixed and mobile broadband connections by households and individuals. As a consequence, the proportion of household expenditure devoted to communications has grown rapidly in OECD countries since 1995 (Figure 5.4).

One significant, recent trend in online services is the inclusion of connection costs in the price of the mobile device. Examples include e-book readers (e.g. Amazon's Kindle) and GPS devices (e.g. Tomtom Live Services). As a result, there is no longer a direct relationship between the customer and the network provider, such as via a monthly subscription or prepaid card; the content provider subsidises the network access cost as part of their content services. 
Figure 5.4. Changes in the proportion of OECD household's expenditure by category

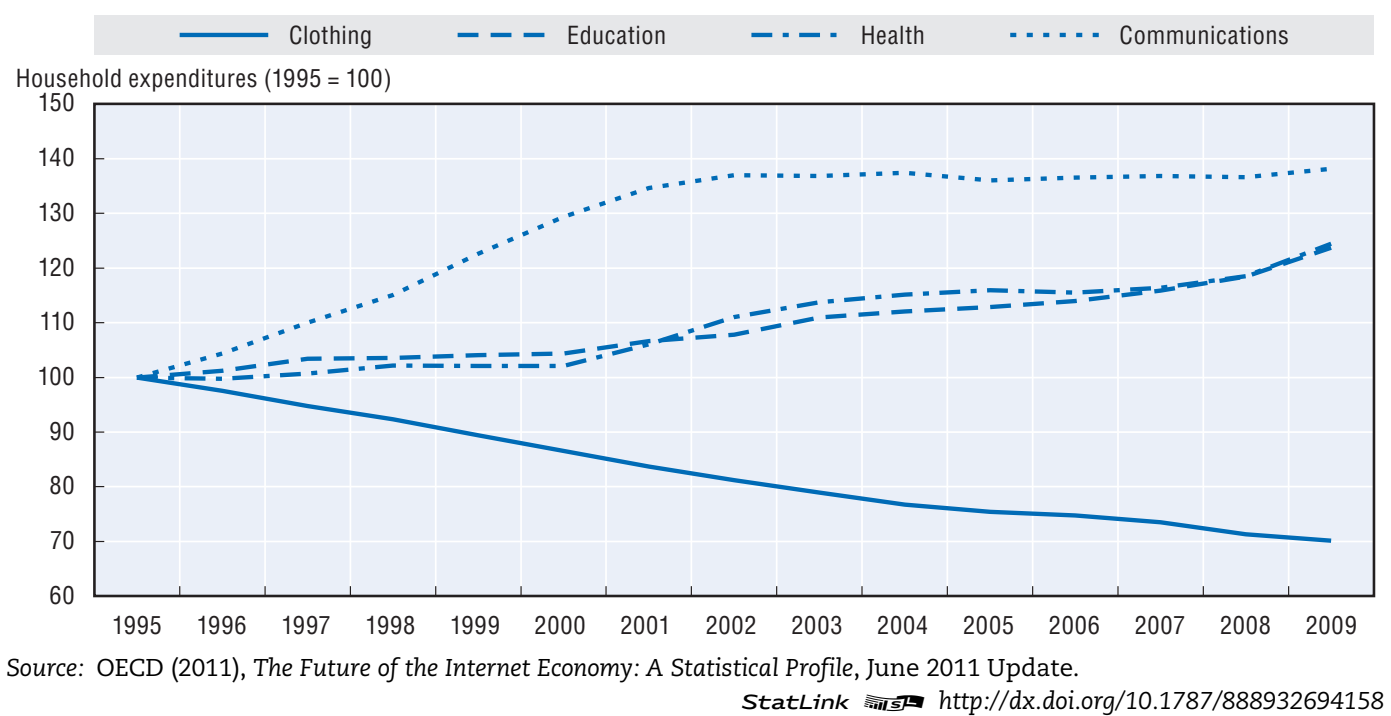

In recent years, mobile broadband subscriptions that are fuelling mobile digital content growth have outstripped wired connections. Since 2005, the number of mobile phone subscriptions worldwide has more than doubled, with particularly strong growth in non-OECD countries where the number has tripled (Figure 5.5). Smartphones or other wireless devices constitute a growing proportion of these subscriptions. This number is still relatively low but is increasing rapidly. It is important to note, however, that this growth has brought new challenges. As wireless devices such as smartphones generate more traffic, operators increasingly need to bring fixed networks closer to users in order to offload this traffic.

Figure 5.5. Growth of telephony as a communication tool

Subscriptions from 1961-2011, worldwide

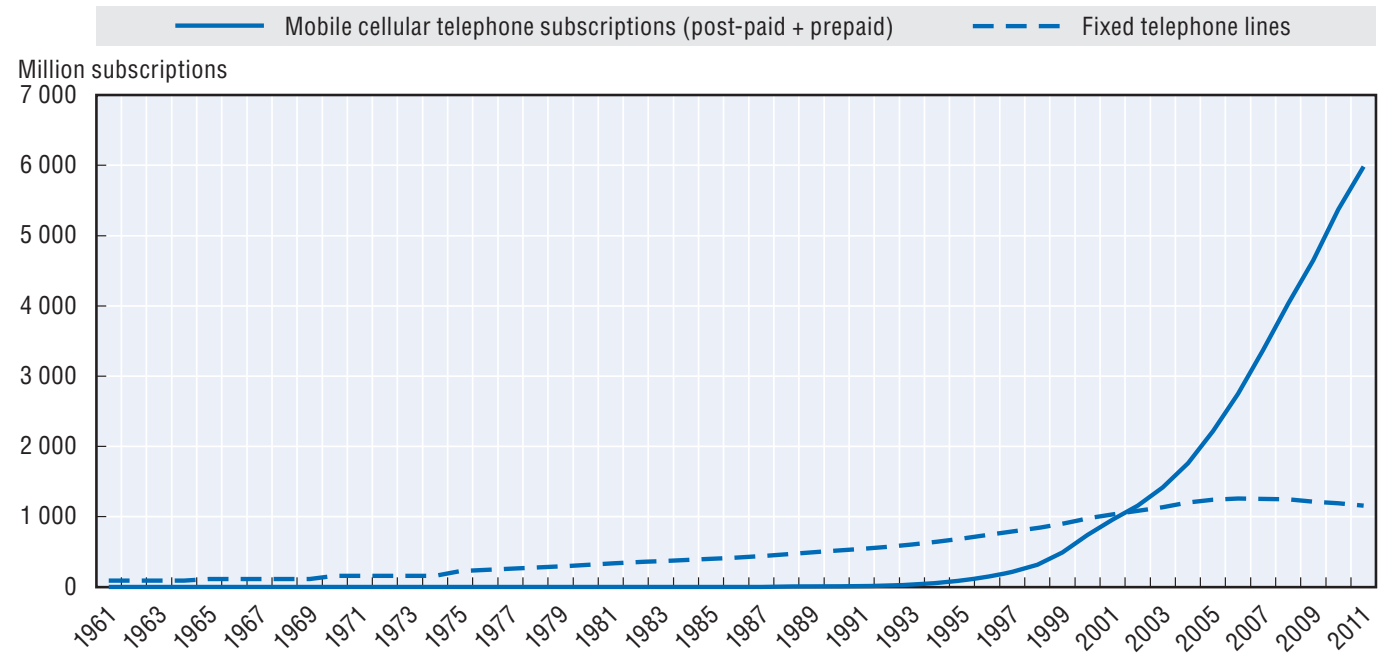

Note: Data for 2011 is an estimate.

Source: Based on data from OECD Broadband Portal, December 2011 and ITU (International Telecommunication Union) (2011), Measuring the Information Society, ITU, Geneva. 


\section{Devices}

Ten years ago, a new set of personal devices appeared that effectively extended digital content beyond the previous confines of the PC. In 2001, Apple released its first iPod music player and early smartphones started to become available, promising a mobile digital content experience. During the last two years, however, users have adopted, en masse, the powerful combination of smart handheld devices and mobile Internet connectivity.

The Android smartphone operating system (OS) represented $47 \%$ of the OS market at the end of 2011, according to comScore (2012). Google's Android and Apple's iOS currently exceed $60 \%$ of the market, and the global smartphone installed base is predicted to top 1 billion by 2012 (Gartner, 2011).

Strong growth in smartphone, tablet and e-reader adoption has constituted a key part of the infrastructure necessary to support the widespread use of digital content. According to Nielsen, in February 2012, smartphones accounted for 50\% of all mobile handsets in the United States (Figure 5.6), (Nielsen, 2012).

According to comScore, smartphones and tablets now drive approximately $7 \%$ of all global digital wireless traffic. Another important trend is that smartphones commonly attach to Wi-Fi networks to access faster connectivity or as a way to offload traffic onto the wireless network. comScore found that more than one third (37.2\%) of digital traffic coming from mobile phones in the United States occurred via a Wi-Fi connection. comScore also tracked device brands, noting that iPads now deliver $97.2 \%$ of all tablet traffic in the United States, Android now has the largest smartphone market share (43.7\%), and that Apple tops the connected device market with a $43.1 \%$ share, as a result of the iPad.

In June 2011, spending on digital platforms accounted for $26 \%$ of all spending on entertainment and media, and was expected to increase to nearly $34 \%$ by 2015 , as a result of growing access by consumers to online content from smart devices (PwC, 2011a). A Nielsen survey suggested that iPad user behaviour differs from that of other device users: iPad users seem more receptive to advertising and their interest in accessing videos, books and magazines is twice that of iPhone users (Nielsen, 2010; see also endnote 2). While the scope of this analysis comprised only Apple devices, in general there is a different consumption pattern for advertising between smartphone and tablet users.

The phenomenal growth of these content delivery platforms has also helped to create a global market for locally produced content and applications by reducing the barriers to entry for application development. In July 2011, the iOS platform featured over 100000

Figure 5.6. Smartphone penetration and share in the United States, February 2012
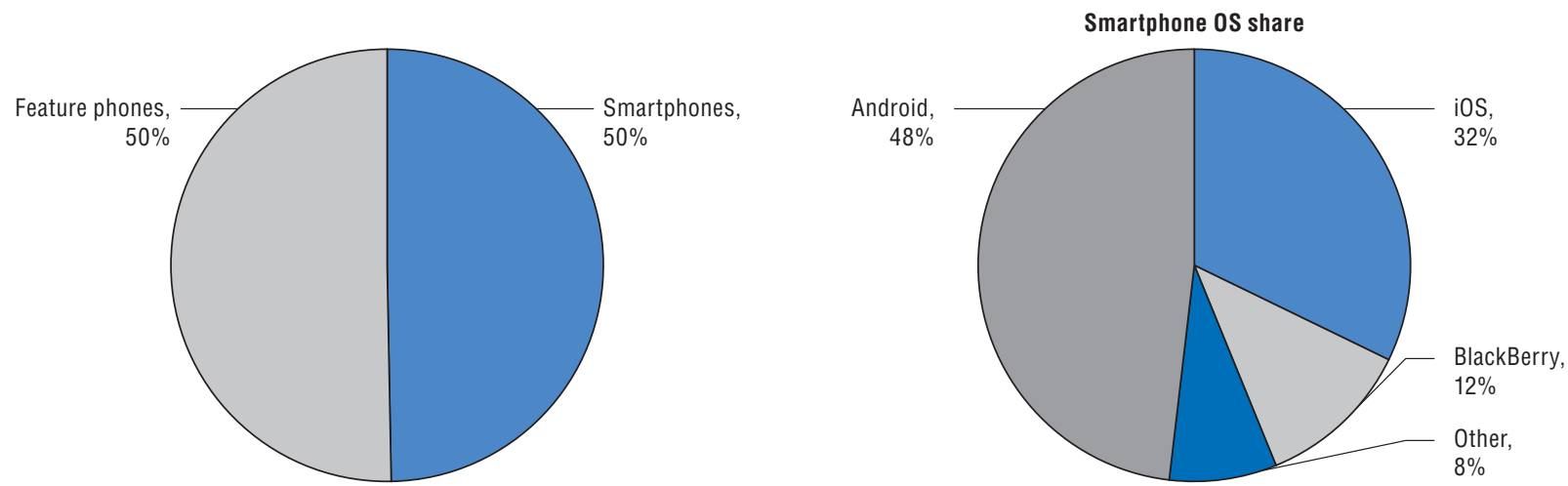

Source: Nielsen (2012), Smartphones Account for Half of all Mobile Phones, Dominate New Phone Purchases in the US, March 2012.

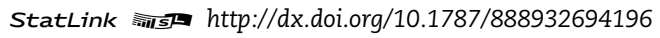


active application developers, which translates into an average of approximately four applications per developer (148apps.biz, 2011). This high number indicates that small companies or individuals are able to develop and sell their mobile apps worldwide. These platforms have therefore expanded business opportunities to many SMEs and individuals who would otherwise be unable to access business end of the mobile application value chain.

\section{Availability}

\section{Content needs to be created or converted into digital formats}

The mobile platform will remain vital for content creation (via camera phones, audio recording capabilities and applications) and distribution (via Internet access over the mobile network). Mobile smartphones are rapidly becoming important tools for content creation in developed and developing countries alike. The mobile platform, while important everywhere, is particularly important in countries that lack reliable, wired network infrastructure.

Recent years have seen an explosion in digital content created by users. Smartphones with cameras and video-editing software allow consumers to easily upload and download content from sites such as Blogger, DailyMotion, Flickr, Vimeo, YouTube, and so forth. Given the uptake and increase in use of digital content for mobile devices, traditional publishers are putting their existing and new content online. Examples of these include traditional retailers (Wal-Mart, Amazon), specific platform providers (e.g. iTunes) and streaming services (e.g. Hulu, Netflix).

\section{Content needs to be available for users to purchase}

One of the key issues facing consumers is that the content they want is not always available to buy in a convenient digital format. There are also information disclosure problems concerning usage, functionality, interoperability of a product, available dispute resolution, redress procedures, and misleading or unfair commercial practices. However, markets are evolving and new digital content services are flourishing with the rise of consumer broadband.

Consumers can now purchase single music tracks instead of full albums, or selected book chapters in ways that were not possible before. On-demand "windows" for both film and television enable consumers to watch television event or movie premieres. Companies such as Hulu (the video platform of News Corp, Walt Disney and NBC Universal) are expanding their on-demand windows offers by enabling consumers, for example, to watch full seasons of television series based on a monthly subscription fee. Moreover, consumers can do so from a variety of platforms including smartphones, console game players, Internet-enabled television and PCs. ${ }^{5}$

\section{Content, once purchased, needs to be available anywhere, anytime and on any device}

The goal of broadband content "anywhere, anytime and on any device" is still limited in some areas. Challenges for ubiquitous broadband access anywhere refer to access points, mobile access and geographical access restrictions, as just a few examples. There are still significant regions within the OECD where access to bandwidth-intensive digital content is a challenge.

To ensure better availability of content for users some companies are starting to store their available digital content in the cloud, thus allowing users to access content anywhere and on any device. Examples include Amazon's cloud service for music in the United States and 
Apple's new iCloud service. At the same time, podcasts remain an important source of content, which people often download via a wired connection and then use at their convenience.

While service providers are moving in the direction of always available content, certain challenges still have to be addressed. In particular, issues related to copyright, geographical restrictions, network rollout and compatible devices need to be resolved.

Traditional content offers such as film and music are mostly limited to specific geographic regions, and such services are inaccessible from other countries (e.g. Hulu, Netflix and Pandora are only available in the United States, but not in many other countries) (Table 5.1). National boundaries apply on the Internet for commercial, legal or cultural reasons. These segmented markets are often viewed as less beneficial for consumers and impose significant costs on content delivery services, which have to adapt their services to multiple markets. However, it is important to underline that territorial limitation to content offers is a side-effect of the European film-financing model, whereby distributors usually buy the exploitation rights during the pre-production phase and thus play a critical role in the financing of films. European producers are dependent on the pre-sale of their rights and try to maximise revenues by selling different rights (e.g. theatrical rights, broadcasting rights, online rights, etc.) for different territories.

Table 5.1. Geographical access to digital content

\begin{tabular}{|c|c|c|c|c|c|}
\hline & North America & Latin America & Europe & Asia & Africa \\
\hline Music & $\begin{array}{c}\text { Spotify (US only) } \\
\text { Pandora (US only) } \\
\text { Slacker (US and Canada) } \\
\text { MOG (US only) } \\
\text { Vevo } \\
\text { Apple iTunes } \\
\text { Rdio (Canada, US) } \\
\text { Napster (Canada, US) }\end{array}$ & $\begin{array}{l}\text { Ideas Telcel, Mixup Digital, } \\
\text { Cyloop Radio Station, } \\
\text { Tvolucion (Mexico) } \\
\text { Bazuca, Claroides, } \\
\text { Wapmania (Chile) }\end{array}$ & $\begin{array}{c}\text { Spotify (Denmark, Finland, } \\
\text { France, the Netherlands, } \\
\text { Norway, Spain, Sweden, UK) } \\
\text { Deezer } \\
\text { Last.fm } \\
\text { We7 } \\
\text { WiMP (Norway and Denmark) } \\
\text { Mflow } \\
7 \text { digital } \\
\text { eMusic (Lativa, Greece, } \\
\text { Luxembourg, Malta, Italy) }\end{array}$ & $\begin{array}{c}\text { Naver Music, } \\
\text { Daum Music, Nate } \\
\text { (South Korea) } \\
\text { Aniloco, Dwango, Lismo, } \\
\text { mu-mu (Japan) } \\
\text { Guevara, Intertia, } \\
\text { Bandit.fm, } \\
\text { Jamster (Australia) }\end{array}$ & $\begin{array}{l}\text { Alamelphan, Mazzika Box } \\
\quad \text { (Egypt) } \\
\text { GETM0, Pick n Play, Jamster, } \\
\text { Vodafone live (South Africa) }\end{array}$ \\
\hline Film & $\begin{array}{c}\text { Netflix } \\
\text { Hulu (US only) } \\
\text { Amazon Unbox } \\
\text { Apple iTunes } \\
\text { BitTorrent, Inc. (US only) } \\
\text { Cinema Now (US only) } \\
\text { Jaman (US only) } \\
\text { MovieFlix (US only) }\end{array}$ & Netflix & $\begin{array}{c}\text { Glowria (France) } \\
\text { Lovefilm (UK) } \\
\text { Maxdome (Germany) } \\
\text { SF Anytime (Sweden) }\end{array}$ & Gyao (Japan) & \\
\hline
\end{tabular}

Note: This list is not intended to be exhaustive.

Different content sectors have different infrastructure requirements (Figure 5.7). Bandwidth requirements, for example, are very high for video and gaming, but much lower for chat and messaging services.

Mobility is vital for certain services, for example, music streaming, but is less of an issue for the delivery of digital content services such as high-definition video delivery to a television. Mobile and geographical access are important factors for digital music, as are prices and the size of the online catalogue.

Online catalogue depth and personalisation of interactive and community features are valued as highly important for the user-created content sector, followed by the computer 
Figure 5.7. Digital content product characteristics and broadband functionalities

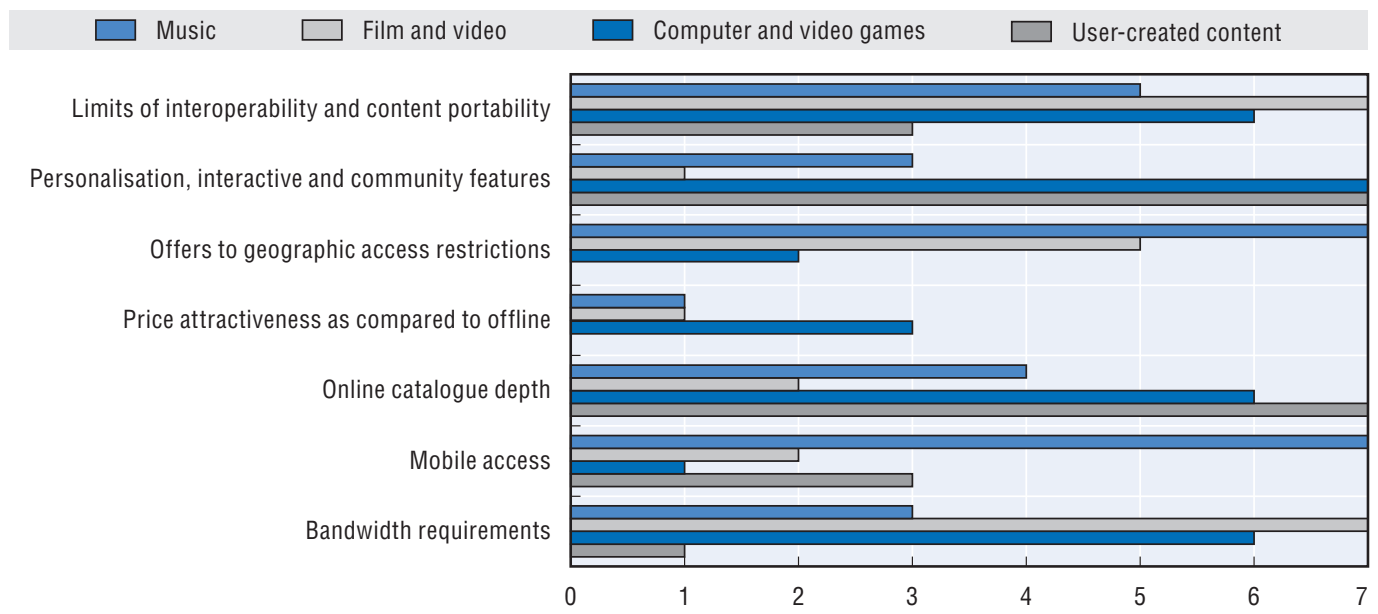

Note: Values were ranked from 1 to 7 , where 1 refers to low, 2 assigned to low-medium importance, 3 assigned to medium, 4 assigned to medium-high, 5 assigned to high, 6 to high-very high, and 7 assigned to very high product characteristics and broadband functionality.

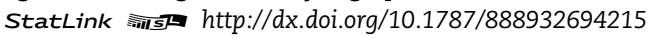

and video games sector. Price attractiveness, as compared to offers offline, is more sensitive for the UCC sector than for online music and film distribution.

Consumers have recently shown, however, that they are still price-sensitive to certain types of digital content. Netflix recently experienced a dramatic change in their forecasted revenue for Q3 2011, widely attributed to a large number of cancellations after the introduction of a new price structure. The company quickly switched back to the earlier structure in response to customer demands (Netflix, 2011).

Challenges to make digital content available at anytime refer primarily to connectivity. Users must have connections available to them wherever they are at prices they find attractive and can afford. User patterns change when they have Internet connectivity at all times. For example, improved bandwidth enables users previously unable to upload photos from a standard digital camera to their computer and then to the Internet, to now take a picture with their smartphone and upload it to a social networking site with the click of a button. The demand for connectivity "anytime" will continue, and will continue to transform how digital content is created and used.

Greater online interactivity and the willingness to share, contribute and to create online communities are changing the media consumption habits of Internet users, in particular, among younger age groups. According to Cisco's VNI Index, global Internet video traffic surpassed global peer-to-peer (P2P) traffic in 2010, and by 2012 Internet video will account for over 50\% of consumer Internet traffic (Figure 5.8). Globally, Cisco predicts that mobile data traffic will increase 26 times between 2010 and 2015, and that IP traffic in Latin America will grow at a compound annual growth rate (CAGR) of 50\% between 2010 and 2015, followed closely by the Middle East and Africa (Figure 5.8).

Challenges to make digital content available on any device refer to issues of high interoperability restraints and content portability, mostly related to hardware, software and "built-in by design" as part of a business model (e.g. tying music purchases to specific portable music players or imposing limitations due to DRM software). Sometimes the challenges are the result of the inability of the industry to agree on common standards or interoperability criteria. 
Figure 5.8. Global consumer Internet traffic, 2010-15

PB per month

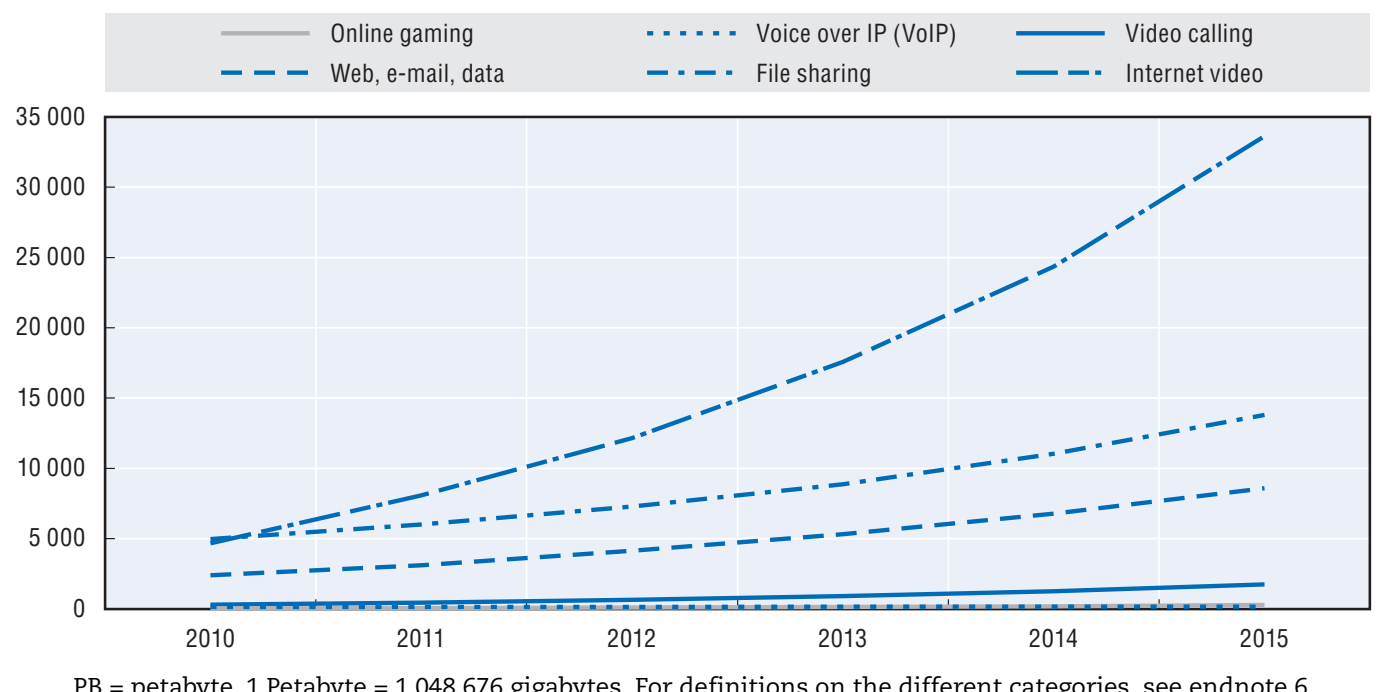

Source: Cisco (2011), Cisco Visual Networking Index: Forecast and Methodology, 2010-15.

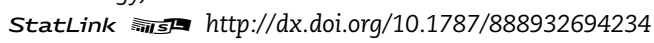

The portability of content from one device to another (PC, telephone, television, set-top box) is usually extremely limited. However, increasing user frustration and concerns among OECD governments, competition authorities and consumer associations, have led to the advent of small but potentially growing interoperability solutions (e.g. the rise of DRM free content; and the ability to play online videos on PC, television or portable devices). At the same time, growing competition among UCC platforms may result in new formats and interoperability restrictions.

Digital Rights Management technology has been used to manage access to copyrighted digital content. Apple Inc.'s DRM system, called Fairplay, was used by the iTunes music store to place restrictions on the use of digital content purchased there. However, the use of DRM led to the French online music unit of Virgin to file complaints against Apple, alleging unfair competition, as well as complaints filed against Sony BMG. In 2009, Apple announced that they had reached an agreement with major record labels to sell all music on the iTunes Store free of DRM restrictions. From that day, 8 million tracks were made available with FairPlay restrictions removed with the remainder of the music store converted to DRM-free by March 2009. However, movies and television shows purchased from the iTunes Store still contain FairPlay restrictions.

There has been some progress, however, in the move to enable access to content on any device. The Digital Entertainment Content Ecosystem (DECE) is a cross-industry consortium working to create a consumer-friendly, open market for digital content distribution. They recently announced the development and availability of a cloud-based licensing system called UltraViolet (Box 5.1), which is meant to allow access to purchased content on any device.

\section{Skills}

Digital content is of less use if people do not have the basic skills necessary to access content. Governments view the growth of digital content as beneficial to their economies and have directly promoted the development of local skills and local content. In Australia, 


\section{Box 5.1. UltraViolet}

UltraViolet ${ }^{\mathrm{TM}}$ is a digital rights authentication and cloud-based licensing system that has the goal of allowing consumers of digital home entertainment content to stream and download purchased content to multiple platforms and devices, thereby allowing consumers to purchase digital content and watch it wherever and whenever they choose. This is a direct response to consumer complaints that their legal content purchases are often tied to one hardware or software platform or an individual user's account.

The goal of the project is to allow consumers who purchase UltraViolet entertainment to have an easy and consistent way to watch film and television content across multiple branded platforms, such as computers, connected TVs, game consoles, smartphones and tablets.

The system works by allowing each household to create an account for up to six members who can access the household's UltraViolet movies, television and other entertainment via participating retailers, streaming providers and devices.

Consumers will also be able to register up to 12 devices so that UltraViolet content can be easily downloaded to those devices, or shared among them.

UltraViolet streaming access will enable consumers to access their collections via set-top boxes and most places they can access the web, via computers, web-connected home video devices such as Blu-ray players and Internet televisions, and mobile apps for smartphones and tablets.

The Digital Entertainment Content Ecosystem (DECE) intends to make the Common File Format used in UltraViolet widely available for use in other areas of video content preparation and delivery.

Source: Digital Entertainment Content Ecosystem (DECE), www.uvvu.com/faqs.php.

for example, the establishment of community websites and portals and the creation of "virtual town squares" are made available to support the development of high-quality educational digital content. In Ireland, the National Centre for Technology in Education (NCTE) has expanded its digital content for schools through the provision of World Book and Britannica Online via the Scolinet website and the Schools Broadband Programme. This central resource for teachers, pupils and parents offers access to a growing repository of advice, information, evaluated and categorised web sources, software and multimedia resources for use in teaching and learning.

In the quest to further deploy broadband networks, several countries such as Austria, Estonia, Latvia and Portugal have highlighted the issue of the digital divide and the importance of deploying broadband in rural and remote areas. In Mexico, for example, the government has launched a "National Campaign for Digital Inclusion Vasconcelos 2.0" to address the issue of digital inclusion. The campaign will provide a digital education to nearly 30 million Mexicans in the coming years who do not use ICTs, thus narrowing the digital divide.

\section{Digital content sectors}

The increase in digital content availability and heavier Internet use continue to transform consumer behaviour and to challenge traditional business models. Companies must innovate constantly to survive; adapt to changes in product content and delivery means; provide better quality, higher speed at lower prices, better payment facilities and 
better coverage and improve customer service. As online businesses strive to remain competitive and to gain market share, growing Internet uptake in emerging markets is pressuring companies to search for new frontiers, and to adapt to changing consumer preferences and environments. New business models are emerging, some of which mirror offline models (e.g. pay-per-item digital content sales) and some of which are new (e.g. sale of virtual items or professional subscription accounts). It is possible to illustrate eight main and existing generic categories and summarise examples of their business approaches (Figure 5.9).

Figure 5.9. Digital broadband content business models

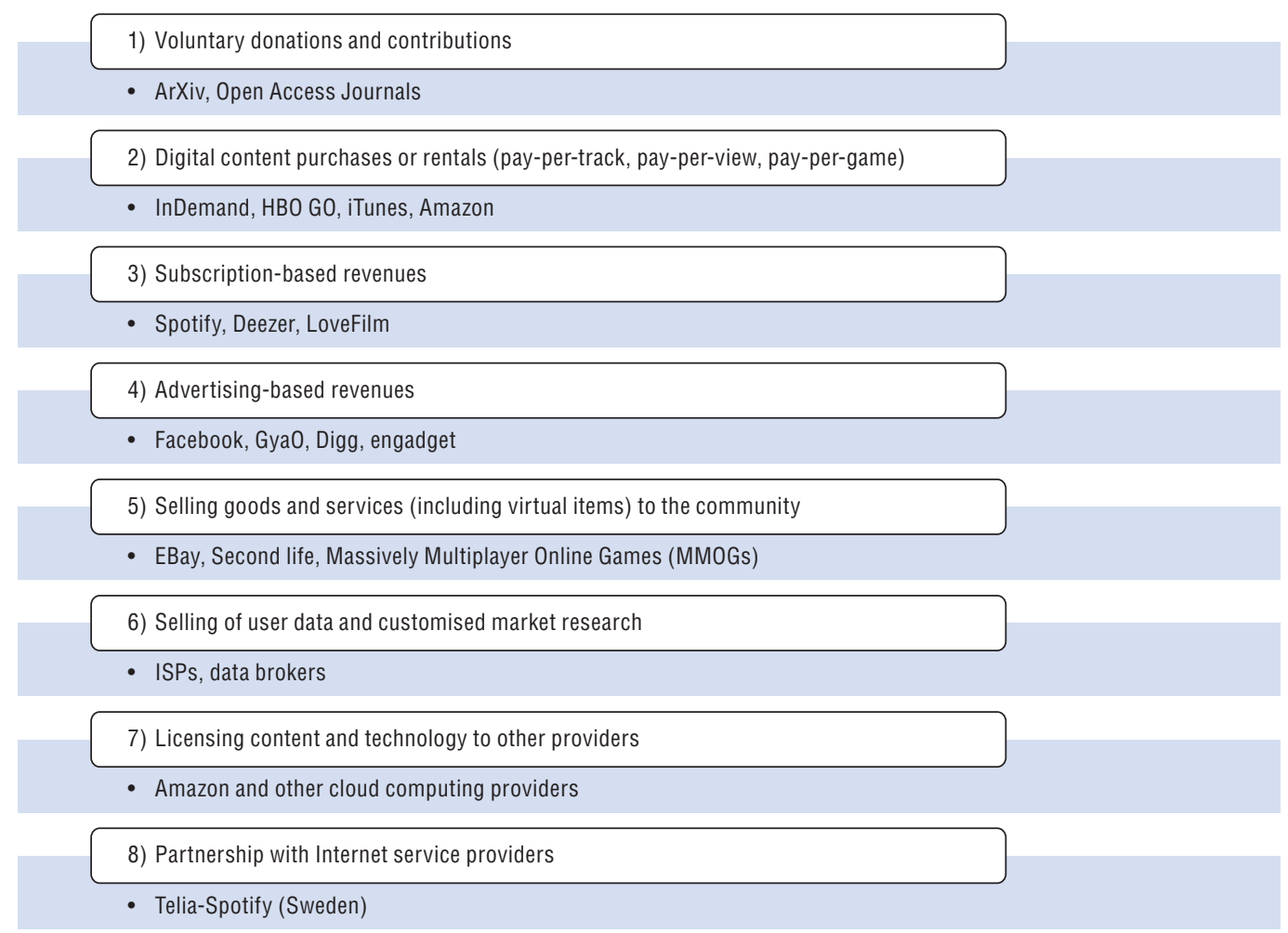

Business models are rapidly adjusting to allow the delivery of sophisticated, integrated broadband content offers that cover a range of digital content. New, complex value chains involve a number of new actors, but the changes, maturity of business models and user acceptance are not identical across content sectors. Some key similarities and differences among sectors are outlined in Table 5.2.

\section{User-created content and social networks}

\section{Market}

User-created content (UCC) is defined as content that is made publicly available over the Internet, reflects a "certain amount of creative effort", and is "created outside of professional routines and practices" (OECD, 2007). There are a variety of UCC platforms (Table 5.3).

Initially, most user-created content was not linked to expectations of remuneration or profit. Motivating factors included connecting with peers, self-expression, notoriety or prestige. Today, UCC sites are of increasing interest to investors and businesses. A number 


\section{Table 5.2. Evolving sector-specific online business models}

\begin{tabular}{ll}
\hline User-created content & Mostly free or voluntary donations and contributions. \\
& Increasingly subscription- and advertisment-based revenues and business -to-business licensing technologies. \\
- Revenue increasingly generated by selling user information or offering access to the user community. \\
Computer \& video games
\end{tabular}

Table 5.3. Platforms for user-created content

\begin{tabular}{|c|c|}
\hline Type of platform & Examples \\
\hline Blogs & $\begin{array}{l}\text { BoingBoing, Engadget, OhMyNews; blogs on sites such as LiveJournal, } \\
\text { Window Live Spaces, Cyworld, Skyrock., WordPress, Blogger, Tumblr }\end{array}$ \\
\hline Wikis and other text-based collaboration formats & Wikipedia, Wiktionary, PBWiki, Google Docs, FanFiction.Net, \\
\hline Photo-sharing sites & Flickr, Picasa, Kodak Gallery \\
\hline Podcasting & iTunes, FeedBurner (Google), @Podder \\
\hline Social Network Sites & Facebook, Linkedln, MySpace, Hi5, Bebo, Orkut, Cyworld, Imeem, ASmallWorld \\
\hline Virtual Worlds & Second Life, Active Worlds, Entropia Universe, Dotsoul Cyberpark \\
\hline Video & YouTube, Vimeo \\
\hline
\end{tabular}

of new entities are now involved in content provision as more and more users are actively engaging in Internet activities. These include the advertising industry, search engine operators and media firms that own UCC platforms or select content from these platforms for distribution over traditional media and publishing channels.

In what was termed "Web 2.0", the Internet saw users increasingly becoming content creators, in addition to content consumers. On average $16 \%$ of Internet users in OECD countries created web pages in 2011. In Korea and Iceland, at least one Internet user out of three has created a web page (see Chapter 3, Figure 3.10).

While web page creation has long been a platform for dissemination information, the new trend is to use social networking platforms to quickly share information among specific groups with particular interests or characteristics. These platforms are much more user friendly in terms of uploading and formatting content, and this has been a key to their success. Social networking has rapidly gained importance as nearly $50 \%$ of OECD Internet users are active social network users. In 2010, at least $60 \%$ of Internet users in Poland, Portugal, Turkey and the United States engaged in social networking on the web.

The ability to access social media is a commonly used feature among mobile owners. According to a recent study by Nielsen (2011), nearly two out of five social media users access these services from their mobile phones. The report shows how social networking compares with other features consumers have on their phones and what features they value the most (Figure 5.10).

One of the key challenges is the affordability of smartphones. The spectrum of digital content is expanding, in particular with user-created content, and smartphones are a key tool. Smartphone prices are following the general trends of ICTs and are falling to the point where they will soon be affordable to a large portion of the population. 
Figure 5.10. Features and value of mobile use

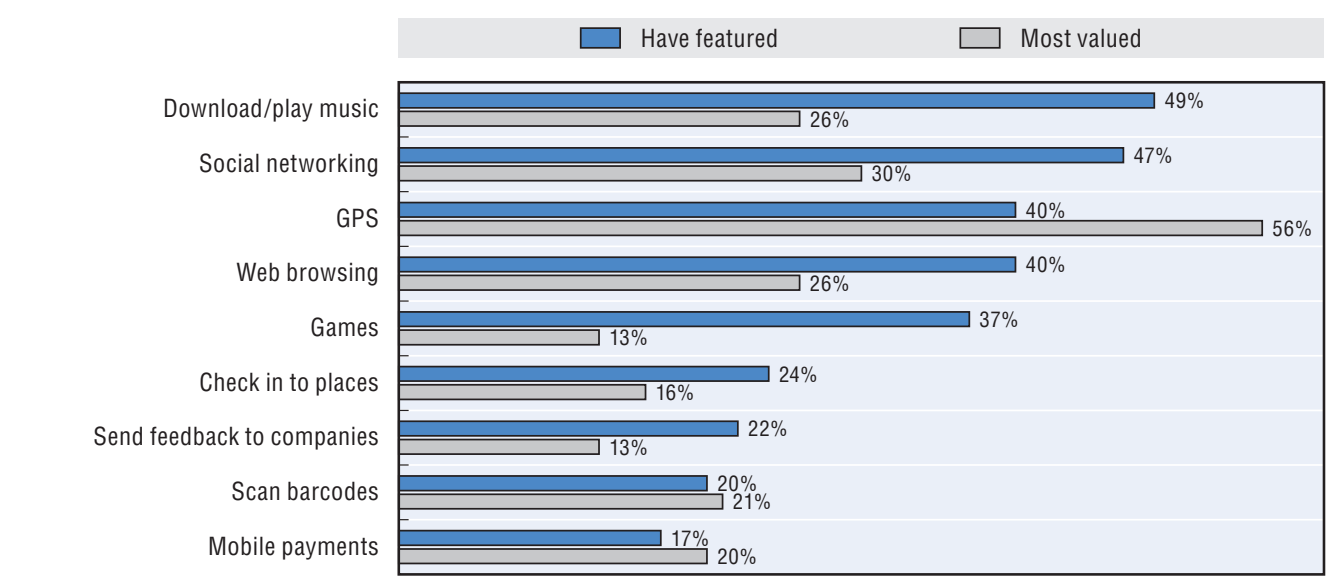

Source: Nielsen (2011), NMIncite, a Nielsen/Mckinsey company, The Social Media Report Q3, 2011.

The combination of inexpensive equipment and new web platforms for hosting UCC have led to a rapid expansion in the amount of video content available on the Internet. According to Google, over 48 hours of video are uploaded to YouTube each minute. Google has also calculated that YouTube users create and upload more video content each month than the combined output of all three major US television networks for the past 60 years. The YouTube audience views approximately 2 billion videos each day.

Other sources suggest similar statistics. Accustream Research claims that user-created content is far more viewed online than professionally produced content. In this respect the agency states that there are 93.2 billion views of UCC videos, nearly double the number of views for "professionally produced content" (AccuStream, 2010). The PEW Centre study established that as "digital natives" grow, UCC will grow. In 2007, 64\% of teenagers had engaged in some form of online content creation, and by $2010,37 \%$ of Internet users had contributed to the creation of news, commented about it, or disseminated it via postings on social media sites like Facebook or Twitter (PEW, 2010). User-created content is growing; 250000 words are written each minute on Blogger, and more than half a trillion words have been written since the service launched in 1999. Flickr users, for example, upload more than 3000 photos each minute and have uploaded a total of more than 5 billion images to the service (see: www.flickr.com).

\section{Distribution}

The distribution of digital content has evolved over the past few years. This section examines specific examples of new digital content distribution platforms.

Social networks: Facebook. The growth of social networks over the past two years stands out as arguably one of the biggest developments in digital content. There are many social networks available to users, but Facebook is the largest. In May 2011, Facebook ranked among the top 10 websites in all OECD countries (based on data collected from the web traffic ranking site Alexa.com). In many of these economies, it was the second most visited website, only trailing behind Google.

Facebook's popularity (more than 900 million active users) makes it a facilitator of exchange in local languages. For many individuals, Facebook provides a way to be connected 
to news and current events. In addition to personal Facebook pages, Facebook is also a low-overhead way for small businesses to advertise and get involved in the community.

Facebook makes data on the number of users in each economy publically available through their advertising tool. According to Facebook.com, Facebook has over 900 million active users. Its penetration rate of use provides companies with a means by which to effectively target their marketing efforts toward a specific audience (Figure 5.11). The number of users per 1000 residents in OECD countries economies along with the Alexa.com in-country ranking of Facebook relative to other sites is shown here (Table 5.4).

Figure 5.11. Facebook facts

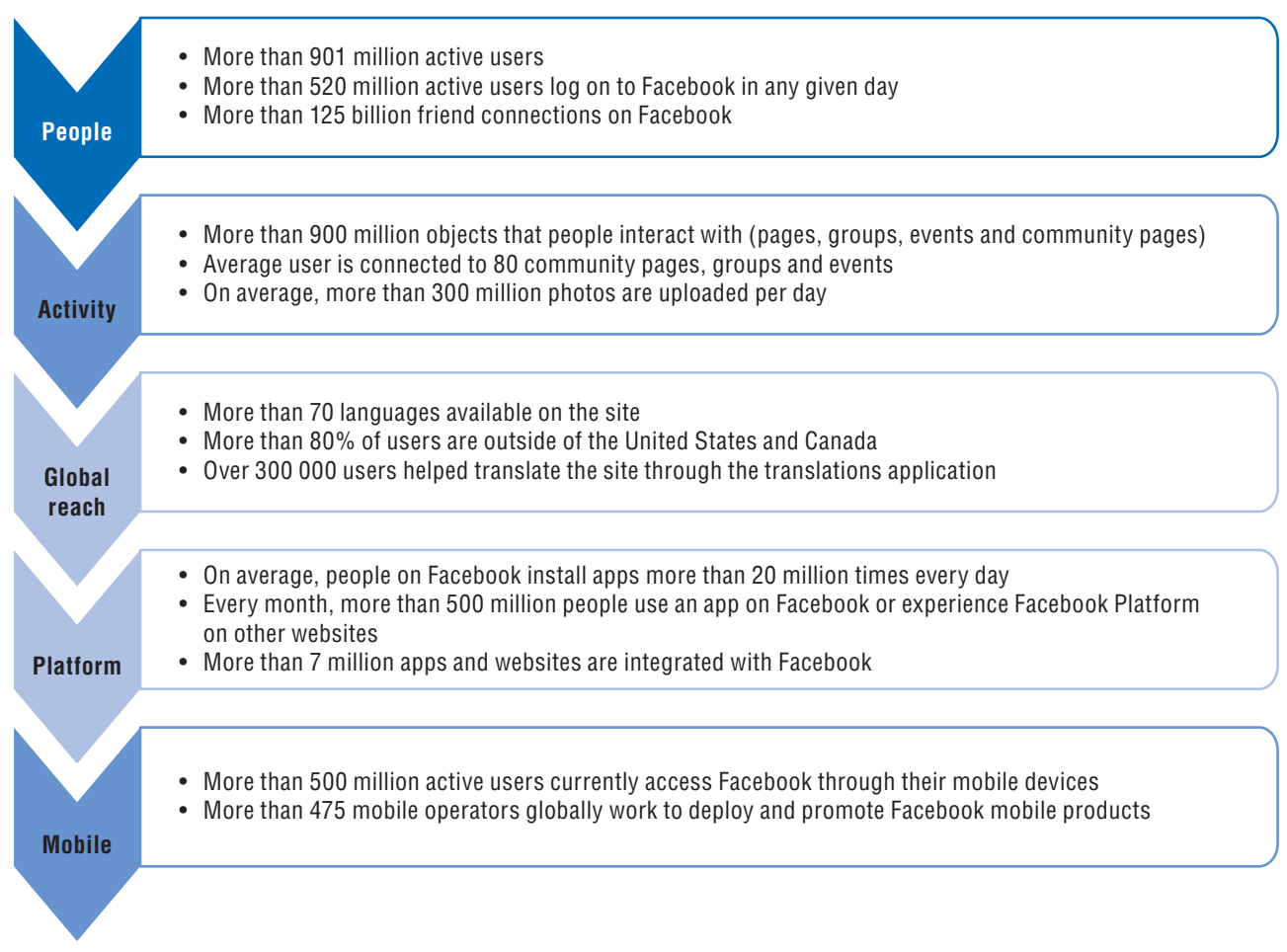

Source: http://newsroom.fb.com/content/default.aspx?NewsAreaId=22.

Knowledge bases: Wikipedia. Information from many knowledge bases is readily available on the Internet, but Wikipedia has become a key source for information on specific topics. Wikipedia is a free, web-based, collaborative, multilingual encyclopaedia project supported by the non-profit Wikimedia Foundation. Its 18 million articles (over 3.6 million in English) have been written collaboratively by volunteers around the world. Almost all of its articles can be edited by anyone with access to the site. Wikipedia was launched in 2001 and has become the largest and most popular general reference work on the Internet, ranking around seventh among all websites on Alexa and having 365 million readers.

Wikipedia's departure from the expert-driven style of encyclopaedia building and the large presence of un-academic content has been noted several times. Time magazine recognised "You" as its Person of the Year for 2006, citing Wikipedia as an example of online collaboration and interaction by millions of users around the world.

Although the policies of Wikipedia strongly espouse verifiability and a neutral point of view, critics of Wikipedia accuse it of systemic bias and inconsistencies (including undue weight given to popular culture), and allege that it favours consensus over credentials in its 
Table 5.4. Facebook usage and web-traffic rankings in OECD countries

\begin{tabular}{|c|c|c|c|c|c|}
\hline Economy & $\begin{array}{c}\text { Facebook users } \\
\text { per } 100 \text { inhabitants }\end{array}$ & $\begin{array}{l}\text { Facebook ranking } \\
\text { among the websites } \\
\text { in the economy }\end{array}$ & Economy & $\begin{array}{l}\text { Facebook users } \\
\text { per } 100 \text { inhabitants }\end{array}$ & $\begin{array}{l}\text { Facebook ranking } \\
\text { among the websites } \\
\text { in the economy }\end{array}$ \\
\hline Australia & 46 & 2 & Japan & 3 & 10 \\
\hline Austria & 30 & 2 & Korea & 7 & 3 \\
\hline Belgium & 42 & 2 & Luxembourg & 40 & 1 \\
\hline Canada & 53 & 2 & Mexico & 22 & 1 \\
\hline Chile & 49 & 1 & Netherlands & 27 & 3 \\
\hline Czech Republic & 32 & 2 & New Zealand & 46 & 2 \\
\hline Denmark & 50 & 2 & Norway & 55 & 1 \\
\hline Estonia & 30 & 2 & Poland & 17 & 2 \\
\hline Finland & 37 & 2 & Portugal & 36 & 2 \\
\hline France & 36 & 2 & Slovak Republic & 34 & 2 \\
\hline Germany & 23 & 2 & Slovenia & 33 & 3 \\
\hline Greece & 30 & 1 & Spain & 32 & 2 \\
\hline Hungary & 33 & 2 & Sweden & 46 & 2 \\
\hline Iceland & 66 & 1 & Switzerland & 34 & 2 \\
\hline Ireland & 46 & 3 & Turkey & 38 & 1 \\
\hline Israel & 47 & 2 & United Kingdom & 51 & 2 \\
\hline Italy & 33 & 2 & United States & 51 & 2 \\
\hline
\end{tabular}

Note: Information on data for Israel: $h t t p: / / d x$. doi.org/10.1787/888932315602.

Source: OECD, ISOC, UNESCO (2012), The Relationship Between Local Content, Internet Development and Access Prices, OECD, Paris.

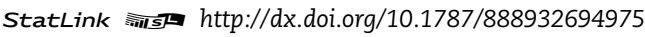

editorial processes. Its reliability and accuracy are also targeted. Other criticisms centre on its susceptibility to vandalism and the addition of spurious or unverified information; however, scholarly work suggests that vandalism is generally short-lived. An investigation in Nature found that the science articles they analysed came close to the level of accuracy of Encyclopæedia Britannica and had a similar rate of "serious errors" (Giles, 2005).

Wikipedia's user-created nature means that barriers to entry for individuals wishing to post information on Wikipedia are very low. Wikipedia articles are also reflective of the overall Internet trend away from a single dominant language. Wikipedia.org contains information on 274 languages represented on the site.

The proportion of first language English-speaking Internet users relative to other languages has been declining. Wikipedia mirrors the overall move of Internet use, expanding beyond English. For the first few years after its inception in 2001, Wikipedia was primarily dominated by articles in English. By 2010, only about $20 \%$ of Wikipedia articles were in English, while it was estimated that 27\% of Internet users were English speakers. The evolution of the share of English Wikipedia articles relative to other languages from 2001 to 2010 is shown in Figure 5.12.

The median growth for all languages in the data is $89 \%$ per year; this translates to a doubling time of just under 13 months. A caveat, however needs to be noted. The average growth of a language, especially for one with a small number of articles, might be misleading as the addition of just a few articles could potentially translate into growth of several hundred percent.

Self publishing: blogs. One of the most basic and effective ways to publish content and distribute it on the Internet is via a blog. A blog is a web page that records content updates in descending chronological order. Blog users can easily upload text, pictures and video 


\section{Figure 5.12. Proportion of Wikipedia articles by language (top 5 languages)}

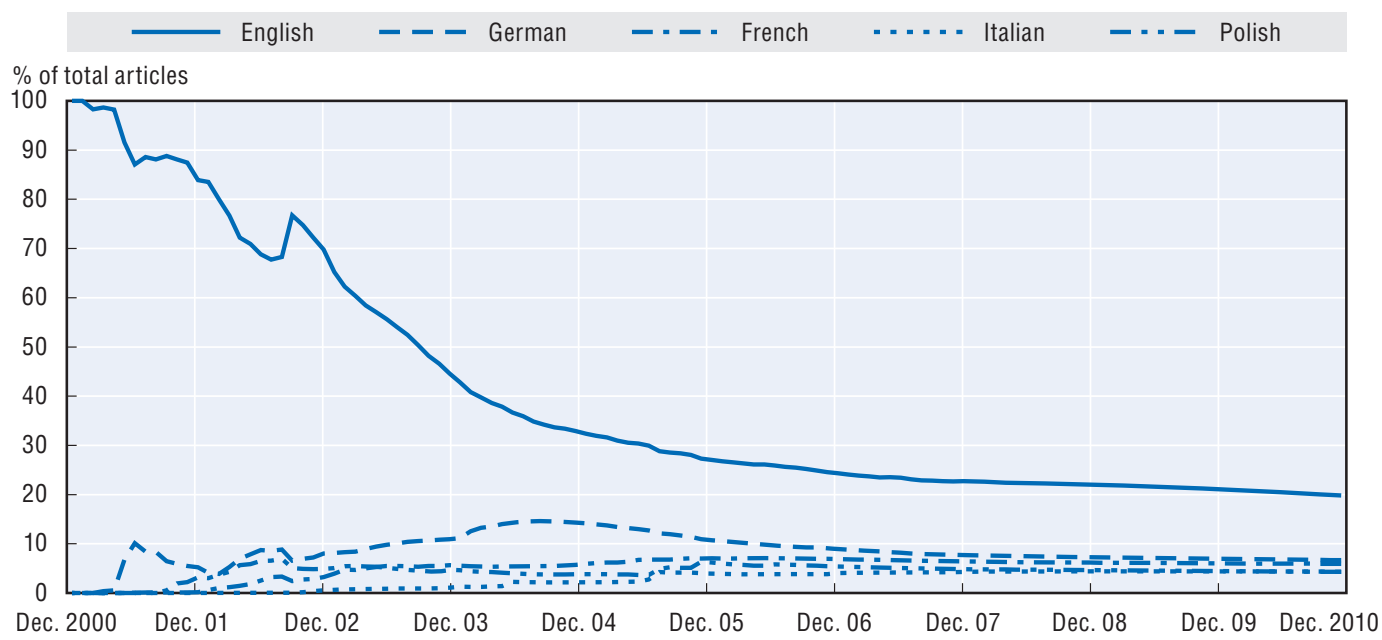

Source: OECD, ISOC, UNESCO (2012), The Relationship Between Local Content, Internet Development and Access Prices, OECD, Paris.

StatLink त्ञाज http://dx.doi.org/10.1787/888932694272

onto the Internet and into a blog. Google's Blogger service is available in 49 languages. ${ }^{7}$ Blogs are often thematic or follow the activities of an individual or group. The total number of blogs indexed by Google has been decreasing since 2008 when it reached its peak. This is due primarily to a sharp decline in the number of English-language blogs in the listings. The number of blogs indexed in other languages continues to grow across different languages for both the top (Figure 5.13a) and bottom (Figure 5.13b) languages listed.

Figure 5.13. Number of blogs indexed by Google

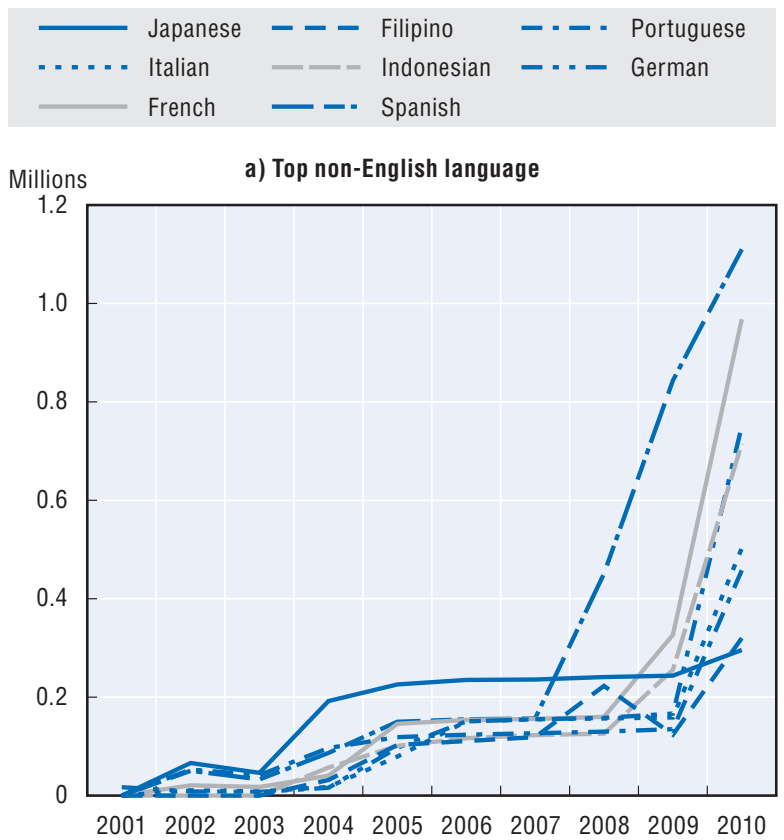

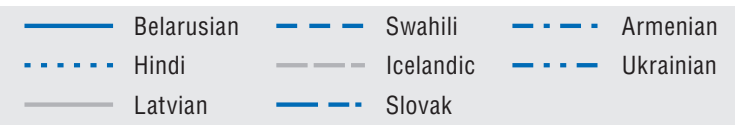

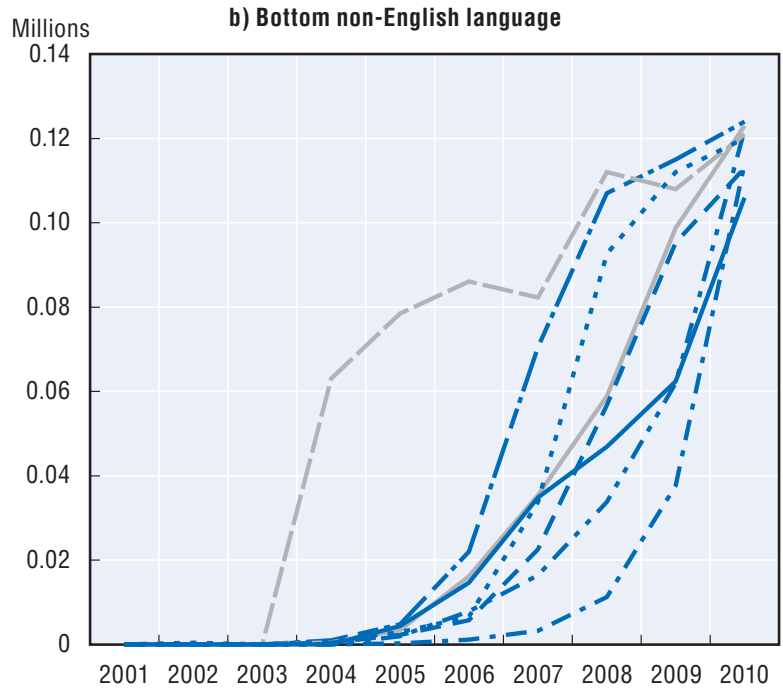

Source: OECD, ISOC, UNESCO (2012), The Relationship Between Local Content, Internet Development and Access Prices, OECD, Paris.

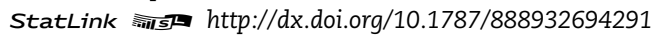


A large number of blogs are written by academic or professional experts, and are considered credible sources of information. For example, Paul Krugman, a Nobel Prize-winning economist, maintains a blog which was ranked the 69th most popular blog in May 2011 by a blog search engine (Technorati, 2011). Krugman's blog generates large amounts of commentary and engenders frequent debate. In addition to this type of informational blog, many blogs are used by local and national officials to reach out to the public (the official White House blog in the United States also featured in the top 100).

Blogs were among the most important early developments in the participative web. The estimated number of blogs varies between sources. The discrepancy can be attributed to the fact that blog search engines use the "number of links and the perceived relevance of blogs" to tabulate the numbers (OECD, 2007). Survey and sampling methods have also been employed to estimate the number of blogs, but these estimates vary as well.

Internet short messaging: Twitter. Twitter is a social networking site launched in 2006. Twitter permits users to share short text-based messages (tweets) with a 140 character limit. Because of its availability to those with Internet connections, Twitter has increased in popularity worldwide. Today, it is estimated that there are over 106 million accounts on Twitter, and that this number grows by 300000 every day (Online Marketing Trends, 2011). Although the majority of tweets are in English, a market research firm has estimated that $11 \%$ are in Portuguese, $6 \%$ in Japanese, $4 \%$ in Spanish and $18 \%$ in other languages. Less common local languages such as Haitian Creole, Maori and Wolof are even present on Twitter (Indigenous Tweets, 2011).

Twitter is designed to be an online form of SMS or texting (i.e. there is a character limit for each message). Tweets make frequent use of a specialised Internet vocabulary including abbreviations. The short length of Twitter messages makes the site a popular rebroadcasting tool; links to other popular media sources are often sent as Twitter messages. Twitter is not solely a creative platform for new content, but also a means for retransmission of extant content.

\section{Business models}

Most business models in this sector are shifting to monetise UCC platforms given the increased uptake in use over the last five years. There are essentially six approaches to monetising UCC. The various models are provided below.

- Voluntary donations and contributions: Content creators make content freely available but solicit donations from users (via PayPal). Blogging and citizen journalism sites such as Global Voices Online are supported by bloggers who provide content for free; operating expenses are funded by grants from foundation or start-up companies.

- Digital content purchases: Pay-per-item model where users make per-item (micro) payments to UCC platforms or creators to access individual pieces of content. Subscription models allow consumers to subscribe to services for enhanced hosting services or access to other users' content.

- Advertising-based models ("monetising the audience"): This is often seen as the most promising source of revenue for content creators, and some UCC platforms are distributing revenues with those who upload their own content. "Branded channels" have been launched on UCC platforms with content from a special brand or media publishing. Virtual worlds allow firms to create and display advertisements. 
- Licensing content and technology to third parties: Users may agree to license the site to use their content without payment, sometimes reserving the right to exploit their work commercially. Mobile carriers are increasingly acquiring licenses to distribute UCC and technologies that enable sharing of content.

- Selling goods and services to the community ("monetising the audience via online sales"): Owing to network effects, successful UCC sites are likely to have a large user base. This can be monetised by selling items and services directly to users or developing transactions among them (e.g. sale of avatars, virtual accessories or even virtual land).

- Selling of user data: Other business models may involve the sale of information about users to market research and other firms.

The growth of UCC has been impressive across OECD countries and around the world, but one of the biggest challenges has been locating ways to monetise content in order to create sustainable content production. Most business models are still in flux, and revenue generation for content creators or firms is only beginning. There are, however, a number of interesting models emerging. These include (adapted from OECD, 2008, and OECD, 2010):

- Consumer electronics and ICT goods. Sell hardware to create and access content.

- Software producers. Provide software for creation, hosting and delivery of UCC.

- ISPs and web portals. Attract customers to build a user base for premium Internet services.

- UCC platforms and sites. Build Internet audience and then add subscription and advertising revenue.

- Creators and users. Generate revenues through donations.

- Traditional media. Promote, broadcast and host content for UCC audiences.

- Search engines. Use UCC audiences to attract advertising revenues.

- Web services that benefit from UCC. Build websites for customers.

- Advertising. Use UCC content in advertising campaigns to draw in views.

- Marketing and brands. Expand customer loyalty by promoting brands through UCC communities.

\section{Film/video}

Market

Another key digital content sector is the film and video market. The market for movies has changed significantly, with Netflix, Apple, Amazon and others having a profound impact on distribution practices. The market for online film delivery will grow from USD 4.8 billion this year to USD 7.6 billion in 2015 according to PwC. This represents a significant increase from just USD 1.2 billion in revenue in 2006. According to PwC predictions, electronic distribution will be the fastest-growing segment of the North American film industry between $2011-15$, with $13.8 \%$ compound annual growth. This will be followed by cinema advertising $(6.7 \%)$, box office receipts $(6.1 \%)$, physical sell-through $(3.9 \%)$ and in-store rentals (1.4\%). Globally, the predictions for growth are nearly identical, with the exception of box office revenues slightly outpacing cinema advertising (PwC, 2011a).

\section{Business models}

In some respects, the basic structure of the film industry has not changed significantly in nearly 100 years, despite the rapid adoption of new technologies. The potential for Internet distribution of films is significant. The adoption of high-speed broadband and the 
development of popular video-sharing platforms have helped to introduce mainstream audiences to online video viewing. Media conglomerates owning both film studios and Internet-based platforms with large viewer bases (e.g. Internet portals such as AOL or Myspace) are increasingly using this new window to release films and video.

The major innovation in the film industry is the increasingly rapid introduction of digital cinema, following the development of industry standards and new financing mechanisms for the conversion of existing cinemas to the digital format.

There are four principal online film business models:

- Digital Content Rentals: The film is downloaded for a specified period of time (DRM disables playback beyond the agreed rental period, sometimes offering up to 30 days). Download rentals are on average comparable or cheaper than DVD rentals, but the period of use is shorter.

- Digital Content Purchases: The purchased movie is delivered online; prices are comparable to and even slightly less expensive than offline forms of distribution. Content portability is often restricted and video libraries may be small.

- Subscription-based revenues: This model allows consumers to access a range of titles on a monthly or yearly basis for a single subscription fee. DRM technologies prevent the video from being watched once a subscription expires. Transfer to other devices is highly restricted if allowed at all. "Triple-play" Internet providers are increasingly adding unlimited video-on-demand (VoD) offers to their broadband subscriptions. Prices may be a considerable bargain over DVD and cable (see Box 5.2).

- Advertising-based revenues: Initially this business model applied to independent and low-budget productions only; examples include platforms such as Joost and Guba. But major studio productions and recent television productions can increasingly be viewed online for free. Gyao, a Japanese Internet portal backed by the Usen Group, streams a limited catalogue of older studio content; and Hulu, an Internet portal backed by NBC Universal and News Corp., streams feature films and TV shows in North America.

\section{Box 5.2. Netflix}

Netflix is the world's leading Internet subscription service for movies and TV shows with over 25 million subscribers in the United States. The service offers a monthly subscription that provides unlimited movie and TV episode streaming over the Internet to computers and televisions.

Netflix has also partnered with hardware manufactures to integrate video streaming as a feature. There are currently more than 450 devices that stream from Netflix and are available worldwide (e.g. Microsoft XBox 360, Nintendo Wii and Sony PS3 console).

Source: Netflix (2011).

\section{Competition/pricing}

The film and video industry has been driven to transform its traditional business models to allow the distribution of its products over digital platforms. This transition has been helped by a greater willingness among consumers to pay for content provided online. Relative to other media products, film production requires a very large initial investment per unit, most of it high-risk in terms of return. For example, the film industry has historically 
attempted to maximise revenues by carefully timing the release of films through various channels. These include: i) cinema box-office markets, ii) television markets, iii) consumer markets (including home video sales and rentals), and increasingly via iv) online markets (including video services, interactive television and wireless digital content). This model has come under significant pressure; in particular, the Internet has helped to open up international demand for content that can be viewed quickly in all geographic locations.

One potentially significant source of new revenue for video content is digital download-to-own streaming services. These types of services (e.g. such as LoveFilm) are familiar to users who may be accustomed to buying DVDs for their personal libraries. New streaming services, downloads and digital content storage solutions will certainly help drive growth in this sector. Some estimates for the United States predict that electronic distribution will reach USD 6.9 billion by 2015 (PwC, 2011a).

Other promising trends for the film industry include the shift to enhanced digital cinemas, upgrading of existing cinemas, and the creation of new cinemas in many parts of the world. All these efforts aim to increase revenues as the global spending on filmed entertainment is expected to rise from USD 81 billion in 2006 to USD 103 billion in 2011, equating to a $4.9 \%$ CAGR.

One way in which the Internet is spurring transformation of the film and video sectors is increased competition for viewers. As a result, companies must develop new ways to attract and maintain customers. One of the most successful entrants to the market for film and video content delivery has been Netflix, which has the largest subscription base in the online film sector and, in mid-2011, reported revenues of USD 770 million (Netflix, 2011). Netflix's largest competitor over time is likely to be improved service offerings from cable companies and Internet service providers with expanding video-on-demand catalogues.

The United States has one of the earliest and most developed markets for online video delivery and the service offerings there can provide some insight into market developments that could emerge in other countries. Of the different online full-feature film services and price offerings, more than half provide online films through rental and purchasing schemes (Table 5.5).

\section{Music}

Market

In the digital music sector, digital channels now account for an estimated $29 \%$ of overall recorded music revenues, up from $25 \%$ in 2009. In 2010, the global digital music market was worth an estimated USD 4.6 billion, up 6\% from 2009 (IFPI, 2011). The digital music market is evolving and there remains plenty of room for growth. Revenue distribution for the digital music market is changing, with a higher proportion resulting from music downloaded or streamed via the Internet (Figure 5.14). Almost $30 \%$ of individuals in OECD economies download music or play games on the Internet (see Chapter 3, Figure 3.22). According to IFPI's Digital Music report, music downloads remained the dominant source of digital revenue and continued growth in 2010. iTunes has delivered more than 10 billion downloads since its inception, and has now been joined by a range of competitors including Amazon, 7digital, Walmart, HMV and Tesco (IFPI, 2011). Similarly, PwC estimates that by mid 2013 the digital recorded music will surpass that from the physical recording. 
Table 5.5. Online full-feature film providers, selected examples from the United States, October 2011

\begin{tabular}{|c|c|c|c|c|c|}
\hline Movie downloads & Netflix & Blockbuster & iTunes & CinemaNow & GreenCine \\
\hline \multicolumn{6}{|l|}{ Costs of instant viewing per month } \\
\hline One movie & 7.99 & 8.99 & 3.99 & 3.99 & Mail only \\
\hline 10 movies & 7.99 & 39.99 & 39.99 & 39.99 & Mail only \\
\hline 50 movies & 7.99 & 199.5 & 199.5 & 199.5 & Mail only \\
\hline 100 movies & 7.99 & 399 & 399 & 399 & Mail only \\
\hline \multicolumn{6}{|l|}{ Membership features } \\
\hline No late fees & - & $\bullet$ & - & - & $\bullet$ \\
\hline Watch instantly (stream or download) & - & - & - & - & \\
\hline Unlimited per month DVD rental & - & - & - & $\bullet$ & - \\
\hline No due dates & - & $\bullet$ & & & - \\
\hline Free two-way shipping & - & $\bullet$ & & & - \\
\hline Free trial & $\bullet$ & $\bullet$ & & & \\
\hline Total movies to chose from & $100000+$ & $95000+$ & & $6000+$ & $30000+$ \\
\hline Average delivery time (in days) & Mail 1-2 / Instant & Mail 1-2 / Instant & Instant & Instant & Mail 1-4 \\
\hline \multicolumn{6}{|l|}{ Accessibility } \\
\hline Watch with television & - & $\bullet$ & - & - & - \\
\hline Watch with Mac laptop & - & - & $\bullet$ & - & - \\
\hline Watch with Windows laptop & - & - & - & - & - \\
\hline Access by mail & - & $\bullet$ & & & - \\
\hline Accessibility with Blu-ray & - & - & & - & \\
\hline Instant access on iPad & - & & - & & \\
\hline
\end{tabular}

Source: Top Ten Reviews (2011), Movie Download Review, http://movie-download-review.toptenreviews.com, accessed October 2011.

StatLink न्ताइ http://dx.doi.org/10.1787/888932694994

Figure 5.14. Digital and physical recorded music forecast, 2006-15

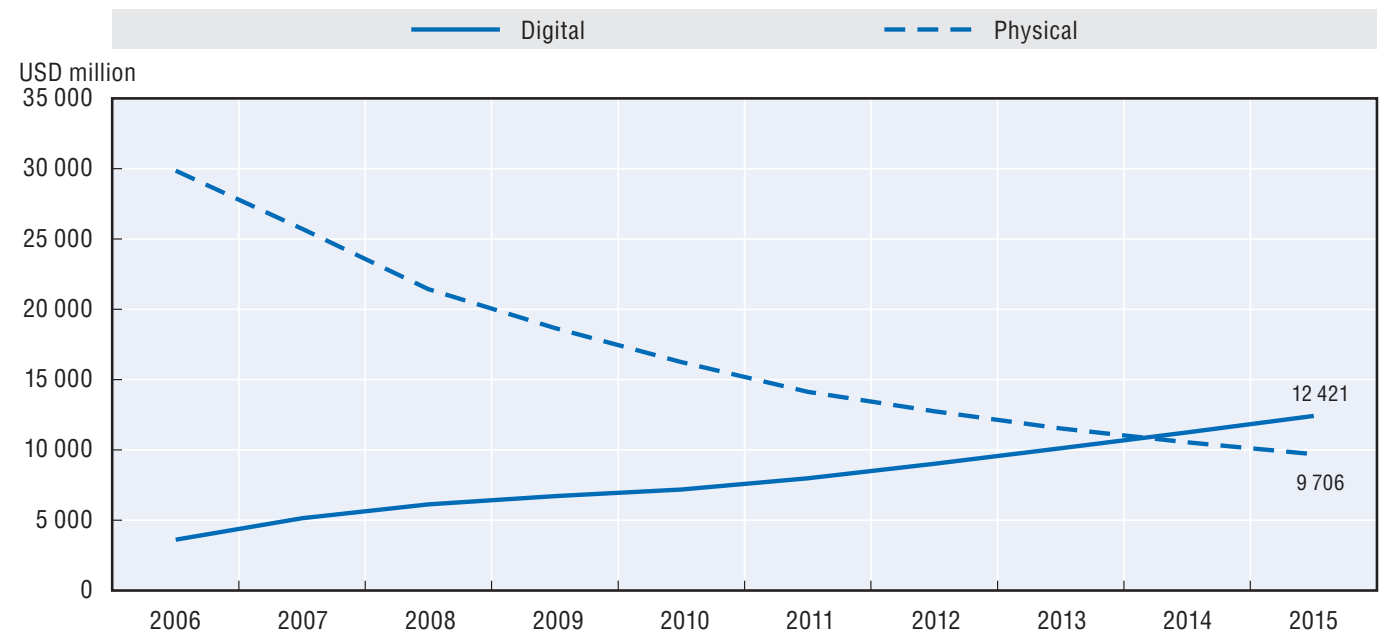

Source: Based on PwC Media \& Entertainment Outlook 2011.

StatLink Ailst http://dx.doi.org/10.1787/888932694310

According to IFPI, one of the key challenges for record companies is migrating users of unlicensed services to legitimate digital services. A new generation of subscription services aims to do this by attracting the large "lean-back" audience. 
One new area of focus for music companies is the living room. Music providers want to ensure that they have deals in place that put them in the set-top boxes in households and on mobile devices that accompany users wherever they go (IFPI, 2011). Cloud services are seen as a key part of the future strategy of music, as is witnessed by new cloud music offerings from Apple and Google (Table 5.6).

Opportunities for new digital channels for the music industry are being developed, and more music is being commercially released. For example, Tune Core is a service that helps independent artists to make their works available through iTunes stores. The service issued 90000 new releases in 2009, nearly as much music as released by major music labels. Independent artists also reach end users via Myspace, YouTube and other platforms. Another example of companies altering traditional business processes to attract new customers is the BBC's "Introducing" programme, which supports unsigned, undiscovered and under-the-radar musicians. Users upload their music which can be distributed via BBC radio shows and broadcast nationwide every week. It also opens the door to potential participation in major events and festivals, such as Glastonbury, Reading \& Leeds and the BBC's Electric Proms.

\section{Distribution}

Online radio stations per economy. Radio is a vital source of information for millions of people around the world. In many parts of the developing world, radio has filled the information vacuum, giving locals access to knowledge that has directly improved their quality of life. Because of the perceived importance of radio, large amounts of aid money have been spent establishing and maintaining local radio stations. For example, the Bill \& Melinda Gates Foundation sponsors a project that endeavors to use radio to provide information to farmers in developing economies, thereby increasing agricultural security. Academic research has shown that access to radio and other media in the developing world improves agricultural efficiency, public health and other aspects of life such as social equality (Westoff and Bankole, 1999).

As Internet penetration in many developing areas increases, local radio content is finding a second home online. The growing number of online radio stations is creating more opportunities for people to get local information from increasingly diverse sources. In addition, the Internet is lowering the entry costs of publishing audio by removing the need to install large broadcasting facilities.

Data are drawn from two different sources: live-radio.net and radio-locator.com. In total, information was collected for over 220 economies. Although minor differences exist between the two sources, both give a similar picture of economies with many radio stations per capita and those with few. The average number of stations per million residents from Live-Radio.net is slightly higher (8.8) than from Radio-Locator.com (7.7). Because there are no systematic differences between the two sources, the figure here uses the more comprehensive Live-Radio.net data. (Figure 5.15).

\section{Business models}

The increase in the demand for online music has enabled the creation of new distribution models for streaming and downloading music, with newer approaches such as advertising-supported services. Other broadband-based business models such as Internet radio are helping to generate music industry revenues and are also developing rapidly. 
Figure 5.15. Online radio stations per economy

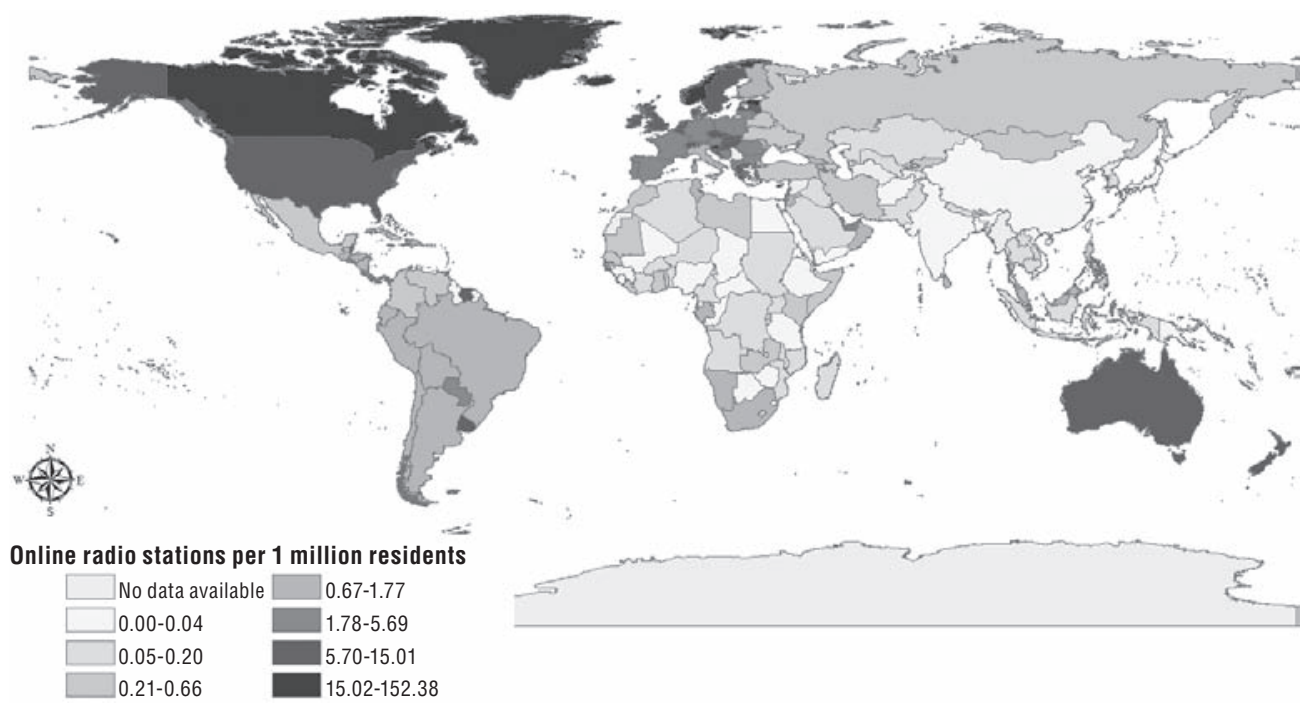

Note: This document and any map included herein are without prejudice to the status of or sovereignty over any territory, to the delimitation of international frontiers and boundaries and to the name of any territory, city or area.

Source: OECD, ISOC, UNESCO (2012), The Relationship Between Local Content, Internet Development and Access Prices, OECD, Paris.

At the end of 2010, there were more than 400 legitimate music services worldwide (IFPI, 2011). IFPI argues that the music industry is addressing challenges to provide quality and ease of use. Demand from consumers to access music across multiple channels and platforms have spawned increasingly diverse models. IFPI reports that the digital music industry is searching for more licensing models, as the industry is not homogeneous, but rather a portfolio of different business models developing at different speeds. Examples include downloads, premium access, ringtones, and streaming, advertising or other revenue streams.

New business models are mainly built around digital download and streaming subscription models, although portable subscriptions, online music bundled with subscriptions by ISPs, and advertising-based business models are also developing. However, most online music sales still rely on pay-per-track or pay-per-album download models.

There are three main online music business models:

- Digital content purchases: The pay-per-track business model is dominated by a few firms, which are not directly linked to the music industry, but generate revenues from the sale of portable music players or have an interest in setting software standards (e.g. Apple, Microsoft). While the number of online music stores is growing globally, the supply side is still consolidating as many new online music stores cannot generate enough revenue. This is especially the case for those that rely exclusively on music and are not affiliated with an existing business. Many either close (Virgin Digital in United Kingdom) or are merged (MTV Urge into Real's Rhapsody). The leading store (iTunes) is witnessing challenges from competitors with comparable catalogues and DRM-free sales, as well as cheaper offers from retailers such as Amazon and Wal-Mart. 
- Subscription-based revenues: The music subscription model made major advances in 2010, firmly establishing itself in the market and among consumers. Subscription services such as Rhapsody and Napster have existed for several years, but portable subscriptions only worked on certain devices, limiting flexibility for consumers. Only recently has the sector been able to take advantage of improved compatibility, underlying technology and broadband penetration levels. Today, consumers can use subscription services widely across mobile devices, vastly improving quality and the consumer experience. Services such as Spotify, Deezer, We7 and Slacker broadly present two kinds of offerings to consumers: a free advertising-supported streaming service, and a premium paid-for service. The use of these two tiers by a single service has become commonly known as the "freemium model".

- Advertisement-based revenues: Models that offer free on-demand streaming and remunerate the creation of music (artists, record companies, etc.) through revenues generated by advertising. Social network activities are thus becoming more attractive to advertisers and marketers.

- Partnership with ISPs: A significant number of music industry-ISP partnerships were established worldwide in 2010. These generally follow one of two models: the ISP develops its own-branded music service, such as TDC Play; or the ISP partners with an existing music service, such as Telia-Spotify in Sweden (Table 5.6).

\section{Table 5.6. Music industry-ISP partnerships}

\begin{tabular}{|c|c|c|}
\hline ISP & Country & Description \\
\hline Telia & Sweden, Finland & ISP Telia offers a four-month free Spotify subscription to its customers when they sign up to a mobile package. \\
\hline TDC & Denmark & TDC offers unlimited music downloads to its mobile and broadband customers at no additional charge. \\
\hline Telenor & Norway, Denmark & $\begin{array}{l}\text { Telenor launched a subscription service, WiMP, in cooperation with mobile content provider, Aspiro and } \\
\text { Platekompaniet, Norway's largest chain of music stores. WiMP does not offer an ad-supported tier, but } \\
\text { its free trial period has managed to convert } 70 \% \text { of subscribers into paying subscribers. }\end{array}$ \\
\hline FASTWEB & Italy & $\begin{array}{l}\text { FASTWEB launched a music service in partnership with Dada to enable fans to access millions of songs } \\
\text { from major and independent labels for EUR } 6 \text { per month. They can download } 15 \text { high-quality tracks and } \\
\text { stream the entire catalogue. }\end{array}$ \\
\hline Eircom & Ireland & $\begin{array}{l}\text { Eircom launched its MusicHub service, which offers free and unlimited streaming of } 4 \text { million tracks } \\
\text { without advertising to existing Eircom broadband customers. Users can also download DRM-free tracks } \\
\text { for USD } 0.32 \text { cents, which they can keep if they leave the service. }\end{array}$ \\
\hline SK Telecom & South Korea & SK Telekom launched MelOn, a monthly subscription service. \\
\hline AAPT & Australia & $\begin{array}{l}\text { AAPT partnered with EMI Music to offer a subscription service bundled with its broadband and fixed-line } \\
\text { packages. }\end{array}$ \\
\hline Slacker & North America & $\begin{array}{l}\text { Slacker partnered with four of the seven largest mobile operators. Its application is pre-loaded on millions } \\
\text { of devices, while the operator integrates the billing for the subscription and markets the service. }\end{array}$ \\
\hline
\end{tabular}

Source: IFPI (International Federation of the Phonographic Industry) (2011), IFPI Digital Music Report 2011: Music at the Touch of a Button.

StatLink त्तils http://dx.doi.org/10.1787/888932695013

\section{Competition/pricing}

Sales of recorded music on physical media have declined rapidly over recent years as users shifted to online music distribution platforms. A report from The Economist states that "sales of CDs, tapes and records have slid by $40 \%$ in Britain since 2001, according to the BPI, which represents record labels". In Japan, the world's biggest CD sales market, the number of discs sold fell by $6 \%$ in 2008 and by $24 \%$ in 2009 . Price cuts meant that revenues associated with physical media products dropped even more steeply (The Economist, 2010). 
Digital spending in the recorded music industry will overtake physical spending in the United States in 2011 and some are forecasting that by 2015 it will account for $70 \%$ of total spending (PwC, 2011a). Digital album sales increased more sharply than singles in 2010 , and accounted for $17.5 \%$ of all album sales in the United Kingdom and $26.5 \%$ in the United States (IFPI, 2011).

Despite the decline in physical media sales and the stalling of digital sales, the music industry no longer relies entirely on these channels to generate revenues, representing a radical transformation in their business models and revenue generation. Market revenues for the music industry have been growing steadily, but money is flowing to artists through alternative channels such as higher ticket prices, merchandising or sponsorship, publishing, online streaming, proliferation of FM radio and multichannel television, and charging for ringtones on mobile phones, while emerging markets have come to counterbalance losses from declining $\mathrm{CD}$ sales.

The music industry relies heavily on live/performance music, and has been able to increase revenues by charging higher entry fees for concerts. According to The Economist, a ticket to one of America's top concert tours in 1996 cost USD 25.81. Pollistar, a research firm that tracks the market said that in 2010, the worldwide average ticket price to see Madonna was USD 114. This report also stated that leading musicians have also, by roundabout means, seized a larger share of "service" charges, which are often added to the ticket price. Sales of merchandise account for nearly a half of income, which used to come from concerts and now comes from retail stores. Another area where the music industry is looking for new revenue is sponsorship. One example is the musical group Rascall Flatts, which has a sponsorship deal from American Living, a label carried by the retailer JCPenny (The Economist, 2010).

Another key trend is the emergence of free music-streaming services, such as We7 and Spotify that have proliferated in Europe: the latter claims 10 million users. The music industry itself is working to gain more control over how its content is delivered for free over the Internet. Once seen as a threat to music distributors, video-sharing sites are increasing embraced by music groups as an important avenue to market their artists. One example is Vevo, a music-video website linked to YouTube and owned in part by Universal Music Group and Sony Music Entertainment. Because Vevo's content is consistently professional, it draws advertisers, as companies pay from USD 25 to USD 30 to reach 1000 viewers. The partnership also allows Vevo to control the look of the site and cross-market new singers on the borders of videos by popular artists.

\section{News}

Thousands of newspapers around the world provide some or all of their content online. As online sources of news complement and compete with printed news sources, online newspapers have become an important provider of professionally created news. Local newspapers are the quintessential local content providers. They cover local news and culture and are generally written by a professional staff and provide high-quality content. Transplanting this reliable source onto the Internet accurately represents an important facet of digital local content.

There is a potential source of bias, however, in using newspapers to measure local content, as newspapers (print or online) might be more prevalent in certain regions than in others, and may reflect other demographic characteristics such as literacy rates. Moreover, large newspapers might potentially contain translated content in order to attract a wider readership. 
Data on the number of online newspapers in an economy was collected from www.onlinenewspapers.com. This site provides links to online newspapers in hundreds of economies around the world (Figure 5.16).

\section{Figure 5.16. Online newspapers per economy}

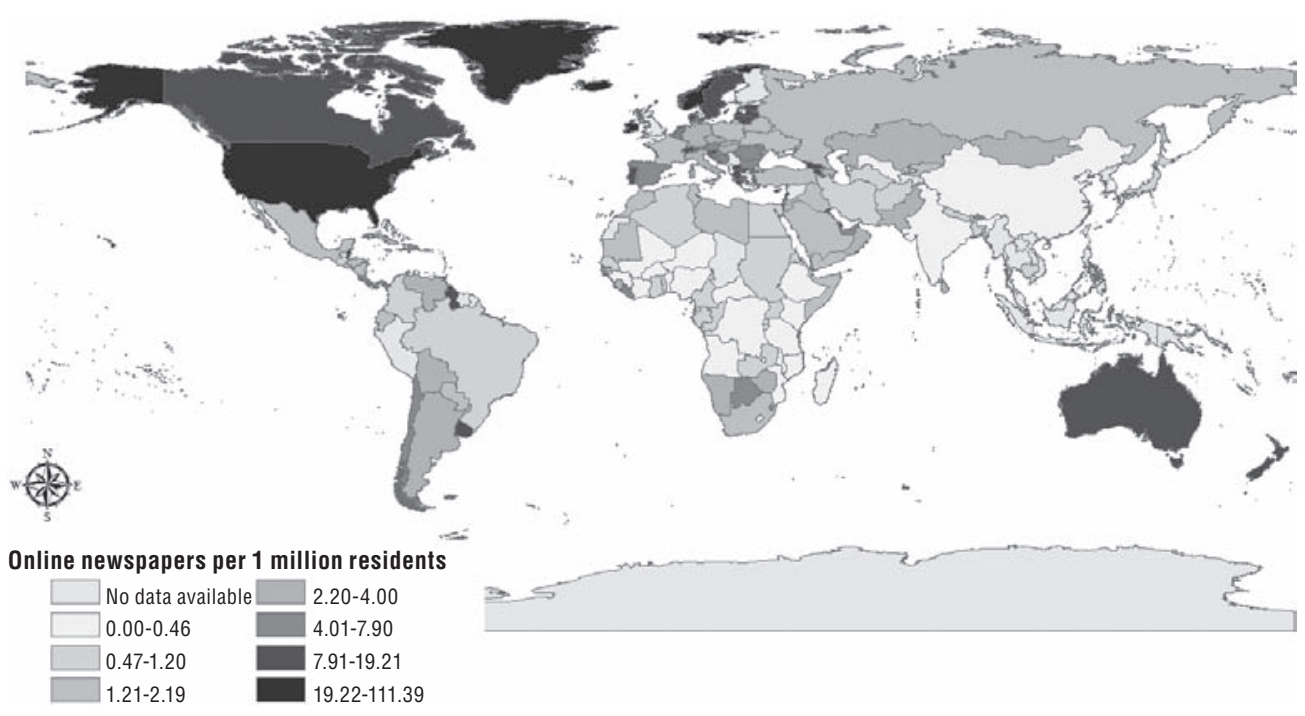

Note: This document and any map included herein are without prejudice to the status of or sovereignty over any territory, to the delimitation of international frontiers and boundaries and to the name of any territory, city or area. Source: OECD, ISOC, UNESCO (2012), The Relationship Between Local Content, Internet Development and Access Prices, OECD, Paris.

\section{Online advertising}

\section{Market}

The advertising market has evolved with the Internet in a way that has completely transformed the industry in just a matter of 15 years. According to Zenith Optimedia, Internet advertising will increase its share of the advertising market from $14.4 \%$ in 2010 to $18.9 \%$ in 2013, when it will overtake newspapers to become the world's second-largest medium behind television. Although television accounted for $46 \%$ of new advertising dollars globally between 2010 and 2013, the Internet is growing much faster than any other medium, at an average of 14.6\% a year between 2010 and 2013 (Figure 5.17).

\section{Business models}

Online advertising has become one of the chief digital content market enablers. Companies tend to offer a "free" service to the end-user large enough to attract companies to offer their services on their platforms, thus allowing the target audience greater exposure to their label or brand. Companies such as Facebook and Google have grown tremendously over the past years following this revenue model.

Online advertising models can be classified into five main groups. Search ads are the most popular form of online advertising mostly due to the market share of search engines as entry portals for Internet users. However, display ads are the fastest-growing segment, growing by $17.2 \%$ a year, driven mainly by online video and social media. Streaming video ads are also growing extremely quickly, thanks to the emergence of do-it-yourself tools that have allowed local advertisers to enter the market (Zenith Optimedia, 2011) (Figure 5.18). 
Figure 5.17. Advertising expenditure by medium

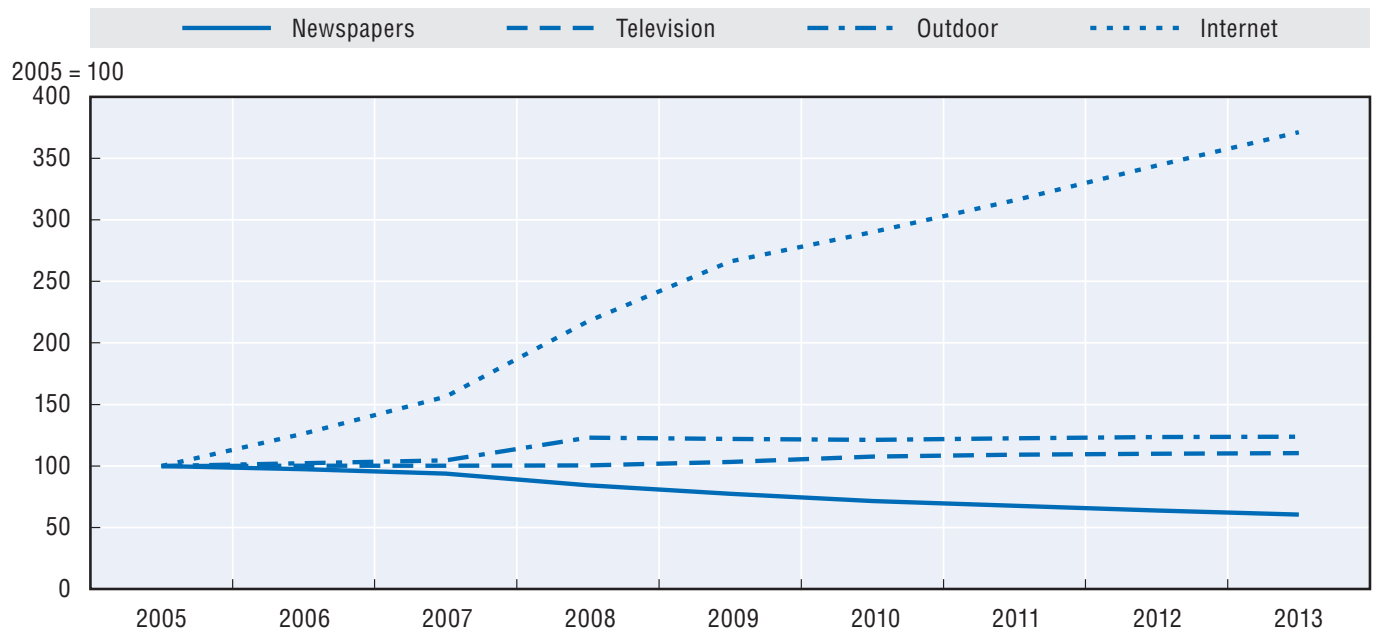

Source: OECD (2011), The Future of the Internet Economy: A Statistical Profile, June 2011 Update.

StatLink तiाls' http://dx.doi.org/10.1787/888932694329

- Search ads involve advertisers bidding on keywords that affect the position of their text ads on the user's result page.

- Display ads tend to be static or hyperlinked banners for which an advertiser pays an online company in order to appear on one of its pages.

- Classified ads are listings of certain products or services on a web page (e.g. eBay's gumtree.com).

- Email advertising consists of ads delivered through any type of electronic mail.

- Referrals are a method by which advertisers pay fees to online companies that refer purchase requests or provide customer information.

Figure 5.18. Share of Internet advertising by type

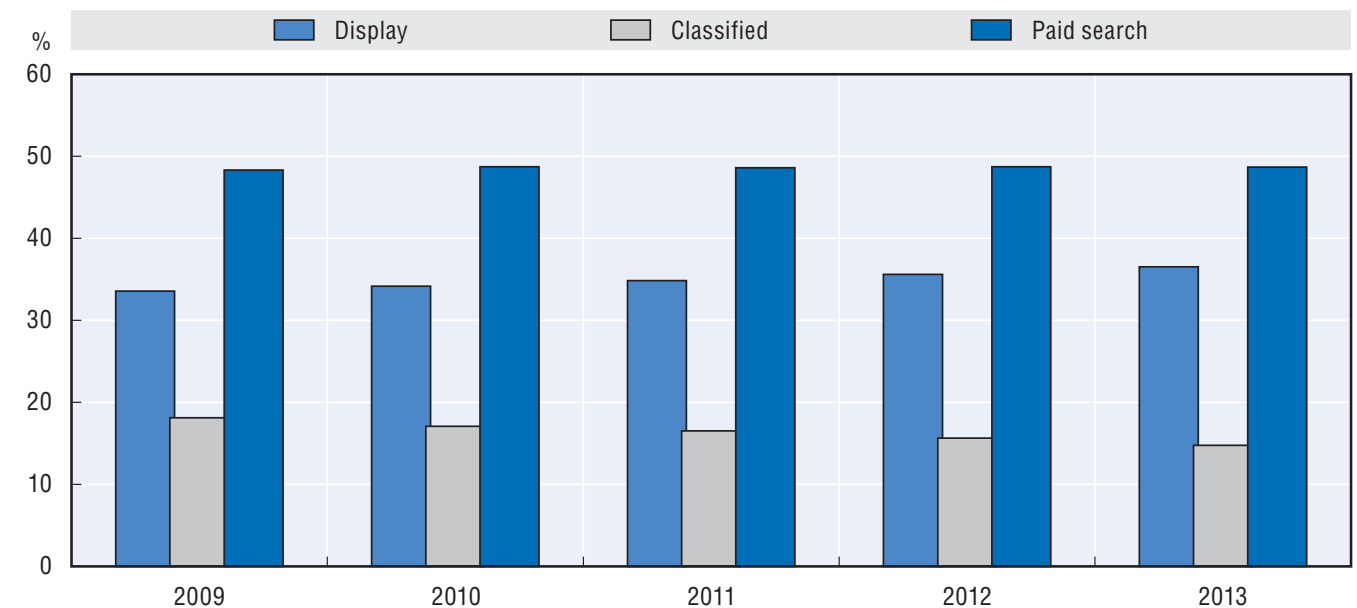

Source: Based on data from Zenith Optimedia (2011). 


\section{Competition/pricing}

Advertising is an important driver of free content services and content offered to consumers in newspapers, radio or broadcasting. In this two-sided market, publishers are often willing to subsidise one group (usually consumers), in order to have a large enough audience to attract the other (usually advertisers). Online advertising has developed highly efficient and high-revenue business models. For example, targeting and cost-per-click models seem to have an advantage over traditionally advertising because they can track responses to ads placed. Other sectors are still experimenting with means of generating more, increasingly advertising-based, digital content revenue.

The creation, placement and media purchasing services for large advertising campaigns are provided by vertically integrated structures, for example, Omnicom, WPP, Interpublic and Publicis Group, each of which controls various marketing service, advertising and media agencies (OECD, 2008). These firms can intermediate between advertisers, content publishers and the consumer. There are also numerous mid-sized holding companies, for example, Havas, Aegis, Dentsu and Hakuhodo DY, and small businesses that specialise in one or more of these value-adding steps or in direct marketing services. Companies such as Google and Facebook lead the online advertising market and offer companies not only a vast number of users, but also a global presence and precision in terms of targeted ads previously unavailable via other media. For example, firms can now target specific advertising to certain users in a given region or one user that has a particular set of revealed tastes. For 2011, Facebook was forecasted to collect USD 3.2 billion in worldwide advertising revenue, more than doubling its USD 1.86 billion revenue from 2010, and more than quintupling its USD 0.74 billion from 2009.

Social networking sites have overtaken other large web portals as the places where users spend most of their time on the Internet, and this makes them a prime location for advertisers. In July 2011, comScore revealed that users in the United Kingdom were spending, on average, $16 \%$ of their web time on Facebook, versus $12 \%$ of their time, which was spent on all of Google's properties (Gmail, YouTube, etc.) combined (comScore, 2011).

This social networking functionality is coming to other sites across the Internet. It has enabled companies to cross from one platform to the other, allowing these to diversify and attract a bigger share of the market. Facebook, the world's largest social network, is allowing companies to integrate their websites by making their applications more personal and social through its Open Graph service. Examples of companies using the Open Graph service are: DailyMotion, Deezer, Earbits, The Guardian, Hulu, iHeartRadio, The Independent, Izlesene, Jelly, mixcloud, MOG, MyVideo, Netflix, Rdio, Rhapsody, Slacker, Songza, Spotify, The Washington Post and Yahoo! (Facebook, 2011).

Another important trend is that advertising platforms are making it easier for websites, created by individuals or businesses, to monetise their services. For example, Google's AdSense is a free programme, with over 1 million advertisers worldwide, that empowers online publishers to earn revenue by displaying relevant ads on their online content. By using this programme, paid website publishers (which include individual bloggers, small businesses, large online news sites and myriad others) produced over USD 5.2 billion in revenue in 2009 (Google, 2011).

Pricing for online advertising initially mirrored traditional pricing models, where approximately $50 \%$ of online advertising is charged at cost-per-thousand-impressions (CPM). This means that each time an ad is displayed the publisher is entitled to receive revenue. This model means less risk for publishers, but fails to exploit the Internet's possibilities for performance tracking. Consequently, performance-based pricing is gaining importance, 
including cost-per-click (CPC), which requires users to click on an ad in order to generate revenue, and cost-per-action (CPA) models, which generate revenue to the publisher only when a user takes an action which actually benefits the advertiser, such as purchasing online. These models depend on measuring exposure to advertising in terms of occurrence and time, as well as tracking user actions across websites (adapted from PwC, 2011c).

Partnerships between ISPs and content broadcasters, distributers or hosts have increased digital content use. Online advertising has also contributed to this increase, especially through social media. For example, Nielsen found that $46 \%$ of United States consumers were influenced by standard web ads on social media sites, but that $51 \%$ were influenced by standard web ads on social media sites that show which of their friends like or follow the advertised brand. In addition, they found that $48 \%$ were influenced by web ads on social media sites that appear as a news feed update (Nielsen, 2011).

Companies are offering online market targeting and segmentation, which enable companies to better design effective and accurate advertising campaigns. This helps to ensure that the message reaches the target audience. Behavioural advertising through targeting and pay-per-click models seems to be giving online advertising a considerable advantage by reducing ineffective advertising budgets and securing enhanced levels of engagement from recipients by tracking responses to ads placed. Behavioural targeting allows an unusual level of precision in identifying a potential consumer and his/her likelihood to purchase a product.

A significant development in marketing strategies is crowdsourcing, an online, distributed problem-solving and production model that has emerged in recent years. Crowdsourcing enables a company to broadcast an issue to a diverse audience (using web-based collaboration solutions) and ask consumers to contribute ideas to solve the problem (PwC, 2011b). This form of mass collaboration has been successfully used by corporations for product design and marketing, for example, PepsiCo's crowd-created Super Bowl XLV commercials (Box 5.3). Other notable examples of the model include the Goldcorp Challenge, InnoCentive, iStockphoto, Threadless and user-generated advertising contests.

\section{Box 5.3. PepsiCo's crowd-created commercials}

PepsiCo sponsored a crowd-driven contest in which consumers created 30-second commercials for its Doritos $₫$ and Pepsi MAX® products. More than 5600 videos were submitted, and consumers voted at the company's "Crash the Super Bowl" contest website to select six commercials that would air during the game. These contests were a success: one user-generated ad ranked no. 1 among all commercials broadcast during the game and two others were placed in the top five. PepsiCo got six commercials for a bargain of 1.4 million USD in prizes to winners, while fully engaging its customers in its brands and further building its social networking base. PepsiCo also replicated this strategy in Mexico, releasing the name of the prize winner before national transmission of the Mexico-South Africa inaugural match in South Africa's World Cup 2010.

Source: PepsiCo, PwC, Harnessing the Power of Crowdsourcing, 2011.

\section{Games}

The market for computer and video games is evolving as a result of very high growth, new devices and innovative business models. High-growth sectors include casual gaming (often via social networks) or downloads and stand-alone applications called "apps". According to projections by Digi-Capital, online and mobile games are forecast to grow the total video games 
market size to USD 82 billion and take 50\% of revenue share at USD 41 billion (Digi-Capital, 2011). They also forecast that the Asia-Pacific and European regions will represent almost $90 \%$ of the revenue share for online and mobile games by 2015 with the following distribution: China (36\%), Europe (20\%), South Korea (12\%) and Japan (10\%) (Figure 5.19).

\section{Figure 5.19. Global computer and video games sector revenue}

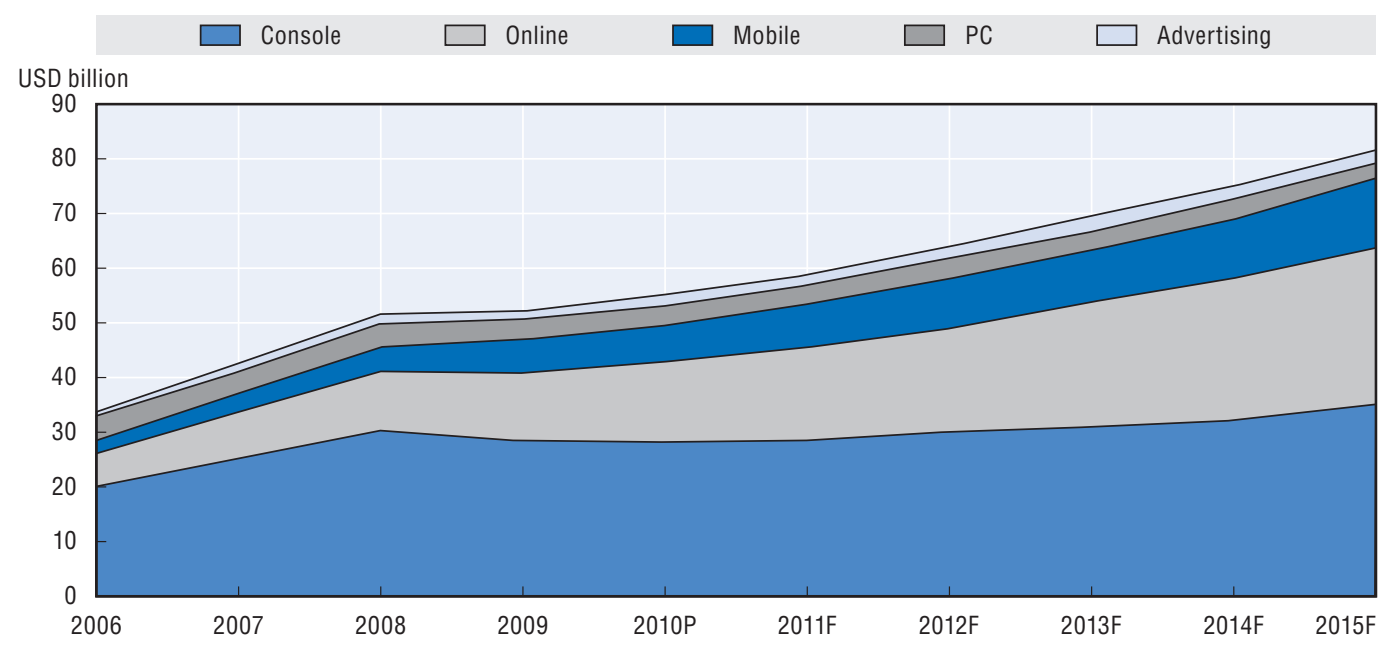

Source: Digi-Capital (2011), Global Video Games Investment Review, Digi-Capital Ltd, London.

\section{Local content}

The content most important to people is typically that presented in their own language and relevant to the communities in which they live and work. This relevant content is often referred as "local content". Individuals are mainly concerned with information that is relevant to them; therefore, a key policy goal is promoting the development of relevant content and ensuring that it is available in the language and format that applies to them. The dissemination of information among the population is often referred to as information and knowledge sharing, and it plays an important role in helping respect the universality, indivisibility and interdependence of human rights, especially, freedom of expression. The United Nations Educational, Scientific and Cultural Organization (UNESCO) has defined "local content" as an expression and communication of a community's locally generated, owned and adapted knowledge and experience that is relevant to the community's situation, OECD, ISOC, UNESCO (2012) (Table 5.7).

Digital technologies are important tools for content creation and delivery at the local level and around the world. The Internet has helped to empower users as content creators and has also allowed individuals to exercise greater choice and control over the content they consume in contrast to the limited channels of traditional broadcasting.

The Internet delivers free tools for content creation that were previously provided as software for users to purchase. For example, music editing software is available online from sites such as JamStudio.com, which provide artists with the ability to create and record music without access to physical instruments.

Countries such as Belgium are promoting the development of local content through their Heritage 2.0 project, which focuses on the digital accessibility of cultural heritage. This project provides the user with the ability to map a visit at a historical or cultural site according to 
Table 5.7. Summary of measures of local content

\begin{tabular}{|c|c|c|c|}
\hline \multirow{2}{*}{ Indicator } & Description & Benefits & Drawbacks \\
\hline & \multicolumn{3}{|c|}{ Measures by economy } \\
\hline ccTLDs & $\begin{array}{l}\text { Number of country code top-level } \\
\text { domains per } 1000 \text { residents } \\
\text { per economy }\end{array}$ & $\begin{array}{l}\text { No ambiguity in identification, } \\
\text { good fit for local content criteria }\end{array}$ & $\begin{array}{l}\text { Narrow measure of local content due to } \\
\text { barriers to entry }\end{array}$ \\
\hline Facebook subscribers & $\begin{array}{l}\text { Number of Facebook subscribers } \\
\text { per } 1000 \text { residents per economy }\end{array}$ & $\begin{array}{l}\text { Popular (ranked no. } 2 \text { site worldwide } \\
\text { by Alexa.com), platform for local } \\
\text { advertisers }\end{array}$ & $\begin{array}{l}\text { Unavailable in certain areas, substitute } \\
\text { products exist }\end{array}$ \\
\hline Online newspapers & $\begin{array}{l}\text { Number of online newspapers } \\
\text { per } 1 \text { million residents per economy }\end{array}$ & $\begin{array}{l}\text { Measures professional content } \\
\text { creation }\end{array}$ & $\begin{array}{l}\text { Varying popularity across economies } \\
\text { due to presence of substitute products } \\
\text { such as blogs }\end{array}$ \\
\hline Streaming radio stations & $\begin{array}{l}\text { Number of streaming online radio } \\
\text { stations per } 1 \text { million residents } \\
\text { per economy }\end{array}$ & $\begin{array}{l}\text { Good source of local news, } \\
\text { language and cultural media }\end{array}$ & $\begin{array}{l}\text { Regulatory differences between } \\
\text { economies, potential variation } \\
\text { in the amount of foreign aid used } \\
\text { to support local radio across economies }\end{array}$ \\
\hline Geotagged Flickr photos & $\begin{array}{l}\text { Number of Flickr photos geotagged } \\
\text { per } 1000 \text { residents per economy }\end{array}$ & $\begin{array}{l}\text { Measures a unique niche } \\
\text { of local content not captured } \\
\text { by the other measures }\end{array}$ & $\begin{array}{l}\text { Includes photos taken by tourists and } \\
\text { other non-locals (i.e. photos } \\
\text { not intended for a local audience) }\end{array}$ \\
\hline \multirow[t]{2}{*}{ YouTube uploads } & $\begin{array}{l}\text { Number of YouTube uploads per } \\
1000 \text { residents per economy }\end{array}$ & $\begin{array}{l}\text { Popular (ranked no. } 3 \text { site } \\
\text { worldwide by Alexa.com), } \\
\text { primarily user-created }\end{array}$ & $\begin{array}{l}\text { Might be biased towards certain } \\
\text { cultures }\end{array}$ \\
\hline & \multicolumn{3}{|c|}{ Measures by language } \\
\hline Web pages & Number of web pages per language ${ }^{1}$ & $\begin{array}{l}\text { Broad measure of local content } \\
\text { relative to ccTLDs }\end{array}$ & $\begin{array}{l}\text { Classification difficulties, language } \\
\text { overlap between economies }\end{array}$ \\
\hline Wikipedia articles & $\begin{array}{l}\text { Number of Wikipedia articles } \\
\text { per language }{ }^{1}\end{array}$ & $\begin{array}{l}\text { Free and easily accessible, reflective } \\
\text { of overall shift of the Internet } \\
\text { community away from English } \\
\text { language }\end{array}$ & Easy to automate creation of articles \\
\hline Blogs & Number of blogs per language ${ }^{1}$ & $\begin{array}{l}\text { Free, accessible to all with Internet } \\
\text { access }\end{array}$ & $\begin{array}{l}\text { Measured imprecisely, classification of } \\
\text { multilingual blogs is ambiguous }\end{array}$ \\
\hline Tweets & Number of Tweets per language ${ }^{1}$ & $\begin{array}{l}\text { Low overhead, anecdotal evidence } \\
\text { showing Twitter communities } \\
\text { of minority languages }\end{array}$ & $\begin{array}{l}\text { Measured imprecisely, potential bias } \\
\text { due to use of lack of text message } \\
\text { vocabulary in given language }\end{array}$ \\
\hline
\end{tabular}

1. These measures should be weighted by the number of speakers of the particular language per economy. Source: OECD, ISOC, UNESCO (2012).

StatLink ints $h t t p: / / d x . d o i . o r g / 10.1787 / 888932695032$

personal interests and preferences by time period. In Canada, the Canadian Interactive Fund supports the creation of new forms of interactive cultural content and services, developed by aboriginal, ethnocultural and OLM (Official Language Minority) communities and other not-for-profit cultural organisations, to better reflect today's environment (Box 5.4).

\section{Box 5.4. Indigenous Tweets}

Dr. Kevin Scannel, a professor of mathematics and computer science at Saint Louis University, maintains a blog called Indigenous Tweets. The purpose of the site is to help speakers of endangered languages find each other on Twitter. This enables young people, in particular, to use social media available on the Internet to connect and form online language communities. Dr. Scannel hopes that his site will help to preserve and even revive many endangered languages. Presently Dr Scannel's software and his blog track 82 minority languages. The largest languages followed by his software are Haitian Creole, Welsh and Castilian. Smaller languages, such as Wolof, only have two Twitter users tracked by the software for the moment. With help from speakers of these small languages, Dr. Scannel hopes to expand the number of languages supported on his site.

Source: Indigenous Tweets (2011). 


\section{Twitter}

Twitter provides an outlet through which people can express themselves in a wide variety of languages. Its growth internationally is testament to its value as a platform for the production of local content. Twitter permits people to share with a wide audience of speakers of the same language and discuss topics of interest to the community.

The Indigenous Tweets blog and companion website indigenoustweets.com are evidence that online-communities of speakers of local languages are present. This anecdotal evidence suggests that Twitter is becoming an important location for the creation of language-preserving local content.

\section{Geotagged Flickr photos}

The Internet has become one of the largest sources of photographs. A relevant example of the Internet helping support local digital content is the ability to assign a geographic marker (geo-tag) to photographs posted on the Internet. Photo-sharing sites such as Flickr provide storage space to users where they can upload, store and share photos, and provide a geo-location marker that assigns the picture to a specific location, thus creating a repository of photographs from a particular area that is available and searchable online. According to Flickr, the number of geotagged photos per 1000 inhabitants varies across countries, but the Cayman Islands, Iceland and Monaco are at the top of the list.

Presently, there are over 150 million geotagged photos on Flickr. These photos catalogue a wide range of local art, architecture, geography, culture and activities. Although many photographs might be taken by visitors, they are understandable and appreciable by locals. An overview using the Flickr API tool shows the number of geotagged photos in 221 economies (Figure 5.20).

\section{Figure 5.20. Geotagged Flickr photos per economy}

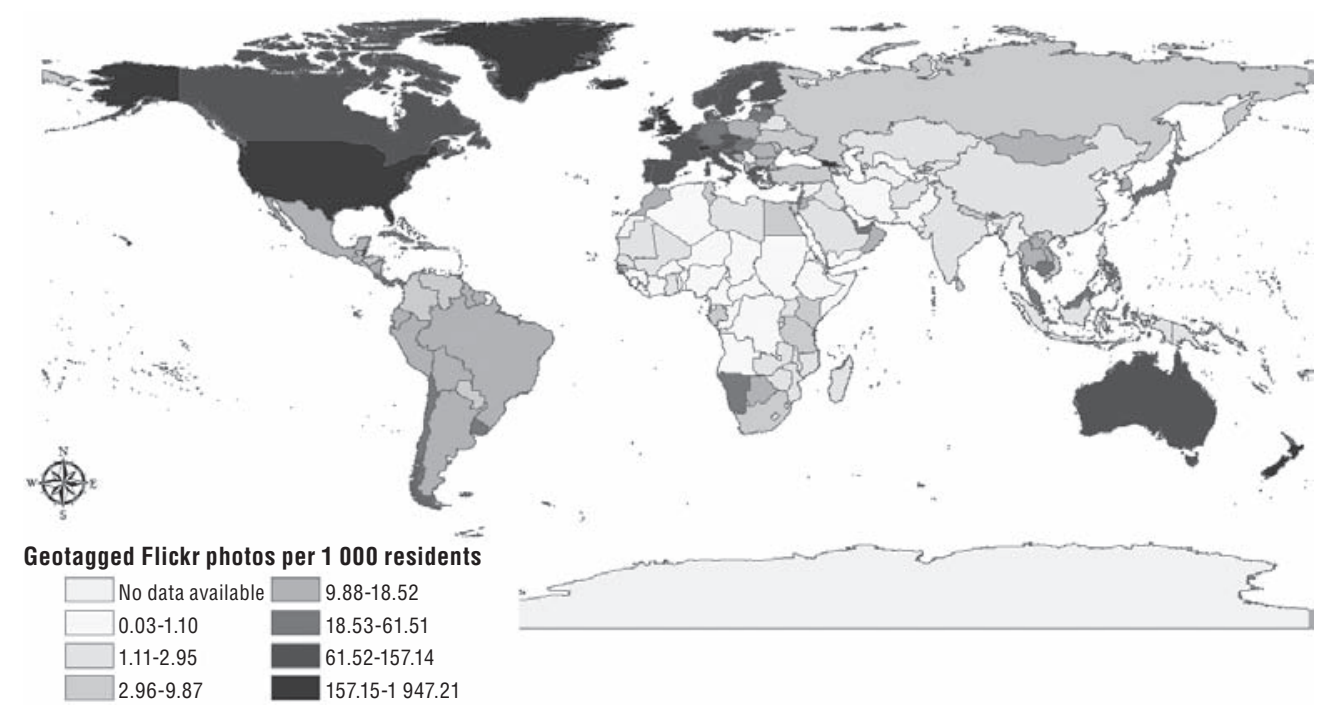

Note: This document and any map included herein are without prejudice to the status of or sovereignty over any territory, to the delimitation of international frontiers and boundaries and to the name of any territory, city or area. Source: OECD, ISOC, UNESCO (2012), The Relationship Between Local Content, Internet Development and Access Prices, OECD, Paris. 


\section{YouTube uploads}

YouTube is one of the most popular video-sharing sites on the Internet, and in 2010 they reported that their platform hosted hundreds of millions of videos. The site also serves more than 2 billion views per day. The amount of content on the site is growing rapidly as well, with approximately 24 hours of video content added every minute (YouTube, 2010). YouTube data is instructive, showing how video-sharing sites extend the reach of local content beyond national borders.

It is possible to depict content uploaded to YouTube in the first half of 2011 by country of origin and then categorised by viewers as domestic or international (Figure 5.21). Poland is the country in the sample with the highest percentage of domestic views of domestically uploaded content. Approximately $64 \%$ of views of content uploaded from Poland were watched domestically and the remaining $36 \%$ of views were from abroad. At the other end of the spectrum, $97 \%$ of views of content uploaded from Luxembourg were from abroad. The data show that domestically uploaded content is viewed more from abroad than from home in 17 of the 22 countries in the sample, highlighting the potential for sharing domestically created content with a global audience.

\section{Figure 5.21. YouTube: national and international viewing of domestically uploaded content}

Selected countries in Europe, first half of 2011.

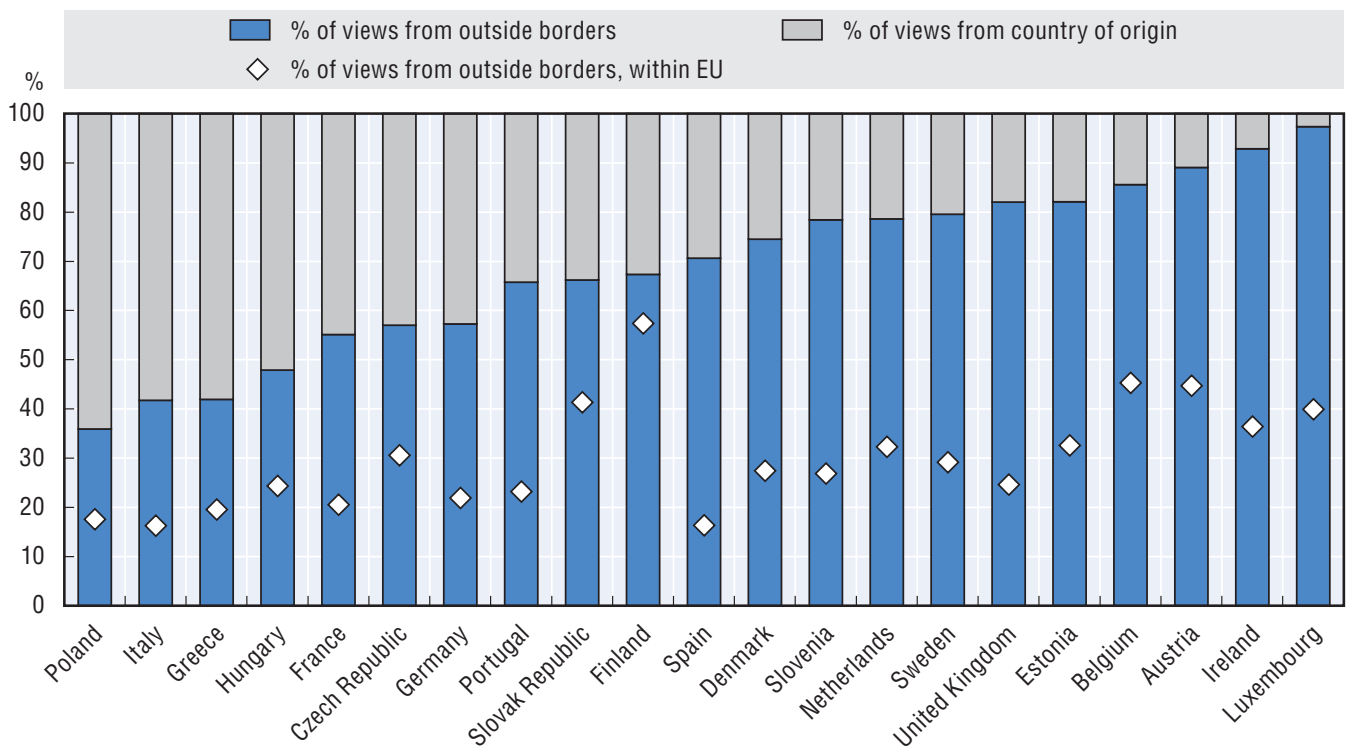

Note: Percentage of views of domestically uploaded content viewed from within and outside the country of origin. Source: OECD, ISOC, UNESCO (2012), The Relationship Between Local Content, Internet Development and Access Prices, OECD, Paris.

StatLink न्तारा http://dx.doi.org/10.1787/888932694367

\section{Conclusion}

The last two years have seen significant growth in devices capable of accessing digital content over the Internet in formats appealing to consumers. Sources of digital content are also expanding, with social networking and new video and audio services helping to drive ICT industry growth and creating new business models. In turn, these models are transforming traditional industries and delivering a wide range of benefits for consumers. 
Digital content markets have grown dramatically during this period. The fast adoption of social media has led to massive growth in user-created content (UCC), as users increasingly make digital content part of their daily lives. Increasing demands for mobility are also transforming the ways in which digital content is consumed. The combination of these changes and the development, rollout and adoption of legal platforms for video and music have pushed companies to alter traditional business models.

Digital content markets have increased their proportion of revenue in the following industry sectors: user-created content, games, music, film and online advertising. These industries share a number of characteristics and challenges. However, the differences between them have resulted in a variety of strategies to enable them to compete in the evolving marketplace. These include the development of new revenue streams, the transformation of traditional value chains, and the design of innovative business models. One particular revenue source supporting the creation and delivery of online content is the growth of online advertising.

Digital content programmes are in place in many OECD countries. Most efforts in recent years have focused on fostering development of a domestic content-based ICT services industry, which can benefit from the Internet to reach global markets; and on making public sector (and publicly funded and publicly held) information easily available to spur innovation and growth in the commercial use of public sector data. Chapter 8 provides more detailed information on how government policy is helping promote the development of digital content.

\section{Notes}

1. This chapter analyses intangible digital content: products that are downloaded, streamed or hosted in the "cloud". Digital content products delivered through tangible media are not discussed.

2. Information included in an analytic report being developed by the OECD Committee on Consumer Policy on empowering consumers in the purchase of digital content products; the work is based on discussion at a roundtable on digital content held on 13 April 2011 and an OECD Committee on Consumer Policy workshop on digital content held on 23 April 2012 [DSTI/CP(2011)14/FINAL].

3. See note 2.

4. See note 2.

5. See note 2.

6. The following definitions were considered for the elaboration of this data: Web, email and data: Includes web, email, instant messaging, and other data traffic (excludes file sharing). File sharing: Includes peer-to-peer traffic from all recognised P2P systems such as BitTorrent and eDonkey, as well as traffic from web-based file sharing systems. Gaming: Includes casual online gaming, networked console gaming, and multiplayer virtual-world gaming. Video Communications: Includes Internet video calling over instant messenger and soft-client video calling programmes such as Skype. VoIP: Includes traffic form retail VoIP services and PC-based VoIP, but excludes VoIP transport. Internet Video: Includes short-form Internet video (for example YouTube), long-form Internet video (for example Hulu), live Internet video, Internet-video-to-TV (for example Netflix through Roku), online video purchases and rentals, webcam viewing, and web-based video monitoring (excludes P2P video file downloads).

7. Blogger's language selection page is found at: www.blogger.com/language.g. 


\section{References}

148apps.biz (2011), App Store Metrics, http://148apps.biz/app-store-metrics/, accessed 18 August 2011.

AccuStream (2010), Pro and UGV Viewing Share Analytics: 2005-2009, Accustream www.accustreamresearch.com/news/20100302.htm.

Cisco (2011), Cisco Visual Networking Index: Forecast and Methodology, 2010-2015, www.cisco.com/en/US/ solutions/collateral/ns341/ns525/ns537/ns705/ns827/white_paper_c11-481360.pdf.

comScore (2011), More Time Spent on Facebook Than Any Other UK Site July 2011, www.comscoredatamine.com/ 2011/07/more-time-is-spent-on-facebook-than-any-other-uk-site/.

comScore (2012), Vital Digital Market Intelligence for the Telecommunications Industry, www.comscore.com/ Industry_Solutions/Telecommunications.

Digi-Capital (2011), Global Video Games Investment Review, Digi-Capital Ltd, London, http:// copenhagenentertainment.dk/fileadmin/user_upload/Pdf/DigiCapital-Global-Video-Games-InvestmentReview_1_.pdf.

The Economist (2010), "Having a Ball: In the Supposedly Benighted Music Business, a Lot of Things are Making Money", The Economist, October 2010, www.economist.com/node/17199460/print.

European Commission (EC) (2010), Communication from the Commission to the European Parliament, the Council, the European Economic and Social Committee and the Committee of the Regions, A Digital Agenda for Europe, COM/2010/0245/f/2, 26 August 2010, http://eurlex.europa.eu/LexUriServ/ LexUriServ.do? uri=CELEX:52010DC0245R(01):EN:NOT.

Gartner (2012), Gartner Forecast: Mobile Devices by Open Operating System, Worldwide, 2008-2015, Press release, www.gartner.com/it/page.jsp?id=1622614.

Giles, J. (2005), “Special Report: Internet Encyclopaedias Go Head to Head”, Nature, Vol. 438, pp. 900-901, doi: $h$ ttp://dx.doi.org/10.1038/438900a.

Google (2011), www.google.com/adsense.

IFPI (International Federation of the Phonographic Industry) (2011), IFPI Digital Music Report 2011: Music at the Touch of a Button, IFPI, London, www.ifpi.org/content/library/DMR2011.pdf.

Indigenous Tweets (2011), Online blog, http://indigenoustweets.blogspot.com/.

ITU (International Telecommunication Union) (2011), Measuring the Information Society, ITU, Geneva.

Jansen, J. (2010), Paying for Online Content, Pew Internet \& American Life Project, www.pewinternet.org/ / media/Files/Reports/2010/PIP-Paying-for-Online-Content_final.pdf.

Netflix (2011), Netflix's letter to shareholders Q2 2011, 25 July 2011, Netflix.com.

Nielsen (2010), The Increasingly Connected Consumer: Connected devices, a look behind the growing popularity of iPads, Kindles and other devices, September 2010, http://blog.nielsen.com/nielsenwire/consumer/ the-connected-devices-age-ipads-kindles-smartphones-and-the-connected-consumer/.

Nielsen (2011), NMIncite, a Nielsen/McKinsey Company, State of the Media: The Social Media Report, Q3 2011, http://cn.nielsen.com/documents/Nielsen-Social-Media-Report_FINAL_090911.pdf.

Nielsen (2012), Smartphones Account for Half of all Mobile Phones, Dominate New Phone Purchases in the US, March 2012, http://blog.nielsen.com/nielsenwire/online_mobile/smartphones-account-for-half-of-allmobile-phones-dominate-new-phone-purchases-in-the-us/.

OECD (2007), Participative Web and User-Created Content: Web 2.0, Wikis and Social Networking, OECD Publishing. doi: http://dx.doi.org/10.1787/9789264037472-en.

OECD (2008), OECD Information Technology Outlook 2008, OECD Publishing. doi: http://dx.doi.org/10.1787/it_outlook-2008-en.

OECD (2010), OECD Information Technology Outlook 2010, OECD Publishing. doi: http://dx.doi.org/10.1787/it_outlook-2010-en.

OECD (2011), The Future of the Internet Economy: A Statistical Profile, June 2011 Update, OEDE, Paris.

OECD, ISOC, UNESCO (2012), “The Relationship Between Local Content, Internet Development and Access Prices", OECD, Paris, www.oecd.org/dataoecd/9/8/50305352.pdf.

PepsiCo: Media and Press Release https://www.pepsico.com/Media/Articles.html.

PwC (PricewaterhouseCoopers) (2011a), Annual Global Entertainment and Media Outlook report 2011-2015, PwC, London, www.pwc.com. 
PwC (2011b), Harnessing the Power of Crowdsourcing, PwC, London, www.pwc.com/en_US/us/peoplemanagement/assets/crowdsourcing-paper.pdf.

PwC (2011c), IAB Internet Advertising Revenue Report: First Six Months Results September 2011, PwC, London, www.iab.net/media/file/IAB-presentation-HY2011_FINAL.pdf.

Technorati (2011), Technorati Top 100 (blogs), May 2011, http://technorati.com/blogs/top100/.

Top Ten Reviews (2011), Movie Download Review, http://movie-download-review.toptenreviews.com, (accessed October 2011).

Westoff, C.F. and A. Bankole (1999), Mass Media and Reproductive Behavior in Pakistan, India, and Bangladesh, Demographic and Health Surveys Analaytical Report No. 10, DHS, Calverton, USA, www.measuredhs.com/pubs/pdf/AR10/AR10.pdf.

YouTube (2010), Key YouTube Stats @ 5 years, GooglePress, https://sites.google.com/a/pressatgoogle.com/ youtube5year/home/5-year-metrics.

Zenith Optimedia (2011), Global Ad Expenditure Continues to Grow Despite Stock Market Turmoil. Press release, 4 October 2011, www.zenithoptimedia.com. 


\section{Chapter 6}

\section{ICTs for health and ageing}

This chapter examines recent trends in information and communication technologies for health and ageing. The use of ICTs in the health sector still lags behind many other parts of the economy in most OECD countries, yet the advantages and potential savings are evident. The ability of health ICTs to deliver better health in addition to an economic growth dividend is motivating significant public investment. Most efforts in recent years have focused on fostering the adoption of electronic health records (EHRs) by general practitioners and in hospitals. But the potential applications for health extend well beyond EHRs. Telehealth is increasingly seen as an important tool for enhancing healthcare delivery, particularly in rural and remote areas where healthcare resources and expertise are often scarce or even non-existent. Mobile health applications and social networks also provide unique and unprecedented opportunities for empowering patients and addressing the growing needs of ageing populations. Without question, there are challenges ahead in the evolution of the ICT health ecosystem. As business models change, the issues of privacy, security and quality of service are becoming increasingly important. Continued commitments to broadband, open standards and interoperability are essential for successful change. 


\section{A broad range of health ICT initiatives}

Many OECD governments see investment in health ICTs as part of the inevitable modernisation of healthcare systems, and view "e-health as the cost of doing business in 21st century healthcare" (AHIC, 2008). An extensive study completed by the OECD (2010) identifies the range of potential applications and benefits from ICT implementation. The study classifies these benefits according to four broad, inter-related objectives:

- Increasing quality of care and efficiency.

- Reducing operating costs of clinical services.

- Reducing administrative costs.

- Enabling entirely new modes of care.

A wide range of ICT systems can play a role in addressing these objectives. One example is electronic health records (EHRs). These enable timely access and better transmission of medical information across the healthcare continuum, thereby making patient care more responsive and efficient. Effective use of EHRs can also help evaluate the quality of healthcare interventions at the practice level, and assist with clinical research and effective public health planning. Much recent literature addresses the experiences of specific organisations and providers in implementing EHRs and other related applications, including e-prescriptions and computerised physician order entry (CPOE) systems (Chaudry et al., 2006; Scott et al., 2005; Shekelle and Glodzweig, 2009). The overall consensus is that, given the right conditions, health ICTs can drive improvements in quality and efficiency in healthcare.

The potential of ICT applications for health extend well beyond EHRs. For example, telehealth is increasingly viewed as an important tool for enhancing healthcare delivery, particularly in rural and remote areas where healthcare resources and expertise are often scarce or even non-existent. Mobile health applications and social networks provide unique and unprecedented opportunities for empowering patients and addressing the growing needs of ageing populations. Health ICTs that support self-management (e.g. personally controlled health records, smartphones, social networks) allow individuals to actively participate in making better-informed decisions about their own healthcare, and thus have an important and growing role to play in addressing the "information asymmetry" between healthcare providers and consumers/patients.

ICTs are opening up possibilities of entirely new ways of delivering care. OECD governments have recognised this potential and are significantly leveraging these technologies to pursue a range of health system reforms (e.g. primary care renewal, pay for performance, etc.). A number of countries have also made initial attempts to extend action into the social care sector for greater integration of the social and healthcare sectors. 
A recent review of 27 EU countries (Hämäläinen et al., 2008) found that most governments in these countries had formulated specific strategies about their intentions and priorities in the field of e-health. ${ }^{1}$ The most commonly stated policy targets in the strategic plans reviewed were: efficiency, improving or reforming the healthcare system, improving quality of care, and promoting citizen/patient-centred services.

In $13 \mathrm{EU}$ countries, e-health is one of several topics collected under the umbrella of broader information society goals (eHealth ERA, 2007). In 2004, as part of the overarching e-Europe strategy, the European Commission adopted the E-health Action Plan. The Plan states that "e-health tools or solutions include products, systems and services that go beyond simply Internet-based applications. They include tools for both health authorities and professionals, as well as personalised health systems for patients and citizens" (EC, 2004).

The Action Plan is now firmly embedded within the i2010 policy framework for Europe. The first of its three pillars include the targets "social inclusion, better public services and quality of life", and the actions in the Plan touch on all these areas and complement the related flagship initiative "Ageing Well in the Information Society".

Through the Europe i2020 strategy framework and its "Innovation Union" flagship initiative, the European Commission aims to improve conditions and access to finance for research and innovation, and in particular, to promote innovation in addressing major social challenges. The Commission selected European Innovation Partnerships (EIPs) for Active and Healthy Ageing (AHA) as a pilot area.

In Australia, health ministers agreed upon a National E-Health Strategy, launched in 2008. This strategy is a useful guide to the further development of e-health in Australia, and adopts an incremental and staged approach to developing e-health capabilities:

- Leverage existing capacity and resources in the Australian e-health landscape.

- Manage the underlying variation in capacity across the health sector, states and territories.

- Allow scope for change as lessons are learned and technology is developed further.

The strategy reinforces existing collaboration among Commonwealth, state and territory governments on the core foundations of a national e-health system, and identifies priority areas where collaboration can be progressively extended to support health reform. It also provides sufficient flexibility for individual states and territories and the public and private health sectors to determine implementation strategies within a common framework, and set of priorities to maximise benefits and efficiencies.

The lead agency for e-health implementation in Australia is the National E-Health Transition Authority (NEHTA). Its focal initiatives, as of 2011, are based upon five strategic priorities:

- Deliver, operationalise and enhance the essential foundations required to enable e-health.

- Operationalise and enhance the national Healthcare Identifiers service.

- Deliver and operationalise the National Authentication Service for Health (NASH).

- Operationalise and enhance a National Clinical Terminology and Information Service (NCTIS).

- Operationalise and enhance a secure messaging product for health information transfer. 
In the United States, the Office of the National Coordinator (ONC) for Health Information Technology is at the forefront of the administration's health IT efforts. ONC is organisationally located within the Office of the Secretary for the US Department of Health and Human Services (HHS). The position of National Coordinator was created in 2004, through an Executive Order, and legislatively mandated by the Health Information Technology for Economic and Clinical Health (HITECH) Act as part of the American Recovery and Reinvestment Act of 2009. HITECH represents the most visible and expansive public sector driver of health information technology in the United States to date. The centrepiece of this legislation, known as the "meaningful use" programme, creates financial incentives for individual providers and hospitals to use certified EHRs and begin to engage in health information exchange.

In 2008, ONC released the Coordinated Federal Health IT Strategic Plan: 2008-12. The plan has two overarching goals, patient-focused healthcare and population health, with four objectives under each goal and 43 strategies that describe the work needed to achieve each objective. The themes of the four objectives are privacy and security, interoperability, IT adoption and collaborative governance. As a group, the strategies are characterised by:

- Commitment to the engagement of multiple stakeholders across the public and private sectors.

- Concern for reliability, confidentiality, privacy, and security when exchanging, storing and using electronic health information.

- Focus on the consumer of healthcare as a critical participant in achieving the two overarching goals of the Strategic Plan.

In Canada, the government established an independent, not-for-profit corporation, Canada Health Infoway, to accelerate the development and adoption of information technology. Since 2001, it has received over CAD 2 billion in funding to distribute (as a strategic co-investor) with provinces and territories for the implementation of electronic health information systems such as diagnostic imaging, telehealth and client and provider registries. The projects are managed with a view to broadly sharing findings among jurisdictions to avoid needless duplication.

Canada Health Infoway also funds and manages the Standards Collaborative, a national body that provides leadership, expertise and core services to support the development, maintenance and implementation of pan-Canadian health information standards.

In 2003, Canada Health Infoway released the EHR Solution Blueprint. This reflects agreement between Canada Health Infoway and its stakeholders upon a common business and technical framework for EHR and other health ICT capabilities, including the use of standards. A companion document, EHRS Privacy-Security Conceptual Architecture, covers the issues of privacy and security in the healthcare context.

In Japan, the government released a "New IT Reform Strategy" (2006), followed by a "New IT Reform Strategy Policy Package" (2007) and a "Priority Policy Program" (2008), which includes directions on realising the objectives set forth in the strategy. These objectives are (IT Strategic Headquarters, 2008):

- Promote organised and effective computerisation for all medical, healthcare, nursing care and social welfare fields.

- Support advanced preventative healthcare and evidence-based medicine by utilising health information and high-quality medical care. 
- Realise full transition to online medical insurance claims.

- Realise more effective communication in healthcare and improved care coordination.

- Realise a social security card that will act as a pension book, health insurance card and nursing-care insurance card.

- Realise an environment that enables citizens to obtain, review and utilise their own health and social information with security and ease (personally controlled health records and patient-centred care).

This brief overview of international strategic plans and initiatives illustrates the strong and growing public commitment to ICTs in the health sector. Notwithstanding the differences in approach across countries, the key policy concerns driving greater use of ICTs in the health and social sectors are broadly similar:

- Patient safety and quality concerns in the provision of healthcare, particularly in remote areas.

- Greater need for efficiency and accountability in terms of clinical performance and value for money (evidence-based care).

- The growing health workforce crisis.

- Changing demographics and shifting epidemiological profiles (ageing) contributing to a rise in chronic conditions.

- The need for improved prevention and monitoring.

An increased drive towards integration of services is also emerging across countries internationally, connecting traditional community, primary, secondary and specialist/ tertiary services. This enables patients and their families to experience healthcare as a single system rather than as a series of poorly coordinated "settings".

In addition to these health-related objectives, most OECD governments recognise the potential opportunities of health ICTs as a new source of economic growth. For example, e-health is one of the six market areas in the European Lead Market Initiative. The e-health sector includes a number of large European-based companies of specialised e-health solutions that are world leaders in their fields, as well as an estimated 5000 European small and medium-sized enterprises (SMEs) that operate in the various sub-sectors of e-health. The health sector in the European Union employs almost $10 \%$ of the total workforce and corresponds to almost 9\% of GDP.

\section{Growing public investment in health ICTs}

The ability of health ICTs to deliver better health and, at the same time, an economic growth dividend is motivating substantial public investments. Investment costs are difficult to determine, but the collected evidence seems to indicate that governments are taking on an increasingly larger share of implementation costs, so as to ensure that the potential benefits of health ICTs are realised.

Costs estimates reported by the OECD (2010) were approximate, as it can be difficult to separate health ICT costs within overarching budgets. In some cases, national and local projects are phased and only the budgets for the first phase, the feasibility study, can be estimated. Actual budgets clearly depend on the final scope of the projects. The sums indicated may be a mix of capital or operational expenditure and may or may not include purchase and implementation costs, such as training. Notwithstanding these difficulties, 
the following table provides estimates of budgets for 2008-09 of three major national ICT agencies funded by governments (Table 6.1). Government funding is in the range of $0.1 \%$ to $0.3 \%$ of total expenditure on health in the three countries with investment per capita varying from USD 7 to USD 14. Australia's per capita investment has risen as a result of its 2010-11 budget announcements on e-health.

Protti (2007) reported approximate total investment costs per capita ranging from an estimated USD 129 in Canada to USD 552 per enrolee in Kaiser Permanente (United States) with the level of investment varying with the degree of sophistication of the system. Anderson et al. (2006), developed similar estimates for six countries including Canada and the United Kingdom. The relatively large per capita health ICT investment in the United Kingdom is striking in both the Protti and Anderson estimates, as well as those of the OECD (Table 6.2). Although well within the range of the per capita costs of Kaiser Permanente, it stands out in comparison with other countries.

\section{Table 6.1. Current budget for ICT initiatives in three OECD countries}

\begin{tabular}{lccc}
\hline & United States & Canada & Australia \\
\cline { 2 - 4 } Agency/Initiative & $\begin{array}{c}\text { Office of the National } \\
\text { Coordinator }\end{array}$ & $\begin{array}{c}\text { Canada Health } \\
\text { Infoway }\end{array}$ & $\begin{array}{c}\text { Australian Government } \\
\text { Department of Health } \\
\text { and Ageing }\end{array}$ \\
\hline Total expenditure on health (million USD PPP) and \% of GDP & 2450164 & 155566 & 80581 \\
Current budget for ICT initiatives (million USD at exchange rate) & $17.6 \%$ of GDP & $11.4 \%$ of GDP & $9.1 \%$ of GDP \\
Current investment per capita (USD) & $2061^{1}$ & $455^{2}$ & $268^{3}$ \\
13.5 & 6.7 & 12.2 &
\end{tabular}

Note: Data in this table refer to 2009 and for Australia, 2009-10. Data for total expenditure are expressed in million USD PPP ( for more details see OECD Health database).

1. The current budget for fiscal year 2009 includes American Recovery and Reinvestment Act funds (ARRA).

2. The current budget figure does not include provincial/territorial investments in e-health initiatives, made on their own, or in collaboration with Canada Health Infoway. Infoway projects are cost-shared with the provinces/ territories (typically Infoway: 75\%, provinces/territories: 25\%). Data for 2009, exchange rate: USD $1=$ CAD 1.10 .

3. Data for 2009-10, exchange rate: USD 1 = AUD 1.1476.

Sources: Based on OECD Health database, 2012; US Department of Health and Human Services, Fiscal Year 2010, Office of the National Coordinator for Health Information Technology; Canada Health Infoway, "Building a Healthy Legacy Together", Annual report 2008/09; Australian Institute of Health and Welfare, "Australia's health 2010".

StatLink ants http://dx.doi.org/10.1787/888932695051

The fact that the total costs reported for the UK programme run through 2015 may in part explain this high figure. In addition, the total includes central costs paid and recorded by "NHS Connecting for Health", as well as estimates of the local costs incurred in deploying the systems. Although the UK National Audit Office (2008) has suggested that local costs are underestimated, it appears that, unlike many other countries, both the United Kingdom and the United States may have more realistic estimates of total health ICT costs given the top down and centralised nature of their programmes.

The costs in implementing health ICT solutions are incurred up front, and the benefits, both financial and clinical, are not always immediately realised. It takes a long time to reach the level of functionality needed to truly serve the needs of clinicians and purchasers. The evidence produced by a review of Canadian investments into ICT (Canada Health Infoway, 2005) estimates a strongly positive social return on investment over a 20-year period. 
Table 6.2. Total budget allocated by national government in two OECD countries

\begin{tabular}{lcc}
\hline & Canada & United Kingdom \\
\cline { 2 - 3 } Agency/lnitiative & Canada Health Infoway & $\begin{array}{c}\text { NHS Connecting for Health } \\
\text { Programme (2002-15) }\end{array}$ \\
\hline Total expenditure on health (million USD PPP) and \% of GDP & 145566 & 208864 \\
Total budget allocated (million USD at exchange rate) & $11.4 \%$ of GDP & $9.8 \%$ of GDP \\
Total investment per capita (USD) & $1430^{1}$ & $20633^{2}$ \\
\hline
\end{tabular}

Note: Data in this table for total expenditure are expressed in million USD PPP (for more details see OECD Health database) and refer to 2009 .

1. The budget figure does not include provincial/territorial investments in e-health initiatives, made on their own, or in collaboration with Canada Health Infoway. Infoway projects are cost-shared with the provinces/territories (typically Infoway: 75\%, provinces/territories: 25\%). As of March 2009, exchange rate: USD 1 = CAD 1.10.

2. As of December 2015, exchange rate: USD $1=$ GBP 0.61.

Sources: Based on OECD Health Data, 2012; Canada Health Infoway (2009), "Building a Healthy Legacy Together", Annual report 2008/09; National Audit Office (2008).

StatLink Aillst http://dx.doi.org/10.1787/888932695070

\section{Building broadband capacity for health ICTs}

High-speed and universal networks are essential to obtain the full benefits of ICTs in health. Dial-up connections of 56 kilobits per second (kbit/s) or broadband connections of $256 \mathrm{kbit} / \mathrm{s}$ are too slow for many important online applications, for example, remote monitoring of patients with long-term chronic conditions, or near real-time exchange of high-resolution images and other rich media content between health providers.

Broadband refers to high-speed, always-on Internet access with the capacity to transfer large amounts of information. Broadband access has many potential benefits for the health sector. Investment in broadband and next generation networks is a priority across all OECD countries, and the European Commission has included broadband as a central item in its Digital Agenda for Europe (the EC strategy on the Information Society up to 2020).

According to a recent EC survey (2011), practically all hospitals in EU27 countries are connected to broadband (92\%), although significant variations exist in the bandwidth employed. For example, $100 \%$ of hospitals in Denmark have broadband speeds over $50 \mathrm{Mbit} / \mathrm{s}$, compared to only $20 \%$ in Greece. Narrowband is still present in hospitals in several European countries. For example, $67 \%$ of hospitals surveyed in Iceland and over $27 \%$ of hospitals in Bulgaria had narrowband. On average, half of European hospitals surveyed had a bandwidth below $50 \mathrm{Mbit} / \mathrm{s}$ (52\%). Low bandwidth limits the range of ICT technologies that can be used and, consequently, the quality of outcomes compared to those achievable using higher speed platforms.

Other OECD countries including the United States and Australia report similar constraints. Australia recently launched the National Broadband Network ${ }^{2}$ (NBN), which will offer high-speed broadband to $93 \%$ of Australian homes, schools and business via fibre optic cabling, and connect the remaining $7 \%$ of premises via a combination of next-generation, high-speed wireless and satellite technologies. These next-generation wireless and satellite technologies represent a significant step-change over speeds currently experienced by users of those technologies. The United States has similar aims with its National Broadband Plan, ${ }^{3}$ which includes four actions: 1 ) promote world-leading mobile broadband infrastructure and innovation; 2) accelerate universal broadband access and adoption, and advance national purposes such as education and healthcare; 3 ) foster 
competition and maximise consumer benefits across the broadband ecosystem; and 4) advance robust and secure public safety communications networks.

In summary, broadband use is widespread, but limited availability of higher speed broadband or applications is restricting the potential of health ICTs. There is room for improvement with regard to the implementation of next generation broadband ( $>100 \mathrm{Mbit} / \mathrm{s}$ ) and actions are being taken to address this situation.

Figure 6.1. Type of Internet connection in hospitals

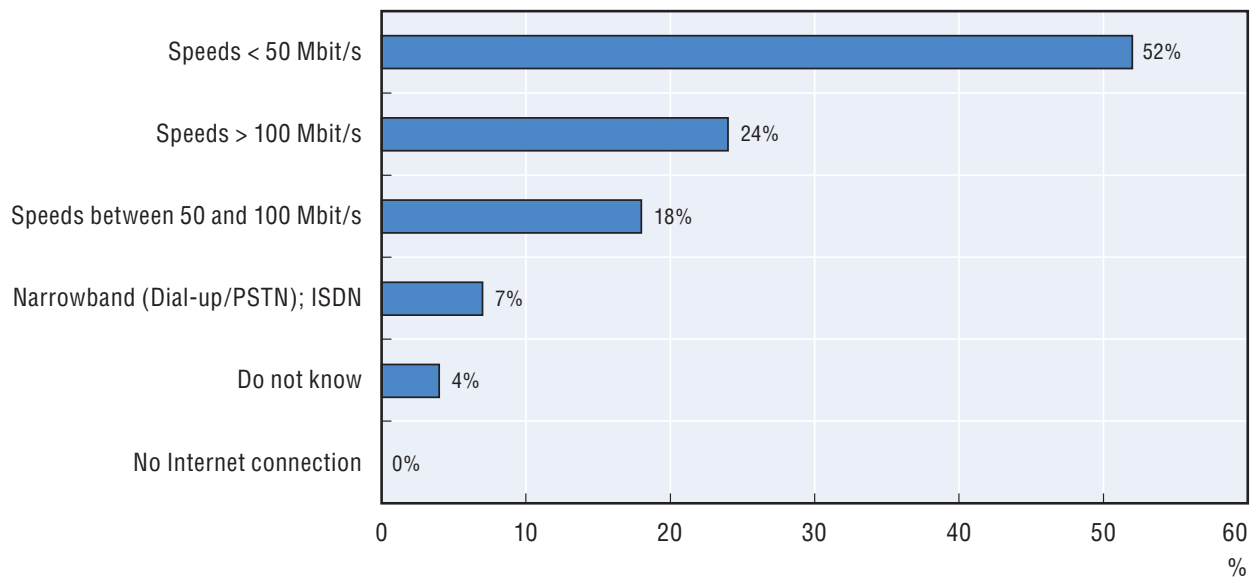

Source: European Commission - eHealth Benchmarking III - Deloitte \& Ipsos 2011.

StatLink त्ताड़ी http://dx.doi.org/10.1787/888932694386

\section{Extending broadband to rural areas}

Obtaining access to health services is a significant problem for many residents of rural communities, many of whom often have to travel to receive even routine diagnosis and treatment or relocate to utilise these services. As discussed in the next sections, a range of health-related ICTs, and specifically telehealth, combined with picture archiving and communications systems (PACS), can be used to great effect in areas with large rural or remote populations, to reduce the impact of physician shortages, reduce the need for travel and/or relocation to an urban hospital and associated costs, and improve access to care. However, rural areas in numerous OECD countries are still significantly disadvantaged when it comes to access to broadband in relation to their urban peers. Connecting these areas is crucial to enable them to benefit from changes in healthcare technology. Fixed wireless access is available in some rural areas, however, dependence on available spectrum means that this is not always a viable solution (Box 6.1).

To bridge the gap, governments across OECD countries are putting in place a range of special funds and programmes to extend broadband in rural areas. For example, in 2010 the United States Federal Communications Commission initiated a pilot funding programme to facilitate the creation of a nationwide broadband network dedicated to healthcare, connecting public and private non-profit healthcare providers in rural and urban locations. 


\section{Box 6.1. Getting broadband to physicians' offices in rural British Columbia}

The geography of Canada is extremely diverse and population distribution varies greatly. The country has a long history of leveraging communications technologies to overcome the challenges of its vast geography, sparse population and difficult terrain. Through strategic public policy initiatives, the Canadian government has created a framework that has facilitated the pervasive deployment of radio, telephone, television and cable throughout the country.

The basic premise fuelling such public policy initiatives is that these technologies and services offer important social and economic benefits for Canadians, and thus every citizen should have the opportunity to access them at a reasonable price. However, getting broadband across the most rural and remote areas remains a significant challenge. Optical networks are not widely available in remote regions and may never become widely available in the far north. The cost of fibre optic network installation and the required return on invested capital (both in terms of investment recovery and the leveraging of invested capital) might never make such installations viable for commercial carriers.

As a result, many rural communities in British Columbia lack easy access to broadband connectivity. The required quality of service and security needed to support the types of applications beneficial to physicians can be technically out of reach or too expensive for individual physicians to acquire. Northern Health in British Columbia recognised these barriers and the programme "Physician Connect" worked to overcome them.

The Northern Health Authority purchased its own spectrum and chose to employ a licensed microwave technology fast enough to support instant downloads of web-based information and able to support applications such as video-conferencing.

The system is relatively low-cost. Northern Health used a CAN 1.2 million grant from the federal government's Primary Healthcare Transition Fund to set up the wireless infrastructure. This investment is expected to provide service to the region's doctors for at least 10 years.

In 2008, the on-going operating costs to pay for the wireless spectrum rental were about CAN 25/month per doctor's office. In comparison, a physician's office in a large city could expect to pay on average CAN 50/month for an ADSL or cable line.

Source: OECD (2010).

\section{Telehealth}

Telehealth works by transmitting voice, data, images and information, rather than physically moving patients or health practitioners and educators. The aim is to improve access, timeliness and convenience, and reduce travel costs. Today, telehealth is used in many situations to overcome and redress workforce shortages and the often-skewed distribution of physicians and clinical specialists between rural and urban settings (Balamurugan et al., 2009; Jackson et al., 2005). Telehealth can enhance access to care for rural or remote patients with less common conditions, or those in need of specialist care, without the need for an increase in the number of specialists, many of which are under-represented in rural regions for a variety of reasons.

Improved access to specialty care can be life saving. For instance, in the Balearic Islands (Spain), telehealth is now used to deliver emergency stroke care to patients who live in remote areas without access to specialists care. During telestroke consultations, doctors in the emergency units of small clinical hospitals consult with stroke specialists and decide whether to administer tissue plasminogen activator (tPA) treatment within a 
crucial three-hour window (tPA can cause dangerous bleeding in the brain if administered after three hours). Results on outcomes show that the efficacy and safety of telestroke is comparable with face-to-face care. Use of telestroke services also seems to reduce inappropriate variations in practice (Schwab et al., 2007; Wechsler, 2008).

The introduction of telehealth in Canada has enabled assessments of patients in rural areas closer to home. A recent study by Canada Health Infoway showed that, as of the end of the 2009-10 fiscal year, Canada had 5710 telehealth systems in place in at least 1175 communities (Praxia/Gartner, 2011). Many of these systems serviced 21\% of the Canadian population who live in rural or remote areas. There were nearly 260000 telehealth events in Canada in 2010: jurisdictions reported 187385 clinical events, 44600 educational events and 27538 administrative events, as well as nearly 2500 patients receiving telehomecare (Figure 6.2).

\section{Figure 6.2. Total number of telehealth sessions performed in Canada, 2010}

Number in the last 12 months

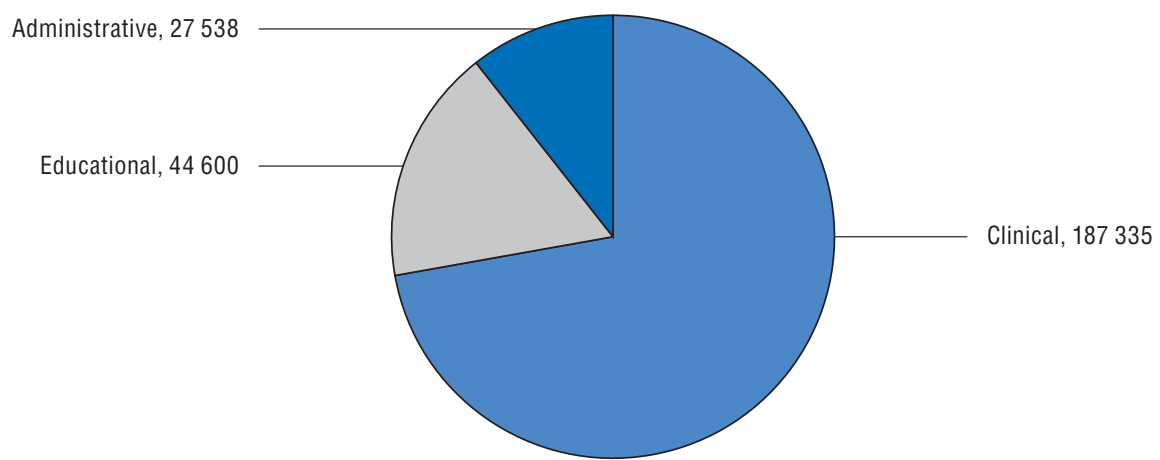

Source: Based on Praxia/Gartner (2011); Quebec data and Alberta administrative numbers were collected.

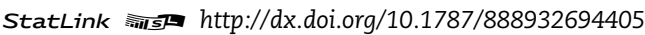

The province of Ontario has the largest telehealth programme in Canada, accounting for more than half of reported telehealth events. Telehealth has many clinical applications throughout Canada. Three clinical service areas generated about $73 \%$ of measured telehealth clinical sessions: mental health (including addictions, forensic mental health, general mental health services, psychiatry, psychology and psychometry) accounted for $54 \%$; internal medicine, $15 \%$ and oncology, 13\%. The extent of use varies from small pilot projects to well-established clinical services. Estimates for the last five years give an annual growth rate of over $35 \%$ for telehealth nationally. Assuming two scenarios of growth, at $20 \%$ and $40 \%$ per year, Canada Health Infoway predicts that 1.2 million consultations could be reached within five to ten years, with benefits to the health system valued at approximately CAN 730 million, and an additional CAN 440 million in cost avoidance for patients.

In Australia, telemedicine is a critical component of the country's strategic plans for delivering care to the indigenous population (OECD, 2010; Western Australia Country Health Services, 2007). In 2012, the Australian National Broadband Network (NBN) launched the NBN-Enabled Telehealth Pilots Program, which will provide up to AUS 20.6 million for innovative telehealth pilots over the next two years.

Widespread adoption of telehealth is, however, not yet a reality. A host of factors have slowed the expansion of telehealth, including limited reimbursement, legal and regulatory 
barriers, limited provider capacity, and a lack of general public knowledge and/or acceptance of telehealth technologies and services. The importance of adequate broadband infrastructure will continue to play a significant role as telemedicine continues to expand.

\section{Electronic medical claims processing}

Electronic billing is a smart process that aims to trim the substantial administrative costs of the medical claims review, prevent fraud and monitor outcomes.

Medical claims have to be reviewed for accuracy and authenticity before payment. Reimbursement services and insurance companies employ physicians and, at times, attorneys to review claims to establish their validity. Such evaluation involves close scrutiny of medical records and comparison with medical bills, an intricate and time-consuming task. ICTs can improve the productivity and efficiency of this process. Electronic claims records document many aspects of the process and outcome of medical care, and can also be used to assess quality of care, for example, by helping to identify hospitals that may benefit from programmes to reduce patient readmission rates.

In one case study, experts in Massachusetts (United States) reported large administrative cost savings as a result of introducing electronic claim processing through the New England Healthcare Electronic Data Interchange Network (NEHEN), a consortium of providers and payers established in 1997. After the introduction of NEHEN, insurance claims previously costing on average USD 5.00 per paper transaction were processed electronically at 25 cents per transaction. By 2006, the network was processing more than 4.5 million claims submissions every month, representing $80 \%$ of all transactions in the State of Massachusetts. Intensive use of NEHEN has significantly reduced cumulative annual administrative costs for members. For example, the healthcare provider Baystate Health was able to save more than USD 1.5 million through lowered transaction fees in less than three years (September 2006 to April 2009). Savings are driven in large part by administrative simplification and significant reductions in the time taken to manually process billing and claims-related information (OECD, 2010).

Despite the evidence of cost reductions, however, an estimated $35 \%$ to $40 \%$ of US physicians still relied on paper claims submissions in 2009. Although the level of savings observed in the United States may not be a good predictor of expected gains in other OECD countries, particularly in single-payer healthcare systems, streamlining claims and payment processing through ICTs is today widely recognised as a cost-effective way to realise considerable administrative efficiencies.

For example, online claiming became available in Australia in 2002 with the introduction of Medicare Online. The latest Medicare Australia software releases for electronic claiming were developed as a collaborative effort between Medicare Australia, private health funds, medical peak bodies, billing agents, hospitals, health departments and software vendors. Online claiming software is integrated directly into practice management software and uses the Internet to lodge claims with Medicare Australia. Healthcare providers can know immediately if a transmission has been delivered or not. The Australian online claiming solution uses Public Key Infrastructure (PKI) to ensure the security of communications across the health sector. This technology ensures data transmitted to Medicare Australia can be identified, and that the data will be secure and private. PKI secures online communications using digital certificates, electronic identity documents that are used to digitally sign and encrypt electronic transmissions. 
In Korea, all hospital bill requests are completed through an Electronic Data Interchange (EDI) system implemented in 2003 (HIRA, 2010). Each year, the Health Insurance Review and Assessment Service (HIRA) manages a flow of nearly 1.2 billion cases of hospital bill requests. In 2010, the number of claims was 1.3 billion. All the data is transferred and stored in HIRA's medical information system. With 1751 staff assigned to the review process, HIRA is able to process over $40 \%$ of these bills electronically. HIRA is planning to increase electronic review in the next four years to $65 \%$ to maximise efficiency and simplify the process.

Figure 6.3. Percentage of claims processed electronically by HIRA, Korea, 2003-09

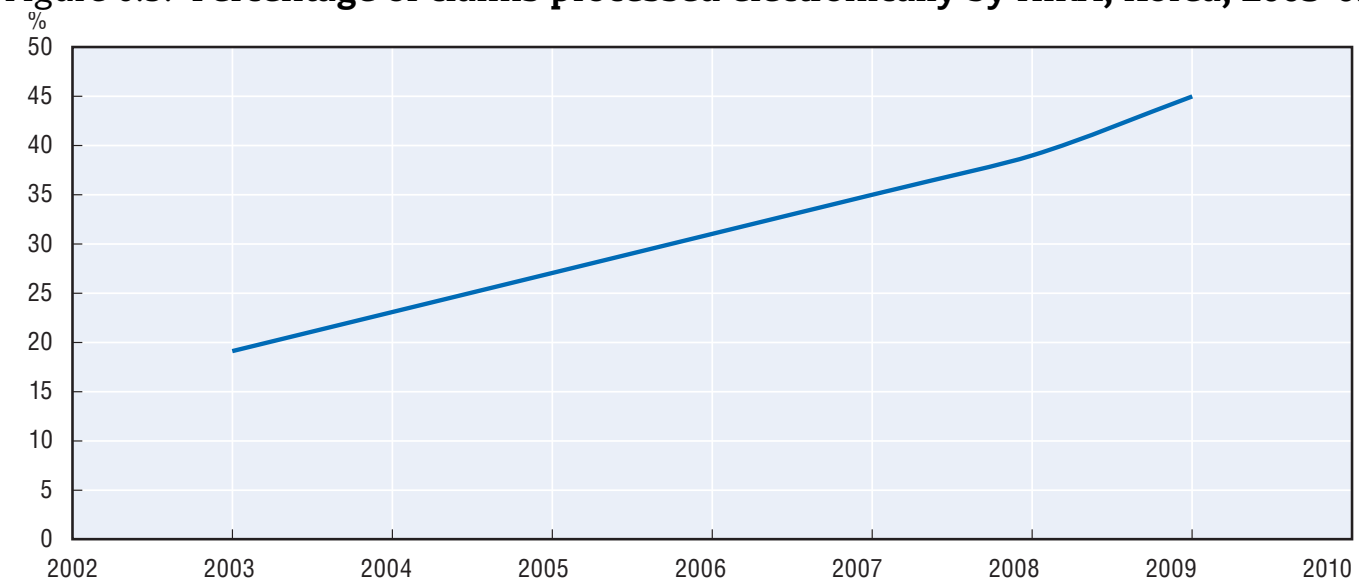

Source: Health Insurance Review and Assessment Service - Korea (2011).

The Japanese government began promoting online processing for medical claims in 2006. All medical institutions have been asked to adopt this online system by 2012. The objective is to increase the productivity of the claims review process.

Pilot projects began in 2006 and involved more than 12 large hospitals and their regional screening and payment institutions. The government provides 30 Yen (about USD 0.25) per medical bill claim to each medical institution as an incentive to use the online system (the incentive applies only to institutions that use the online system along with some other IT system). In addition, 35 million national health insurance e-cards have been issued in Japan since 2003, and the implementation of a personalised medical file is under consideration for 2011.

\section{Computerisation of general practices}

A recent focus of OECD country investments in health ICTs has been the computerisation of primary care. According to a recent survey of EU27 countries (EC, 2008), about $93 \%$ of practices with four or more general practitioners (GPs) and $84 \%$ of single GP practices used computers in 2008.

In the United Kingdom, GPs have used computers for clinical records, electronic prescribing and decision support since the 1980s with substantially growth in recent decades (Figure 6.4). All administration of practices, including medical audits and claims handling is dealt with electronically.

In 1990, the new GP contract required GPs to collect extensive data in order to maintain their practice income. This explains the sharp increase in growth around 1990 (Figure 6.4). The next period of growth related to GP fund holding, which again required 
Figure 6.4. Computerisation of GP practices in the United Kingdom

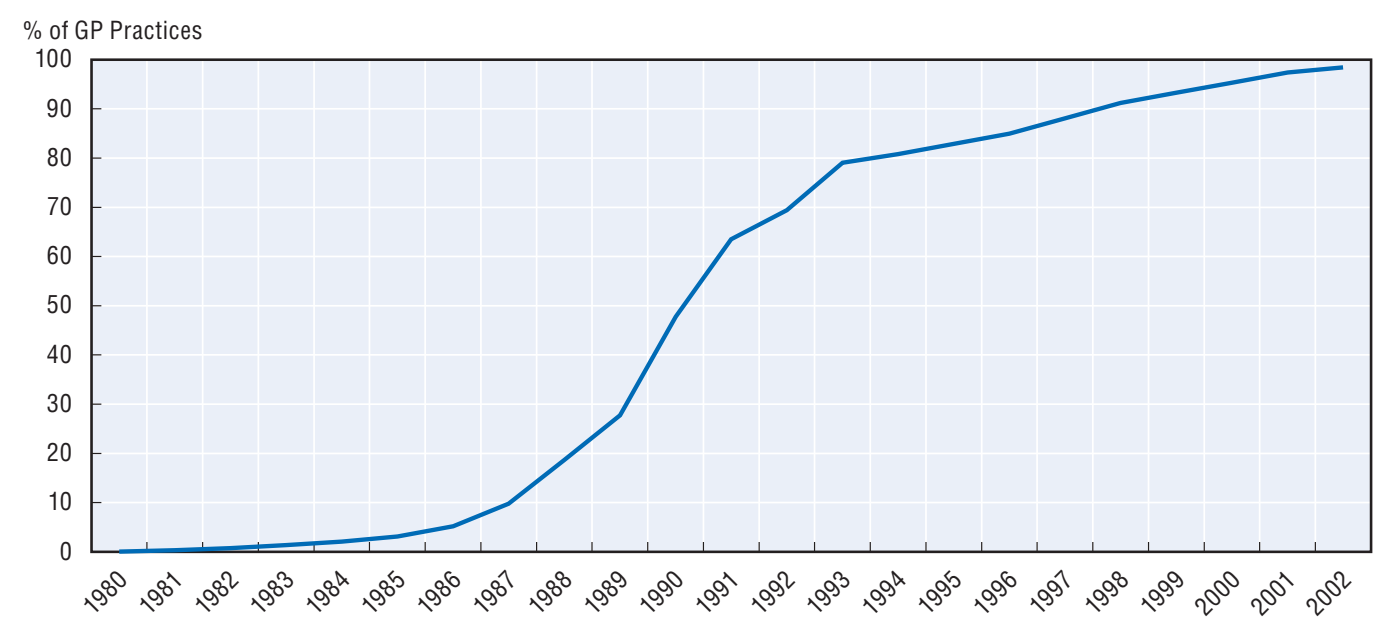

Source: Hayes et al. (2009), Independent Review of NHS and Social Care IT, commissioned by S. O'Brien, Chairman of the Review Group.

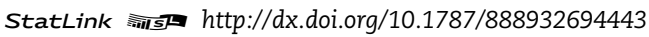

computers. By 2002, nearly all GPs in the United Kingdom were making use of IT solutions. Over $90 \%$ of GP-issued prescriptions were processed electronically, in other words, entered into the electronic medical record, checked by the IT systems and then printed on paper. A large proportion of GPs have ceased to use paper medical records, opting instead for electronic medical records (EMRs).

Close to $100 \%$ of GPs across the UK now use EMRs that share core functionalities of recording clinical notes, managing laboratory results and electronic prescribing. Similar high rates of EMR adoption and use were recently reported for Australia, New Zealand and The Netherlands (Figure 6.5) (Jha et al., 2008; Schoen et al., 2009).

Definitions of EMR and EHR vary significantly across countries. In Canada, the term EMR is used to refer to a partial health record under the custodianship of a healthcare provider(s), whereas the EHR is a complete health record that holds all relevant health information about a person over their lifetime. This is often described as a person-centric health record, and can be accessed by many approved healthcare providers or healthcare organisations. Despite these differences, there is, however, agreement on the high-level functionalities that comprise an EHR: 1) storage of patient data, 2) results management, and 3) clinical documentation. The majority of countries also include: 4) computerised order entry and 5) clinical decision support.

If compared according to these functionalities, the United States appears to lag behind other OECD countries (Jha et al., 2008; Schoen et al., 2009). Recent estimates of EHR adoption among outpatient providers range from 48\% to 52\% (Hsiao, 2009; MGMA, 2010) for any EHR, and around $25 \%$ for a basic system that includes clinical information, provider orders and imaging/laboratory results. Among US hospitals, adoption of basic EHRs stands at around 7.8\% to $11.4 \%$ (Blavin et al., 2010; Jha et al., 2009). However, the United States is among the leaders in certain categories of technology adoption, such as computerised provider order entry (CPOE) (Aarts and Koppel, 2009). There has also been more widespread adoption of individual EHR components, such as electronic medication lists $(46.6 \%)$ or clinical decision support (36\%-61\%) (Blavin et al., 2010). 
Figure 6.5. Use of electronic medical records by physicians in seven OECD countries, 2006 and 2009

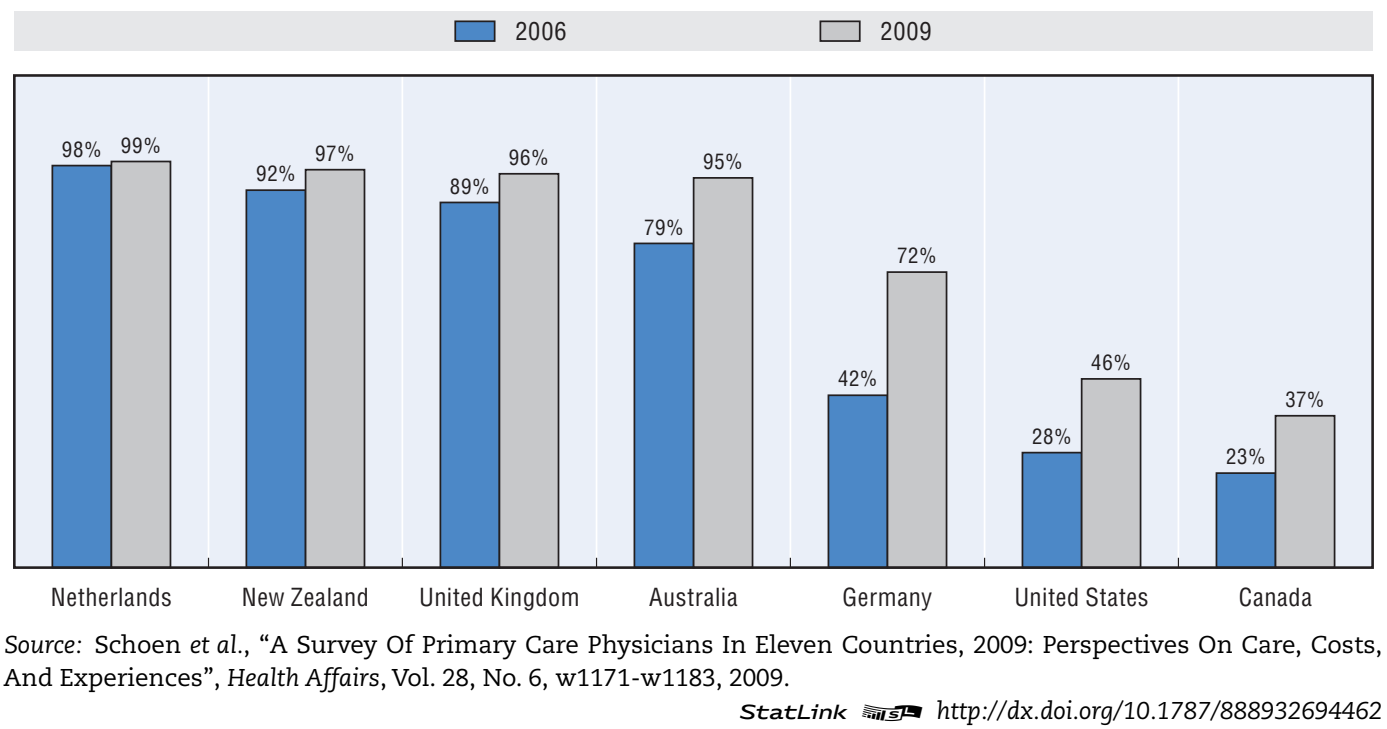

Uptake and use of EMRs across Canada (CMA, 2010) varies widely across provinces. While all jurisdictions acknowledge the need to support EMR adoption, only about half of Canada's 13 provinces and territories currently have formal programs in place, usually involving financial incentives for physicians. However, Canada's federal government provided significant funding to Canada Health Infoway in 2010 to work with all jurisdictions to help accelerate EMR adoption by physicians and nurse practitioners across the country. As a result, a number of EMR projects are now underway across the country.

National estimates of physician adoption (GPs and specialists) of EMRs range from $36 \%$ in 2009 (Schoen et al., 2009) to 50\% using EMRs at least some of the time (2010). While the uptake and use of EMRs by Canadian doctors remains limited, it continues to grow and few now question the need for EMRs in all physician offices as a prerequisite for a truly integrated and efficient healthcare system. Many provinces have, therefore, put in place funding to support and encourage EMR adoption.

According to Schoen et al. (2009), GP practices in Australia have reached nearly universal computerisation, with 95\% of GPs reporting the use of EMRs. By 2006, $89 \%$ of primary care practices were already reporting the use of computers for clinical purposes (McInnes et al., 2006). Most GP practices had computer software and hardware to perform administrative and clinical functions, and most (78.3\%) had a high-speed Internet connection. Over half of these practices $(55.6 \%)$ had received incentive payments (Medicare Australia Practice Incentive Payments) for the adoption of information technology/ information management applications, and nearly one third (31.5\%) had received payments through another incentive programme intended to stimulate broadband uptake (Broadband for Health). An earlier study by AC Nielsen (1998) found only 31.0\% of practices with computers, most of which were used only for administrative purposes (AC Nielsen, 1998). This statistics describe a rapid uptake in the use of computers to access crucial patient information at point of care and to support clinical decision in general practice over about half a decade from implementation of the incentive schemes. 


\section{Electronic prescriptions}

Electronic prescribing makes use of computer technology to simplify and improve the traditional paper-based prescribing process. Under an e-prescribing system, a care provider such as a doctor or a nurse enters information concerning a patient's medication into a computer system, and then electronically transmits that data to the retail or mail order pharmacy of the patient's choice. The pharmacy receives the data and can immediately begin the process of filling the prescription.

More advanced e-prescribing systems can be combined with decision support systems to help improve care in even more ways. These systems can provide detailed drug information to doctors to help them decide what medication is best for patients after reviewing their medical and drug history. The system can also provide warnings with regard to conflicting drugs, allergic reactions to a particular drug, and whether the prescription makes sense given a patient's medical history. In this way, e-prescribing can lead to safer, more informed prescribing, helping patients to receive the care that best fits their needs.

According to a recent survey of EU countries (EC, 2008), transmission of analytic results from a laboratory to the GP occurred with comparatively high frequency (40\%); however, on average, only $6 \%$ of GPs reported using e-prescribing, the exceptions being Denmark (97\%), Sweden (81\%), and The Netherlands (71\%).

In Sweden, the first large-scale e-prescription implementation effort began in Stockholm in 2001 (Astrand, 2007). It was launched by Apoteket, the country's sole wholesale pharmaceutical supplier, which had made a decision to move rapidly ahead with national deployment of e-prescription in cooperation with the different regional healthcare bodies and national players. Apoteket's ownership of all pharmacies in Sweden effectively eliminated the need for negotiations with individual pharmacies, while its standardised corporate pharmacy ICT systems also facilitated implementation. In just a little over seven years, Apoteket went from 100000 e-prescriptions (3\% of total) to over 2 million (66\% of total) (Figure 6.6).

Figure 6.6. E-prescription as a \% of total prescriptions in Sweden, by region, 2000-07 Percentage of total prescriptions
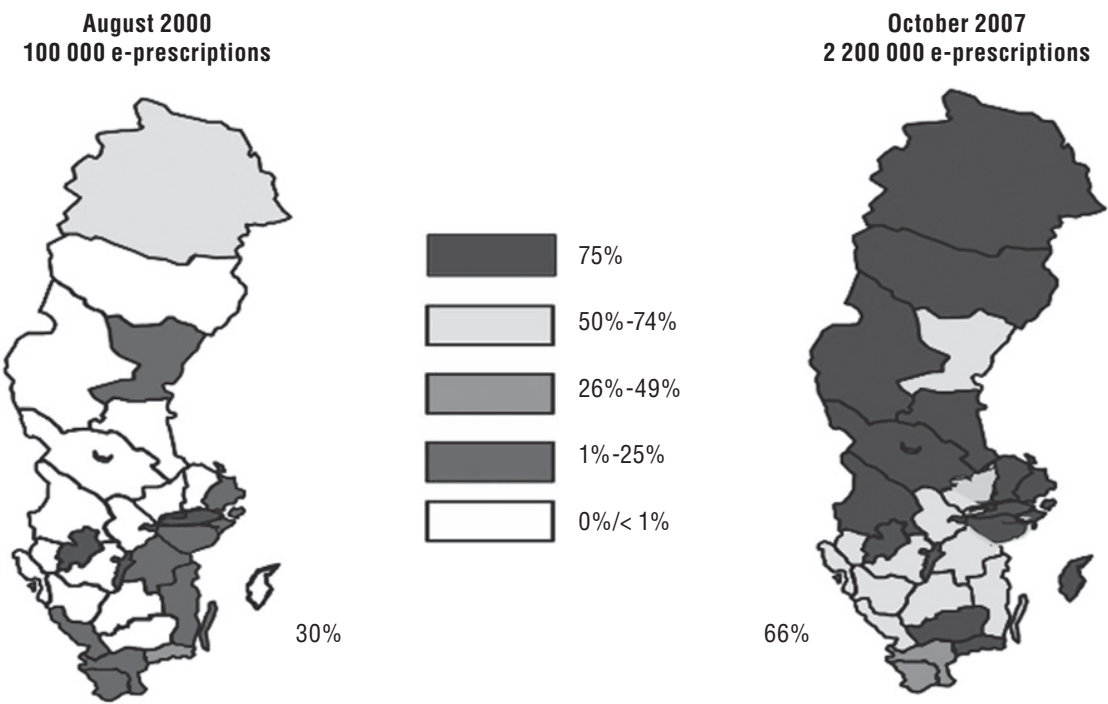

Source: Apoteket Sweden 2009; presentation to the OECD by B. Astrand. 
E-prescribing is also widespread in Australia with rates estimated at 93\%-98\% (Schoen et al., 2009, McInnes et al., 2006). In addition, close to 90\% of GPs use electronic decision support (McInnes et al., 2006).

\section{Health information exchange}

Cross-institutional electronic medical information exchange is still rare. While healthcare organisations have access to an ever-increasing number of information technology products, many of these systems cannot talk to each other, and health information exchange remains a serious problem. Electronic medical data exchanges outside the hospital with other providers are still not common in European acute hospitals. A full $54 \%$ of acute hospitals do not engage in electronic exchange of clinical care information, $57 \%$ do not exchange laboratory results, and $57 \%$ do not exchange medication lists (EC, 2011). This problem is common to all OECD countries, even those where deployment of EHRs has proven particularly successful. Finland has seen $100 \%$ adoption of EHRs in hospitals and nearly the same for primary care. However, electronic exchange of key documents such as referrals and discharge letters between these settings has lagged. EHR adoption and use levels are similarly remarkable in Norway, but in 2007 there was still a stark gap in the use of e-discharges and particularly e-referrals (Figure 6.7).

\section{Figure 6.7. Use of EHRs and electronic discharge and referrals by primary care centres in Finland and Norwegian Health Trusts, 2007}
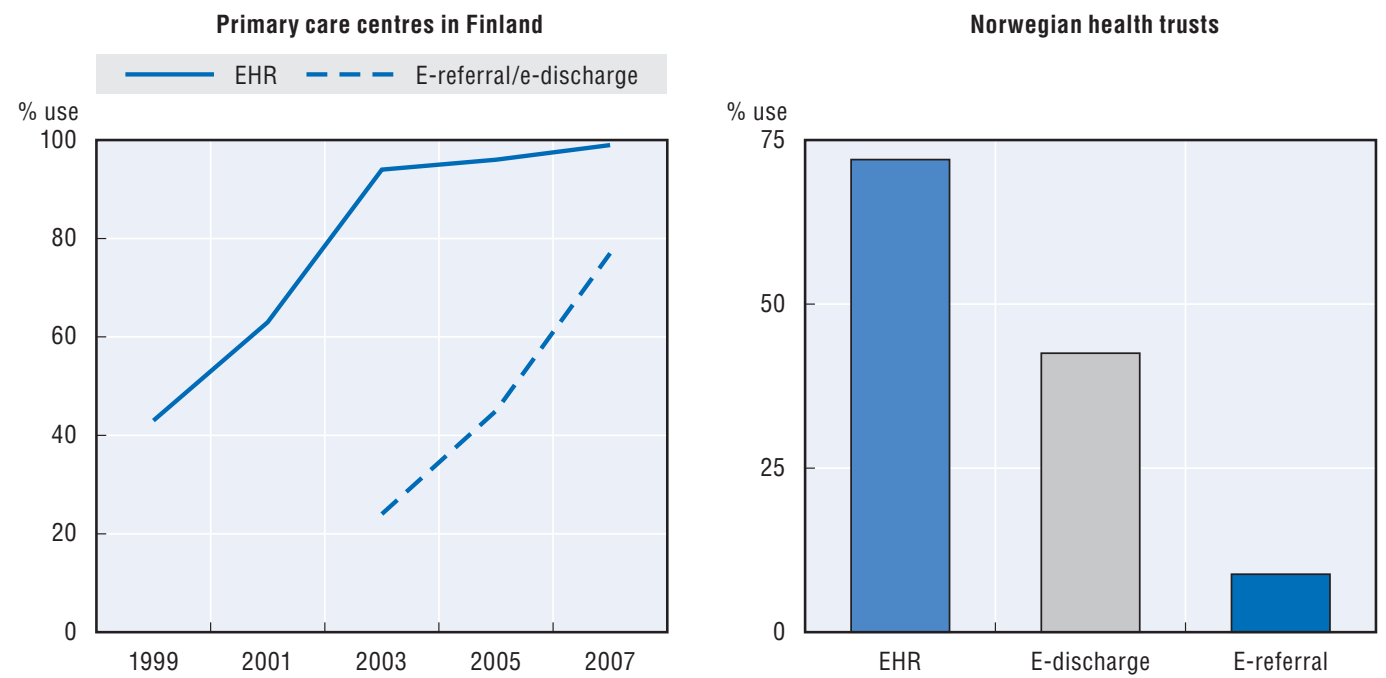

Source: OECD (2010) Improving Health Sector Efficiency: The role of Information Technologies.

StatLink तilst $h t t p: / / d x . d o i . o r g / 10.1787 / 888932694481$

Several countries have set up specific bodies or agencies to coordinate standards-adoption activities and to develop strategies at the national level.

In the United States, the Office of the National Coordinator (ONC) has been working on interoperability for several years. It has demonstrated a range of solutions, adopted an initial set of standards, established a certification process, and funded direct use of standards. The ONC works closely with the Health Information Technology Standards Committee (HITSC), a federal committee with an advisory role on federal HIT standards issues, EHR certification criteria, and implementation specifications for the meaningful use of EHRs in Medicare and Medicaid EHR Incentive Programs. Eligible professionals and 
eligible hospitals that seek to qualify for incentive payments under the Medicare and Medicaid EHR Incentive Programs are required by statute to use Certified EHR Technology. To this end, in June 2010, HHS released the Temporary Certification Program Final Rule, which established certification programmes for the purposes of testing and certifying health information technology.

However, despite encouraging progress in the United States towards furthering the national agenda on standards and interoperability, communities attempting to establish interoperability among competing vendor systems still need to commit considerable technical and organisational efforts to achieve even the simplest clinical data exchange (Goroll et al., 2009).

In Australia, the National E-Health Transition Authority (NEHTA) has led efforts since 2005 to develop uniform national standards and infrastructure requirements for the electronic collection and secure exchange of health information. NEHTA has been working in collaboration with Standards Australia, and has released various standards and specifications for a range of clinical and administrative functions including a unique patient identifier.

In Europe, the European Commission is actively addressing the issue of interoperability. In 2008, it launched the Smart Open Services for European Patients (epSOS) in $12 \mathrm{EU}$ countries, specifically to allow and enhance data exchange between different European countries. Since January 2011, a total of 20 member states and three associated countries have joined epSOS, involving more than 700 people. When fully operational, the epSOS pilot is expected to engage more than 30000 healthcare professionals exchanging patient summaries between 3400 points of care.

The overarching goal of epSOS is to develop a practical e-health interoperability framework and ICT infrastructure, setting principles, standards and methodologies to enable secure access to patient health information, in particular, with respect to basic patient summaries and e-prescriptions between different European healthcare systems. It is the first European e-health project to involve a large number of countries in practical cooperation. The epSOS vision, however, necessitates a long and challenging journey. The exchange of data that lies at the heart of the epSOS pilot requires the development of a robust architecture, as well as a normative framework that all parties can agree upon. This framework must ensure that healthcare professionals can rely upon the authenticity of clinical data on which they will base decisions, that suitable systems of security exist to ensure unauthorised parties cannot access data, and that all parties duly respect patient rights.

In addition to epSOS, the European Commission has recently launched a series of initiatives to improve semantic interoperability in e-health. For example, the Semantic HealthNet is a Network of Excellence that aims to develop a scalable and sustainable pan-European organisational and governance process for the semantic interoperability of clinical and biomedical knowledge. Other projects include: eHealth Monitor, eHR4CR (Innovation in Medicine Initative project), Eureca, Mobiguide, MPower, Ponte, Salus and Transform.

In October 2011, the European Commission adopted a plan to improve Europe's transport, energy and digital networks. This plan, the Connecting Europe Facility, aims (among other objectives) to deploy the information and infrastructure for the provision of cross-border ICT services, including e-health services in EU member states. 
In summary, the potential of e-health can only be fully exploited if tools and solutions are interoperable. The reasons for promoting e-health interoperability are evident to all stakeholders, as is the approach. The difficulty lies in finding a common pace of change for all countries. Implementing interoperability requires a complex set of framework conditions, organisational structures and procedures that need to be agreed upon by all relevant stakeholders. For this purpose, many governments have set up specific bodies or agencies to coordinate standard setting, and have developed strategies at the national level with the aim of moving the interoperability agenda forward. Under pressure, vendors and users, as well as international standards organisations, have also started to collaborate more openly in the development and progression of standards. This collaboration has resulted in some level of success. However, even when standards are available, they are often applied in different ways by different institutions. Additional mechanisms are needed to promote their consistent implementation in a manner that achieves interoperability. In addition to technological specifications, appropriate incentives, consensus building and other enabling policies all have to be in place (OECD, 2010).

\section{Health ICTs deliver greater convenience and closer connections with health professionals}

The ways in which patients/users are allowed to interact electronically with care providers and hospitals differ across OECD countries. One increasingly common and convenient application for patients, as well as healthcare administrators, is electronic booking or "e-booking". E-booking of appointments with clinicians and other health professionals is widely available in most OECD countries. According to a recent survey of EU countries it is used by $71 \%$ of European hospitals.

The system is more prevalent in university hospitals and large hospitals. Hospitals that belong to hospital groups are more likely to have these systems in place compared to their independent counterparts.

\section{Figure 6.8. Electronic booking of medical appointments in EU hospitals}

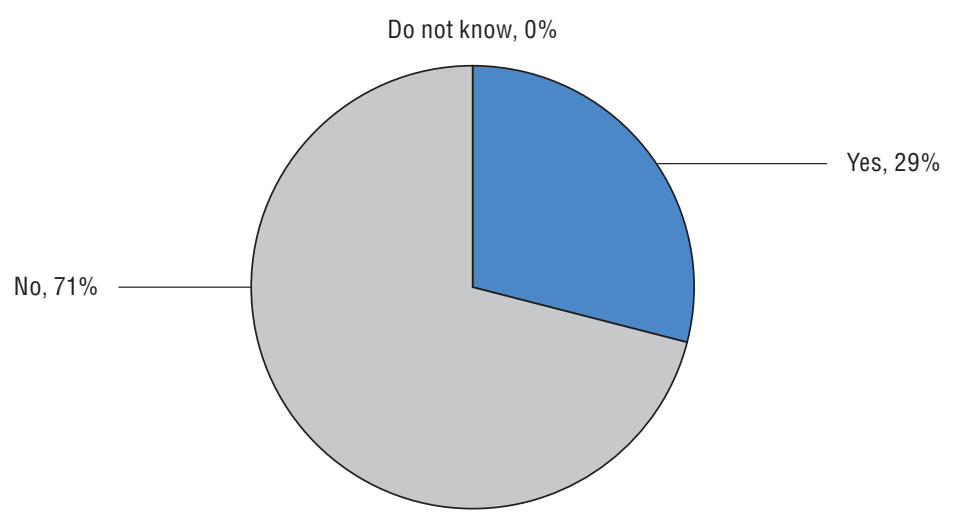

Source: EC (2011), eHealth Benchmarking III: SMART 2009/0022, Final Report by Deloitte \& Ipsos Belgium, Brussels, European Commission Information Society and Media Directorate General, Brussels.

StatLink inilst http://dx.doi.org/10.1787/888932694500

In the United Kingdom, the National Programme for Information Technology (NPfIT) has made the electronic appointment service, Choose and Book, available to general practitioner practices. In $2011,97 \%$ of GP practices had the service and $88 \%$ of GP practices used it to make a booking over the course of a week in August of that year. 
Another growing area is patient and provider electronic communication. In the United States, the Kaiser Permanente (KP) health system began phasing in secure e-mail communication nationwide in 2004. By 2010, 64\% of KP's 3.6 million members in Northern California had signed up for online access. In 2010, Northern California KP's 7000 physicians received 5.8 million secure messages. Secure messaging has been associated with a decrease in office visits, an increase in measurable quality outcomes (at least in primary care), and excellent patient satisfaction (Baer, 2011).

In 2009, the American Recovery and Reinvestment Act called for implementing "secure patient-physician messaging" as part of electronic health records by 2013.

\section{The connected patient}

Advocates of patient-centred health have long argued that citizens should be able to take responsibility for their own health. The argument today widely applies to the management of chronic diseases such as diabetes and obesity, and health systems increasingly see their roles as agents of support. To the extent that individuals are the best judges of their own welfare, the chances of success of any care or prevention programme

\section{Figure 6.9. Percentage of broadband and narrowband users who report seeking health information, 2010 or latest available year}

Differences in the shares (\%) of broadband and narrowband users

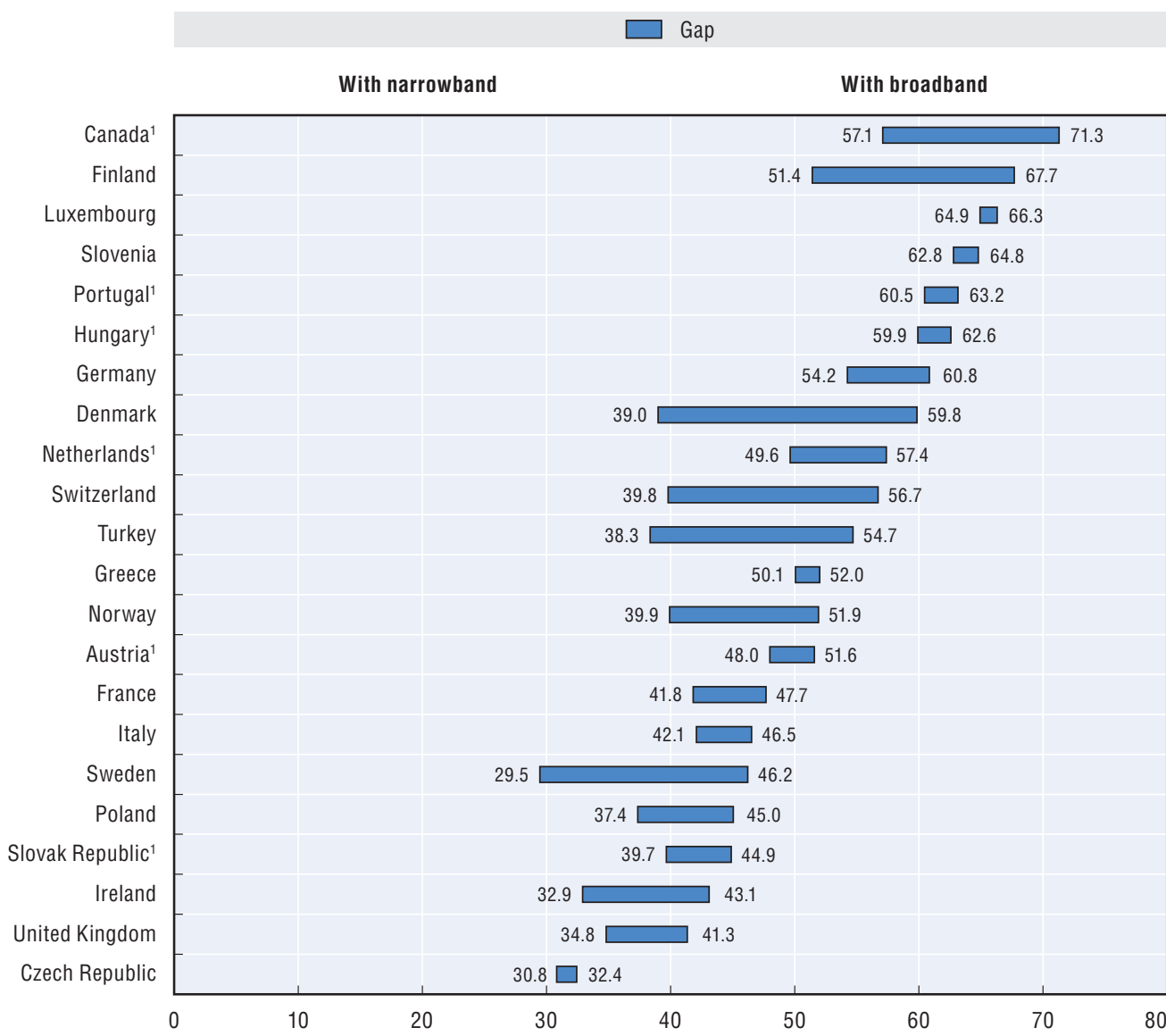

1. Figures for 2009. See OECD (2011a) for more information on data sources and notes. Source: OECD (2011a), The Future of the Internet Economy: A Statistical Profile, June 2011 Update. 
will depend on patient engagement and meaningful co-ownership and co-production of healthy behaviours. To this end, patients today explore local and global information sources, leading to the concept of an "expert connected patient".

Seeking information on health is a frequent use of the Internet. In 2010, more than $50 \%$ of adults in Canada, Denmark, Finland and Luxembourg sought health information on the web, as did over 45\% of adults in Germany, Norway and the Netherlands (OECD, 2011a).

Internet users today also increasingly search online to find other users who might have health concerns similar to their own. Disease interest groups, social network sites and self-help information-sharing Internet sites facilitate and fuel this trend, while awareness and information on healthy choices today are increasingly transmitted via these networks.

In 2010, an average of $49 \%$ Internet users reported social networking activity (Figure 6.10), while Research Center reported that $62 \%$ of adult US Internet users used a social network site such as Myspace or Facebook. Of that group, 23\% of social networking site users followed their friends' personal health experiences or updates on the site. This translates to $11 \%$ of all adults. A further $17 \%$ had used social network sites to highlight or memorialise other people who suffered from a certain health condition; another $15 \%$ of respondents had obtained health information on the sites; and $14 \%$ had raised money for or drawn attention to a health-related issue or cause.

\section{Figure 6.10. Internet users with a social networking activity, 2010}

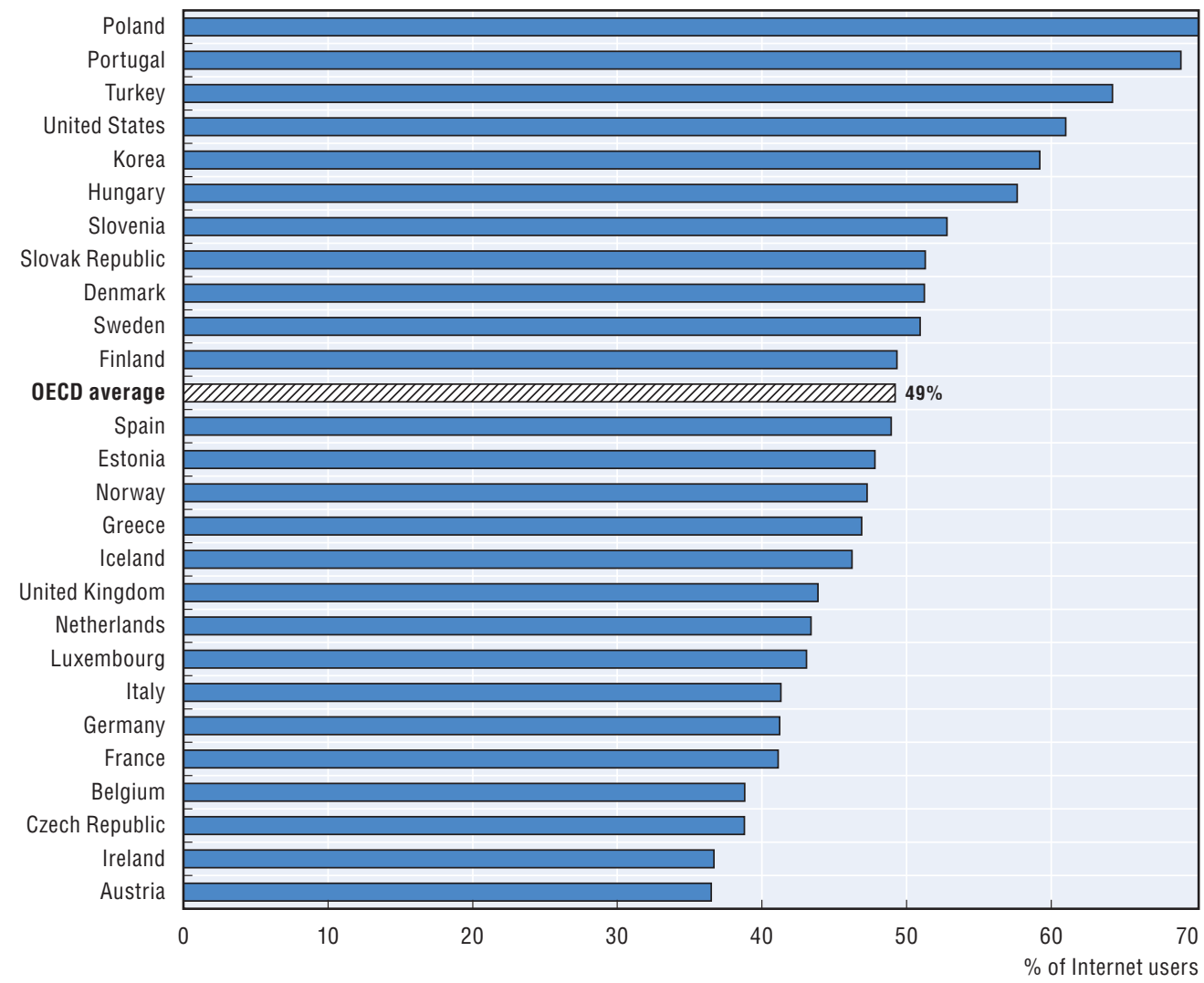

Note: See OECD (2011a) for more information on data sources and notes.

Source: OECD (2011a), The Future of the Internet Economy: A Statistical Profile, June 2011 Update.

StatLink त्ताI http://dx.doi.org/10.1787/888932694538 
Social networks appear to trigger and influence innovative care behaviours at the individual, organisational and community levels. Willingness to share health data through these communities is also opening entire new public health research opportunities to understand disease progression, patterns of illness and responses to treatments, including patient experiences (Fox, 2011).

\section{The growing promise of ICTs for healthy ageing}

A key agenda item in many OECD countries is harnessing the strengths of ICTs to enable healthy ageing. The last few decades have witnessed an increase in the share of the population aged over 65 in OECD countries: in 1960, 9\% of the OECD population was above 65 years old, but by 2010 the proportion had increased to around 15\% (OECD, 2011b).

This trend is expected to continue into the future as life expectancy keeps on rising. In 2050 , the share of the population aged $65+$ will reach $26 \%$ of the total OECD population, according to estimates, while the over-80 age group is projected to increase its share by 2.5 times between 2008 and 2050 (OECD, 2011c). As fertility rates are likely to remain low in most OECD countries, the ratio of people at work to the remaining population is likely to fall dramatically. The size of the "dependent" population relative to the "working age" population, who theoretically provide social and economic support, will increase by 2050 particularly in Korea and Japan, followed by Italy and Finland. In Japan, the total dependency ratio is projected to rise to 82 dependents for every 100 people of working age by 2050. As the proportion of seniors increases, these trends will put serious pressure on the social models and public finances of most OECD countries. While today's seniors are generally healthier than those of previous generations, they are much more likely than younger people to have poor health or chronic conditions and suffer from disabilities.

ICTs have a very important role to play in this context. New technologies can help elderly individuals improve their quality of life, stay healthier, live independently for longer, and counteract reduced physical capabilities, which are more prevalent with age. In addition, ICTs can help improve conditions for people working in the care sector and, as such, help to make care work more attractive in the future.

ICT-based solutions are many and diverse. They facilitate travel, easy social communication via phone and broadband, uptake of public services and daily shopping through Internet access. They can improve safety, and make the home environment easier to manage through user-friendly interfaces. Telecare and telemedicine open up new opportunities for care provision, and also make for more efficient workflows in care by integrating health and social care through information sharing, monitoring and coordinated follow-up.

Some key emerging technologies underpin developments in many of these areas, including robotics, new materials and biosensors. In addition, the emerging concept of ambient intelligence offers great potential with the possibility of embedding intelligence for the whole environment, including the home, transport, and the street, to help address some of the important needs of everyday life. ICT-enhanced equipment, processes and delivery mechanisms can help to increase the quantity, value and quality of services provided to older persons (at equal or lower cost), especially in terms of short and medium-term health and social care, informal care givers and personal assistance service. 
The potential of more widespread use of ICT and new technologies is huge, yet the market in support of healthy, active ageing is still in a nascent phase. As a result, the vast majority of older people are not as yet reaping the benefits of the digital age.

In 2008, the OECD reported at the Seoul Ministerial that older people are less likely to use the Internet than young people. This is still true in 2011, although there are significant differences across countries. Around 65\% of the Danish, Japanese, Norwegian and Swedish population aged $65+$ report using the Internet, while $13 \%$ of the Italians aged $65+$ and $25 \%$ of the Koreans aged 65+ are Internet users (Figure 6.11).

\section{Figure 6.11. Senior people using the Internet from any location by age group, 2011 or latest available year}

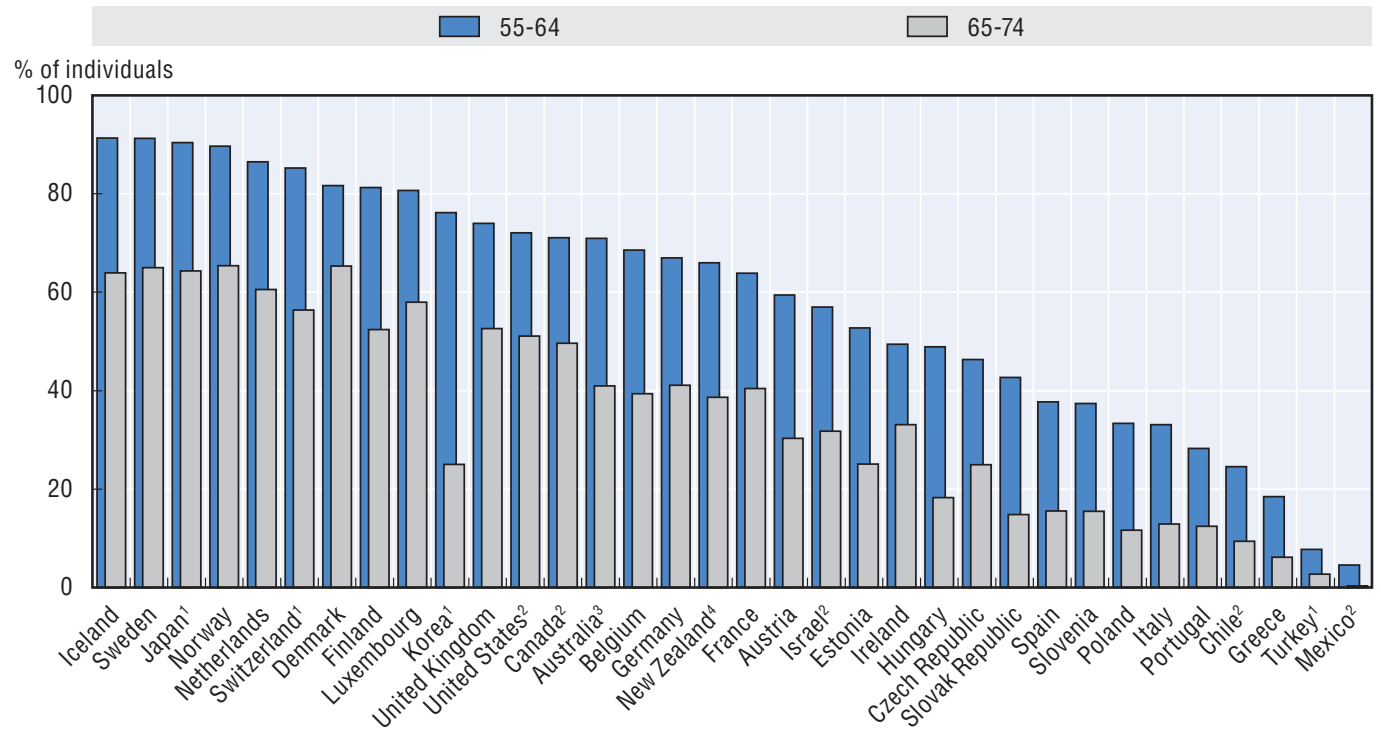

Notes: Data from the EU Community Survey covers EU countries plus Iceland, Norway and Turkey. Individuals aged 16-74 years, except for Israel (20-74) and Japan (6+)

Age group breakdown for Eurostat countries and Canada: 55-64 and 65-74. For non-Eurostat countries: $45-64$ instead of 54-64.

For Israel: Data refer to the use of the Internet in the last 3 months.

For Japan: Age group breakdown: 40-59 and 60-69.

For Switzerland: Data refer to Internet users who used the Internet at least once within the last six months.

Information on data for Israel: $h t t p: / / d x$.doi.org/10.1787/888932315602.

1) 2010; 2) 2009; 3) 2008; 4) 2006.

Source: OECD ICT Database and Eurostat Community Survey on ICT usage in households and by individuals, May 2012.

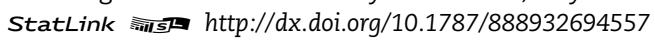

Mobile telephone use is more prevalent than Internet use among older people. As a result, mobile telephones are emerging as the key means to provide valuable services to older generations.

At the end of 2009, mobile telephone usage among the 60+ age group in Japan had reached $70 \%$, while $3 \mathrm{G}$ mobile Internet usage was about $60 \%$. Companies that recognise the opportunities of the ageing society have fostered this uptake of mobile telephones through the incorporation of universal design principles.

There is a need for significant effort, at various levels, to facilitate the introduction and diffusion of advances in ICTs to strengthen older people's autonomy and independence. Such efforts must include strengthening investment in R\&D, encouraging innovation, and 
tackling the range of existing obstacles. These include barriers to market-driven innovation, insufficient awareness of market opportunities, lack of innovation-stimulating public policies, unclear business models for industry, and the high cost of technology development and validation.

\section{Conclusion}

Recent trends paint a picture of an ever-increasing number of information technology products. Today the range of possible applications of information and communication technologies (ICTs) in the health sector has expanded significantly, opening up possibilities of entirely new and more efficient ways of delivering care.

OECD governments have recognised this potential and are taking on an increasingly larger share of implementation costs, so as to ensure that the potential benefits of health ICTs are realised. Most efforts in recent years have focused on fostering the adoption and use of electronic health records (EHRs) by general practitioners and in hospitals. While GP practices in most OECD countries have reached nearly universal computerisation, and most have a high-speed Internet connection, uptake and use of EHRs varies widely both within and across countries. Electronic medical data exchange outside the hospital with other providers is also still not common, even in those countries where deployment of EHRs has proven particularly successful.

Telehealth is increasingly seen as an important tool for enhancing healthcare delivery, particularly in rural and remote areas where healthcare resources and expertise are often scarce or even non-existent. The extent of its use varies from small pilot projects to well-established clinical services. A host of factors have slowed its expansion, including poor broadband infrastructure, limited reimbursement, legal and regulatory barriers, limited provider capacity, and a lack of general public knowledge and/or acceptance.

Mobile health applications and social networks hold the promise of unique and unprecedented opportunities for empowering patients. Awareness and information on healthy choices today are increasingly transmitted via these networks.

Many of the ICT systems today, however, cannot talk to each other, and health information exchange remains a serious problem. Addressing privacy, security and quality of service concerns as well as continued commitments to broadband, open standards and interoperability is essential for successful change. Chapter 8 provides more information on e-health in respect to national strategies.

\section{Notes}

1. The report defined e-health as "encompassing ICT-enabled solutions providing benefits to health, be it at the individual or at the societal level".

2. For more details, see: www.nbn.gov.au/about-the-nbn/.

3. For more details, see: www.broadband.gov/plan/1-introduction/.

\section{References}

Aarts, J. and R. Koppel (2009), "Implementation of Computerized Physician Order Entry In Seven Countries", Health Affairs, Vol. 28, No. 2, pp. 404-414.

AC Nielsen (1998), “A Study into Levels of, and Attitudes Towards Information Technology in General Practice", AC Nielsen Research Pty Ltd, Sydney, Australia. 
AHIC (Australian College of Health Informatics) (2008), E-Health Future Directions Paper, AHIC, Sydney, Australia.

AIHW (Australian Institute of Health and Welfare) (2010), Australia's Health 2010, AIHW, Canberra.

Anderson, G. (2006), "Health Care Spending and Use of Information Technology in OECD Countries", Health Affairs, Vol. 25, No. 3, pp. 819-831.

Astrand, B (2007), E-Prescribing: Studies in Pharmacoinformatics, Dissertation Series No. 48, School of Pure and Applied Natural Sciences, University of Kalmar, Sweden.

Baer, D. (2011), "Patient-physician E-mail Communication: the Kaiser Permanente Experience”, J. Oncol Pract., Vol. 7, No. 4, pp. 230-233, http://jop.ascopubs.org/content/7/4/230.full.pdf+html (accessed November 2011).

Balamurugan, A. et al. (2009), "A Pilot Study of Diabetes Education via Telemedicine in a Rural Underserved Community: Opportunities and Challenges”, Diabetes Educator, Vol. 35, pp. 147-154.

Blavin, F.E., M.E. Buntin and C.P. Friedman (2010), "Alternative Measures of Electronic Health Record Adoption Among Hospitals", American Journal Of Managed Care, Vol. 16, No. 12, pp. 293-301.

Canada Health Infoway (2005), Pan-Canadian Electronic Health Record: Projected Costs and Benefits, www2.infoway-inforoute.ca/Admin/Upload/Dev/Document/VOL3_CHI\%20Costs\%20\&\%20Benefits.pdf (accessed November 2011).

Canada Health Infoway (2009), Building a Healthy Legacy Together, Annual Report 2008/2009, www2.infoway-inforoute.ca/Documents/ar/Annual_Report_2008-2009_en.pdf.

Chaudhry, B. et al., (2006), "Systematic Review: Impact of Health Information Technology on Quality, Efficiency and Costs of Medical Care", Annals of Internal Medicine, vol. 144, pp. E12-E22.

CMA (Canadian Medical Association) (2010), Information Technology and Health Care in Canada, Status Report, CMA, Toronto, www.cma.ca/multimedia/CMA/Content_Images/Inside_cma/HIT/ 2007_status_report/IT-handbook-e.pdf.

Department of Health and Human Services (US) (2010), Fiscal Year 2010 Congressional Justification, http://dhhs.gov/asfr/ob/docbudget/2010gdmcj.pdf.

EC (European Commission) (2004), e-Health - Making Healthcare Better for European Citizens: An Action Plan for a European e-Health Area, Communication from the Commission to the Council, the European Parliament, the European Economic and Social Committee and the Committee of the Regions, 30 April 2004, Brussels, EC, http://eur-lex.europa.eu/LexUriServ/LexUriServ.do?uri=COM:2004: 0356:FIN:EN:PDF.

EC (2008) Pilot on Ehealth Indicators: ICT Use among General Practitioners in Europe, Brussels, European Commission Information Society and Media Directorate General, http://ec.europa.eu/information_society/ eeurope/i2010/docs/benchmarking/gp_survey_final_report.pdf (accessed November 2011).

EC (2011), eHealth Benchmarking III: SMART 2009/0022, Final Report by Deloitte \& Ipsos Belgium, Brussels, European Commission Information Society and Media Directorate General, Brussels, http:// ec.europa.eu/information_society/eeurope/i2010/docs/benchmarking/ehealth_benchmarking_3_final_report.pdf.

eHealth ERA (2007), eHealth Priorities and Strategies in European Countries: eHealth ERA Report March 2007, prepared on behalf of the European Commission, EC, Luxembourg, http://ec.europa.eu/ information_society/activities/health/docs/policy/ehealth-era-full-report.pdf.

Fox, S. (2011), The Social Life of Health Information, Pew Research Center, Washington, DC, http:// pewinternet.org/Reports/2011/Social-Life-of-Health-Info.aspx (accessed November 2011).

Goroll, A. et al., (2009), "Community-wide Implementation of Health Information Technology: the Massachusetts eHealth Collaborative Experience", Journal of the American Medical Informatics Association, Vol. 16, pp. 132-139.

Hämäläinen, P., P. Doupi and H. Hyppönen (2008), Ehealth Policy and Deployment in the European Union: Review and Analysis of Progress, STAKES, Helsinki, www.stakes.fi/verkkojulkaisut/raportit/ R26-2008-VERKKO.pdf.

Hayes et al. (2009), Independent Review of NHS and Social Care IT, commissioned by S. O'Brien, Chairman of the Review Group, www.e-health-insider.com/img/document_library0282/NHS_and_Social_Care_IT_Review[1].pdf (accessed November 2011).

HIRA (Health Insurance Review and Assessment Service) (2010), Going Together Toward Better Health, Better Life: HIRA Sustainability Report, Korea: HIRA. 
Hsiao, C. et al. (2009), Electronic Medical Record/Electronic Health Record Use by Office-based Physicians: United States, 2008 and Preliminary 2009 State Estimates, National Center for Health Statistics (NCHS), Hyattsville, United States.

IT Strategic Headquarters (2008), Policy Priority Programme 2008, Strategic Headquarters for the Promotion of an Advanced Information and Telecommunications Network Society, Tokyo, www.kantei.go.jp/foreign/policy/it/Program2008.pdf, (accessed November 2011).

Jackson, J. et al. (2005), "A National Study of Obesity Prevalence and Trends by Type of Rural County", Journal of Rural Health, Vol. 21, pp. 140-148.

Jha, A.K. et al. (2008), "The Use of Health Information Technology in Seven Nations", International Journal of Medical Informatics, Vol. 77, No. 12, pp. 848-854.

Jha, A.K. et al. (2009), "Use of Electronic Health Records in US Hospitals", New England Journal of Medicine, Vol. 360, No. 13, pp. 1628-1638.

McInnes, D.K., D.C. Saltman and M.R. Kidd (2006), “General Practitioners' Use of Computers for Prescribing and Electronic Health Records: Results from a National Survey", Medical Journal of Australia, Vol. 185, Vol. 2, pp. 88-91.

MGMA (Medical Group Management Association) (US) (2011), Electronic Health Records: Status, Needs and Lessons: 2011 Report Based on 2010 data, www.mgma.com/WorkArea/DownloadAsset.aspx?id=1248574.

National Audit Office (2008), The National Programme for IT in the NHS: Progress since 2006, NAO, London, www.nao.org.uk/publications/0708/the_national_programme_for_it.aspx (accessed November 2011).

NEHTA (National eHealth Transition Authority) (2011), NEHTA Strategic Plan, NEHTA, Sydney, Australia.

OECD (2009), Society at a Glance 2009: OECD Social Indicators, OECD Publishing. doi: http://dx.doi.org/10.1787/soc_glance-2008-en.

OECD (2010), Improving Health Sector Efficiency: The Role of Information and Communication Technologies, OECD Health Policy Studies, OECD Publishing. doi: http://dx.doi.org/10.1787/9789264084612-en.

OECD (2011a), “The Future of the Internet Economy: A Statistical Profile”, June 2011 Update, OECD, Paris.

OECD (2011b), Health at a Glance 2011: OECD Indicators, OECD Publishing. doi: http://dx.doi.org/10.1787/health_glance-2011-en.

OECD (2011c), OECD Employment and Labour Market Online Statistics 2011, OECD, Paris, http:// stats.oecd.org/.

Praxia/Gartner (2011), Telehealth Benefits and Adoption Connecting People and Providers Across Canada, A study Commissioned by Canada Health Infoway, https://www2.infoway-inforoute.ca/Documents/ telehealth_report_summary_2010_en.pdf.

Protti, D. (2007), “Canada's EHR Journey: Pragmatic Progress and Promising Potential”, PowerPoint presentation to OECD Expert Meeting on ICT in the Health Sector, OECD, Paris.

Schoen, C. et al. (2009), "A Survey Of Primary Care Physicians In Eleven Countries, 2009: Perspectives On Care, Costs, And Experiences”, Health Affairs, Vol. 28, No. 6, w1171-w1183.

Schwab, S. et al. (2007), "Long-Term Outcome after Thrombolysis in Telemedical Stroke Care", Neurology, Vol. 69, pp. 898-903.

Scott, J.T., T.G. Rundall et al. (2005), "Kaiser Permanente's Experience of Implementing an Electronic Medical Record: A Qualitative Study", BMJ, doi: http://dx.doi.org/10.1136/bmj.38638.497477.68.

Shekelle, P. and C.L. Goldzweig (2009), "Costs and Benefits of Health Information Technology: An Updated Systematic Review", The Health Foundation, London.

Wechsler, L. (2008), “Advances in Technology Increase Telestroke's Viability," American Academy of Neurology, 25 November 2008, www.aan.com/news/?event=read\&article_id=6811.

Western Australia Country Health Services (2007), "Foundations for Country Health Services: The Western Australia Country Health Services Strategic Plan 2007-2010”, Western Australia Country Health Services, Perth. 



\section{Chapter 7}

\section{Security and privacy}

The chapter presents trends in research and development (R\&D) investments in the area of security and privacy and their outcome in terms of patent fillings. It examines the emergence of innovative products (goods and services) related to security and privacy as measured by trademarks and analyses the emerging new business models required to deploy these products. The chapter then briefly discusses the role of employment and skills as enabling factors for innovation in security and privacy, focusing in particular, on statistics on the availability of security and privacy professionals. 
$\mathrm{T}_{\mathrm{h}}$ he ultimate role of the Internet in the economy will depend on whether users, businesses and governments feel safe using the network and trusting it for critical applications and services. As a result, governments are paying increasing attention to cybersecurity and data privacy threats emerging from the Internet. Media reports on incidents compromising the confidentiality, integrity and/or availability of information systems and networks used by Internet participants, are also increasing.

Malware, denial of service (DoS) attacks or other sources (see Box 7.1) are typically the causes of such incidents. Where personal data are being collected, stored or processed, these incidents also heavily affect privacy as recent high-profile data breaches ${ }^{1}$ demonstrate. In 2008-09, a malicious software hack compromised the Heartland Payment Systems Inc. (an online payments and credit card company based in the United States), involving more than 130 million credit and debit card numbers (Voreacos, 2009; Zetter, 2009). In 2010-11, security breaches of Sony's PlayStation Network and Sony Online Entertainment systems resulted in the exposure of 104 million records containing personally identifiable information, including names, addresses, birthdates, passwords and login details (Goodin, 2011; Reuters, 2011; Seybold, 2011).

\section{Box 7.1. Security-related threats}

- Malware is "a piece of software inserted into an information system to cause harm to that system or other systems, or to subvert them for use other than that intended by their owners" (OECD, 2009b). It includes malicious software code often referred to as "viruses", "worms" and "Trojans".

- Denial of Service (DoS) or distributed Denial of Service (DDoS) attacks "seek to render an organisation's website or other network services inaccessible by overwhelming them with an unusually large volume of traffic" (OECD, 2009b). The United States Computer Emergency Readiness Team (US-CERT) classifies an incident as a DoS attack if it "successfully prevents or impairs the normal authorised functionality of networks, systems or applications by exhausting resources. This activity includes being the victim or participating in the DoS" (US CERT, n.d.).

- Unauthorised access is a successful intrusion into an information system to gain logical or physical access without permission. The following incidents are examples of unauthorised access: "An attacker runs an exploit tool to gain access to a server's password file" or "a perpetrator obtains unauthorised administrator-level access to a system" (NIST, 2004).

- Phishing is the malicious means of acquiring user information, such as usernames and credit card details, through the use of websites or e-mails masquerading as those of a trustworthy entity. 
These cybersecurity and data privacy threats are resulting in the emergence of new technologies (usually in the form of new products) and new processes and business models, some of which are explicitly designed and deployed to enhance security and privacy. Examples include antivirus tools that protect computers against malware and cookie management tools that help users to control personal data collection by web browsers. In addition, new technologies, processes and business models not specifically related to security and privacy are now integrating these elements to prevent future security and privacy risks.

This chapter examines the ways in which the private sector has responded to developments in security and privacy threats through new or significantly improved products, processes and business models. It emphasises the importance of innovation for ensuring security, privacy and trust in the Internet economy, acknowledging the role of malicious users and malicious practices as a driving force in this innovation process (Box 7.2). Given the significant role of skills as enabling factors for innovation, this chapter also discusses the availability of skills needed for security and privacy-related technologies, processes and business models.

\section{Box 7.2. Defining innovation}

The Oslo Manual developed jointly by the OECD and Eurostat defines innovation as "the implementation of a new or significantly improved product (good or service), or process, a new marketing method, or a new organisational method in business practices, workplace organisation or external relations" (OECD-Eurostat, 2005). This definition comprises four types of innovation:

- Product innovation: the introduction of a good or service that is new or significantly improved with respect to its characteristics or intended uses. This includes significant improvements in technical specifications, components and materials, incorporated software, user friendliness or other functional characteristics.

- Process innovation: the implementation of a new or significantly improved production or delivery method. This includes significant changes in techniques, equipment and/or software.

- Marketing innovation: the implementation of a new marketing method involving significant changes in product design or packaging, product placement, product promotion or pricing.

- Organisational innovation: the implementation of new organisational methods in a firm's business practices, workplace organisation or external relations.

Source: OECD (2010a).

The following section presents trends in research and development (R\&D) investments and their outcomes in terms of patent fillings. The second section examines the emergence of innovative products (goods and services), as measured by trademarks, as well as the emerging new business models required to deploy these products. The third section briefly discusses the role of employment and skills as enabling factors for innovation in security and privacy, with a particular focus on available statistics regarding the availability of security and privacy professionals. Finally, the concluding section summarises the main findings. 


\section{Research and development in security and privacy}

Many security and privacy enhancing technologies depend heavily on research and development (R\&D). For instance, the antivirus tools needed to protect information systems and networks against quickly evolving malware require continuous improvements (Box 7.3). In addition, the ICT development process needs continual enhancement to reduce the number and severity of exploitable vulnerabilities. R\&D efforts are therefore aiming to integrate security and privacy concerns into ICTs at the design stage, a process termed "security and privacy by design" (OECD, 2008b), ${ }^{2}$ so as to prevent future security and privacy risks that could lead to higher overall economic and social costs. The importance of this approach grows as information systems and networks become more open and cybersecurity incidents increasingly threaten the smooth functioning of critical infrastructures and the society as a whole (Box 7.4).

\section{Box 7.3. Increasing sophistication of cybersecurity threats}

Malicious users continuously improve malware technologies, increasing their sophistication and capacity to bypass and neutralise cybersecurity technologies and processes. This sophistication challenges IT departments, IT security companies and law enforcement alike, who are forced to keep pace through continuous innovation, in particular, as networks become more open. Malware developers increasingly use multiple attack vectors that include social engineering and (zero-day) vulnerability exploits of popular client-side applications to increase the effectiveness of their attacks. Furthermore, techniques and technologies such as polymorphisms and encryption have become standard tools in the repertoire of malware developers looking to thwart antimalware programs and make functional analysis of malware (e.g. through reverse engineering) as difficult as possible following detection (Golovanov, Gostev and Monastyrsky, 2008; Microsoft, 2012). Malicious users also continuously monitor antivirus databases so as to (automatically) update their malware when new antivirus signatures are released. For example, some security experts consider Virut among one of the fastest-mutating viruses, generating new variants as often as once a week (Zakorzhevsky, 2010).

The increasing complexity of malware attacks is also due to the fact that malicious users are exchanging innovative practices and technologies, reusing existing malicious code, and even buying "off-the-shelf" malware kits with ready-made and continuously updated vulnerability exploits. In this context, the discovery, marketing and exploitation of zero-day-vulnerabilities remains one of the most critical success factors for malware developers and the biggest threat to Internet participants. Bootkit, ${ }^{1}$ for example, uses the browser as an infection vector (i.e. "drive-by download") combined with rootkit technologies and migrating command and control (C\&C) botnet servers among others. In the past, individual techniques were used; now these are combined within one malware. Bootkit utilises the Neosploit bundle of vulnerability exploits, sold since 2007 on the black market for between USD 1000 and USD 3000 (Golovanov, Gostev and Monastyrsky, 2008). To give an idea of the scale of its impact, as of 2008 Bootkit had attacked over 200000 US-based users per day and successfully infected almost 100000 machines, assimilating them to its botnet.

Operation Aurora is another recent example. This sophisticated and targeted attack focused on the intellectual property repositories of high-tech companies such as Adobe Systems, Google, ${ }^{2}$ Juniper Networks and Rackspace. According to McAfee (2010), the primary goal of Operation Aurora was to gain access to and potentially modify intellectual property repositories in high-tech firms. The attack involved social engineering techniques, the exploitation of a zero-day-vulnerability (in a web browser), and the usage of distributed C\&C botnet servers (Zetter, 2010). Further analysis revealed that Operation Aurora used hosts primarily located in China, Germany, Chinese Taipei, the United Kingdom and the United States. It is estimated that Operation Aurora affected more than 34 organisations including Dow Chemical Northrop Grumman, Rand Corp. and Yahoo!, (Damballa, 2010).

1. Kaspersky estimated in 2008 that developing Bootkit must have taken "several months" requiring "several groups of cyber criminals who are working closely together, each taking responsibility for separate areas of the project" (Golovanov, Gostev and Monastyrsky, 2008).

2. Google was the first company to publicly disclose the attack in its official blog on 13 January 2010 (Google, 2010). 


\section{Box 7.4. Increasing sophistication of cybersecurity threats: the case of Stuxnet}

No malware has attracted as much attention from security experts and the media as Stuxnet. Security experts described it as "groundbreaking", "incredible large and complex", and even "perfect from a technical point of view" (Falliere, Murch and Chien, 2011; Keizer, 2010; Matrosov et al., 2011). Some have also spoken of Stuxnet as a new-generation "cyber weapon" (Langer, 2012). In any case, security experts agree that the following attributes make this malware special and contribute to its high level of sophistication:

- Stuxnet exploits up to four zero-day Microsoft vulnerabilities, ${ }^{1}$ an unprecedented number within a single malware. Two of these vulnerabilities have allowed Stuxnet to propagate undetected over multiple channels, namely over local area networks (LAN) and through removable drives.

- Stuxnet was built to target and compromise a very specific configured system, namely a supervisory control and data acquisition (SCADA) system controlled by a Siemens programmable logic control (PLC) software. These systems are often not even connected to the Internet (Falliere, Murch and Chien, 2011).

- Stuxnet uses up to two valid digital signatures making the infected systems believe the malware is legitimate.

- Stuxnet includes a built-in uninstall mechanism and an infection counter to enable it to self-destruct after it reaches a maximum number of infections. This results in a more controlled infection and minimises the prevalence and as such the potential discovery of the malware.

As of September 2010, Symantec had counted approximately 100000 Stuxnet infected hosts worldwide ${ }^{2}$ with Iran hardest hit (Figure 7.1). Security experts believe that this fact and the presence of a damage control to prevent uncontrolled infection increase the likelihood of Stuxnet having been designed and deployed explicitly to target SCADA systems in Iran.

Figure 7.1. Stuxnet infection rates by country, September 2010

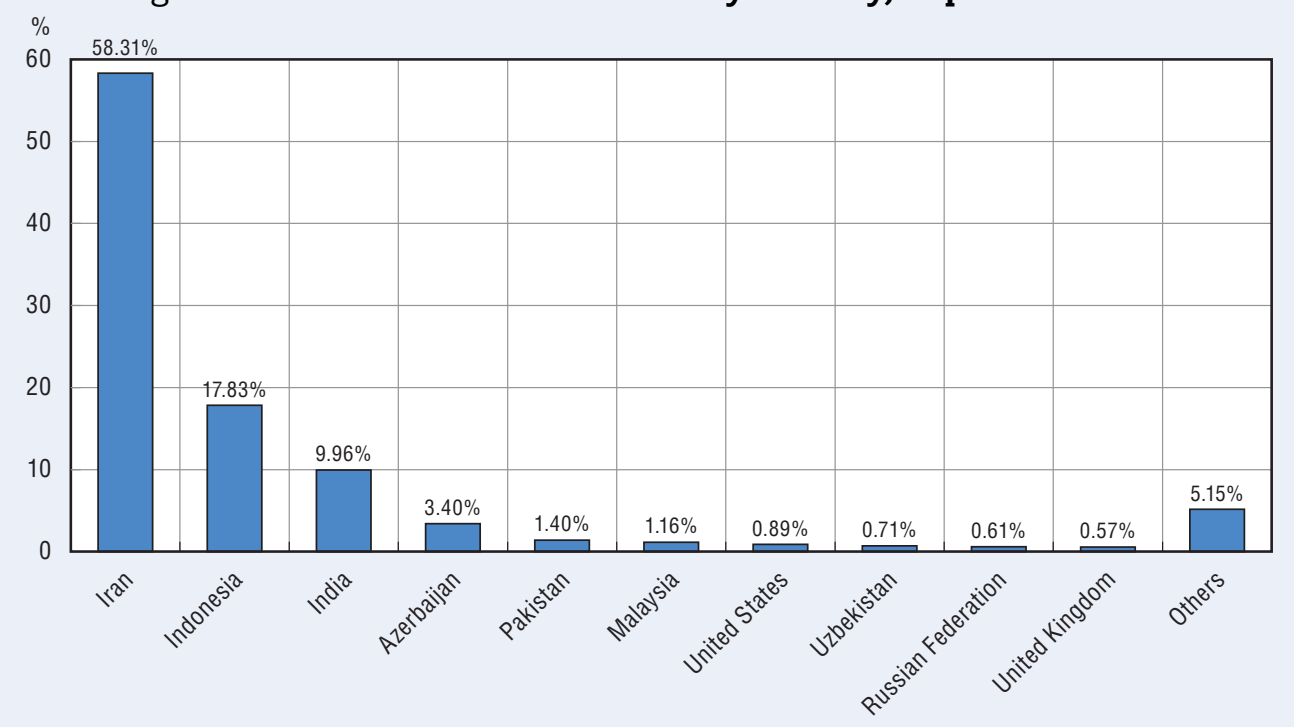

Source: Falliere (2011).

StatLink न्नाIst http://dx.doi.org/10.1787/888932694576

1. Stuxnet exploits four unpatched (zero-day) and one patched Microsoft vulnerabilities (Falliere, Murch and Chien, 2011; Matrosov et al., 2011).

2. These numbers are based on traffic monitoring to the Stuxnet C\&C servers by Symantec (Falliere Murch and Chien, 2011). 
Box 7.4. Increasing sophistication of cybersecurity threats: the case of Stuxnet (cont.)

Another indication of the high level of sophistication of Stuxnet is the amount of person-hours required to develop the malware. Security experts from Kasperky, Symantec and other firms estimate that it may have taken six to nine months and five to ten core developers to develop Stuxnet, "not counting numerous other individuals, such as quality assurance and management" (Falliere, Murch and Chien, 2011; Matrosov et al., 2011). Some experts further estimate the development cost of Stuxnet at around USD 3 million (Hesseldahl, 2010). Based on these figures, in particular, the sophistication of Stuxnet and the knowledge required to successfully launch the attack, some security experts suggest that this type of attack would require resources only available at the level of a national government (Fildes, 2010; Halliday, 2010).

The next section analyses R\&D activities to highlight to the extent to which the private sector has responded to these emerging threats. It focuses on trends in R\&D investment in security and privacy and their direct outcomes in terms of new patents. ${ }^{3}$ It should be noted that, although R\&D investments constitute an important input measure for innovation, innovation itself, as defined by the OECD Innovation Strategy, is clearly a much broader notion than R\&D (see OECD, 2010a). Furthermore, data presented in the following only capture innovation to a limited extent in security and privacy by design, which tends to be more related to process innovation than technology innovation.

\section{Research and development investments}

Official statistics on R\&D in information security and privacy do not exist. However, business R\&D expenditures in the ICT sector (ICT BERD) can be used as an indicator for overall R\&D investment in information security and privacy, if it can be assumed that R\&D in information security and privacy tend to be high in countries with high ICT BERD specialisation (Figure 7.2). This is likely the case in the area of security, in particular, as ICT policy analysis shows that information security is often listed among the top ICT R\&D priority areas (see Chapter 8; OECD, 2008b, 2010b). Furthermore, some OECD governments have implemented cybersecurity strategies in which R\&D featured prominently, and these countries tend to have a high ICT R\&D specialisation. The Strategic Plan for the Federal Cybersecurity Research and Development Program of the United States National Science and Technology Council (NSTC, 2011), for example, "defines a set of interrelated priorities for the agencies of the US government that conduct or sponsor research and development (R\&D) in cybersecurity". Overall, data on ICT BERD reveals that Finland, Israel and Korea have the highest ICT BERD intensity (see Chapter 1 endnote 8) among OECD countries with over $1 \%$. Sweden, the United States, Japan and Iceland follow with relatively high rates (Figure 7.2). Investments in R\&D related to information security, in particular, are more likely to be relatively high in those countries with high ICT-R\&D specialisation.

Firm-level data are another possible source for information on R\&D in cybersecurity, in particular, and permit a focus on those firms providing cybersecurity-related products. ${ }^{4}$ However, this may not be always possible, as some firms may not report their R\&D investments in financial reports. This is especially the case for privately held firms (not listed on stock markets) such as Kaspersky Lab. Furthermore, in some firms, revenues related to cybersecurity products may only account for a low share of overall revenues. This is the case, for example, 
Figure 7.2. ICT business expenditure in R\&D, 2010 or latest available year

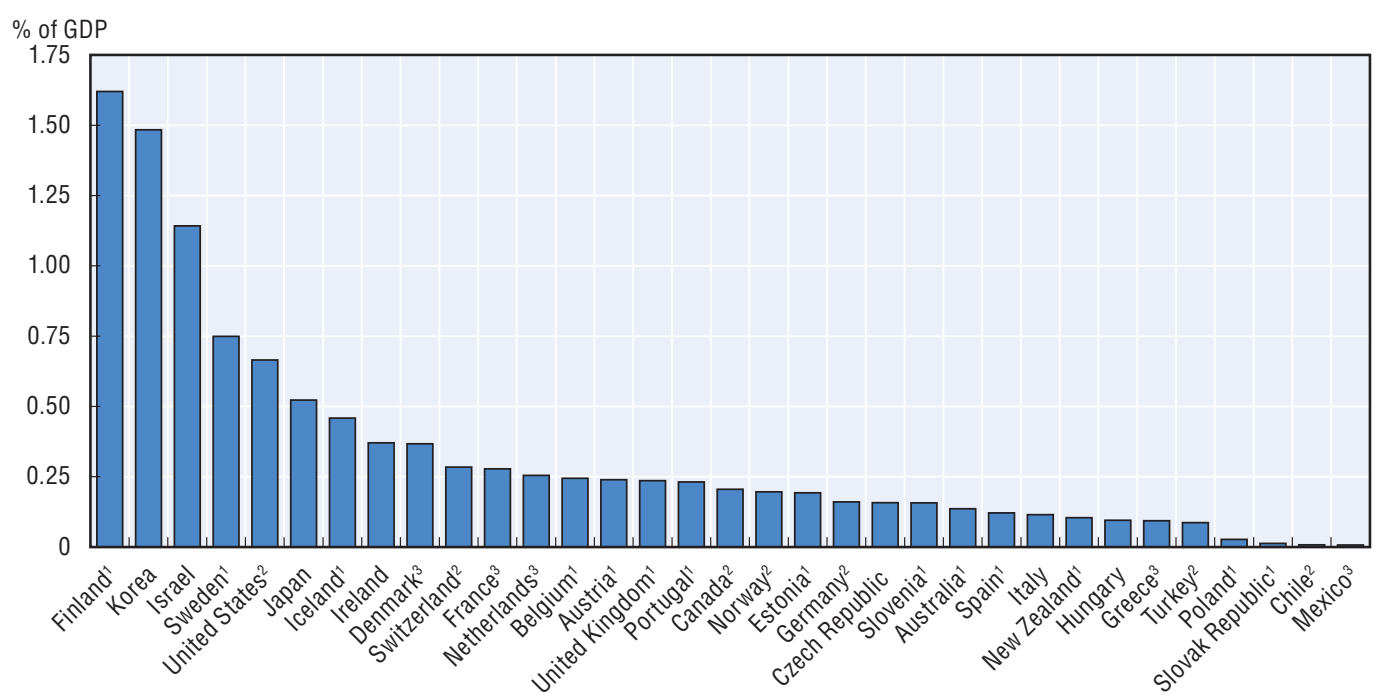

Notes: The ICT sector is defined here as the sum of the following categories in ISIC 3 Rev. 1: 30, 32, 642 and 72. In some cases this aggregate can be underestimated, e.g. Canada, Finland, Greece, Ireland, Iceland, Slovak Republic and Switzerland only covers category ISIC 32 for ICT manufacturing. Canada, Chile, Denmark, Estonia, Finland, Hungary, Ireland, Israel, Japan, Netherlands, New Zealand and Slovak Republic only covers category ISIC 72 for ICT services. Switzerland only covers category 642 for ICT services.

Country notes: For Belgium and France: Data are distributed according to the product field of the R\&D. For Czech Republic: Data are distributed according to the main activity of the enterprise carrying out the R\&D. Since 2004, the R\&D of enterprises in the Research and development industry (ISIC, R-3: 73) has been redistributed to the industries for which the R\&D was carried out. For the United Kingdom: Data are distributed according to the product field of the R\&D for large firms, while for small firms the R\&D is allocated to their main activity. R\&D firms are redistributed to the industry served. Telecommunications (ISIC, R-3: 642) includes Post (ISIC, R-3: 641). For the rest of the countries, data are distributed according to the main activity of the enterprise carrying out the R\&D. For Chile, Israel and New Zealand: Data on ICT manufacturing are not available. For Germany: Data on ICT services are not available.

Information on data for Israel: http://dx.doi.org/10.1787/888932315602.

1) 2009; 2) 2008; 3) 2007.

Note: OECD ANBERD and RDS databases, June 2012; Statistics Sweden, June 2011.

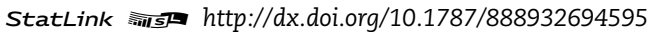

with Intel which acquired McAfee in 2010, but which mainly generates its revenues through semiconductors and related products. Despite these limitations, firm level data remain the only source for timely data on R\&D investments, in particular, in cybersecurity.

R\&D intensity varies among IT security companies of different size (Figure 7.3). The largest firms in terms of annual revenue are Symantec (United States) with more than USD 6 billion in 2010, followed by McAfee (United States) with almost USD 2 billion in 2009, and Trend Micro (Japan) with USD 1 billion in 2010. Comparison of these selected firms shows that R\&D intensity, defined as R\&D expenditure as a share of sales revenue, is significantly high (around 15\% of revenues). This suggests that ICT security firms are more R\&D intensive than the average top 250 ICT firms, which spent around 5\% of revenue on R\&D during 2011 (see Chapter 1). Among the selected firms, Ahnlab (Korea) spent the highest share of revenue on R\&D at KRW 20 billion (out of KRW 74 billion), followed by Imperva (United States), which spent USD 13 million (out of USD 55 million). Trend Micro had the lowest R\&D intensity with JPY 3.5 billion invested in R\&D (out of JPY 95 billion). Symantec and McAfee had the largest investments in R\&D (in absolute numbers) with USD 857 million (14\% of revenues) and USD 324 million (17\% of revenues), respectively. Overall, these data suggest that cybersecurity is significantly R\&D intensive and that innovation is vital for promoting a secure Internet 
Figure 7.3. R\&D intensity of selected IT security firms, 2010

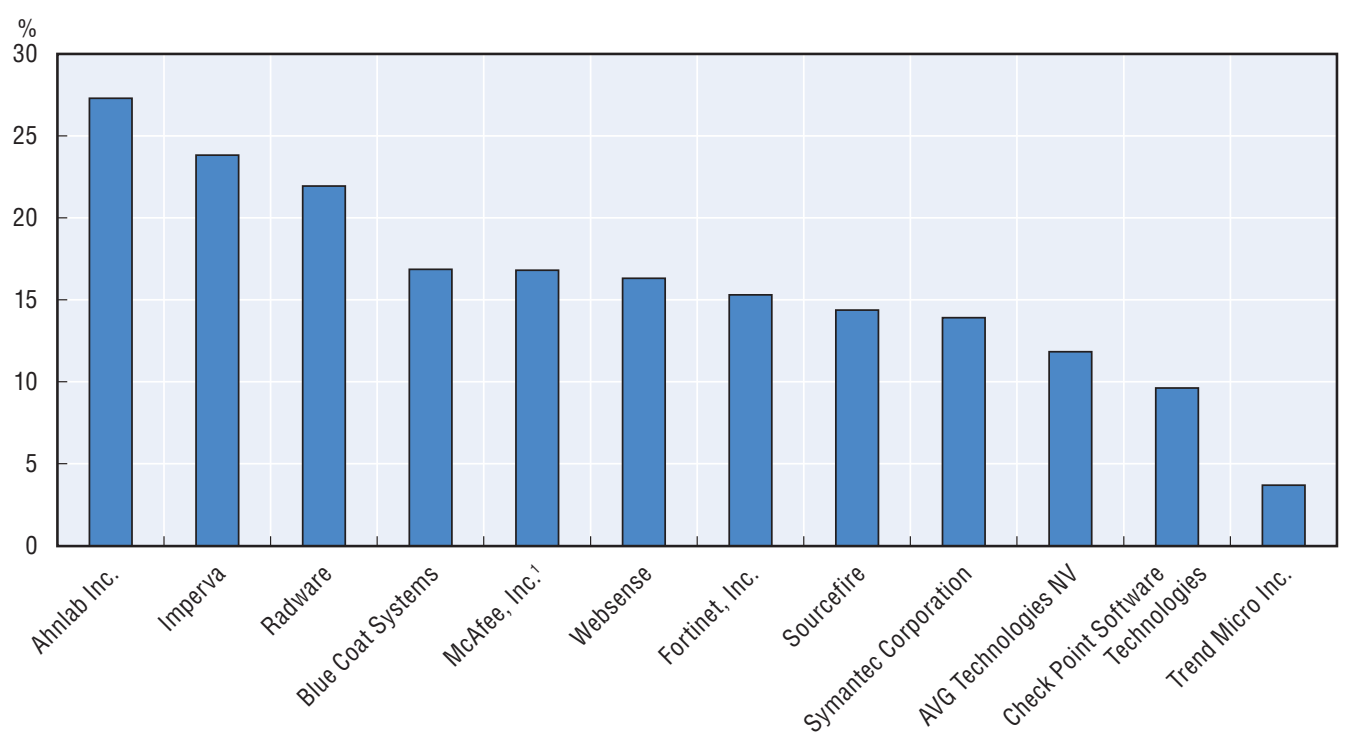

1. Intel Corp acquired McAfee for USD 7.68 billion in 2010. The values here correspond to 2009.

Source: OECD Information Technology Database, compiled from annual reports, SEC filings and market financials.

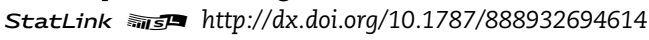

economy. This conclusion, however, is based on a small sample of firms, and further analysis based on a larger sample would be needed to confirm this observation.

\section{New patents for security and privacy enhancing technologies}

R\&D investments sometimes lead to new patents that can be exploited internally for new products (goods and services) or licensed to third parties. Patent data are an important resource for the study of innovation alongside other science and technology indicators such as R\&D investments (OECD, 2009a). They provide detailed information on inventive activities as the output of R\&D activities. It should be noted, however, that patents are an indicator of invention rather than innovation, since not all patents are commercialised and some types of technology are not patentable. ${ }^{5}$

The number of Patent Cooperation Treaty (PCT) patent applications related to information security and privacy is increasing faster than the number of ICT patent applications (Figure 7.4). In 2006, the share of patent applications related to information security was the highest ever, with more than 15 patent applications related to information security for each 1000 ICT patent applications. ${ }^{6}$ However, since 2006 the share of ICT patent applications related to security has decreased, reaching 12 patent applications for each 1000 ICT patent applications in 2010. This indicates that the number of security-related patents is growing at a slower pace compared to overall ICT patent applications. Further analysis reveals that organisations in the United States filed the most patent applications related to security, followed by organisations in China, Germany, France and the United Kingdom.

In contrast to security-related patent applications, privacy-related patent applications remain relative low (with not even one application per 1000 ICT patent applications). A slight increase, however, is observable in 1998. One should add at this point that the number of patent applications in security and privacy does not fully reflect ongoing innovation. This is because innovation related to security and privacy is to a large extent embodied in advanced processes and software. In the case of software, the application and 
Figure 7.4. Relative number of patent applications in information security and privacy filled under PCT, 1990-2010

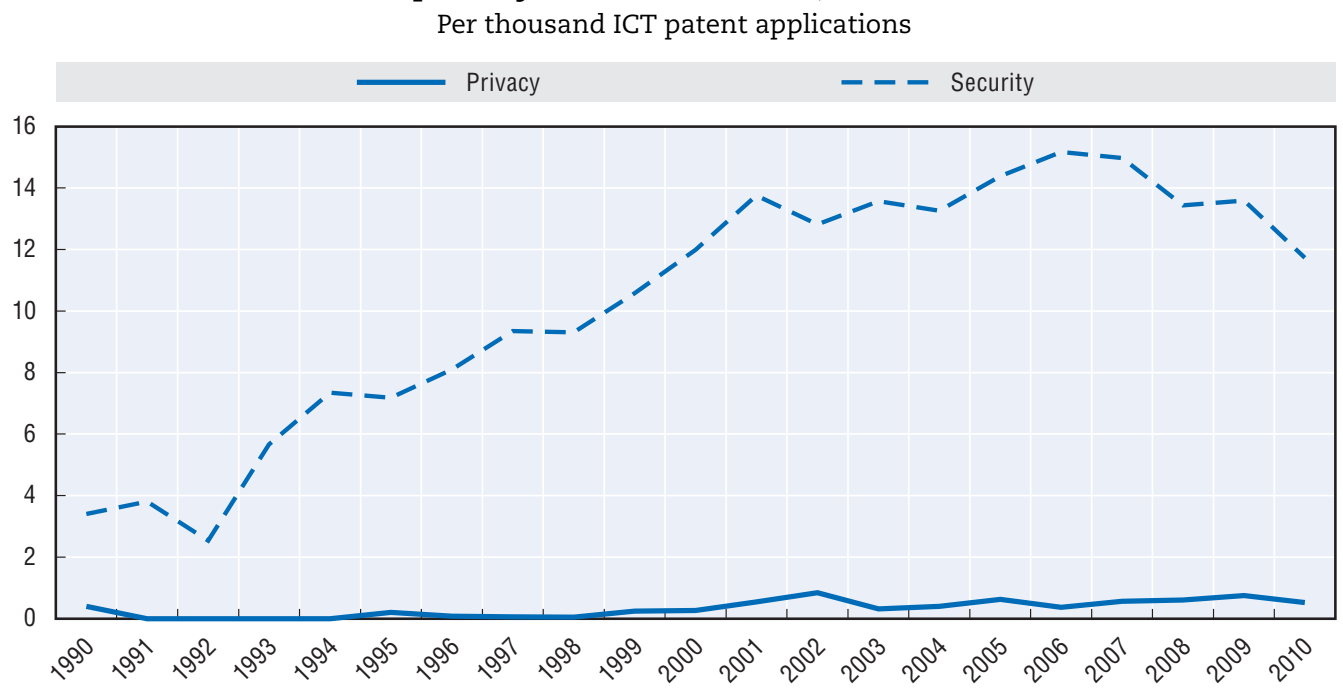

Notes: Security-related applications are identified with keywords such as "recovery" "virus" and "spyware" "security" and "computer"). Privacy-related applications are identified with keywords such as "anonymity", "identity" and "privacy". Source: OECD Patent Database, June 2012.

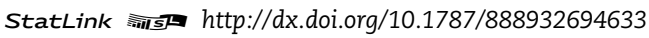

the grant of a patent may vary between countries, and statistics on trademarks are more likely to better reflect ongoing innovation (see the next section).

\section{Innovative products and business models}

New technologies are usually deployed through goods and services offered on the market. In contrast to patents that may not end up being commercialised, trademarks provide a better indicator for measuring the diffusion of non-technological innovation (Millot, 2009). In the case of security and privacy, in particular, non-technological innovation is more frequent and patents play less of a role. The emergence of innovative goods and services is also related to new business models, which are critical to the adoption of innovative solutions. The following two sections analyse security and privacy-enhancing products and business models, respectively.

\section{New security and privacy enhancing products}

A trademark is a sign (a word, a logo, a phrase, etc.) that enables the goods or services of one party to be distinguished from those of another. Trademarks thus play a role in the commercialisation of new products, with new trademarks indicating the launch of new goods and services. Trademarks can also indicate marketing innovations, as they can become the reference on the market for a product (e.g. the "Walkman", first launched by Sony in 1979) (Millot, 2009). Furthermore, trademarks can indicate changes in marketing strategies that aim to reach new customers or change market position. Several studies have highlighted the significant positive relationship between trademark deposits and various innovation variables (patents, R\&D, share of turnover associated to new products, number of new products launched, etc.) in various industries, such as knowledge-intensive services (Mendonça, Pereira and Godinho, 2004; Schmoch, 2003) and high-tech industries (Malmberg, 2005; Mendonça, Pereira and Godinho, 2004). 
Trademarks are a promising alternative to patent statistics for measuring innovation in security and privacy. ${ }^{7}$ The number of trademark applications in security and privacy per thousand ICT trademark applications in the United States Patent and Trademark Office (USPTO) (Figure 7.5) and the European Office of Harmonization for the Internal Market (OHIM) (Figure 7.6) are around six times higher than for patent applications (see previous section). In 2010, around 50 and 60 trademarks per thousand ICT trademarks related to security were registered with USPTO and OHIM, respectively. In particular, one can note that trends observed in USPTO (Figure 7.5) confirm patterns observed in patent applications (Figure 7.4), namely a sharp increase starting in 1999 to 2003-04. Data for OHIM to some degree also confirm these trends. ${ }^{8}$

\section{Figure 7.5. Relative number of trademark applications in information security and privacy at USPTO, 1990-2010}

Per thousand ICT trademark applications

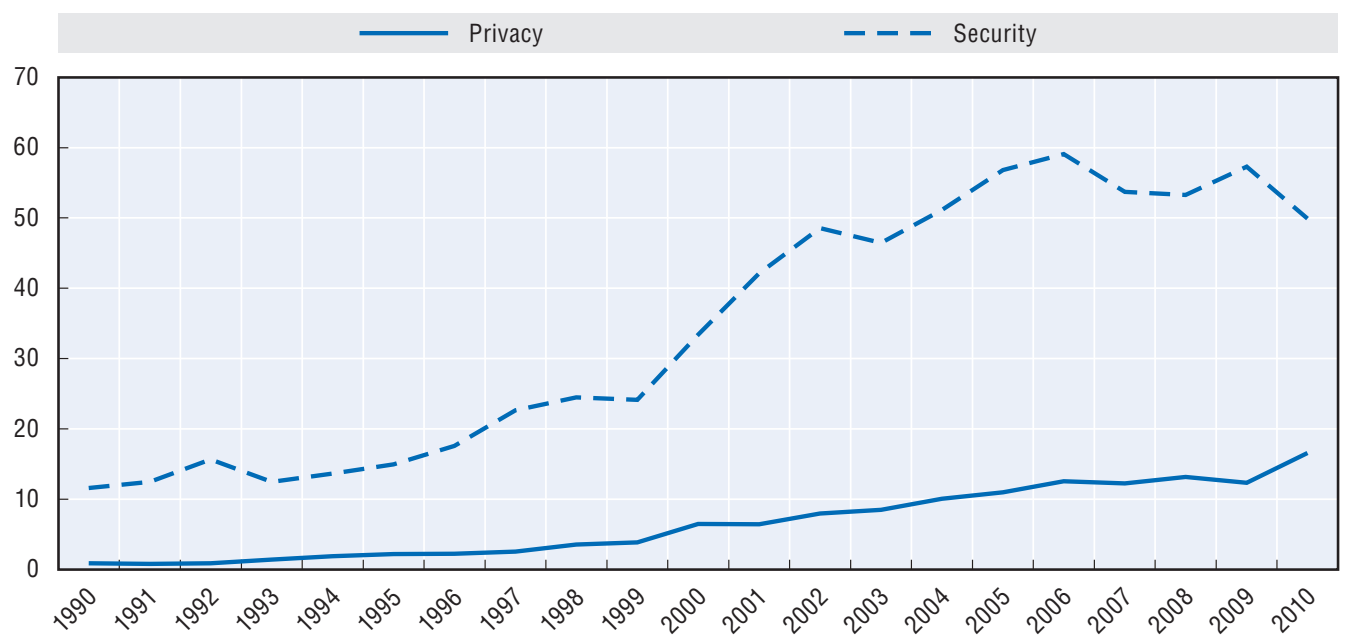

Notes: Security-related applications in classes 9, 38, 42, 45 with the keywords "recovery", "virus", "spyware", ("security" and "computer"). Privacy-related applications in classes 9, 38, 42, 45 with the keywords "anonymity", "identity" and "privacy".

Source: Based on US Patent and Trademark Office (USPTO) data.

StatLink त्ञाजम http://dx.doi.org/10.1787/888932694652

\section{Emerging business models}

New business models play a critical role in the adoption of innovative goods and services. In the area of cybersecurity an increasing number of start-ups, such as FIXMO (Canada), 6Scan (Israel) and OneID (United States), are providing new goods and services covering issues as diverse as mobile risk management, vulnerability exploitation mitigation, and digital identity and authentication management. In the area of privacy, start-ups such as Reputation.com (United States), Qiy (the Netherlands) and Diaspora (United States) aim to provide individuals with more control of and benefit from their own data. These emerging start-ups and their business models are briefly discussed to illustrate the point that security and privacy by design can be a condition for the success of a business, as the challenges leading to Google Buzz shutting down have demonstrated (Arthur, 2010; Carlson, 2010a, 2010b, 2010c), as well as constituting a competitive advantage if implemented well. 
Figure 7.6. Relative number of trademark applications in information security and privacy at OHIM, 1996-2010

Per thousand ICT trademark applications

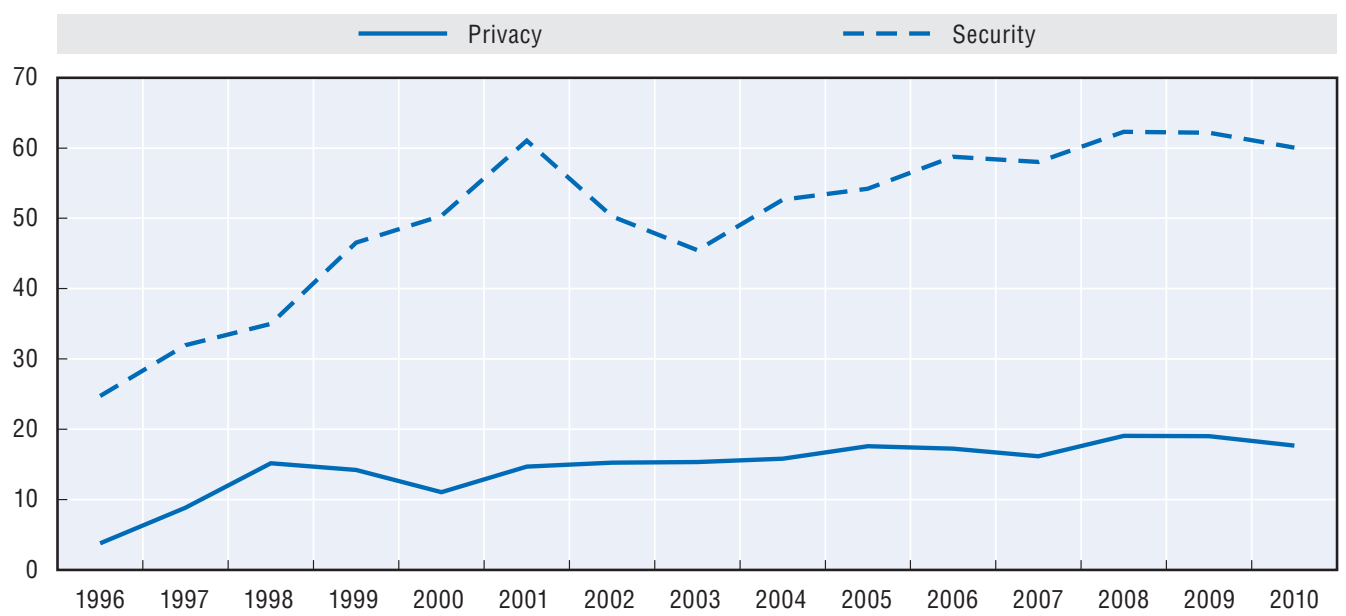

Note: Security-related applications in classes 9, 38, 42, 45 with the keywords "recovery", "virus", "spyware", ("security" and "computer"). Privacy-related applications in classes 9, 38, 42, 45 with the keywords "anonymity", "identity" and "privacy". Source: Based on the European Office of Harmonization for the Internal Market (OHIM) data.

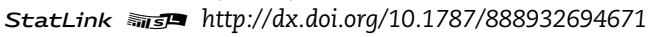

\section{Cybersecurity}

FIXMO is a Canada-based company that provides software solutions such as Fixmo SafeZone for government agencies and enterprises to manage the risks associated with the use of personal mobile devices belonging to employees on internal organisational networks. In addition, FIXMO provides mobile applications (apps), such as Fixmo's Wifi File Transfer and Fixmo Extend, to consumers over mobile app market places such as Google Play. The company is responding to emerging trends in mobile computing and increasing security threats that explicitly target mobile operating systems and apps. FIXMO considers itself the "leader in mobile risk management" (MRM), emphasising its risk management approach to security, which includes device, application and content management, as well as anti-malware and data-loss prevention mechanisms. ${ }^{9}$ Fixmo's MRM technology was developed as part of the Co-operative Research and Development Agreement (CRADA) with the US National Security Agency (NSA). The company has been financed through USD 31 million in venture capital (VC) (Finsmes, 2011; Hartley, 2011).

6Scan is an Israeli-based start-up claiming to provide "the first website protection suite to offer automatic detection and fixing of security vulnerabilities" (PRWeb, 2011). The company was founded in 2011 with venture capital from YL Ventures, a VC company that has prior experience with security-related start-ups, such as Seculert. 6Scan's technology portfolio includes Patrol for active scanning of website vulnerabilities and Bodyguard for automatic mitigation of discovered vulnerabilities. 6 Scan provides three service plans: i) a free plan providing basic e-mail notifications for vulnerabilities detected through Patrol as well as support to fix these vulnerabilities; ii) a plan for USD 10 per month including Bodyguard, zero-day research premium support and sms/email notifications; and iii) a plan provided to large companies that offers a number of customised services.

OneID is a start-up founded in 2011 in the United States. Its goal is to provide a user-centric Internet-scalable digital identity system to replace the username-password paradigm. ${ }^{10}$ The service is expected to provide a more secure authentication experience by 
"eliminating" phishing and other password vulnerabilities, thereby making business sites less vulnerable to password-related attacks (OneID, 2012). OneID's decentralised architecture is also expected to prevent large-scale data breaches: user digital identities can be stored at any "OneID-approved provider, such as an employer, bank, or government agency" (OneID, 2012). In contrast to conventional password-protected sites, where provider keys encrypt passwords (if at all), OneID digital identities are encrypted and decrypted using keys only available on the devices of individual users. Businesses can add OneID support to their existing websites with the addition of a few lines of code. Pricing will depend on the options selected, including: i) OneID Sign In for one-click sign-in, ii) OneID AccuFill for automatic form filling, easy sign-up and checkout, and iii) OneID Checkout for one-click checkouts.

\section{Data privacy}

Reputation.com is a company based in the United States that helps businesses and consumers control their online reputation and privacy. This is achieved through a number of services including, among others: i) the continuous monitoring of personal information on the Internet and handling requests for their removal whenever they become visible (myprivacy), ii) the active creation and promotion of online profiles (myreputation), and iii) the improvement of Internet search results "by increasing positive content and blocking false, misleading or irrelevant content" (reputationdefender). The costs of these services range from USD 130 to USD 5000 per year for individuals. Since January 2010, the company has raised around USD 65 million through a series of VC investments. Among the first VC investors were Kleiner Perkins Caufield \& Byers, well known for their portfolio, which includes Amazon and Google, as well as Bessemer Venture Partners, who also invested in popular web brands like Skype and LinkedIn.

Diaspora is a project initiated by four students in the United States as a response to the increasing privacy concerns related to social networking sites such as Facebook. One of the founders explained their motivation by highlighting the large discrepancy between the relative low value that social networking sites provide and the privacy users have to give up in return (Dwyer, 2010; Suster, 2010). Diaspora provides a decentralised platform that allows users to save their data on their own servers (at home or at the web-hosting provider). ${ }^{11}$ Users can share these servers, called "pods", with other users not willing or not able to install their own pod. The funding required to develop Diaspora was collected by donations, received via the online platform Kickstarter (2012). As of March 2012, almost 6500 users had donated more than USD 200 000, surpassing the target figure of USD 10000 (Kickstarter, 2012). November 2010 saw the release of a free test version of Diaspora with open-source software, enabling users to contribute to the development of the platform or to install it on a private server or cloud (Siegler, 2010). As of March 2012, they were 113 pods installed worldwide with almost 1.5 million user accounts. ${ }^{12}$

\section{Employment and skills as enabling factors}

Businesses are increasingly looking for professionals with skills in IT security and privacy, not only to develop, deploy and operate new security and privacy-enhancing tools, but also to better assess and manage the risks related to security and privacy that they are facing online. The following sections briefly discuss demand for IT security and privacy professionals and the extent to which this demand can be met. They highlight, in particular, the provision of high-skilled people as an enabler for innovation in security and privacy. 


\section{IT security professionals}

The increasing relevance of cybersecurity to organisations is reflected in the growing demand for skilled employees who can handle cybersecurity risks. Demand for these skills remained high even during the recent financial crises in many OECD economies. According to IT training provider GlobalKnowledge (2010), IT security skills ranked second among the top 10 IT skills in 2010. A recent survey undertaken by InformationWeek (2012) of 418 IT staff and 307 IT managers revealed that "securing data and applications" were considered the business and technical skills most critical for their jobs (90\% of IT staff and $92 \%$ of IT managers). In the United Kingdom, demand for IT security professionals increased in 2011, mainly driven by high-profile cyber attacks and growing spending on cloud computing security, increased use of penetration testing services, and "the January 2012 deadline for all PCI DSS assessments to be under version 2.0 of the standard" (Ashford, 2011). As a result, increases in salaries of IT security professionals peaked at 13\% in the first half of 2011 , suggesting that supply for IT security professionals could not meet rapidly growing demand.

Some OECD countries may not be able to meet the increasing demand for IT security professionals, which may prevent the adoption of innovative solutions in these countries. ${ }^{13}$ This is partly reflected in the share of ICT specialists, which differs significantly across countries. ICT specialists accounted for approximately $3 \%$ to $4 \%$ of total employment in most OECD countries in 2010 (Figure 7.7). The share has risen consistently in recent years in most countries. However, it remains low (below 3\%) in countries such as Greece, Portugal and Turkey. The extent to which countries with a low share of ICT specialists may suffer skill shortages will depend on increase in demand, in particular, for IT security professionals.

Figure 7.7. Share of ICT specialist users in the total economy, 1995 and 2010

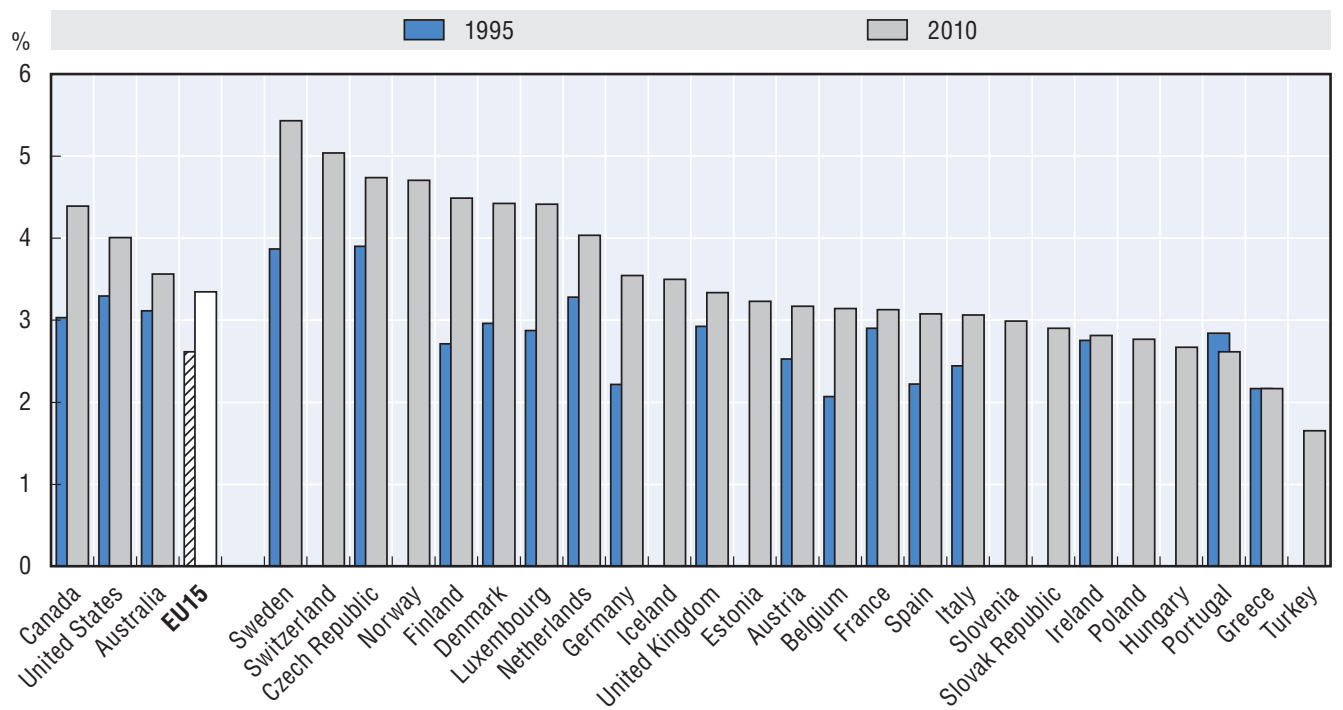

Notes: For Australia, Finland and Sweden, 1997 instead of 1995. For Australia: 2009 instead of 2010. "Specialist users" corresponds to the narrow definition based on the methodology described in Chapter 6 of OECD (2004). Shares for non-European countries are not directly comparable with shares for European countries, as the classifications are not harmonised.

Sources: OECD calculations based on European Labour Force Statistics (EULFS), US Current Population Survey, Statistics Canada, Australian Bureau of Statistics, May 2011. 
Certification bodies issuing certifications for security-related skills constitute another important source for data on IT-security professionals. The International Information Systems Security Certification Consortium [(ISC) $\left.{ }^{2}\right]$, for example, provides certifications ${ }^{14}$ for security-related skills in more than 130 countries (ISC $\left.{ }^{2}, 2010\right) .{ }^{15}$ In 2010, (ISC) ${ }^{2}$ had 74000 certified individuals (i.e. members) worldwide (Figure 7.8). This represents a 13\% increase since 2009, and the fastest year-on-year increase since 2007. According to a member survey, the average annual salary of (ISC) $)^{2}$ members increased from almost USD 81000 in 2006 to almost USD 99000 in 2010, an average compound annual growth rate (CAGR) of more than $5 \%$ per year. The exact number of surveyed members is unknown, however, the distribution of (ISC) $)^{2}$ members by country suggests that the figures on average annual salary are most likely biased towards the Americas, and the United States in particular.

Figure 7.8. Number of (ISC) ${ }^{2}$ certified individuals worldwide, 2003-10

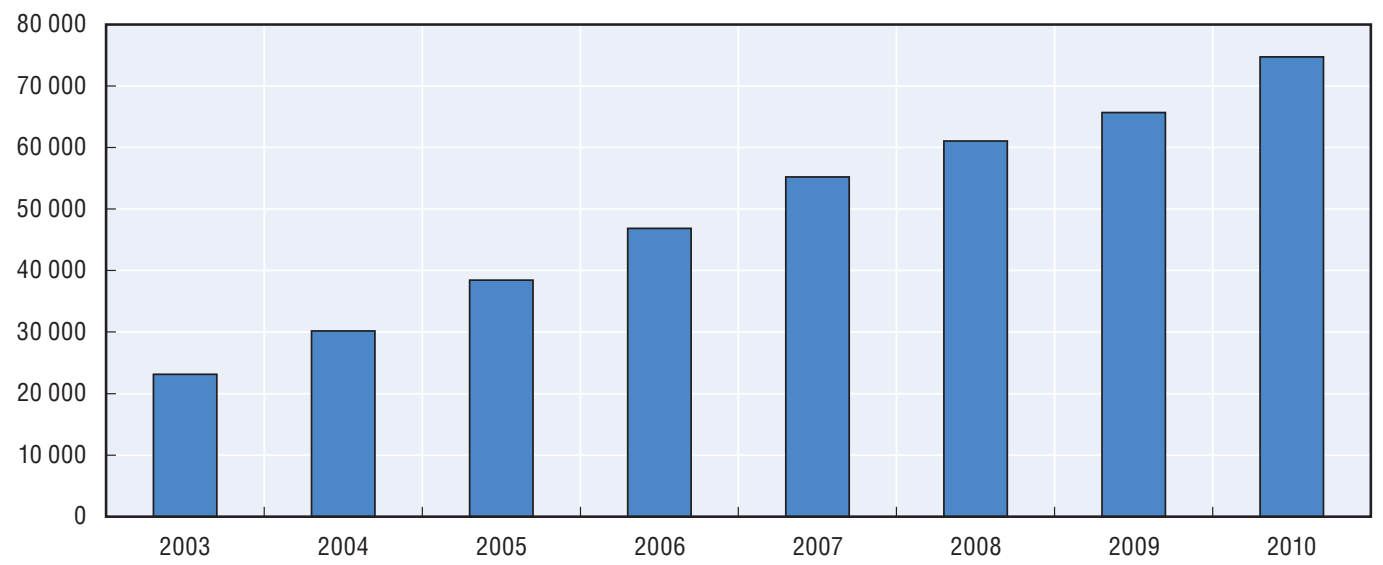

Source: Based on International Information Systems Security Certification Consortium (ISC $\left.{ }^{2}, 2011\right)$, (ISC) ${ }^{2}$ Annual Report 2010.

It is important to note that cybersecurity does not only rely on high-skilled specialists. End-users also need to understand their responsibilities in keeping corporate and private information systems and networks as secure as possible. Awareness-raising is thus crucial, as highlighted in the OECD (2002) Guidelines for the Security of Information Systems and Networks: Towards a Culture of Security, ${ }^{16}$ while organisations also have an important role to play (ACMA, 2011). In 2010, almost half of all firms in the EU27 implemented actions to inform staff of their ICT security obligations (Figure 7.9). The most frequently used approaches were voluntary training or generally available information (more than $30 \%$ of enterprises) while compulsory training or presentations were less frequent ( $20 \%$ of enterprises).

\section{Privacy professionals}

Available statistics on privacy professionals also suggest an increasing demand for employees who understand the benefits but also the privacy risks linked to data. As the relevance of personal data as an intangible asset in the Internet economy increases (OECD, 2012), demand can be expected to increase further. A number of countries already include a requirement for data protection officers (DPOs) in companies as part of their legislation. The European Commission (EC, 2012) proposed directive, for example, requires DPOs for companies with 250 and more employees. This trend could lead to further adoption of privacy by design as the internal expertise of firms with regard to data privacy increases. 
Figure 7.9. Approaches used to inform staff of their ICT security obligations, by country, 2010

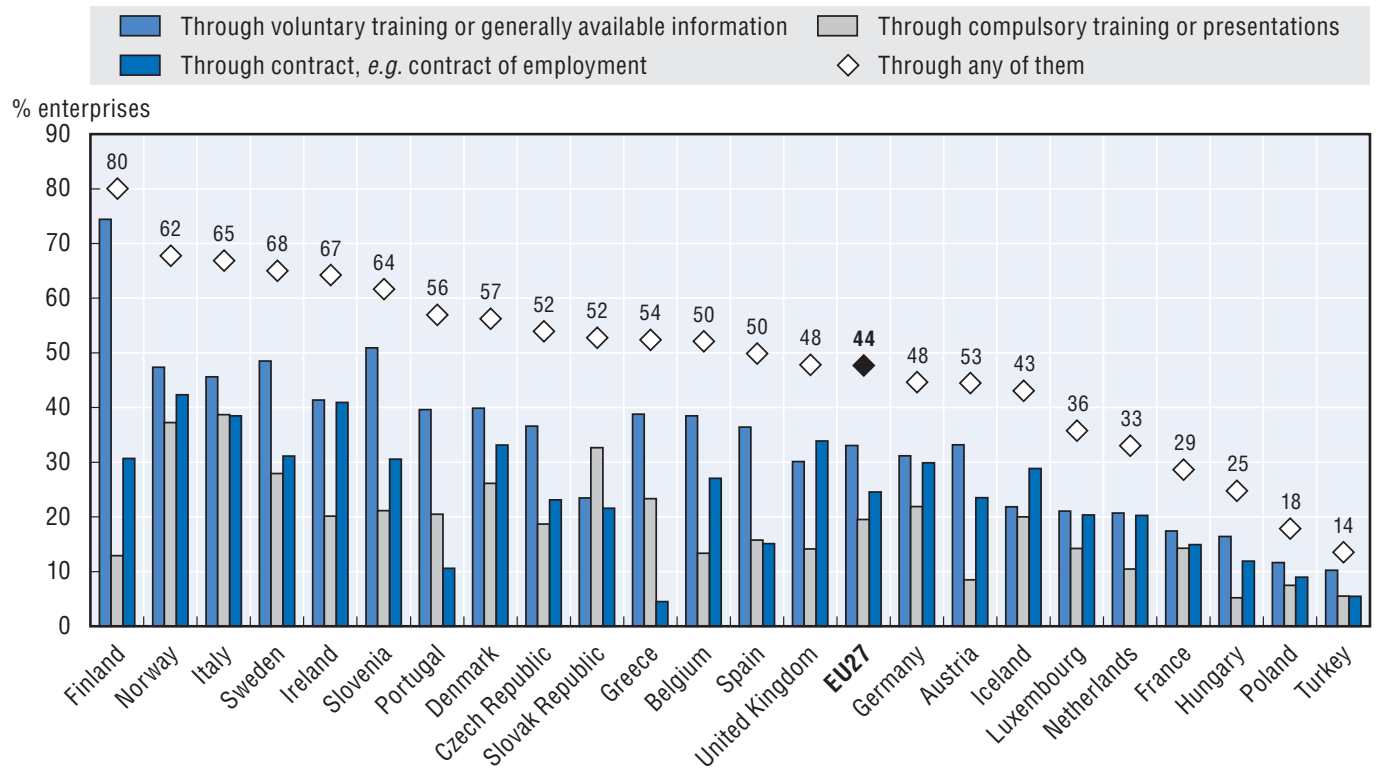

Note: Enterprises with 10 or more persons employed. For further details see Chapter 4, endnote 1. Source: Based on Eurostat Community Survey on ICT usage in businesses, June 2012.

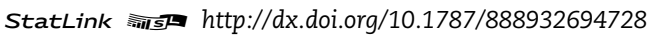

The International Association of Privacy Professionals (IAPP), "the world's largest association of privacy professionals", is one of the few sources for statistics on privacy professionals (IAPP, 2012). ${ }^{17}$ As of 2012, the IAPP has more than 10000 members in 70 countries (Figure 7.10). ${ }^{18}$ This is an increase of around $34 \%$ compared to the previous year. According to the 2012 IAPP salary survey of its members, salaries of privacy professional averaged around USD 120000 at the end of 2011, a slight decrease compared to the previous year $(-4 \%)$, but still an increase of $9 \%$ compared to 2010 . This suggests that demand for

Figure 7.10. Total number of IAPP members, 2000-12

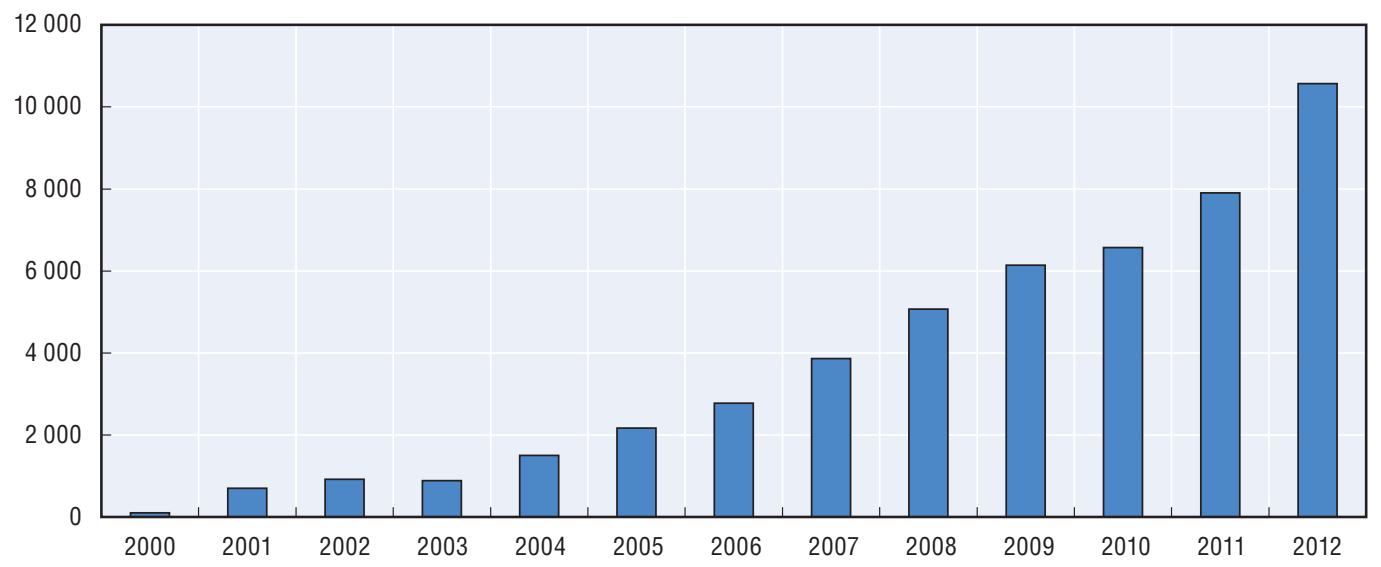

Note: The number for 2012 reflects members as of June 2012.

Source: Based on IAPP (International Association of Privacy Professionals) (2012), Privacy Professional's Role, Function and Salary Survey, IAPP, Portsmouth, USA. 
privacy professional has increased faster than supply since $2010 .{ }^{19}$ However, distribution of the number of surveyed privacy professionals by region in 2012 shows that figures on salaries are most likely biased towards the United States, in which most IAPP members were located.

Policy makers in OECD countries place a relatively high priority on the security of information systems and networks. Chapter 8 provides the rankings of policy priorities in OECD governments and includes information on domestic level strategies in several OECD countries.

\section{Conclusion}

This chapter highlights the role of innovation for securing trust in the Internet economy. It highlights the emergence of new services and goods as well as new business models related to cybersecurity and privacy. The data presented in this chapter suggest that $R \& D$ is a significant factor for increasing innovation, in particular, in the field of cybersecurity. The data also suggest that the IT security industry is an R\&D-intensive industry when compared to other ICT industries. The few cases presented in this chapter suggest that venture capital (VC) is an important means of financing innovation in cybersecurity. However, more research would be needed to confirm these observations.

Data on the role of innovation in the area of privacy is more elusive, either because R\&D figures are harder to find or because privacy-enhancing technologies are less frequently patented. Statistics on trademarks seem to capture innovation in privacy much better; however, the number of trademark applications related to privacy is six times lower than that of trademark applications related to information security. This possibly suggests a lower level of ongoing technological and product innovation in the field of privacy compared to information security.

The challenge in measuring the skill aspects of information security and privacy is apparent. However, the increasing relevance of information security and privacy at the organisational, national and international level, suggests that demand for security and privacy professionals will increase, making skills a potential bottleneck for enhancing innovation in information security and privacy.

Overall, this chapter shows that innovation should be considered as an important factor for securing trust in the Internet economy. However, further research is needed to investigate the degree to which the private sector may be able to adequately enhance innovation in cybersecurity and, in particular, in privacy, given that data on R\&D, patents, trademarks and employment is limited in these areas. The private sector needs to be encouraged to share better data on their innovation-related activities in cybersecurity and data privacy. This would also include information related to financial loss due to cyber crime, which would constitute their principle expected motivation for investment in security and privacy.

Chapter 8 continues with results of the OECD ICT policy questionnaire that ranks policy priorities. Security and privacy were signalled as a priority by 16 out of the 23 countries participating in the questionnaire. 


\section{Notes}

1. A data breach is "a loss, unauthorised access to or disclosure of personal data as a result of a failure of the organisation to effectively safeguard the data" (OECD, 2011). Where the security breach involves intellectual property not including personal data the term "unauthorised access" is used instead.

2. According to the OECD (2008b), R\&D activities focusing on cyber security result in "significant impetus for improving the integrity, availability and confidentiality of digital information as well as the privacy of individuals comes from natural processes (e.g. quantum cryptography, self-healing computing systems, and intrusion detection inspired by immunology). Technological solutions to prevent and tackle criminal activity such as online fraud and identity theft and terrorist activities are being sought, including digital investigation and retaliation".

3. This section focuses on IT security companies, and will exclude analysis of the emerging cyberdefence sector.

4. This chapter focuses on firms providing IT security goods and services for civilian purposes mainly.

5. Information provided through patent data include geographical location, technical and institutional origin, and networks.

6. The identification of relevant patents is based on keywords considered to be relevant to security and privacy. Given that the search term "security" alone would identify all ICT-related patents used for security purposes outside the ICT sector, a more complex chain of key words had to be defined. It includes terms (in different variation of spelling) such as "information security", "information network security", "confidentiality", "integrity", "availability", "crypt" and "authentication", as well as type of attacks and exploitations such as "malware", "denial of service" "sql injection", "buffer overflow" and "cross-site scripting". For identifying patents for privacy-enhancing technologies the search term "privacy" delivered a very good precision.

7. In the case of security, this is more straightforward given that trademarks are grouped by classes including, among others, "Recovery of computer data" (C0082) and "Computer virus Protection services" (P0076). In the case of privacy, search terms have to be applied. This chapter uses the term "privacy" to identify privacy-related trademarks.

8. At this point, it should be noted that the identification of trademarks related to security and privacy are based on ICT-related classes that have been narrowed down based on keywords. Security-related applications are located in classes 9, 38, 42, 45 with the keywords "recovery" "virus" and "spyware" ("security" and "computer") being used. In the case of privacy-related applications, classes 9, 38, 42, 45 have been used with the keywords "anonymity", "identity" and "privacy".

9. For more details, see: http://fixmo.com/solutions/mobile-risk-management.

10. As highlighted by Empson (2012), many companies have tried to provide a single sign-on system for the Internet, but have failed "because no one wants to hand over all their sensitive personal information to one company".

11. See Wauters (2010) for other social networking alternatives.

12. For more details see: https://diasp.eu. For comparison, as of January 2011 Facebook had more than 850 million users and Google+ had 90 million users.

13. Not all IT security experts may offer their skills through the labour market. Some may offer they labour rather to criminals through (online) black markets. The reasons for this can be as diverse as the personalities of these individuals, but research on the motivations behind cybercrime suggests that socio-economic factors are the dominant determinants (Ngafeeson, 2010). Furnell (2001, cited from Ngafeeson, 2009), for example, highlights i) money; ii) (intellectual) challenge; iii) ideology; iv) ego; and $v$ ) revenge as the most likely motivations of cyber criminals; followed by vi) mischief; and vii) espionage. Although the likelihoods of these motivational factors may have changed in the course of the last ten years, they still can be considered the main factors.

14. These include the following six certificates: i) Certified Information Systems Security Professional (CISSP); ii) Information Systems Security Architecture Professional (ISSAP); iii) Information Systems Security Management Professional (ISSMP); iv) Information Systems Security Engineering Professional (ISSEP); v) Certification and Accreditation Professional (CAP CM); and vi) Systems Security Certified Practitioner (SSCP).

15. According to the 2009 (ISC) ${ }^{2}$ annual report, 70\% of (ISC) $)^{2}$ certified individuals (members) were located in the Americas, $16 \%$ in Europe, the Middle East and Africa (EMEA), and 14\% in the Asia-Pacific region. 
16. As the OECD (2002) Security Guidelines highlight, "Participants should be aware of the need for security of information systems and networks and what they can do to enhance security. Awareness of the risks and available safeguards is the first line of defence for the security of information systems and networks. Information systems and networks can be affected by both internal and external risks. Participants should understand that security failures may significantly harm systems and networks under their control. They should also be aware of the potential harm to others arising from interconnectivity and interdependency. Participants should be aware of the configuration of, and available updates for, their system, its place within networks, good practices that they can implement to enhance security, and the needs of other participants."

17. It should be noted, however, that some IAPP members do not work as data protection officers. Other represented occupations include lawyers and policy analysts, who became IAPP certified for a variety of reasons. Furthermore, concerns have been expressed regarding the degree to which IAPP membership truly reflects the acquisition of technical skills required as privacy professionals. In this respect, IAPP membership would constitute a weaker metrics for privacy-related skills than (ISC) $)^{2}$ membership for cybersecurity-related skills.

18. For more details see: https://www.privacyassociation.org/about_iapp/.

19. The decrease in the average salary could be due to "the slight drop in the average seniority of survey respondents" (IAPP, 2012).

\section{References}

ACMA (Australian Communications and Media Authority) (2011), An Overview of International Cyber-Security Awareness Raising and Educational Initiatives: Research Report Commissioned by the Australian Communications and Media Authority, ACMA, Canberra, www.acma.gov.au/webwr/assets/ main/lib310665/galexia_report-overview_intnl_cybersecurity_awareness.pdf.

Arthur, C. (2010), “Google Buzz's Open Approach Leads to Stalking Threat”, The Guardian, 12 February, www.guardian.co.uk/technology/blog/2010/feb/12/google-buzz-stalker-privacy-problems.

Ashford, W. (2011), "Information Security Skills in High Demand for 2011", Computer Weekly, 9 August, www.computerweekly.com/Articles/2011/08/09/247560/Information-security-skills-in-high-demand-for2011.htm.

Carlson, N. (2010a), "WARNING: Google Buzz Has A Huge Privacy Flaw", Business Insider, 10 February, www.businessinsider.com/warning-google-buzz-has-a-huge-privacy-flaw-2010-2.

Carlson, N. (2010b), "Google Buzz Still Has Major Privacy Flaw", Business Insider, 12 February, www.businessinsider.com/googles-nice-improvements-to-buzz-dont-correct-major-privacy-flaw-2010-2.

Carlson, N. (2010c), “Google Making More Changes To Buzz After Huge Privacy Outcry”, Business Insider, 13 February, www.businessinsider.com/google-making-more-changes-to-buzz-after-privacy-outcry-2010-2.

Damballa (2010), "The Command Structure of the Aurora Botnet: History, Patterns and Findings", Damballa, 3 March, www.damballa.com/downloads/r_pubs/Aurora_Botnet_Command_Structure.pdf.

Dwyer, J. (2010). "Four Nerds and a Cry to Arms Against Facebook", New York Times, 11 May, www.nytimes.com/2010/05/12/nyregion/12about.html?_r=1.

EC (European Commission) (2012), Proposal for a directive of the European parliament and of the council on the protection of individuals with regard to the processing of personal data by competent authorities for the purposes of prevention, investigation, detection or prosecution of criminal offences or the execution of criminal penalties, and the free movement of such data, COM/2012/010 final - 2012/0010 (COD), EC, Brussels, http://eur-lex.europa.eu/LexUriServ/LexUriServ.do?uri=COM:2012:0010:FIN:EN:HTML.

Empson, R. (2012), "Multiple Usernames \& Passwords No More: OneID Unveils Its Next-Gen Identity Service”, TechCrunch, 13 March, http://techcrunch.com/2012/03/13/oneid-beta-launch/.

Falliere N., L.O. Murch and E. Chien (2011), W32.Stuxnet Dossier, Symantec Security Response, Version 1.4, February, www.symantec.com/content/en/us/enterprise/media/security_response/ whitepapers/w32_stuxnet_dossier.pdf.

Flides, L. (2010), “Stuxnet Worm 'Targeted High-value Iranian assets'”, BBC News, 23 September, www.bbc.co.uk/news/technology-11388018.

Finsmes (2011), “Fixmo Closes \$23M Series C Funding”, FinSMEs, www.finsmes.com/2011/11/fixmo-closes23m-series-funding.html. 
Furnell, S.M. (2001), “The Problem of Categorising Cybercrime and Cybercriminals", paper presented at the 2nd Australian Information Warfare and Security Conference 2001, 29-30 November, Perth, Australia.

GlobalKnowledge (2010), Top 10 Skills in Demand in 2010, www.globalknowledge.com/training/ generic.asp?pageid=2568 (accessed 1 March 2012).

Golovanov, S., A. Gostev and A. Monastyrsky (2008), Bootkit: the challenge of 2008, SecureList, 18 December, www.securelist.com/en/analysis/204792044 (accessed 15 March 2012).

Goodin, D. (2011), “Sony Says Data for 25 Million More Customers Stolen”, The Register, 3 May, www.theregister.co.uk/2011/05/03/sony_hack_exposes_more_customers/.

Google (2010), “A New Approach to China”, Google Official Blog, 13 January, http://googleblog.blogspot.fr/ 2010/01/new-approach-to-china.html.

Halliday, J. (2010), “Stuxnet Worm is the 'Work of a National Government Agency", The Guardian, 24 September, www.guardian.co.uk/technology/2010/sep/24/stuxnet-worm-national-agency.

Hartley, M. (2011), “Toronto's Fixmo Lands \$23.4-Million in Funding from Top VCs”, Financial Post, http:// business.financialpost.com/2011/11/28/torontos-fixmo-lands-23-4-million-funding-round-from-top-vc-firms/.

Hesseldahl, A. (2010), “Computer Worm May Be Targeting Iranian Nuclear Sites”, Bloomberg, 24 September, www.bloomberg.com/news/2010-09-24/stuxnet-computer-worm-may-be-aimed-at-iran-nuclear-sitesresearcher-says.html.

IAPP (International Association of Privacy Professionals) (2012), Privacy Professional's Role, Function and Salary Survey, IAPP, Portsmouth, United States.

InformationWeek (2012), “2012 Salary Survey: IT’s Hottest 'Necessary Evil’”, April, Report ID: R4150412.

ISC $^{2}$ (International Information Systems Security Certification Consortium) (2010), (ISC) ${ }^{2}$ Annual Report 2009, ISC ${ }^{2}$, Vienna, United States, www.isc2.org/aboutus/default.aspx.

ISC $^{2}$ (2011), (ISC) $)^{2}$ Annual Report 2010, Vienna, United States, www.isc2.org/aboutus/default.aspx.

Keizer, G. (2010), “Is Stuxnet the 'Best' Malware Ever?”, Computerworld, 16 September, www.computerworld.com/s/article/9185919/Is_Stuxnet_the_best_malware_ever_.

Kickstarter (2012), "Decentralize the Web with Diaspora”, www.kickstarter.com/projects/196017994/ diaspora-the-personally-controlled-do-it-all-distr (accessed 25 March 2012).

Langer, R. (2012), "Ralph talks about cyber weapons", Blog: When there is more at risk then information, 24 January, available at: www.langner.com/en/2012/01/24/ralph-talks-about-cyber-weapons/.

McAfee (2010), “Protecting Your Critical Assets: Lessons Learned from 'Operation Aurora'”, White Paper, www.wired.com/images_blogs/threatlevel/2010/03/operationaurora_wp_0310_fnl.pdf.

Malmberg, C., (2005), “Trademark Statistics as Innovation Indicators? - A Micro Study”, CIRCLE Electronic Working Paper Series, 2005-17, CIRCLE (Centre for Innovation, Research and Competence in the Learning Economy), Lund University, Sweden.

Matrosov, A, E. Rodionov, D. Harley and J. Malcho (2011), "Stuxnet Under the Microscope", ESET, January, Revision 1.3.1, http://go.eset.com/us/resources/white-papers/Stuxnet_Under_the_Microscope.pdf.

Mendonça, S., T.S. Pereira and M.M. Godinho (2004), “Trademarks as an Indicator of Innovation and Industrial Change", Research Policy, Vol. 33, No. 9, pp. 1385-1404.

Microsoft (2012), The Evolution of Malware and the Threat Landscape - a 10-year Review, Microsoft Security Intelligence Report: Special Edition, February, http://download.microsoft.com/download/1/A/7/ 1A76A73B-6C5B-41CF-9E8C-33F7709B870F/Microsoft_Security_Intelligence_Report_Special_Edition_10_ Year_Review.pdf.

Millot, V. (2009), “Trademarks as an Indicator of Product and Marketing Innovations”, OECD Science, Technology and Industry Working Papers, No. 2009/06, OECD Publishing. doi: http://dx.doi.org/10.1787/224428874418.

NIST (National Institute of Standards and Technology) (2004), Computer Security Incident Handling Guide - Recommendations of the National Institute of Standards and Technology, Special Publication 800-61, NIST, Boulder, USA, csrc.nist.gov/publications/nistpubs/800-61-rev1/SP800-61reu1.pdf.

NSTC (National Science and Technology Council) (2011), Trustworthy Cyberspace: Strategic Plan for the Federal Cybersecurity Research and Development Program, US Government, Washington, DC, www.whitehouse.gov/sites/default/files/microsites/ostp/fed_cybersecurity_rd_strategic_plan_2011.pdf. 
Ngafeeson, M. (2010), “Cybercrime Classification: A Motivational Model”, paper presented at the Southwest Decision Sciences Institute Conference, 3-6 March 2010, www.swdsi.org/swdsi2010/ SW2010_Preceedings/papers/PA168.pdf.

O’Dell, J. (2011), “In a World Without Tracking \& Cookies, Can Online Commerce Succeed?", mashable.com, 10 May, http://mashable.com/2011/05/10/buyosphere/.

OECD (2002), OECD Guidelines for the Security of Information Systems and Networks: Towards a Culture of Security, OECD Publishing. doi: http://dx.doi.org/10.1787/9789264059177-en-fr.

OECD (2004), OECD Information Technology Outlook 2004, OECD Publishing. doi: $h$ ttp://dx.doi.org/10.1787/it_outlook-2004-en.

OECD (2008a), Recommendation of the Council on Protection of Critical Information Infrastructures, OECD, Paris, www.oecd.org/dataoecd/1/13/40825404.pdf.

OECD (2008b), OECD Information Technology Outlook 2008, OECD Publishing. doi: http://dx.doi.org/10.1787/it_outlook-2008-en.

OECD (2009a), OECD Patent Statistics Manual, OECD Publishing. doi: http://dx.doi.org/10.1787/9789264056442-en.

OECD (2009b), Computer Viruses and Other Malicious Software: A Threat to the Internet Economy, OECD Publishing. doi: http://dx.doi.org/10.1787/9789264056510-en.

OECD (2010a), The OECD Innovation Strategy: Getting a Head Start on Tomorrow, OECD Publishing. doi: $h$ ttp://dx.doi.org/10.1787/9789264083479-en.

OECD (2010b), OECD Information Technology Outlook 2010, OECD Publishing. doi: http://dx.doi.org/10.1787/it_outlook-2010-en.

OECD (2011), “The Evolving Privacy Landscape: 30 Years After the OECD Privacy Guidelines”, OECD Digital Economy Papers, No. 176, OECD Publishing. doi: http://dx.doi.org/10.1787/5kgf09z90c31-en.

OECD (2012), "New Sources of Growth: Knowledge-Based Capital Driving Investments and Productivity in the 21st Century, Interim Project Findings", OECD, Paris, www.oecd.org/dataoecd/62/20/50498841.pdf.

OECD/Statistical Office of the European Communities, Luxembourg (2005), Oslo Manual: Guidelines for Collecting and Interpreting Innovation Data, 3rd Edition, The Measurement of Scientific and Technological Activities, OECD Publishing. doi: http://dx.doi.org/10.1787/9789264013100-en.

OneID (2012), What is OneID?, OneID, www.oneid.com/for-businesses/how-it-works (accessed 26 March 2012).

PRWeb (2011), "YL Ventures Completes a Venture Capital Investment in 6Scan", PRWeb, www.prweb.com/ printer/8688678.htm.

Reuters (2011), “UPDATE 2-Sony Breach Could Cost Card Lenders $\$ 300$ mln”, Reuters, 28 April, www.reuters.com/article/2011/04/28/sony-creditcards-cost-idUSN2826485220110428.

Schmoch, U. (2003), "Service Marks as Novel Innovation Indicator", Research Evaluation, Vol. 12, No. 2, pp. 149-156.

Seybold, P. (2011), "Update on PlayStation Network and Qriocity", PlayStation.Blog, 26 April, http:// blog.us.platstation.com/2011/04/26/update-on-playstation-network-and-qriocity.

Siegler, M. (2010), "Facebook Competitor Diaspora Revealed: Sparse, But Clean; Source Code Released", TechCrunch, 15 September, http://techcrunch.com/2010/09/15/diaspora-revealed/.

Suster, M. (2010), “Social Networking: The Future”, TechCrunch, 5 December, http://techcrunch.com/2010/ 12/05/social-networking-future/.

US CERT (United States Computer Emergency Readiness Team) (n.d.), Federal Incident Reporting Guidelines, www.us-cert.gov/government-users/reporting-requirements.html.

Voreacos, D. (2009), "Hacker Agrees to Plead Guilty in Second Computer Data Theft", Bloomberg, 9 December, www.bloomberg.com/apps/news?pid=newsarchive\&sid=aE0.80_7QcGc.

Zakorzhevsky, V. (2010), "Review of the Virus.Win32.Virut.ce Malware Sample”, SecureList, 10 June, www.securelist.com/en/analysis/204792122 (accessed 15 March 2012).

Zetter, K. (2009), “TJX Hacker Charged With Heartland, Hannaford Breaches”, Wired, 17 August, www.wired.com/threatlevel/2009/08/tjx-hacker-charged-with-heartland.

Zetter, K. (2010), “'Google' Hackers Had Ability to Alter Source Code”, Wired, 3 March, www.wired.com/ threatlevel/2010/03/source-code-hacks/. 


\section{ANNEX 7.A1 \\ Basic Principles of National Application (OECD Privacy Guidelines, Part 2)}

\section{Collection Limitation Principle}

There should be limits to the collection of personal data and any such data should be obtained by lawful and fair means and, where appropriate, with the knowledge or consent of the data subject.

\section{Data Quality Principle}

Personal data should be relevant to the purposes for which they are to be used, and, to the extent necessary for those purposes, should be accurate, complete and kept up-to-date.

\section{Purpose Specification Principle}

The purposes for which personal data are collected should be specified not later than at the time of data collection, and the subsequent use limited to the fulfilment of those purposes or such others as are not incompatible with those purposes and as are specified on each occasion of change of purpose.

\section{Use Limitation Principle}

Personal data should not be disclosed, made available or otherwise used for purposes other than those specified in accordance with Paragraph 9 except: (a) with the consent of the data subject; or (b) by the authority of law.

\section{Security Safeguards Principle}

Personal data should be protected by reasonable security safeguards against such risks as loss or unauthorised access, destruction, use, modification or disclosure of data.

\section{Openness Principle}

There should be a general policy of openness about developments, practices and policies with respect to personal data. Means should be readily available of establishing the existence and nature of personal data, and the main purposes of their use, as well as the identity and usual residence of the data controller. 


\section{Individual Participation Principle}

An individual should have the right:

a) to obtain from a data controller, or otherwise, confirmation of whether or not the data controller has data relating to him;

b) to have communicated to him, data relating to him i) within a reasonable time; ii) at a charge, if any, that is not excessive; iii) in a reasonable manner; and iv) in a form that is readily intelligible to him;

c) to be given reasons if a request made under subparagraphs (a) and (b) is denied, and to be able to challenge such denial; and

d) to challenge data relating to him and, if the challenge is successful to have the data erased, rectified, completed or amended.

\section{Accountability Principle}

A data controller should be accountable for complying with measures which give effect to the principles stated above. 


\section{Chapter 8}

\section{Government priorities and policy developments}

This chapter reviews government priorities for different ICT policy areas. The first section maps ICT policy priorities in OECD countries against the wider economic, social and political context. This is followed by a discussion of specific ICT policy areas including security of information systems and networks, enhancing current infrastructure through the deployment of broadband and IPv6, e-government, $e$-health, ICT skilling and digital content. The final section examines ways to foster innovation with a focus on green ICT programmes. Analysis is based on detailed information provided by 22 OECD member countries and the European Commission, as well as recent OECD work. 


\begin{abstract}
A s the Internet and related ICTs have become increasingly vital to economies and societies around the world, the importance of generic and specific policies for the Internet economy has increased. The recent policy emphasis on areas that directly contribute to growth, to more sustainable fiscal positions and to social cohesion, including universal broadband, e-government, and ICT skills and employment, provides evidence of the key role that ICT policy can and must play in enabling sustainable growth and structural reform.

ICT policies have changed considerably over the past decade. They started as sectoral policies to strengthen domestic industry sectors, and have since become mainstream economic policies aimed at underpinning growth and jobs, increasing productivity, enhancing delivery of public and private services, and achieving broader socioeconomic objectives. In recent years, a number of OECD countries have developed cross-cutting digital strategies that touch upon all these issues (Table 8.1). The underlying vision is one of the Internet economy as a fundamental platform to enable economic modernisation and structural change. The target areas range from government, healthcare and education to climate change, energy efficiency, employment and social developments. Strategies are evolving from policies targeting improved connectivity towards a broader focus on developing seamless, ubiquitous network environments where people can receive services easily.
\end{abstract}

Table 8.1. Examples of digital strategies per country

\begin{tabular}{|c|c|c|}
\hline Country & Strategy name & Date \\
\hline Australia & Australian National Digital Economy Strategy & May 2011 \\
\hline Austria & Strategy for Research, Technology and Innovation (RTI strategy) & March 2011 \\
\hline Canada & $\begin{array}{l}\text { Canada's digital economy strategy built upon the Government's economic plan, } \\
\text { Advantage Canada }\end{array}$ & In the implementation process \\
\hline Czech Republic & Smart Administration Strategy for the period 2007-15 & September 2006 \\
\hline Estonia & The Estonian Information Society Strategy 2007-13 & January 2007 \\
\hline European Community & Digital Agenda for Europe (DAE) & May 2010 \\
\hline France & Plan Numérique 2012 & November 2011 \\
\hline Germany & Digital Germany 2015 & November 2010 \\
\hline Hungary & The Digital Renewal Action Plan & December 2010 \\
\hline Japan & New Strategy in Information and Communications Technology & May 2010 \\
\hline The Netherlands & Digital Agenda.nl & May 2011 \\
\hline New Zealand & Directions and Priorities for Government ICT & October 2010 \\
\hline Norway & Digital Agenda for Norway & Under development \\
\hline Portugal & Digital Agenda 2015 & September 2010 \\
\hline Spain & Plan Avanza 2 & July 2010 \\
\hline Sweden & Digital Agenda for Sweden & September 2011 \\
\hline Switzerland & Strategy for an Information Society in Switzerland & Updated March 2012 \\
\hline Turkey & The e-Transformation Turkey Project since 2003 & $\begin{array}{l}\text { New strategy to be formulated } \\
\text { by end- } 2012\end{array}$ \\
\hline United Kingdom & Digital Economy Act & June 2010 \\
\hline United States & Many ICT initiatives form part of the Strategy for American Innovation & December 2010 \\
\hline
\end{tabular}


Hesitant recovery and crippling budget deficits, alongside sovereign debt crises in Europe, have led policy makers to refocus limited resources on improving online government services delivery and engagement, and on key ingredients for economic growth, productivity and employment. National governments are increasingly aligning Internet economy priorities directly with socioeconomic objectives, such as improving health and aged care, improving environmental sustainability, and promoting growth and employment. Broadband networks and promotion of ICT innovation continue to be a leading priority in this context. In parallel, countries are seeking to address the challenges and risks arising from greater digital engagement through a focus on comprehensive online security strategies. Finally, policy makers have become increasingly aware of the potential role of the Internet in advancing social and democratic values. The OECD High Level Meeting on the Internet Economy, which took place in June 2011, for example, recognised the role of the Internet in allowing people to give voice to their democratic aspirations (OECD, 2011a).

This chapter reviews the ways in which governments prioritise different ICT policy areas. The first section maps ICT policy priorities in OECD countries against the wider economic, social and political context. This is followed by a discussion of specific ICT policy areas surveyed in the OECD Internet Economy Outlook Policy Questionnaire 2012. Analysis is based on detailed information provided by 22 OECD member countries and the European Commission, as well as recent OECD work.

\section{Overview: ICT policy priorities and developments}

\section{ICT policies to stabilise the economic recovery and strengthen fiscal positions}

Recovery from the financial crisis remains very tentative and budget deficits and unemployment rates are at historically high levels. Governments have responded by prioritising measures targeting the ICT sector that promote ICT-based innovation, diffusion and uptake of Internet technologies. Responses to the OECD questionnaire from a majority of countries indicate priority areas that have increased due to the current economic context (Figure 8.1).

Figure 8.1. Recently increased priority ICT policy areas

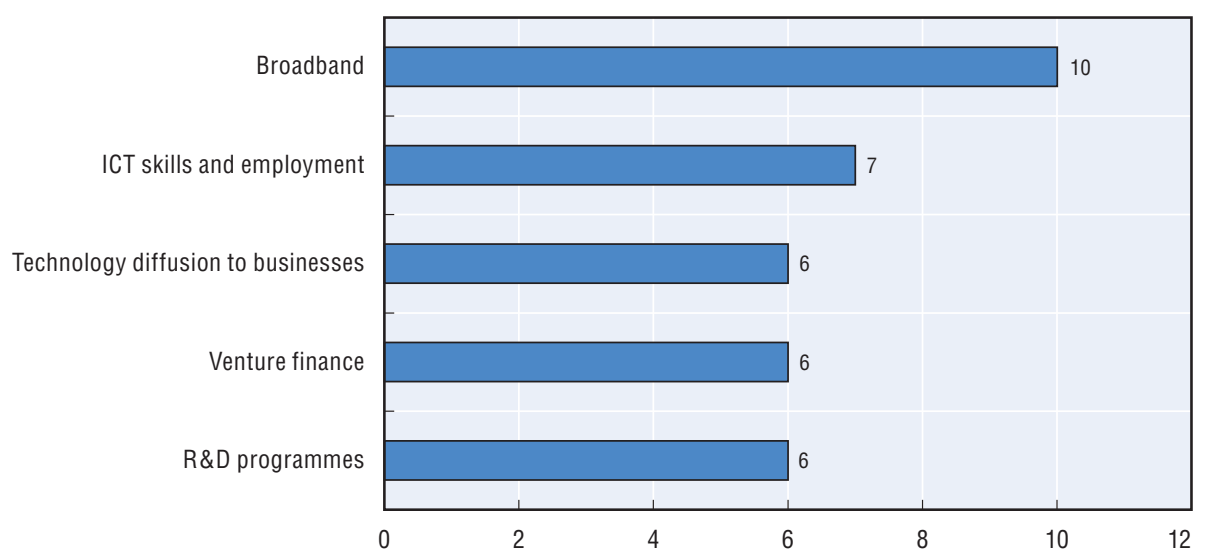

Note: The chart ranks ICT policy areas by the number of countries attributing particular prioritisation for the economic recovery ("increased" priority).

Source: Based on 23 responses to the OECD Internet Economy Outlook Policy Questionnaire 2012, section "Current IT policy priorities and new directions". 
Rolling out broadband Internet infrastructure remains a top priority for economic recovery. Governments have traditionally set a high priority on expanding broadband (fixed and mobile) to households and businesses. As the importance of the Internet for economic, social and political processes increases, the availability and affordability of broadband connections will affect inclusiveness. Many broadband policies therefore focus on connecting so far unserved or underserved areas (e.g. rural areas) and socioeconomic groups (e.g. the elderly, the unemployed).

Following the economic crisis, governments continue to strengthen capabilities for the Internet economy, with ICT skills and employment remaining a priority. This includes policies to further develop a highly skilled workforce for the production of ICT goods and services, and increasing the skills sets of individuals to stimulate diffusion and use of innovative ICTs and ICT services.

Survey results make clear that governments regard ICTs and the Internet as a major platform for research and innovation across all economic sectors. Support for ICT research and development (R\&D), provision of venture finance to innovative entrepreneurs, and technology diffusion to businesses are seen as key components of strategies for innovation and economic growth.

\section{Overall ICT policy priorities in the longer term}

The top ICT policy priorities of OECD countries in the longer term are: structural reforms, preserving social cohesion, moving to more sustainable fiscal positions, tackling environmental concerns, and enhancing confidence and trust. Top policy long-term priorities in 2012 were: broadband, ICT skills and employment, government online, and the security of information systems and networks. Also ranking highly were R\&D programmes, technology diffusion to business, electronic settlement/payment and digital content.

The security of information systems and networks is an increasingly high priority of governments. This can be explained by the ubiquity of ICTs in OECD economies and the high uptake rates among individuals and organisations. Governments are increasingly aware of the potential risks of greater reliance on Internet infrastructures by the economy and society.

Figure 8.2. Overall ICT policy priority areas

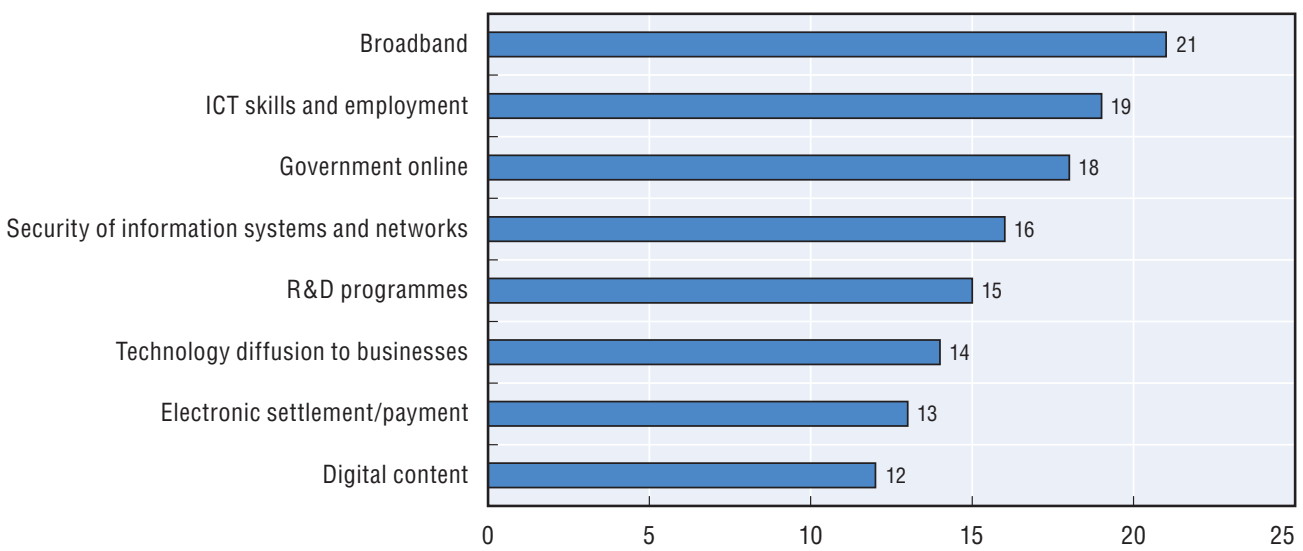

Note: The chart ranks ICT policy areas by the number of countries attributing particular prioritisation for the economic recovery.

Source: Based on 23 responses to the OECD Internet Economy Outlook Policy Questionnaire 2012, section "Current IT policy priorities and new directions".

StatLink न्ता sta $h t t p: / / d x . d o i . o r g / 10.1787 / 888932694785$ 
Fewer governments are according high priority to framework policies for the development of the ICT sector ("ICT business environment"). This downward trend was already identified several years ago in the OECD Information Technology Outlook 2008 and is partly due to the fact that policies enacted earlier remain in force. From policies aiming to create an optimal legal context for ICT sector development, governments have shifted towards promoting uptake of innovative ICT applications and services. This includes policies to use ICTs for improvements in delivering the services of public administrations and healthcare and education institutions (Figure 8.A1.1 in Annex 8.A1).

\section{Specific ICT policies and programmes}

This section outlines developments in policy areas to which governments have assigned high priority.

\section{Security of information systems and networks}

The centrality of the Internet to various aspect of life demands that policy makers place a high priority on ensuring trust and security online, and take adequate measures to protect users (OECD, 2011b). Preventing and reacting to online security threats, notably cyber attacks, has become a major priority in the organisation of national security in many OECD countries. Most countries have developed strategies and implementation programmes that set main priorities areas for cybersecurity. These cybersecurity strategies are increasingly adopted through one major policy document at a high level of government and are often linked to reviews of larger national security policies. They recognise that the scope and scale of the risks expand beyond individuals and organisations to nations as a whole, and are beyond the capacity of these individuals and organisations to deal with (OECD, 2012a).

Current cyber-security strategies and implementation programmes include measures to enhance government security and to protect critical information infrastructures (CII) (OECD, 2012a). Many countries implement additional measures to combat cybercrime. Education and awareness programmes on information security, as well as research and development, also feature prominently in current strategies. For some countries, recent policy priorities include the development or enhancement of the ability to collect real-time information on online threats, and the protection of military networks and development of offensive cyber capabilities.

Reflecting these trends, at the domestic level strategies focus on public-private cooperation and cross-government coordination. Several countries have recently created or expanded the role of government agencies to coordinate network and information security nationally. For example, the mission of the French national agency for the security of information systems (ANSSI), created in 2009, is to: i) detect and react to cyber attacks; ii) prevent threats by supporting the development of trusted products and services for governmental entities and economic actors; iii) provide reliable advice and support to governmental entities and operators of critical infrastructure; and iv) promote awareness-building and education. In the United Kingdom, the Office of Cyber Security and Information Assurance (OCSIA) provides strategic leadership and coherence across government from within the Cabinet Office. At the domestic level:

- Most countries have established national programmes for CII protection, although a few, such as Slovak Republic and Slovenia, are still in the development process. These programmes define technical and functional criteria for ICT that help identify the infrastructures that could potentially become critical, and establish rules and procedures to ensure access to public networks in times of crisis. 
- Most OECD countries, including Australia, Austria, Belgium, Czech Republic, Denmark, Finland, The Netherlands, Portugal, Sweden, Switzerland and the United Kingdom, among others, have set-up Computer Emergency Response Teams (CERTs) to facilitate information-sharing and collaboration with private sector organisations, and to coordinate Computer Security Incident Response Teams (CSIRTs). Countries are continuing to establish sector and regional CSIRTs, often in partnership with large industry actors (in particular, in important sectors such as defence, telecommunications and banking).

- Developing skills in cyber-security is increasingly viewed as a priority in some countries, including Estonia and Portugal. Research and development is a strong component of strategies, such as that of Portugal with its Innovation Network on Security and Critical Infrastructure Protection Policies. Fostering the development of a cybersecurity industry sector is an additional focus in some cases, such as the United Kingdom. Cybersecurity industry sectors would also directly contribute to economic development through growth, jobs and innovation.

All countries share the view that international co-operation is essential and have placed more emphasis on this than in previous strategies (OECD, 2012a). They recognise the importance of continued international policy dialogue, as well as of concrete operational initiatives such as international and regional cybersecurity exercises, capacity building frameworks, and other forms of bilateral and multilateral assistance. Canada and the Unites States, for example, have developed the Canada-US Action Plan for Critical infrastructures. European countries, with support from the European Commission and the European Network and Information Security Agency (ENISA), are engaging internationally on cybersecurity with a strong focus on public-private co-operation.

Cyber security exercises that simulate responses to cyber-attacks are being conducted on an increasing basis to test national capacity and international crisis response coordination. Recent exercises in which OECD countries participated include Cyber Europe (2010), Cyber Storm III or the Cyber Coalition 2010 initiatives. Directories to help establish contact with stakeholders in other countries are deemed very valuable. At the operational level there is increasing day-to-day contact between the relevant national bodies and their counterparts around the world, as well as increasing participation in the Forum for Incident Response and Security Teams (FIRST) and in regional CERTs such as the European Government CERTs Group or the Asia-Pacific CERT (APCERT).

Other recent security initiatives vary across countries and include voluntary initiatives involving ISPs in combating malicious software (malware) and providing greater assistance to end-users. Early initiatives in Japan and Korea have had positive results, which recent efforts in Australia, Germany and the Netherlands are trying to emulate. The United Kingdom and the United States are also actively investigating policies in this area (OECD, 2011c).

\section{Enhancing the infrastructure}

Broadband

Policies to encourage further development of broadband network infrastructure continue to have a high priority in OECD countries. The availability of high-speed broadband is considered to be a driver of innovation, growth and jobs in the ICT industry and beyond. This implies, however, that high-quality broadband infrastructures must reach a critical mass of potential users to enable the development and uptake of broadband applications from economic sectors such as healthcare, education and entertainment. 
The past few years have seen the development and implementation of national broadband plans (OECD, 2011g). Many governments help fund or provide targeted interventions to assist the geographic expansion of broadband access networks, the upgrading of existing networks to higher speeds, and broadband adoption among specific social and economic groups. As governments wind down stimulus spending they emphasise the continuing role of private sector investment in high-speed broadband networks, and many have reviewed their legal and regulatory frameworks to ensure these are appropriate for the levels of investment necessary to achieve their policy goals (OECD, 2011f). There are significant variations between national plans in terms of their approaches to the following issues:

- Technology: some plans are technology-neutral (e.g. Belgium, the Netherlands and Switzerland), while others focus on the deployment of specific technologies, notably fibre (e.g. Australia, Luxembourg, Singapore and Japan).

- Funding base: while many plans are largely market-driven (e.g. Canada), some countries adopt public private partnership (e.g. Spain) or largely public (e.g. Australia) funding models.

- Connection speeds and implementation timeframes: most governments have set speed targets and target dates for achievement as part of their plans, for example, requiring certain levels of geographic coverage and minimum or average transmission speeds (e.g. $100 \mathrm{Mbit} / \mathrm{s})$. Some targets are relatively short term, while others are longer term, less specific and expected to require further refinement and development. Minimally, governments aspire to reach an OECD average level of broadband, though some wish to be "world class" or a global broadband leader.

- Network access: provisions relating to open access for ISPs to existing (e.g. DSL) and new (e.g. fibre) infrastructures also differ.

- Mobile versus fixed broadband development is also a matter of diverging priorities in countries.

- Rural and remote areas: making high-speed broadband available at affordable prices in rural and remote areas has been an important focus area. While several countries have programmes for existing technologies, such as the provision of satellite services in remote areas, many plan further measures to ensure the availability of higher speed broadband in remote areas.

Increasingly, targets are being set for the adoption rather than for the availability of broadband. This has required governments to develop new skills and awareness-building programmes to address socioeconomic groups that have been slower in their adoption of ICTs, as a complement to economic measures for infrastructure provision. It is noteworthy that civic engagement and political involvement in broadband plans has increased recently. Indeed, some politicians have been elected with commitments towards achieving faster broadband services.

\section{Box 8.1. Broadband policies in selected OECD countries}

Australia's government established NBN Co as a public-private enterprise in April 2009 to design, build and operate a national broadband network (NBN). It plans to invest up to AUD 27.5 billion out of a total of AUD 35.9 billion to provide access to high-speed broadband to $100 \%$ of Australian premises, connecting $93 \%$ of homes, schools and businesses with optical fibre networks of up to $1 \mathrm{Gbit} / \mathrm{s}$. Australia's budget for extending broadband to remote rural areas is considerably smaller, around AUD 250 million. 


\section{Box 8.1. Broadband policies in selected OECD countries (cont.)}

Canada's programme to extend broadband coverage to rural and remote areas is the result of joint initiatives by the federal, provincial and territorial governments.

Denmark has set a broadband target of ensuring access for all to a broadband connection with a minimum speed of $100 \mathrm{Mbit} / \mathrm{s}$ by 2020. The country's strategy is to provide an enabling environment for private sector investment. In particular, the Danish Telecommunication Authority re-examined the broadband services market in 2011 and plans to update regulation in 2012 to ensure equal competition.

The European ambition for broadband deployment is to ensure that by 2020: i) all Europeans have access to broadband with speeds of at least $30 \mathrm{Mbit} / \mathrm{s}$, and ii) $50 \%$ or more of households subscribe to Internet connections with speeds of at least $100 \mathrm{Mbit} / \mathrm{s}$.

Finland's national Plan of Action for improving the infrastructure of the information society aims to offer high-speed broadband services to end-users in sparsely populated areas. The government target is to ensure that nearly all permanent residences, permanent offices of businesses and public premises are no more than within $2 \mathrm{~km}$ from an optical fibre, cable network or other similar network enabling $100 \mathrm{Mbit} / \mathrm{s}$ connections by end-2015. Public financing will be used in areas where the broadband programme's target levels cannot be achieved commercially (i.e. sparsely populated areas inhabited by some $4 \%-5 \%$ of the Finnish population).

Germany's broadband strategy set ambitious targets of country-wide coverage of broadband networks of at least $1 \mathrm{Mbit} / \mathrm{s}$ by end-2010, high-speed broadband connections of at least $50 \mathrm{Mbit} / \mathrm{s}$ covering $75 \%$ of German households by end-2014, and country-wide coverage of high-speed broadband as soon as possible thereafter.

Hungary's Digital Renewal Action Plan aims to provide full broadband coverage by 2014.

New Zealand's government is investing up to NZD 1.5 billion, alongside private sector investment, in open-access infrastructure. It is funding the roll out of ultra-fast broadband to $75 \%$ of New Zealanders, concentrating in the first six years on priority broadband users such as businesses, schools and health services, plus greenfield developments and certain tranches of residential areas.

The United Kingdom announced its ambition for a "digital hub" in every community in the country In December 2010, and committed up to GBP 830 million to develop its broadband strategy. In November 2011 the government set aside an additional GBP 100 million to invest in high-speed broadband infrastructure in 10 cities across the nation to deliver ultrafast fibre optic-based 80-100 Mbit/s between 2012 and 2015. The Government's ambition is to provide everyone in the United Kingdom with access to broadband speeds of at least $2 \mathrm{Mbit} / \mathrm{s}$ with superfast broadband available to $90 \%$ of people in each local authority. The broadband market will provide superfast broadband to around two thirds of the country. The government believes it is essential that the entire United Kingdom share in the benefits of high-speed Internet access and as part of its Broadband Strategy has allocated GBP 530 million to bring superfast broadband to the remaining third of UK homes and businesses.

In the United States, the Department of Agriculture's Broadband Initiatives Program (BIP) funds loans, grants and loan/grant combinations to help expand access and quality of broadband services across rural America to meet the objectives of the Recovery Act. In September 2010, 320 awards had been obligated for USD 3.5 billion. In addition, the Federal Communications Commission (FCC) has undertaken comprehensive reforms of its Universal Service Fund (USF) and Intercarrier Compensation (ICC) systems to accelerate broadband build-out to the 18 million Americans living in rural areas who currently have no access to robust broadband infrastructure.

The US National Telecommunications and Information Administration (NTIA), which forms part of the Economic Recovery Act, will invest close to USD 5 billion to implement the Broadband Technology Opportunities Program (BTOP). The bulk of funding will go towards the deployment of networks in unserved and underserved areas, as well as to increase broadband access and adoption; provide broadband training and support to schools, libraries, healthcare providers, and other organisations; improve broadband access to public safety agencies; and stimulate demand for broadband. 


\section{IPv6 deployment}

There are two versions of the Internet Protocol in active use: IP version 4 (IPv4) and IP version 6 (IPv6). IPv4, deployed since the 1980s, is the most commonly used version, but the supply of available unallocated IPv4 addresses started to run out in early 2011, and the Internet Assigned Numbers Authority (IANA) distributing its last five IPv4 blocks to the five Regional Internet Registries (RIRs) in February 2011. The lack of availability of IPv4 addresses has therefore increased the urgency of more widespread deployment of the newer version of the Internet protocol, IPv6.

Most OECD countries now have policy initiatives in place to raise awareness of IPv6 and coordinate deployment of the new protocol within government networks. IPv6 deployment is seen as critical to enable the Internet to scale to support new uses and devices, and to foster an open environment for long-term growth, competition and innovation. Government policy actions generally include: i) co-ordinating the deployment of IPv6 within government agency networks; ii) IPv6 awareness-building efforts; and iii) IPv6 research and development initiatives. While countries such as Japan, Korea and the United States have had long-standing policies in this area, many initiatives are quite recent.

The main focus area is the co-ordination of IPv6 deployment within government agency networks and services. As major consumers of networking equipment, government agency network strategies reflect a high level of commitment to IPv6 deployment on the part of some OECD governments, with a significant follow-on effect on industry, small business and home users. The Australian Government Information Management Office (AGIMO) developed a strategy in 2008 to have IPv6-ready hardware and software in place in all government agencies by the end of 2012, and to have all systems IPv6-enabled. In 2008, the European Commission produced an Action Plan for deployment of IPv6 with all actions foreseen for the following three years. In some cases, IPv6 deployment forms part of national broadband plans (e.g. Czech Republic and Slovenia) or e-government strategies (e.g. Hungary). Since 2010, IPv6 is mandatory in the Netherlands for all new procurement by government bodies, and by 2013 all Dutch government websites and email will be IPv6 ready. In 2011, countries including Belgium, Canada and Hungary were actively investigating strategies to transition government infrastructure from IPv4 to IPv6. Finally, in the United States, the National Telecommunications and Information Administration (NTIA) released an IPU6 Readiness Tool in 2011 to help businesses to prepare for the transition to IPv6. ${ }^{1}$

\section{E-government}

E-government continues to be a high strategic priority for OECD countries, which have, for the most part, developed specific e-government strategies. The priority accorded to e-government reforms stems from two objectives. In the context of fiscal pressure and budgetary constraints, government are being compelled to use ICT to deliver more efficient government operations and to help to optimise the results of public sector reform programmes, in other words, to better and more efficiently support the delivery of public services and the execution of public policies (OECD, 2010b).

At the same time, governments must deliver openness and build trust with the public. In particular, there is a need to better harness ICTs to improve citizen engagement, government relations with citizens, transparency, inclusion, responsiveness and ultimately, to advance democratic values (OECD, 2012b). The Japanese "New Strategy in Information and Communications Technology" (2010), aims to help forge a new society 
where sovereignty resides with the people. Governments are considering how to best leverage new technological and social trends such as mobile technologies or social media. Austria has put in place an e-government innovation centre (EGIZ) to investigate innovative technologies and solutions for e-government. Providing online governmental services for citizens is also one of the most important parts of the e-Transformation Turkey Project. In Finland, the Government has set the following target for 2015: "Finland has a networked public administration where administrative services are available on multiple channels and are effortlessly accessible so that they lend support to citizens in every life situation and to businesses throughout their life cycle. The interface in public administration will take shape in a uniform and comprehensive way for both citizens and companies."

Uptake of e-government services is been growing fast. In the European Union, for example, the proportion of citizens using the Internet to interact with public authorities has risen by 3 percentage points to $41 \%$ in 2011. The share of e-government users filling in forms in Europe has also increased, to $50 \%$. Denmark is one of the front-runners in terms of regular and frequent use of the Internet: $88 \%$ of the population access the Internet at least once a week and $78 \%$ every day; $81 \%$ of the population used the Internet in the last twelve months to interact with the public authorities, with the level rising to $91 \%$ in the case of businesses (EU, 2012).

European Union governments have reoriented online public services towards greater interaction, and have made user-centric design and mobility cornerstones of the future e-government agenda. ${ }^{2}$ To facilitate access to electronic public services, a number of OECD governments have established centralised Internet portals, including Austria, ${ }^{3}$ Denmark, ${ }^{4}$ Luxembourg, ${ }^{5}$ Mexico, ${ }^{6}$ Norway, ${ }^{7}$ Portugal ${ }^{8}$ and the United Kingdom. ${ }^{9}$ These portals are becoming increasingly interactive so as to provide better provider-user communication. In some countries they include personal document-delivery applications, which can be used to exchange documents with the public administration, for example, Austria's electronic delivery and filing systems, Czech Republic's Data boxes and Denmark's Digital document box. Spain's "Plan Avanza 2" is aiming for a "paperless" administration by 2015.

The Government of Japan is also working to enhance the quality and transparency of deliberation at the Diet through the use of paperless discussion material, and to reinforce information dissemination through the use of the Internet.

Strategies and policies to foster stronger digital identity management (idM) are critical to many e-government plans with the launch of electronic identification cards in many countries to uniquely identify and authenticate citizens and businesses. Examples include the "Electronic National Identity Card" or dNIE in Spain, and "Citizen Cards" in Austria and Portugal. The main objective of IdM strategies is to realise e-government and foster innovation in public e-services. A second important objective is strengthening cybersecurity. Spill-overs are also expected in the private sector. For example, Austria, Canada, Denmark, Germany, Korea, Luxembourg, Portugal, Slovenia, Spain and the United States all use or plan to use digital credentials in both public and private sector contexts (OECD, 2011e).

Governments are also increasingly integrating mobile Internet devices in their e-government strategies. The aim is to enable citizens to access information and services in a number of policy areas, for example, legal information, health, education, finance, employment, transportation and public safety (OECD/ITU, 2011). "M-government" is increasing access to existing services, but also enabling the design and delivery of new services, such as through new levels of civic engagement in policy development and democratic decision-making. 
Many governments, such as Australia, Japan and the United States, are actively investigating the opportunities and challenges of cloud computing services and social media applications for e-government in terms of improved services and cost savings. Essentially, cloud computing means a shift from ICT procured by organisations as their own infrastructure, to a new model in which computing resources are provided as a utility. Several countries, including the United States, the United Kingdom and Korea, have started to move some of their low and medium-sensitivity as well as low-risk data and applications such as email services, to the cloud (OECD, 2010c and forthcoming). Research based on several initiatives in the United States estimates that the cost savings can be significant (OECD, forthcoming). The United States has developed a federal cloud computing strategy and the United States General Services Administration (GSA) operates a web portal that provides "cloud computing" services to government agencies. ${ }^{10}$ This includes typical IT services such as computing and storage, as well as applications for business intelligence and social media/social networking. Countries such as Denmark, Germany and Spain have regional initiatives underway.

\section{E-health}

A number of OECD countries incorporate e-health as a leading focus of their national ICT strategies, although the prominence of e-health varies widely from country to country. Significant progress has been made in e-health technology over recent years with a wide range of possible applications (OECD, 2010a). Many governments are now looking at new ways to implement e-health that can result in care that is both higher in quality, safer and more responsive to patients' needs, while being efficient in terms of appropriateness, availability and cost (see Chapter 6 on "E-health" for an in-depth review).

The need to optimise health expenditure is an important driver of e-health. In 2009, estimates for health spending in OECD countries were close to $10 \%$ of GDP, of which the public sector share was $72 \%$ on average (OECD, 2011d). Many OECD governments are trying to exploit ICT technologies in national health reform strategies to contain expenditure and enable innovation in health care delivery.

Countries including Australia, Canada, or Denmark have developed e-health strategies that set national priorities to maximise benefits and efficiencies (see Chapter 6). These strategies identify four broad objectives from ICT implementation in healthcare: i) increasing quality of care and efficiency through better information transfer; ii) reducing operational costs of clinical services through electronic medical records or electronic health records (EHR); iii) reducing administrative costs such as billing and processing claims, and; iv) enabling entirely new modes of care such as telemedicine or remote monitoring.

Implementation measures range from the development of foundational communication infrastructures to sophisticated electronic health record systems (e.g. in Austria, Denmark, Hungary, New Zealand). Countries such as Australia, Canada, Estonia and New Zealand focus on cost-effective solutions for remote and rural areas through telemedicine and other telehealth technologies to improve care. Some countries, such as Canada through its funding of Canada Health Infoway, highlight the importance of ensuring uptake through change management and adoption-based milestones. In many cases, e-health initiatives are being integrated with national e-government projects, for example, with regard to citizen or patient identification systems. 


\section{ICT skills and employment}

Information and communication technologies and particularly the Internet, are driving innovation, labour productivity and growth (OECD, 2010d). ICT-related skills are vital to the creation of new jobs; however, these are in short supply in some OECD countries (OECD, 2012c). With unemployment rates still high in most OECD economies, fostering ICT skills and employment has remained a key priority for governments in the short and long-term. Governments have proposed a wide range of policies to support ICT-related employment and skills, emphasising measures to tackle unemployment, some of which relate to green ICTs (see later). Overall, most OECD governments have established policies and programmes to: i) further IT education and training, ii) improve labour market information, and iii) promote international sourcing of ICT skills.

As ICTs and the Internet become ever more pervasive and OECD economies "smarter", ICT-skills become crucial to ensuring social inclusion and permitting and complementing the production and use of Internet-based products and services. In most cases, policies include the promotion of ICT skills in higher education, followed by vocational and on-the-job training. In contrast, primary and secondary education has attracted less attention. Most initiatives focus on promoting advanced rather than basic ICT skills, and target young rather than older workers.

- Most OECD governments promote ICT skills in higher education. Austria's recent efit21 digital agenda for education, the arts and culture focuses on the deployment and use of new ICTs in Austrian educational, artistic and cultural institutions. Universities in OECD countries are also encouraged to consider industry needs when developing and offering graduate programmes. Governments also promote ICT skills through investment of ICT infrastructures in higher education institutions and deployment of e-learning applications.

- Vocational training ranks high among government policies promoting IT education. In many cases, these initiatives focus on specific target groups such as ICT specialists, employees with no or basic ICT skills, or the unemployed, and many include technical certification schemes. In Austria, for example, the Labour Market Service offers IT training courses to upgrade the ICT skills of the unemployed.

With the rising unemployment of ICT workers, provision of labour market information has become more important to better match the demand for and supply of ICT workers. Many governments are improving the availability of labour market information, in most cases, by providing Internet-based portals for job ads and searches. Austria's "eJob-Room" is used by individual job seekers to screen available jobs, and by firms to post job announcements or look for potential employees from the applicant pool. In 2011, the US Department of Commerce launched DigitalLiteracy.gov, an online portal for librarians, educators and other digital literacy practitioners to share content and best practices to help Americans find jobs and obtain the ICT skills being sought by employers.

At the EU level, the Digital Agenda for Europe has set a number of actions to promote ICT skills, which include: i) prioritising digital literacy and competencies in the European Social Fund regulation (2014-20); ii) developing tools to identify and recognise the competencies of ICT practitioners and users, linked to the European Qualifications Framework and to EUROPASS; iii) encouraging Member States to implement long-term e-skills and digital literacy policies and to promote relevant incentives for SMEs and disadvantaged groups; and, iv) launching a multi-stakeholder sectoral council for ICT skills and employment to address demand and supply aspects. 


\section{Box 8.2. Canada's Digital Technology Adoption Pilot Program (DTAPP)}

In fall 2011, the National Research Council of Canada's Industrial Research Assistance Program (NRC-IRAP) launched an USD 80 million Digital Technology Adoption Pilot Program (DTAPP) to be delivered over three years and designed to accelerate the adoption of digital technologies by SMEs in collaboration with colleges i.e. from identifying the technology to be used, right through to adapting that technology to their business processes and gauging its effect on the SMEs productivity.

DTAPP is divided into three elements: i) increasing pilot SMEs' adoption of digital technologies in all economic sectors through targeted digital technology advisory services and financial assistance; ii) collecting information from pilot participants, as well as supporting national surveys to better understand barriers to technology adoption; and, iii) raising awareness of the benefits and importance of adopting digital technologies.

\section{Digital content}

Digital content programmes are in place in many OECD countries. Most efforts in recent years have focused on fostering development of a domestic content-based ICT services industry, which can benefit from the Internet to reach global markets; and on making public sector (and publicly funded and publicly held) information easily available to spur innovation and growth in the commercial use of public sector data.

\section{General digital content development}

Digital content development policies largely focus on stimulating the supply of content from areas such as education, news, media, entertainment and interactive software development. They can also be part of larger "e-inclusion" policies (e.g. to increase access to and use of the Internet). Examples of digital content development programmes include: Australian Government's "Online curriculum support" programme for the development of educational digital content; Canada's funds for media (CMF), interactive content (CIF), periodicals and books (CBF), which aim to promote creation of digital and interactive content in their respective areas; New Zealand's "Digital Content Partnership Fund", which aims to promote development of new multi-format audiovisual content; and the "Digital Promise" national centre launched by the US Congress in 2011 to advance transformative teaching and learning technologies.

\section{Public-sector information and content}

Public sector information (PSI) is produced and collected by public bodies and includes digital maps, meteorological, legal, traffic, financial, economic and other data. Most of this raw data can be re-used or integrated into new products and services used on a daily basis, such as car navigation systems, weather forecasts, and financial and insurance services. The European Union's 2003 Directive on the reuse of public sector information (PSI Directive), implemented by all $27 \mathrm{EU}$ Member States, regulates how public sector bodies should make their information available for reuse in order to remove barriers such as discriminatory practices, monopoly markets and lack of transparency. The 2008 OECD Recommendation on public sector information provides policy guidelines designed to improve access and increase use of public sector information through greater transparency, enhanced competition and more competitive pricing. 
Public-sector information (PSI) and publicly funded data are increasingly being digitised, made available online and used for innovative services in "open data" initiatives across the OECD (Box 8.3; see also OECD, 2012b). With "mash-up" technologies, PSI can be used and linked to create commercially viable applications. Data sources typically include mapping, weather and cadastral information, and cultural heritage items from museums and libraries. Many policies plan for the digitisation of cultural heritage (e.g. Czech Republic, Estonia, Hungary, Sweden and Switzerland) and the archiving of public service audiovisual content (e.g. New Zealand). Health and environmental data from public sources can be used to support research and policy-making as well as to underpin emergency response systems. There is also an increasing focus on policies to enhance the accessibility of public sector websites in line with the World Wide Web Consortium's (W3C) standards (e.g. Australia and Estonia). Finally, countries such as Australia are making available large amounts of public sector information under Creative Commons licensing schemes by default.

\section{Box 8.3. Examples of national policies to promote the use of public-sector information}

In Australia, the Principles on Open Public Sector Information and the site Data.gov.au form part of a core vision for government information management. The principles rest on the democratic premise that public sector information is a national resource that should be available for community access and use:

- Principle 1: Open access to information;

- Principle 2: Engaging the community;

- Principle 3: Effective information governance;

- Principle 4: Robust information asset management;

- Principle 5: Discoverable and useable information;

- Principle 6: Clear reuse rights;

- Principle 7: Appropriate charging for access and

- Principle 8: Transparent enquiry and complaints processes.

Denmark's Open Data Innovation Strategy (ODIS) is designed to provide easy and uniform access to public data as raw material for the private sector in the development of innovative digital products and services, useful analyses, data visualisations and data journalism. The Danish Data Catalogue website displays Danish open public datasets.

Finland issued a resolution in March 2011 on the promotion of reuse of public sector digital information. The Government undertakes measures as part of its strategic project on the issue.

In France, the Government issued a decree in 2011 creating the Etalab mission. By the end of the year a beta version of the website data.gouv.fr was available online with information on over 350000 topics as varied as the national budget or the geographic location of French airports. Its stated goal is to offer a new, open and participative governance model adapted to the Internet and the information society.

Germany has launched a service to allow its citizens to view sources of industrial pollution across the country down to neighbourhood granularity. Another PSI policy initiative aims to integrate all cultural heritage and academic information contained in the German Digital Library (DDB) into the European digital library Europeana.

* For more details, see: http://data.digitaliser.dk. 


\section{Box 8.3. Examples of national policies to promote the use of public-sector information (cont.)}

Italy launched its Open Data initiative Dati.gov.it in 2011.

Japan aims to disclose administrative information in formats that will allow secondary applications while protecting personal data by 2013.

New Zealand is improving access to government data through open data initiatives, allowing users to directly download data and directories, and enabling them to develop a wide range of online services and tools. The Wynyard Quarter Innovation Precinct in Auckland has a special focus on digital content creation.

Portugal's National Digital Library project plans to digitise a large part of the national library's documents and books. The Open Access Scientific Repository of Portugal provides free online access to various institutional repositories, including all public universities.

Spain's Aporta Project, which forms part of Plan Avanza 2, promotes a culture of information reuse in the public administration sector.

The United Kingdom's Data.gov.uk website provides free access to datasets generated or funded by the public sector. It has the twin aims of providing information and "unlocking innovation". Its key focus areas include education, environment, finance and health.

In the United States, the Obama administration established Data.gov as a "one-stop shop" for public, machine-readable access to all datasets generated by the Executive Branch of the federal government. The Open Government Initiative requires federal agencies to take specific steps to achieve greater transparency, participation and collaboration, including in many areas of PSI. At the end of 2011, the White House Office of Science and Technology Policy issued two requests for Information on public access to the output of federally funded research, one regarding scholarly publications and one regarding digital data. The National Science and Technology Council (NSTC) is drawing on comments received to coordinate policies on the dissemination of federally funded research, as required by the America COMPETES Reauthorization Act of 2010.

\section{Fostering ICT R\&D and innovation}

National ICT strategies generally consider ICT R\&D programmes a key priority for economic recovery: essential to industrial capacity and to the capacity to innovate in OECD countries. In 2012, 16 out of 22 countries indicated a high or medium priority for this policy area. ICT R\&D programmes also feature among the top 3 priorities for a sustainable economic recovery. In many OECD countries, the Internet economy and the ICT sector represent a sizeable portion of jobs and GDP and an even larger portion of GDP value added (see Annex 8.A1). They also represent a large portion of private and public investments in R\&D.

Research strategies in OECD countries often involve improving the R\&D intensity of the corporate sector. Funding and promotion of ICT R\&D in OECD countries are typically channelled through government agencies and, in many cases, public investments aim to jumpstart private investment in priority areas. Some agencies are solely dedicated to ICTs. Two examples are National ICT Australia (NICTA) and Austria's dedicated ICT Research Strategy. More often, ICT R\&D promotion forms part of larger science and research promotion agencies. Examples include: Austria's Science Fund (FWF) and Research Promotion Agency (FFG), Denmark's Council for Strategic Research and Council for Technology and Innovation, the Estonian Science Foundation, Finland's TEKES, Italy's Institute for Technology (IIT), Portugal's "Commitment to Science for the Future of 
Portugal", the Avanza Competitividad (I + D + I) ICT R\&D component of Spain's Plan Avanza 2 Strategy, Turkeys' TÜB TAK “Vision 2023" R\&D and Innovation strategies, and the United States' National Science Foundation. There are also a number of priority areas for ICT R\&D (Box 8.4).

\section{Box 8.4. Current priority areas for ICT R\&D with country examples}

- Technology and elderly people: Austria's Ambient Assisted Living (AAL) Joint Programme extends the time people can live in their preferred environment by increasing their autonomy, self-confidence and mobility. The European Commission has also proposed a European Innovation Partnership (EIP) on Active and Healthy Ageing.

- Cloud computing: Japan is investing in next-generation cloud networking. Germany has launched its Cloud Computing Action Programme on a trusted cloud.

- Converging technologies and scientific disciplines: Austria's FIT-IT research programme focuses on interdisciplinary projects such as embedded systems. Australia's CSIRO ICT Centre researches ICT-based applications for national challenges in areas such as water and energy management. The joint Spanish-Portuguese Iberian Nanotechnology Laboratory (INL) crosses disciplinary boundaries to include ICT-related research. Italy's National Research Programme (NRP) 2011-13 defines a programme for the "ICT of the future", seen as the integration between electronics, telecommunications and IT and well as with other disciplines, to enable "ICT anytime, anywhere, for everybody".

- Digital content/semantic technologies: Germany has launched the Theseus programme for R\&D on semantic web applications and the Internet of services. Switzerland has initiated a Web 2.0 project within its larger Enabling Sciences package.

- Smart grids: Portugal's National Grid Initiative (INGRID) facilitates R\&D on GRID computing and on the application of this high-performance distributed computing technology on large-scale computer simulations of systems in areas such as meteorology, oceanography, genomics, proteomics, high-energy physics, and particle physics experiments. Sweden has initiated a smart grid energy storage programme. The US Department of Energy (DOE) gas has launched smart grid activities.

- Smart transportation: Austria has launched the smart transportation programmes Intelligent Transport Systems and Services plus. Germany has a research programme entitled ICT for Electric Mobility.

- Network infrastructures: Canada's CANARIE Inc. is a broadband network connecting over 50000 researchers, including dedicated broadband research programmes. The Netherland's eInfrastructures project involves research networks, supercomputing, data storage and eScience solutions. Japan has a focus on new-generation optical networks. Hungary has launched the New Széchenyi Plan. Portugal's Science, Technology and Society Network (RCTS) provides very high-speed connectivity to scientific and higher education institutions and a wide range of advanced e-science services.

- Software engineering and data analytics: The US Networking and Information Technology Research and Development Program (NITRD) undertakes high-end computing research. Canada has initiated machine learning with data analytics.

- ICT and Internet security and safety: One of Austria's FIT-IT programmes focuses on trust in IT systems. In Portugal, the Carnegie Mellon-Portugal Programme focuses on critical infrastructures and trust. Czech Republic has launched a National Security Research Strategy. 


\section{Green R\&D}

Information and communication technologies are a key enabler of "green growth" in all sectors of the economy (OECD, 2010e). They are a key part of government strategies for a sustainable economic recovery. "Greener and smarter" ICTs include ICTs with better environmental performance than previous generations (direct impacts) and ICTs that can be used to improve environmental performance throughout the economy and society (enabling and systemic impacts) (OECD, 2011h). Governments tend to give increasing priority to green R\&D activities and to renewable energy and environmental technologies as part of supply-side side strategies for sustainable growth.

Examples of green ICTs include Estonia's ELIKO Competence Centre and Software Technology and Applications Competence Centre (STACC) and Spain's “TIC Verdes". The European Commission supports a wide range of research and development projects that aim to enhance energy efficiency, water management and adaptation to climate change through the use of ICTs, as part of its Seventh Research Framework Programme (FP7) and Competitiveness and Innovation Framework Programme (CIP). Key targeted areas are energy-efficient buildings, smart grids, ICT for water management and smart sustainable cities.

\section{Conclusion}

In summary, this chapter highlights how digital strategies in OECD countries have evolved over the past decade to reach a stage where ICTs in many countries are mainstreamed to help deliver sustainable economic and social benefits.

Rolling out broadband Internet infrastructure, especially to previously underserved areas and groups, remains a top priority. In parallel, countries are seeking to address the challenges and risks arising from greater digital engagement through a focus on comprehensive online security strategies.

Complementary and system-wide ICT policy measures include measures to improve ICT skills and employment, support ICT research and development (R\&D), use ICTs to improve health and aged care, improve environmental sustainability, and promote growth and employment. Policy makers are also increasingly aware of the important role of the Internet in improving online government services delivery and engagement, and in advancing social and democratic values.

\section{Notes}

1. For more details, see: www.ntia.doc.gov/category/ipu6.

2. For more details, see the "Ministerial Declaration on eGovernment" by EU Member States, Malmö, November 2009 and the EC eGovernment Action Plan 2011-2015.

3. For more details, see: www.help.gu.at.

4. For more details, see: www.borger.dk.

5. For more details, see: www.guichet.lu.

6. For more details, see: www.gob.mx.

7. For more details, see: www.norway.no.

8. For more details, see: www.portaldocidadao.pt.

9. For more details, see: www.direct.gou.uk.

10. For more details, see: www.apps.gou. 


\section{References}

EU (2012), Digital Agenda Scoreboard, June, Denmark Country Profile, Brussels.

OECD (2010a), Improving Health Sector Efficiency: The Role of Information and Communication Technologies, OECD Health Policy Studies, OECD Publishing.

doi: $h$ ttp://dx.doi.org/10.1787/9789264084612-en.

OECD (2010b), High-level OECD E-Leaders Meeting 2010, Paris, OECD, www.oecd.org/governance/eleaders.

OECD (2010c), OECD Information Technology Outlook 2010, OECD Publishing. doi: http://dx.doi.org/10.1787/it_outlook-2010-en.

OECD (2010d), The OECD Innovation Strategy: Getting a Head Start on Tomorrow, OECD Publishing. doi: http://dx.doi.org/10.1787/9789264083479-en.

OECD (2010e), "Greener and Smarter: ICTs, the Environment and Climate Change", in OECD, OECD Information Technology Outlook 2010, OECD Publishing. doi: http://dx.doi.org/10.1787/it_outlook-2010-7-en.

OECD (2011a), Communiqué on Principles for Internet Policy-Making, OECD High Level meeting: "The Internet Economy: Generating Innovation and Growth", 28-29 June 2011, OECD, Paris.

OECD (2011b), “Chair's Summary, OECD High Level Meeting - The Internet Economy: Generating Innovation and Growth", 28-29 June 2011, OECD, Paris.

OECD (2011c), The Role of Internet Intermediaries in Advancing Public Policy Objectives, OECD Publishing. doi: http://dx.doi.org/10.1787/9789264115644-en.

OECD (2011d), Health at a Glance 2011: OECD Indicators, OECD Publishing. doi: $h t t p: / / d x . d o i . o r g / 10.1787 /$ health_glance-2011-en.

OECD (2011e), "National Strategies and Policies for Digital Identity Management in OECD Countries", OECD Digital Economy Papers, No. 177, OECD Publishing. doi: $h$ ttp://dx.doi.org/10.1787/5kgdzun5rfs2-en.

OECD (2011f), "National Broadband Plans", OECD Digital Economy Papers, No. 181, OECD Publishing. doi: http://dx.doi.org/10.1787/5kg9sr5fmqwd-en.

OECD (2011g), "Laying the Foundation for the Internet Economy: Access to the Internet via a High-speed Infrastructure”, OECD Digital Economy Papers, No. 201, OECD Publishing. doi: http://dx.doi.org/10.1787/5k95z9cumnr6-en.

OECD (2011h), Towards Green Growth: Monitoring Progress: OECD Indicators, OECD Green Growth Studies, OECD Publishing. doi: http://dx.doi.org/10.1787/9789264111356-en.

OECD (2012a), "Comparative Analysis of Cybersecurity Strategies: Comparison of Strategies in Australia, France, Japan, Spain, United Kingdom and the United States", OECD, Paris.

OECD (2012b), "New ICT Solutions for Public Sector Agility", summary report of OECD E-leaders meeting, Mexico City, 26-27 March, www.oecd.org/governance/eleaders.

OECD (2012c), "ICT Skills and Employment: New Competences and Jobs for a Greener and Smarter Economy", OECD Digital Economy Papers, No. 198, OECD Publishing. doi: $h$ ttp://dx.doi.org/10.1787/5k994f3prlr5-en.

OECD (forthcoming), "Cloud Computing: Impacts and the Role of Government Policy", OECD Digital Economy Papers, OECD, Paris.

OECD/ITU (2011), “M-Government: Mobile Technologies for Responsive Governments and Connected Societies", OECD, Paris. 
ANNEX 8.A1

Figure 8.A1.1. ICT policy framework

\begin{tabular}{|c|c|c|c|c|}
\hline & & ICT policies & & \\
\hline $\begin{array}{l}\text { Fostering ICT } \\
\text { innovation }\end{array}$ & Increasing diffusion/use & $\begin{array}{l}\text { Maintaining a healthy ICT } \\
\text { business environment }\end{array}$ & $\begin{array}{c}\text { Enhancing } \\
\text { the infrastructure }\end{array}$ & Promoting trust online \\
\hline $\mathrm{R} \& \mathrm{D}$ programmes & Diffusion to businesses & Competition in ICT markets & Broadband & $\begin{array}{l}\text { Security of information } \\
\text { systems and networks }\end{array}$ \\
\hline $\begin{array}{l}\text { Government } \\
\text { development }\end{array}$ & Organisational change & Intellectual property rights & Standards & Privacy protection \\
\hline $\begin{array}{l}\text { Government } \\
\text { procurement }\end{array}$ & $\begin{array}{l}\text { Professional/managerial } \\
\text { ICT skills }\end{array}$ & Trade and FDI & $\begin{array}{l}\text { Electronic } \\
\text { payment/settlement }\end{array}$ & Consumer protection \\
\hline Venture finance & $\begin{array}{l}\text { Diffusion to households } \\
\text { and individuals }\end{array}$ & International co-operation & $\begin{array}{l}\text { General network } \\
\text { infrastructure* }\end{array}$ & \\
\hline \multirow[t]{4}{*}{ Innovation networks } & \multicolumn{2}{|l|}{ E-government } & & \\
\hline & \multicolumn{2}{|l|}{ Content } & & \\
\hline & \multicolumn{2}{|l|}{ Government demonstration } & & \\
\hline & RFID & & & \\
\hline
\end{tabular}

Note: Policy areas have been developed on the basis of priorities expressed in national replies, a framework developed in a series of peer reviews on ICT diffusion to business, and other completed work of the Working Party on the Information economy. Policy areas with an asterisk $\left({ }^{*}\right)$ are examined in the OECD Communications Outlook. 



\section{ANNEX A}

\section{Methodological considerations}

\section{Approaches to measure the Internet economy}

In September 2011, the OECD organised an expert roundtable that focused on appropriate terminology, measurement concepts and methodologies to measure the Internet economy. The roundtable assembled policy makers, researchers and representatives from academia and the business community. The participants concluded that the term "Internet economy" referred to various quantifiable economic impacts of the Internet, and recognised that this concept varied in scope. Consequently, the roundtable adopted three general approaches that involved measuring the: i) direct impact; ii) dynamic impact; and iii) indirect impact of the Internet economy (Figure A1).

\section{Figure A1. Classification mechanism}
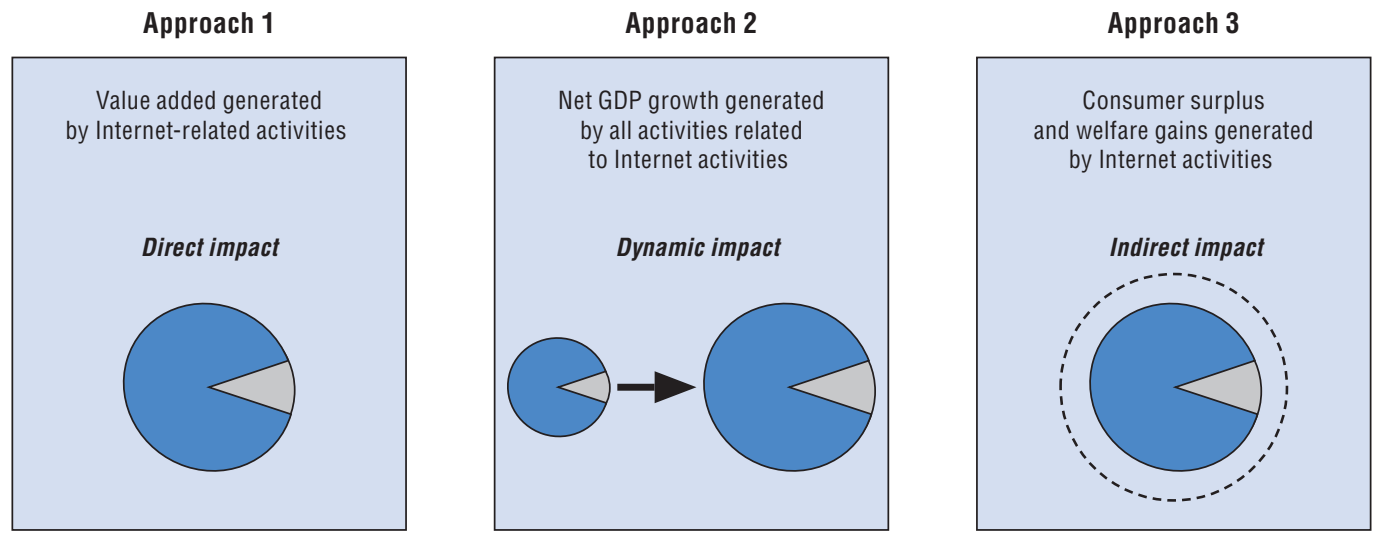

Approach 1 (direct impact) is the most conservative and relies mainly on official data. It groups studies that measure the size of the Internet economy expressed as a part of GDP. Studies that follow this approach examine those parts of the economy closely related to the Internet. These parts are then aggregated, and the result is interpreted as a conservative measure of the Internet economy, since they only capture effects that can be unambiguously separated out of specific sectors of the economy.

Approach 2 looks at the dynamic impact that the Internet might have on all industries, and hence on rates of productivity growth and eventually GDP growth. The scope of studies that follow this approach includes the beneficial effects that the Internet has on the productivity and profitability of firms. Consequently, these studies evaluate the contribution of the Internet to the net growth of the economy, as measured by official statistics. 
Finally, Approach 3 takes into account the indirect impact of the Internet. Studies within this broader approach examine the effects of the Internet on economic phenomena like consumer surplus, or explore how the Internet contributes to social welfare gains. These studies look at additional impacts of the Internet on economic welfare that are not measured by official statistics.

Each of the approaches plays an important part in increasing understanding of the process of measuring the Internet economy. The following sections outline each approach in turn, together with relevant literature and initial estimates. The box at the beginning of each section briefly explains the approach, findings, and highlights areas for continued research. Methodological details for each of the approaches are summarised at the end of this Annex.

\section{Approach 1. Direct impact of the Internet}

For a number of companies and industries, the emergence of the Internet opened new ways of delivering products and services, introduced new advertising possibilities, and even enabled entirely new business models. Key examples include the recent growth of e-commerce and e-payments and changes in the modes of operation of creative industries.

The Internet has also enabled the creation of numerous new activities that rely solely on its networks. These include the emergence of the Internet-based software industry, cloud computing, and the introduction of completely new products such as online social networks and search engines relying on new, Internet-enabled business models (online advertising or pay-per-click advertising).

\section{Box A1. Summary of Approach 1: Direct impact of the Internet}

\section{The approach}

This approach attempts to measure the share of GDP value added that is generated by Internet-related activities. This includes value added generated by:

- Activities that support the Internet (e.g. ISPs, Internet equipment manufacturers, etc.).

- Activities based purely on the Internet (e.g. search engines, e-commerce services, etc.). Studies within this approach do not include benefits outside of those captured by GDP.

\section{Existing results}

Several recent studies have attempted to estimate the size of the Internet economy in developed economies. The results vary widely by economy and depend on the methodology used. Boston Consulting Group found that Internet-related activities accounted for approximately $7.2 \%$ of GDP in the United Kingdom (BCG, 2010). Deloitte made a similar study in Australia that estimated the impact at 3.4\% of GDP (Deloitte, 2011). McKinsey undertook a similar study that estimated the average volume of the Internet Economy for G8 and BRIC countries as equal to 3.4\% of GDP (McKinsey, 2011). It is necessary to exercise caution when interpreting these results as methodologies vary across groups and are not necessarily explicit.

\section{The OECD study}

Detailed statistics are available for the United States regarding Internet-related activities in the information sector and e-commerce across the economy. The current study uses revenue data for the information sector together with e-commerce statistics from other sectors of the economy to estimate the value added attributable to the Internet. 


\section{Box A1. Summary of Approach 1: Direct impact of the Internet (cont.)}

Information sector: To calculate the relevant value added from the information sector, it is assumed that the share of revenue from Internet-related activities in total revenue for the information sector is proportional to the share of value added from these activities in total value added for that sector.

Other sectors: To calculate the relevant value added from e-commerce activities, it is assumed that the share of revenue from e-commerce in total revenue for each industry is proportional to the share of value added from e-commerce in total value added for that same industry. Depending on the industries chosen, two measures of value added can be derived. The first incorporates a narrow view that includes only wholesale and retail sectors; the second takes a broader view and includes all sectors across the economy for which data are available.

This exercise and its simplifying assumptions are meant to provide an order of magnitude, rather than a precise measure of Internet value added. When applied to data for the United States (2010) this approach gives the result that at least 3\% (narrow view) and up to $13 \%$ (broad view) of US business sector value added could be attributed to Internet-related activities. Business sector overall represents $62 \%$ of total value added (GDP).

\section{Future research}

Future research in this area will focus on: i) refinement of input data and ii) investigation of data availability to enable analysis of the Internet economy in other countries.

* In order to get a comparable aggregate across countries, the business sector is defined as per ISIC Rev. 4, activities $05-66,69-82$. It does not take into account agricultural activities, real estate, or community, social and personal services.

\section{The approach}

The Internet economy may be defined as the value generated by undertaking economic activities either supporting the Internet or purely based on the Internet (see Figure A2). This definition includes the value generated by two sets of economic activities:

- Activities undertaken for the operation and use of the Internet, e.g.production of broadband equipment, provision of ISP services, etc. (Figure A2, bottom box).

- Activities purely based on the Internet, e.g. e-commerce, digital content, search, etc. (Figure A2, middle box).

In terms of this approach, the activities reported above are referred to as Internet-related activities. These activities are narrowly defined as the direct impact that the Internet has on economies.

Moreover, it is important to underline that the economic impact is not limited only to the activities that support the Internet or that are purely based on the Internet. In fact, the economic impact of the Internet is much broader through, for example, reduced search costs for firms, better access to information or improved search and matching processes in the economy. Hence, the total economic impact of the Internet is much broader than this approach can capture, and reaches virtually all economic activities.

\section{Existing results}

There have been only a few attempts to define and measure the value of Internet-related activities. These include recent studies by BCG $(2010,2011)$, Deloitte (2011), Hamilton Consultants (2009) and McKinsey (2011). All of these studies analyse the size of 
Figure A2. Direct impact of the Internet

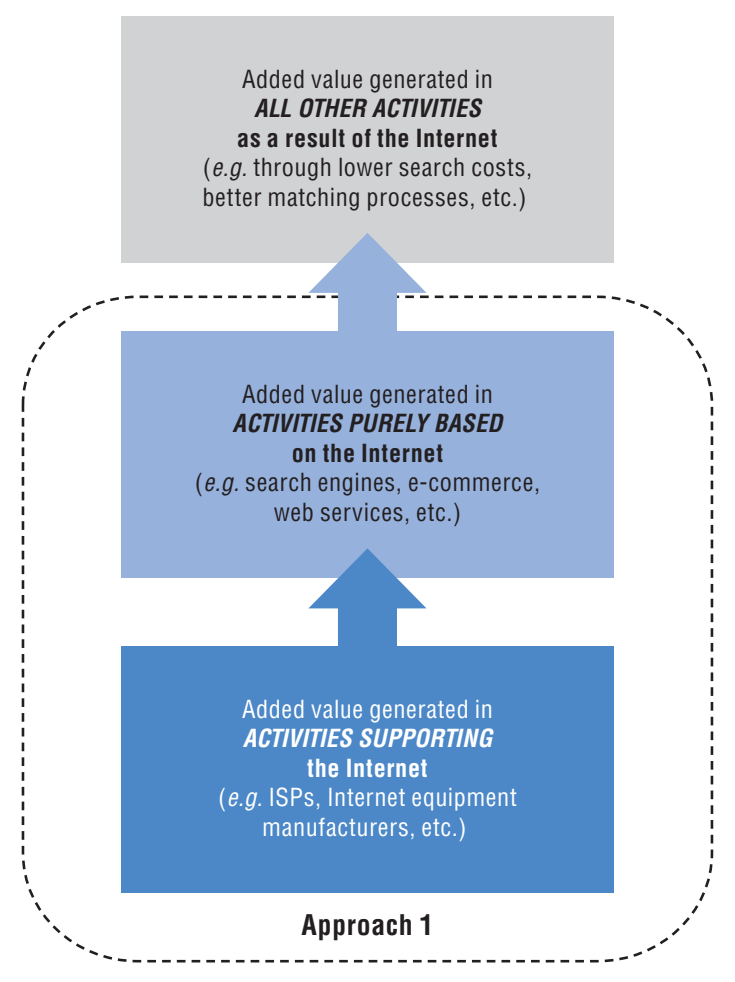

the Internet-related activities as a percentage of total GDP for different developed economies. The estimated results range between $0.8 \%$ and $7 \%$ (Table A1), but the methodologies differ across research firms.

One of the earliest studies to estimate the share of Internet-generated output within total GDP was that of Hamilton Consultants (2009). This study estimates the contribution of the Internet to total GDP based on a proxy of Internet-related jobs, and concludes that the contribution of the Internet to US GDP in 2008 was $2 \%$.

The result likely underestimates the contribution of the Internet to GDP because the approach is based upon the number of jobs deemed to be Internet-related. The study focuses on some key sectors, but does not take into consideration all Internet-related employment in other sectors throughout the economy.

The Boston Consulting Group (BCG, 2010) put forward another approach that looks at the size of the Internet economy in the United Kingdom. In particular, the report attempts to define and quantify the Internet economy and evaluate how the Internet is transforming the UK economy. In particular, the BCG (2010) report distinguishes four areas of direct economic impact of the Internet: $i)$ The share of GDP attributed to the Internet, including consumption, investment, government spending and net exports, ii) consumer and business economic impacts not captured by GDP, including e-commerce, online advertising and consumer benefits, iii) productivity impacts, including gains from e-procurement in manufacturing and productivity gains through e-sales in wholesale and retail trade, and iv) broader social impacts, including user-generated content, social networking, fraud and piracy.

The report concludes that the Internet economy amounts to $7.2 \%$ of GDP in the United Kingdom. BCG subsequently reapplied the methodology for other economies (BCG, 2011; see Table A1). The results range from 1.2\% in Turkey to $6.6 \%$ in Sweden. 
Table A1. Internet-related value added in various economies; results from existing studies

\begin{tabular}{|c|c|c|}
\hline Study & Analysed economy & $\begin{array}{l}\text { Estimated Internet-related } \\
\text { value added ( } \% \text { of GDP) }\end{array}$ \\
\hline Hamilton Consultants (2009) & United States & 2.0 \\
\hline BCG (2010) & United Kingdom & 7.2 \\
\hline BCG (2011) & Sweden & 6.6 \\
\hline BCG (2011) & Hong Kong & 5.9 \\
\hline BCG (2011) & Denmark & 5.8 \\
\hline BCG (2011) & The Netherlands & 4.3 \\
\hline BCG (2011) & Czech Republic & 3.6 \\
\hline BCG (2011) & Germany & 3.4 \\
\hline BCG (2011) & Poland & 2.7 \\
\hline BCG (2011) & Belgium & 2.5 \\
\hline BCG (2011) & Spain & 2.2 \\
\hline BCG (2011) & Italy & 1.9 \\
\hline BCG (2011) & Egypt & 1.6 \\
\hline BCG (2011) & Russia & 1.6 \\
\hline BCG (2011) & Turkey & 1.2 \\
\hline Deloitte (2011) & Australia & 3.6 \\
\hline McKinsey (2011) & $\begin{array}{l}\text { Brazil, Canada, China, France, Germany, India, Italy, Japan, Korea, } \\
\text { Russian Federation, Sweden, United Kingdom, United States }\end{array}$ & 3.4 on average \\
\hline
\end{tabular}

Deloitte Access Economics published a related report on the share of the Internet economy in Australia's GDP (Deloitte, 2011.) The authors conclude that in 2010 the direct contribution of the Internet was equal to $3.6 \%$ of Australia's GDP. The study uses the approach introduced by BCG (2010) and evaluates the amount consumers, businesses and government spent on Internet-related goods and services produced in Australia.

A similar report by McKinsey (2011) applies a similar methodology to assess the share of the Internet in the GDP of 13 economies, including the G7 countries and the BRIC countries. The results vary between $0.8 \%$ and $6.3 \%$ of GDP (Table A1)

The McKinsey report takes an approach similar to that of BCG (2010) for calculating the share of the Internet in total GDP, by aggregating the components of GDP that correspond to Internet-related consumption, investment, government spending and net exports.

These studies are well known and their research goals are well defined. However, the studies typically do not discuss the methodologies employed and do not present their input data. Therefore, these results should be interpreted cautiously.

\section{The OECD study}

The goal of this specific research is to provide a clear, statistical methodology to assess the size of the direct, economic impact of the Internet. In particular, this exercise looks at possible ways:

- To identify Internet-related activities (supporting the Internet or purely based on the Internet) within commonly available international industrial classification systems (ISIC Rev. 4).

- To measure the value added created by these industries, following the concept of value added set out in the System of National Accounts (SNA).

Unfortunately, as described below, the level of detail of data typically available and published by official statistical agencies is rarely sufficient to identify such activities and to derive such estimates. Therefore, the research presented here uses revenue data provided 
by businesses in the information sector, together with e-commerce statistics from other sectors of the economy, as indicators for value added that can be attributed to the Internet.

Internet-related activities and the System of National Accounts (SNA). In the System of National Accounts, the statistical concept of value added is used to capture the value generated by an economic activity. This concept consists of measuring the value that the firm adds to that of the firms that supply its inputs (Lequiller and Blades, 2007). Consequently, the value added is defined as the value of output minus the value of intermediary inputs, that is, all inputs that a firm buys from other firms and uses in its own production.

Most OECD countries are able to provide official estimates of value added, according to the International Standard Industrial Classification of all Economic Activities (ISIC), although at different levels of detail (Box A2). This classification outlines a structure of economic activities subdivided into a hierarchical, four-level structure of mutually exclusive categories.

The OECD has used the concept of value added systematically in the past to measure the economic value generated by the ICT sector ${ }^{1}$ (OECD, 2010a). This concept of value added can be also employed to measure the Internet economy as defined in Approach 1, that is, the direct economic value generated by activities that support the Internet and activities purely based on the Internet.

This requires identifying these activities within the relevant industrial classification sectors. Some of these activities are captured or fall within the OECD ICT sector and the Content and Media sector. ${ }^{2}$ OECD has defined these well-known sectors according to International Standard Industrial Classification (ISIC Rev. 4).

The Internet economy within ISIC: challenges. Unfortunately identifying the Internet-related categories within these sectors across the entire economy is extremely difficult for two main reasons. First, the available categories are, in most cases, too broad to identify relevant activities; hence, identifying Internet-related categories using the most detailed level of ISIC (4-digit) is insufficient. A good example of this could be the newspaper publishing industry, which includes mainly offline activities (traditional newspaper publishing), but also includes some activities that are purely based on the Internet (e.g. publishing of online newspapers). Only some categories within these sectors seem to refer fully to Internet-related activities, but even within these categories there are numerous aspects that may or may not be considered as Internet-related.

Second, available data is presented at a level that is too aggregated to identify the Internet-related activities. Even though some categories within the industrial classifications seem to refer fully to the activities that support the Internet or are purely based on the Internet, the corresponding existing datasets on value added are not detailed enough. This means that without detailed, firm-level data or data held in more detailed national classification systems, the creation of an internationally consistent mechanism to identify the activities that support the Internet and activities purely based on the Internet within ISIC categories is virtually impossible.

Beyond ISIC: revenues and e-commerce. Given that detailed data on Internet activities is usually not readily available in terms of value added, it is necessary to look for other datasets that could provide detailed information about the activities that support the Internet and are purely based on the Internet. This data could in turn be used to approximate value added estimates of the direct economic impact of the Internet. 


\section{Box A2. Industry classification systems}

The International Standard Industrial Classification of All Economic Activities (ISIC) consists of a coherent and consistent classification structure of economic activities based on a set of internationally agreed concepts, definitions, principles and classification rules. The classification is used to classify statistical units, such as establishments or enterprises, according to the economic activity in which they mainly engage.

These economic activities are subdivided into a hierarchical, four-level structure of mutually exclusive categories, facilitating data collection, presentation and analysis at detailed levels of the economy in an internationally comparable, standardised way. The categories at the highest level are called sections, which are alphabetically coded categories intended to facilitate economic analysis. The sections subdivide the entire spectrum of productive activities into broad groupings, such as "Agriculture, forestry and fishing" (section A), "Manufacturing" (section C) and "Information and communication" (section J). The classification is then organised into successively more detailed categories, which are numerically coded: two-digit divisions (e.g. 27 Manufacture of electrical equipment), three-digit groups (e.g. 273 Manufacture of wiring and wiring devices) and, at the greatest level of detail, four-digit classes (e.g. 2731 Manufacture of fibre-optic cables).

The most recent version of ISIC is Revision 4 (ISIC Rev. 4), which has been released to comply with the new statistical concepts introduced by the revision of the SNA in 2008 (SNA, 2008).

Apart from ISIC, there are numerous classification schemes of industrial activity that are used regionally. For example, the European countries have a common industry standard classification system (NACE) consisting of a 4-digit code linked closely to ISIC. Australia and New Zealand use the Australian and New Zealand Standard Industrial Classification (ANZSIC), also consisting of a 4-digit code system linked to ISIC, but more detailed at the lower level. Canada, Mexico and the United States follow the North American Industry Classification System (NAICS), which is a more detailed (6-digit) classification, also linked to ISIC. In general, every country has its own national industrial classification at various levels of detail, which usually link to ISIC (e.g. JSIC for Japan, KSIC for Korea, etc.).

Two industry-related datasets seem to be particularly relevant in this context: i) data on revenues collected through surveys, and ii) data on e-commerce activities (also collected through surveys). Available statistics as well as a more detailed industrial classification (NAICS) make this type of analysis possible for the United States.

The Internet economy in the United States. The following statistics can be used in order to proxy Internet-related activities and their value added for the United States:

- Detailed revenue data on services, in particular on Internet-related activities within the information sector, identified in the North American Industry Classification System (NAICS 2002) as NAICS Code 51 (for more details see Table A3) (US Census Bureau, 2010 Annual Services Report).

- E-commerce revenue reported across a large number of industries, also in NAICS 2002 (Table A4) (US Census Bureau, 2010 E-commerce Multisector E-Stats report).

These two datasets serve to identify a number of activities that support the Internet and/or are purely based on the Internet. ${ }^{3}$ These proxies can be combined with value added data for each industry to estimate the value of the Internet-related activities. In the case of the United States, this can be done with value added per industry sector at an aggregate level, two or three digits (Table A2). 
Table A2. Value added (VA) in the United States (NAICS 2002)

USD million and as share of business sector value added

\begin{tabular}{|c|c|c|c|c|c|c|}
\hline \multirow{2}{*}{$\begin{array}{l}\text { Value added (USD million) } \\
\text { Industry title }\end{array}$} & \multirow[b]{2}{*}{2008} & \multirow[b]{2}{*}{2009} & \multirow[b]{2}{*}{2010} & \multicolumn{3}{|c|}{ As share of business sector VA } \\
\hline & & & & 2008 & 2009 & 2010 \\
\hline Total & 14291543 & 13938950 & 14526547 & & & \\
\hline Agriculture, forestry, fishing, and hunting & 159375 & 139972 & 156984 & & & \\
\hline Mining & 319166 & 213366 & 239511 & $4 \%$ & $3 \%$ & $3 \%$ \\
\hline Utilities & 257663 & 258324 & 264862 & $3 \%$ & $3 \%$ & $3 \%$ \\
\hline Construction & 614204 & 541905 & 511639 & $7 \%$ & $6 \%$ & $6 \%$ \\
\hline Manufacturing & 1628498 & 1540226 & 1701937 & $18 \%$ & $18 \%$ & $19 \%$ \\
\hline Wholesale trade & 824067 & 768548 & 797348 & $9 \%$ & $9 \%$ & $9 \%$ \\
\hline Retail trade & 848629 & 837205 & 884877 & $9 \%$ & $10 \%$ & $10 \%$ \\
\hline Transportation and warehousing & 414994 & 391672 & 402524 & $5 \%$ & $5 \%$ & $4 \%$ \\
\hline Information & 636843 & 615445 & 623472 & $7 \%$ & $7 \%$ & $7 \%$ \\
\hline Finance and insurance & 1041460 & 1098964 & 1241946 & $12 \%$ & $13 \%$ & $14 \%$ \\
\hline Real estate & 1671470 & 1679218 & 1563893 & & & \\
\hline Rental and leasing services and lessors of intangible assets & 203692 & 186350 & 201346 & $2 \%$ & $2 \%$ & $2 \%$ \\
\hline Professional, scientific, and technical services & 1100205 & 1033270 & 1095758 & $12 \%$ & $12 \%$ & $12 \%$ \\
\hline Management of companies and enterprises & 263215 & 248970 & 263699 & $3 \%$ & $3 \%$ & $3 \%$ \\
\hline Administrative and waste management services & 419750 & 395837 & 423380 & $5 \%$ & $5 \%$ & $5 \%$ \\
\hline Accommodation and food services & 404907 & 387604 & 416693 & $5 \%$ & $5 \%$ & $5 \%$ \\
\hline Community social and personal services* & 3483406 & 3602075 & 3736677 & & & \\
\hline Business sector & 8977293 & 8517686 & 9068992 & $100 \%$ & $100 \%$ & $100 \%$ \\
\hline Total VA & $100 \%$ & $100 \%$ & $100 \%$ & & & \\
\hline Business sector as share of total VA & $63 \%$ & $61 \%$ & $62 \%$ & & & \\
\hline Agriculture, forestry, fishing, and hunting as share of total VA & $1 \%$ & $1 \%$ & $1 \%$ & & & \\
\hline Real estate as share of total VA & $12 \%$ & $12 \%$ & $11 \%$ & & & \\
\hline Community social and personal services as share of total VA & $24 \%$ & $26 \%$ & $26 \%$ & & & \\
\hline * Community social and personal services includes: & 3483406 & 3602075 & 3736677 & & & \\
\hline Educational services, health care, and social assistance & 1153947 & 1210420 & 1272289 & & & \\
\hline Arts, entertainment, and recreation & 132370 & 130009 & 139112 & & & \\
\hline Other services, except government & 342693 & 340791 & 356766 & & & \\
\hline Government & 1854396 & 1920855 & 1968510 & & & \\
\hline
\end{tabular}

Notes: In order to get a comparable aggregate across countries, the business sector has been calculated following the business sector aggregate defined by ISIC Rev. 4 activities 05-66 and 69-82 (not italicized above). It does not take into account agricultural activities; real estate; nor community, social and personal services. The community social and personal services category includes industries such as: educational services, health care and social assistance; arts, entertainment and recreation, and other services except government, and government services. Source: OECD based on US Bureau of Economic Analysis data, April 2012.

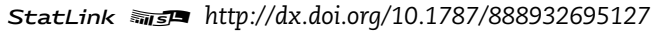

The first dataset focuses on the information sector and captures some of the activities supporting the Internet (e.g. Internet access services), as well as some of the activities performed purely on the Internet (e.g. online newspapers, publishing and broadcasting of content on the Internet). For a complete list, see below (Table A3).

The data on e-commerce report the value of goods and services sold online in various sectors. This corresponds to the activities purely based on the Internet. There are two ways to approach e-commerce value added. The first is a narrow approach that only takes into account value added from the wholesale and retail sectors. This is because it can be argued that all of the value added generated by e-commerce in these sectors is directly related to the Internet. The second approach takes a broader view and includes all industries across the economy (business sector) for which data are available.

E-commerce data were collected in four separate Census Bureau surveys: Annual Survey of Manufactures (ASM), Annual Wholesale Trade Survey (AWTS), Annual Retail 


\section{Table A3. The information sector in the United States (NAICS 51), estimated revenue} for employer firms, 2006-10

Revenue (USD million)

\begin{tabular}{|c|c|c|c|c|c|c|}
\hline NAICS 02 & Industries & 2006 & 2007 & 2008 & 2009 & 2010 \\
\hline 51 & Information sector revenues & 1027063 & 1072341 & 1108349 & 1074959 & 1110225 \\
\hline 511 & Publishing industries (except Internet) & 269907 & 282223 & 284613 & 264194 & 265718 \\
\hline 5111 & Newspaper, periodical, book and directory publishers & 144704 & 146822 & 141896 & 125213 & 120293 \\
\hline 511110 & Newspaper publishers & 48949 & 47563 & 43919 & 36358 & 34695 \\
\hline Of which & Online newspapers & 1449 & 1655 & 2045 & 1277 & 1699 \\
\hline 511120 & Periodical publishers & 44757 & 46003 & 44985 & 39099 & 38395 \\
\hline Of which & Online periodicals & 2889 & 2776 & 3233 & 2903 & 3153 \\
\hline 511130 & Book publishers & 26722 & 27807 & 28032 & 27404 & 28121 \\
\hline Of which & Online books & 864 & 1009 & 1143 & 1295 & 2055 \\
\hline 511140 & Directory and mailing list publishers & 17617 & 18515 & 18371 & 16670 & 13475 \\
\hline Of which & Online directories, databases and other collection of information & 2767 & 3390 & 3805 & 4199 & 4204 \\
\hline 511191 & Greeting card publishers & 4609 & 4779 & 4443 & 3862 & 3852 \\
\hline 511199 & All other publishers & 2050 & 2155 & 2146 & 1820 & 1755 \\
\hline 5112 & Software publishers & 125203 & 135401 & 142717 & 138981 & 145425 \\
\hline 511210 & Software publishers & 125203 & 135401 & 142346 & 138714 & 138714 \\
\hline 512 & Motion picture and sound recording industries & 93265 & 94986 & 95271 & 90398 & 95118 \\
\hline 5122 & Sound recording industries & 16821 & 15189 & 15267 & 14419 & 13787 \\
\hline 512210 & Record production & 301 & 338 & 351 & 425 & 453 \\
\hline 512220 & Integrated record production/distribution & 10642 & 9082 & 8953 & 8665 & 8258 \\
\hline 512230 & Music publishers & 4646 & 4466 & 4713 & 4155 & 3793 \\
\hline 512240 & Sound recording studios & 831 & 854 & 810 & 749 & 839 \\
\hline 512290 & Other sound recording industries & 401 & 449 & S & 425 & 444 \\
\hline 515 & Broadcasting (except Internet) & 96311 & 99919 & 104584 & 98934 & 107520 \\
\hline 515111 & Radio networks & 3829 & 4124 & 4341 & 4307 & 4883 \\
\hline 515112 & Radio stations & 14616 & 14871 & 13912 & 11643 & 12135 \\
\hline 515120 & Television broadcasting & 36959 & 35998 & 36762 & 31553 & 35334 \\
\hline 515210 & Cable and other subscription programming & 40907 & 44926 & 49569 & 51431 & 55168 \\
\hline 516 & Internet publishing and broadcasting & 11510 & 15035 & 17763 & 19111 & 21273 \\
\hline 516110 & Internet publishing and broadcasting & 11510 & 15035 & 17760 & 19504 & 19504 \\
\hline Of which & Publishing and broadcasting of content on the Internet & 6344 & 7669 & 8998 & 10014 & 10696 \\
\hline Of which & Online advertising space & 2579 & 3469 & 4298 & 4957 & 5623 \\
\hline 517 & Telecommunications & 459315 & 480030 & 498058 & 495062 & 507533 \\
\hline 517110 & Wired telecommunications carriers & 193434 & 186060 & 184197 & 172675 & 168759 \\
\hline Of which & Internet access services & 15272 & 20045 & 22468 & 25020 & 28640 \\
\hline Of which & Internet telephony & 1826 & 2049 & 2333 & 2314 & 2966 \\
\hline 517211 & Paging & 1294 & 889 & 846 & 742 & 710 \\
\hline 517212 & Cellular and other wireless telecommunications & 154719 & 169694 & 180629 & 184942 & 194815 \\
\hline Of which & Internet access services & 7650 & 12731 & 20069 & 24598 & 28604 \\
\hline 517310 & Telecommunications resellers & 11530 & 11853 & 11105 & 10044 & 9817 \\
\hline 517410 & Satellite telecommunications & 4758 & 4450 & 4767 & 5203 & 5296 \\
\hline 517510 & Cable and other programme distribution & 88474 & 100416 & 109351 & 114327 & 121300 \\
\hline Of which & Internet access services & 13736 & 16281 & 18070 & 19332 & 20944 \\
\hline Of which & Internet telephony & 1577 & 3433 & 5167 & 6309 & 6601 \\
\hline 517910 & Other telecommunications & 5106 & 6668 & n.a. & 7129 & 6836 \\
\hline 518 & Internet service providers, web search portals and data processing services & 90427 & 93804 & 101411 & 100719 & 106582 \\
\hline 518111 & Internet service providers & 12366 & 11093 & 10614 & 10441 & 9974 \\
\hline 518112 & Web search portals & 12038 & 16059 & 19099 & 18664 & 20452 \\
\hline 518210 & Data processing, hosting and related services & 66023 & 66652 & 71698 & 71614 & 76156 \\
\hline Of which & Website-hosting services & 2237 & n.a. & 1718 & 1868 & 2188 \\
\hline \multirow[t]{3}{*}{519} & Other information services & 6328 & 6344 & 6649 & 6541 & 6481 \\
\hline & Internet-related activities revenues & 83594 & 101659 & 123060 & 133191 & 147799 \\
\hline & $\begin{array}{l}\text { Share of Internet-related activities revenues in total information sector } \\
\text { revenues (51) }\end{array}$ & $8.1 \%$ & $9.5 \%$ & $11.1 \%$ & $12.4 \%$ & $13.3 \%$ \\
\hline
\end{tabular}

Note: Industries italicized above represent the identified Internet-related activities, both supporting and purely based on the Internet. Source: OECD based on US Census Bureau, 2010 Annual Services report, February 2012. 
Trade Survey (ARTS) and Service Annual Survey. These surveys used different measures of economic activity such as shipments for manufacturing, sales for wholesale and retail trade, and revenues for service industries. The E-Stats data for 2010 does not cover the entire US economy and sectors such as agriculture, mining, construction and some services-related industries are not included.

The e-commerce data illustrates only the share of e-commerce in revenues in relevant industry classes, not in their value added (see Table A4).

For the purposes of this exercise, the data on value added only takes into account the business sector (i.e. non-agricultural business sector excluding real estate and community social and personal services). In the United States this sector accounted for $62 \%$ of total value added (GDP) in 2010.

To estimate the Internet-related value added, two separate procedures are applied: one for the information sector and another for other sectors (Figure A3).

Figure A3. Estimation of the direct impact of the Internet

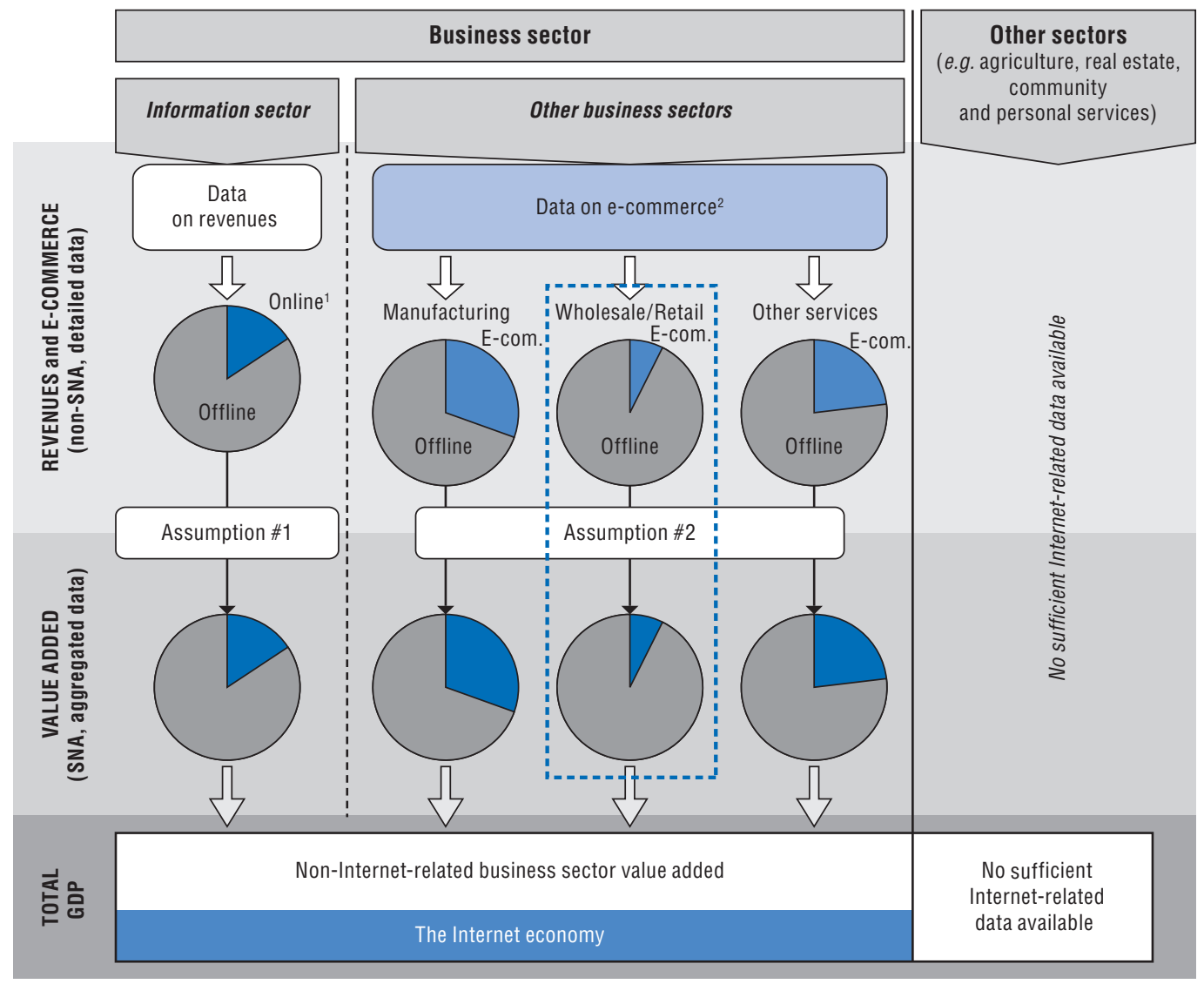

Note: The narrow scope focuses on Internet-related activities in the following business sector industries: Information services sector and the wholesale and retail sectors. The broader scope takes into account Internet-related activities across all industries in the business sector for which data are available.

1. The term "online" refers to Internet-related activities, both supporting the Internet and activities purely based on the Internet within the information sector (see Table A3).

2. Data on e-commerce refer to the activities purely based on the Internet and statistics on e-commerce are based on different measures of economic activity such as shipments for manufacturing, sales for wholesale and retail trade, and revenues for service industries (see Table A4). 
Table A4. E-commerce in the United States in selected industries (NAICS 2002)

As percentage of total shipments, sales or revenues

\begin{tabular}{|c|c|c|c|c|}
\hline NAICS 2002 & Industries & 2008 & 2009 & 2010 \\
\hline 11 & Agriculture, forestry, fishing, and hunting & n.a. & n.a. & n.a. \\
\hline 21 & Mining & n.a. & n.a. & n.a. \\
\hline 22 & Utilities & n.a. & 0.2 & 0.2 \\
\hline 23 & Construction & n.a. & n.a. & n.a. \\
\hline $31,32,33$ & Manufacturing & 39.7 & 42.8 & 46.4 \\
\hline 321 & Wood products & 22.1 & 25.4 & 28.4 \\
\hline 327 & Nonmetallic mineral products & 23.1 & 27.0 & 30.5 \\
\hline 331 & Primary metals & 38.7 & 40.4 & 45.7 \\
\hline 332 & Fabricated metal products & 27.5 & 31.8 & 36.0 \\
\hline 333 & Machinery & 36.4 & 41.2 & 46.6 \\
\hline 334 & Computer and electronic products & 38.7 & 41.8 & 44.6 \\
\hline 335 & Electrical equipment, appliances, and components & 34.1 & 40.2 & 43.8 \\
\hline $3361,3362,3363$ & Motor vehicles, bodies and trailers, and parts & n.a. & n.a. & n.a. \\
\hline $3364,3365,3366,3369$ & Other transportation equipment & n.a. & n.a. & n.a. \\
\hline 337 & Furniture and related products & 31.0 & 34.3 & 39.5 \\
\hline 339 & Miscellaneous manufacturing & 25.1 & 28.9 & 31.0 \\
\hline 311,312 & Food and beverage and tobacco products & 40.6 & 45.0 & 48.1 \\
\hline 313,314 & Textile mills and textile product mills & 42.3 & 47.4 & 50.2 \\
\hline 315,316 & Apparel and leather and allied products & 28.9 & 34.4 & 35.4 \\
\hline 322 & Paper products & 37.8 & 42.9 & 46.5 \\
\hline 323 & Printing and related support activities & 30.4 & 31.7 & 35.2 \\
\hline 324 & Petroleum and coal products & 44.1 & 44.3 & 46.0 \\
\hline 325 & Chemical products & 40.1 & 42.2 & 44.2 \\
\hline 326 & Plastics and rubber products & 35.8 & 40.9 & 43.9 \\
\hline 42 & Wholesale trade ${ }^{1}$ & 17.3 & 20.5 & 20.2 \\
\hline 44,45 & Retail trade & 3.6 & 4.0 & 4.4 \\
\hline 48, 49 (except 491) & Transportation and warehousing & n.a. & n.a. & n.a. \\
\hline 481 & Air transportation & n.a. & 28.1 & 26.2 \\
\hline 482 & Rail transportation & n.a. & n.a. & n.a. \\
\hline 483 & Water transportation & n.a. & 17.3 & 8.7 \\
\hline 484 & Truck transportation & 3.5 & 3.6 & 3.5 \\
\hline 485 & Transit and ground passenger transportation & n.a. & 0.8 & n.a. \\
\hline 486 & Pipeline transportation & n.a. & 1.0 & 0.9 \\
\hline $487,488,492$ & Other transportation and support activities & n.a. & n.a. & n.a. \\
\hline 493 & Warehousing and storage & n.a. & n.a. & n.a. \\
\hline 51 & Information & 4.6 & 5.0 & 5.0 \\
\hline 511,516 & Publishing industries (includes software) & n.a. & n.a. & n.a. \\
\hline 512 & Motion picture and sound recording industries & n.a. & n.a. & n.a. \\
\hline 515,517 & Broadcasting and telecommunications & n.a. & n.a. & n.a. \\
\hline 518,519 & Information and data processing services & n.a. & n.a. & n.a. \\
\hline 52 & Finance and insurance & n.a. & 1.4 & 1.5 \\
\hline 53 & Real estate and rental and leasing & n.a. & n.a. & n.a. \\
\hline 531 & Real estate & n.a. & n.a. & n.a. \\
\hline 532 & Rental and leasing services and lessors of intangible assets & 6.9 & 8.7 & 8.5 \\
\hline 54 & Professional, scientific, and technical services & 1.6 & 1.9 & 1.9 \\
\hline 55 & Management of companies and enterprises & n.a. & n.a. & n.a. \\
\hline 56 & Administrative and waste management services & 2.7 & 2.9 & 3.0 \\
\hline 61 & Educational services & n.a. & 7.5 & 7.6 \\
\hline 62 & Health care and social assistance & 0.1 & 0.1 & 0.2 \\
\hline 71 & Arts, entertainment, and recreation & 2.1 & 2.2 & 2.4 \\
\hline 72 & Accommodation and food services & 2.8 & 2.7 & 3.0 \\
\hline 81 & Other services, except government & 2.0 & 2.1 & 2.3 \\
\hline
\end{tabular}

1. Wholesale trade refers to merchant wholesale trade sales, excluding manufacturers' sales branches and offices.

Source: OECD based on US Census Bureau, 2010 E-commerce Multi-sector "E-Stats" report, May 2012. 
To calculate the relevant value added from the information sector the following assumption is applied:

Assumption 1: It is assumed that the share of revenue from Internet-related activities in total revenue for the information sector is proportional to the share of value-added from these activities in total value added for that sector.

The added value generated by the Internet-related activities of the information sector in the United States is estimated at $0.9 \%$ of total business sector value added for 2010.

Consequently, in order to calculate the relevant value added from e-commerce activities in other business sectors of the economy, the following assumption is applied:

Assumption 2: It is assumed that the share of revenue from e-commerce in total revenue for each industry sector is proportional to the share of value added from e-commerce in total value added for that same industry sector.

Applying the shares of e-commerce in revenues of relevant industries and aggregating the results yields the total added value generated by e-commerce in certain sectors of the US economy (excluding the information sector) as 2.2 (according to the narrow scope) or $12.1 \%$ of total business sector value added in 2010 .

Adding together the estimate of the value added generated by the Internet-related activities of the information sector, and the estimate of the value added generated by e-commerce in certain sectors of the US economy (excluding the information sector), provides an order of magnitude of the value added in US business sector that relies on the Internet.

In particular, at least 3\% (narrow scope) and up to 13\% (broad scope) of US business sector value added could be attributed to Internet-related activities in 2010. It is important to note that the broad scope estimate is based on the limit assumption that online sales are adding to traditional sales, with no substitution occurring. Moreover, these numbers are based on data that reflect only a part of the US economy since agricultural activities, real estate, and community and personal services are not included (see Figure A3). The business sector accounted for 62\% of total US value added (GDP) in 2010.

This result is graphically presented in the upper pie chart (Figure A4).

Three elements should be highlighted:

First, the presented share of value added (GDP) attributed to Internet-related activities is not an independent sector, as other sectors of the US economy. Instead, it is distilled from shares of other sectors and overlaps with them. The share of the Internet presented on the pie chart is represented in contrast to the share of non-Internet related only and also highlight the distinction between the narrow and $\mathrm{b}$ road measures depending on the scope of the definition (Figure A4).

Second, the Internet as a general-purpose technology is not directly reflected in the national accounts system, so the results presented rely on the strong assumption that revenues are proportional to value added.

Third, the direct impact of the Internet on the economy is presented in gross terms. In particular, some of the activity based on the Internet may replace activity generated in another, offline environment. For example, online shopping can substitute for traditional shopping and online banking has replaced some traditional, face-to-face banking. Indeed, several empirical studies highlight the fact that the rapid evolution of the Internet and the emergence of this fast-changing technological environment resulted in some 
Figure A4. Sizes of various sectors in the United States economy

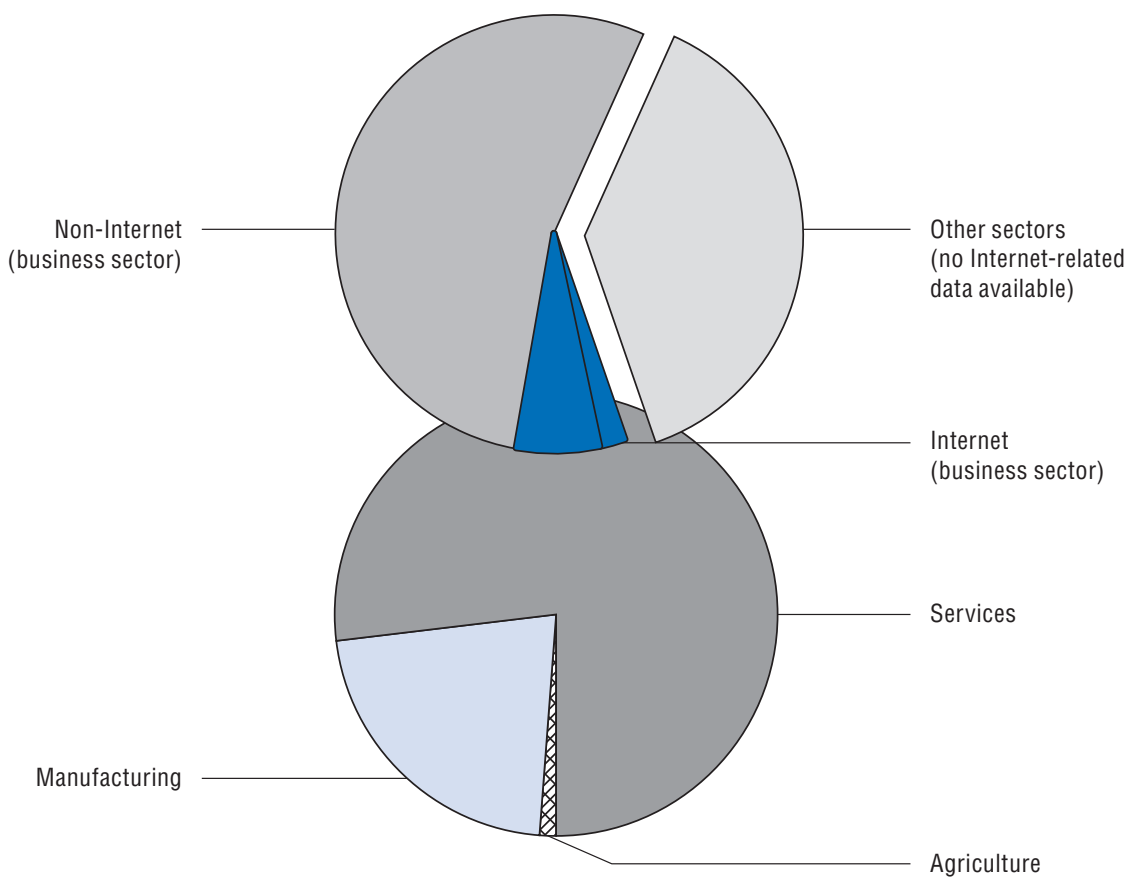

displacement of economic activities (Brynjolfsson and Hitt, 1996; Eisenach and Lenard, 1998, Katz and Shapiro, 1986; McAfee and Brynjolfsson, 2007).

\section{Future research}

There is a lack of a clear, statistical methodology to identify directly the activities that support the Internet and which are purely based on the Internet within the SNA. There is a therefore need for more research in this area to assess the size of the direct, economic impact of the Internet.

Future research in this area will focus on two key areas: i) investigating the data available for other countries and ii) refining the methodology as required. More granular data collection by national statistical agencies would be required to undertake these exercises.

\section{Approach 2. The dynamic impact of the Internet}

As noted earlier, the economic impact of the Internet, as captured in GDP and the system of national accounts, reaches beyond those firms that support and operate purely on the Internet. In fact, the emergence of the Internet effected significant shifts in the existing business environment and resulted in improved company efficiency across all sectors, at various stages of activity.

These shifts resulted in major changes to traditional business models and activities for many industries, and as a consequence, ushered in a new structure for the creation of added value, from offline to online. 


\section{Box A3. Summary of Approach 2: Dynamic impact of the Internet}

\section{The approach}

This dynamic approach to measuring the impact of the Internet looks at the net share of additional GDP generated by all Internet-related activities across the economy. This requires examination of the statistical relationship between measures of Internet development and economic variables such as GDP growth or employment. This implies a trade-off as the approach captures the net GDP benefits of the Internet across all sectors of the economy, but without the level of detail necessary to understand the precise sources of these benefits. Furthermore, this approach captures only "net" benefits; the Internet's full impact could be tempered by GDP or employment losses in other sectors as a result of Internet development.

\section{Existing results}

A number of academic studies have used varied econometric approaches to assess the economic impact of the Internet (or broadband) on GDP. The results indicate a certain magnitude of impact common across all studies. In general, the findings show that if the Internet grows $1 \%$ faster in one of two otherwise identical countries, GDP growth in the country with more Internet growth will be up to $0.025 \%$ higher.

\section{The OECD study}

This section presents a simulation exercise using estimations from existing econometric studies on the impact of the Internet on GDP growth. The scenario was: "what if there was no Internet". The study concluded that in 2010 the Internet in the United States contributed up to $7 \%$ of total GDP.

\section{Future research}

A key area for future research will be more detailed work on the causality of the relationship between GDP and Internet development. Similarly to Approach 1, the methodology of this exercise could be refined and applied to other economies.

\section{The approach}

This approach examines the: i) aggregated and ii) net impact that the Internet has on GDP. Studies within this approach take into account:

- All possible industries that generate added value as a result of the Internet (not only industries supporting the Internet and operating purely on the Internet).

- The net economic effect of the Internet on GDP.

The concept of value added generated as a result of the Internet rests upon the observation that the Internet results in efficiency gains in virtually all sectors, including those that are seemingly unrelated to the Internet such as the gas and oil extraction industry (Box A4) that eventually add to GDP.

Internet-based solutions impact industrial performance at various stages of firms' activity; for example, the Internet improves R\&D efficiency and facilitates cross-firm collaboration. Several empirical studies have demonstrated the positive influence of the Internet on research efficiency within firms and R\&D collaboration between firms. Consequently, Internet use positively impacts innovation activity among firms (Bertschek et al., 2011; Forman and van Zeebroeck, 2010; Polder et al., 2009).

In terms of economic activity, Internet connectivity enables greater interaction among all market players. It also leads to more intense information flows, creates better and faster 
matching processes, and consequently results in a higher rate of productivity. Numerous empirical studies have documented the positive impact of the Internet on companies (Bertschek et al., 2011; Grimes and Ren, 2009; Majumdar et al., 2009; Polder et al., 2009; Varian et al., 2002).

\section{Box A4. The impact of the Internet on the gas and oil extraction industry}

ICTs and the Internet play a significant role in the gas and oil extraction industry. An UNCTAD report highlighted the importance of the Internet and its applications for various activities in these sectors undertaken by companies such as BP, Royal Dutch Shell, China National Petroleum Corporation and Gazprom (UNCTAD, 2006.)

Examples include solutions to improve communications for the mobile workforce. These are especially useful for employees travelling frequently to remote locations and for crisis management in cases of natural disasters. Quick communication saves precious time and automated data consolidation allows for quicker reaction times. Internet solutions in the gas and oil extraction industries facilitate remote collaboration across project teams, and create a foundation for business intelligence applications, stronger content management, and consistent communications with external stakeholders.

Clearly, these benefits achieved as a result of the Internet across all the sectors result in improved savings and consequently higher profits. One of the earliest studies (Varian et al., 2002) noted the beneficial impact of the Internet on company profits. The report analysed the impact of Internet technologies on economic activity, based on a survey of companies from various industries. The study, based on collected responses, found that even at the early stage of broadband development (2002), companies actively used the Internet to look for solutions, which helped them to cut costs and increase revenues. Specifically, firms in France, Germany, the United Kingdom and the United States reported realising a cumulative cost savings of USD 163.5 billion with the majority of the savings occurring since 1998 (Varian et al., 2002).

From an economic perspective, these efficiency gains translate into higher added value, reported across all industries. This added value is generated as a result of the Internet and hence could be viewed as part of the total Internet economy. However, studies that measure specific Internet-related activities within existing industries (e.g. e-commerce) would not capture this added value, as it is neither generated to support the Internet nor purely based on the Internet. For example. the efficiencies generated as a result of the Internet in the gas and oil extraction industry (Box A4) that consequently led to improved efficiency and higher profits, would not be entirely captured by these studies, as they are neither supporting the Internet nor purely based on the Internet. Moreover, they do not appear in the e-commerce statistics so in that event the general approximation methodology applied in this study would not take them into account.

To illustrate this mechanism, assume the following dynamic sequence of events. The first stage is the development of Internet infrastructure, the industries that support the Internet (Figure A5, bottom row). This includes companies that build, install or manage Internet infrastructure.

During the second stage, service providers, such as search companies, e-mail hosting and other content firms, use this infrastructure to establish themselves and provide new 


\section{Figure A5. Dynamic impact of the Internet}

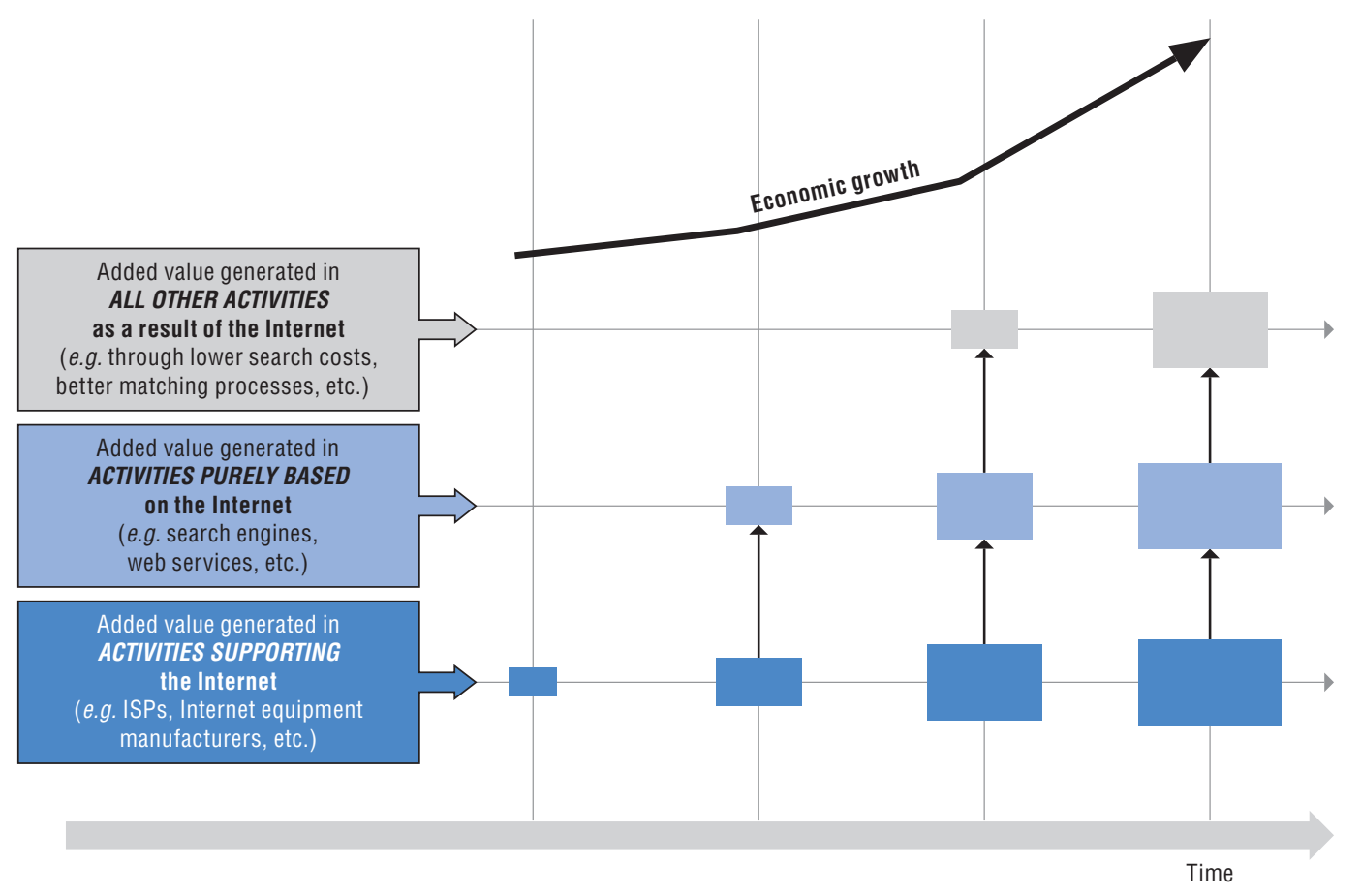

services. These activities also include the broad spectrum of e-commerce-related businesses (e.g. online shopping, e-banking etc.). These Internet-specific services add to GDP, but also become a key platform for the next stage (Figure A5, middle row).

In the third stage, the Internet's impact spreads to virtually all activities in all sectors of the economy. Many of the benefits achieved lie outside the traditional Internet sector (Figure A5, top row), including sectors as diverse as automotive, agriculture and government. The benefits in these outlying sectors rely on services and infrastructure in the bottom two levels.

The dynamic co-existence of these industries can be in turn observed at the aggregated macroeconomic scale in terms of a higher rate of economic growth.

Studies that follow the second approach focus on a second property: assessment of the net effect of the Internet economy. As mentioned above, the introduction of the Internet has resulted in the migration of some economic activities from the offline environment to the online. Indeed, numerous industries have observed the dynamic introduction of online channels of distribution in parallel with the reduction in importance of traditional offline channels. This approach takes into account only the net change, that is, the surplus in added values generated by the Internet.

To reiterate, the Internet does not only impact industries that support the Internet or operate primarily on the Internet; it has a clear impact on a myriad of activities in virtually all industries. The impacts are measurable and hence are captured by the SNA, but it is extremely difficult in many sectors to separate out which parts of value added are attributable to the Internet and which are not. Moreover, these transformational effects of the Internet at the company level might also imply some shift in the structure of GDP, which implies that the total net effect should be lower than simple aggregation of all the added values generated as a result of the Internet. 
A number of studies consider these general net economic effects, and discuss the role of the Internet in the macroeconomic context.

\section{Existing studies}

A study by Crandall, Lehr and Litan (2007) used state-level data in the United States to examine the effects of broadband penetration on output and employment, in the aggregate and by sector. To check the macroeconomic impact of the Internet, the authors employed an ordinary least-squares regression analysis, ${ }^{4}$ using the number of broadband lines per capita as a proxy of the Internet, and the ratio of employment or output in 2005 to its level in 2004 (or 2003) as dependent variables. They found that non-farm private employment and employment in several industries was positively correlated with the use of broadband. Specifically, for every $1 \%$ increase in broadband penetration in a state, the corresponding level of employment was higher by $0.2 \%$ to $0.3 \%$ per year.

An extensive study by Franklin, Stam and Clayton (2009) used a large dataset from several European countries to examine the effects of broadband. This statistical analysis found broadband use to be correlated with higher firm-level productivity. Moreover, firm-level analyses in Sweden and the Netherlands link this to the role of ICTs as a facilitator of wider innovation.

Qiang and Rossotto (2009) also found a positive relationship between the adoption of broadband and the rate of economic growth. Apart from a substantial literature overview, the study introduced a cross-country empirical model to analyse this relationship. The authors used data from 120 developing and developed countries in an endogenous growth model based on Barro (1991). This approach allowed them to test the quantitative relationship between broadband penetration rates and the average growth rate of per capita GDP between 1980 and 2006, while controlling for other factors that may impact growth rates. The study found a correlation between broadband penetration rates that are 10 percentage points higher and annual per-capita economic growth rates that are 1.21 percentage points higher.

Clearly correlation does not imply causation since this basic association between Internet development and economic growth may be driven by reverse causality and other variables. If fact, several studies identified economic growth as one of the main determinants of Internet development (Chinn and Fairlie, 2007; Kiiski and Pohjola, 2002). These conclusions highlight the mutual dependency between Internet development and economic growth. More developed countries invest more in Internet development, while more developed Internet may contribute to the rate of economic growth.

Several studies have addressed the question of whether Internet development drives economic growth by applying econometric techniques (e.g. Czernich et al., 2009; Koutroumpis, 2009). The results suggest that Internet development might indeed have some causal effect on growth.

Czernich et al. (2009) examined the effect of broadband infrastructure on economic growth in a number of OECD countries (1996-2007), using broadband penetration rates as the proxy for Internet development. To overcome the potential problem with endogeneity, the authors performed the analysis in two steps. First, they established a predicted pattern of broadband evolution (free of shocks and policy interventions) using data on cable TV and phone lines as instruments. They then used this predicted estimator to explain the rates of 
economic growth. The study found that an increase in broadband penetration by 10 percentage points raises annual per-capita growth by 0.9 to 1.5 percentage points.

Koutroumpis (2009) also investigated how the Internet (measured by broadband penetration rates) affects economic growth, using a macroeconomic production function based on a micro-model for broadband investments. Specifically, a structural econometric model (a framework that endogenised telecommunications investment) was inserted within the macroeconomic production function. The results suggested that the increasing returns to broadband investments corresponded to the persistence of network externalities.

To reiterate, with regard to macroeconomic effects, the available evidence confirms that the intuitive dynamic net effects of the Internet are in fact real, and can often be quantified.

The quantitative studies discussed here provide a strong indication of the positive net economic impact of the Internet, but it is important to stress that this impact cannot be measured quantitatively with great precision. The meta-study by Holt and Jamison (2009) confirms this conclusion. The existing studies produce the same ranges of magnitude, but more precise results are restricted by data limitations.

Moreover, it must be stressed that measuring the macroeconomic impact of the Internet requires a large, consistent, underlying dataset to produce econometrically solid and robust results. Given that the Internet is a relatively new, and rapidly growing phenomenon this data requirement cannot be fully met. Hence, the results presented above cannot be interpreted as a robust confirmation of the causal effect that the Internet has on economic growth, but as a preliminary indication of such an effect.

\section{The OECD study}

The results of studies that assess the dynamic, net economic impact of the Internet provide a useful tool to calculate the current net value of GDP generated as a result of the Internet. In particular, the measures of the casual effect of the Internet on economic growth can be used to evaluate the net impact of the Internet on the total GDP of a given economy.

Two findings presented by Koutroumpis (2009) are used as the basis of a simulation exercise using the US economy:

- The first finding is the estimate of the impact of Internet development (measured by broadband penetration rates) on GDP growth. Specifically, Koutroumpis (2009) measures how a $1 \%$ higher growth rate of broadband penetration rates affects economic growth. Depending on the estimation technique, the study concludes this is equal to $0.023 \%$ or to $0.025 \%$.

- The second finding is that the causal and positive effects of the Internet on growth are particularly visible, once a critical mass of Internet infrastructure is present. In economies with low rates of Internet development, the impact on economic growth may even be undetectable, whereas in countries with rapidly developing networks the impact of the Internet on growth increases more than proportionally.

These conclusions can be used to check the size of the net share of GDP generated as a result of the Internet. It is evaluated in a quantitative simulation process according to the following scenario: Once the Internet becomes economically important its development freezes and the rate of broadband growth equals zero.

Following the findings of the empirical research presented above, this lack of Internet development would in turn have an effect on economic growth. Moreover, using the 
measures calculated by Koutroumpis (2009), it is possible to calculate the value of the GDP that would be generated without the economic influence of the Internet.

In particular, the difference between the hypothetical value of GDP, potentially generated without the Internet, and the currently observed value of GDP is the measure of net value added generated as a result of the Internet. It is generated based on all the activities supported, enabled and facilitated as a result of the Internet, across all industries.

The study by Koutroumpis (2009) estimates two alternative proxies of the economic impact of the Internet, depending on the estimation method chosen. Consequently, the simulation exercise includes two corresponding scenarios. The higher value $(0.025 \%)$ refers to the stronger impact of the Internet, the lower value $(0.023 \%)$ refers to the weaker impact.

Moreover, Koutroumpis (2009) highlights the importance of a critical mass in Internet development, without precisely estimating it. It is possible to address this issue by checking various scenarios of Internet development that vary with respect to the year when this critical mass is reached. The scenario with the highest impact then corresponds to the upper boundary of the possible economic impact of the Internet.

In particular, four different scenarios of Internet development are analysed (see Box A5). These scenarios correspond to cases of: i) high economic impact of the Internet, and ii) low economic impact of the Internet as well as passing of the threshold value. Each scenario is analysed for 2001-10 and for 2002-10.

\section{Box A5. Simulation exercise}

The simulation exercise aims to evaluate the possible net dynamic impact of the Internet on the US economy. Table A5 and Figure A6 present the results of the simulation.

\section{Scenarios}

The four different scenarios are:

- High impact of the Internet on growth, effects begin to be observed in 2001.

- Low impact of the Internet on growth, effects begin to be observed in 2001.

- High impact of the Internet on growth, effects begin to be observed in 2002.

- Low impact of the Internet on growth, effects begin to be observed in 2002.

\section{Input data}

The input data are:

- GDP per capita (USD current prices) (BEA, 2009).

- Internet development measured by broadband penetration rates (OECD Broadband portal).

- Impact of the Internet on growth (Koutroumpis, 2009):

- High: $1 \%$ increase in the penetration rate increases economic growth by an average of $0.025 \%$ (scenarios 1 and 3 ).

- Low: $1 \%$ increase in the penetration rate increases economic growth by an average of $0.023 \%$ (scenarios 2 and 4 ).

The results of the simulation vary between $4.65 \%$ (low impact of the Internet, passing the critical threshold in 2002) and 7.21\% (high impact of the Internet, passing the critical threshold in 2001). The results of the latter scenario are presented here (Figure A7). 
Table A5. The impact of the Internet on the US economy under four scenarios Share of US GDP generated as a result of the Internet

\begin{tabular}{llcccccccccc}
\hline & 2001 & 2002 & 2003 & 2004 & 2005 & 2006 & 2007 & 2008 & 2009 & 2010 \\
\cline { 2 - 11 } & & \multicolumn{7}{c}{$\%$} & \multicolumn{7}{c}{$\%$} \\
\hline \multirow{2}{*}{ Higher impact } & Scenario 1 & 2.27 & 3.54 & 4.53 & 5.28 & 5.91 & 6.45 & 6.81 & 7.01 & 7.09 & 7.21 \\
& Scenario 2 & & 1.30 & 2.32 & 3.09 & 3.73 & 4.28 & 4.64 & 4.85 & 4.94 & 5.05 \\
& Scenario 3 & 2.09 & 3.26 & 4.17 & 4.87 & 5.45 & 5.95 & 6.28 & 6.46 & 6.54 & 6.65 \\
& Scenario 4 & & 1.20 & 2.13 & 2.84 & 3.43 & 3.95 & 4.28 & 4.47 & 4.55 & 4.65 \\
\hline
\end{tabular}

Sources: Based on OECD data and Koutroumpis (2009).

Figure A6. The impact of the Internet on the US economy under four scenarios

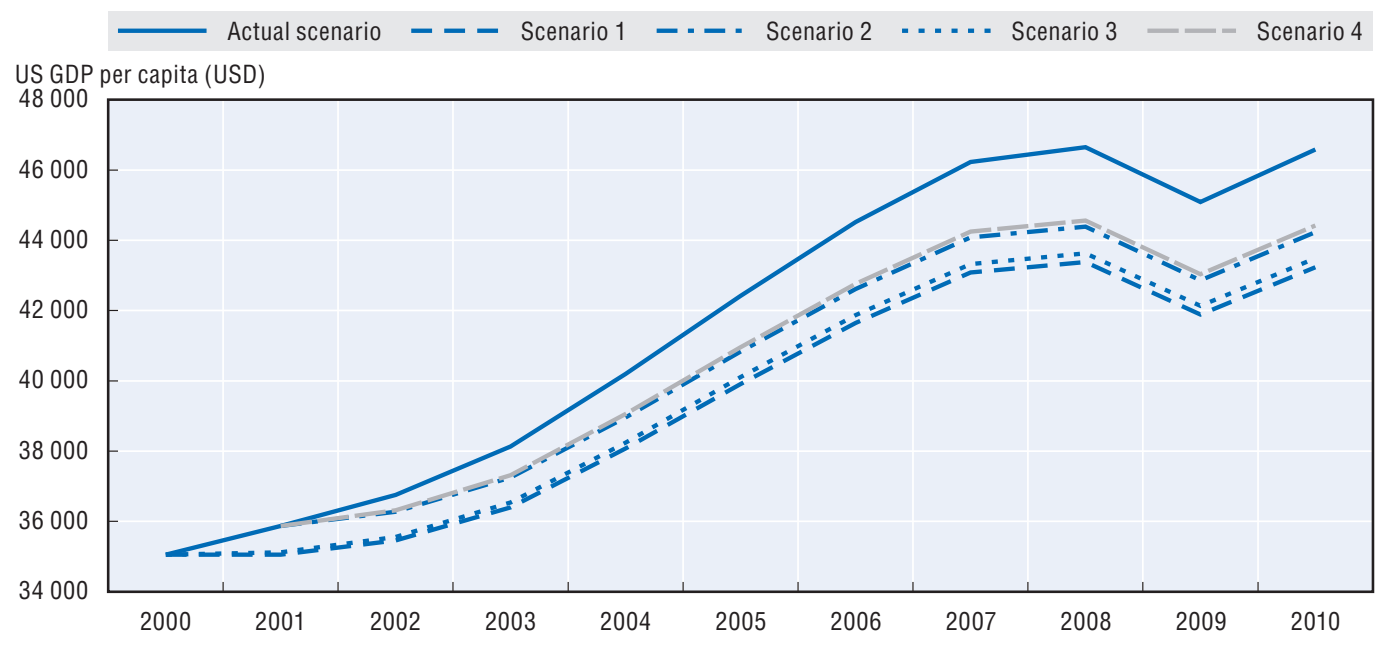

Sources: Based on OECD data and Koutroumpis (2009).

StatLink Ailst http://dx.doi.org/10.1787/888932694804

Figure A7. Dynamic impact of the Internet on the US economy

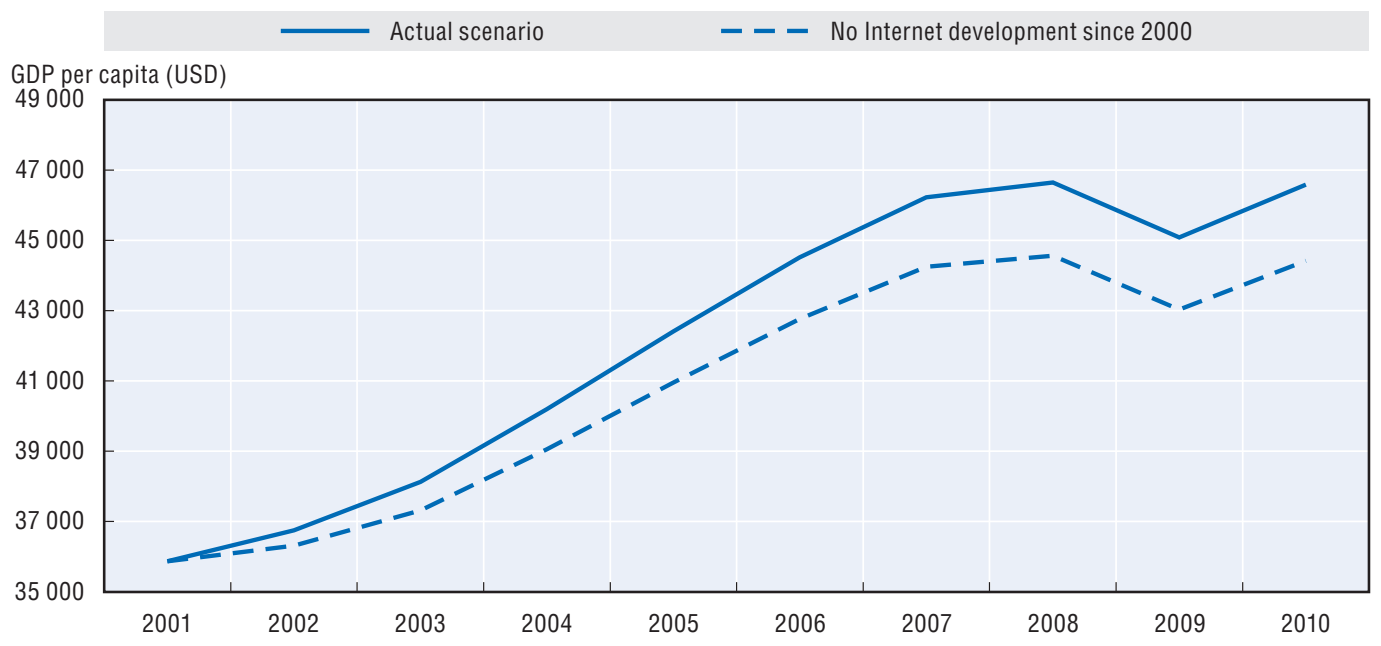

Source: BEA (US Bureau of Economic Analysis), Industry Economic Accounts, US Dept. of Commerce, Washington, DC.

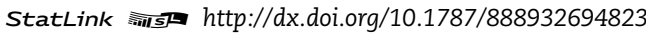


The solid line (Figure A7) presents the actual evolution of US GDP between 2001 and 2010. The dashed line illustrates the assumed scenario of no-Internet development since 2000. The difference between these two lines illustrates the net, dynamic effect that Internet has on the US economy, assuming that the economic impact of the Internet was high and the critical mass was reached in 2001.

This specific approach for impact estimations and US GDP data signals that in 2010, up to $7.21 \%$ of US gross domestic product was generated as a result of the Internet. This result is presented on the upper part of the pie chart (Figure A8).

Figure A8. The Internet economy in the US (measured by Approaches 1 and 2)

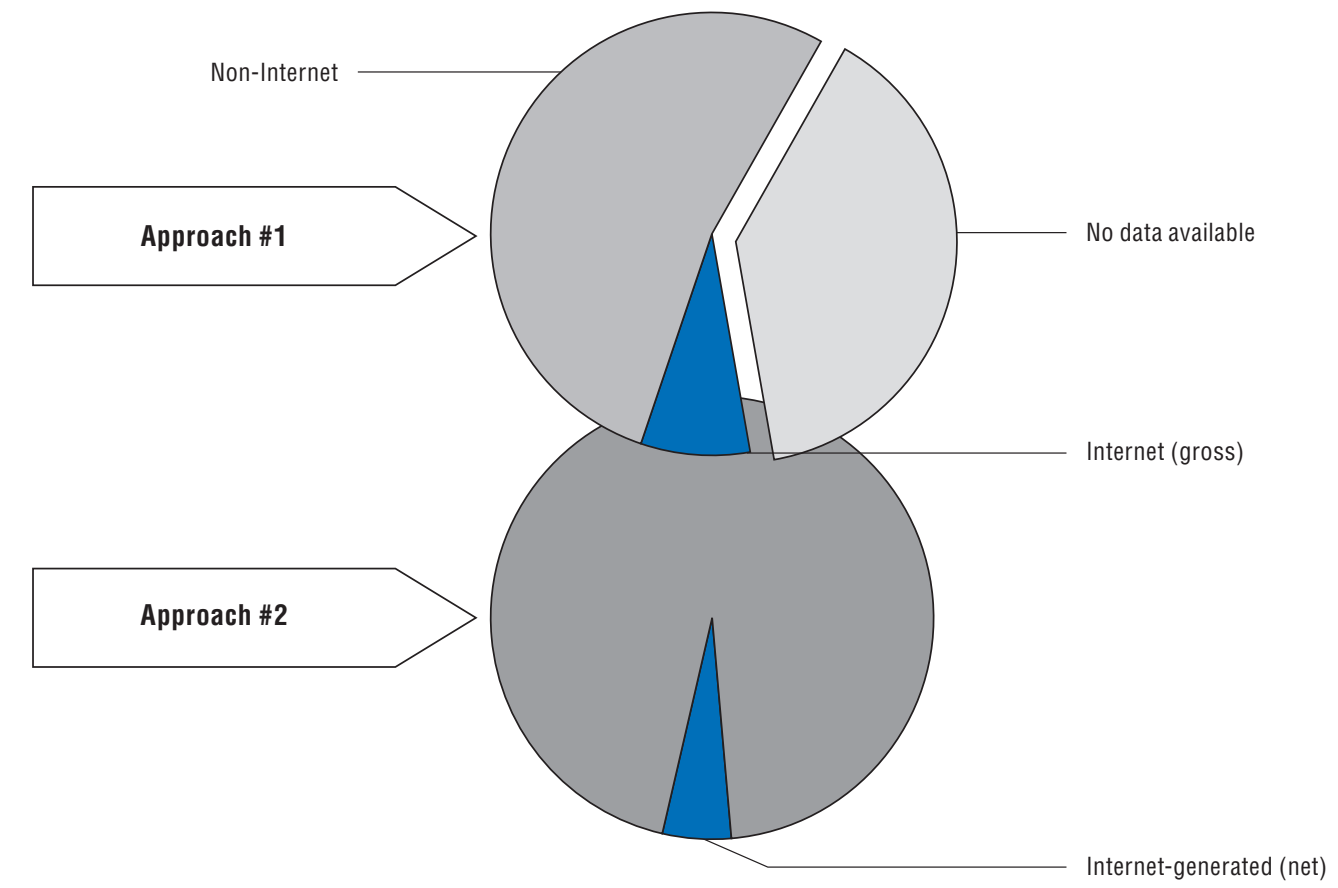

There are two key differences between the result of this exercise and the size of the Internet economy estimated according to Approach 1. First, the result of Approach 2 takes into account the net effect, which is the additional extra value generated as a result of the Internet (excluding added value re-allocated from offline to online). Second, it looks at all Internet-related activities that result in higher added value in all industries across the economy, not only activities that support the Internet and are based purely on the Internet.

Therefore, it is important to stress that the results generated following Approach 2 (Figure A8, upper chart) cannot be added to the results of Approach 1 (Figure A8, lower chart). Because there is a certain overlap between the focus areas of these two approaches (i.e. net value generated by activities that support the Internet or are purely based on the Internet) their results cannot be aggregated. Such aggregation would inevitably result in double counting and the final result would be overestimated. 


\section{Future research}

The results of the Approach 2 simulation, presented above, should be interpreted as an indication of the order of magnitude of impact, rather than an exact estimation. As noted by Lehr (2012), the Internet is a fast-changing phenomenon, and any attempt to measure its dynamic impact is extremely difficult. Current statistics are already dated, as they can only measure yesterday's impact. Moreover, the simulation exercise relies on a set of strong assumptions that to some extent cannot be tested given current data limitations.

It is possible to improve the simulation exercise, for example, by checking different scenarios and performing respective robustness tests. Future research can undertake work in this area. Moreover, this simulation exercise could be repeated for other economies to analyse their net contributions to GDP from the Internet economy.

\section{Approach 3. Indirect impact of the Internet}

The many types of interaction that take place on the Internet occur within the context of market and non-market environments, or a combination of the two. Market interactions involve transactions between buyers and sellers of a product or service and are characterised by a price and market-clearing mechanism. Some of these transactions are captured by traditional measures of economic activity in national account systems and, in turn, can be measured by one of the previous approaches.

While the Internet's impact on market transactions has been undoubtedly far-reaching, its effect on non-market interactions is even more profound. These interactions and impacts contribute to individual utility and the well being of the entire society. They are not, however, captured within the traditional measures of national accounts. The measures of these impacts are within the scope of Approach 3 to measure.

\section{Box A6. Summary of Approach 3: Indirect impact of the Internet}

\section{The approach}

This approach examines the economic impacts of the Internet that reach beyond GDP. It studies two main impact areas:

- The impact of the Internet on consumer surplus.

- The broader welfare gains generated as a result of the Internet (e.g. welfare gains derived from non-monetary transactions, impact on the environment, social capital formation, etc.).

\section{Existing results}

Little research has been undertaken to quantify the economic impact on consumer surplus. More studies focus on selected broader impact areas (e.g. impact on the environment or governance).

\section{The OECD study}

This study establishes a structure to understand the impact of the Internet on consumer welfare. It also proposes a simulation scheme to calculate the impact that the Internet and ICTs may have on consumer welfare.

\section{Future research}

More work needs to be done to understand and quantify the impact of the Internet on welfare in various selected areas (e.g. science, health, ageing, etc.). 


\section{The approach}

The economic impact of the Internet reaches beyond what we can measure using existing statistics. The Internet not only alters business models and intensifies competition in existing markets; it also introduces totally new economic models and paradigms, whose impact goes beyond effects captured within the classical SNA framework.

Two broad impact areas can be distinguished in this context (Figure A9):

- The positive impact that the Internet has on consumer surplus.

- The broader welfare gains generated as a result of the Internet (e.g. welfare gains derived from non-monetary transactions, impact on the environment, social capital formation etc.).

Figure A9. Indirect impact of the Internet

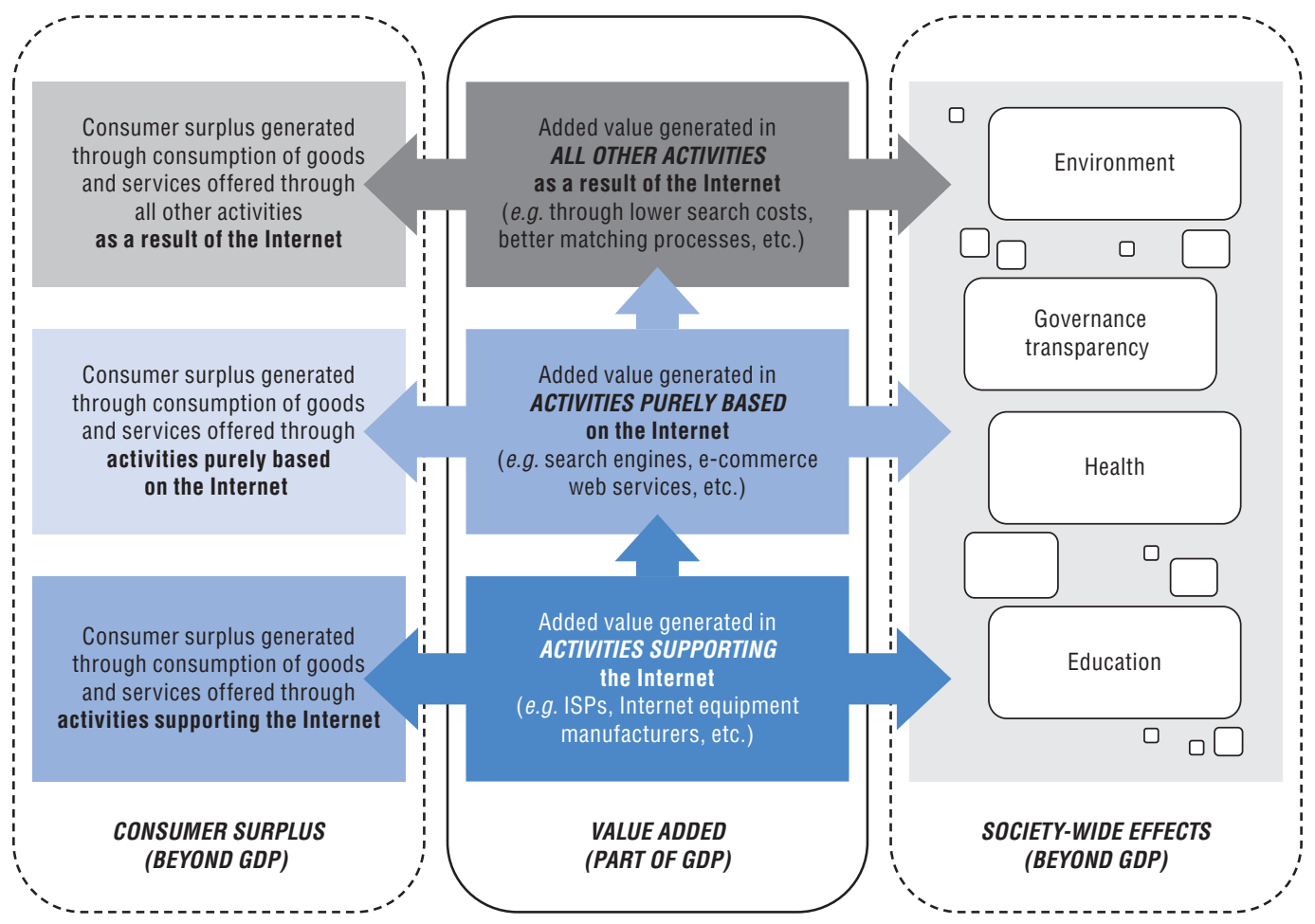

These impacts are described within the modern economic framework and in certain circumstances can be quantified. Nevertheless, such quantification is usually extremely difficult because it requires large amounts of data and a number of strong assumptions. Consequently, studies that fall into the Approach 3 are usually partial and present just a share of total impact of the Internet on consumer surplus and social welfare.

\section{Existing results}

Several studies provide empirical evidence regarding the positive and measurable impact of the Internet on consumer surplus (Dutz et al., 2009; Greenstein and McDevitt, 2011, 2012; Morton, 2006). These studies focus mostly on economic benefits to the consumer that arise from affordable access to the Internet. This corresponds to consumer surplus derived only from the consumption of products from industries producing for the Internet, so findings of these studies are limited to only one (although noticeable) component of consumers' welfare. 
Some studies focus on the economic impact of the Internet on consumers and study the effects on individual utility and well-being. Several studies indicate that online social networking websites, such as Facebook or Myspace, tend to contribute to social capital formation that in turn can raise individual perception of well being (Gibson and McAllister, 2009; Shah, Kwak and Holbert, 2001). These benefits remain, however, a challenge to capture quantitatively.

Indeed, only a few of the impacts of the Internet on welfare have been quantified. Certain effects, although significant and observed, cannot be economically measured and expressed in economic value terms; for example, the satisfaction individuals derive from various services offered through the Internet such as participation in social networks (see Box A7.)

\section{Box A7. Online social networks and well-being}

Online social networks (e.g. Facebook or Myspace) are often cited as prominent examples of services enabled by the rapid development of the Internet. Whereas certain social networks serve business and professional networking purposes (e.g. LinkedIn), most are designed solely for social networking.

According to recent studies, online social networks are an important medium of formation and maintenance of social capital. Some research has shown, for example, that these networks are particularly useful for people who otherwise have difficulties generating and maintaining interpersonal relationships. Online social networks can lower barriers to interaction, encourage people to interact socially, and increase psychological well-being.

Even though these impacts can to some degree be observed and quantified at the individual level, it is not possible to taken into account individual benefits of the Internet on individuals or the "benefits of happiness" and aggregate these into broader economic measures (e.g. as a component of GDP).

Sources: Bargh and McKenna (2004); Bargh, McKenna and Fitzsimons (2002); Ellison, Steinfield and Lampe (2007).

Aside from the effects the Internet has on consumer surplus, other broader, society-wide impacts include the myriad of effects on environment, education, scientific research, governance, social capital, health, ageing, science and so on. Given the lack of proxies for this phenomena and consistent datasets, these impacts are extremely difficult to quantify in an aggregated manner. This also means that most of these impacts are not accounted for within GDP and cannot be quantified by Approaches 1 and 2.

The Internet enables solutions that could have a significant positive impact on the environment (OECD, 2010b). This broad impact is captured by the term Green ICT, which in turn encompasses various solutions such as smart grids, smart buildings and smart cities. For example, Internet connectivity will have a significant impact on the environment and company efficiency in the electricity sector. The Internet can serve as the communication foundation of smart electrical grids (advanced metering infrastructure) by addressing a historical information gap between end-users and distributors. Smart grids use a communication network to inform consumers of their electricity consumption in real time, as well as the overall supply and demand situation on the network, allowing them to adjust consumption based on price signals. On the supply side, electricity providers can benefit from the smart grid because it enables them to smooth out demand by monitoring and influencing consumption in real time, 
either through technical intervention or variable demand-based pricing. While some of the benefits of smart grids will be captured in GDP, many of the environmental benefits will not.

The Internet is also increasingly used in the field of education (Lenhart, Simon and Graziano, 2001; Spiezia, 2010). Remote education over radio and television has been in use for many years in rural and remote areas, but the Internet enables a more general and dynamic development of education services. Approaches 1 and 2 will not capture these impacts for at least two reasons. First, even though the social benefits of education are clear, its macroeconomic impact on GDP is disputed (Krueger and Lindahl, 2000). Second, even if the impact of education were detectable, it would occur over the very long term, which is for the moment outside the scope of Approaches 1 and 2.

There are two key ways in which Internet access can help make education more efficient. First, the Internet improves education by enhancing remote communication and delivering teaching or training materials. Second, the Internet greatly facilitates gathering of information using a myriad of services and applications, including online classes and seminars, dedicated web pages and online forums for expertise exchange.

An example of the Internet's impact on education can be found at Stanford University in the United States, where certain classes are available online to the general public for free. After each class meeting the university posts videos of the class and copies of the slides shown on a dedicated webpage for a few days. ${ }^{5}$ Stanford University developed this initiative in cooperation with Apple. In terms of economic benefits for individuals, the content provides a great opportunity to acquire state-of-the-art knowledge; while for Stanford it is a novel way to demonstrate teaching quality and the richness of its curriculum.

Apart from general education the Internet also has certain impacts on scientific research. The primary impact comprises areas where Internet technologies have improved access to information and facilitated communication between researchers and research centres. Notable examples include instant access to digitised scientific articles and databases offered by various providers over the Internet (e.g. JStore and ScienceDirect). The development of the Internet has also enabled new forms of cooperation in research that rely on public domain and open-access models of information creation (e.g. science commons). Such benefits often fall outside of GDP measures.

Healthcare is a sector where the Internet and other communication technologies are increasingly employed to address escalating healthcare costs. As an example, Internet technologies could help reduce the number of physical doctor visits needed by elderly patients who still choose to live at home. The Internet and evolving sensor technologies make remote check-ins economical. Currently, the share of GDP spent on healthcare is rising across OECD economies. Moreover, these costs have been rising over the past decades. According to recent figures in OECD countries, health expenditure amounts to 9.5\% of GDP (OECD, 2012). This is due to the aging processes, high costs of related education, and technological progress and the economic complexity of healthcare issues.

E-health is an effective solution that could be applied to at least partially address this problem. The term "e-health" refers to a range of Internet-enabled solutions and services solutions that enhance healthcare efficiency (e.g. telemedicine), enhance access to information and health records, and offer other ways of healthcare improvement, for example, through better access to medical journals, epidemiological tracking or sharing of patient-specific information. E-health could lead to a significant reduction of costs in the healthcare system. It is expected that these services will be rapidly developed and that the 
share of e-health among other services offered through the Internet will continue to grow. Note that since the implementation of Internet-based solutions in the health sector is expected to reduce costs and raise efficiency, this in turn will not translate into final consumption (as "better health" is not a component of consumption.) Hence, most of the benefits of improved health outcomes would fall outside of traditional GDP measures.

In addition to issues related to the environment and healthcare, there are significant areas where the Internet affects governments, with e-government services constituting an illustrative example. This term refers to the digital, mostly Internet-enabled, interaction between government and citizens, firms and other public agencies. The Internet acts here as a channel to enhance the efficiency and effectiveness of the public sector. The benefits of e-government are clear: Internet-based solutions improve the accessibility, efficiency and convenience of public services by permitting instantaneous communication and removing the requirements of physical presence at the government agency. Increased interaction with the government and easy access to documentation can also raise transparency, promote democratisation and reduce levels of corruption (Andersen et al., 2011). Even though the benefits of e-government are straightforward, they do not directly impact GDP, as the efficiency of public institutions, their accessibility and openness to citizens, does not fully and directly translate into value added.

Another channel through which the Internet might have impact on government activities is through intensified social capital. Higher social capital in a society translates in turn into intensified political participation on the part of the individual (Gibson and McAllister, 2009; Shah, Kwak and Holbert, 2001).

\section{The OECD study}

The contribution of this research on Approach 3 focuses on two areas:

- Creation of a consistent framework to study the impact of the Internet on consumer surplus.

- Quantification of some aspects of the impact of the Internet on consumer surplus.

The Internet and consumer surplus: a framework for analysis. One of the main ways in which the Internet affects individuals is through improvements in consumer surplus. This term refers to the difference between the monetary value individuals are willing to pay for a product or service and the amount they actually pay (explicit or implicit price). One way to look at the Internet's impact on consumer surplus is to examine pricing on the Internet (Scholten, 2012).

While the Internet's impact on market transactions and value added has been undoubtedly far-reaching, its effect on non-market interactions and consumer surplus is even more profound. Non-market interactions on the Internet are broadly characterised by the absence of a price and market-clearing mechanism. In other words, neither the production nor consumption sides of markets have well-defined pricing or market-clearing mechanisms. Non-market interactions on the Internet span economic agents ranging from businesses and consumers to governments. Typical examples of non-market Internet interactions range from electronic communications (either between private individuals or within/across business organisations) to consumption of Internet information goods content, for example, Wikipedia.

Part of the difficulty in evaluating the Internet's impact on consumer surplus is that no single model exists for market or non-market interactions. Indeed, little attention has been 
paid to non-market interactions since few, if any, well-defined and well-grounded measurements have been commonly adopted. Part of the problem is that non-market activity is typically conducted internally within an organisation or by an individual. As such, it is not directly observable or currently measured. However, even when non-market activities are external to organisations, it is not clear which activities are important to measure.

Following Scholten (2012), a set of Internet-related mechanisms that lead to higher consumer surplus is proposed. These mechanisms include: i) business-to-business (B2B) interactions, ii) business-to-consumer (B2C) interactions, and iii) consumer-to-consumer (C2C) interactions (Figure A10).

\section{Figure A10. The Internet and consumer surplus: channels of transmission}

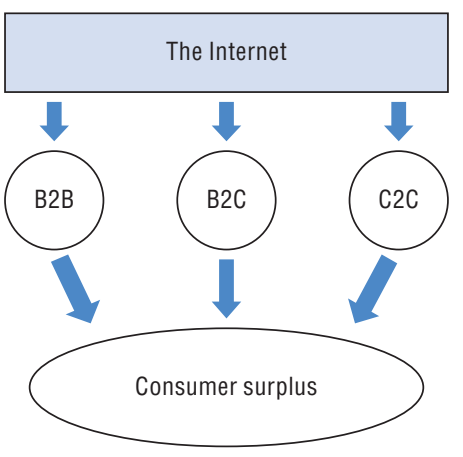

Source: Scholten (2012).

The most fundamental Internet activity in the B2C interaction is how individuals connect to the Internet. Without an Internet connection, individuals and organisations are neither interconnected nor have access to certain information. Business-to-consumer interactions are not limited only to Internet access. Indeed, consumers transact with business for a wide array of products and services. Some of the models describing these interactions include: versioning, licensing, tying, consumer search, product differentiation, branding, switching costs and consumer lock-in. Each of these models has different consumer surplus implications.

The number of B2B transactions far outweighs those of business-to-consumer. This is primarily due to the fact that for every $\mathrm{B} 2 \mathrm{C}$ transaction, there are many sub-component or raw material supply chain management transactions. The Internet introduces many opportunities for efficiency in products and intensifies competition between producers.

Moreover, the introduction of the Internet implies cost reductions and intensified competition, which in turn result in lower prices for consumers. The effect that the Internet has on consumer prices has been well described in the existing empirical literature (Ancarani and Shankar, 2004; Bolton, Shankar and Montoya, 2010).

Finally, the emergence of the Internet and the introduction of new competing technologies result, to some extent, in changes to traditional business models, and therefore a new GDP structure. Some industries might observe a shift of added value from offline to online channels.

The Internet has facilitated global C2C transactions by linking consumers with one another through third-party intermediaries. These intermediaries may be online auctions or other Internet-related classified advertising. Internet intermediaries facilitating these 
C2C transactions impact economic well-being on at least two dimensions. First, global interconnectivity means consumers have greater variety of access to (sometimes esoteric) items. Also, there are a variety of online auction mechanisms. These auctions have important implications for economic and social well-being.

While social networks predate the Internet, their pervasiveness in online environments is enormous. A social network is a group of individuals linked by a common interdependency, ranging from friendship to interest in a common theme such as music or sports. Internet web properties dedicated to building individuals' social networks are called social networking services. Some of the largest social networking services are: Badoo, douban, Facebook, Flickr, LinkedIn, Myspace, Tumbler, Twitter and Yelp. Social networking is currently listed as a non-market interaction between individuals; however, the social networking service provider attempts to monetise the model by selling targeted advertising based on information gathered from social networks.

Measurement of Internet-generated consumer surplus. Although the influence of the Internet in transforming the way in which business and consumer transactions are done is clear to all participants in the production-consumption process, it is difficult to attribute a specific value to and precisely measure the importance its role in raising consumer surplus.

Two additional approaches can be highlighted in this context. Greenstein and McDevitt (2012) attribute a monetary value to the consumer surplus in OECD countries based solely on the use of Internet-services. Cooper (2012) presents a simulation exercise based on a quantitative model to measure the value of Internet-generated consumer surplus.

Greenstein and McDevitt (2012) estimate the economic value created by the diffusion of broadband from 1999 to 2010 in OECD countries. The study observed that the switch from dial-up to broadband access was associated with USD 4.8 billion to USD 6.7 billion in consumer surplus in the United States alone, which is not measured via GDP. An Internet-access Consumer Price Index (CPI) would have had to decline by $1.6 \%$ to $2.2 \%$ per year for it to reflect this creation of value.

The second study by Cooper (2012) employs an economic model that examines the end result (observations on changes in the pattern of consumer spending behaviour) and econometrically estimates the extent of the link between these behavioural changes and their drivers. These drivers are traditional economic stimuli as well as changes in the economic environment due to advances in technology and improved provision of public sector IT infrastructure. Counterfactual simulations with the estimated model provide money-metric measures of the welfare benefits of innovations in Internet-based public sector IT infrastructure in a variety of OECD economies.

Indeed, in the new Internet-based economy it is arguably becoming more difficult to track the detailed price plans available to consumers for custom applications of IT-enhanced products and services as the range of options expands. The pace of innovation in IT and the complementary field of telecommunications has meant that official price statistics, especially aggregate price indexes, lag behind innovations, with quality-adjusted prices only following after the event, if they are computed at all.

Endorsing the view that the influence of these events is evident in changed consumer expenditure patterns, Huttner (2007) noted the ubiquitous increase in final demand for the 
Internet. Arguably the Internet has saturated all aspects of the economy to a level that makes it difficult to measure. In response to the measurement problem, Cooper (2012) utilises a specially developed economic model that econometrically explains the trends in consumer spending with main economic stimuli and changes in the Internet environment and public IT infrastructure.

Although the model developed and used in this research is highly aggregative and cannot trace out the precise process of transmission of IT productivity enhancements, it nevertheless corroborates the hypothesis of a positive end result for the macro-economy, implicit in the views of Huttner (2007).

\section{Future work}

The framework for analysing the impact of the Internet on consumer surplus suggested by Scholten (2012) indicates some areas for future research. Indeed, the broader welfare gains generated as a result of the Internet have their origin in some non-monetary transactions, as well as from broader impacts that the Internet has on the environment, social capital formation and so on.

Future research in this area could focus on targeted analyses of these impacts areas that raise consumer surplus and levels of social well being, but which are not fully captured by national accounts, and hence are not captured in GDP. These analyses could be done at individual, governmental or societal levels.

At the individual level, the analysis could determine and analyse the channels of impact of the Internet on consumer welfare. Following Scholten (2012), the analysis would then focus on $\mathrm{B} 2 \mathrm{~B}, \mathrm{~B} 2 \mathrm{C}$ and $\mathrm{C} 2 \mathrm{C}$ relationships in order to determine the potential for surplus generation and to identify the possible scope for policy intervention.

At the governmental level, the analysis could assess the benefits of the Internet that cannot be accounted for within existing SNA frameworks. The analysis could then suggest ways to leverage and fully exploit these benefits.

Finally, at the societal level, the analysis would add to our measurement of the wider impact of the Internet that affects welfare but falls outside GDP statistics. This would include the identification of impact areas, the assessment of possible measurement techniques, and the determination of potential scope for policy intervention.

\section{Conclusions}

The Internet has recently become a ubiquitous economic infrastructure, but measuring the size of the Internet economy is not straightforward. Measurement of the economic impact of the Internet depends largely on the approach taken and can be performed at different levels, according to different approaches.

The three approaches presented in this Annex set a methodological structure for studies that attempt to quantify the Internet economy. Moreover, the initial investigations within each approach provide some information about the order of magnitude of the economic impacts of the Internet.

In terms of next steps, these investigations indicate the data requirements necessary to refine methodologies and to broaden the scope of measurement to other economies. Further research is needed both on the causal nature of the Internet-GDP relationship, and to increase understanding of Internet impacts on important areas of life that do not manifest in SNA statistics. 


\section{Notes}

1. "The ICT sector consists of all industries (manufacturing and services) whose production is primarily... intended to fulfil the function of information processing and communication by electronic means including transmission and display" (OECD, 2011a, p. 59).

2. The Content and Media sector consists of all industries (manufacturing and services) whose production is primarily ... intended to inform, educate and/or entertain humans through mass communication media. These industries are engaged in the production, publishing and/or the distribution of content (information, cultural and entertainment products), where content corresponds to an organised message indented for human being (OECD, 2011a, p. 164).

3. For the United States, the only sector for which information on Internet-related activities (both supporting and purely based on the Internet) is available is the information sector (NAICS 51). For the other sectors, only information on e-commerce (purely based on the Internet) is available.

4. Thus, the quantitative results present the correlation rather than causality.

5. These are available at: http://itunes.stanford.edu.

\section{References}

Ancarani, F. and V. Shankar (2004), "Price Levels and Price Dispersion Within and Across Multiple Retailer Types: Further Evidence and Extension", Journal of the Academy of Marketing Science, Vol. 32, No. 2, pp. 176-188.

Andersen, T. et al. (2011), "Does the Internet Reduce Corruption? Evidence from U.S. States and across Countries", World Bank Economic Review, Vol. 25, No. 3, pp. 387-417, www.econ.ku.dk/pabloselaya/ publications/WBER\%202011\%20Pablo\%20Selaya.pdf (accessed 29 March 2012).

Bargh, J. and K. McKenna (2004), "The Internet and Social Life”, Annual Review of Psychology, Vol. 55, No. 1, pp. 573-590.

Bargh, J.A., K. McKenna and G.M. Fitzsimons (2002), "Can You See the Real Me? Activation and Expression of the 'True Self' on the Internet”, Journal of Social Issues, Vol. 58, No. 1, pp. 33-48.

Barro, R. (1991), "Economic Growth in a Cross Section of Countries", Quarterly Journal of Economics, Vol. 106, No. 2, pp. 407-443, www.econ.uchile.cl/uploads/docencia/013421852878cc3a76dadb11c73d09e42e5adbbb.pdf (accessed 29 March 2012).

BCG (Boston Consulting Group) (2010), The Connected Kingdom, How The Internet Is Transforming the UK Economy, BCG, Boston, USA, www.connectedkingdom.co.uk/downloads/bcg-the-connected-kingdom-oct10.pdf (accessed 29 March 2012).

BCG (2011), Turning Local: From Madrid to Moscow, the Internet is Going Native, BCG, Boston, USA, www.bcg.de/documents/file84709.pdf (accessed 29 March 2012).

BEA (US Bureau of Economic Analysis) (2009), Industry Economic Accounts, US Dept. of Commerce, Washington, DC, www.bea.gov/industry/index.htm (accessed November 2011).

Bertschek, I., D. Cerquera, and G. Klein (2011), More Bits - More Bucks? Measuring the Impact of Broadband Internet on Firm Performance, Discussion Paper No. 11-032, Centre for European Economic Research (ZEW), Mannheim, Germany, ftp.zew.de/pub/zew-docs/dp/dp11032.pdf (accessed 29 March 2012).

Bolton, R, V. Shankar and D. Montoya (2010), “Recent Trends and Emerging Practices in Retailer Pricing", in M. Krafft and M. Mantrala (eds.), Retailing in the 21st Century, Springer, Berlin.

Brynjolfsson, E. and L. Hitt (1996), "Paradox Lost? Firm-level Evidence on the Returns to Information Systems Spending," Management Science, Vol. 42, No. 4, 541-558.

Chinn, M. and R. Fairlie (2007), "The Determinants of the Global Digital Divide: A Cross-country Analysis of Computer and Internet Penetration", Oxford Economic Papers, Vol. 59, No. 1, pp. 16-44.

Cooper, R. J. (2012), "Measuring the Impact of Innovations in Public IT Infrastructure on the Standard of Living in OECD Economies", OECD Digital Economy Papers, No. 196, OECD Publishing. doi: http://dx.doi.org/10.1787/5k9bf8ktf4kc-en.

Crandall, R., W. Lehr and R. Litan (2007), The Economic Impact of Broadband on Growth: A Simultaneous Approach, Issues in Economic Policy No. 6., The Brookings Institution, Washington, DC.

Czernich, N. et al. (2009), "Broadband Infrastructure and Economic Growth", Economic Journal, Royal Economic Society, Vol. 121, No. 552, pp. 505-532. 
Deloitte (2011), The Connected Continent, How the Internet is Transforming the Australian Economy, Deloitte Access Economics, Sydney.

Dutz, M., J. Orszag and R. Willig (2009), The Substantial Consumer Benefits of Broadband Connectivity for US Households, mimeo.

Eisenach, J. and T.M. Lenard (1998), Competition, Innovation, and the Role of Antitrust in the Digital Marketplace, Kluwer Academic Publishers, Boston, USA.

Ellison, N.B., C. Steinfield, and C. Lampe (2007), “The Benefits of Facebook 'Friends': Social Capital and College Students' Use of Online Social Network Sites", Journal of Computer-Mediated Communication, Vol. 12, No. 4, pp. 1143-68, http://jcmc.indiana.edu/vol12/issue4/ellison.html (accessed 29 March 2012).

Forman, C. and N. van Zeebroeck (2010), "From Wires to Partners: How the Internet has Fostered R\&D Collaborations within Firms", paper presented at the Conference "ICTs \& Economic Growth", Munich, 4-6 November 2010, www.misrc.umn.edu/workshops/2011/spring/Forman\%20van\%20Zeebroeck\%20\%20From\%20wires\%20to\%20partners\%20-\%20Minnesota.pdf (accessed 29 March 2012).

Franklin, M., P. Stam and T. Clayton (2009), "ICT Impact Assessment by Linking Data”, Economic and Labour Market Review, Vol. 3, No. 10, pp. 18-27, www.ons.gou.uk/ons/rel/elmr/economic-and-labourmarket-review/no-10-october-2009/ict-impact-assessment-by-linking-data.pdf (accessed 29 March 2012).

Gibson, R.K. and I. McAllister (2009), Revitalising Participatory Politics? The Internet, Social Capital and Political Action, APSA 2009 Toronto Meeting Paper, http://ssrn.com/abstract=1451462 (accessed 29 March 2012).

Greenstein, S. and R. McDevitt (2011), “The Broadband Bonus: Estimating Broadband Internet's Economic Value", Telecommunications Policy, Vol. 35, No. 7, pp. 617-632.

Greenstein, S. and R. McDevitt (2012), "Measuring the Broadband Bonus in Thirty OECD Countries", OECD Digital Economy Papers, No. 197, OECD Publishing. doi: http://dx.doi.org/10.1787/5k9bcwkg3hwf-en.

Grimes, A. and C. Ren (2009), The Need for Speed: Impacts of Internet Connectivity on Firm Productivity, Ministry of Economic Development, Wellington, https://community.oecd.org/servlet/JiveServlet/ previewBody/23097-102-1-43317/grimes-ren-stevens.pdf (accessed 29 March 2012).

Hamilton Consultants (2009), Economic Value of the Advertising-Supported Internet Ecosystem, Internet Advertising Board report, Hamilton Consultants, Shrewsbury, UK, www.iab.net/media/file/flyin09deighton.pdf (accessed 29 March 2012).

Holt, L. and M. Jamison (2009), "Broadband and Contributions to Economic Growth: Lessons from the US Experience”, Telecommunications Policy, Vol. 33, No. 10-11, pp. 575-581.

Huttner, S. (2007), “The Internet Economy: Towards a Better Future”, OECD Observer, November, www.oecdobserver.org/news/fullstory.php/aid/2330/ (accessed 29 March 2012).

Katz, M.L., and Shapiro, C. (1986), "Technology Adoption in the Presence of Network Externalities", Journal of Political Economy, Vol. 94, pp. 823-841.

Kiiski, S. and M. Pohjola, (2002), "Cross-Country Diffusion of the Internet", Information Economics and Policy, Vol. 14, No. 2, pp. 297-310.

Koutroumpis, P. (2009), "The Economic Impact of Broadband on Growth: A Simultaneous Approach" Telecommunications Policy, Vol. 33, No. 9, pp. 471-485.

Krueger, A. and M. Lindahl (2000), Education for Growth: Why and For Whom?, NBER Working Paper No. 7591, National Bureau of Economic Research, Cambridge, United States.

Lehr, W. (2012), “Measuring the Internet: The Data Challenge”, OECD Digital Economy Papers, No. 194, OECD Publishing. doi: http://dx.doi.org/10.1787/5k9bhk5fzuzx-en.

Lenhart, A., M. Simon and M. Graziano (2001), The Internet and Education: Findings of the Pew Internet and American Life Project, PewInternet, Washington, DC, www.pewinternet.org/Reports/2001/The-Internetand-Education/Summary-of-Findings.aspx (accessed 29 March 2012).

Lequiller, F. and D. Blades (2007), Understanding National Accounts, OECD Publishing. doi: http://dx.doi.org/10.1787/9789264027657-en.

Majumdar, S.K., O. Carare, and H. Chang (2009), "Broadband Adoption and Firm Productivity: Evaluating the Benefits of General Purpose Technology", Industrial and Corporate Change, Vol. 19, No. 3, pp. 641-674. 
McAfee, A. and E. Brynjolfsson (2007), "Dog Eat Dog: Industries that Buy a lot of Technology are Becoming as Cutthroat as those that Produce Technology", Wall Street Journal, 28 April 2007, http:// online.wsj.com/article/SB117735476945179344.html (accessed 29 March 2012).

McKinsey (2011), Internet Matters: The Net's Sweeping Impact on Growth, Jobs and Prosperity, McKinsey Global Institute, www.mckinsey.com/Insights/MGI/Research/Technology_and_Innovation/ Internet_matters (accessed 29 March 2012).

Morton, F.S. (2006), “Consumer Benefit from Use of the Internet”, A.B. Jaffe, J. Lerner and S. Stern (eds.), Innovation Policy and the Economy, Vol. 6, National Bureau of Economic Research (NBER), Cambridge, United States.

OECD (2010a), OECD Information Technology Outlook 2010, OECD Publishing. doi: $h$ ttp://dx.doi.org/10.1787/it_outlook-2010-en.

OECD (2010b), "Greener and Smarter: ICTs, the Environment and Climate Change", in OECD, OECD Information Technology Outlook 2010, OECD Publishing. doi: http://dx.doi.org/10.1787/it_outlook-2010-7-en.

OECD (2011a), OECD Guide to Measuring the Information Society 2011, OECD Publishing. doi: http://dx.doi.org/10.1787/9789264113541-en.

OECD (2011b), Broadband Portal, OECD, Paris, www.oecd.org/sti/ict/broadband.

OECD (2011c), The Role of Internet Intermediaries in Advancing Public Policy Objectives, OECD Publishing. doi: $h t t p: / / d x . d o i . o r g / 10.1787 / 9789264115644-e n$.

OECD (2012), Health Data 2012, OECD, Paris, www.oecd.org/health/healthdata (accessed 11 July 2012).

Polder, M. et al. (2009). Productivity Effects of Innovation Modes, Discussion Paper, Statistics Netherland, The Hague, mpra.ub.uni-muenchen.de/18893/1/200933x10pub.pdf (accessed 29 March 2012).

Qiang, C.Z. and C.M. Rossotto with K. Kimura (2009), "Economic Impacts of Broadband", Information and Telecommunications for Development 2009: Extending Reach and Increasing Impact, World Bank, Washington, DC.

Scholten, P. (2012), "The Economic Impact of the Internet on Consumer Surplus", OECD Digital Economy Working Paper, OECD, Paris, forthcoming.

Shah, D.V., N. Kwak and R.L. Holbert (2001), "'Connecting' and 'Disconnecting' with Civic Life: Patterns of Internet Use and the Production of Social Capital”, Political Communication, Vol. 18, No. 2, pp. 141-162.

Spiezia V. (2010), "Does Computer Use Increase Educational Achievements? Student-level Evidence from PISA", OECD Journal: Economic Studies, Vol. 2010/1.

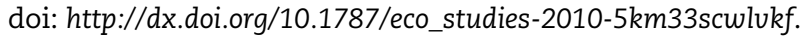

UNCTAD (United Nations Conference on Trade and Development) (2006), Information Economy Report 2006: The Development Perspective, UNCTAD, Geneva, www.unctad.org/en/docs/ sdteecb20061ch4_en.pdf (accessed 29 March 2012).

Varian, H. et al. (2002), The Net Impact Study: The Projected Economic Benefits of the Internet in the United States, United Kingdom, France and Germany, mimeo. 


\section{ORGANISATION FOR ECONOMIC CO-OPERATION AND DEVELOPMENT}

The OECD is a unique forum where governments work together to address the economic, social and environmental challenges of globalisation. The OECD is also at the forefront of efforts to understand and to help governments respond to new developments and concerns, such as corporate governance, the information economy and the challenges of an ageing population. The Organisation provides a setting where governments can compare policy experiences, seek answers to common problems, identify good practice and work to co-ordinate domestic and international policies.

The OECD member countries are: Australia, Austria, Belgium, Canada, Chile, the Czech Republic, Denmark, Estonia, Finland, France, Germany, Greece, Hungary, Iceland, Ireland, Israel, Italy, Japan, Korea, Luxembourg, Mexico, the Netherlands, New Zealand, Norway, Poland, Portugal, the Slovak Republic, Slovenia, Spain, Sweden, Switzerland, Turkey, the United Kingdom and the United States. The European Union takes part in the work of the OECD.

OECD Publishing disseminates widely the results of the Organisation's statistics gathering and research on economic, social and environmental issues, as well as the conventions, guidelines and standards agreed by its members. 
